




\title{
508
}

. 4498 copy 3

Mamm

OBRAS COMPLETAS Y CORRESPONDENCIA CIENTÍFICA

\section{FLORENTINO AMEGHINO}

VOLUMEN VIII

\section{LOS MAMIIFEROS FÓSILES \\ DE LA REPÚBLICA ARGENTINA}

\author{
PARTE UI
HOMALODONTES
}

\author{
EDICIÓN OFICIAL \\ ORDENADA POR EL GOBIERNO DE LA PROVINCIA \\ DE. BUENOS AIRES
}

DIRIGIDA POR

ALFREDO J. TORCELU

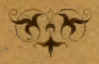

LA PLATA

TALAR DE IMPRESTOXES OFHATIES 

OBRAS COMPLETAS Y CORRESPONDENCIA CIENTÍFICA

DE

\section{FLORENTINO AMEGHINO}

VOLUMEN VIII

PARTE III

HOMALODONTES 

OBRAS COMPLETAS Y CORRESPONDENCIA CIENTÍFICA

$\mathrm{DE}$

FLORENTINO AMEGHINO

VOLUMEN VIII

\title{
LOS MAMÍFEROS FÓSILES
}

DE LA REPÚBLICA ARGENTINA

\author{
PARTE III \\ HOMALODONTES \\ EDICIÓN OFICIAL \\ ORDENADA POR EL GOBIERNO DE LA PROVINCIA \\ DE BUENOS AIRES \\ DIRIGIDA POR
}

ALFREDO J. TORCELLI

त्रत्र

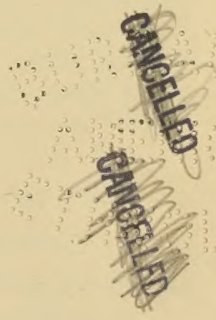

LA PLATA

TALLER DE IMPRESIONES OFICIALES

1918

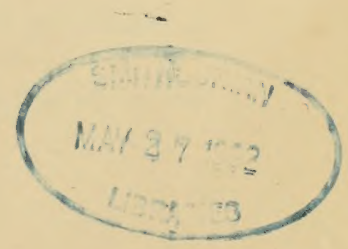



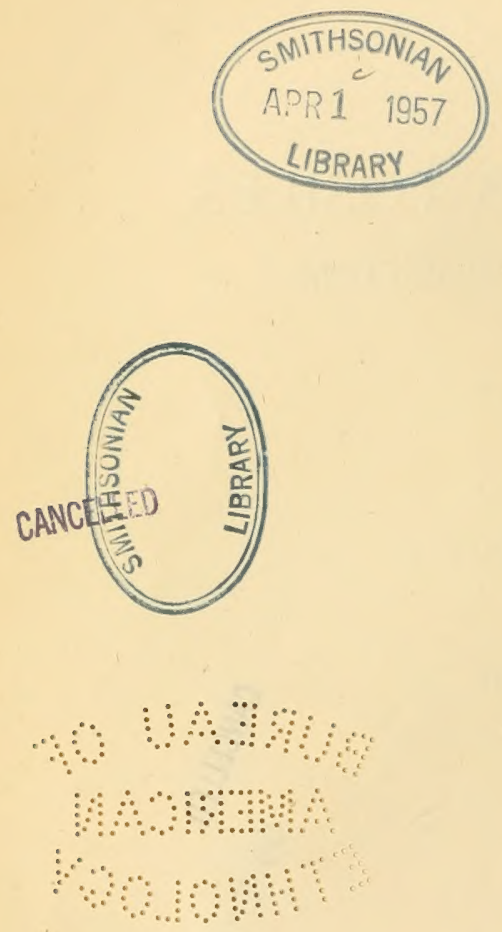


\section{A M M A I A}

\section{HOMALODONTA}

Mamiferos ditremados con dientes simples, que nunca tienen más de una raíz, por lo general de base abierta, a menudo sin esmalte y en algunas familias atrofiados o completamente desaparecidos.

Se dividen en dos grandes secciones, caracterizadas por la forma de los miembros, de este modo:

Miembros dispuestos para la locomoción terrestre: Bruta.

Miembros dispuestos para la locomoción acuática: Cetácea.

\section{BRUTA}

Mamíferos homalodontes con los miembros dispuestos para la locomoción terrestre, con las falanges ungueales armadas de uñas largas, comprimidas, acuminadas o falciformes. Mandibula inferior generalmente con rama ascendente. Dentición generalmente incompleta, y raramente con incisivos; dientes casi siempre sin esmalte o con vestigios poco perceptibles de él.

Se dividen en cuatro órdenes, que se distinguen de este modo:

I. Incisivos en ambas mandibulas. Dientes esmaltados.

1. Mandibula inferior estiliforme, sin rama ascendente: Priodonta.

2. Mandíbula inferior con rama ascendente: Pleiodonta.

II. Incisivos inferiores siempre ausentes. Dientes generalmente no esmaltados.

1. Sin exoesqueleto. No más de 4 a 6 muelas en cada ladó de cada mandíbula: Anicanodonta.

2. Con exoesqueleto. No menos de 7 muelas en cada lado de cada mandibula: Hicanodonta. 


\section{PRIODONTA}

Cráneo largo y mandibulas estiliformes, sin rama ascendente. Incisivos en ambas mancíbulas y en número no menor de ${ }_{3}^{3}$. Todos los dientes cónicos puntiagudos, con esmalte, de base abierta y en número no menor de 50 en cada lado de cada mandibula. Huesos marsupiales existentes.

Grupo teórico, descendiente de Aguhodonta y antecesor de Pleiodonta. Hasta ahora no le conozco representantes.

\section{PLEIODONTA}

Incisivos presentes en ambas mandibulas y dentición en serie contimua. Mandibula inferior con rama ascendente. Dientes con vestigios de esmalte más o menos perceptible.

Grupo tecirico, en el cual tienen colocación algunos géneros fósiles argentinos que constituyen la familia de los

\section{Entelopsida}

Tres incisivos superiores y tres inferiores, cónicocilíndricos, con capil de esmalte sólo en la cúspide y que luego desaparece con la masticación. Caninos de la misma forma que los incisivos. Todos los dientes en serie continua. Sinfisis de la mandíbula comprimida transversalmente.

\section{ENTELOPS Ameghino}

AMEGrivo: Enumeración sistemática de los mamiferos, etc., página 23, 1887.

Tal como hasta ahora se presentaban, éste es, entre los desdentados, un género verdaderamente anómalo, pues tiene incisivos en la mandibula superior y la mandibula inferior con dentición en serie continua en toda su parte anterior, hasta la misma sinfisis que forma una barba casi vertical. Sólo conozco hasta el día un pequeño fragmento de mandíbula superior y la parte anterior de la mandíbula inferior.

\section{Entezots dispar Ameghino}

AMEghivo: Enumeración sistemática de los mamiferos, etc., página 23, número ro7, 1887 .

La parte de mandihula superior mencionada consiste en un fragmento de la parte anterior del maxilar, con dos dientes, al cual, ade- 
lante, está adherido un pequeño trozo del intermaxilar con la base de un incisivo.

El diente incisivo implantado en el intermaxilar lo está en su parte posterior, de manera que también está casi en contacto con el maxilar. La raiz del diente, que es todo lo que se conserva de él, es elíptica, će 4 milímetros de diámetro anteroposterior y 2 milímetros de diámetro transverso. El interior del diente es sólido al nivel de la rotura; su espesor disminuye rápidamente descendiendo hacia la base, hasta terminar en una punta cónica con una pequeña abertura en su parte inferior.

El diente que sigue, implantado en la parte anterior del maxilar, se halla inmediatamente a continuación del precedente. Es de corona elipticocomprimida, con su parte posterior mucho más angosta que la anterior, de 5 milimetros de diámetro anteroposterior y 3 milímetros de diámetro transverso, arqueado hacia adentro, con la cara perpendicular interna un poco convexa y la externa casi plana. La parte que sale fuera del alvéolo tiene de 7 a 8 milimetros de aito. La parte engastada en el alvéolo debe disminuir de tamaño hacia abajo, como sucede con el incisivo, hasta terminar en punta casi cónica y abierta.

El otro diente que le sigue inmediatamente es de la misma forma general, con la única diferencia de que es un poco más pequeño; la corona sólo tiene 4 milímetros de diámetro anteroposterior y 2 milímetros de diámetro transverso, con su parte superior gastada en declive hacia adentro. La parte que sale fuera del alvéolo tiene unos 8 milímetros de alto y la parte engastada en el alvéolo disminuye de grueso hacia la base hasta terminar en una extremidad pequeña y enteramente abierta.

Los tres dientes ocupan un espacio longitudinal de 15 milímetros en el bòrde alveolar.

E1 trozo de mandibula inferior consiste en la parte anterior de la rama horizontal izquierda con la sinfisis completa, con tres dientes en la parte anterior y hacia atrás los restos de los dos alvéolos. Esta parte ce la mandíbula es gruesa y sumamente corta, con una impresión sinfisaria de 17 milímetros de largo y 6 de ancho. Inmediatamente al lado de la impresión sinfisaria y casi en contacto con ésta, hay un diente muy pequeño, de sección elíptica, con su eje mayor de adelante hacia atrás y comprimido transversalmente, de 2 milímetros de diámetro anteroposterior y apenas 1 milímetro de diámetro transverso.

Inmediatamente al lado y casi en contacto hay un diente más gran. de, elípticotriangular, de 4 milímetros de diámetro mayor y 2 milímetros de diámetro menor.

En seguida y también sin interrupción hay otro diente bastante más grande, de sección elíptica, excavado perpendicularmente sobre la cara 
interna por una depresión ancha y cóncava y de cara externa convexa; tiene $0^{n} 0055$ de diametro auteroposterior y $0^{\text {m }} 0025$ de diámetro transverso. La corona, que está destrozada en los dos dientes anteriores. está aquí entera y forma un plano inclinado hacia afuera y adelante.

Estos tres dientes ocupan un espacio longitudinal de 11 milimetros y supongo que son verdaderos incisivos, que faltan por completo en los demás desdentados que hasta ahora se conocen.

Detrás del último diente mencionado, o sea del incisivo externo, y también sin interrupción, viene un gran alvéolo que indica que allí se implantaba un diente dos tantos mas grande, que supongo corresponde a) caniniforme inferior de los demás gravigrados. Por último, en la parte inferior de la mandíbula se ven pequeños vestigios de otro alréolo que seguía hacia atrás también inmediatamente después del precedente.

De ello puede legitimamente deducirse que la mandíbula inferior de este animal estaha provista de un número considerable de dientes colocados sin interrupción en serie continua y por lo que concierne a la parte anterior de la mandíbula no queda duda de que era realmente así, lo cual constituye, como desdentado, la verdadera particularidad del animal.

En esta parte la mandíbula es algo parecida a la de Bradypus pero con su sinfisis $Y$ ion la harba más vertical, y con tres pequeños agujeros mentonianos escalonacos, uno muy pequeño debajo del borde alveolar, entre los incisivos primero y segundo; otro más grande entre los incisivos segundo y tercero; y el tercero un poco más pequeño y más abajo al lado del incisivo tercero.

La rama horizontal de la mandibula dehe liaber sido muy corta, quizá más todavía que en el Bradypus.

Procedencia: - Los restos de este sigular animal han sido descubiertos por Carlos Ameghino en las barrancas del río Santa Cruz, en Patagonia austral.

Horizonte:- Piso santacruceño (eoceno inferior).

DEILOTHERIUM, $n . g e n$.

Este género se distingue por presentar un intermaxilar bien desarrollado pero corto, por los dientes cónicocilíndricos a cada lado, el interno muy pequeño o rudimentario y los externos más grandes. Las muelas eran numerosas y de la misma forma que los incisivos, de corona muy corta y raíz muy larga. Todos los dientes en serie continua. 
Era éste un animal de talla muy pequeña y de caracteres reptiloides indiscutibles; por desgracia, sólo está representado hasta ahora por un fragmento de maxilar superior izquierdo con el intermaxilar del mismo lado, con el alvéolo rudimentario del primer incisivo, en el cual se ve el alvéolo del segundo incisivo, el incisivo tercero o interno intacto, siguiendo hacia atrís en el maxilar, dos dientes intactos de la misma forma, luego un trecho de maxilar destruído en el cual debian implantarse cuatro dientes, siguịendo después tres dientes en los que falta la corona; aquí el maxilar está roto, pero se conoce que se extendía por un espacio considerable, pues en la superficie del paladar del fragmento existente no se ven vestigios del palatino.

El intermaxilar jzquierdo, muy corto y arqueado en el lado externo, tiene la forma de un segmento de circulo cuya cuerda determina su largo en sentido anteroposterior, que no alcanza a 6 milímetros. La sutura del intermaxilar con el maxilar es bien visible tanto en el lado interno como en el externo. La parte existente del maxilar prueba que el paladar (cuando menos en su parte anterior), era de un ancho uniforms, bastante excavado y de fondo cóncavo; en su parte anterior presentil una escotadura, que es la prolongación del agujero incisivo, que era muy ancho y bastante largo.

Los dientes implantados en este fragmento, tanto en el intermaxilar como en el maxilar. son de forma parecida, presentando únicamente algunas variaciones en el tamaño relativo, aunque no de gran importancia. Son cónicocilíndricos, con la parte superior de la corona un poco comprimida y la base de la raíz apenas un poco más delgada y semiahierta. Estos dientes estín implantados en alvéolos bien separados y profundos, en cuyo fondo no se ven gérmenes de dientes de reemplazamiento continuo como en los reptiles, y con una raiz muy larga en proporción de la corona, cuyos caracteres considerados en conjunto, demuestran que en realidad se trata de un mamífero y no de un reptil, como a primera vista se tendría la tentación de creer. Los más grandes de esos dientes tienen un diámetro de apenas $0^{\text {mo0 }} 012$ y están todo's separados entre sí por espacios regulares que no tienen más de medio milímetro de ancho. La parte superior que forma la corona de cada diente tiene apenas unos dos milímetros de alto y está cubierta For una capa de esmalte de superficie casi lisa, $\sin$ las rayas o estrias longitudinales que se encuentran en tantos reptiles, pero un poco rugosa; esta capa de esmalte es considerablemente más gruesa en el lado externo y muy delgada, casi rudimentaria, en el interno; hacia atajo desaparece cuhierta por una capa delgada más obscura, que refresenta el cemento. 
En los dientes, rotos un poco más abajo de la corona, el corte transversal examinado bajo un fuerte aumento, muestra una capa periférica sumamente delgada que es el cemento: hacia el interior una segunda capa, gruesa en el lado externo y delgada en el interno, que representa el esmalte; una masa interna, más compacta hacia afuera y más porosa en el interior, que corresponde a la dentina y la vásculodentina de las muelas de los desdentados actuales; y por último, hacia el centro, una perforación relativamente consiterable, que representa la parte superior de la cavidad basal de los dientes.

Del primer incisivo superior sólo queda el vestigio del alvéolo, visihe en la parte lestrozada del intermaxilar, pero que no se abría sobre el borde alveolar. lo que demuestra que este diente era sumamente pequeno, que súlo existia durante la juventud y era luego reabsorbido, de donde se deduce que en el Deilotherium ya existía la tendencia a la desaparición de los incisivos, que llevada a su último extremo dió por resultado la formación de los desdentados actuales completamente desprovistos de incisivos.

El incisivo segundo sólo está representado por el alvéolo, que demuestra quć éste cra un diente más largo y más grueso que los demás. por lo matios de dohle tamaño que cualquicra de los otros dientes, pues el alvéolo tiene algo más de 2 milímetros de diámetro.

El fragmento de maxilar existente tient un poco más de 16 milímetros de largo y en él se implantaban 9 dientes, dos que existen intactos adelante, tres un poco rotos atrás y cuatro debían implantarse en la parte destruida del alvéolo; los dos dientes posteriores son un poco más pequeños que los demás. Todos estos dientes son rectos o casi rectos, manifestándose un poco de curva hacia adentro únicamente eli la parte superior de cada uno.

Descle la parte anterior del intermaxilar hasta la parte posterior del fragmento de maxilar existente hay una distancia de 21 milímetros.

Procedencia:- Esta pieza ha sido descubierta por el teniente de fragata Carlos M. Moyano sobre las barrancas del rio Sa:ıta Cruz, en P'atagonia austral.

Hori:onte: - Piso santacruceño de la formación santacruceña (eoceno inferior).

\section{ANICANODONTA}

Los representantes de esta tribu carecen tanto arriba como abajo por completo de incisivos; y las muelas son siempre en corto numero, no más de 4 a 6 en cada lado de cada mandibula, y a veces son completamente desdentados. Dientes generalmente sin esmalte. Carecen 
siempre de un esqueleto externo, aunque en el espesor de la piel de algunos géneros se desarrollaban innumerables pequeños huesecillos. pero sueltos, sin formas definidas y sin constituir, por consiguiente, lo que se llama un exoesqueleto.

Se dividen en tres órdenes que se distinguen de este modo:

I. Arco cigomático incompleto, o por lo menos siempre sin proceso descendente.

a. Dientes en corto número, rudimentarios o ausentes. Cráneo de rostro muy largo: Vermilinguia.

II. Arco cigomático siempre bien desarrollado y con un fuerte proceso descendente que desciende más abajo de las muelas.

a. Cráneo muy corto y aglobado. Cola rudimentaria: Tardigrada.

b. Cráneo cilíndrico. Cola larga y gruesa: Gravigrada.

\section{VERMILINGUIA}

Los representantes de este grupo se distinguen por el cráneo muy alargado, el rostro casi puntiagudo, el paladar muy estrecho y prolongado y la lengua delgada y vermiforme. El cuerpo, sin presentar un exoesquueleto está en algunos géneros cubierto de escamas córneas y er. otros de pelos sumamente gruesos. Gerieralmente carecen de dientes, o éstos son en corto número y rudimentarios o formados por una substancia blanda de menor consistencia que los huesos.

Los géneros que conozco, se agrupan en tres familias, caracterizadas de este modo:

Dientes en corto número o rudimentarios: Orycteropida.

Dientes ausentes. Ramas mandihulares estiliformes y separadas: Myrmecophagida.

Dientes ausentes. Ramas mandibulares soldadas adelante formando un pico que estaba envuelto por un estuche córneo: Phororhacida.

\section{Orycteropidæ}

Esta familia está representada en la actualidad por un solo género, el Orycteropus, exclusivo de Africa, que parece tuvo representantes en 1a República Argentina durante los tiempos eocenos. Hasta este mo. mento, por lo menos, no encuentro otra colocación para el curioso gé. nero que sigue: 


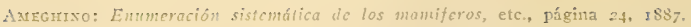

Parece que este género tuvo sólo dos o tres dientes en la parte posterior de la mandibula, mientras la rama ascendente está inclinada hacia atrás formando una prolongación de la rama horizontal. El tamaño del animal ha sido muy pequeño y he designado a la especie con el nombre de

SCOTAEOPS SIMPLEX Aneghino

Amérino: Enumeración sistcmática de los mamiferos, etc., página 24 , número $108,1887$.

Sólo está representado por un fragmento de mandíbula inferior del lado derecho, formado por la parte posterior de la rama horizontal y la parte anterior de la rama ascendente, cuyo fragmento sólo tiene 19 milímetros de largo. La rama horizontal es de un alto uniforme y sólo tiene 8 milimetros de elevación y $0^{m} 0035$ de espesor, con un canal alveolar de gran tamaño en su parte inferior. El horde superior o alveolar es bastante espeso, pero sólo presenta dos alvéolos pequeños y cilíndricos, de sólo un milímetro de diámetro en su parte posterior, de manera que parece que adelante no tuvo otros dientes. Detrás del último alvéolo, la rama horizontal se prolonga algunos milímetros más, pasando insensiblemente a la rama ascendente, inclinada hacia atrás como una simple prolongación de la rama horizontal.

Pruedencia: Esta pieza ha sido descubierta por Carlos Ameghino en las barrancas del rio Santa Cruz, en Patagonia austral.

Horizonte: - Piso santacruceño (eoceno inferior).

\section{Myrmecophagidæ}

Estos animales, completamente desprovistos de dientes, están representados en la actualidad por dos géneros, uno, el género Manis, profio de Asia y Africa; y otro, conocido con el nombre de Myrmecophaga, que vive en América del Sud.

\section{MYRAECOPIIAGA Limeo}

Linnto: Systoma Naturae, etc., tomo I, página $\leq 2$,

Cráneo sumamente largo y estrecho, de figura casi cilindrica. Plano cocinital pequeno e inclinado hacia adelante. Superficie superior del críneo lisa. Parietales pequeños y angostos. Frontales muy prolongados. Nasales largos y estrechos. Intermaxilar corto. Arco cigomático in. 
completo pero no desprovisto de malar, que es pequeño y articulado con el maxilar sin que su parte posterior se ponga en contacto con la apófisis cigomática del temporal. Orbitas confundidas con las fosas temporales por la ausencia de apófisis postorbitarias. Paladar angosto y sumamente largo, extendiéndose hacia atrís hasta el nivel del meatus auditorio externo. Ramas mandibulares largas, estiliformes, de sinfisis corta y sin apófisis coronoides. No más de 17 vértebras dorsolumbares. Esternon de diez piezas. Omoplato bastante parecido al de los gravigrados. Clavículas ausentes o rudimentarias. Los huesos de los miembros todos separados.

Hay dos especies existentes que forman parte de la fauna actual de nuestro territorio.

- Mrrmecopilagi jlibata Linneo

I,INNEO: Systoma naturae, etc., tomo I, página 52 .

Cuvier: Règre antịnal, tomo I, página 231 .

Habita los territorios de Misiones y el Chaco. No se conoce fósil en la República Argentina, pero según Liais existe fósil en las cavernas de Brasil.

MYRMECOPHAGA TETRADACTYLA Linneo

Myrmecophaga tefradactyla. L, inné: Systema naturae, tomo I, página 52.

Myrmecophaga tamandua. CuVIER: Règne animal, tomo I, página 232.

Habita los territorios del Chaco y de Misiones. No se conoce fósil en 12 Reptiblica Argentina, pero según Liais se han encontrado sus restos en los depósitos fosilíferos de las cavernas de Brasil.

\section{Phororhacida}

Familia completamente extinguida, cuyo tipo es el género

\section{PHORORIIACOS Ameghino}

AMEgrino: Einumeración sistemátic de los mamiforos, etc., página 24 , r88.

Desdentado singular, de colocación incierta, de gran talla, con manc:bula inferior muy prolongada y al parecar completamente desdentada, como la del género Myrmecophaga, de la cual difiere por caracteres notables que la acercan a la de los reptiles.

\section{Phorokuracos Loncrssime's Ameghino}

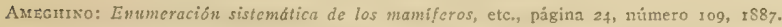

Este animal sólo está representado por ia parte media de la mandíbula inferior comprendiendo la sinfisis, en la que falta la punta, $y$ las ramas horizontales, en las que falta la parte posterior. Esta man- 
díbula, cuando entera, tuvo por lo menos la talla de la del Scelidotherium leptocephalum y fué seguramente más prolongada.

Las dos ramas mandibulares están completamente soldadas, habiendo desaparecido casi todo vestigio de sutura, formando una sinfisis sólida, gruesa, cóncava arriba, convexa abajo y prolongada hacia adelante en forma le pico. La parte existente de la sínfisis tiene 13 centímetros de largo, pero está rota en la parte anterior y es posible que cuando entera se prolongara unos 8 a 10 centímetros más. La parte sinfisaria tiene 67 milímetros de ancho en su extremidad posterior, angostándose gradualmente hacia adelante hasta que en la parte anterior, donde está rota, sólo tiene 32 milímetros de ancho. Su grueso, hacia atrás, alcanza en algunos puntos hasta cerca de 4 centímetros, pero disminuyo considerablemente hacia adelante.

La parte externa de la sinfisis, formada por las caras laterales y la inferior, presenta una superficie muy convexa, rugosa en toda su extensión, con un considerable número de agujeros vasculares de diferentes diámetros, que reemplazan al agujero mentoniano, acompañados de una considerable cantidad de surcos y canales vasculares, unos muy pequeños y otros de uno a dos milímetros de diảmetro.

La superficie superior o interna es fuertemente excavada en su parte posterior, en donde forma una depresión de fondo cóncavo limitada por altas paredes laterales, que se hacen más bajas hacia adelante, siendo ya poco pronunciadas en la parte donde la sínfisis está rota $y$ donde muestra una ancha superficie casi plana, de manera que la parte anterior de la sinfisis que faita debia presentar una superficie superior completamente plana. La superficie de la cara superior de la sínfisis es igualmente rugosa, con perforaciones, surcos y canales vasculares como la inferior y externa y con fuertes impresiones musculares en su parte posterior.

En su parte libre, las ramas horizontales divergen gradualmente hacia atrís. fero aún no es posible formarse una idea de su conformación general, pues las partes conservadas son muy incompletas. De las dos ramas, la izquierda es la que se presenta más completa, extendiéndose la parte que de ella se conserva unos 11 centímetros atrás de la parte posterior de la sínfisis: es delgada, comprimida lonsitudinalmente hacia la mitad ce su a!tura, con borde superior delgado y rugoso y sin el más minimo vestigio de dientes ni de alvéolos, ni aun atrofiados. E1 alto de la rama horizontal inmediatamente detrás de la parte sinfisaria es de 55 milímetros, y su espesor varía entre 72 a 20 milímetros. La parte rota de la rama deja en parte a descubierto el canal alveolar Gue la recorre en todo su largo penetrando en la sínfisis. La cara interna es relativamente lisa, un poco más rugosa hacia arriba y con una serie de perforaciones colocadas en serie longitudinal más o menos a la mi- 
tad de su altura. La cara externa es más rugosa y con la misma línea longitudinal de perforaciones longitudinales, pero más grandes y más numerosas, que se prolongan más adelante en la parte sinfisaria aunque acercándose más al borde superior.

Mirando de lado la mandibula, representa una especie de pico gigantesco cuya linea inferior representa una especie de S prolongada que forma una línea cóncava debajo de la rama horizontal, una línea convexa debajo de la parte posterior de la sínfisis, que se prolonga luego hacia adelante en línea ascendente, al mismo tiempo que la línea formada por el borde superior desciende hacia abajo, disminuyendo así gradualmente hacia adelante el diámetro perpendicular de la sínfisis.

El trozo existente de esta curiosa mandíbula tiene 24 centímetros de largo, pero cuando entera debia tener otro tanto más.

Por los caracteres mencionados puede deducirse con perfecta segu. ridad no sólo que la mandibula no tuvo dientes, sino que su parte ante. rior, constituida por la sínfisis y la parte anterior de las ramas horizontales, estuvo durante la vida del animal envuelta en un estuche córneo, parecido al pico de las aves y más todavía al que envuelve la mandibula de las tortugas.

Procedencia: - Esta notabilísima pieza ha sido descubierta por Car- . los Ameghino en las barrancas del río Santa Cruz, en Patagonia austral.

Horizonte: - Piso santacruceño (eoceno inferior).

\section{TARDIGRADA}

Forman este grupo los animales de las regiones cálidas de América, conocidos con el nombre de perezosos, de una conformación tan singular que un naturalista y anatomista ilustre como de Blainville, llegó a considerarlos como cercanos de los monos. Sin embargo, el estudio de la conformación del sistema dentario y demás caracteres morfológicos ciel esqueleto, han demostrado que ambos grupos están separados por un verdadero abismo.

El cráneo de los perezosos es corto, oval, de rostro corto y truncado adelante, con la parte anterior ocupada por la abertura nasal que adcuiere un desarrollo considerable. El intermaxilar es rudimentario. El arco cigomático es incompleto, porque su apófisis posterior no se une con la apófisis cigomática del temporal, pero presenta en cambio una fuerte apófisis descendente que llega más abajo del borde alveola: de la mandíbula inferior. La mandíbula inferior tiene una abertura externa del canal alveolar. Los dientes son siempre en número de ${ }_{4}^{5}$. 
Tienen de 24 a 28 vértebras dorsolumbares. El sacro consta de 5 a 7 vértebras. La cola es rudimentaria, nula o poco visible en el exterior y compuesta de 5 a 10 vértebras. Todos los huesos largos de los niembros son separados. Omoplato con acromion y apófisis coracoides muy desarrolladas. Casi tojos los huesos del tarso y del carpo son soldados entre si ! con los metacarpianos y metatarsianos. Falanges también en parte soldadas. Dedos en número de dos o tres en cada pie.

No se conocen hasta ahora representantes fósiles de este orden.

\section{GRAVIGRADA}

La dentición de los gravígrados consta, por regla general, de $\frac{5}{4}$ dientes, como en los perezosos, pero la disposición, desarrollo y aspecto de estos dientes varía de una manera extraordinaria, según los géneros.

Hasta ha poco tiempo vino considerándose a los desdentados en general como mamíferos de una dentición imperfecta, sin incisives, sin caninos, de muelas de forma sencilla y uniforme, más o menos parecidas en todos los géneros y presentando en todos una estructura de composición más sencilla y uniforme, carentes de esmalte todos y presentando, por consiguiente, sólo una capa externa de cemento y una interna de dentina que se divide a su vez en dos partes, una capa externa más dura y una masa interna más blanda, conocida con el nombre de vásculodentina.

La opinión se ha modificado por cuanto se refiere a la forma sencilla ₹ uniforme de la dentadura de los desdentados, no habiendo contribuido poco por mi parte a ese cambio de ideas que sólo estaban fundadas en un pequeño número de géneros. Hoy sabe todo el mundo que hay desdentados, desde los que carecen absolutamente de muelas hasta los que tienen un centenar: que hay desdentados con muelas cuadradas, circu lares, elípticas, triangulares, lameliformes, etc.; que hay desdentados con muelas simples como los armadillos o compuestas como los Gliptodontes, o bilobadas en distintas formas; que hay desdentados con incisi. vos; que en algunos. los dientes anteriores adquieren forma de incisivos de roedores, como en el Megalochnus; que en otros toman la forma de formidahles caninos, como en el Lestodon; que en otros representahan formidables defensas, como en el Diodomus, etc.; y en mi Filogenia, he dado variados ejemplos de cómo casi todos los géneros de desdentados pueden caracterizarse por una fórmula dentaria distinta, de una representación gráfica sencillisima (1).

(x) Amegnino: Filogenia, páginas 229 y siguientes, 1884 ; y página 397 y siguientes. del volumen IV de esta edición. 
Me parece que idéntico cambio de ideas se efectuarí en breve con respecto a la pretendida sencillez y uniformidad de composición de las muelas de los desdentados. Así si sólo se toma en cuenta a los desdentados fósiles pampeanos, ya no es posible identificar la capa externa más o menos gruesa, llamada cemento, que rodea a las muelas de los Mylodon y los Lestudon, quebradiza y que se separa y fragmenta con la mayor facilidad, con la capa de cemento externo que rodea a las muelas de Megatherium, menos vidriosa, homogénea, compacta y resistente. Ni es posible tampoco identificar la masa interna de dentina blanda de las muelas de los Mylodon y los Lestodon con la lámina interna de dentina dura de las muelas de los Glyptodon. Y hay algunos desdentados que tienen muelas de una composición aún más simple (Pliomorphus) en las que no se ve más que una delgada capa externa de cemento y una masa interna de dentina homogénea. Pero también los hay que presentan una composición más complicada, y de ella voy a ocuparme, aunque por ahora no con la extensión que la importancia de la cuestión requiere. pues sólo puede ser tratada con la amplitud que merece en un trabajo que le sea especialmente dedicado.

Ya por razonamientos distintos habia llegado a probar que los mamiferos de dientes simples, sin esmalte, provistos únicamente de cemento, dentina y vasidentina, debian esa simplicidad no a una causa originaria, sino a una modificación evolutiva de un tipo anterior, cuyas muelas estahan provistas de esmalte (1). Esa modificación, en grado más o menos avanzado, no se ha limitado sólo a los desdentados, sino también a varios otros órdenes, de entre los cuales puedo mencionar, como que están de un modo especial en este caso, el extinguido orden de los Toxodontes y el todavía existente de los roedores, en el cual se puedent encontrar, ejemplos de esta evolución y en un grado ya muy avanzado, en el existente género Ctenomy's. Estudiando los diferentes géneros de los dos órdenes mencionados se pueden encontrar numerosos estados intermedios de la lámina de esmalte, desde la substancia vidriosa y sumamente dura, comparable a la que guarnece la superficie de las muelas de los mamíferos bunodontes, hasta aquella que ha perdido su trillo y aspecto vidrioso y se confunde con la dentina.

En definitiva, las mismas muelas de los desdentados conocidos como que presentan una composición simple, se componen de tres capas dis. tintas, una interna de dentina blanda en vez de dentina dura y una intermedia de dentina dura en vez de esmalte, pero ocupando la misma posición relativa que ocupa este último en las muelas de los arimales provistos de esmalte.

Si en realidad las muelas sin esmalte son una modificación evolutiva

(2) Filogenia, página 268, x884; y página 427 del volumen IV de esta edición. 
de las muelas provistas de esmalte, es natural suponer que esta lámina de dentina interna ha reemplazado poco a poco al esmalte, substituyéndosele de modo que entre esta forma, en que la lámina de esmalte está representada por una capa de dentina y el estado esmaltado primitivo, deben existir numerosos estados intermedios.

Las muelas del Megatherium americanum de la formación pampeana presentan a menudo ejemplos de una pequeña modificación en su composición, que está fuera de la regla normal admitida. Obsérvase en algunas de ellas, que al lado de la capa intermedia de dentina dura, hay en el lado interno otra capa de dentina algo más ancha, más blanda que la anterior, de la cual se distingue apenas por el color, pero que es más dura que la vásculo dentina interna a la cual rodea.

Pero esta subdivisión de la capa dura intermedia es mucho más perceptible en los gravigrados de los terrenos terciarios antiguos; y cuando menos en ciertos géneros, a menudo completa, conservando una de las capas que representa la dentina dura un color blancoamarillento, mientras que la otra más dura y más delgada que representa al esmalte, es de aspecto vítreo, más o menos transparente y con un brillo de porcelana.

El cráneo de los gravigrados es relativamente largo, pero en vez de tender hacia la forma esférica es más bien cilíndrico y presenta a veces casi el mismo grueso adelante y atrás, teniendo siempre la parte anterior como truncada, con una apertura nasal muy ancha y limitada por los maxilares y nasales, con exclusión del intermaxilar, que en muchos casos es rudimentario. La parte superior del cráneo es generalmente lisa, presentando raras veces una cresta sagital y más rarariente todavía, una cresta occipital. El llano occipital es siempre pecitieño e inclinado oblicuamente de adelante hacia atrás $y$ de arriba hacia abajo. La cavidad cerehral es siempre pequena. La región dentaria de los maxilares y de la mandibula inferior ocupa una extensión considerable. debido al gran desarrollo en longitud de las muelas. La mandíbula inferior, muy fuerte, tiene una rama ascendente muy ancha; y el canal alveolar de la rama horizontal presenta en su parte fosterior una rama externa que se abre sobre el lado externo en la base de la rama ascendente. El arco cigomático es incompleto, a causa del malar, de una forma muy particular, con dos ramas principales, de las cuales la que se dirige hacia atrás y que debiera unirse a la apófísis cigomática del temporal, no alcanza hasta este hueso, quedando entre ambas apófisis un espacio bastante ancho, con excepción de un solo género: el Megatherium, en el cual el arco cigomático es completo; la segunda apófisis del malar se dirige hacia abajo, descendiendo considerablemente más abajo que el borde alveolar de la mandibula inferior. Las órbitas son pequeñas y mal delimitadas. 
Las vértebras dorsales son, por lo general, 16 y las lumbares 3 , todas con sus apófisis espinosas dirigidas hacia atrás. El sacro consta de 5 vértebras, pero a menudo se le unen una o dos y a veces las tres lumbares. La cola se compone de 18 a 24 o más vértebras las primeras sumamente gruesas y con grandes neurapófisis y hemapófisis.

Los huesos largos carecen siempre de cavidad medular. El miembro anterior es siempre un poco más largo que el posterior, terminando en una extremidad más o menos prehensil. Las claviculas son muy fuertes El omoplato es muy grande y con un acromion enorme cuya apófisis sc desarrolla hasta ponerse en contacto con la apófisis coracoides, con 1i que se suelda dando a este hueso una forma particular y caracterıstica, presentando además una perforación bastante grande detrás de la apófisis coracoides. El cuibito y el radio son siempre separados.

La cadera presenta un desarrollo extraordinario, con huesos iliacos sumamente grandes y el isquion soldado al sacro. El fémur es un hueso corto, extremadamente ancho y relativamente muy delgado, que cası presenta el aspecto de un hueso plano. La tibia y el peroné son más cortos y generalmente soldados. La articulación de la rodilla tiene, además de la rótula, una fabella y un tercer hueso sesamoides designado por Burmeister con el nombre de sepiculum.

El pie posterior es siempre plantígrado, pero oblicuo y con un calcáneo de tamaño extraordinario.

Los huesos del carpo y del tarso varían en número, encontrándose algunos soldados; y los dedos son igualmente en número variable, según los géneros. En diversos géneros se desarrollaban en el espesor de li piel un considerable número de huesecillos informes que están en contacto entre si, sin interrupción sobre toda la superficie del cuerpo, pero que no formaban un exoesqueleto.

Todos los representantes de este orden son hoy extinguidos y parecen haber sido exclusivos de América, y en particular de América del Sud.

Fácil era en un tiempo dividir en secciones a los desdentados sin coraza o con coraza rudimentaria comprendidos en el nombre de perezosos. Una sección, los tardigrados (Tardigrada), era formada por los perezosos que actualmente existen, todos de pequeña talla, rostro corto y cola rudimentaria. Otra sección, designada con el nombre de gravígrados (Gravigrada), comprendía tres o cuatro géneros extinguidos que sa distinguian fácilmente de los existentes por su talla gigantesca y su colı muy desarrollada. Pero a medida que avanzaban las investigaciones paleontológicas aumentaba también el número de representantes de esta sección, hasta que se sintió la necesidad de subdividirla.

En 1885, en mi tercera Nilemoria sobre los Mamíferos fósiles oligocinns del Paraná ( «Boletín de la Academia Nacional de Ciencias», tomo VIII), propuse la división de los gravígrados en dos grupos que 
denominé Granistalu rudimurph y. Grantigrada mylomorpha, colocando en el primer grupo a aquellos cuyo primer par de dientes anteriores afectaban la forma de incisivos o caninos, como en el Megalochnus y el Lestuiton; y en el segundo a aquellos que presentaban todas las muelas dispuestas para mascar, como el Megatherium y el Mylodon. Pero esta división no satisfacia mis deseos y tuve buen cuidado de agregar que no la creía natural, y que súlo la proponía provisoriamente como un ensayo para facilitar el estudio. dejando al tiempo el cuidado de darnos la clave para una división en grupos naturales.

En el notabilísino trabajo que el doctor Burmeister acaba de publicar sotre el esqueleto de los gravígrados 1 «Osteología de los gravigrados - perezosos gigantescos $\%$, 1SS6), ensaya también una división de los sravigraulos en dos grupos naturales, designándolos con el nombre dz Oryadonta y Colutodonta, hasándose en primer término en la forma Je las muelas, que dice son en los Oxyodontes con dos crestas transversales agudas, como en el Megatherium y el Neoracanthus; y en los Colutodontes de corona más obtusa y excavada en el centro como en el Myloton y el Scclidutherinm. Agrega que cada una de estas dos formas de muelas está acompanada de una posición distinta en la abertur. externa del canal alveolar, que es siempre en el lado interno de la rama ascendente en el primer grupo o de los Oxyodontes y en el lado externo en el segundo o de los Colutodontes.

Pero esta division no es natural tampoco, pues coloca entre los Oxyodontes a gémeros que tienen la abertura externa del canal alveolar en el lado externo de la rama ascendente, como sucede con el Colodon.

En esta división de los gravígrados efectuada por el ilustre maestro, lo que más me ha llamado la atención es el empleo de la posición de la abertura de la rama externa del canal alveolar como distintivo de dos grupos. pues éste parece un carácter sujeto a pocas variaciones para nuevas adaptaciones, que aplicado a la caracterización de los gravígrados pampeanos, los divide en dos grupos que me parecen realmente naturales, el que presenta la perforación en el lado interno de la rama ascendente y el que la tiene sobre el externo, pero a los que no son aplicables los nombres de Oxvodonta y Colutodonta que se refieren a los dientes y que ya he dicho no concuerdan siempre con la posición del agujero de la rama externa del canal alveolar.

Con todo, habria adoptado esta división si los desdentados relativamente numerosos traidos por mi hermano Carlos Ameghino de los terrenos eocenos de Patagonia austral no fueran rebeldes a toda división por este sistema, pues en su casi totalidad no presentan la abertura de la rama externa del canal alveolar ni sobre el lado interno de la rama ascendente como en el Megutherium, ni sobre el externo como en el Alylodon, ocupando en cambio una posición intermedia entre uno y 
ntro, en la parte anterior de la base de la linea anterior de la rama ascendente. Otro tanto sucede con la dentadura, pues también en la mayoria de los casos las muelas no se parecen ni a las de los Oxyodontes, ni a las de los Colutodontes, presentando una forma intermedia entre ambos tipos.

Pero no sólo hay dificultales para sublividir a los gravigrados, sino que también se hace cada vez más dificil separar a éstos de los tardigrados.

Las dificultałes empiezan ya con algunos géneros pampeanos, por ejemplo: el Nothropus, considerado por Burmeister como un tardigradu antecesor del Cholopus, por más que a ello se oponga su tamaño considerable. su sinfisis mandibular demasiado prolongada, sus muelas so. bre el tipo de las del Neoracanthus y el Celodon y hasta el mismo diente caniniforme muy diferente del que presenta el género Cholcpus, que cfrece más parecido con el del Lestodon. Y por mi parte encuentro mucho más parecido entre las mandibulas de Mylodon y Bradypus que entre las de Nothropus y Cholopus.

Por lo que atañe a los géneros del eoceno, son en su mayor parte demasiado pequenos para ser considerados como gravigrados, siendo algunos de talla más reducida todavía que la de los Bradypus actuales. Pero con todo sería demasiado aventurado asegurar que sean más bien tardigrados, pues éstos por su cola rudimentaria indican un alto tipo de especialización, que debe haherse constituido en tiempos geológicos relativamente recientes, y se puede suponer con mayores probabilidades de no incurrir en error que los antiguos perezosos tuvieron una cola larga y gruesa como la de los gravígrados pampeanos.

En definitiva, la posición de la abertura de la rama externa del canal alveolar, dividiría a los gravigrados no en dos, sino en tres grupos diferentes, pero algunos de ellos con géneros muy heterogéneos por la disposición del aparato dentario. Para una Jivisión en grupos naturales habría que tomar en cuenta tanto la posición de la abertura de la rama externa del canal alveolar como la forma de las muelas en general; y luego, en particular, las diferentes disposiciones que en ciertos géneros toman la primera y la úítima muela de cada mandíbula. Entonces, en lugar de dos o tres, tendremos seis grupos o familias diferenter, que se distinguen de esta manera: 


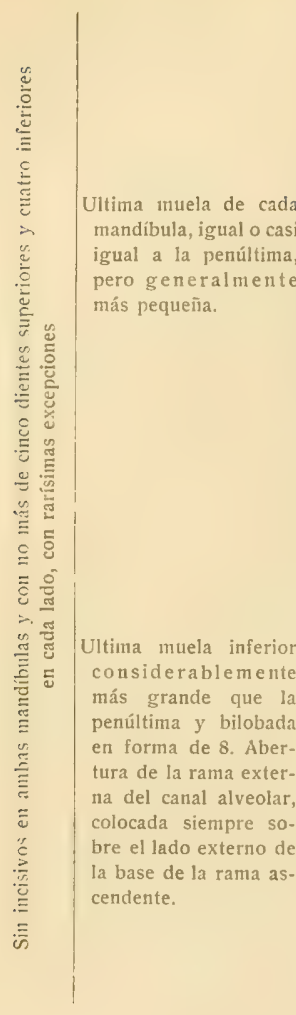

Muelas en forma de prismas cuadrangulares con dos crestas transversales en la corona y todas más o menos de la misma forma. Abertura de la rama externa del canal alveolar sobre el lado interno de la rana ascendente. Intermaxilar largo y bien desarrollado

Megatherida.

Muelas en forma de prismas cuadrangulares con dos crestas transversales en la corona, menos la anterior de cada mandibula, que es elípticocilindrica y a veces bastante separada de la segunda. Abertura de la rama externa del canal alveolar en la parte anterior de la base de la rama ascendente. Orthotheride.

Muelas en forma de prismas subcuadrangulares con dos crestas transversales en la corona, menos la primera que está colocada en la parte anterior de la mandibula en forma de incisivo. Abertura de la rama externa del canal alveolar sobre el lado externo de la base de la rama ascendente. Intermaxilar rudimentario.

Megalonj'cida.

\begin{tabular}{|c|c|}
\hline $\begin{array}{l}\text { Intermaxilar } \\
\text { muy largo y } \\
\text { bien desarro- } \\
\text { llado. }\end{array}$ & $\begin{array}{l}\text { Muelas subprismáticas triangulares } \\
\text { la primera de cada mandibula no } \\
\text { separada de la segunda. Ultima } \\
\text { muela superior muy pequeña } \\
\text { triangular. }\end{array}$ \\
\hline & $\begin{array}{l}\text { Muelas intermedias de cada mandi } \\
\text { bula prismáticas y diferentes } \\
\text { Ultima superior bilobada. Primera } \\
\text { de cada mandíbula apenas un poco } \\
\text { separada de la segunda. } \\
\text { Mylodontida }\end{array}$ \\
\hline $\begin{array}{l}\text { it erma xilar } \\
\text { rudimentario. }\end{array}$ & $\begin{array}{l}\text { Muelas intermedias de cada man- } \\
\text { dibula elipticocilindricas. U1tima a } \\
\text { superior de la misma forma y más } \\
\text { pequeña. La primera de cada man- } \\
\text { dibula muy separada de las otras, } \\
\text { tomando la forma de grandes ca- } \\
\text { ninos. Lestodontide. }\end{array}$ \\
\hline
\end{tabular}

\section{Megatheridæ}

Los representantes de este grupo se distinguen fácilmente por un conjunto de caracteres que no permiten confundirlos con ninguno de los géneros de las familias cercanas.

Las muelas, generalmente en número de cinco arriba y cuatro abajo, en cada lado de cada mandibula. son todas uniformes, constituyendo un frisma cuadrangular muy largo, abierto en la base y con dos crestas transversales en la corona más o menos desarrolladas; todas las mue. 
las son, con poca diferencia, del mismo tamaño, exceptuada la última que, por lo general, es un poco más pequeña; y todas las muelas de cada lado formando una serie continua en el fondo del paladar, it igual distancia unas de otras.

El paladar es angosto y con poca diferencia del mismo ancho en todo el espacio octupado por la serie dentaria.

El intermaxilar es muy desarrollado aunque carece de dientes, prolongándose adelante en forma de punta delgada y aislada, acompañada por la parte anterior de la mandíbula inferior, cuya parte situada delante de las muelas se angosta y se dirige adelante acompañando en su prolongamiento al intermaxilar.

En la mandíbula inferior, la abertura externa del canal alveolar está colocada constantemente sobre el lado interno de la base de la rama ascendente, en el lado externo de la última o de la penúltima muela.

Calcáneo ancho y aplastado de arriba hacia abajo.

Conozco seis géneros de esta familia, que se distinguen de esta manera:

I. Muelas sin vestigios de la capa interna de esmalte.

1. Las dos crestas transversales de la corona de cada muela bien desarrolladas durante la vida.

a. Muelas $\frac{5}{4}$ : Megatherium.

b. Muelas $\frac{4}{3}$ : Essonodontherium.

2. Muelas con una sola cresta transversal en la corona, bien desarrollada, cuando adultos.

a. Una sola cresta transversal, tanto en la juventud como en la vejez: Ocnopus.

$b$. Dos crestas bien desarrolladas en la juventud, una de las cuales desaparece con el desgaste: Neoracanthus.

II. Muelas con vestigios de una capa de esmalte interno, más o menos rudimentaria.

1. Tamaño considerable, comparable al de un gran Mylodon.

a. Muelas cuadrangulares, de ángulos bien marcados y con dos crestas transversales en la corona, bien desarrolladas: Promegatherium.

b. Muelas de ángulos redondeados y con las crestas transversales de la corona ausentes o poco acentuadas: Interodon.

2. Tamaño muy pequeño, comparable al de un perezoso actual: Zamicrus. 


\section{MEGATHERIUTI Cuvier}

Cuvrer: Tableans tementaire de l'Histoire Naturelle, página $246,1798 .-\$ 4 n$ nales du Muséum d'Histoire Naturelles, tomo Y, 2804.

El género Megatherium tiene is muelas dispuestas según la fórmula ${ }^{j}$, casi todas de tamaño considerable, presentando cada una la forma Le una columna prismátioa cuadrangular, oblonga, de diámetro transverso un poco mayor que el diámetro anteroposterior, con las caIas perpendiculares anterior y posterior planas o ligeramente convexas y las caras perpendiculares externa e interna generalmente un poco deprimidas perpendicularmente en el centro. La base está completamente abierta y al principio tiene paredes tan delgadas como una hoja de papel, pero se vuelven progresivamente más gruesas hacia irriba. achicándose la cavidad en la misma proporción hasta que desaparece antes úe llegar a la mitad de la altura de la muela, presentando un aspecto infundibuliforme. La corona de cada diente presenta dos crestas transversales agudas que aparecen desde la primera juventud Y persisten durante toda la vida, separadas por una ranura transversal profunda que divide a la muela en dos partes iguales o casi iguales, una anterior y otra posterior.

Cada muela se compone de una masa interna muy porosa y blanda, cue es la vásculodentina. rodeada por una capa de dentina dura relativamente muy delgada, que envuelve completamente a la vásculodentina y asciende en forma de lámina delgada para constituir la cúspide o arista de cada una de las crestas transversales. La dentina está a su vez cubierta por una capa de cemento muy delgada en las caras externa e interna, pero muy gruesa en las caras perpendiculares anterior y posterior.

De las cinco muelas superiores, la última es mucho más pequeña qque las otras y la primera de cara perpendicular anterior bastante convexa. En la mandíbula inferior las cuatro muelas son más iguales, cunque la posterior es siempre un poco más pequeña que la primera.

El cráneo es estrecho y largo, de tamaño pequeño en proporción del cuerpo del animal.

El intermaxilar es estrecho, delgado y muy largo, prolongándose considerablemente más adelante que los nasales.

La ragicin frontal es ancha adelante, un noco convexa y más estrecha cietrás de las orhitas. Las crestas temporales ascienden hacia arriba hasta formar una superficie sagital estrecha y larga, a lo cual no puede dársele el nombre de cresta y que se prolonga hasta la cresta occipital.

El arco cigomático, al contrario de 10 que sucede con los demás gravígrados conocidos, se une por su apófisis posterior a la apófisis cigomá- 
tica del temporal para formar un arco ininterrmpijo que hacia atris, conjuntamente con la prolongación posterior de la apófisis cigomática del temporal (de un desarrollo enorme) y las crestas temporales supe. riores, limitan una fosa temporal de dimensiones extraordinarias.

El paladar es estrecho, casi plano y de superficie rugosa, con numerosas perforaciones vasculares.

Los cóndilos occipitales son de gran tamaño, pero la superficie del hueso occipital es peụuena, semicircular y casi perpendicular, limitada arriba y a los costados por una cresta no muy elevada pero gruesa.

Los maxilares superiores son notahles por su alto extraorjinario en relación con el largo enorme de las muelas, lo que le da al cráneo en esa región un diámetro vertical desproporcionado.

La mandibula inferior es de una forma singular y enteramente característica de este género; la rama ascendente es muy alta y delgada; la parte sinfisaria con sus dos mitades soldadas es angosta, haja y muy prolongada hacia adelante; el cuerpo de la rama horizontal en que están implantadas las muelas es, al contrario, sumamente grueso y alto, formando hacia abajo una gran curva descendente, destinada a contener los grandes alvéolos en que se implantan los enormes prismas que constituyen las muelas inferiores, no menos largas que las superiores. Las vértebras cervicales son de proceso transverso perforado; y a excepción de las dos primeras, de tamaño relativamente pequeño (siendo su número de siete como en la casi totalidad de los mamíferos), todas de cuerpos cortos y sensiblemente planos, constituyendo un cuello relativamente corto.

Las vértebras dorsales, en número de 16 , son de tamaño mucho mayor y casi todas con apófisis espinosas sumamente largas.

La región lumbar consta de tres vértebras. cuyos cuerpos presentan un desarrollo extraordinario.

El sacro consta de 5 vértebras soldadas, que por dos puntos distintos se ponen en contacto con la cadera.

La cola, sumamente fuerte y gruesa, consta de 19 vértebras; las primeras de un tamaño extraordinario y con arco neural completo, conservándose el canal vertebral hasta la décimacuarta y con hemapófisis igualmente bien desarrolladas, pero separadas y no soldadas a los cuerpos vertebrales, con los cuales se unen por superficies articulares que persisten durante toda la vida.

El esternón se compone de 8 piezas o esternebras distintas y no de 7 como algunos afirman, a las cuales se unen directamente 8 o 9 pares de costillas, articulándose las demás por medio de piezas esternocostales completamente osificadas.

Toda la mitad anterior del tronco, és, en su conformación, más delgada y menos sólida que la posterior. 
Los miembros anteriores son igualmente más delgados y menos fuertes que los posteriores, pero bastante más largos. La clavícula, bastante larga, redondeada, un poco arqueada en forma de S y engrosada en sus dos extremidades, es, no obstante, de un tamaño extraordinario. El omoplato, de forma triangular, es también de grandes dimensiones.

El húmero es largo pero muy delgado, un poco más robusto en su extremidad distal y desprovisto de perforación sobre la epitroclea. El cúbito y el radio son igualmente largos, delgados y separados en todo su largo.

El pie anterior es más robusto de 10 que denotarian los huesos largos de los miembros, de gran tamaño y alcanza una longitud casi iguai a la del antehrazo. El carpo está formado por ocho huesos, aunque el trapecio está soliado al metacarpo del dedo primero o pulgar, que está atrofiado, no existiendo de él más vestigio que el metacarpiano mencionado. E1 liejo quinto también está en parte atrofiado, pero tiene un metacarpo completo e independiente, seguido de dos falanges achaparradas y sin uña. Los tres dedos del medio son bien Jesarrollados, con grandes metacarpianos, pero con falanges cortas y gruesas, de aspecto cuboide, terminando cada dedo en una falange ungueal de tamaño enorme. Las dos primeras falanges del dedo del medin están soldadas formando un solo hueso.

E1 miembro posterior es un poco más corto que el anterior, pero mucho más robusto to lavia. La cadera fresenta un desarrollo tan extraordinario que parece incompatible con un animal dotado de la facultad de locomoción; los huesos ilíacos forman dos crestas triangulares enormes que se dirigen a los lados formando casi un ángulo recto con la columna vertebral; y los isquion presentan atrás una segunda soldadura de la cadera con la parte posterior del sacro, formando asi un l:ueso de una resistencia excepcional. Los huesos pubis están soldados en su parte inferior formando un gran arco, y la gran cavidad cotiloides destinada a recibir la cabeza del fémur estŕ casi completamente vuelta hacia ahajo, dando a este liltimn hueso el aspecto de un pilar que sostiene un aparato inmenso.

El fémur tiene una forma rectangular, con un ancho casi igual en sus dos extremidades y una circunferencia tres veces mayor que el del elefante, con la gran cabeza articular casi en la misma dirección que la línea del fémur y sin cuello o con cuello apenas rudimentario.

La rótula es un huteso pequeño en proporción de los demás huesos y en proporción clel tamaño que presenta en los demás representantes del mismo orden.

La tibia y el peroné son más cortos que el fémur, presentando el aspecto de dos columnas separadas en el centro, formando algo asi como una ventana y soldados en sus dos extremidades distal y proximal. 
El pie posterior es de una potencia extraordinaria, con un calcáneo macizo, largo, plano en su parte inferior, con la tuberosidad fusterior muy extendida hacia atrás. El astráģalo es también sumamente fuerte y de una forma particular, pero parecida a la que presenta en los demás gravigrados. El escafoides también es de gran tamaño. El mesotarso se compone del cuboides y de dos cuneiformes, faltando el entocuneiforme. El pie termina por tres dedos que corresponden al tercero, cuarto y quinto, faltando completamente el primero y el segundo, de los cuales no se conservan ni rudimentos de los metatarsianos. De los tres dedos existentes, sólo el tercero tiene uña; es éste un dedo enorme. sumamente largo, con un metatarsiano de tamaño extraordinario, al que sigue una sola falange. que corresponde a las dos primeras falanges de los demás mamiferos, soldadas y en este caso en un solo hueso, terminando en una falange ungueal de tamaño monstruoso. Los dedos c!rarto y quinto constan cada uno de un metatarsiano, la primera falange y la segunda falange achaparrada, que terminaba los dedos, de manera que éstos carecian de falanges ungueales.

Las diferentes especies del género Megatherium son hasta ahora, en su mayor parte, conocidas muy superficialmente, para que sea posible establecer de una manera precisa sus respectivos caracteres distintivos.

\section{MEGATHERIUAL AMERTCANUM Cuvier}

Megatheribm americanum (Cuvier), en SHaw: General Zoology, volumen I, página r65, afio 1800 .

Cuvier: «Ann. du Muséum d'Histoire Naturelle», tomo V, r804- - Idem: Recherches sur les ossements fossiles, etc., tomo V, parte $\mathrm{I}$, página $174,18=5$.

Megatherium Anericanum Blumenbach.

OWEN: Memoir on the Megatherium, 186r.-Idem: Odontography, página 338, lámina LXXXIII, 1845 .

BURMEISTER: «Anales del Museo Público de Buenos Aires», tomo I, página 150, 1865. Idem: Verhandl. d. k. k., zool. bot. Gesellsch. z. Wien, 1870, página $381 .-$ Idem: Archif. f. Arat. und physiolog., etc., 1873, página 626. - Idem: Description physique de la Republique Argentire, tomo III, página 286, 1879.

Cornalia: Sui fossili delle Pampas, etc., páginas 17 y $55, x 872$.

BUCKLAND, WIEL: Britgewater Treatises, 1836 .

LYDERKER: Catal. of Fossil. Mamm., parte V, página 86, 1887.

Megatherium Cuvieri. DEsMarest: Mammalogié, página 365, 1804.

Bradypus giganteus. PANDER y D'AtTon: Die Reisen faulthiere, abgeb. und beschrieber, aกั่ 1821 .

Megatherium australe. OKEN: (Sinonimia citada por LEIDY en $A$ memoir on the extinct sloth-tribe, etc. No he encontrado el trabajo original).

HorL: Handbuch der Petrefactenkunde, página 27, 1829.

Jose Garrica y Juan Bautista Bry: Descripción del esqueleto de un cuadrúpedo muy corpulento y raro, que se conserva en el Real Gabinete de Historia Natural de Madrid, con cinco láminas, 1796 , in folio.

Los primeros restos de esta espezie, que es la que ha servido de tipo rara la fundación del género, fueron encontrados a fines del siglo pasado, en 1789, a poco más de una legua al Oeste de la Villa de Luján. 
a orillas del rio del nombre de la Villa. Mandados exhumar por el Marqués de Loreto, entonces V'irrey de Espana en Buenos Aires, fueron erviados a Madrid, conjuntamente con algunos fragmentos de coraza de Glyptodon recogidos en el mismo yacimiento. Alli, el esqueleto fué montado, conservándose como una de las reliquias más preciosas, llamando extraordinariamente la atención de los sabios de aquella época. La nrimera descripción, acompanada de ilustraciones, fué dada por los señores José Garriga y Juan Bautista Bry; y poco tiempo después, Cuvier designó al animal con el nombre genérico de Megatherium, de. mostrando la afinidad de ese monstruo extinguido con los perezosos ut la upoca actual. Además. los fragrmentos de coraza de Glyptodon que se habian recogido conjuntamente con los huesos, le hicieron creer que ul Megatherinm hahía estacto protegido por una coraza ósea como los amadillos, cuya opinión fué defendida después sucesivamente po: W'eiss, Buckland y de Blainville, pero que Owen ha demostrado que carece por completo de fundamento.

Después de Cuvier, el esqueleto de Madrid fué ilustrado de un? manera mas completa por Panter y D Alton en 1821, quienes demostraron de una manera más positiva su parentesco con los perezosos.

Más tarde se recogieron sucesivamente varios otros esqueletos más o menos completos, que se conservan en los Museos de Londres, París, Turín, Milán y Buenos Aires, habiendo dado lugar a varios trabajos de importancia, nero ninguno de los cuales iguala a la descripción mionumental hecha por Owen y publicada en 1860 .

E1 Megatherium americanum es el más gigantesco de los desdentados conocidos hasta el día; y ciertamente uno de los mamíferos más colosales que hayan existido sohre la superficie de la tierra. pues su talla podía alcanzar 7 metros de largo, y era mayor a veces, con una corpulencia extraordinaria.

Sin embargo, como sucede con todos los animales de grandes proporciones, las variaciones individuales eran notabilisimas, conociéndose esqueletos cuyo largo total no alcanza a 5 metros, además de otras variaciones producidas por la edad y por el sexo.

En vista de estas diferencias, en vez de un resumen único de las medidas de las partes más notables del Megatherium americanum, me pa. rece preferible transcribir las medidas que Cornalia ha dado de los cuatro primeros esqueletos de Megatherium americanum conocidos en Europa, que se conservan en los Museos de Londres, Madrid, Turín y Milan, precisamente porque ellas demuestran la cautela con que debe procederse al tratar de fundar nuevas especies basadas únicamente en la talla, cuando se trata de animales de grandes proporciones, cuyos caracteres son mucho más variables que en las especies de pequeña talla: 
Longitud total iel esqueleto

Longitud del cráneo desde el cóndilo occipital hasta la extremidad anterior del intermaxilar ..

Altura de los huesos nasales sobre el intermaxilar ..

Distancia descle el cóndilo occipital hasta la parte anterior de los nasales.

Altura del hueso frontal en la extremidad de la apófisis cigomática descendente

Distancia desde el hueso occipital hasta la apófisis cigomática descendente

Longitud del borde alveolar superior ................

Altura del cráneo en las alas esfenoides.............

Distancia desde la punta de la apótisis cigomática ascendente hasta el cóndilo occipital

Distancia desde la punta de la apófisis cigomática ascendente hasta la extremidad de los nasales

Distancia desde el misno punto hasta la extremidad del liueso incisivo

Longitud de la parte del intermaxilar que se prolonga adelante de los nasales

Distancia entre las dos márgenes internas de la tercera imuela superior

Distancia desde el margen palatino posterior hasta el agujero occipital

Distancia entre las dos márgenes externas de la ter-

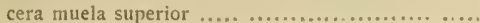

Distancia entre los dos arcos cigomáticos (cara externa).

Longitud de la mandibula inferior .....................

Altura máxima de la rama ascendente...............

Altura de la rama horizontal debajo de las muelas....

Distancia desde el primer diente de la mandibula inferior hasta la punta anterior de la sinfisis...........

Longitud del omoplato ......................

Ancho máximo del omoplato .....................

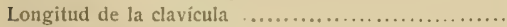

Longitud del húmero . .........................

Circunferencia mínima del húmero en la diáfisis ......

Longitud del cúbito ..........................

Longitud del radio ............................

Longitud total del pie anterior .....................

Diámetro transverso de la pelvis $\ldots \ldots \ldots \ldots \ldots \ldots . . . . .$.

Diámetro de la cavidad cotiloides ...............

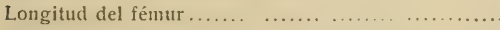

Diámetro máximo del fémur en la extremidad proximal

Circunferencia máxima del fémur de 0900 a..

Longitud de la tibia y el peroné.

Longitud total del pie posterior

Longitud del calcáneo

Ancho del calcáneo

\begin{tabular}{|c|c|c|c|}
\hline 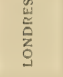 & 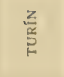 & $\stackrel{Z}{E}$ & $\frac{\hat{a}}{\frac{\hat{n}}{\pi}}$ \\
\hline 7260 & $+\$ 800$ & 5500 & - \\
\hline $0 \leqslant 00$ & 0850 & 0720 & $0 \$ 25$ \\
\hline 0130 & 0100 & 0200 & - \\
\hline 0650 & 0600 & 0600 & - \\
\hline 0384 & 0510 & $(1+00)$ & - \\
\hline 0400 & $0+40$ & $0+10$ & $\therefore$ \\
\hline 0260 & 0230 & 0210 & - \\
\hline 0328 & 0 328 & 0300 & - \\
\hline 0300 & 0500 & 0200 & - \\
\hline 0376 & 0350 & 0340 & - \\
\hline 0540 & $0+20$ & 0520 & - \\
\hline 0128 & 0190 & 0140 & - \\
\hline 52 & 0050 & 0060 & - \\
\hline
\end{tabular}

$0283+\ldots$

$0160 \quad 0150 \quad 0100$

$\begin{array}{lllll}0350 & 0430 & - & -\end{array}$

\begin{tabular}{c|ccc}
0680 & 0630 & 0720 & 0630 \\
- & - & - & 0534
\end{tabular}

$0240 \quad 0230 \quad 0220 \quad-$

$\begin{array}{llll}0230 & 0210 & 0250 \quad-\end{array}$

0 \$20 -

0500 -

$0+10$

0610 -

$0310 \ldots$

0580

$05 \$ 0$

0640 ..

1200

0110

0650 -

0650 -

1010 -

$0500-$

0 S00 -

$0+10=$

0 180 - 
Procedencia: - Parece que esta especie ha habitado toda Aniérica del Sud, pero sus restos sólo se encuentran con frecuencia en la pro. vincia Buenos Aires.

Horizonte:- En la provincia Buenos Aires, los restos del Megatherium americanum se encuentran en los pisos belgranense, bonaerense y lujanense de la formación pampeana; y parece que prolongó su existencia hasta el principio de los tiempos cuaternarios.

Megatmerium tarijense II, Gervais y Ameghino

Limlan XLT, Gäurn 5

Megatherium tarijense. H. GeRvaIS y AMEGHivo: Los manifcros fósiles, etc., página z 38 , año 1880

Megatherium, sp., P. GervaIs: Recherches sur les nammifères fossiles de l'Amerique Méridionale, página 52 , lámina XII, figura 6 , 1855 .

Megatherium Filholhi. Moreno: Informe prcliminar, etc., página I7, Julio de 1888 .

Esta especie ha silo fundada sobre un calcáneo procedente de Tarija, ya descripto y figurado por P. Gervais como proveniente de un animal a buen seguro específicamente distinto del Megatherium americanum pero al cual no designó con un nombre especial, por no tener seguridad de que se tratara de un verdadero Megathcrium. Los descubrimientos paleontológicos verificados desde esa época no han mostrado hasta ahora, sin embargo, ningún animal de gran talla con un calcáneo pare. cido al del género Megatherium, como ocurre en el caso del descripto y figurado por Gervais; y, por consiguiente, no puede dudarse que dicha pieza provenga de un Megatherium, pero indudablemente de un especie distinta del Megatherium americanum, del cual difiere por un tamaño bastante menor, pero sohre todo por una forma considerablemente distinta.

El calcáneo del Megutherium americanum tiene un largo variable entre 35 y 41 centímetros, según los individuos; mientras el del Megatherium turiicnse no tiene más de 28 centímetros de largo. La diferencia es más considerable todavía por 10 que respecta al ancho; en el calcáneo del Megatherium americanum varía entre 17 a 18 centímetros, mientras el ancho máximo del calcáneo del Megatherium tarijense no alcanza a 12 centímetros. La forma de este calcáneo es, en su disposición general, muy parecida al del Megatherium americanum, pero difiere de éste por ser relativamente más angosto, por su extremidad posterior casi aguda $y$ por el centro de la tuberosidad o prolongamiento posterior de una forma más regular y no tan ensanchada como en el Mlegatherium americanum. La parte anțerior es también menos voluminosa; y el estrechamiento que se pronuncia inmediatamente detrás de la articulación astragaliana es mucho más pronunciado. 
Pertenecen a esta especie los restos de un Megatherium casi una mitad más pequeìo que el Megatherium americanum, que se encuen. tran con bastante frecuencia en la provincia Buenos Aires, del cual yo poseía una parte del esqueleto y un miembro posterior con el pie completo, fero dicha pieza se encuentra en el Museo de La Plata, por 10 cual no puedo dar más amplios detalles acerca de ella. Sólo recuerdo su tamaño considerablemente menor y la circunstancia de que la tibia y el peroné, soldados en su parte superior, permanecen libres en la inferior.

Procedencia: - Los restos de esta especie se han encontrado en Tarija y en distintos puntos de la provincia Buenos Aires.

Horizonte: - Pisos ensenadense, belgranense $y$ bonaerense de la formación pampeana.

Megatuerium I,Undi II. Gervais y Ameghino

Megatherium Lundi. H. GERVAIS y AMEGrino: Los namfferos fósiles, etc, pág. I38, I8So. LydeKKER: Catal. of Foss. Mamm., parte V, página $90,1887$.

Megatherium Medinae Philippi.

En colaboración con el doctor H. Gervais fundé la especie sobre un astrígalo de forma un poco diferente del mismo hueso del Mcgatherium americanum, pero considerablemente más pequeño, pues su volumen puede evaluarse en un tercio del de la especie mencionada. Desgraciadamente, esta pieza se encuentra en el Museo de La Plata, por lo cuai no puedo dar más detalles acerca de ella, aunque puedo avanzar la afirmación de que la especie es idéntica a la que posteriormente designó el doctor R. A. Philippi con el nombre de Megatherium Medina, de 10 que he podido cerciorarme por medio de la comparación directa del original del astrágalo del Megatherium Lundi (cuyo modelo en yeso existe en el Museo de París) con el molde del astrágalo del Megatherium Medino de Philippi.

Philippi fundó la especie sobre un críneo imperfecto y una parte considerable del esqueleto, pero hasta el momento de escribir estas líneas no conozco su descripción. He tenido en mis manos los moldes de las piezas originales, y ellas demuestran que era de un tamaño mucho menor que el Megatherium americanum, no tanto por su taila general, que no debía ser muy inferior a la de la otra especie (Megatherium tarijense), cuanto por sus proporciones muy diferentes, pues cra mucho más esbelto, separándose completamente de las formas macizas del Megatherium americanum. El cráneo es de frente bastante convexa y la sinfisis de la mandibula es notablemente corta. Todas las muelas son un tercio más pequeñas que las correspondientes del Megatherium americanum. 
Lydekker, en el Catálogo de los mamíferos fósiles del Museo Británico, menciona un astraigalo como probablemente perteneciente $A$ esta especie, oute por sus dimensiones me parece concuerda exactamente con el del Megatherium Lundi; y debe pertenecer a la misma especie, pues como procedente de la formación pampeana no conozco otra de la misma talla. El autor registra la mencionada pieza en los siguientes terminos: wl left astragalus, probluly belonging to this form; from the Pleistucine of Buenus Aires, Areentine Republic. This specimen, of nich the transverse diameter is only $0^{m} 110$, differs from the corresponding bune of Hegatherium anericanum by the higher position of the nulicular cup, wich is also marnomer; in these respects the present specimen $i$. intermadiste hetnech Megatherium americanum and Mvlodon, in wich the cup is absent》.

Proccitencia:- Recogi la pieza original en que fundé la especie en Mercedes, provincia Buenos Aires, pero ella ha existido fuera de in República Argentina, pues los restos iescriptos por Philippi como de Megatherium .lledine proceden de la provincia Tarapacá, en Chile.

Horizonte:-En la provincia Buenos Aires, los restos de esta especie proceden del piso bonaerense de la formación pampeana.

Megatirerium antrouUa Ameghino

Lxmins XI, Aguras I $y$;

Megatherium antiguum. AMEGHINo: eBoletin de la Acad. Nacional de Ciencias», t. VII, página $116,1885 .-$ Idem: tomo IX, página $178, x 886$.

Megatherium Gaudryi. MoRño: Informe preliminar, etc., página 12, I888 (nomen nudum).

Fundé esta especie en 1885 sobre algunas muelas sueltas que me mostró don Santiago Roth, provenientes de una especie más pequeña que el Megatherium americanum y procedentes de terrenos más antiguos.

Posteriormente pude examinar otros restos de la misma procedencia que confirman la existencia de una especie de Mcgutherium relativamente pequeria, durante las épocas oligocena y miocena, la cual, aunque hasta ahora es conocida por escasos restos, no es de creer sea idéntica a las demás especies encontradas en el pampeano, que parecen ser bastante más robustas, con excepción, naturalmente, del Megatherium americanum.

Las piezas de este animal que he podido examinar con algún detenimiento son:

Una muela suelta con una pequeña curva lateral que parece indicar proviene de la mandibula superior. Es un prisma cuadrangular de 30 milimetros de diámetro anterior, 35 milímetros de diámetro transverso en su extremidad más ancha y sólo 29 en la más angosta. El largo es de 115 milímetros, pero está un poco rota en la base, pudiéndose 
calcular su largo total en 125 milimetros. Por 10 demás, no presentai nada notable.

Un fragmento de mandibula inferior del lado derecho, con las tres primeras muelas implantadas en el hueso.

Las tres muelas implantadas en este fragmento de mandibula están rotas en la base y a las tres les falta la corona, pues están quebradias al nivel del mismo hueso. Por las quebraduras se ve en cada muela la capa de dentina dura bastante ancha dividida en dos capas poco perceptibles, una externa un poco más dura y apenas algo mas brillante y $1 \mathrm{a}$ otra interna más blanca y más blanda, sin ningún vestigio visible de la capa de esmalte que hay presente en el Promegatherium.

\section{DIMENSIONES}

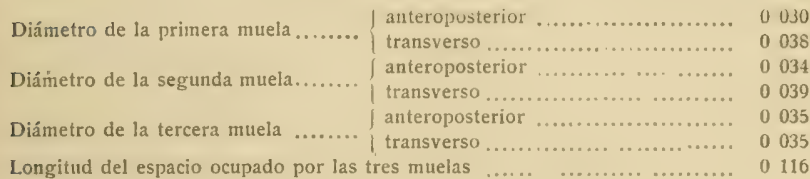

Estas dimensiones me parecen justificar suficientemente el tamano relativamente más pequeño de la especie antigua, aunque por sus caracteres se presenta como intimamente aliada al Megutherium americanum, cuyo antecesor directo es, probablemente.

A esta especie deben atribuirse los restos de un Megatherium que Moreno pretende son de una especie nueva, apenas un poco más pequeña que el Megatherium americanum y a la cual designa con el nombre de Megatherium Gaudryi, dando como único carácter para distinguirla, que «el cuerpo de la mandibula no presenta una curva tan pronunciada como en el Megatherium americanum y el Megatherium Leidyi» (?).

Procedencia: - - Los restos por mi estudiados han sido descubiertos por el profesor Scalabrini en las barrancas de los alrededores de la ciudad del Paraná, encontrándose restos de la misma especie en Monte Hermoso, a 60 kilómetros de Bahía Blanca.

Horizonte:- Piso mesopotámico de la formación patagónica y piso hermósico de la formación araucana.

Durante la época cuaternaria o durante los últimos tiempos de la época pliocena, el género Megatherium habitó también América del Norte, donde no son raros sus restos, aunque no se encuentran con tanta frecuencia como en la República Argentina. Todos esos vestigios son 
atribuidos a una sola especie, llamada por Leidy Megatherium mirabile: muy parecida al Mesatherium americanum, del que se distingue principalmente por su talla un poco menor.

\section{ISSONODONTHEKIUM Ameghino}

AMrchino: Filogenia, página 230, I884.

Este género es, en su conformación general, muy parecido al $\mathrm{Mega-}$ therium, pero tiene una muela menos en cada lado de cada mandibula, lo que importa una diferencia considerable, que me indujo a separarlo del Megatherium.

La fórmula dentaria, de una simplicidad excesiva, puede representarse de este modo:

$$
\text { "i. "c. }{ }_{3}^{4} \text { 11. 14, }
$$

nimero reducido iel que sólo hay dos o tres ejemplos en todo el grupo de los gravigrados. Por 10 demás las muelas tienen absolutamente la misma forma y composición que en el Megatherium.

Essonodontherium Gravalst (H. Gervais y Ameghino) Ameghino

Iegalterium Gerraisi. 11. GERVAIS y AMEgrino: Los mamiferos fósiles, etc, página 136, año 1880 .

Fundé esta especie en colaboración con el doctor Gervais. Como no he tenido ocasión de observar nuevos restos característicos de este aninıal ni he podido volver a examinar el original que nos sirvió de base para nuestra descripción, que se encuentra en el Museo de París, no puedo por el momento hacer otra cosa que transcribir lo que sobre él decíamos al establecer la especie, y es cuanto sigue:

«Proponemos designar con este nombre una especie nueva de Megaterio, representada en las colecciones del Museo de París por una cabeza completa, que por el conjunto de sus formas se parece bastante a la del Meguthcrium americanum, pero de la que difiere, sin embargo, por caracteres hastante distintos, entre otros el de no poseer más que 14 muelas, cuatro de cada lado de la mandibula superior y tres a cada lado de la mandibula inferior.

«Esta diferencia en el número de las muelas ha producido también un acortamiento del rostro. La apófisis descendente del arco cigomático es menos oblicua yue en el Megatherium americanum; y viendo el cráneo de costado no oculta más que la última muela y parte de la penúltima. La primera muela inferior en esta especie es, además, más 
grande que en el Megatherium americanum, y la primera de la mandíbula superior es, por el contrario, más pequeña.»

El espacio ocupado por la serie dentaria en la mandíbula superior es de $0^{\text {n' }} 180$, mientras que en los diferentes individuos del Megatherium cimericanum que he podido estudiar, el espacio ocupado por las muelas superiores varía entre 21 y 26 centímetros.

Puedo agregar que el cráneo es notablemente más pequeño que el cel Megatherium americunum, lo que prueba que era sin duda un anımal de talla bastante menor.

Posteriormente el doctor Burmeister ha emitido la opinión de que el Essonodontherium Geivisi podia representar el estado juvenil del Mcgatherium americanum, en el cual no hubiera aparecido aún la últira muela de cada mandíhula: pero me parece que esta indicación no clebe tomarse en cuenta, pues resulta contraria a lo que enseña el estudio del desarrollo de estos animales, que los muestra con las mue. las en número completo desde la primera juventud. Por otra parte. todos los caracteres del cráneo de que se trata, y particularmente la obliteración de casi todas las suturas, demuestran con evidencia qu se trata de un individuo adulto.

Procedencia: - Este cráneo, conjuntamente con partes del esqueleto, fué recogido por F. Seguin a orillas del río Salado, en la provincia Buenos Aires.

\section{XEORACANTHUS Ameghino}

Oracanthus. AmecniNo: Oracanthus Burmeisteri, nuevo desdentado extinguido, ete, en \&Boletin de la Academia Nacional de Ciencias thiss y Coclodon, géneros distintos de una misma familia, en \&Boletin de la Academia Nacional de Ciencias», tomo VIII, nágina 394, 1885. - Idem: Sitzungsberichte d. Kön, preus. Akademie der IVissenschaflen, ₹. Berlin, Phy's, nat. cl., página 463. 1856.

Lürkan: Antikritiske Beacnerkninger i Anledning, of kaenpe-Dovendyr-Slacgten Coclodon, año 1886.

BuRMitstre: Ostcologia de los gravígrados, I886. - Idem: Siť., etc., página 1127, i 886. Coelodon (Lund). BurMeISTER: Berichtingung au Coelodon, in Sitzmngsberichte der Kön. preus. Akad,, etc., 1886, página 567.- Idem: Nochmolige Berichtigung zu Coelodon en Sitzung., etc., página $1127,1886$.

Fundé este nuevo género en 1885, con el nombre de Oracanthus, sobre una media mandíbula inferior del lado derecho, considerándolo como muy cercano del Megutherium pero genéricamente distinto, expresándome entonces al respecto en los siguientes términos:

«El lado derecho de la mandíbula inferior, dibujado en la lámina adjunta, presenta la rama horizontal casi intacta y tiene cuatro muelıs de forma prismáticocuadrangular más o menos parecidas a las de los géneros Megatherium Cuvier, Essonodontherium Ameghino, Ocnopus Feinhardt, Colodon Lund, Interodon Ameghino, Megalnchnus Leidy, 
Pliomorplus Ameghino y Nothropus Burmeister, todos géneros extinguidos sudamericanos.

«Esta mandibula no puede identificarse, sin embargo, con la de ninguno de los géneros mencionados. Difiere de la del Megatherium Cuvier, por su rama horizontal mucho más baja, que no forma la grai citrva descendente que distingue a la de este último género. Difiere de la del Essunodontherium Ameghino, por ese mismo carácter y por eí número de dientes, que es de tres en la mandibula inferior de este género y de cuatro en la del Oracanthus. Tampoco puede identificarse con el Culodon Lund, pues éste también está caracterizado por tres muelas inferiores. No puede pertenecer al Ocnopus, porque éste es un género de una talla gigantesca y de muelas de forma bastante distinta. Lil Oracanthus se distingue del Interodon por la forma de la mandibula mucho más corta y más espesa en aquel que en este género y de forma completamente distinta. Si bien el Megalochnus y el Pliomorphus sa acercan bastante a mi nuevo género por la forma de sus muelas posteriores, difieren de él por la primera muela o anterior, que tiene en los mencionados géneros la forma de un incisivo. El animal que presenta milis analogía con el de la mandibula en cuestión es el curioso Nothropus, pero la mandíbula de éste no es tan maciza como la del nuevo género. su parte sinfisaria es mucho más prolongada hacia adelante y la primera muela está separada de las que siguen, tomando la forma de un canino, en vez de mostrar cuatro muelas de forma más igual y en serie continua como las que están implantadas en la mandibula de que me ocupo. Después de los mencionałos no conozco ningún otro género con muelas parecidas; de modo, pues, que véome obligado a considerar a uste animal como representante de un nuevo género hasta ahora desconocido, que propongo designar con el nombre de Oracanthus a causa de las cuspides puntiagudas $y$ punzantes que forman las esquinas de la arista o colina transversal posterior de cada una de las muelas, designando a la especie con el de Burmcistcri, en honor del sabio naturulista doctor Germán Burmeister, decano de los paleontólogos residentes en Sud América, quien recientemente ha dado a conocer el interesante género Nothropus, cercano del que ahora describo.»

Poco tiempo después el doctor Burmeister dió algunos datos sobre dos medias mandibulas del mismo género, atribuyéndolas al Colodon y haciéndome al mismo tiempo un fuerte cargo por haberle dedicado 1a especie sin consuitarle ni haherle pedido antes su consentimiento.

Me parece inútil entrar en detalles sobre los fundamentos de la opirión del doctor Burmeister, pues la he refutado bastante extensamente en el trabajo más arriba mencionado, publicado en el «Boletín de la Academia Nacional de Ciencias» de la República Argentina y en las Actas de la Academia de Ciencias de Berlín, casi al mismo tiempo 
que el doctor Lütken hacia en las publicaciones de la Academia de Ciencias de Copenhague una contracritica del trabajo de Burmeister demostrando la sinrazón con que pretendía unir el Oracanthus al $C \propto$ lodon. Por otra parte, el mismo Burmeister ha reconocido el poco fundamento de su critica, admitiendo posteriormente el Oracanthus como género distinto que el Colodon.

Sin embargo, como resulta que el nombre de Oracanthus ya habia sidu empleado por Agassiz desde el año 1835 para designar un género de Ictyodorulhites, no puede conservarse para continuar distinguiendo al desdentado nombrado y lo cambio, por consiguiente, por el de Neoracanthus.

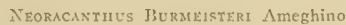

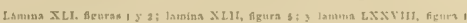

Oracanthus Burneisteri. Amegrino: «Boletín de la Academia Nacional de Ciencias», tomo VII, página 499, lámina I, I884. - Idem: tomo VIII, página 394, $1885_{.}$- Idem: Sitsungsberichte, etc., ya citada.

La mandibula inferior del Neoracunthus es corta, alta y sumamente gruesa, denotando un animal de una talla comparable a la del tapir, pero de formas más macizas y, en proporción, más robusto que el misinn Megatherium. La rama horizontal, sumamente gruesa, no forma la gran curva descendente que caracteriza a la mandibula inferior del Megutherium, pareciéndose en esto más al Nothropus y sobre todo al Mylodon. Li parte sinfisaria es corta y gruesa, más parecida al Mylodon, en vea de prolongarse hacia adelante como en el Megrathcrium, el Glossotheritum y el Scclidotherium, pero dehía ser estrecha como en este último género o aún mís. pues las dos ramas de la mandihula inferior debian estar separatias por un espacio de sólo unos dos centímetros de ancho. La unión de las dos ramas mandibulares empezaba debajo de la parte anterior de la segunda muela, de manera que el maxilar inferior debia constituir un hueso excesivamente sóliđo. Ja rama ascendente está rota en su parte superior, pero por lo que de ella queda se conoce era muy parecida a la del Megathcrium y el Nothropus, pero no empezaba a levantarse tan hacia atrás como en este último género. En efecto, viendo dc lado la mandíbula del Neoracanthus, la rama ascendente cubre 13 parte posterior de la última muela, mientras que mirando la mandibula del Nothropus en la misma posición la misma muela cuarta queda por completo a descubierto.

EI agujero mentoniano se halla más hacia atrás que en la mayor parte de los desdentados, inmediatamente delante de la primera muela, a unos 20 milímetros debajo del borde superior de la mandíbula, con tu diámetro de 8 a 12 milimetros, mientras que en el Nothropus el mismo agujero estaba situado mucho más adelante. 
La abertura de la rama externa del canal alveolar se abre sobre el lado interno de la rama ascendente, como en el Megatherium.

Las cuatro muelas implantadas en esta mandíbula son de un volumen considerable y colocadas en serie continua, aunque separadas unas de otras por espacios regulares de dos o tres. milimetros de ancho. Las tres anteriores son de forma prismática cuadrangular, más o menos del mismo tamano y con dos surcos longitudinales laterales, uno por cada lado. I.a última es de tamaño bastante menor y de sección triangular. La corona de estos dientes está muy gastada por la masticación, demostrando que pertenecen a un individuo muy viejo, de modo que ya no queda más que una colina o cerro transversal en la parte posterior de cada muela, en vez de los dos cerros transversales separados por un surco profundo que tienen las muelas del individuo joven, que entonces son casi idénticas a las cel Megatherium. El cerro anterior desaparece poco a poco a medida que avanza la edad del animal, debido al C'segaste producido por la masticación, hasta que la parte anterior dz la corona de cada muela baja hasta el nivel del surco que en la edad juvenil separaba a los dos cerros transversales.

La primera muela es algo convexa en su cara anterior, casi plana en lit cara posterior y con los dos surcos laterales, interno y externo, poco nurcados. En la corona no queda presente más que el cerro transversal posterior, que forma una arista cortante y termina en la parte posteroexterna de la muela en una cúspide elevada y puntiaguda. Esta muela está implantada oblicuamente de adentro hacia afuera.

La segunda muela es de la misma forma general que la precedente, con la única diferencia de que su cara anterior no es tan convexa y los surcos laterales son algo más profundos. En la corona ha desaparecido también por completo el cerro transversal anterior, pero el posterior es más elevado que en la precedente, formando una arista $\mathrm{cos}^{-}$. tante que termina en una cuspide puntiaguda en el lado interno y en otra aún más elevada y punzante en el lado externo. Esta muela no está implantada tan oblicuamente como la precedente.

La tercera muela es de la misma forma general que la anterior, pero I. corona presenta un aspecto distinto por no haber desapareciủo aún completamente el cerro transversal anterior y estar más gastado y de consiguiente más bajo y como el cerro transversal posterior, que en su parte externa termina en una cúspide poco elevada. Esta muela est $i$ implantada en la mandibula en sentido perfectamente transversal.

La cuarta y última muela se angosta tanto en su parte posterior, que toma una forma completamente distinta, representando un prisma de sección triangular con los dos surcos laterales interno y externo y los dos cerros transversales de la corona poco gastados y que se reunen en una cuispide interna elevada y puntiaguda, dándole a la corona un fuerte 
cieclive hacia el lado externo. Esta muela es bastante más chica que las precedentes.

DIMENSIONES

Longitud de la parte sinfisaria delante de la primera muela ............ 0 "060?

Alto de la mandibula en la parte sinfisaria a 0 '025 delante de la primera muela. 0066

|de la primera muela .................... 0073

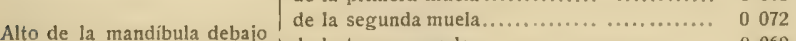

de la tercera muela.. ..................... 0069

de la cuarta muela....................... 0060

Espesor de la mandibula hacia la mitad de su largo .... . ............ 0400

Diámetro de la primera muela | anteroposterior..................... 0017

Diámetro de la segunda muela anteroposterior......................... 00165

Diámetro de la segunda muela transverso ................................ 0017

Diámetro de la tercera muela / anteroposterior..................... 0017

transverso ......................... 0016

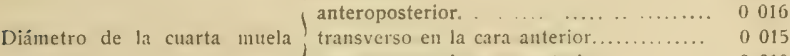

I transverso en la cara posterior........... 0010

Longitud del espacio ocupado por las cuatro muelas...................... 00 0s6

Longitud probable de la mandíbula inferior entera....................... 0250

Todas estas muelas se elevan unos 10 a 20 milimetros sobre el borde alveolar. En cuanto se refiere a la estructura interna o materiales de que se componen no difieren de los del Megatherium y géneros cercanos; sus tres componentes: vásculodentina, dentina y cemento, conservan la misma relación y proporción que en el género mencionado.

Poseo un maxilar superior izquierdo desgraciadamente muy entoscado, pero en el cual se conservan en bastante buen estado las cinco muelas. que se distinguen por los anchos diastemas que las separan. en verdad desproporcionados comparativamente al tamaño de las muelas y del animal.

La primera muela es mucho más pequeña que la segunda, de contorno triangular, estrecha y redondeada adelante, ancha y aplastada atrás, un poco excavada perpendicularmente en el centro de la cara externa y de diámetro anteroposterior un poco menor que el diámetro transverso. La segunda muela es la de mayor tamaño; es de sección rectangular. de mayor diámetro transverso que anteroposterior, fuertemente excavada perpendicularmente sobre la cara externa. La muela tercera es de la misma forma y apenas un poco más pequeña. La muela cuarta es notablemente más pequeña y de sección más cuadrangular. La muela quinta es más pequeña todavía, de sección irregularmente triangular, ancha y aplastada en la cara perpendicular anterior, más angosta y redondeada en la posterior. El surco transversal está bien 
indicado en todas las muelas; y de las dos crestas transversales la anterior es siempre más elevada y comprimida y la posterior más ancha y más baja.

DIMENSIONES

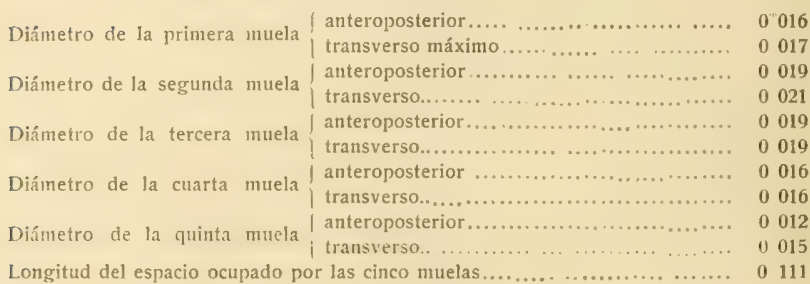

He visto, además, en una colección particular, la parte anterior de tu cráneo con la dentadura, pero sin el intermaxilar, proveniente de un individuo de talla un poco mayor todavía. La parte superior del críneo desde las órbitas hacia a Jelante forma un plano inclinado dirigido hacia abajo, terminando en una abertura nasal relativamente pequeña. Los huesos nasales son angostos pero de un largo considerable, puesto que alcanzan a 125 milimetros; en la parte anterior, que es la más ancha, tiene 48 milímetros de diảmetro transverso, angostándose rápidamente atrás hasta no presentar más que 21 milímetros de diámetro transverso, pero vuelven a ensancharse un poco en la parte posterior. Por la parte que de él queda, el rostro parece haber sido bastante ancho y un poco deprimido en el principio o arranque de los nasales, inmediatantente adelante de los frontales. La hase de la apófisis cigomática se encuentra encima de la segunda muela. La abertura nasal posterior está colocada más adelante que en los demás fravigrados, pues su horde anterior está colocado entre el líltimo par de muelas. El paladar es un poco deprimido entre las muelas anteriores y posteriores, pero más elevado en el medio; y su parte interdentaria es notablemente más angosta adelante (donde tiene unos 25 milímetros de diámetro transverso), que atrás, entre las últimas muelas (donde alcanza un ancho de 44 milímetrosi. Adelante de las primeras muelas el paladar se angosta todavía de una manera notable, formando a cada lado una curva entrante, para volver a ensancharse un poco en el punto de unión de los maxilares con los intermaxilares. La parte palatina de los maxilares que se extiende delante de las muelas tiene 26 milímetros de largo. 
Procedencia: - He descuhierto los restos de esta especie en el fondo cel cauce del río Luján, en el pueblo del mismo nombre; y en los alrededores de La Plata.

Horizonte:- Piso belgranense de la formación pampeana.

Neoracantus Prackenuschianus, $n$. sp.

LAmias XL, figura 19; $y$ lamana L.XXVIII, ggura 2

Además del Neoracanthus Burmeisteri existe una segunda especie, considerablemente más pequeña, de la cual, en el Museo de La Plata, hay una rama de mandibula inferior con las cuatro muelas que pude comparar con la especie típica y asegurarme de que en realidad proviene de una especie distinta; pero como no conservo de ella dibujos ri otras indicaciones, no podría mencionar la especie si no fuera la circunstancia bastante rara de que la mitad de mandíbula inferior dibujada y descripta erróneamente por Burmeister como de Colodon y que él creyó idéntica a la que me sirvió de base para fundar el Neoracanthus Burmeisteri, no proviene de esta especie, sino de la mencionada nueva especie más pequeña. Basta comparar los dibujos de 1: mandibula y de las muelas publicados por Burmeister, que reproduzco en el Atlas, con los que doy del Neoracanthus Burmeisteri, para convencerse de que se trata ie dos animales especificamente distintos.

La parte existente de la mandibula inferior del Neoracanthus Burmeistcri mide un poco más de 20 centímetros de largo, pero si se restaura la parte que falta se encuentra que el largo de la mandíbula entera no podía ser menor de 25 centímetros, mientras que la rama entera figurada por Burmeister sólo tiene 21 centímetros de largo. La diferencia en espesor y en altura es mayor todavía, pues mientras i? rama horizontal del Neoracuntlus Burmeisteri alcanza en la región dentaria una elevación de 73 milimetros, la rama horizontal del Ncortcanthus Brackehuschianus no alcanza en ningún punto de la región dentaria una elevación de 6 centímetros. La región sinfisaria es tambićn considerahlemente más alta y más gruesa, pero más corta en el Neoracanthus Burmeisteri que en el Ncoracanthus Prachchuschianus, mientras que dicha parte es notablemente más prolongada en éste, pre. sentando una mayor longitud no sólo relativa sino también absoluta.

Todas estas diferencias, tanto en el tamaño como en la forma y la disposición, se reproducen en el aparato dentario. Así las cuatro muelas inferiores del Neoracunthus Burmeisteri ocupan un espacio longitudinal de 88 milimetros, mientras que apenas alcanzan a ocupar un espacio de 70 milimetros en el Neoracanthus Brackebuschianus.

La primera muela inferior del Neoracanthus Brackcbuschianus es considerablemente menor que la segunda y con su cara anterior bas- 
tante más angosta quue la posterior, como sucede con la misma muela del Megatherium; pero en el Neoracanthus Burmeisteri la primera muela inferior es apenas algo más pequeña que la segunda y su cara anterior presenta casi el mismo ancho que la posterior.

La última muela inferior del Neoracanthus Brackebuschianus presenta el mismo diámetro anteroposterior que la penúltima, pero es más angosta y con su parte posterior mucho más estrecha que la anterior, aunque conservando siempre la forma rectangular; en el Ncoracunthus Burmeisteri, al contrario, la última muela es todavía más pequeña, de menor diámetro anteroposterior que la penúltima, con su parte posterior un tercio más angosta que la anterior, tomando un contorno decididamente prismáticotriangular en vez de rectangular.

Por su forma, disposición y tamaño relativo entre ellas, las cuatro muelas inferiores del Neoracunthus Brackebuschianus presentan un parecido mucho más considerable con las del Megatherium americanum que con las del Neoracanthus Burmeisteri.

Las dimensiones de las cuatro muelas inferiores del Neoracanthus Erackchuschianus son, segun el dihujo de Bumeister, las que siguen:

DIMENSIONES

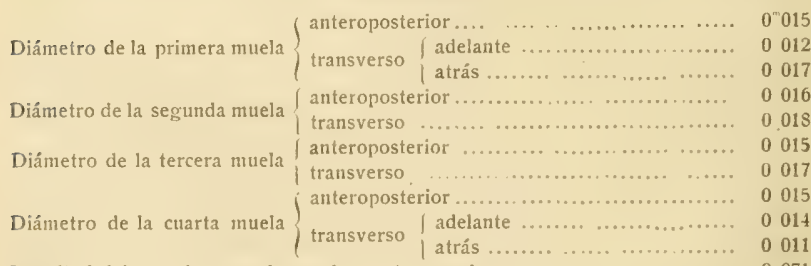

Longitud del espacio ocupado por las cuatro muelas ................... 0071

Conozco, además, la última muela superior de la misma especie, que, por su tamaño excesivamente pequeño en proporción de la muela corespondiente de la otra, confirma la diferencia especifica. La corona śblo tiene 11 milimetros de diámetro anteroposterior por 1.3 milimetros de diámetro trasnverso, siendo el prisma del diente aplastado en su cara anterior y convexo en la posterior. Dedico la especie al doctor Brackebusch. catedrático de Geologia y Mineralogía en la Univer. sidad de Córdoba.

Procedencia: - Los restos de esta especie se han encontrado en las toscas del fondo del río de la Plata, en el municipio de Buenos Aires; y en las excavaciones del puerto de La Plata, en la Ensenada.

Horizonte:- Piso ensenadense de la formación pampeana. 
Amegrnvo: «Boletin de la Academia Nacional de Ciencias», tomo $V$, página 293. $18 \$ 3$.

Las muelas de este género son de sección prismáticocuadrangular, con dos crestas transversales elevadas en la corona. separadas por un surco profundo, como en el Megatherium. El corte transversal de las muelas muestra: una capa de cemento externo, una capa intermedia compuesta de una o dos hojas de una substancia brillante parecida a esmalte aún no completamente atrofiacio, con una lámina de dentina dura, y en el medio una masa más blanda de vásculodentina.

Promegatireriem smatitume Ameghino

Lomina XXvit, fitura e

AmEgmivo: «Boletín de la $\Lambda$ cademia Nacional de Ciencias», tomo $V$, página 293,1883 . -Idem: tomo VIII, página 115, 1\$85. - Idem: tomo IX, página 170, 2\$86.

La subdivisión de la capa intermedia entre el cemento y la vásculo. dentina es muy perceptible en esta especie, y las dos capas de un aspecto distinto, presentándose la interna como compuesta de lentina muy dura y compacta y la externa como compuesta de una substancia vidriosa, muy dura y transparente, comparable al esmalte; esta es la capa de esmalte primitiva, en parte atrofiada y en vía de desaparición: pero sin que aún se haya verificado la evolución completa tal como s? presenta en los Megaterios pampeanos y mejor aún en los Milodontes, los Lestodontes, etc.

La primera observación de la existencia de esta capa de esmalte en vía de desaparición la hice en una sola muela en la cual la capa de aspecto vitreo sólo se mostraba en la corona, de mado que no pude conocer bien la estructura que presentaba en el interior del diente. Tengo ahora a mi disposición varios ejemplares y entre ellos algunos fartidos longitudinalmente y otros transversalmente, que muestran muy bien la estructura interna del diente y la relación de la capa de esmalte con la capa de dentina dura en vía de formación; la estructura interna de la muela con estas distintas capas presenta una complicación verdaderamente notable, que no era de esperarse en muelas de desdentados, consideradas siempre como de una composición interna mucl:o más simple que las de los otros mamíferos. Parece que el espesor dc esta capa de esmalte primitivo aumentó progresivamente, subdividiéniose en cuatro láminas distintas, dos externas les decir: una hacia el lado externo y otra hacia el interior del diente) y dos internas más anchas, una de ellas, la que se encuentra hacia afuera que representa todavía el esmalte: y la otra hacia el lado interno, la dentina en via de formación, que en sus sucesores reemplazó por completo a las 
cuatro láminas que menciono, para no formar más que una sola capá de dentina dura, a menudo de un espesor bastante notable.

De estas cuatro láminas, las dos intermedias más anchas alcanzan su espesor máximo en los lados transversales anterior y posterior, adelgazándose hacia los costados hasta que en el medio de los lados laterales se confunden conjuntamente con las dos láminas externas en una sola lámina de substancia vítrea tan delgada que apenas tiene medio milimetro de espesor, mientras que sobre los lados anterior y posterior las cuatro láminas juntas presentan un grueso de 0 m0025.

Para dar una jdea más completa de la estructura de estas muelas, he aqui el aspecto que presenta el corte transversal de una de ellas, visto con un fuerte lente, examinando la estructura de afuera hacia adentro sobre uno de los lados anterior o posterior.

La primera capa o externa es en la parte externa, de un color amarillo que tira un poco al rojo; y en la interna, de un color más obscuro: es el cemento.

Sigue hacia adentro una lámina sumamente delgada, de sólo unos 0m002 de espesor. Ae suhstancia vitrea, de color negro brillante y traslúcida; son los últimos vestigios de la antigua capa de esmalte homogénea.

Sigue después una capa un poco más gruesa, de un milímetro de espesor, de color negro, menos brillante que la lámina anterior, de una subsiancia muy dura. de aspecto algo vitreo y le una estructura radiada, con las lineas radiales dirigidas hacia el centro y la base de la muela; esta es la masa de la antigua capa de esmalte, ensanchada y en vía de transformación, perdiendo grałualmente su aspecto vitreo v su iureza.

Más adentro todavia viene otra capa algo más gruesa, de poco más cie un milimetro de espesor, de color blanco ligeramente amarillentos $y$ de estructura igualmente radiada. Las líneas radiales dirigense también hacia el centro y la base de la muela, como que no son otra cosa que la continuación hacia el interior de las líneas radiales de la capa cxterna inmediata ya nombrada. Esta capa blancoamarillenta es la dentina dura, destinada a reemplazar a las otras capas y láminas en los desdentados más modernos, constituyendo en ellos la capa de dentina dura que envinelve a la vásculodentina. Pero aquí esta capa está separada de la vásculodentina por otra lámina muy delgada de distinta naturaleza.

En efecto: inmediatamente después de la capa mencionada, sigue en el lado interno una hoja sumamente delgada de menos de 0 m0002 de espesor. de color rojo amarillento, de una substancia vítrea, brillante y transparente que tapiza el interior del estuche formado por la lámina precedente como una capa de barniz brillante. Esta hoja es también cl último resto en el lado interno de la capa de esmalte primitivo, paula- 
tiramente ensanchada y luego separada en dos hojás, para dar en ei medio origen a las dos láminas intermedias, incluso la de verdadera dentina.

En fin sigue, por último, hacia el interior la masa de la substancia de la muela, constituida por la vásculodentina, más blanda y de colnr pajizo obscuro.

Esta estructura se encuentra en todas las muelas del mismo género, siempre con el mismo aspecto y aun en ciertos casos todavia más comflicada, pues hay una muela en la cual la capa intermedia se subdivide no en cuatro sino en cinco hojas secundarias. Nótase aúemás una estructura más o menos parecida en muelas de otros géneros de la misma época.

Por ahora, conténtome con fijar la atención en este estadio particular de la evolución de las muelas de los antiguos desdentados, con el propósito de ocuparme extensamente de él en un trabajo especial.

El diente sobre el cual fundé primero esta especie es una muela en forma de prisma cuadrangular, de seccion oblonga, de 18 milimetros de diámetro anteroposterior, 25 milimetros de diámetro transverso en la cara más ancha y sólo 21 en la cara opuesta más angosta. De las dos caras perpendiculares anterior y posterior, que son las mis anchas, una es un poco excavada longitudinalmente y la otra es ligeramente convexd, siendo además el prisma de la muela un poco arqueado en sentido anteroposterior. Las dos caras perpendiculares interna y externa, que son las más angostas, están asimismo excavadas perpendicularmentc. y las cuatro esquinas redondeadas. Las dos colinas transversales presentan la parte superior de la cúspicie o le la cresta transversal formada por una delgada lámina de substancia transparente y dura, parecida al esmalte, que da vuelta alrededor formando un tubo de la misma forma que la figura general de la muela, rellenado por la dontina más blanda o visculodentina. La lámina de substancia vítrea, es bastante gruesa en las dos crestas transversales, pero muy delgada en las dos carns más estrechas del diente. En el exterior está cubierta por la capa de subs. tancia quebradiza comparable al cemento del diente del Megaterio y de un espesor muy desigual. En las dos caras más angostas, interna y externa, esta capa de cemento es tan delgada, que sólo tiene $0{ }^{m} 0005$ de espesor, mientras que, por el contrario, en la cara transversal más ancha alcanza un espesor de 3 a 4 milímetros, dándole a la cresta transversal la forma de caballete que también tiene en el Megatherium. pero en la otra cara transversal más angosta la capa de cemento sólo alcanza en su parte más gruesa un milímetro de espesor, con la lámina ce substancia vítrea que casi forma el borde, por lo cual la cresta transversal no tiene ahí la misma forma de caballete que la anterior, distinguiéndose en ésto de las muelas del Megatherium, en las cuales 
las dos crestas transversales tienen dicha forma. La base de la muela, abierta y ocupada por una cavidad en forma de pirámide, está quebrada: y esta rotura permite ver en la superficie interna de la lámina de substancia vítrea y adherida a ésta una muy delgada capa de den. tina distinta y más homogénea que la vásculodentina; representa la capa de dentina dura, que en el Megatherium alcanza un desarrollo tân grande y aquí está en estado rudimentario o apenas en principio de formación.

Posteriormente se han encontrado varios otros ejemplares, pero todos más o menos parecidos al descripto. Uno de los más completos, con la corona intacta, tiene un diámetro anteroposterior de 20 milímetros y 23 milímetros de diámetro transverso. Las dos crestas transversales sun muy altas; y la parte superior mas angosta, en forma de caballete, está constituída por la masa de substancia vítrea que sobresale sobre ia capa de dentina dura que le sigue inmediatamente en el lado interno y sobre la masa de cemento en el lado externo. De las caras perpendiculares laterales, una, la más angosta, está ocupada por un surco longitudinal ancho, profundo y de fondo cóncavo, y la otra, más ancha, muestra dos surcos longitudinales, pero más angostos y más bajos, separados uno de otro por una columna media longitudinal convexa, de manera que la muela presenta en esta cara tres columnas longitudinales, estando las otras dos formadas por las esquinas perpendiculares anterior y posterior.

Procedencia: - Los restos de esta especic han sido descubiertos por el profesor Scalabrini en las barrancas de los alrededores de la ciudad del Paraná y pertenecen al Museo provincial de Entre Ríos.

Hurizonte: Piso mesopotámico de la formación patagónica (oligoceno inferior).

ProMECATIERILM RFMLLSUN Ameghino

Lamina $\mathrm{X} x \mathrm{X} 1 \mathrm{H}$, liguran $\gamma$ y 0

AMEGHino: \&Boletin de la Academia Nacionalo, etc., tomo IX, página 177, 1886.

Conozco varias otras muelas, todas más o menos fragmentadas, que presentan los mismos caracteres de composición interna que han mostrado las del Promegutherium smultatum, por lo cual las incluyo en el mismo género, pero presentan con las anteriores una diferencia de tamano tan considerable que no es permitido dudar un solo instante que se trata de una especie distinta, de talla gigantesca, no muy inferior a la del Megutherium americanum, mientras que el Promegatherium smaltatum apenas sobrepasaba un poco en tamaño al Neoracanthus Burmeisteri Ameghino.

Una sola de ellas presenta la parte superior completa con la corona 
intacta. Las dos crestas son muy elevadas y separadas por un surco transversal muy profundo. Es el ejemplar más pequeño; $y$, sin embargi), tiene 29 milímetros de diámetro anteroposterior y 40 milimetros de diámetro transverso.

Otro ejemplar es un trozo del medio con el prisma completo, pero en el cual faltan la cúspide y la base. La rotura deja ver una subdivisión de la capa intermedia en cinco láminas, tres de esmalte más o menos atrofiado y dos intermedias de dentina dura. El prisma tiene $35 \mathrm{mi}$ límetros de diámetro anteroposterior y $40 \mathrm{~mm}$. de diámetro transierso.

Los demás ejemplares son mitades perpendiculares formadas por in división del diente, cuya rotura sigue la dirección perpendicular de la gran. ranura traǹsversal de la corona, de modo que estos trozos sólo dan el diámetro transverso o ancho de las muelas, que en dos ejemplares es exactamente de 38 milímetros. Pero hay uno que tiene 45 milimetros de ancho, cuyo tamano corresponde a las mais grandes muelas del Megatherium americunum. Este trozo muestra después Lel cemento externo una capa de substancia vítrea, color café, brillante y transparente, que corresponde al esmalte, de un milímetro de espesor; y luego una capa de substancia blanca, ligeramente amarillenta, de textura estriada y salpicada de hermosas dendritas, con un espesor de dos milímetros, que corresponde a la capa de dentina dura.

Procedencia: - Estos restos han sido descubiertos por el profesor Scalabrini en las barrancas de los alrededores de la ciudad del Paraná y pertenecen al Museo provincial de Entre Ríos.

Horizonte: - Piso mesopotámico de la formación patagónica (oligoceno inferior).

\section{INTF,RODON Ameghino}

Amzomino: \&Boletin de la Academia Nacional de Ciencias», tomo VIII, página II7, r885.

Las muelas de este animal son de un tamaño excesivo para el tamaño de la mandibula y de una forma cuadrangular un poco más ovalada que cn el .llegatherium, pero de composición complicada como en el PromeRatherium; la corona de las muelas carece de las crestas transversales, presentando, sin embargo, el centro notablemente más gastado que en 1a periferia. La mandíbula es de forma bastante parecida a las de Mylodon y Lestodon, pero no conozco la parte posterior, de manera que no puedo determinar la posición de la abertura de la rama externa del canal alveolar. De modo, pues, que no estoy bien seguro de que este género pertenezca a la familia de los Megatherida, pero quizá pueda entrar en la de los Orthotheridee. 


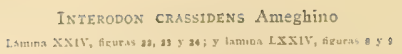

Adegrixo: «Boletin de la Academia Nacional de Ciencias», tomo VIII, página 1 I7, 1885 .

Fundé esta especie en dos muelas sueltas y un fragmento de mandibula, tres piezas pertenecientes a tres individuos distintos, pero que por su conformación parecen provenir de una misma especie.

Una de las muelas, la mejor conservada, por su forma general pertenece a la manúbula superior y por la curra que presenta podria considerarse como del lado izquierdo. Su forma es la de un prisma cuaArangular, de dos diámetros distintos y de ángulos redondeados. La corona, como sucede en la mayor parte de las muelas de los animales de estos grupos, es algo más gastada en el centro que en los borúes, uno de los cuales (que creo el interno) es varios milimetros más elevado que el externo, de modo que la corona, en su conjunto, formaba una especie de plano inclinado de adentro hacia afuera, lo que constituye una analogia con el género pampeano Lanivion, aunque en este ultimo ese caricter se halla mucho más acentuado y la superficie masticatoria es un plano regular, mientras en la muela del Interodon hay un principio de depresión transversal. La superficie de la muela es fuertemente estriala y acanalaúa en sentido perpendicular. La cara perpendicular, que supongo la anterior, es un poco convexa; y la opuesta t:1: poco deprimida. Las dimensiones de la corona son : 20 milímetros de diámetro anteroposterior for 24 milimetros de diámetro transverso. En cuanto a la longitud de la muela, la parte existente tiene 64 milínietros de largo; la base está rota, pero como está bastante abierta, puede calcularse que el largo total no debia pasar, a lo sumo, de unos is milimetros, 10 cual no es proporcionado al tamaño de la muela.

La otra mueia se adapta muy bien al alvéolo, bastante roto, es cierto, de la segunda mucla del hado derecho lel fragmento de mandíbula que atribuyo al mismo género, por lo cual creo que es la segunda del lado derecho de la mandibula inferior. Representa igualmente la forma de un prisma cuadrangular, de ángulos bastante redondeados, pero no está tan fuertemente estriada y acanalada longitudinalmente como la precedente. Sus caras anteriores e interna son redondeadas; la posterior es más bien aplastada y la externa tiene una depresión longitudinal que corresponde a una arista o columna longitudinal que se observa en la pare 3 interna del alvéolo. La corona está bastante destrozada, pero parece tuvo en el medio una depresión transversal poco acentuada, com.s las muelas del Megatherium. Tiene 22 milimetros de diámetro anteroposterior y otro tanto de diámetro transverso.

El fragmento de mandíbula que atribuyo al mismo género es un pediazo de la parte anterior del lado derecho de la mandíbula inferior, 
en el cual se conserva intacto el alvéolo de la primera muela y una parte considerable del alvéolo de la segunda. Las dimensiones de esta parte de la mandibula corresponderían al íamaño de una especie de Mylodon; pero los alvéolos son tan grandes, que las muelas que estaban antes implantadas en ellos eran de doble tamaño que las correspondien. tes en el género mencionado, como en efecto lo son las dos muelas aisladas ya descriptas, que atribuyo al mismo género.

El alvéolo del primer molar es de forma casi cilíndrica, con sus borcies anterior, posterior y externo redondeados y el borde interno más aplastado y con una cresta perpendicular en el medio, poco elevada. Tiene 23 milímetros de diámetro anteroposterior, 20 milímetros de diámetro transverso y 55 milímetros de profundidad.

El segundo alvéolo, del que sólo existe el tabique anterior y el tabique interno, parece haber sido de forma más cuadrangular y sigue inmediatamente al primero con un intervalo de sólo un milimetro. El tabique anterior es más aplastado y no redondeado como en el primer alvéolo; y el tabique interno muestra la misma cresta perpendicular que existe en el alvéolo anterior, pero más desarrollada. Tiene unos 24 milímetros de diámetro anteroposterior y otro tanto de diámetro transverso.

Al nivel del primer molar, la mandíbula tiene 51 milimetros de alto en su lado externo, 24 milimetros de espesor en el borde alveolar y 32 milimetros de espesor hacia la mitad del alto de la mandíbula.

La parte superior de la mandibula adelante del alvéolo del primer molar (ella existe en una extensión de 45 milímetros), es bastante aelgada y se va levantando suavemente hacia arriba en su parte anterior. Ahi, debajo de ese borde, existen dos agujeros mentonianos; uno, pequeño, de unos 5 milímetros de diámetro, situado a unos 23 milimetros adelante del borde alveolar anterior dei primer molar y a 14 milímetros debajo del borde superior de la mandibula; otro, mucho más grande, está situado 8 milimetros más hacia adelante y hacia abajo del anterior y a 16 milímetros más abajo del borde superior de la mandíhula; es de forma elíptica y tiene unos 17 milímetros de largo por 9 milímetros de ancho.

La curva para formar la sínfisis de la mandibula parece empezar justamente debajo de estos agujeros; y como están situados más adelante que en el Mylodon, resulta que la sínfisis del Interodon debía ser más prolongada hacia adelante, pero no tanto como en el Scelidotherium. En la forma general, esta parte de la mandibula se parece más a la de Mylodon, Lestodon y Pseudolestodon que a la de Scelidotherium; pero los alvéolos son de tamaño mucho mayor que en los géneros mencionados y de forma distinta. Las dos muelas aisladas en su forma prismáticocuadrangular tienen lago de las de Megatherium, Cœlodon, 
Pliomorphus, etcétera, sin ser idénticas con ninguna de las de estos géneros.

La talla del Interodon crassidens era comparable a la del Mylodon robustus.

Procedenciu: -.. Los restos de este animal han sido descubiertos por el profesor Scalabrini en las barrancas de los alrededores de la ciudad del Paraná y pertenecen al Museo provincial de Entre Rios.

Horizonte: Piso mesopotámico de la formación patagónica (oligoceno inferior).

\section{ZAMICRUS, nt. gen.}

Este genero se distingue for muelas de sección rectangular, como en el Megatherium, colocadas igualmente en las mandibulas en sentido transwersal y con la corona con dos elevadas crestas transversales, separadas por una hendedura transversal, como en el mencionado género, pero con la capa de cemento externo delgada, presentando una capa intermedia de substancia vitrea, como en el Promegatherium; y un tamaño excesivamente reducido, no mayor que el de las especies del género Bradypus actual.

ZAMICRIS ADMTRABILIS, 11, sp.

Lamina XII. figurs ?

Conozco de este animal la dentadura inferior, compuesta de cuatro muelas a cada lado, de tamaño casi igual, pero excesivamente pequeño, tratándose de un animal que es evidentemente un intimo aliado del Megatherium. Las muelas intermedias de la mandibula inferior, que son las más grandes, sólo tienen de $0^{\mathrm{m}} 003$ a $0^{\mathrm{m}} 0035$ de diámetro anteroposterior, de 5 a 6 milimetros de diámetro transverso y de 12 a 13 milímetros de largo desde la raiz a la corona. Las caras perpendiculares opuestas, más grandes, anterior y posterior, son un poco deprimidas; $y$ de las dos caras perpendiculares laterales más pequeñas, una es un poco excavada perpendicularmente en el medio y la otra es plana o apenas un poco deprimida. Las dos crestas transversales de la corona son elevadas, muy comprimidas de adelante hacia atrás y de cúspide en forma de arista muy cortante; el valle transversal que separa a ambas crestas es ancho arriba, más estrecho abajo, profundo y completamente abierto en sus dos extremidades, lo que les da a las muelas un aspecto completamente igual a las del Megatherium, distinguiéndolas de las de los representantes.del grupo de los Orthotherida, en las cuales el surco transversal es considerablemente más profundo en el medio 
y de consiguiente con las extremidades imperfectamente abiertas. Otra paiticularidad de estas muelas, que sirve para distinguirlas de las del Megatherium, Promegatherium, y Neoracanthus, consiste en la capa de cemento externo, que en vez de ser, como en los mencionados géneros, sumamente gruesa adelante y atrís y muy delgada sobre los costados laterales, presenta un espesor más uniforme, siendo muy delgada en toda su extension y apenas un poco más gruesa en las caras perpendiculares, anterior y posterior.

Procedencia: - Barrancas del río Santa Cruz, en Patagonia austral.

Horizonte:- Piso santacruceño (eoceno inferior).

OBSERVACIONES GENEIRALES SOBRE LOS MEGATHERIDAE

El grupo de los Megatheriud aparece constituido con sus principales caracteres ya desde el principio de los tiempes terciarios, en la base del eoceno, pero era representado entonces por animales de tamaño muy pequeño, verdaderos pigmeos comparados con sus colosales descendientes.

El tamaño de los representantes de este grupo fué aumentando progresivamente hasta los tiempos cuaternarios, en los cuales se extinguen sus últimos y más gigantescos representantes. En este punto, la sucesión geológica está completamente de acuerdo con las leyes filogénicas de la evolución, que, como ya he tenido ocasión de repetirlo, establecen que los antecesores deben ser siempre de tamaño menor que los sucesores.

El más antiguo representante de este grupo, el Zamicrıs, es también el más pequeño y, por consiguiente, puede considerarse como el tronco antecesor de toda la familia.

Aqui la serie se interrumpe, no conociéndose por ahora otros representantes hasta el oligoceno del Paraná, en donde aparece el Promegatherium, de tamaño considerable, pero un poco menor que el .Hegatherium y de evidentes caracteres más primitivos. El Megatherium es un sucesor directo e inmediato del Promegatherium y un antecesor del Essonodontherium, de época algo más moderna y con una muela menos en cada lado de cada mandibula, carácter de evolución mas avanzada, indiscutible.

El género Neoracanthus, no puede ligarse a ninguno de los tres mencionados por su tamaño menor; y desciende probablemente de un antecesor común cor el Promegatherium. El Intcrodon presenta caracteres más divergentes, y su separación debe remontar a una época más le- 
jana, pero faltan las formas intermedias que permitan ligarlo al tronco antecesor de la familia.

Esta serie, puede representarse en esta forma:

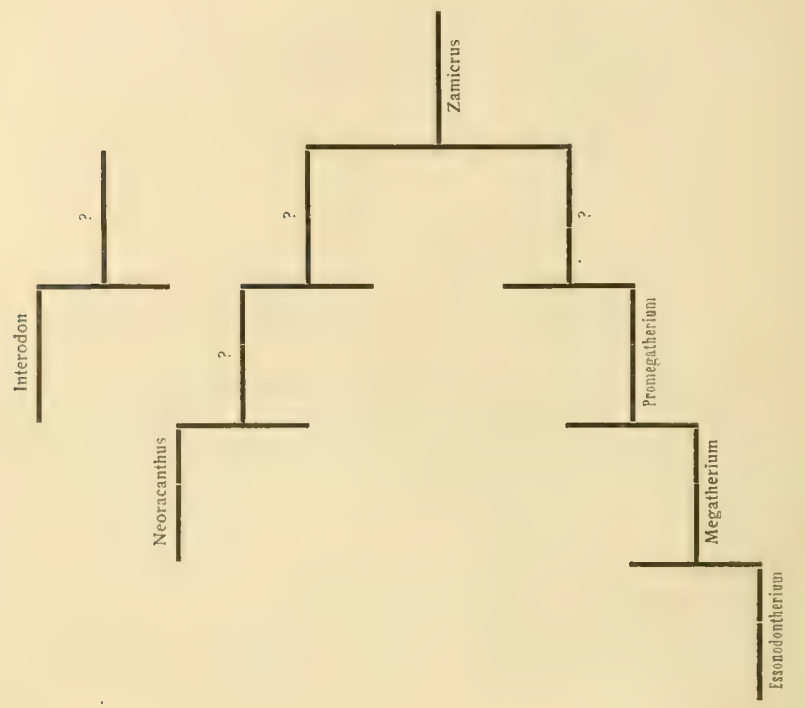

Orthotheridæ

Los representantes de este grupo tienen las muelas construídas sobre el mismo tipo fundamental que las de los Megatherida, de los cuales se distinguen por la abertura de la rama externa del canal alveolar que se abre en la parte anterior de la base de la rama ascendente, en una posición que no puede considerarse ni interna ni externa, sino intermedia entre la interna de Megatherium y Neoracanthus y la externa de Megalonyx, Cœlodon, etc. La primera muela puede ser un poco más pequeña y un poco separada de la precedente, pero sin afectar nunca un aspecto verdaderamente caniniforme; y el surco transversal de la corona de las muelas es más profundo en el centro y abierto de un modo imperfecto en las extremidades. 
Conozco cinco representantes de este grupo, que se distinguen por los siguientes caracteres:

I. Muelas rectangulares.

a. Primera muela inferior pequeña y cilindrica: Orthotherium.

b. Las cuatro muelas inferiores rectangulares: Schismotherium.

II. Muelas elípticorrectangulares o subelipticas.

A. Sinfisis larga.

a. Primera muela inferior pequeña, elípticocilíndrica y truncada horizontalmente: Hapalops.

b. Primera muela superior pequeña, elípticocilíndrica, separada por una larga barra y de aspecto caniniforme: Planops.

B. Sinfisis mandibular corta, levantada hacia arriba y puntiaguda: Xyophorus.

\section{ORTHOTHERIUM Ameghino}

AMégrio: «Boletín de la Academia Nacional de Ciencias», tomo VIII, página Irr, 1885.

La mandibula inferior es corta, baja y gruesa, con cuatro muelas, la primera muy pequeña y cilíndrica y las tres posteriores de sección prismática cuadrangular y muy grandes. La abertura externa posterior del canal alveolar está situada en la parte anterior de la base de la rama ascendente. Talla muy pequeña.

\section{Orthothertum Laticurvatum Ameghino}

Latulan LXX, fgura a; lamina LXXI, figuras 12 y la

AmzGHro: \&Boletín de la Academia Nacional de Ciencias», tomo VIII, página ir r, 1883. - Idem: tomo IX, página $167,1886$.

Fundé la especie sobre parte de la rama horizontal del lado izquierdo de la mandíbula inferior, con el alvéolo del primer diente pequeño y cilíndrico y los tres alvéolos de las grandes muelas cuadrangulares que siguen.

La mandibula es baja, gruesa, sumamente corta y como dada vuelta sobre si misma, de donde resulta que la pared externa forma como una protuberancia convexa, muy pronunciada, particularmente en su parte superior. Tiene debajo de la segunda muela 37 milimetros de alto, 21 milímetros de espesor y 41 milímetros de largo a partir del punto de la rama horizontal en que empieza a levantarse la rama ascendente hasta el alvéolo de la primera muela de aspecto caniniforme. La rama 
ascendente empieza a levantarse inmediatamente detrás del tercer diente y al lado del cuarto, existiendo de ella sólo una pequeña parte.

La abertura de la rama externa del canal alveolar es una perforación elíptica, de unos 8 milímetros de diámetro mayor, colocada en el principio de la rama ascendente al lado del alvéolo del último molar y a distancia de 7 milimetros del borde alveolar.

La sinfisis de la mandibula empieza debajo del primer diente, que. a juzgar por el alvéolo, era muy pequeño, de forma cilíndrica algo elíptica, colocado un poco afuera de la linea dentaria y dirigido un poco hacia adelante, de manera que tenia una pequeña tendencia a un aspecto caniniforme. Entre éste y el segundo diente hay una barra bastante corta en donde la mandibula no es tan espesa; y siguen detrás los alvéolos de tres enormes muelas en proporción del tamaño de la mandibula, de forma algo rectangular, de íngulos redondeados, colocadas con su mayor diámetro en sentido transversal y muy apretadas unas a otras, de manera que los alvéolos están separados por tabiques que tienen menos de un milímetro de espesor. El primero de estos alvéolos es más bien de figura prismáticotriangular y el de la última muela está en su mayor parte destrozado y perdido, pero por io que queda parece tuvo la misma forma y dimensiones que el penúltimo.

\section{DIMENSIONES}

Alto de la rama horizontal debajo de la barra que separa el diente caniniforme

del diente segundo ............................................. 0 n 033

Alto de la rama horizontal debajo del segundo diente $\ldots \ldots \ldots \ldots \ldots \ldots \ldots \ldots . . . .6035$

Alto de la rama horizontal debajo del tercer diente....................... 0039

Grueso de la mandibula en su parte superior en el borde de la Barra......... 0006

Grueso debajo de la barra en la parte inferior ....................... 0014

Grueso debajo del segundo diente ................................. 0021

Diántetro del alvéolo del primer diente .............................. 0006

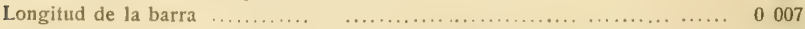

Diámetro del alvéolo de la segunda muela $\mid$ anteroposterior ............... 0012

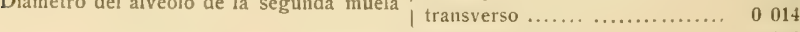

Diámetro del alvéolo de la tercera muela $\mid$ anteroposterior $\ldots . . . \ldots \ldots \ldots . .6010$ transverso ..................... 0014

Los alvéolos de esta mandibula, muy profundos, descienden hasta la base misma del hueso, de modo que el canal alveolar, aunque bastante pequeño, no teniendo espacio en la parte inferior del maxilar, corre al lado de los dientes sobre la cara interna, más o menos a un tercio de la altura de la mandíbula. La forma exacta de las muelas que se implantaban en los alvéolos no puede apreciarse exactamente, por estar éstos bastante destruídos, particularmente los dos últimos; pero, sin embargo, es dable deducir que debían ser de forma más o menos prismáticocuadrangular y de esquinas perpendiculares redondeadas. 
Conozco dos muelas muy pequeñas, que, precisamente, presentan esta forma y además parecen concordar tan exactamente con los alvéolos vacíos del maxilar que no dudo provengan del mismo género y de la misma especie.

Uno de los dos ejemplares, el más pequeño, del cual sólo existe la parte superior, corresponde exactamente por su forma y su tamaño al alvéolo vacío del segundo diente del maxilar inferior izquierdo y debe ser, en efecto, el correspondiente al mencionado alvéolo. Es de sección prismáticocuadrangular, de esquinas perpendiculares muy redondeadas, y más angosto en una de las caras perpendiculares laterales (la externa, si es la muela supuesta) que en la otra. Tiene 10 milímetros de diámetro anteroposterior sobre el lado interno, sólo 7 milímetros sobre el lado externo y 13 milímetros de ancho o de diámetro transverso. La corona muestra en la superficie una cavidad oblonga, a causa de las Jos crestas transversales que estín unidas por sus extremos por aristas un poco más bajas, que sin duda desaparecian con la edad, abriendo ia hendedura en sus extremos, convirtiéndose así en ranura transversal.

La composición de la muela es: una capa externa muy delgada de cemento de color azulejo obscuro, amarillento en algunos puntos y de aspecto muy quebradizo. Sigue a éste una hoja muy delgada, de apenas $0^{m} 0004$ de espesor, de una substancia más obscura, más brillante y semividriosa, a la que sigute otra hoja muy delgada de dentina blanca dura que rodea a la vásculodentina interna. Esta pieza me ha sido proporcionada por el señor D. León Lelong Thévenet.

E1 segundo ejemplar procede de las colecciones reunidas por el profesor Scalabrini. Es de un volumen mucho más considerable que el precedente, pero precisamente en la mandibula descripta el alvéolo de la tercera muela también presenta dobles dimensiones que el de la segunda; y como la muela no se adapta a este alvéolo, por presentar la forma de él invertida, supongo sea la tercera inferior del lado derecho. Es igualmente de figura prismáticocuadrangular con esquinas perpendiculares redondeadas, pero de cara perpendicular anterior mucho más angosta que la posterior. Tiene 13 milímetros de diámetro anteroposterior, 12 milímetros de ancho o de diámetro transverso en la cara perpendicular anterior y 18 milimetros en la posterior. La corona muestra dos crestas transversales poco elevadas, separadas por un surco poco profundo, siendo, de acuerdo con la conformación general de la muela, la anterior mucho más corta que la posterior. Presenta una capa de cemento externo delgada en la cara anterior y en sus dos caras laterales pero gruesa de 2 milímetros en la posterior. Sigue a esta capa otra de un milímetro de espesor, de substancia semividriosa y de textura radiada, que examinada con un lente parece estar separada de la precedente por una hoja mucho más delgada, de apenas $0^{\mathrm{m}} 0001$ de grueso, 
de una substancia lustrosa, amarilloobscura. Sigue luego hacia el interior otra capa bastante gruesa de substancia amarilloclara, que es la dentina dura que rodea a la vásculodentina, pero ahí está todavía separada de esta última por una hoja muy delgada de sólo $0{ }^{\text {ri }} 0001$ de grueso ce una substancia amarilloobscura, brillante y vidriosa, que es la que realmente rodea a la vásculodentina que forma la masa interna del diente. Estas distintas capas son muy visibles en la parte inferior del diente. que está roto en un punto donde aún no empieza la cavidad interna, pero, aunque menos distintamente, son también visibles en la corona.

Procedencia: - Los restos de esta especie se han encontrado en las barrancas de los alrededores de la ciudad del Paraná.

Horizonte: - Piso mesopotámico de la formación patagónica (oligoceno inferior).

\section{SCHISMOTHFRIUM Ameghino}

Amegrino: Enumeración sistemática de los mantforos eocenos, etc., página 21, I887.

La mandíbula inferior sostiene cuatro muelas rectangulares, en serie continua, de ángulos redondeados, implantadas con su diámetro mayor en dirección transversal al eje longitudinal de la serie dentaria. El agujero de la abertura de la rama externa del canal alveolar se abre en la parte anterior de la base de la línea oblicua externa que va a terminar en la apófisis coronoides.

SCHISMOTHERIUM TRACTUM Ameghino

Axegrino: Enumeraciśn sistemática de los mamiferos, etc., página 21, número 94, 1887.

El animal, desgraciadamente, sólo está representado por un fragmento de mandibula inferior del lado izquierdo con parte de los alvéolos de las dos primeras muelas y las dos muelas posteriores, cuya pieza indica que esta especie, por sus caracteres, fué aliada del género Orthotherium, pero de tamaño muy pequeño.

La primera muela, a juzgar por el fragmento de alvéolo que queda en la pieza mencionada, parece haber sido la más pequeña y la segunda muela inferior la más grande, pues el alvéolo en que se implantaba tiene 11 milímetros de diámetro anteroposterior.

El tercer diente de la mandíbula inferior tiene la corona intacta; ésta es de sección rectangular, con sus cuatro ángulos redondeados y con dos crestas transversales, una adelante y otra atrás, incompletamente separadas en sus dos extremidades, de manera que el centro de la corona queda profundamente excavado. De las cuatro caras perpendiculares, la 
anterior es la más ancha y plana, la posterior es un poco más angosta y ligeramente convexa y las dos laterales más angostas son del mismo ancho, la externa con una pequeña depresión perpendicular y la interna ligeramente convexa. Tiene $0^{\mathrm{m}} 0075$ de diámetro anteroposterior y $0^{\mathrm{m}} 011$ de diámetro transverso.

La muela cuarta o posterior es apenas un poco más pequeña y difiere de la precedente por su cara anterior un poco convexa y la posterior plana.

Las dos últimas muelas ocupan un espacio longitudinal de 20 milimetros y a juzgar por lo que queda de los alvéolos de las dos primeras muelas, las cuatro juntas debían ocupar un espacio longitudinal de 42 a 45 milímetros.

La cara externa de la rama horizontal debajo de las dos muelas intermedias es bastante convexa en el centro.

Procedencia: - Ha sido descubierta por Carlos Ameghino en las barrancas del río Santa Cruz, en Patagonia austral.

Horizonte:- Piso santacruceño (eoceno inferior).

HAPALOPS Ameghino

AMEgrino: Énumeración sistemática de los mamiferos, etc., página 22, 1887.

Este género es conocido por fragmentos de mandíbulas inferiores, todas pertenecientes a animales de talla relativamente pequeña. La primera muela inferior es pequeña, más o menos cilíndrica y separada da las que siguen atrás; éstas tienen una forma más o menos elíptica rectangular, siendo la última un poco más pequeña que la penúltima, más cilíndrica e implantada con su eje mayor en dirección oblicua al de la serie dentaria. El agujero de la rama externa del canal alveolar es bastante grande, eliptico y colocado en la base de la línea ascendente de la rama ascendente, en su parte anterior.

\section{Hapalops rectangularis Ameghino}

Lamina XLt bgura a

Avegrino: Enumeración sistzmática de los mamiferos, etc., página 22, número 98, 1887 .

La especie está representada por dos fragmentos de mandibula, la parte posterior del lado izquierdo con las dos últimas muelas y la parte posterior del lado derecho con las dos últimas muelas y parte de la antepenúltima.

La antepenúltima muela, a juzgar por la parte del alvéolo que se conserva en uno de los fragmentos, parece haber sido igual a la pe- 
núltima; ésta es de sección rectangular, de ángulos regularmente acentuados, con las caras perpendiculares anterior y posterior un poco convexas y las caras interna y externa con un pequeño surco perpendicular en el medio. La corona presenta dos crestas transversales unidas en sus extremos y tiene 6 milímetros de diámetro anteroposterior y $0^{\mathrm{m}} 0085$ de diámetro transverso.

La última muela inferior es de sección más circular, completamente redondeada en el lado interno, pero más angulosa sobre el externo y colocada un poco oblicuamente de adelante hacia atrás y de afuera hacia adentro. La corona presenta en todo su contorno una cresta periférica más elevada en la parte anterior y con la parte interna de la corona formando un pozo profundo. Tiene 8 milímetros de diámetro mayor y 6 de diámetro menor.

Las dos últimas muelas ocupan un espacio longitudinal de 16 milímetros.

La rama horizontal de la mandíbula tiene debajo de la penúltima muela 23 milímetros de alto.

El agujero de la rama externa del canal aiveolar tiene 6 milímetros de diámetro mayor.

Procedencia: - Los restos de esta especie han sido descubiertos por Carlos Ameghino en las barrancas del río Santa Cruz, en Patagonia austral.

Horizonte: - Piso santacruceño (eoceno inferior).

Hapalops EhLipticus Ameghino

Lrmina $X L$, nguras 30 y 31

AMECHiNo: Enumeración sistemática de los mamffcros, etc., página 22, número 100, 1887.

Esta especie está representada por tres fragmentos de mandibulas inferiores, de los cuales el más completo es la parte posterior de la rama horizontal del lado izquierdo con las tres últimas muelas, aunque con la corona destrozada. Difiere de la especie precedente por un tamaño un poco mayor y por ser proporcionalmente más robusta. Las muelas son relativamente más pequeñas y más elipticas que en la especie anterior, con sus caras interna y externa angostas y redondeadas y la última inferior es de sección casi completamente circular.

La primera muela que sigue al caniniforme o sea la antepenúltima muela, tiene 6 milímetros de diámetro anteroposterior y 9 milímetros de diámetro transverso.

La penúltima muela inferior tiene, con muy escasa diferencia, las mismas dimensiones que la antepenúltima y la última tiene unos $8 \mathrm{mi}$ limetros de diámetro. Las tres muelas ocupan un espacio longitudinal 
de 25 milímetros. La rama horizontal de la mandibula tiene debajo de la penúltima muela 26 milímetros de alto y 17 milímetros de espesor.

Procedenciu: - Los restos de esta especie han sido descubiertos por Carlos Ameghino en las barrancas del río Santa Cruz, en Patagonia austral.

Horizonte:- Piso santacruceño (eoceno inferior).

IAAPALOPS INDIFTERENS Ameghino

Lamina XXXIX, ñgura \&

Amegrivo: Enumeración sistemática de los namíferos, etc., página 22, número 99, 1887.

Esta especie, representada por una mitad derecha de la mandibula inferior, es de tamaño todavía un poco mayor que la precedente, de la cual difiere además por sus muelas de tamaño un poco mayor y más rectangulares, a lo menos a juzgar por los tres alvéolos vacíos de la mandibula, pues no hay ninguna muela, con excepción del diente anterior caniniforme, del cual existe la parte que se implantaba en la mandíbula, faltando la corona. Este diente es muy pequeño y ligeramente elíptico, de 5 milímetros de diámetro mayor y 4 de diámetro menor, estando separado del molar que sigue por una barra de 7 milímetros de largo, en la que la prolongación del borde alveolar es de un espesor: de 7 milimetros sobre el lado externo de la mandibula: entre el caniniforme y la muela que sigue, inmediatamente debajo de la barra hay una depresión cóncava y profunda.

Los alvéolos de las dos primeras muelas que siguen al caniniforme tienen, con pequeñisimas diferencias, las mismas dimensiones de 8 milímetros de diámetro anteroposterior y 10 milímetros de diámetro transverso, pero el de la última inferior es de tamaño un poco más reducido.

Los tres dientes molares ocupaban un espacio longitudinal de 30 milimetros; y la distancia desde la parte posterior de la última muela hasta la parte anterior del caniniforme es de 42 milímetros.

La mandíbula tiene una parte sinfisaria fuerte y larga que se prolongaba adelante del caniniforme cuando menos por un espacio de 25 milimetros, dirigiéndose hacia adelante y hacia arriba; casi en la parte anterior y superior de este prolongamiento se abre el agujero mentoniano. La parte posterior de la sinfisis llega hasta debajo de la primera muela.

La rama horizontal de la mandíbula es corta y muy gruesa con su borde inferior casi recto y de consiguiente con el mismo alto en casi todo su largo. La cara interna de la rama horizontal es completamente vertical y de consiguiente plana, pero la cara externa es fuerte- 
mente convexa, particularmente enfrente de la penúltima muela. El alto de la rama horizontal en este punto y sobre el lado externo es de 29 milimetros y su grueso máximo de 20 milímetros.

Procedencia: - Ha sido descubierta por Carlos Ameghino en las barrancas del río Santa Cruz, en Patagonia austral.

Horizonte:- Piso santacruceño (eoceno inferior).

PLANOPS Ameghino

AMegrino: Énumeración sistemática de los mamiferos, etc., página 23, 1887.

Este animal sólo me es conocido por un fragmento de maxilar superior derecho con el primer diente y parte del alvéolo del segundo, perteneciente a un individuo adulto; y la misma parte con el mismo diente de un individuo joven.

El primer diente es un poco caniniforme y separado del segundo por una barra corta, pequeña y elíptica. El diente segundo y probablemente también los demás eran de tamaño mayor y de forma elípticorrectangular. El paladar se extendía adelante del diente caniniforme, formando un hocico muy prolongado.

Planofs zoxcirostratus Ameghino

Amzonino: Eummeración sistemática de los manziferos, etc., página 23, número 104, 1887.

El caniniforme superior es poco elevado sobre el borde alveolar con la corona gastada en declive ce adelante hacia atrás, pero un poco más gastada en el centro que en la periferia. El diente tiene $0^{\mathrm{m} 0065}$ de diámetro anteroposterior, 5 milímetros de diámetro transverso y su mayor elevación sobre la superficie del paladar es de 4 milímetros. La barra que lo separaba del diente segundo tiene 8 milimetros de largo.

La cara externa del maxilar se levanta hacia arriba casi perpendicularmente, formando sólo una pequeña protuberancia el alvéolo del caniniforme, seguida adelante de una pequeña depresión y de otra atrás entre el caniniforme y el diente segundo, más grande y más profunda.

La parte del paladar correspondiente al fragmento de maxilar mencionado, se conserva intacta y permite medir el ancho del paladar entre el par de dientes caniniformes, que era de 22 milimetros, pero se angostaba notablemente hacia atrás entre las muelas, donde sólo debia tener unos 12 a 14 milímetros de ancho.

La parte del paladar comprendida entre el caniniforme y el segundo diente es de superficie convexa. La parte que se extiende adelante del 
caniniforme muestra un surco longitudinal cerca de la sutura media y paralelo a ésta, que se pierde luego en la parte anterior. La linea alveolar adelante del caniniforme se prolonga en forma de canaleta que se va estrechando $y$ volviendo más angosta hacia adelante, hasta que termina en una profunda hendedura muy estrecha. La pared externa del maxilar desciende verticalmente sobre esta canaleta, sobresaliendo varios milímetros sobre la superficie del paladar en forma de arista longitudinal alta y delgada.

La parte del paladar adelante del caniniforme existente en el fragmento en cuestión, tiene 20 milímetros de largo; pero está rota en su parte anterior y de la rotura se puede deducir que se extendia hacia adelante por lo menos otros 10 milímetros.

Procedencia: - Ha sido descubierta por Carlos Ameghino en las barrancas del río Santa Cruz, en Patagonia austral.

Horizonte:- Piso santacruceño (eoceno inferior).

XYOPHORUS Ameghino

Amegrino: Enumeración sistemática de los mamiferos, etc., página 23, 1887.

El género está representado hasta ahora por la parte sinfisaria de cos ramas mandibulares, cada una con el diente primero y parte del alvéolo del segundo, provenientes de dos individuos de especie distinta. Estas mandíbulas se parecen un poco a las de Mylodon pero son de parte sinfisaria más corta y con el borde superior y anterior levantado hacia arriba en forma de punta. La primera muela es pequeña, un poso separada de la segunda y con la corona de superficie un poco excavada en el centro y algo en declive hacia adelante.

XYophorus rostratus Ameghino

AMÉGINo: Enumeración sistemática de los maniferos, etc., página 23, nímero 105, I885.

Es la especie más pequeña del género; está representada por la parte anterior de la rama horizontal izquierda de la mandibula inferior, con parte del alvéolo del diente segundo, el diente primero y la sínfisis intacta.

La primera muela es muy pequeña y elíptica, de 0 m0035 de diámetro anteroposterior y $0^{\mathrm{m}} 0024$ de diámetro transverso; sobresale fuera del alvéolo apenas unos dos milímetros y tiene la corona excavada en el centro y un poco inclinada hacia adelante. El diastema que separa a este diente del que sigue no alcanza a 3 milímetros de largo. El diente segundo era considerablemente mayor, pero la pequeña parte existente del alvéolo no permite formarse una idea de su configuración. 
La punta de la mandibula tiene 11 milímetros de largo adelante del primer diente, sin que en su parte anterior forme curva hacia adentro para formar la sínfisis. La sínfisis empieza abajo, adelante del primer diente y se prolonga hacia adelante y hacia arriba sin producir ensanchamiento de la mandíbula, tanto que al juntarse las dos ramas debían formar en la parte anterior como una arista perpendicular. La impresión sinfisaria tiene 6 milimetros de ancho y 17 milimetros de alto, terminando arriba en punta àguda.

El agujero mentoniano se abre a mitad de distancia entre el primer diente y la punta de la mandibula y casi sobre el borde superior de ésta.

La rama horizontal debajo del primer diente tiene 11 milimetros de alto y 5 de espesor máximo.

Procedencia: - Esta especie ha sido descubierta por Carlos Ameghino en las barrancas del río Santa Cruz, en Patagonia austral.

Horizonte:- Piso santacruceño (eoceno inferior).

XYopHores simus Ameghino

Amécrino: Enumeración sistenática de los mamiferos, ete., página 23, numero 106, I887.

Esta especie, de tamaño bastante mayor que la precedente, está representada por la farte inferior de la rama horizontal del lado derecho ce la mandibula inferior con el primer diente y parte del alvéolo del segundo.

E1 diente primero es casi completamente cilíndrico, de unos 4 milímetros de diámetro y de 19 milímetros de largo desde la raíz a la corona. Está implantado en el alvéolo inclinado hacia adelante, con la corona un poco gastada en el centro, un poco en declive hacia ałelante y algo más elíptica que el cuerpo del diente. El diastema que separa a este diente del segundo, sólo tiene 4 milímetros de largo.

El diente segundo, cuya parte anterior del alvéolo existe, era de tamaño considerablemente mayor, pero como en el caso anterior, la parte existente no permite determinar su forma.

La parte de la mandíhula que se extiende adeiante del primer diente esté rota, pero se conoce que era relativamente más corta que la de la especie precedente, con la parte anterior un poco encorvada hacia adentro para formar la sínfisis, que era más espesa, pero dirigida igualmente hacia arriba, aunque probablemente no formaba una punta tan aguda.

El agujero mentoniano se encuentra en la misma posición que en Xyophorus rostratus. La cara externa de la mandíbula, entre el primero y el segundo diente e inmediatamente debajo del borde alveolar, present. una depresión profunda y de fondo cóncavo. 
El alto de la rama horizontal al nivel del primer diente y medido sobre la cara externa, que es un poco más alta que la interna, es de 20 milimetros.

Procedencia: - Los restos de esta especie han sido descubiertos por Carlos Ameghino en las barrancas del ric Santa Cruz, en Patagonia austral.

Horizonte:- Piso santacruceño (eoceno inferior).

No hay hasta ahora suficientes materiales para ensayar un bosquejo de la filiación de los Orthotherida.

\section{Megalonychidæe}

Los representantes de este grupo se distinguen por sus muelas de sección prismáticocuadrangular u oblongocuadrangular, excepto la primera anterior, tanto de arriba como de abajo, que está siempre separada de la segunda por una larga barra y afecta la forma de canino o de incisivo; sin embargo, en algunos casos puede faltar este diente por completo, conservando los demás su disposición y su simplicidad normales. La abertura de la rama externa del canal alveolar se abr: siempre sobre el lado externo de la base de la rama ascendente de la mandíbula inferior. El calcíneo es muy comprimido transversalmente y elevado representando la forma de una hacha.

Los siete géneros que existen o se han mencionado como existentes en la República Argentina, se distinguen de la siguiente manera:

I. Cuatro muelas en cada lado de la mandibula inferior.

A. Muelas subelípticas.

a. Caniniformes truncados horizontalmente: Megalonyx.

b. Caniniformes truncados oblicuamente: Eucholoops.

B. Muelas rectangulares o cuadrangulares.

a. Primera muela muy separada de la segunda, muy gruesa y caniniforme: Pliomorphus.

$b$. Primera muela muy pequeña y cilindrica.

aa. Primera muela muy próxima de la segunda: Trematherium.

$b b$. Primera muela muy separada de la segunda: Valgipes.

II. Tres muelas en cada lado de la mandíbula inferior.

A. Muelas cuadrangulares: Colodon.

Imperfectamente conocido: Gnathopsis. 
JefFerson: Transact. Amer. Phil. Soc, tomo IV, rágina 246, 2797.

Este género es de cráneo un poco más convexo que en la generalidad de los representantes de la misma familia, con la parte anterior muy ensanchada, truncada perpendicularmente, presentando una abertura nasal enorme. La mandibula inferior es de rama ascendente débil, rama horizontal formando una curva bastante descendente hacia abajo y sinfisis corta, elevada y sumamente fuerte. E1 intermaxilar es rudimentario. Las muelas son en número de ${ }_{4}^{5}$, las cuatro últimas superiores y las tres últimas inferiores, de forma subrectangular con una tendencia a la forma prismáticotriangular.

El primer diente de cada mandíbula es de tamaño mayor, de sección elíptica y muy separado de los demás, colocado en la parte anterior de la mandíbula tomando la forma de incisivos, pero de corona truncada transversalmente. El húmero es largo, delgado y con una perforación sobre la epitroclea. El pie anterior, que no se conoce completo, se supone tuvo cinco dedos, los tres del medio completos y con uña y los dos laterales, primero y quinto, rudimentarios. El fémur no es proporcionalmente tan fuerte como en Scelidotherium y Negatherium, sino algo más delgado y con un trocánter tercero más desarrollado. Tibia y peroné separados. Pie posterior probablemente con cinco dedos, los tres internos con uñas.

Los representantes de este género han sido hallados en América del Norte, especialmente en los Estados Unidos, pero nada autoriza hasta ahora a suponer que hayan penetrado en Sud América, aunque repetidas veces se ha citado al Megalonyx como uno de los representantes de la fauna extinguida de nuestro suelo.

La primera noticia de la existencia de restos de Megalonyx en Sud América, fué dada por Lund, pero luego reconoció su error, estableciendo sobre ellos los nuevos géneros Coclodon y Platyonyx.

Casi al mismo tiempo describía Owen una mandibula inferior recogida por Darwin en la extremidad austral de Patagonia, atribuyéndola a un Megalonyx que consideró como específicamente idéntico al Megalonyx Jeffersoni de Norte América; pero Leidy, que es el autor que mejor ha estudiado este género, no reconoce a dicha pieza los caracteres del Megalonyx y funda sobre ella un nuevo género que denomina Gnathopsis.

Leidy reconoce igualmente que un astrágalo, considerado por Owen como de Megalonyx, proviene de un género diferente, que cree puede ser el mismo representado por la mandíbula inferior; pero Burmeister 
ha demostrado que no proviene ni del uno ni del otro, sino de un animal muy distinto, que él considera como una especie de Mylodon al cuai denomina Mylodon giganteus, aunque, sin embargo, constituye un género muy distinto, conocido ya, bajo el nombre de Lestodon, con anterioridad a los trabajos de Burmeister.

Los restos de Megalonyx mencionados casi en la misma época por el doctor Francisco J. Muñiz, provienen igualmente de especies del género Lestodon.

Bravard también creyó reconocer en algunos huesos recogidos por él en nuestro territorio una especie del género Megalonyx que designa con el nombre de Megalonyx meridionalis («Registro Estadístico de la provincia de Buenos Aires», tomo I, página 9, año 1857); y Burmeister atribuyó al principio a la mencionada especie la parte inferior de un fémur de las colecciones del Museo de Buenos Aires («Anales del Museo Público de Buenos Aires», tomo I, página 180); pero más tarde ( Description Physique, etc.», tomo III, página 386 ) se apresuró a declarar que dicha pieza, por su conformación, está en oposición con la misma parte bien conocida del verdadero $11 \mathrm{egalonyx}$ y que, por consiguiente, proviene de un animal diferente.

Por otra parte, cuando Bravard mencionó la existencia de restos de Megalonyx en nuestro suelo, este género era todavía imperfectamente conocido, pues aunque entonces acababa de publicarse la notable Memoria de Leidy que da una idea bastante completa de la osteología del mencionado género (Leidy: «A memoir on the extinct sloth tribe of North America», 1855), dicho trabajo no fué conocido en Buenos Aires durante esa época. La idea que Bravard tenia del Megalonyx era tan imperfecta que no encontraba diferencias entre el Mcgalonyx y el Scelidotherium. En efecto, a propósito del Scelidotherium se expresa Bravard en estos términos: «Ce genre, ćtabli par $M$. Owen, ne l'a pas été avec la précision qui caracterise les travaux de cet habile professeur. Áinsi, il n'a pas va que l'arcade zygomatique est ouverte comme dans les Bradypus. Il n'a pas v'u non plus, que cet animal avait deux vertèbres dorsales de plus que le Megatherium et le Mylodon, et que son humérus etait percé alt-dessus du condyle externe d'un trou pour le passage de l'artère cubitale comme cela s'observe dans l'humérus du Megalonyx. Pour nous le genre Scelidotherium cst un double cmploi du Megalonyx et nous pensons que $M$. Lund avait cu raison d'attribuer à ce dernier genre les animaux du Brésil qu'il avait dédié à MM. Cuvier et Buckland. Tous ce que nous connaissons du Megalonyx justifie notre manière de voir, cependant comme ce n'est pas ici le lieu de discuter la valeur de ces distinctions ostéologiques nous emploiron provisoirement le nom générique proposé par $M$. Owen». Y un poco más adelante, al mencionar su pretendida nueva especie que designa con el nombre de Mega- 
lonyx meridionalis, dice: «S'il existe des differences génériques entre le Megalonyx ct le genre qui precède (Scelidotherium) la seule qui il nous soit permis de signaler au moyen de 36 morceaux que nous possedons de cet animal, consiste en un unguéal de plus au pied de devant. Cet os termine la pouce qui n'est qu'un vestige dans le Scelidotherium. Du reste ces morceaux constituent cvidentement une espèce distincte du Megalonyx Jeffersoni. L'humérus du nôtre a deux pouces de longueur de moins que celui dont il est parlé dans la description du Mylodon de M. Ou'cn. Nous nommerons cette espèce Megalonyx meridionalis.» (Bravard: «Resumé du catalogue des collections paléntologiques», 1856. Ms). Esto basta para demostrar que se trata de restos de un animal parecido al Scclidotherium y de ninguna manera de un Megalonyx. Con estos datos el doctor Burmeister, en cuyo poder se encuentran las colecciones formadas por Bravard, podrá sin duda decirnos algún día a qué animal pertenecen los restos que atribuia a un Megalonyx.

Quedan todavia algunas indicaciones de P. Gervais sobre la existencia en las colecciones del Museo de Paris, de algunos húmeros incompletos, procedentes de la República Argentina, que tienen algunas analogias con los del Megalonyx y que presentan, como los de este animal, una gran perforación encima de la epitroclea (P. Gervais: «Sur plusieurs espèces de mamm. foss, propres à l'Am. Mer.", página 24, año 1873), pero tienen también con los de éste algunas diferencias de importancia; y es casi seguro que, como en los casos anteriores, provienen de animales genéricamente distintos del Megalonyx.

Pero si nada prueba la existencia de animales idénticos como género al Megalonyx, es, sin embargo, indudable que han existido en la República Argentina animales muy parecidos y que con los de Norte América forman un grupo natural bien definido.

Uno de estos géneros es el

EUCHOLOEOPS Aneghino

AxECHiNo: Enumerací́n sistemática de los mamiferos, etc., página 21, 1887 .

Este género ofrece en su conformación general una mezcla de los caracteres de los géneros Cholœpus, Mcgatherium, Mylodon y Lestodon.

La fórmula dentaria es la misma que en los géneros mencionados, pero los dientes son de distinta forma o dispuestos de otro modo.

El primer par de dientes, tanto superiores como inferiores, están muy separados de los demás y toman la forma de caninos.

El paladar es estrecho atrás entre las muelas, pero se ensancha hacia adelante como en el Lestodon, particularmente en la parte anterior, que comprende los caninos. Estos están implantados en la parte anterior del paladar en los ángulos externos, en una protuberancia convexa que 
los maxilares forman hacia afuera; tienen una forma triangular y de ángulos redondeados como el mismo diente del Pseudolestodon myloides, con la corona igualmente cortada en bisel de atrás hacia adelante y de abajo hacia arriba terminando en cúspide estrecha y aguda.

Detrás de los caninos sigue una larga barra, en cuyo trayecto e! paladar se angosta gradualmente hacia atrás hasta llegar a las muelas. Estas, en número de cuatro en cada lado, forman una serie continua, colocadas a igual distancia una de otra y todas de la misma forma. Cada muela representa una sección rectangular de ángulos muy redondeados o más bien una elipse muy prolongada, con su diámetro mayor en dirección transversal al eje de la serie dentaria y con la corona con dos crestas transversales que se unen en sus extremos, encerrando una excavación elíptica profunda.

En la mandíbula inferior el canino no está colocado en la extremidad anterior, sino más atrás, en una posición parecida a la que presenta en el Cholœpus. Es un diente igualmente triangular, más grueso que el superior e implantado en un ensanchamiento externo de la mandibula cn forma de protuberancia convexa; está implantado fuertemente inclinado hacia adelante y un poco hacia afuera, con la corona cortada en bisel de adelante hacia atrás y de abajo hacia arriba, terminando también en cúspide estrecha y aguda.

Atrás del caniniforme viene una barra notablemente más corta que la de la mandíbula superior y luego siguen tres muelas a cada lado, de la misma forma que las superiores, e implantadas igualmente con su eje mayor en sentido transversal. Estas muelas, así como también las superiores, tanto por la forma como por su modo de implantación, presentan un notable parecido con las del Mcgatherium y del Neoracanthus.

En su conformación general, el cráneo se parece más al de Mylodon, y sobre todo de Pseudolestodon, que al de cualquier otro género, pero con algunas desviaciones notables hacia géneros muy distintos.

A causa de su gran ensanchamiento y de la separación de los caninos de las muelas, el paladar muestra en su parte anterior más parecido con Lestodon. En su parte posterior, por lo contrario, se parece más a Mylodon y Bradypus.

La abertura nasal posterior se aleja, al contrario, del Mylodon y de los gravígrados en general, en los que se abre muy atrás de $1 x$ última muela; en el Eucholacops, al contrario, se abre inmediatamente detrás de la última muela como en el cholcopus y el Bradypus y aun puede decirse que está situada un poco más adelante que en estos géneros.

La abertura nasal anterior es de la misma forma que en el Mylodon y el Pseudolestodon. 
La parte superior del cráneo también se parece mucho a la del Mylodon, con la diferencia de ser un poco más aplastada y presentar algunos huesos entre sí una relación un poco diferente. Así los nasales son relativamente más cortos que en el Mylodon y más anchos; y la parte posterior en vez de angostarse como en aquel género, se ensancha, enviando a cada lado una prolongación triangular que penetra entre el frontal y el maxilar, acercándose bastante a los lacrimales aunque no llegan a ponerse en contacto con ellos; una disposición parecida se observa igualmente en el Cholœpus y el Bradypus.

El agujero suborbitario es de dimensiones regulares, más bien chico que grande y más parecido al Cholopus que al Bradypus.

Los lacrimales son bien separados por sutura visible en toda su extensión; estos huesos son de tamaño relativamente mayor que en el Mylodon y se extienden hacia atrás en forma de prolongamiento triangular que se dirige oblicuamente hacia abajo.

La mandibula inferior se prolonga adelante de los caninos en forma le pico largo y angosto que se comprime todavía más en su parte anterior, afectando una forma casi igual a la de la mandíbula del Cholopus.

La perforación de la rama externa del canal alveolar parece que estaba colocada mis sobre el lado externo de la rama ascendente que sobre el interno.

Eucholozors Incexs Ameghino

Amrghixo: Enumeración sistemática de los mamiferos, etc., página 21 , número 95, IS87.

Esta es la especie más grande del género, representada por un cráneo completo con la dentadura y la mandíbula inferior, pero envuelto en su mayor parte en un trozo de piedra muy dura, de la que no ha sido posible desembarazarlo y que dificulta su estudio.

Las cuatro muelas superiores son de bordes laterales muy redondeados y las caras perpendiculares anterior y posterior un poco convexas; la última superior es algo más pequeña y colocada un poco oblicuamente con su parte interna que avanza más atrás.

El paladar entre los molares contiene una pequeña cresta media longitudinal con una depresión o surco paralelo a cada lado, limitados ellos mismos por otras dos aristas más anchas y rugosas. Por fin, al lado de cada una de estas aristas hay otra depresión longitudinal formada por una serie de perforaciones que penetran de adelante hacia atrás en el paladar, separadas del borde alveolar por una arista longitudinal irregular. Estas aristas y estos surcos desaparecen en la parte anterior del paladar delante de los molares, presentando ahí una superficie rugosa y con numerosas perforaciones pequeñas, pero de diámetro muy desigual. 
La abertura nasal anterior es de mayor diámetro transverso que vertical.

En la parte anterior de la cara externa de los maxilares superiores entre la protuberancia formada por el lacrimal y la apófisis cigomática atrís y la protuberancia en que se implanta el canino adelante, hay una fuerte depresión ancha y de fondo cóncavo que se extiende hasta cerca del borde del paladar.

La mandibula inferior es de rama horizontal corta, alta y gruesa, con una fuerte depresión de fondo cóncavo detrás de la protuberancia en que se implanta el canino e inmediatamente debajo del borde alveolar. La parte sinfisaria que se prolonga adelante de los caninos es muy comprimida en su parte anterior e inferior, con su borde superior, que se prolonga hacia arriba y que sobrepasa de mucho hacia adelante los nasales y la punta anterior del paladar. La región posterior de la sínfisis se ensancha notablemente en su parte inferior; y ambas ramas mandibulares están completamente soldadas. E1 agujero mentoniano, grande y circular, se abre en la parte anterior de la sinfisis, unos 13 milímetros adelante del canino y muy arriba a unos pocos milímetros del borde superior. La parte posterior de la sinfisis llega hasta debajo de la parte anterior de la corona del canino.

\section{DIMIENSIONES}

Diảnetro del caníno superior | anteroposterior $\ldots \ldots \ldots \ldots \ldots \ldots \ldots \ldots \ldots \ldots . \ldots \ldots$. 01

| transverso .............................. 0010

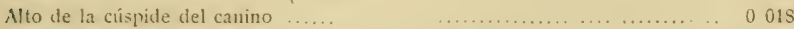

Largo de la barra que separa al canino del molar que sigue ............. 0023

Diámetro de la primera muela f anteroposterior ........................ 00075

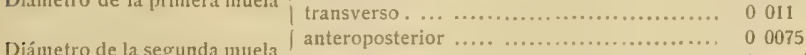

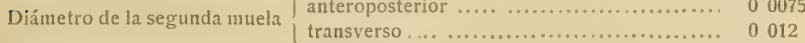

Diâmetro de la tercera muela $\int$ anteroposterior ........................ 00075

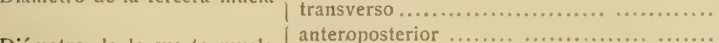

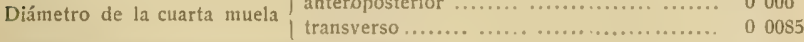

Diámetro anteroposterior del canino inferior.......................... 0011

Alto de la corona ................................................. 0014

Largo de la barra entre el canino inferior y la muela que sigue ............ 0013

Longitud del espacio ocupado por las tres muelas inferiores ............... 0031

Largo de la parte anterior desde el canino inferior hasta la parte posterior de la última muela................................................ 0055

Largo del espacio ocupado por las cuatro muelas superiores............... 0038

Largo de la parte anterior desde el canino superior hasta la parte posterior

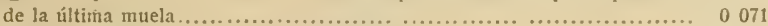

Ancho del paladar entre los caninos superiores......................... 0039

Ancho del paladar entre las muelas superiores............................. 0026

Largo del cráneo desde los cóndilos occipitales liasta la parte anterior del canino superior............................................... 0172

Longitud del paladar ............................................ 0070 
Diảmetro transverso de la abertura nasal anterior .. .................. 0 038

Diámetro vertical de la abertura nasal anterior .......................... 0032

Diảmetro transverso del cráneo en su parte anterior, al nivel de los caninos. 0062

Longitud de la parte de la mandibula inferior que se prolonga en forma de pico adelante del canino ........................................ 0035

Longitud de la sínfisis sobre su cara inferior ....................... 0050

Alto de la rama horizontal debajo de las muelas....................... 0035

Ancho de la punta anterior de la mandibula............................. 0015

Procedencia: - Los restos de esta especie han sido descubiertos por Carlos Ameghino en las barrancas del río Santa Cruz, en Patagonia austral.

Horizonte:- Piso santacruceño (eoceno inferior).

Livcholotops infrenalis Ameghino

Lamina $\mathrm{x} \times \mathrm{X} ı \mathrm{x}$, figuras $\mathrm{B}$, a g 9

Anecrivo: Enumeración sistenatica de los mamiferos, etc., página 21 , número 96, IS87.

Esta especie, de tamaño un poco menor que la precedente, está representada por la parte anterior de un cráneo con el paladar y la dentadura bastante destrozada y varios fragmentos de maxilares superiores y muelas sueltas.

Las muelas son de tamaño un poco menor que las de la especie precedente, pero de la misma forma general; y la última superior propor. cionalmente un poco más pequeña.

La parte anterior del paladar se ensancha mucho menos que en el Eucholocops ingens; y los caninos superiores en vez de ser triangulares sor elípticocilíndricos y mucho más pequeños.

La barra es más corta entre el canino y las muelas, pero la excavación lateral del maxilar arriba de la barra es relativamente mayor y más profunda.

El paladar es relativamente más ancho que en la especie precedente y con dos surcos longitudinales profundos, separados por una arista media, estrecha y elevada; tanto la arista intermedia como los dos surcus se extienden más adelante de las muelas, casi hasta la parte anterior del paladar, donde la arista intermedia se ensancha de un modo considerable y consiguientemente se separan los surcos. El paladar del Bradypus actual presenta una conformación muy parecida.

DIMENSIONES

Diámetro del canino superior anteroposterior $\ldots \ldots \ldots \ldots \ldots \ldots \ldots \ldots \ldots, 007$

Dianetro del canino stpenior | transverso........................... 0006

Largo de la barra que separa el canino de la primera muela superior ....... 0016

Diámetro de la primera muela superior ! anteroposterior................ 0007

itransverso ................... 0009 
(anteroposterior ...................... 0"007

Diametro de la segunda mitula transverso ............................ 00095

Diántetro de la tercera muela f anteroposterior ...................... 0006

transverso.............................. 0009

Diámetro de la cuarta muela f anteroposterior ..................... 0005

Diámetro de la cuarta muela transverso ........................... 0007

Longitud de las cuatro muelas superiores ............................ 0034

Distancia desde la parte anterior del canino superior hasta la parte posterior de la última muela ............................................. 0060

Ancho del paladar entre los molares ................................. 0016

Procedencia: - Los restos de esta especie han sido descubiertos por Carlos Ameghino en las barrancas del río Santa Cruz, en Patagonia austral.

Horizonte:- Piso santacruceño (eoceno inferior).

EUCHOLOgOPS ADTEGER Ameghino

Lamina $\mathrm{x} \times x i x$, ngara

AMEGHivo: Enumeración sistemática de los mamiferos, etc., página 21, número 97, I 887 .

Esta especie está representada por un maxilar superior izquierdo, con parte del alvéolo del canino, las tres primeras muelas y parte del alvéolo de la cuarta muela; otro fragmento de maxilar superior derecho con las dos primeras muelas y un fragmento de la parte anterior de la rama izquierda de la mandíbula inferior con el caniniforme y parte del alvéolo de la primera muela. Estas piezas muestran diferencias tan considerables con las correspondientes de los Eucholocops ingens y Eucholceops infernalis, que probablemente obligarán más tarde a separar como género distinto al animal de que provienen. Pero mientras no conozca otros materiales que me permitan establecer la distinción genérica sobre caracteres bien determinados, lo dejo provisoriamente en el género Eucholcops, con el que sin duda presenta grandes afinidades.

El tamaño de este animal es mucho más reducido que el de las dos especies precedentes, y sus muelas, naturalmente, mucho más pequeñas, son de forma más rectangular y con sus ángulos menos redondeados. Las muelas superiores tienen las caras perpendiculares más anchas, anterior y posterior, más planas que en las otras especies; y las caras perpendiculares más angostas, interna y externa, no convexas, sino más bien planas y con una pequeña depresión perpendicular bien visible, particularmente sobre el lado externo.

El caniniforme superior es pequeño, de sección elíptica y probablemente de corona plana y no cortada en bisel. La barra es corta y con un depresión longitudinal que va desde la primera muela hasta el canino. 
El paladar se distingue del de las especies anteriores por ser ligeramente convexo, con algunos pequeños agujeros de distancia en distancia, pero sin surcos ni aristas longitudinales. Además, la parte anterior entre los caniniformes no se ensancha o el ensanchamiento es apenas visible. La depresión del lado externo del maxilar entre el primer molar y el caniniforme es menos marcada.

El caniniforme implantado en la mandibula inferior es pequeño, eliptico, poco sobresaliente sobre el borde alveolar y la corona un poco gastada en declive de adelante hacia atrás, lo que está en oposición completa con 10 que muestran las otras especies. La mandíbula no forma tampoco la protuberancia hacia afuera que en este punto muestran las especies precedentes; y la barra que separa al canino del molar que sigue atrás es corta.

De la primera muela inferior sólo existe la parte anterior del alvéolo, que demuestra era de la misma forma rectangular que las superiores y de tamaño relativamente considerable.

La sínfisis en su parte posterior llega hasta debajo del canino; la parte anterior está destrozada, pero se conoce que se prolongaba muy adelante $y$ hacia arriba en forma de pico, como en el Eucholoops ingens. El agujero dentario se encontraba en la parte superior de esta prolon. gación, bastante ádelante del caniniforme.

\section{DIMENSIONES}

Diámetro del caniniforme superior | anteroposterior................... 0 . 005

Diânetro del caniniforme superior

Diametro de la primera muela superior 1 anteroposterior.. ................ 0045

Dianetro de la primera mula superior $\mid$ transverso.................... 0005

Diámetro de la segunda muela $\mid$ anteroposterior........................... 00055

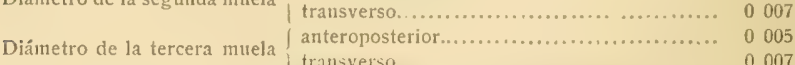

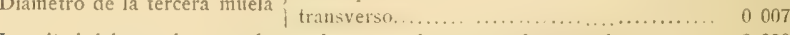

Longitud del espacio ocupado por las tres prineras muelas superiores $\quad \ldots \ldots \ldots 020$

Largo de la barra entre el canino y la muela siguiente.................... 0.010

Largo aproximado del espacio ocupado por los cinco dientes superiores .... 0042

Diámetro del caniniforme inferior I anteroposterior..................... 00045

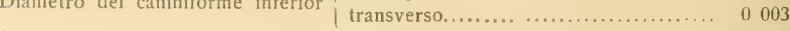

Largo de la barra entre el canino y la muela que sigue................. 0006

Alto de la rmma horizontal debajo del canino. ..................... 0019

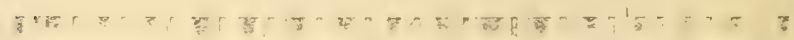

Procedencia: - Los restos de esta especie han sido descubiertos por Carlos Ameghino en las barrancas del río Santa Cruz, en Patagonia austral.

Horizonte:- Piso santacruceño (eoceno inferior). 
AMerrino: «Doletin de la Acadenia Nacional de Cienciass, tomo VIII, página x26, 1885 .

El diente anterior de la mandibula superior está implantado en la parte anteroexterna de la mandibula, presentando una sección prismáticotriangular y corona probablemente plana. E1 segundo diente superior está separado del anterior por una larga barra, es de sección prismáticocuadrangular y presenta una corona con dos crestas transversales separadas por un surco profundo. Los dientes están compuestos por una capa delgada y externa de cemento que envuelve una masa interna homogénea de vásculodentina.

Pliomorpitus MUtizArus Ameghino Lsulma LXX, fiuma,

Axrcmixo: sDoletin de la Academia Nacional de Ciencias», tomo VIII, pägina I28, IS\$5. - Idem: tomo IS, página I91, 1886.

La especie ha sido fundada sobre un fragmento de maxilar superior del lado derecho, en el cual están implantados el diente anterior en forma de canino o de incisivo y el primer molar que sigue hacia atrás.

El diente anterior o caniniforme es de seccion prismáticotriangular, con los tres lados desiguales, comprimido transversalmente, con un diámetro mayor de 24 milimetros y un diámetro menor o transverso de 18 milímetros. Este diente está roto en el alvéolo, por lo cual no sè puedə conocer la forma de la corona; pero hay otro diente anterior aislado que atribuyo a otro individuo de una especie distinta del mismo género, que tiene la corona y está gastada horizontalmente, por lo cual supongo debc ser del mismo modo en el Pliomorphus mutilatus. Por este carícter, de tener la corona del diente caniniforme o anterior, plano, el Pliomorplus se acercaria al Megalonyx, pero difiere de éste por la forma de dicho diente, elíptica en el Megalonyx y prismáticotriangular en el Pliomorphus.

A este diente sigue una barra de 4 centimetros de largo que 10 separa del segundo, que es igualmente distinto del diente correspondiente del Megalonyx por su forma prismáticocuadrangular y por su corona con dos crestas transversales separadas por un surco bastante profundo. La corona tiene 17 milimetros de diámetro anteroposterior y otro tanto de diámetro transverso.

El diente tercero seguía inmediatamente al segundo, del cual sólo estaba separado por un delgado tabique, pero se ha perdido, no quedando otro vestigio que el tabique anterior del alvéolo, que, por su ancho, parece indicar que dicho diente era de dimensiones bastante mayores que el precedente. 
Estos dientes parecen de una estructura aún más simple que la de las muelas de la generalidad de los desdentados, pues examinados con un fuerte lente no se ve más que una delgadísima capa externa de cemento que rodea a una masa interna, al parecer homogénea, de vásculodentina, sin división ni capas distintas.

La parte palatina del maxilar, tiene adelante una anchura de más de tres centímetros, mientras que más atrás, al nivel de la parte posterior del segundo diente, sólo tiene 13 milímetros, lo cual prueba que el paladar era angosto hacia atrás y se ensanchaba gradualmente hacia adelante, pareciéndose en esto más al género Pseudolestodon que a ningún otro desdentado. No se ve ni vestigio de la sutura que debia unir el hueso incisivo al maxilar; y sin duda era tan rudimentario como en el Mylodon y el Pseudolestodon.

La parte lateral del maxilar es aún más notable y hasta cierto punto por ahora enigmática. A partir del primer diente anterior en forma de canino, el ángulo o arista que delimita a ambas partes del maxilar (externa y palatina) describe una curva que se dirige hacia adentro, interrumpiéndose bruscamente al llegar a la segunda muela, que se halla afuera de esa línea, formando el alvéolo una protuberancia externa completamente cubierta, lo mismo que una parte considerable del maxilar hasta cerca del diente anterior, por un depósito de substancia ósea de forma y superficie irregulares, cuyo significado e importancia no puedo fijar con tan escaso fragmento.

La talla del Pliomorphus mutilatus es la de un pequeño Mylodon.

Procelencia: - Esta pieza ha sido descubierta por el profesor Scala. brini en las barrancas de los alrededores de la ciudad del Paraná y pertenece al museo provincial de Entre Ríos.

Horizonte: - Piso mesopotámico de la formación patagónica (oligoceno inferior).

Phromorpitus roeustes Ameghino

Amegrivo: «Boletin de la Academia Nacional de Ciencias», tomo VIII, página 130, I885.

Esta especie está representada por el diente caniniforme superior del lado derecho aislado, que ya he mencionado al hablar de la especie anterior. Por el desgaste de la muela y lo compacto del tejido huesoso, se conoce que el fragmento de cráneo de Pliomorphus mutilatus antes descripto pertenecía a un individuo adulto. El pequeño fragmento de maxilar que acompaña a este diente suelto es más esponjoso; y como el diente es de doble tamaño que el correspondiente del fragmento de mandibula anterior, no dudo que proviene de una especie distinta de mayor tamaño. La corona de este diente apenas sobresalía 
unos dos o tres milimetros fuera del alvéolo; el diente es menos comprimido que en la especie anterior, más ancho en su parte posterior y de ángulos más redondeados. La superficie masticatoria de la corona es un poco más gastada en el centro que en los bordes. Todo el prisma del diente estaba cubierto por una lámina muy delgada de cemento que se desprende con facilidad, habiéndose ya perdido sobre una parte considerable de la superficie. La corona tiene 24 milímetros de diámetro anteroposterior y 21 milímetros de diámetro transverso.

Procedencia: - Ha sido descubierto por el profesor Scalabrini en las barrancas de los alrededores de la ciudad del Paraná.

Horizonte: - Piso mesopotámico de la formación patagónica (oligoceno inferior).

\section{TREMATHERIUMI Ameghino}

AMEgitino: Enumeración sistemática de los mamiferos, etc., página 22, iSS7.

Género bastante cercano del anterior, representado únicamente por la parte posterior de la rama izquierda de la mandibula inferior, que demuestra tuvo un diente adelante muy pequeño y tres más grandes atrás, como en el Hapalops, del que se distingue inmediatamente por la abertura de la rama externa del canal alveolar, situada al lado externo de la base de la rama ascendente, que es de un tamaño más pequeño todavia que en el Bradypus.

Trearatherium intermixtum Ameghino

Aaremino: Enumeración sistemática de los mamiferos, etc., página 22, número 10r, 1887 .

Del caniniforme inferior sólo existe la base del alvéolo, que demuestra era muy pequeño y poco separado de la primera muela; de esta última sólo existe la parte posterior del alvéolo, que prueba era de dimensiones relativamente considerables, pero más o menos de la misma forma que en las especies de los dos géneros precedentes.

De las dos últimas muelas sólo existen los alvéolos, de 9 milimetros de diámetro anteroposterior y 11 milímetros de diámetro transverso cada uno, ocupando los dos juntos un espacio longitudinal de 21 milimetros.

La abertura de la rama externa del canal alveolar, de tamaño suma. mente pequeño y circular, está colocada sobre el lado externo de la base de la rama ascendente, pero hay además una segunda perforación más pequeña todavía sobre el lado interno de la mencionada rama, detrás de la última muela. 
La rama horizontal de la mandibula al nivel de la penúltima muela tiene 27 milimetros de alto y 18 de espesor. La cara interna de la rama horizontal es casi flana, pero la externa es notablemente convexa.

Procedenciu: - Ha sido descubierta por Carlos Ameghino en las barrancas del río Santa Cruz, en Patagonia austral.

Horizonte:- Piso santacruceño (eoceno inferior).

\section{NOTHROPUS Durmeister}

Bermetster: Sitzung. der Kön. Preus. Akad. d. Irissenschafien zu Berlin, tomo Xivirir, låmina XI, figuras I y 2,1882 , página 613 .

El género Nothropus se distingue por cuatro muelas inferiores, la primera muy pequeña, eliptica y colocada hacia adelante a una distancia considerable de la segunda; las otras tres muelas en forma de prisma cuadrangular, con dos crestas transversales en la corona, separadas por un valle transversal profundo, presentan un aspecto parecido a las del Calodon. La rama horizontal de la mandíbula no presenta hacia abajo la gran curva descendente que caracteriza al Megatherium.

Notmaorus priscts Turmeister

1.2mus XI.T. nizira ,

Dermeister: Obra y página arxiba citadas.

La especie sólo es conocida hasta ahora por una mitad derecha de la mandíbula inferior, en la cual falta la extremidad anterior de la sinfisis y la parte posterior de la rama ascendente con la apófisis coronoides y el cóndilo articular; la parte existente tiene unos 11 centímetros de largo; y según la restauración que indica el dibujo de Burmeister, la mandibula cntera tuvo aproximadamente unos 15 centimetros.

La rama horizontal es casi plana en el lado interno, pero fuertemente convexa sobre la cara externa, con el borde inferior un poco curvo (pero no muy descendente) y presentando debajo de la región dentaria tres convexidades poco pronunciadas que corresponden a la base de cada una de las tres muelas. La región sinfisaria, a juzgar por la parte existente, parece haber sido delgada y muy prolongada hacia adelante. La parte anterior estí rota, faltando la región en que existía el agujero mentoniano, de manera que no es posible fijar su posición; pero parece estaba situado muy adelante y cerca del borde superior. La rama externa de la abertura posterior del canal alveolar tiene la perforación colocada sobre el lado externo de la base de la rama ascendente. 
En diente anterior, del cual sólo existe el alvéolo, estaba colocado a una distancia considerable de los otros dientes; era de sección eliptica y sumamente pequeño, pues el alvéolo apenas tiene unos 4 milimetros de diámetro mayor.

El espacio que separa a este diente de la muela que sigue, tiene cerca de 2 centímetros de largo, formando un borde redondeado que se engruesa notablemente de adelante hacia atrás, particularmente en su parte posterior.

Las tres muelas siguientes, de tamaño mucho más considerable y más iguales entre sí, están colocadas a continuación una de otra, separadas únilamente por el espacio formado por los tabiques alveolares. Son prismas muy largos, de una sección transversal rectangular con ángulos redondeados en las dos anteriores y de sección más oval en la última, más gruesas en la base y adelgazándose en la parte superior hasta terminar en una corona formada por dos crestas transversales, separadas por un valle transversal y un poco más excavadas en el centro, afectando una forma parecida a las de las muelas del Megatherium, pero un poco menos acentuada en la última. Las dos primeras de estas muelas, o sea los dientes segundo y tercero, que son los que más claramente afectan la forma rectangular o cuadrangular y por consiguiente las que más parecido presentan con las del Megatherium, son de diámefro transverso un poco mayor que el diámetro anteroposterior y con las crestas transversales de la corona mejor acentuadas.

La primera de estas muelas (o sea la segunda, contando la pequeña muela anterior), tiene, según el dibujo, 9 milímetros de diámetro anteroposterior y apenas un poco más de diámetro transverso, con las tres caras perpendiculares anterior, externa e interna, un poco excavadas longitudinalmente en el medio.

La muela que sigue, o tercera, tiene 9 milímetros de diámetro anteroposterior y 10 milimetros de diámetro transverso, con las caras perpendiculares externa e interna fuertemente excavadas en el medio en sentido longitudinal, pero la depresión longitudinal de la cara anterior es apenas aparente.

La última muela, de contorno más ovoidal, presenta un diámetro mayor, de adelante hacia atrás, de un poco más de 10 milímetros, siendo un poco más estrecha, de contorno más redondeado, con una depresión perpendicular únicamente sobre la cara externa; la corona presenta las crestas transversales imperfectas, no separadas sobre el lado interno, aunque con el centro fuertemente excavado.

Las tres muelas posteriores ocupan un espacio longitudinal de un poco más de 3 centímetros y el alto máximo de la rama horizontal debajo de las muelas es de 38 milímetros. 
El doctor Burmeister separa a este animal del grupo de los Gravigrada para colocarlo en el de los Tardigrada, considerándolo como muy cercano del género Cholcopus, del cual representaria una forma antecesora.

No puedo, de ninguna manera, participar de esta opinión. El tamaño del Nothropus, cuya mandibula inferior es doble más larga que la de los más grandes representantes del género Cholocopus, no concuerda con el de una forma antecesora; y la longitud de la parte sinfisaria de la mandíbula tampoco concuerda con el cráneo corto y como truncado de los tardígrados, indicando claramente un intermaxilar mucho más prolongado, parecido al de los géneros Megatherium o Scelidothcrium entre los gravígrados.

Tampoco se puede ver una afinidad entre la primera muela cuneiforme inferior de Cholaropus y del Nothropus, pues la de aquel género es un diente sumamente fuerte, triangular, fuertemente inclinado hacia adelante y hacia afuera y con la corona cortada en bisel; mientras el mismo diente del Nothropus es mucho más pequeño, simplemente elíptico y colocado siguiendo la dirección del eje de la serie dentaria. Supone Burmeister que este diente era muy elevado y con la corona cortada en bisel, pero, como él mismo lo reconoce, esa es una suposición; y por mi parte prefiero creer, de acuerdo con el tamaño pequeño que presenta, que se trata de una muela atrofiada, en vía de desaparición, de corona plana, simplemente excavada en el medio, como hemos visto varios ejemplos en algunos de los géneros precedentes, y cuyo término de evolución sería su desaparición completa, produciendo entonces una fórmula dentaria parecida a la del Calodon, con el cual presenta el Nothropus las mayores analogías.

Las tres muelas que siguen en la mandibula del Nothropus tampoco indican afinidades con el Cholocopus, pues en vez de presentar una sección más o menos eliptica con una corona con una sola cresta transversal en forma de techo a dos aguas, muestran, al contrario, una sección más o menos rectangular con la corona formada por dos crestas transversales, como en el Megathcrium, el Colodon y varios otros géneros del grupo de los gravigrados. Ni tampoco existe una analogía más pronunciada de este género con el Cholocopus que con el Bradypus, pues la abertura de la rama externa del canal alveolar en la cual el ilustre paleontólogo creyó encontrar diferencias características, existe igualmente en los dos géneros actuales y en la misma posición, con la única diferencia de que es algo más pequeña en el Bradypus que en el Choloopus.

Por las razones indicadas y por sus grandes analogías con los géneros extinguidos, el Nothropus no es para mí un tardígrado sino un gravígrado, es decir: un animal de cráneo largo, de metacarpianos y metatarsianos separajos y de cola larga y fuerte como los demás géne- 
ros del mismo grupo. Confío al tiempo la confirmación de mi deducción.

Procedencia: - La pieza original sobre la cual se fundó este género fué encontrada por el señor Schaffer, en la provincia Santa Fe, sobre el río Carcarañá, en el punto donde éste es cruzado por la via férrea de - Rosario a Córdoba; y se conserva en las colecciones del Musco Nacional de Buenos Aires.

Horizonte: - Piso bonaerense de la formación pampeana (plioceno superior).

\section{COELODON Lund}

LUND: «Ann. de Sciences Naturelies», serie $2^{a}$, volumen XI, página 220, I839.-Idem: Blick pas Bras. Dyr., etc.

Este género, cuyos representantes conocidos hasta ahora son todos de proporciones reducidas en comparación de los grandes gravigrados que le fueron contemporáneos, se distingue inmediatamente por no presentar más que cuatro muelas en cada lado de la mandibula supe. rior y tres en cada rama de la mandíbula inferior, todas de forma más o menos cuadrangular o rectangular y con crestas transversales en la corona, presentando un notable parecido con las del Megatherium. El intermaxilar se prolonga hacia adelante, como en este último género, pero el arco cigomático es interrumpido como en el Scclidotherium, presentando en la conformación de los miembros una notable analogía con el Mlegalonyx, tanto por el número de dedos como por su conformación general.

El Colodon presentaba la particularidad de estar protegido por una piel en cuýo espesor se desarrollaba un considerable número de huesecillos irregulares apretados entre sí, como sucede con los géneros Mylodon y Pseudolestodon.

Todas las especies que se mencionaban hasta hace poco proceden de las cavernas de Brasil y llevan los nombres de Coclodon escrivanensis Reinhardt, de la cual se conoce un esqueleto casi completo; Coclodon maquinensis Lund, que primero fué designada por el mismo autor con el nombre de Megalonyx maquinensis; y el Colodon Kaupi Lund, descripta por primera vez como un Megalonyx Jeffersoni y luego como Megalonyx Kaupi.

Los caracteres distintivos de estas tres especies no han sido hast? ahora establecidos de una manera satisfactoria.

El doctor Burmeister acaba de agregar una cuarta especie, a la cual designa con el nombre de 
Burmeister: Nenc Beobachtungen an Coelodon; en Silaungsberichte der Kön. Preus. Ak. d. Wiss. z. Berlin, pảinina $857,1887$.

La especie está representada por un fragmento de la rama derecha de la mandíbula inferior en la cual faltan la parte anterior y posterior, existiendo la región intermedia con los alvéolos de las tres muelas, el último de los cuales está vacío, mientras que los dos anteriores conservan implantadas las dos muelas intactas. Estas muelas son de sección cuadrangular, con dos crestas transversales en la corona separadas por un valle profundo como las del Megatherium. El trozo existente de la rama horizontal tiene unos 12 centímetros de largo; y su alto, en el medio de la región dentaria, es de 5 centímetros, sin contar la parte de los dientes que sale fuera de los alvéolos, que tiene aproximadamente un centímietro de alto.

A juzgar por los alvéolos, el tamaño de los tres dientes aumenta gradualmente y tienen una forma un poco diferente. El primero o anterior, que es el más pequeño, es de figura rectangular y de diámetro transverso un poco mayor que el diámetro anteroposterior. El segundo diente es tambien rectangular, pero mucho más aplastado de adelante hacia atrás y por consiguiente de diámetro transverso casi dos veces mayor que el diámetro anteroposterior. El alvéolo de la tercera muela es muy ancho adelante $y$ angosto atrís, presentando sobre sus lados posterior e interno un contorno redondeado. Los tres alvéolos ocupan juntos un espacio longitudinal de 52 milimetros. La perforación de la rama externa del canal alveolar se abre sobre el lado externo de la base de Í rama ascendente: y la línea anterior de la rama ascendente es muy inclinada hacia atrás.

Como no tengo a mi disposición piezas originales, no me atrevo a contradecir a mi ilustre maestro: pero no puedo dispensarme de observar que el examen de los dibujos de esta mandibula y de los alvéolos cie los dientes, presentan las mayores analogías con la mandíbula del animal descripto por el mismo autor como Nothropus priscus. ¿ No podría quizá haber existido un diente pequeño igual al del Nothropus en la parte anterior rota del Colodon tarijensis y no ser, por consiguiente, un Colodon sino una especie mayor del género Nothropus?

Procedencia: - Esta pieza ha sido descubierta por Enrique de Carles en el yacimiento fosilifero de Tarija.

Horzionte:- Formación pampeana. 
VALGIPES DEFORMIS P. Gervais

P. Gervais: en Memoires de la Socicté géologique de France, $2^{a}$ serie, tomo IX, nưm. V, aho 1873 . - Idem: «ournal de Zoologie», tomo III, página 162 , lámina V, figuras I a 7 .

Este género y especie fueron establecidos por P. Gervais sobre un calcáneo procedente de las cavernas de Brasil, de una forma muy particular, pues es tan comprimido que colocado en su posición natural tiene casi la forma de una hacha y visto de lado parece un omoplato. Más tarde el mismo Gervais describió como de la misma especie algunos huesos de las extremidades. Tanto el calcáneo como los huesos mencionados presentan grandes analogías con los del Megalonyx y del Colodon y no dudo que provienen de un animal del mismo grupo y de ninguna manera del Neoracanthus o de algún género parecido, como 10 insinúa Burmeister, pues ese último género es del grupo de los Megatherida, que tienen una forma de calcáneo completamente distinta,

A mi me parece mucho más probable que el Valgipes deformis sea el mismo animal que ha llamado Burmeister Colodon tarijensis; y si éste fuera del mismo género que el designado por el mismo autor con el nombre de Nothropus, este último sería entonces un sinónimo de Valgipes. EI hallazgo de materiales más completos permitirá dilucidar estas dudas.

\section{GNATHOPSIS Leidy}

Leidy: Procced. Acad. Nat. Sc. Plith, tomo VI, página Ii7, 1852.

Este género ha sido fundado por Leidy sobre una mandibula inferior encontrada por Darwin en las costas de Patagonia austral y descripta y figurada por Owen en la parte zoológica del viaje del «Beagle», como perteneciente al Mcgalonyx Jeffersoni. Las muelas inferiores eran elípticoovaladas y la primera más pequeña que la segunda, aunque separada de las demás y colocada en la parte anterior de la mandibula, como en el Megalonyx.

\section{GNaTnorsis Oweni Leidy}

Gnathopsis Oweni. Iridx: Obra y página arriba citadas. - Idem: A menoir on the extinct sloth tribe of North America, páginas 14, 4 I y 57, 1855 .

Aegalony.r Jeffersoni (Harlan). OwEN: Zoology of the «Beagle», Fioss. Mammal., página 99,1840 .

Hasta ahora no se conoce de esta especie más que la mandibula descripta y dibujada por Owen; esta pieza conserva sus dos ramas, pero muy destruídas, sin un solo diente y con los mismos alvéolos en parte destrozados, de manera que no es posible formarse una idea satisfactoria de los caracteres que la distinguen. El profesor Owen se 
expresa sobre ella en los siguientes términos: «It is the only fossil brought home by Mr. Darnin, that could be confidently referred to the genus Megalonyx; but the form of the jan' fully justifies this determinution. The forms of the alveoli are best preserved in the right ramus; the first is the smallest, and seems to have contained a toot of wich the transverse section must have been simply elliptical; the sccond tooth is likenise laterally compressed but the transwerse section is ovate, the great end being turned formards; the thirds socket presents a corresponling form, but a larger size; the fourth sncket is too much mutilated to allom of a correct opinion being formed as to the shupe of the tooth wich it contained.»

La circunstancia de ser los dientes elípticoovalados con su diametro mayor dirigido de adelante hacia atrás, y la pequeñez del diente anterior, impiden con razón una identificación con el Megalonyx; pero en realidad el dibujo de una pieza tan mutilada no permite apreciaciones bien definidas y sería de desear un nuevo estudio del original. Dicha fieza indica un animal de la talla de un gran Lestodon.

Procedencia: - Parece haber sido recogida sobre las costas de Patagonia austral, pero sin conocerse aproximadamente el punto fijo dei hallazgo.

Horizonte:-Desconocido.

Los géneros mencionados, con excepción del problemático Gnathopsis, se agrupan en dos series, formadas: una por los géneros Eucholuops, Pliomorphus y Megalonyx, que tienen de común el gran desarrollo del primer diente que toma la forma de canino o de incisivo; la otra serie la forman los géneros Trematherium, Nothropus y Colodon, distinguiéndose, por el tamaño pequeño, casi rudimentario, de la primera muela o su completa ausencia.

El representante más antiguo, que es también el más pequeño de la primera serie, es el Eucholiops; le sucede en el tiempo, aunque separado por una larguisima distancia, el Pliomorphus de tamaño un poco mayor; a éste le sigue hacia los tiempos más modernos, el Megalonyx, de un tamaño mucho más considerable, pero de una conformación tan parecida a la del Pliomorphus que no puede abrigarse dudas de que es un descendiente directo de éste.

El más antiguo representante conocido y que en este caso es igualmente el más pequeño de la segunda serie, es el Trematherium; el género mucho más reciente, llamado Nothropus, difiere por su talla que es mucho mayor y por la primera muela que es más pequeña aún y más separada de la segunda, que son caracteres de sucesor bastante evidentes. El género Colodon, de época probablemente un poco más re- 
ciente todavía, sólo difiere del Nothropus, del que a buen seguro es el sucesor directo, por su talla algo mayor y por la desaparición de $1: a$ primera muela, ya rudimentaria en el género precedente.

No parece que los dos antecesores más lejanos de estas dos series: el Trcmathcrium y el Eucholaops, puedan descender uno de otro y remontan probablemente a uno o más antecesores, que se desprendieron de la familia de los Orthotherida, pues el Trematherium, si se exceptúa la posición de la perforación de la rama externa del canal alveoiar, es un aliado muy cercano del Orthotherium y del Hapalops.

Estas vistas pueden resumirse en esta forma:

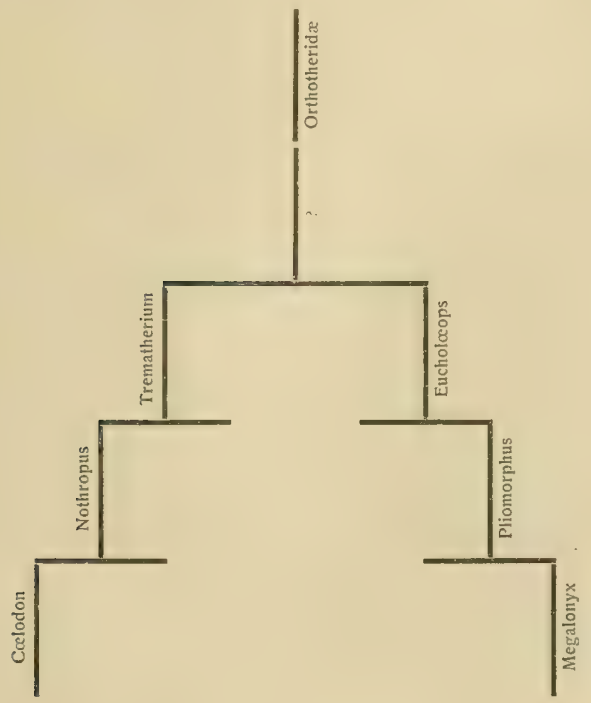

\section{Lestodontidæ}

Los representantes de esta familia se distinguen por el enorme desarrollo de la primera muela anterior tanto arriba como abajo; esta muela está muy separada de la segunda y toma el aspecto de un gran incisivo en unos géneros o de un formidable canino en otros. Las demás muelas son cilindricoaplastadas o elipticocilíndricas, menos la última de la mandibula inferior, que es más grande y bilobada en figura de 5 , 
y están todas implantadas con su eje mayor dirigido de adelante hacia atrás. La parte sinfisaria de la mandibula es siempre corta, el intermaxilar rudimentario y la abertura externa del canal alveolar colocada sobre el lado externo de la rama ascendente.

Los tres géneros de esta familia que hasta ahora me son conocidos, se distinguen de este modo:

I. Primer diente de la mandibula inferior en forma de canino.

a. Muelas truncadas horizontalmente: Lestodon.

b. Muelas truncadas oblicuamente: Laniodon.

11. Primer diente de la mandibula inferior en forma de incisivo: Diodomus.

\section{LESTODON P. Gervais}

Lestodon. P. GERvats: Recherches sur les mammiferes fossiles de l'Amérique Míridionale, página 47, lámina XII, figuras I y 2, I855. - Idem: Mémoire sur plusieurs espèces des nammifères propres á l'Amérique Méridionale, páginas 2I y siguientes, láminas XXV, XXVI, 873.

J. REINHARDT: Bidrag till Kurdskab om Lestodon armatus, en ias Memorias de la Academia Real de Copenhague, serie V, tomo IX, 1875 .

H. GERVAIS y AMEGrixo: Los mamiferos fósiles, etc., página 166,1880 .

Platygnatlus platcnsis. KroYER: Naturh. Tidsk, tomo III, páginas 589-595, I84r.

Mylodon gigantens. Burmeister: «Anales del Museo de Buenos Aires», tomo I, pág. 162, año 1865. - Idem: Descriplion phy'sique, etc., tomo III, página 371, 1879. - Idem: Atlas de la «Description physique, etc. -Idem: Osteologia de los Gravigrados, páginas 95 y $\mathbf{x} x$, año I 887 .

El género Lestodon fué fundado primeramente por Gervais sobre restos bastante incompletos de un desdentado gigantesco de conformación particular, que designó con el nombre de Lestodon armutus, incluyendo en el mismo género una especie de tamaño mucho más pequeño, que denominó Lestodon myloides, pero cuyas afinidades con el Mylodon son indiscutiblemente superiores a las que presenta con el verdadero Lestodon.

Ya con anterioridad a Gervais, Owen y de Blainville habían conocido restos provenientes del mismo género, pero no pudieron determinarlos con exactitud, atribuyéndolos ya a una especie desconocida de Mylodon, ya al género Megatherinm y a veces al Megalonyx. Otro autor, Kroyer, designó los restos de este animal con el nombre de Platygnathus platensis (1840), que tiene prioridad sobre el de Gervais y debería preferirse, si no fuera que ya en 1834 había sido aplicado por Dejardin para designar un género de coleópteros.

Desde la publicación del primer trabajo de Gervais no aparece otra publicación con respecto al mismo animal hasta 1865-1866, en que Burmeister lo describe como una nueva especie del género Mylodon.

En 1873, en una nueva Memoria sobre los fósiles de Sud América, amplificó Gervais su primera descripción, publicando nuevas partes 
hasta entonces desconocidas, y entre ellas una considerable porción del cráneo y el miembro posterior completo, haciendo resaltar las importantes diferencias que presentan el astrágalo y el calcáneo de este género comparados con las mismas partes del Mylodon, del Megatherium y el Scelidotherium. Además introdujo en este género, aunque con dudas, una nueva especie a la cual la designó con el nombre de Lestodon trigonidens, fundándola en un fragnento de mandíbula inferior con el diente caniniforme, que es de un aspecto particular y de grandes proporciones, indicando un animal de talla bastante mayor que la del Lestodon armatus.

En 1875, el profesor Reinhardt describió algunos restos de Lestodon conservados en el Museo de Copenhague, que atribuyó al Lestodon armatus, aceptando la separación genérica del Lestodon y del Mylodon, recordando al mismo tiempo la noticia, que pasó entonces desapercibida, dada por Kroyer sobre esos restos en 1841, bajo el nombre de Platygnathus platensis, aunque al parecer confundiendo bajo tal denominación restos provenientes de dos o tres géneros distintos.

En 1879, en el tercer volumen de la «Description Physique de la République Argentine», se ocupó Burmeister largamente del género Mylodon, esforzándose por demostrar que no existen caracteres que permitan separar genéricamente al Lestodon del Mylodon, designando a los representantes del primer grupo con el nombre de Mylodon giganteus que ya les habia aplicado anteriormente, pero con posterioridad a la denominación de Lestodon armatus que Gervais diera primero.

Al año siguiente (\$880), en mi trahajo sobre Los mamíferos fósiles de iu América Meridional, publicado en colaboración con el doctor $\mathrm{H}$. Gervais, admití la separación de los géneros Lestodon y Mylodon, haciendo una rápida exposición de los caracteres del sistema dentario que separan a ambos géneros, incluyendo en el Lestodon a dos de las especies que en él había colocado Gervais, el Lestodon armatus y el Lestodon trigonidens y además cuatro especies nuevas que denominamos Lestodon Bravardi, Lestodon Gaudryi, Lestodon Blainvillei y Lestodon Bocagei. En cuanto al Lestodon myloides de P. Gervais, nos pareció que era mucho más próximo del género Mylodon que del género Lestodon, pero como, sin embargo, presentaba algunos caracteres que le eran comunes con algunas otras especies, lo consideramos como el tipo de un grupo secundario o subgénero, al que le aplicamos el nombre de Pseudolestodon.

A pesar de esto y de las múltiples formas que se citan como formando parte del género Lestodon, Burmeister en su reciente y notabilísimo trabajo sobre la «Osteología de los gravígrados» continúa sosteniendo que forma parte del género Mylodon. El ilustre maestro de la paleomastología argentina sin duda no se ha dado cuenta de las gran- 
des diferencias que separan al Lestodon del Mylodon, debido probablemente a la falta de materiales que se las pongan en evidencia. Los caracteres distintivos entre el Lestodon y el Mylodon son más notables que los que separan al Mylodon del Scelidotherium y los que distinguen a este último del Megatherium; y de reunir a los dos primeros bajo una sola denominación genérica, sería inútil continuar distinguiendo a los distintos géneros de gravígrados, pues ya no habría razón para separar al Megalonyx del Megalochnus o Pliomorphus, al Mylodon del Scelidotherium, al Scelidotherium del Platyonyx o Glossotherium, etc.

Como esta confusión de los caracteres que sirven para establecer las distinciones genéricas de los gravígrados afectan a la clasificación de todo este grupo, me será permitido examinar esta cuestión con cierta detención, pues se trata nada menos que de cuatro, cinco o probablemente. más géneros distintos que el ilustre paleontólogo reune bajo la misma denominación de Mylodon. Entre esos géneros se encuentra el de que ahora me ocupo, o Lestodon, el Pscudolestodon y el Glossothe. rium, sobre el que ya ha manifestado su opinión, y otros sobre los que con mis razón aún procederia de la misma manera. Vale, pues, la pena examinar en qué se funda esa resistencia que opone para separar al Lestodon como género distinto del Mylodon.

En el tercer volumen de la «Description Plysique», etc., el doctor Burmeister reconoce que el cráneo del Mylodon giganteus es bastante diferente de la forma que presenta en las otras especies de Mylodon, pero no compara estas diferencias con las que presentan los demás géneros del mismo grupo, ni cגamina el valor que para la distinción de los géneros y especies pueda tener, viéndose así obligado a decir que el sistema dentario del Mylodon presenta grandes variaciones según las especies. Del mismo modo, al examinar los demás hutsos del esqueleto, dice que se parecen a los hucsos correspondientes de las otras especies de Mylhivil; pero cuando se encuentra con algunas otras diferencias de importancia, como las que se observan en la conformación del calcáneo y del astrigalo, entunces vuclve a salvar la dificultad diciendo que el castrágalo es muy variable en el género Mylodon, lo mismo que el calcineo, pucsto que puede presentar ya seis facetas articulares coms el dul Siclicitherium y Megutherium, o sólo cinco. El primer caso se presuta, dice, en el Mylodon gigantens; y el segundo en los Mylodon robustus y. . Ylulun gracilis.» Así confiesa él mismo que en una parte tan esencialmente característica como es la conformación del astrágalo Y el calcineo, una especic de Mylolon (que es precisamente el tipo del género Lestotun), se parece más a otros géneros completamente distintos que a las otras especics de Mylodon, reconociendo asi el autor que el género Mylodon, como él lo comprende, es una reunión de especies heterogéneas. 
Compréndese, sin embargo, que esa confusión se produjese al principio, cuando el Mylodon giganteus conocíase sólo por partes del esqueleto, que no ofrecian caracteres genéricos distintos; pero parece que al redactar el magistral estudio sobre los gravígrados tuvo a la vista un esqueleto casi completo de Lestodon, lo que hubiera debido obligarlo a examinar más de cerca los caracteres diferenciales que presenta con el Mylodon. Mas, por el contrario, parece que hace esfuerzos para no distinguir esas diferencias. Así lo vemos en su último trabajo ya mencionado («Osteología de los Gravigrados»), insistir en que no hay caracteres para separar a los géneros Lestodon, Glossotherium y Pseudolestodon en géneros distintos del Mylodon. Es cierto que evita el tratar la cuestión en detalle, dando un resumen de los carazteres que según él distinguen al género Mylodon, ninguno de los cuales es exclusivo de la agrupación heterogénea que él forma.

Esos caracteres, que según Burmeister distinguen al género Mylodon, son los siguientes:

«1 $1^{\circ} \mathrm{La}$ anchura aumentada y longitud disminuída del rostro hacia adelante, unida con la separación más grande del diente anterior de los otros, principalmente en la mandibula;

«2" Las dos series rectas de los dientes no paralelas, sino convergentes hacia atrás y la colocación longitudinal o transversal de cada diente en ellas, sin la dirección oblicua, del género Scelidotherium;

$\ll 3^{\circ} \mathrm{La}$ diferencia notable del tipo de los dientes entre sí;

«4 El arco cigomático cerrado por unión con la apófisis del temporal y no interrumpido;

<5. La colocación oblicua, inclinada hacia atrás por debajo del llano occipital más alto;

$\ll 6^{\circ} \mathrm{La}$ falta del conducto supratroclear del húmero;

$\ll 7^{\circ}$ El número mayor de los dedos, es decir: cinco del pie anterior y cuatro del posterior, con uñas un poco menores;

«8 $8^{\circ}$ El número menor de las vértebras en el lomo y en la cola».

Voy a hacer un rápido examen de esos pretendidos caracteres diferentes, en el mismo orden en que el autor los enumera.

La anchura aumentada y la longitud disminuida del rostro hacia ade. lante no es aplicable en el mismo grado al Mylodon giganteus (Lestodon) que al Mylodon robustus o al Mylodon Durwini (Glossothcrium). La anchura del rostro hacia adelante es menor en el Mylodon Darnini que en el Alcgalonyx, acercándose en su conformación más al Scelidotherium que al Mylodon robustus. La anchura del rostro en el Mylodon giganteus (Lestodon) ocupa el otro extremo, pareciéndose mucho más al Mcgalonyx, al Pliomorphus, etc., que al Mylodon robustus. La diminución del largo del rostro no es mayor en el Mylodon giganteus (Lestodon) que en el Megalonyx, mientras que en el. Iylodon Darmini (Glossotherium) 
el rostro considerablemente más prolongado, presenta un mayor parecido con el Platyonyx o el Scelidotherium, que con el Mylodon robustus.

La separación del primer diente de los otros, tampoco es un carácter del género Mylodon, como lo entiende Burmeister. Esta separación existe muy pronunciada en el Mylodon giganteus (Lestodon), más todavía que en el Megalonj'x y géneros aliados; pero en cambio, en el Mylodon gracilis (Pseudolestodon) es mucho menos acentuada que en los géneros Megalonyx, Megalochnus, Pliomorphus, Eucholœops, etc.; en el Mylodon robustus esta separación está apenas indicada; y en el Mylodon Darmini (Glossotherium) es completamente nula, puesto que hasta falta la muela que corresponde a la primera de las otras especies. En este carácter, los pretendidos representantes del género Mylodon presentan entre si las más grandes diferencias que se pueden observar entre todos los representantes del grupo de los gravígrados conocidos hasta ahora.

Las dos series dentarias no paralelas, sino convergentes hacia atrás, no constituyen tampoco un carácter distintivo del Mylodon en la extensión determinada por Burmeister. Esta forma triangular del paladar es sumamente pronunciada en el Mylodon gracilis (Pseudolestodon) pero mucho menos en el Mylodon robustus. Si en el Mylodon giganteus (Lestodon) las series dentarias convergen hacia atrás, ello es debido a la colocación hacia afuera de la primera muela, formando las cuatro que siguen a cada lado dos series paralelas o casi paralelas; desde ese punto de vista este animal no se distingue del Megalonyx. En cambio, las series dentarias del Mylodon Darwini (Glossotherium) tal como las ha dibujado Reinhardt, no son convergentes hacia atrás como en el Mylodon robustus, sino completamente paralelas como en el Scelidotherium. Es cierto que Burmeister pretende que ello es debido a una mala reconstrucción del objeto, que no lo demuestra el dibujo; el autor da otra figura del paladar, en el cual se ven las series dentarias un poco convergentes hacia atrás, pero el cráneo original de este dibujo, expuesto en las galerías del Museo, tampoco es perfecto en esta región sino igualmente reconstruído y no sería imposible que esa pequeña convergencia dependiera igualmente de un error en la compostura del cráneo, lo que no está probado que haya sucedido con el cráneo descripto por Reinhardt, pues según personas que lo han visto, se encuentra en esta región en un estado más perfecto que el del Museo de Buenos Aires. Pero como quiera que sea, aun admitiendo que realmente las series dentarias fueran un poco convergentes hacia atrás, como las representa el grabado publicado por Burmeister, es indudable que presenta más parecido con el paladar de los representantes de la familia de los Scelidotherida; si el Scelidotherium no es en este punto absolutamente idéntico, por 
presentar las series dentarias paralelas más bien un poco convergentes hacia adelante, en cambio el Scelidodon (que no se puede negar es un Scelidotheridx), presenta el paladar un poco más estrecho hacia atrás, absolutamente igual como se presenta en el Mylodon Darvini (Glossotherium) restaurado por Burmeister. Por consiguiente, también en este carácter presentan los representantes heterogéneos que quiere el autor conservar en el género Mylodon las más grandes diferencias.

La colocación longitudinal o transversal del eje mayor de la corona de cada diente, tampoco es un carácter distintivo de ese grupo artificial que se quiere conservar con el nombre genérico de Mylodon. La colocación longitudinal y la colocación transversal son los dos polos opuestos; de consiguiente, el Scelidotherium con sus muelas colocadas oblicuamente, vendría a ocupar una posición intermedia entre los distintos representantes de los pretendidos Mylodon, lo que no está muy de acuerdo con los principios que rigen la clasificación. Examinando más de cerca, se ve que las muelas intermedias, que son las únicas que en los distintos géneros presentan una diferencia en la dirección de su eje mayor, con. cuerdan en sus diferentes modos de implantación según las distintas agrupaciones genéricas en que se ha separado el antiguo género Mylodon de Owen, cuya autoridad no es justo invocar en este caso, porque cuando dicho autor reunió esos distintos grupos bajo una sola denominación genérica, lo hizo sobre escasos restos que no permitian suponer las diferencia considerables que presentan las demás partes, para él entonces desconocidas.

Si la implantación oblicua de las muelas intermedias es para Burmeister un buen carácter para distinguir el género Scelidotherium, no veo por qué razón la implantación transversal no pueda ser un carácter que distinga constantemente a los representantes de los géneros Mylodon y Pseudolestodon y la implantación longitudinal un carácter distintivo del Lestodon. En cuanto al Mylodon Darwini, digo que presenta en el inodn de implantación de sus muelas una disposición que no puede llamarse ni longitudinal, ni transversal; sin ser precisamente oblicuas como en el Scelidotherium, muestran un principio de oblicuidad bastante notable, sólo comparable a la disposición que se ve en este último género y en sus próximos aliados. Una vez más, pues, resulta heterogéneo el grupo de los animales que Burmeister persiste en conservar bajo la denominación genérica de Mylodon.

La diferencia de los dientes entre sí, que es otro de los caracteres que Burmeister pretende distinguen al género Mylodon con la exten. sión con que él lo comprende, tampoco es un distintivo que permita reunir a todas las especies citadas en un mismo género. Esa diferenci. existe en otros géneros, como el Megalonyx, el Pliomorphus, el Megalochnus, el Eucholcops, el Nothropus, etc., mientras que no existe en el 
Mylodon Darmini (Glossotherium) o no es ella mayor que en el Sceliciotherium, el Scelidodon, el Platyonyx, etc. Luego este no es tampoco un carácter distintivo del Mylodon, tal como lo comprende el autor mencionado, probando, por el contrario, una vez más que se trata de un grupo heterogéneo.

El arco cigomático cerrado por unión con la apófisis del temporal Y no interrumpido, no es un carácter genérico, pues si se presenta en el Mylodon robustus, falta en algunos representantes del género Pseudolestodon, como también en el Lestodon, aunque la distancia que separa al cigomático de la apófisis temporal sea generalmente más corta que cn el Sirlidotrerium; pero resulta que también en este género hay representantes que tienen el arco cigomático casi completo como en el Mylodon: de consiguiente, éste tampoco es un carácter que permita separar de los otros gravígrados a la agrupación que Burmeister designı bajo el nombre de Mylodon.

La colocación oblicua del llano occipital, de atrás hacia adelante y ¿c abajo hacia arriha, tampoco es de un gran valor distintivo, pues más o menos acentuada se encuentra en todos los gravígrados; y si en el Scclidotherium la inclinación no es tan acentuada, tampoco el Myloilon gigunteas (Lestmion) se parece al Mylodon robustus, pues su occipital es considerablemente mís vortical, presentando un mayor parecido con el del Megatherium.

La ausencia del conducto o agujero sobre el cóndilo interno del húmero no es una prueba de identidad genérica, pues es sabido que se fresenta en unos géneros y falta en otros; esto sólo demuestra que el Lcstudin, ci Mylodon y el Pscutolestidon concuerdan en este caricter, existiendo con indo otros gravigrados, como el Platyony, que evidentemente no es un Mylolon y que sin embargo carece de dicho agujero. Por otra parte, su ausencia no está probada en el Mylodon Darvini (Glossotherium) cuyo húmero aún no se conoce.

El número de dedos de todas las especies que se quiere incluir en el siner. Huluton no es atin conocido de una manera satisfactoria; falta liasta alora un pie anterior completo del pretendido Hylodon giganteus (Listuden) y no se conoce nada de los miembros del Mylodon Darmini (Ciussuth tium); pero aun suponiondo que todos ellos tuvieran absoIntaminte el mismo número de dedos, todos los naturalistas saben que si la identidad no se extiende asimismo a su conformación y disposición no es una prueba le identidad genérica; y por lo que concierne a uno de usos pretendicios Mylodon, el Lestodon, sabemos ya que, en cfecto, tiene un pie de una estructura muy distinta de la que presenta el pie posterior del verdadero Mylodon y del Pseudolestodon.

En cuanto al número menor de las vértebras dorsales. que es el último de los caracteres distintivos del género Mylodon que enumera Bur- 
meister, basta recordar que si este número es menor en comparación del Scclidotherinm que tiene 18 vértebras dorsales, el Megatherium tiene 16 dorsales como el Mylodon. Por otra parte, aún se ignora el número de vértebras que tiene el Mylodon Darwini (Glossotherium) y no está probado que el Mylodon giganteus (Lestodon) tenga 16 vértebras dorsales como el Mylodon robustus, pues los esqueletos que hasta ahora se han reconstruido to han sido con restos de varios individuos y el número de vértebras se ha completado por analogía con los otros géneros, es decir: con el Mylodon y el Megatherium. Es cierto que Burmeister dice que la columna vertebral que existe en el Museo tiene 10 vértebras dorsales, pero no sabemos si es realmente completa o si es completada con restos de más de un individuo. El mismo autor dijo también otra vez que el Scelidotherium tenía 16 vértebras dorsales como los demás gravígrados, y, sin embargo, ahora delante de esqueletos completos, declara que tiene 18. Sin embargo, juzgando por analogía, me parece probable que el Lestodon tuvo también 16 vértebras corsales, pero eso no quiere decir de ninguna manera que sea genéricamente idéntico al Mylodon.

En definitiva: el género Mylodon, con las especies que en él coloca el doctor Burmeister, es una agrupación heterogénea para la que no ha podido encontrar caracteres distintivos que le sean comunes, como que no existen, puesto que se compone de la reunión de varios géneros que, según el estado actual de nuestros conocimientos, se reparten en tres familias distintas. Una do estas familias, la de los Lestodontida, trene precisamente por tipo una de esas especies que Burmeister quiere colocar en el género Mylodon: el Mylodon gigantells del mismo autor, çue constituye el género Lestodon de Gervais, cuyos caracteres diferenciales con el Mylodon son tan notables, que sólo guiados por ideas preconcebidas es dado desconocerlos.

Los diferentes géneros de gravigrados presentan en la conformación del rostro diferencias de conformación verdaderamente notables. Así el Scelidutherium y el Megutherium tienen una parte anterior muy prolongada hacia adelante, terminancio en huesos intermaxilares, largos, angostos y delgados. En el Iyloton y el Pseutolestodon, al contrario, el rostro es más corto, más grueso y más ancho, con intermaxilares cortos o rudimentarios. El Megilonyx presenta en este sentido una evolución todavia más avanzada. En todos estos géneros, sin excepción. por más ensanchamientos que presente la parte anterior del rostro, ésta es constantemente más angosta y más delgada.

En el Lestodon, al contrario, el ensanchamiento del rostro en su part: anterior es tan formicable y exagerado, que la parte anterior del rostro es más ancha que la extrenidad posterior del críneo, presentando la abertura nasal anterior truncada una mayor extensión que el llano 
occipital, el que, sin embargo, en proporción, no es más pequeño que en los otros géneros del mismo grupo. El cráneo del Lestodon, en su parte posterior, es comparable por sus proporciones al del Mylodon; y en el centro, si se hace abstracción de los arcos cigomáticos, es más bien estrecho y delgado, pero en su tercio anterior se ensancha de una manera tan extraordinaria, que el paladar forma a cada lado una curva que se dirige hacia afuera, en cuyo ángulo externo se encuentra implantado un diente formidable en forma de defensa, que da al rostro un aspecto completamente único. La abertura nasal anterior es de tamaño extraordinario, sumamente ancha y regularmente alta, angostándose gradualmente hacia arriba.

La mandíbula inferior, de acuerdo con esta conformación particular del cráneo, tiene un borde inferior casi derecho, inclinándose luego hacia adelante y ensanchándose hasta presentar en su parte anterior un borde transversal sin dientes, de un ancho considerable en relación con la misma región de la mandíbula superior.

La parte superior del cráneo forma una curva convexa bastante pronunciada; y las crestas temporales, más fuertes que en el Mylodon y el Scelidotherium, en vez de quedar separadas como en estos géneros limitando un llano sagital elevado, se acercan hasta reunirse sobre la linea media formando una cresta sagital bastante larga y más o menos elevada, según las especies, cuyo carácter separa netamente a este género de los dos viltimamente mencionados, para acercarlo, por el contrario, al Ifegathcrium y al Megalonyx que tienen una cresta sagital parecida. La cresta sagital se bifurca hacia adelante formando dos líneas curvas temporales que vienen a concluir encima de las órbitas, limitando la región frontal muy ancha, que se inclina fuertemente hacia abajo hasta su unión con los nasales, donde la parte superior del cráneo presenta un estrechamiento notable. Hacia atrás la cresta sagital se divide igualmente en dos, que se bifurcan hasta unirse con el occipital, limitando un espacio triangular formado por la parte posterior de los parietales y el interparietal, que sólo es visible en la juventud.

El llano occipital se separa completamente de la forma que presenta en el Mylodon, el Pseudolestodon y el Scelidotherium, por ser relativamente más estrecho y más alto. En los dos mencionados géneros, el cccipital presenta un diámetro transverso considerablemente mayor que el diámetro vertical, mostrándose el llano occipital entero como deprimido de arriba hacia abajo. En el llano occipital del Lestodon los dos diámetros son sensiblemente iguales, afectando una forma circular casi completa, interrumpida únicamente hacia abajo por la escotadura formada por el agujero occipital; pero no sólo el occipital del l.estodon es más elevado y más circular que en los géneros Mỵlodon, 
Pseudolestodon, Glossotherium y Scelidotherium, sino también más vertical. La diferencia entre el Lestodon y el Mylodon es tan considerable, que en la conformación del occipital se aleja mucho más que el Megalonyx, cuyo llano occipital es igualmente aplastado de arriba hacia abajo y de gran diámetro transverso, como en los mencionados géneros.

Esta altura considerable del occipital del Lestodon se comunica a todo el resto del cráneo, apareciendo en toda su extensión notablemente más elevado que el del Mylodon o del Scelidotherium.

El arco cigomático tiene algún parecido con el del Mylodon únicamente en la apófisis posterior del cigomático que se toca o casi se toca con la apófisis opuesta del temporal, pero con esta similitud se presenta Lin desarrollo mucho menor de la apófisis descendente del hueso malai o cigomático y con la apófisis superior que se dirige de adelante hacia atrás, más delgada, pero considerablemente más prolongada que en el Mylodon.

La base del cráneo no presenta diferencias de consideración con la del de Mylodon en su parte posterior, pero adelante, en toda la región palatina, presenta una conformación completamente distinta.

El paladar del Lestodon se divide en dos partes: una posterior, que comprende la región en que están implantadas las cuatro muelas de cada lado que presenta un ancho casi igual en toda su longitud; y la otra anterior, que se extiende desde el segundo diente hasta la parte anterior del intermaxilar, que tiene más o menos el mismo largo que la posterior y hacia atrás el mismo ancho, pero que se va ensanchando rápidamente hacia adelante hasta presentar un diámetro transverso doble del que presenta en su parte posterior, conformación singular que distin. gue al Lestodon de todos los demás gravígrados. El Megalonyx, con el cual se ha comparado alguna vez, se acerca al respecto más a los otros géneros, pues el ensanchamiento de la parte anterior del paladar, es en él apenas acentuado.

Cada uno de los ángulos anteroexternos del paladar del Lestodon forma un fuerte reborde en el cual está implantado el primer diente; $y$ el espacio intermedio, o sea todo el borde anterior del paladar, forma un arco redondeado convexo hacia afuera, constituído en su parte central por el hueso intermaxilar regularmente desarrollado, pero fuertemente soldado a los maxilares. En la mandíbula inferior existe hacia adelante en cada lado un fuerte reborde inclinado hacia afuera, del cual sale igualmente el primer diente, pero entre ambos rebordes la mandibula se extiende con un ancho extraordinario, un poco hacia adelante todavía, terminando en un borde igualmente un poco redondeado, con la convexidad hacia afuera, en correspondencia con la conformación del paladar. 
El sistema dentario consta del mismo número de dientes que en el Mylodon, esto es: cinco arriba y cuatro abajo en cada lado de la mandíbula, pero dispuestos de otro modo y con una conformación distinta.

En el Mrydon los dientes de cada lado de cada mandíbula están colocados toclos a continuación, sin que el primero esté más separado ce los otros, o esta separación mayor es apenas sensible, con la corona truncada como en los demás dientes, sin afectar nunca la forma de un canino. En el Lestodon el diente anterior de cada mandíbula, de sección transversal y de tamano más o menos diferente, según las especies, estí sicmpre separadio de los demás dientos por un largo espacio vacio c harra, cuya longitud puede ser en ciertos casos casi igual a la longilud del sspacio ocupado por los otros dientes. Este diente anterior es siumpre mis largo que los demis, colocado afuera del eje de la serie centaria formada por los otros dientes, oblicuamente inclinado hacia los lados y con la corona cortada en bisel, con el plano inclinado dirigido hacia atrís en los superiores, y hacia adelante en los inferiores. presentando el aspecto de grandes caninos.

El segundo y tercer diente inferiores son en el Lestodon elípticocilinciricos, con su eje mayn de adelante hacia atrás; y en el Mylodon siempre prismáticos y colocados transversalmente.

La última muela inferior es bilobada en ambos géneros, fero e.a el Mylodon con los lóbulos casi prismáticos y con los surcos opuestos, anchos y profundos, mientras que en el Lestodon ambos lóbulos son elípticocilíndricos y con los surcos perpendiculares opuestos muy angostos.

En el Mylodon y el Pseudolestodon, la segunda muela superior es generaimente elíptica, la tercera y cuarta son constantemente prismáticas y la quinta mís pequeña y siempre bilobada. En el Lestodon, las cuatro muelas que siguen al diente caniniforme son todas de la misma forma elípticocilíndricas, como las inferiores. incluso la última que sólo se distingue por un tamaño un poco menor.

Esta conformación del aparato dentario del Lestodon, es tan diferente de la que caracteriza al hiflodon que causa verdadera sorpresa, que, conociendo esas diferencias, haya quienes quieran reunir ambos géneros en una sola denominación.

En la mandíbula superior, las cuatro muelas que a cada lado siguen al diente caniniforme, forman dos series paralelas, o con una pequeñ convergencia hacia atrás apenas sensible.

En las demás partes del esqueleto conocidas hasta ahora, el Lestodon presenta una mezcla de caracteres de varios géneros. Los miembros anteriores son relativamente más delgados y más largos que en el $M_{y}$ lolon. El húmero carece de agujero epitrocleano y se supone que el 
pie anterior ha tenido el mismo número de dedos que en el Mylodon, pero hasta ahora no se conoce ningún ejemplar completo.

El fémur del Lestodon es proporcionalmente más largo, más đ̊elgado, menos macizo y con un trocánter tercero mejor desarrollado que en el Mylodon, acercándose, al contrario, a la forma que caracteriza al del Megalony'x. La tibia y el peroné son más parecidos al del Mylodon y separados como en este género y en la generalidad de los desdentados.

El astrágalo se acerca por algunos caracteres al del Mylodon, particularmente por el tamaño de la faceta articular para el peroné y por la situación de las que lo unen al cuboides; pero en su parte articular con el calcáneo se parece más al del Megatherium, al que también se acerca por su forma general, presentando el mismo número de facetas articulares que en el de este último género y en el del Scclidotherium, lo que prueba la conformación particular de este animal.

El calcáneo es un hueso enorme sólo comparable al del Mcgatherium, al que también se parece en su conformación general, completamente distinta de la que presenta el mismo hueso en el género Mylodon. Dicho hueso sólo difiere del mismo del Mcgatherium, por su parte posterior un poco más redondeada y por el centro de la parte tuberosa un poco menos ensanchada; por lo demás, es de una forma completamente idéntica, articulándose hacia adelante con el astrágalo por medio de dos facetas, como en este género; mientras que en el calcáneo del Mylodon la articulación con el astrágalo se efectúa por medio de una sola faceta, lo que constituye una conformación típica completament? diferente y que demuestra la sinrazón con que se pretende hacer del Lestodon una especie de Mylodon.

El pie se termina en cuatro dedos, como el del Mylodon, faltando completamente el interno o primero y llevando uñas tan sólo el segundo y tercero, pero la conformación de casi todos los huesos es distinta de la que caracteriza al pie del mencionado género.

Hay todavía una diferencia notable de tanta o mayor importancia que todas las precedentes juntas, que confirma claramente la separación genérica del Lestodon y el Mylodon. Siempre que se encuentran restos de Mylodon por incompletos que ellos sean, no tratándose de piezas rodadas, están acompañados de numerosos huesecillos informes que forman una especie de coraza rudimentaria que se desarrollaba en el espesor de la piel. Los restos de Lestodon, ni aun cuando se encuentran en la forma de esqueletos con sus partes todavía articuladas, nunca están acompañados de tales huesecillos, de donde se deduce claramente que carecería de la coraza rudimentaria o de los huesecillos dérmicos que se desarrollaban en la piel del Mylodon.

Las especies del género Lestodon parecen haber sido numerosas. 
pero es dificil distinguirlas, pues el gran temor de fundar especies nuevas nominales ha hecho que se trate siempre de identificar los restos encontrados con los de una especie ya descripta; y ha resultado de aqui que a algunas especies fundadas primitivamente sobre partes del cráneo se le han atribuído restos de otros individuos, que provenían de especies distintas. Además, el deseo, tanto por parte de los coleccionistas como de los Directores de Museos, de presentar o poseer esqueletos completos, ha hecho que se monten algunos con restos que no sólo provienen de varios individuos, sino que también son a veces de especies distintas. Es más que probable que el mismo Gervais ha incurrido en ese error, pues creo que los restos del esqueleto descriptos en su segunda Memoria del año 1873, como provenientes del Lestodon armatus, no son de esta especie, sino más bien de la que el mismo autor designa con el nombre de Lestodon trigonidens. Asi también es probable que una parte de los restos mencionados por Burmeister bajo el nombre de Mylodon gigunteus correspondan en parte al mismo Lestodon trigonidens y otra parte al Lestodon armatus o a otras especies asimismo diferentes.

Las distintas especies se distinguen muy bien por la forma y la disposición del aparato dentario y la conformación del cráneo; en el estado actual de nuestros conocimientos no es posible referir con seguridad a tal o cual especie los restos aislados del esqueleto, si no están acompañados de partes características del cráneo o de la dentadura. Para ello sería necesario establecer las diferencias de los distintos huesos del esqueleto, lo que es tarea del porvenir, que sólo será dado emprenderla cuando se disponga de mayores materiales y recogidos con más orden que los que hasta ahora se han coleccionado.

Por desgracia, aunque conozco varias especies distintas fundadas en los caracteres diferenciales que presentan en el cráneo y en el aparato dentario, tampoco me es posible dar acerca de ellas una buena enumeración de los caracteres distintivos que presentan, pues todos los materiales que con ese objeto habia reunito son hoy propiedad del Museo de La Plata, cuyas colecciones no se me permite consultar. Véome obligado a dar tan sólo una enumeración de las especies establecidas hasta ahora, citando algunos de los caracteres distintivos más culminantes, que, en todo caso, tratándose de piezas regularmente completas, permitirán siempre reconocer la especie a que pertenecen hasta que la adquisición de nuevos materiales me permitan dar una descripción más exacta y detallada. 


\section{LEstodon armatus P. Gervais}

Lamina XLI1, liguras a, a $y$,

Lestodon armatus. P. Gervars: Recherchcs sur les manmifères fossiles de l'Amérique Méradionale, página 47, lámina XII, figuras I y 2, 1855. - Idem: Memoire sur plusieurs cspèces de manmifères propres à l'Amérique Méridionale, página 21 y siguiente, 1873.

ReINIrARDT: Bidrg till Kundskab om Lestoilon armatus, ete., Memoria de la Academia Real de Copenhague, tomo IX, I875.

II. Gervats y AMEghino: Los mamiferos fósiles, etc., página 166, IS80.

Mylodon robustus major. DE BLAinviLLE: Ostégraplie.

Mylodon giganters? BuRMEISTER: «Anales del Museo Público de Buenos Aires», tomo I, página $162,-1865$, - Idem: Description phisique, etc, tono III, página $37 \mathrm{r}, 1879$.

IIylodon armatus? (Gervais). LYDEKKER (parte?): Catalogue of the Fossil Mammalia, parte $\mathrm{V}$, página 110,1887 .

Lestodon giganteus? (Burmeister). 1I. GERvars y AMEGHNo: Los mamiferos fósiles, etc., lágina $172,1880 .(3)$.

Esta es la especie que ha servido de tipo para la fundación del género, la cual, sin embargo, es una de las menos conocidas a causa de 1a confusión del Lestodon con el Mylodon como representantes de un mismo género, lo que ha hecho que se confundan también en una sola especie todos los representantes del género Lestodon.

Las piezas originales sobre las cuales el profesor Gervais estableció el Lestodon armatus son: un fragmento de maxilar superior con el cani. niforme, la muela que sigue y parte del alvéolo de la tercera; y la parte anterior de una rama mandibular con la parte sinfisaria, el caniniforme, las dos muelas que siguen y parte del alvéolo de la cuarta, ambas piezas procedentes de la Banda Oriental, pero de las cuales se han encontrado idénticas en la República Argentina.

Sin embargo, como sucede en estos casos, es sumamente dificil referir a la especie que representan esas piezas los huesos aislados del esqueleto encontrados en distintos puntos y publicados bajo diversos nombres. Así, por ejemplo, aunque Burmeister identifica su Mylodon giganteus con el Lestodon armatus, habiéndose confundido con este nombre a todos los Lestodontes, no es seguro que esos restos correspondan a la misma especie que los que Gervais describió primero, o por lo menos falta demostrarlo; así como también es posible que ellos pertenezcan a más de una especie. Por esto, al redactar conjuntamente con el doctor H. Gervais el Catálogo de los mamíferos fósiles de Sud América, si bien reconocimos que el Mylodon giganteus de Burmeister era un verdadero Lestodon, no pudimos determinar la especie y la conservamos provisoriamente con el nombre de Lestodon giganteus. Es, pues,

(3) Iydekker, en la sinonimia de esta especie, menciona como sinónimo al Lestodon gigunteus de H. Gervais y Ameghino. Debo observar que el Lestodon giganteus, especie de Burmeister, sólo de un modo provisorio fué por nosotros mencionada como especie separada, en la imposibilidad de reconocerla por carencia de una descripción verdaderamente especifica. Puede corresponder realmente al Lestodon armatus, como también a alguna de las otras especies acá mencionadas; pero lo más probable es que haya confundido los restos de todas las especies del género en una sola especie, por lo cual es realmente conveniente suprimirla por completo. 
sin razón que Lydekker pone el Lestodon giganteus (Burmeister) $\mathrm{H}$. Gervais y Ameghino como sinónimo seguro de (Mylodon) Lestodon armatıs; ello es sólo una presunción, que quizá pueda ser confirmada en parte.

Tan embrollada es esta parte de la paleontología argentina que hasta los mismos restos descriptos más tarde por el profesor Gervais en las Memorias de la Sociedad Geológica de Francia, como de su Lestodon armatıs, no es seguro que pertenezcan a esta especie; y estoy más bien dispuesto a atribuirlos, cuando menos en parte, a la otra especie que e! mismo autor designó poco tiempo después con el nombre de Lestodon trigonidens.

Según las piezas originales descriptas por Gervais, la parte anterior Cel paladar del Lcstodon armatus entre los caniniformes es menos ensanchada que en el Lestodon trigonidens.

El caniniforme superior es mucho más grueso que los demás dientes, de sección subtriangular y de ángulos redondeados, con la parte que sale fuera del alvéolo bastante larga y truncada en bisel; este diente tiene 40 milímetros de diámetro mayor y 20 milimetros de diámetro menor.

La barra que separa al caniniforme superior de la segunda muela, tiene un poco más de siete centímetros de largo.

La segunda muela, de sección elíptica, casi circular, sólo tiene de 20 a 21 milímetros de điámetro mayor y era seguida hacia atrás, según el alvéolo, por una muela tercera de doble tamaño que la segunda, pero con poca diferencia de la misma forma.

La parte anterior del paladar entre los caniniformes ha tenido un ancho aproximado de 15 centímetros; pero entre el par de muelas siguientes, sólo un ancho de 8 centímetros.

En la mandíbula inferior el caniniforme está menos separado de la muela que sigue que el correspondiente de la mandíbula superior, pero está colocado más hacia afuera de la línea dentaria, en una protuberancia circular de la rama de la mandíbula, que se dirige hacia adelante y hacia afuera. El diente caniniforme está implantado dirigiéndose hacia arriba y hacia afuera, pero poco inclinado hacia adelante; es de sección clíptica, pero de tamaño relativamente pequeño y mucho menor que el correspondiente de la mandíbula superior.

La barra que separa al caniniforme inferior de la muela que sigue hacia atrás tiene unos 6 centímetros de largo. La primera muela que sigue, de sección elíptica, con su eje mayor dirigido de adelante hacia atrás, tiene 29 milimetros de diámetro mayor; y la tercera, implantada un poco más oblicuamente, es apenas algo más corta.

La talla de este animal era más de un tercio superior a la del Mylodon robustus. 
Procedencia: - Los restos de esta especie se encuentran, aunque al parecer no con mucha frecuencia, en la parte Norte y Nordeste de la provincia Buenos Aires y en la Republica Oriental del Uruguay.

Horizonte:-Piso ensenadense y piso belgranense de la formación pampeana.

L,ESTODON TRIGONIDENS P. Gervais

Lhmun XLII, Hgarns iy?

1. Gervais: Mémoires de la Société Géologique de France, $2^{\text {a }}$ serie, tomo IX, número 5 , año r873.- Idem: «Journal de Zoologie», tomo III, página $16 \mathrm{I}$, lámina $\mathrm{V}$, figuras 1 a 3 , afio 1874 .

H. Gervats y Amechino: Los mamiferos fosiles, etc., página 166, 1880.

Esta especie fué fundada por P. Gervais sobre un pequeño fragmento de mandibula inferior con el diente caniniforme, el cual por su forma y aspecto particulares comprendió inmediatamente provenía de un animal especificamente diferente del Lestodon armatus.

El Lestodon trigonidens era de talla muy superior a la del Lestodion armatıs, acercándose bastante por su tamaño al .Mcgatherium. El cráneo es más ensanchado en su parte anterior y los caniniformes superiores son más triangulares, más gruesos y mis largos, dirigidos oblicuamente hacia abajo y hacia afuera, tomando la forma de grandes caninos.

Las muelas superiores que siguen al caniniforme parecen ser un poco más cilíndricas que en Lestodon armatus; la primera es un poco más pequeña y colocada en dirección longitudinal, la segunda y la tercera son más grandes, casi iguales e implantadas un poco oblicuamente; y la cuarta o última superior es bastante pequeña, colocada longitudinalmente, y más estrecha en la parte posterior que en la anterior.

En la mandibula inferior el diente caniniforme es considerablemente más grande que el del Lestodon armatus y de una forma muy diferente, pues en vez de ser de sección elípticorredondeada, es de sección completamente triangular con sus tres lados casi iguales, pero con una cara cortada en bisel, de manera que termina en cúspide triangular afectando casi la forma de una pirámide; además está colocado de una manera considerablemente más oblicua y más inclinado hacia adelante que en Lestodon armatus; cada uno de los tres costados del caniniforme del Lestodon trigonidens tiene un ancho de $0^{\mathrm{m}} 035$ y unos 4 centímetros de alto.

El cráneo es relativamente largo y delgado, pero bastante alto, con arcos cigomáticos cuyos prolongamientos posteriores inferiores son relativamente largos y angostos.

Puede dar una idea del tamaño enorme que alcanzaba esta especie el hecho de que el cráneo de los más grandes individuos llegaba a veces a tener hasta 75 centímetros de largo. 
He aqui las dimensiones del cráneo de un individuo algo joven, que aún no había alcanzado su completo desarrollo.

DIMENSIONES

Ancho del paladar entre los caniniformes............................. $0^{\mathrm{m}} 202$

Ancho del paladar entre el primer par de muelas que siguen a los caniniformes. 0068

Ancho del paladar entre las últimas muelas ............................ 0056

Diámetro transverso del cráneo detrás de la última muela.................. 0082

Diámetro transverso del cráneo al nivel del primer par de mueias que siguen

a los caniniformes................................................. 0114

Diámetro transverso del cráneo al nivel de los caniniformes................. 0260

Longitud de la barra que separa al canino de la primera muela. ........... 0078

Longitud del espacio ocupado por las cuatro muelas ........................ 0 109

Altura de la abertura nasal anterior en el medio.......................... 0160

Diámetro transverso del caniniforme superior ......................... 0018

Largo desde la-abertura nasal posterior hasta la punta anterior de los inter-

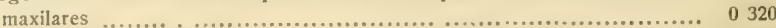

Longitud del cráneo desde los cóndilos occipitales hasta la punta del hueso incisivo 0620

La mayor parte de los restos atribuidos al Lestodon armatus provienen del Lestodon trigonidens, que es la especie más abundante, incluso la casi totalidad de los restos figurados y descriptos por Gervais en las Memorias de la Sociedad Geológica de Francia, así como también probablemente la mayor parte de los que Burmeister atribuye al Mylodon giganteus.

Procedencia: - Los restos de esta especie se encuentran con frecuencia en casi toda la provincia Buenos Aires.

Horizontc: - Pisos lujanense y bonaerense de la formación pampeana.

L,Estodon Bocscet II. Gervais y Ameghino

H. Granvis y Ameghino: Los mamíferos fósiles, etc., página 170, 1880.

Fundé esta especie en colaboración con el doctor H. Gervais, expresándonos acerca de ella en estos términos: «Especie intermedia, por su talla, entre el Lestodon trigonidens y el Lestodon armatus. Las dos series dentarias de la mandibula superior están muy próximas una de otra, a excepción del par de muelas caniniformes que están muy separadas. En el individuo sobre el cual establecemos esta especie faltan las muelas caniniformes inferiores, pero la forma del alvéolo nos permite afirmar que diferían por su forma de las del Lestodon armatus; debían ser prismáticas; y su posición era intermedia a la de las dos especies ya nombradas».

La circunstancia de ser hoy, las piezas en las cuales fundé la espezie, propiedad del Museo de La Plata, me impiden dar acerca de ellas otros 
detalles. Sólo recuerdo, como carácter importante que puede permitir reconocerla inmediatamente, la posición del caniniforme inferior que no está tan separado de las muelas como en Lestodon trigonidens, ni es tan triangular: además, este diente, en vez de ser fuertemente inclinado hacia adelante como en Lestodon trigonidens y hacia afuera como en Lestodon armatus, se inclina muy poco hacia adelante y no mucho hacia afuera, levantándose, al contrario, hacia arriba. La talla era apenas un poco menor que la del Lestodon trigonidens.

Procedencia:- He recogido los restos de esta especie en distintas 10calidades de la provincia Buenos Aires.

Horizonte: - Piso bonaerense de la formación pampeana (plioceno superior).

I. Estodon Gsunryz H1. Gervais y Ameghino

H. Gervais y AMEghiNo: Los maniferos fúsiles, etc., página 168 , IS80.

Fundé esta especie en colaboración con el doctor H. Gervais, expresándonos en los siguientes términos: «Esta especie se acercaba por su talla al Lestodon Bravardi; está fundada sobre una porción de cráneo cuyas muelas tienen absolutamente la misma forma que las del Lestodon armatus, pero son mucho más pequeñas, del tamaño de las del Lestodon Bravardi, aunque difieren de las de esta especie por sus formas. Las dos series dentarias de la mandíbula superior están muy aproximadas la una a la otra. La muela caniniforme es menos gruesa que en las otras; su forma es más o menos la misma que la del Lestodon armatıs, pero está implantada de un modo diferente y menos echada hacia afuera».

Siendo los materiales de que disponía propiedad del Museo de La Plata, no me es permitido, por las circunstancias ya conocidas, agregar nuevos detalles. Además de la talla pequeña, sólo recuerdo como carácter distintivo importante, que siempre permitirá reconocer a la especie, la posición y la forma del caniniforme superior. Este diente, en proporción del tamaño del animal, es muy delgado; y en vez de ser triangular como en Lestodon trigonidens, es elíptico, más elíptico todavía que en Lestodon armatus y con su diámetro mayor colocado en dirección transversal; de esta conformación resulta que el diente es aplastado de adelante hacia atrás, con una cara anterior ligeramente convexa; y la parte superior cortada en bisel, en vez de terminar en ápice triangular agudo como en los demás Lestodontes, termina en un borde cortante del mismo ancho que el resto del diente, presentando así aparentemente, la misma forma general que un incisivo superior de roedor, con la única diferencia de que el ángulo longitudinal interno es redondeado, en vez de formar 
un verdadero ángulo como en los incisivos de los roedores. Esta cara cortada en bisel estaba vuelta hacia atrás y no hacia atrás y hacia afuera como en los demás Lestodontes.

Procedencia: - He recogido los restos de esta especie en Mercedes, provincia Buenos Aires.

Horizonte:- Piso bonaerense y piso lujanense de la formación pampeana.

Listodon Bravardi 11. Gervais y Ameghino

II. Gervais y Amegrino: Los mamiferos fósiles, ete., página r68, 1880.

Fundé esta especie en colaboración con $\mathrm{H}$. Gervais, expresándonos en estos términos. «Especie representada por un fragmento de cráneo acompañado de casi todas sus muelas. El animal a que pertenecían estos restos debía igualar apenas por su talla al Mylodon robustus; es decir que era mucho más pequeño que los dos Lestodontes ya mencionados, (Lestodon trigonidens y Lestodon armatus)》.

No puedo agregar nuevos detalles por la misma circunstancia que en el caso de las especies precedentes; sin embargo, ésta podrá siempre reconocerse con facilidad por su tamaño pequeño, no mayor que el del Mylodon robustus y por los caniniformes inferiores y superiores muy delgados, pero de forma prismáticotriangular como en el Lestodon trigonidens.

Procedencia:- He recogido los restos de esta especie en distintos puntos de la provincia Buenos Aires.

Horizonte:-Piso belgranense y piso bonaerense de la formación pampeana.

LESTODON BLAINVILLEI II. Gervais y Ameglino

II. GriRvis y AMEghiNo: Los namiferos fósiles, etc., página 170, 1880 .

Fundé esta especie en colaboración con $\mathrm{H}$. Gervais, expresándonos en estos términos: «De Blainville ha figurado en una de las láminas de su Atlas, consagrado a la osteografía de los desdentados, una mandíbula inferior clasificada en el texto explicativo como perteneciente al Mylodon robustus major. Por la forma de sus muelas (no tomando provisoriamente en consideración el número de estos órganos), esta pieza entra sin disputa en el grupo de los Lestodontes, en cuya serie representaría un tipo completamente diferente de los que acabamos de nombrar. Pero detrás de la muela más grande, compuesta de dos partes casi iguales, que ocupa el último lugar en todas las especies de este género, se 
ve una pequeña muela cilindrica. ¿Debemos basarnos en la presencia de esta muela para hacer del animal que poseía esta mandíbula el tipo de un nuevo género? ¿ Debemos, por el contrario, no teniendo en cuenta más que los otros caracteres, clasificarla entre los Lestodontes? Creemos que esto último es lo más conveniente, esperando entretanto que nuevas investigaciones vengan a darnos alguna luz acerca de este animal singular».

\section{Procedencia:-Provincia Buenos Aires.}

Horizonte:-Formación pampeana.

Anegrino: «Boletin de la Academia Nacional de Ciencias», tomo VIII, página 124, I8S5. - Idem: tomo IX, página $₫ 88$, I\$86.

Esta especie está representada por un fragmento de la sínfisis de la mandibula inferior con parte del alvéolo del caniniforme del lado izquierdo, tres muelas aisladas y la parte superior de un caniniforme superior.

La parte existente de la sínfisis indica una especie de tamaño bastante menor que las que se conocen de la formación pampeana. Esta parte de la mandíbula es más estrecha y más prolongada hacia adelante que en las especies más modernas; y particularmente la parte anterior sin dientes, que, en los Lestodon trigonidens, Lestodon armatus, Lestodon Bocagei y Lestodon Gaudryi, se ensancha en forma de pala, parece haber sido en el Lestodon antiquus mucho más angosta, más estrecha todavia que en las especies de los géneros Mylodon y Pseudolestodon.

Es una lástima que esta pieza no sea más completa para poder determinar la forma de los caninos, que a juzgar por el fragmento de alvéolo que aún queda parece hubieran sido bastante gruesos, pues la cara interna existente forma una faja casi plana de 25 milímetros de ancho, que representa el diámetro transverso del diente que se implantaba ahí. Por esta cara casi plana se puede también deducir que los dientes cani. niformes inferiores de esta especie eran también de sección prismático. triangular como en el Lestodon trigonidens, en vez de ser elípticos como en el Lestodon armatus y el Lestodon Bocagei.

Otra diferencia muy notable entre esta especie y las pampeanas conocidas hasta ahora, aparece en el modo cómo estaban implantados esos mismos dientes en forma de colmillos. En el Lestodon armatus y especies aliadas, a excepción del Lestodon trigonidens, esos dientes separados de las otras muelas por una larga barra, se desvían de la serie dentaria dirigiéndose hacia afuera y hacia arriba. En el Lestodon trigoni- 
dens son todavia más desarrollados y se dirigen hacia afuera y hacia adelante en sentido más horizontal, figurando dos enormes defensas divergentes. En el Lestodon antiquus en vez de dirigirse hacia afuera se dirigían hacia adelante, tomando más la forma de incisivos.

De las tres muelas aisladas, una tiene una sección transversal de sólo 18 milímetros de diámetro mayor y 12 milímetros de diámetro menor, fiero falta por completo la capa de cemento externo muy gruesa cn las nuelas de este género, que debía dar al diente un tamaño casi doble. La capa de dentina dura tiene un espesor de 2 a 3 milímetros y la masa de vásculodentina interna muy gastada en la corona, donde forma una especie de pozo, tiene 13 milímetros de diámetro mayor y de 6 a 7 milímetros de ancho. La muela está quebrada, existiendo sólo la parte superior en un largo de 40 milimetros, de modo que no se puede apreciar el largo que tenía cuando era entera.

La segunda muela es de figura más circular, de 17 milímetros de largo y 14 de ancho en la corona, donde la vásculodentina también se presenta sumamente gastada formando un pozo bastante hondo. Las dimensiones que doy de este ejemplar son también sin tomar en cuentia la capa de cemento externo que también ha desaparecido ahí, pero que se conserva en un pequeño trecho con un espesor de 2 a 3 milímetros, demostrando que la muela intacta con su capa de cemento externo debia tener un tamaño doble del que presenta actualmente. La parte existente tiene 66 milímetros de largo; y como la cavidad basal es todavía bastante pequeña se puede evaluar el largo de la muela entera en unos 90 milimetros.

El tercer ejemplar es algo más grande en la base que en la corona, probablemente por ser de un individuo bastante joven: Sin embargo la vásculodentina de la corona se presenta asimismo profundamente gastada. La sección de la muela en su parte superior tiene 16 milimetros de largo por 11 de ancho, pero falta también la capa de cemento que ha desaparecido quedando sólo vestigios de ella en un pequeño trecho de la base. También este ejemplar está roto en la parte inferior, no quedando nada más que un trozo de 55 milímetros de largo, en cuya base ya se ve la cavidad pulpal bastante grande, de modo que el largo total no ha debido pasar de 75 milímetros. La muela presenta una curva lateral bastante acentuada, lo que puede hacer creer que proviene de la mandíbula superior.

Todas estas muelas, aun tomando en consideración la capa de cemento externo que debía rodearlas, son de tamaño bastante menor que las de las grandes especies pampeanas, Lestodon armatus P. Gervais, Lestodon trigonidens P. Gervais y Lestodon Bocagei Gervais y Ameghino, indicando así para la antigua especie del Paraná un tamaño bastante más reducido. 
E1 caniniforme superior es la parte que sale fuera del alvéolo a la que le falta la cúspide que está rota. Es de la misma forma prismáticotriangular que caracteriza a este diente en todas las especies del género, con su parte superior cortada en bisel, pero de un tamaño demasiado pequeño en proporción del que presenta el fragmento de mandibula en el cual fundé la especie y las distintas muelas aisladas mencionadas. Tiene 17 milímetros de diámetro anteroposterior y 19 milímetros de diámetro transverso, pero como también este diente ha perdido la capa de cemento externo, su tamaño debió ser algo mayor, aunque no mucho, pues en el canino superior de los Lestodontes la capa de cemento es muy delgada. Ni era esta especie tampoco una excepción al respecto, como lo demuestran algunos pequeños vestigios de la capa de cemento que aún han quedado adheridos en uno que otro punto de la superficie del diente. La esquina longitudinal externa anterior parece, sin embargo, ser más comprimida que en las otras especies y su parte cortada en bisel mucho más prolongada, pues la parte existente tiene 42 milímetros de largo hasta la quebradura y la parte superior desaparecida debía tener por 10 menos la mitad de este largo. El ancho de esta cara cortada en bisel es de 16 milímetros.

Procedencia:- Los restos de esta especie fueron recogidos por el profesor Scalabrini en las barrancas de los alrededores de la ciudad del Paraná y pertenecen al Museo provincial de Entre Ríos.

Horizonte:- Piso mesopotámico de la formación patagónica (oligoceno inferior).

LESTONON (?) PARANENSIS, n. sp.

Lamens XL fikura 12

Este animal está representado por una muela elípticocilíndrica, muy diferente de las de los géneros Pseudolestodon, Mylodon y Scelidotherium, pero más parecida a las del género Lestodon, aunque presenta algunas particularidades, que hacen dudoso provenga del mismo género. Este diente tiene una curva bastante pronunciada, por lo cual supongo muy probable sea de la mandíbula superior; y como la corona no está gastada en declive sino en sentido casi horizontal, con la parte central constituída por la vásculodentina más gastada, me parece probable que se trata de una muela intermedia. Si ésta es realmente una muela superior, según es de regla en los demás desdentados, tenemos que el lado de curva con radio menor es el externo, y el de radio mayor o convexo el interno, y entonces tendríamos que el lado interno de esta muela es notablemente más ancho que el externo. El prisma muestra en su circunferencia un surco perpendicular interno bastante pronunciado y de fondo cóncavo y otro sobre uno de los costados, pero poco marcados. 
La muela está cubierta por una capa de cemento muy resistente, cuyo espesor en algunas partes parece ser considerable. La corona tiene 17 milimetros de largo y 15 milímetros de ancho. El largo del trozo existente es de cerca de 5 centímetros, pero como la base se presenta ya anchamente abierta y con sus paredes bastante delgadas, se conoce que su largo total debia sobrepasar apenas unos pocos milimetros del que presenta actualmente.

Procedencia: - Esta pieza ha sido recogida por el profesor Scalabrini en las barrancas de los alrededores del Paraná y pertenece al Museo provincial de Entre Rios.

Horizonte: - Piso mesopotámico de la formación patagónica (oligoceno inferior).

\section{IANIODON Ameghino}

AMEGHXo: La antigüedad del hombre en el Plata, tomo II, página 308, 188 I.

Este género se caracteriza por muelas intermedias subcilindricas más o menos iguales, todas con la corona gastada en declive sobre un solo lado; y por el caniniforme inferior triangular y bilobado por un profundo surco longitudinal sobre la cara anterior.

LANIODON ROBUSTUS Ameghino

Lamma LxxvI, liguras 8 y 8

Amecriso: Obra y página citadas.

El animal ha tenido la talla del Lestodon trigonidens, pero con las muelas intermedias más pequeñas, de contorno subcircular, con tendencia en algunas a la forma prismática, con depresiones perpendiculares más o menos acentuadas y la corona cortada en declive.

Conozco muelas intermedias superiores e inferiores que he recogido en diversas localidades, pero se encuentran ahora en el Museo de L a Plata. Por el momento sólo dispongo de una muela aislada de la mandíbula. Este diente tiene un poco más de 10 centímetros de largo, 20 milimetros de diámetro menor y 23 milimetros de diámetro mayor; afecta una forma irregularmente triangular, presentando sobre uno de los costados una depresión perpendicular ancha y poco profunda; otro de los costados es convexo y el tercero un poco deprimido. La corona forma un plano oblicuo de superficie completamente lisa. Las muelas superiores tienen la misma forma que ésta con la única diferencia de que son un poco menos prismáticas, más elípticas o circulares y con el prisma de cada diente un poco arqueado, con la concavidad hacia afuera y la convexidad hacia adentro. 
El caniniforme superior y la última muela inferior me son desconocidas, pero dispongo de un soberbio ejemplar del caniniforme inferior izquierdo. Este diente es de sección triangular y del mismo tamaño que el diente correspondiente del Lestodon trigonidens, pero de una conformación bastante distinta. La cara longitudinal del lado interno es fuertemente excavada en sentido longitudinal, de fondo un poco cóncavo y de 33 milímetros de ancho. La cara longitudinal externa es convexa en su parte anterior y más deprimida sobre su parte posterior, en donde presenta un pequeño surco longitudinal poco acentuado; esta cara tiene 35 milímetros de ancho. Estas dos caras al reunirse hacia atrás forman un borde longitudinal posterior comprimido y delgado.

La cara anterior, más o menos del mismo ancho que las precedentes, muestra el carácter genérico más particular de este diente, que es un surco longitudinal que la recorre desde la raiz a la corona, con un ancho de 9 milímetros y otro tanto de profundidad, dividiéndola en dos grandes columnas o lóbulos desiguales, el del lado externo más angosto y convexo y el del lado interno más ancho y más deprimido; el fondo del surco es cóncavo y con un depósito de cemento de superficie irregular. La corona del diente está cortada en bisel como en el mismo diente del I. estodon, formando un plano inclinado piramidal, ancho abajo y angosto arriba, de 33 milímetros de ancho en la base y más de 4 centímetros de elevación; la base de esta superficie está bilobada por el surco de la caia anterior que penetra en ella en una extensión de cerca de dos centímetros, dando a la corona del diente un aspecto particular que no se ebserva en el mismo diente de ningún otro desdentado. Toda la superficie longitudinal del prisma del diente está cubierta por una capa de cemento de menos de 1 milímetro de espesor, cuya superficie externa s.c presenta en todas partes un poco estriada en sentido longitudinal.

Esta pieza pertenece al Museo provincial de Entre Ríos en el Paraná.

Procedencia: - Se han encontrado restos de este animal en las provincias Buenos Aires y Entre Ríos.

Horizonte:- Piso bonaerense de la formación pampeana.

DIODOMUS Ameghino

Diodomus. Arrecrivo: «Boletín de la Academia Nacional de Ciencias», tomo VIII, página 122,1885 .

Platyodon. Aremiro: La antigüedad del hombre en el Plata, tomo II, página 308 , rSS1.

Este género se distingue fácilmente por el par de dientes anteriores, que tanto arriba como abajo afectan la forma de grandes incisivos escalpriformes, colocados en la parte anterior de la mandíbula. El paladar es sumamente estrecho y un poco más estrecho en su parte posterior. 
Los molares son de gran tamaño. pero de forma todavía desconocida, con excepción del último de la mandíbula inferior (que es bilobado en forma de 8), y sin columnas accesorias como en Glossotherium.

Di a conocer la primera especie de este género bajo el nombre genérico de Platyodon, que tiene prioridad sobre el de Diodomus, pero que no puede conservarse por haber sido empleado con anterioridad para designar un género de moluscos; y luego, aunque con distinta desinencia, un género de lepidópteros.

Drodomus Corer Ameghino

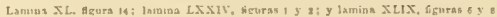

Diodonus Copei. Amegrino: «Boletin de la Academia Nacional de Ciencias», tomo VIII, página 125,1885 .

Lestodon Garachicoi. Moreno: Informe preliminar, etc., página II, Julio de I8S8 (nomen nudum).

Fundé esta especie sobre un trozo considerable de la sínfisis de la mandíbula inferior, de una forma muy particular, en la cual todavía se conserva parte de los alvéolos de dos dientes que estaban implantados más adelante aún que en el Lestodon antiquus, de modo que afectaban la forma de formidables incisivos.

Esta parte de la mandibula difiere completamente de la de todos los desdentados de esta parte de América conocidos hasta el dia, pero presenta, al contrario, un gran parecido con la sínfisis del curioso desdentado de la isla de Cuba, conocido con el nombre de Megalochnus rodens, con la diferencia del tamaño gigantesco de las partes correspondientes del Diıdomus. Sin embargo, la diferencia de forma de la última muela inferior, no permite reunirlos en una misma familia.

La parte posterior de la sínfisis del Diodomus, en vez de formar una gran curva como en el Lestoton, forma una curva de radio mucho menor, demostrando que ambas ramas de la mandibula inferior estaban separadas por un espacio muy pequeño, como en el Megatherium, y subre todo en el Megalochnus.

En su parte inferior es ancha y deprimida hacia atrás, estrechándose hacia adelante, donde todavía está en parte visible la sutura de ambas ramas de la mandibula, cuyos vestigios han desaparecido por completo de la parte interna. En toda esta parte de la superficie de la mandíbula se ven pequeños agujeritos que parecen demostrar que el animal tenía lahios muy carnosos, prolongados hacia adelante y muy movibles.

La sínfisis forma en la parte interna un canal de fondo cóncavo parecido al de Negalochnus, pero proporcionalmente más estrecho y más profundo, de acuerdo con el mayor tamaño del animal y con la forma distinta de los incisivos, de un diámetro anteroposterior mucho más considerable. Este canal empieza en la parte posterior de la sínfisis con un 
ancho de sólo unos 18 a 20 milímetros y con paredes laterales casi verticales que se van separando hacia adelante, donde a una distancia de unos 8 a 9 centimetros de la parte posterior adquiere un ancho de 38 a 40 milímetros. En este punto conócese por los restos de los alvéolos que los dientes en forma de incisivos salían fuera de la mandíbula dirigiéndose hacia adelante y hacia arriba como en los roedores y en el Mlegalochnus; pero se ve perfectamente, aunque está rota la parte intermedia de la sínfisis, que se dirigía hacia adelante, angostándose cada vez más, hasta formar una especie de pico, que difería del que presenta la sinfisis del Megalochnus, en la cual descendia hacia abajo en vez de ascender, como en éste, ligeramente hacia arriba.

De los alvéolos de los dos dientes en forma de incisivos sólo existe parte de los tabiques anteriores y parte de los tabiques internos, que, aunque no son suficientes para que sea posible conocer la forma y las dimensiones de los dientes que en ellos estaban implantados, bastan para demostrar que eran de forma muy distinta de los del Megalochnus y de los demás desdentados conocidos. En la parte posterior de la sínfisis, esos alvéolos sólo se encuentran separados uno de otro por un espacio de 25 a 27 milímetros, pero se dirigen hacia adelante en direc-1 ción algo divergente, de modo que al salir del alvéolo debían estar separados por un espacio de unos 5 centímetros de ancho o quizá más. El tabique anterior o inferior es una banda plana de 31 milimetros de ancho; y 10 que queda del tabique interno forma una pared de 25 milimetros de alto por lo menos, que se une formando ángulo recto con la cara plana anterior. De esto se deduce que los dientes en forma de incisivos del Diodomus, en vez de ser anchos, delgados, convexos en la cara anterior y deprimidos en la posterior como en el Megalochnus, son, al contrario, anchos, excesivamente gruesos y planos en la cara anterior y en la interna.

La última muela inferior es de gran tamaño y bilobada en forma de 8. como la del Lestodon y de tamaño un poco mayor aún que la muela correspondiente del Lestodon trigonidens. Dispongo de un ejemplar de un individuo todavía muy joven; debido a este estado juvenil, la parte superior de la corona (lámina XL, figura 14) es más pequeña que la farte inferior del prisma del diente y la capa de cemento que lo envuelve no alcanza tampoco hasta la superficie masticatoria, perdiéndose Lnos cuantos milímetros antes de llegar a la cúspide. El prisma entero del diente es bilobado por dos surcos perpendiculares opuestos, anchos y profundos, que dan a la corona la figura de un 8 prolongado, con sus lóbulos casi iguales. La corona tiene un diámetro anteroposterior de 25 milímetros y 8 milimetros de diámetro transverso en cada uno de los lóbulos, pero estas medidas aumentaban considerablemente con la edad. 
Conozco además un ejemplar de un individuo adulto, pero rodado $y$ de cuya superficie ha desaparecido por completo la capa de cemento; a pesar de lo cual la corona tiene 44 milimetros de diámetro anteroposterior, 15 milímetros de diámetro transverso en el lóbulo anterior y 17 milimetros en el posterior.

Del cráneo sólo conozco la parte interdentaria anterior del paladar, en la cual se conserva una pequeña parte de los alvéolos de los incisivos y parte de los alvéolos de las muelas primera y segunda. El paladar es muy angosto. pues la parte interdentaria entre la primera muela sólo tiene 22 milímetros de ancho, pero es muy profundo y de fondo cóncavo, con los maxilares completamente soldados. Adelante de la primera muela c! paladar se ensancha un poco, pero sólo se extiende hacia adelante en una extensión de 2 centímetros, formada por los intermaxilares, casi rudimentarios como en el Mylodon; estos huesos están completamente soldados a los maxilares, sin que casi se perciban rastros de sutura, pero permanecen separados uno de otro sobre la línea media por una ancha hendedura, presentando además cada intermaxilar un gran agujero palatino que se extiende hacia adelante hasta la punta del intermaxilar en forma de depresión cóncava.

Aunque to se puede determinar su forma por no existir más que la pared interna del alvéolo, se conoce que la primera muela era de tamaño considerable, pues media sohre su cara interna $0^{\mathrm{m}} 037$ de diámetro anteroposterior. Del alvéolo de la segunda muela, así como también de los alvéolos de los dientes incisiviformes, sólo quedan pequeños vestigios; pero se conoce que estos últimos no estaban colocados en los ángulos anteroexternos del paladar como en el Lestodon, el Mcgalonyx y el Pliomorphus, sino en el centro de la parte anterior de la región palatina, aunque un poco divergentes uno de otro. Este fragmento forma parte de la colección de fósiles del Paraná, del señor Lelong Thévenet.

Procedencia: - Los primeros restos de este animal fueron recogidos por el profesor Scalabrini en las barrancas de los alrededores de la ciudả del Paraná, hahiéndose luego recogido restos de la misma especie en Monte Hermoso, en la provincia Buenos Aires.

Horizonte: - Piso mesopotámico de la formación patagónica y piso hermósico de la formación araucana.

Diodomus AnNakatoner Ameghino

Lamana XLrs, feura?

Platyodon Annaratonci. Axrenjo: La antigüedad del hombre en el Plata, tomo II, página $30 \mathrm{~S}, \mathrm{I} 8 \mathrm{r}$.

En la obra mencionada fundé esta especie en los siguientes términos: ¿Género y especie nueva del orden de los desdentados, familia de los 
Megatéridos, fundada sobre una sola muela, pero de una forma muy característica. Esta muela es la primera anterior de la mandíbula inferior y presenta el aspecto de un diente incisivo. Es comprimida en sentido anteroposterior, lo que le da completamente el aspecto de un diente incisivo de roedor. Su superficie anterior es casi plana y la posterior muy convexa, terminando en una extremidad muy ancha, plana y cortante. Debía estar implantada en la parte anterior de la mandíbula a manera de un incisivo. Este animal debía tener alguna analogía con el Megalochnus rodens.»

No puedo dar otros datos ni el dibujo de la pieza original por ser hoy propiedad del Museo de ${ }^{2}$ La Plata, pero puedo agregar que se trata de ur animal más pequeño que la generalidad de las especies de Mylodon, como lo prueba un trozo de paladar que comprende la parte anterior de la región interdentaria, cuya pieza debo a la obsequiosidad del señor León Lelong Thévenet. Este fragmento comprende los intermaxilares casi intactos con la parte anterior de la región palatina de los maxilares, parte de los alvéolos de los dientes incisiviformes y parte de los alvéolos de las dos primeras muelas de cada lado.

El animal parece haber sido de talla inucho menor que la del Diodomuts Copei, pero el paladar no era tan angosto, pues la región interdentaria entre la primera muela de cada lado tiene 3 centímetros de ancho; además es mucho menos profundo y de fondo más cóncavo.

El alvéolo de la primera muela (del cual sólo existe la pared interna) tiene 27 milímetros de diámetro anteroposterior, presentándose un poco oblicuamente al eje del paladar. De los alvéolos de la segunda muela sólo quedan fragmentos insignificantes.

De los alvéolos de los dientes incisiviformes sólo queda la pared anterior, que parece demostrar eran de forma elípticoaplastada como los inferiores y de un ancho que no pasaba de 17 a 18 milímetros. La barra que separaba de los incisiviformes a la primera muelas sólo tienc 4 centímetros de largo.

Los intermaxilares son muy pequeños y completamente soldados a los maxilares, pero separados uno de otro sobre la línea media por una ancha hendedura incisiva. Cada intermaxilar tiene una gran perforación incisiva de contorno elíptico y de un centímetro de diámetro menor o transverso.

Procedencia:-Recogi la primera pieza de este animal en un depósito de tosquilla rodada de la formación pampeana en la Villa de Luján, lo cual me induce a creer que no se encontraba en su verdadero yacimiento; la pieza precedentemente descripta procede de los alrededores del Paraná.

Horizonte:-Piso mesopotámico de la formación patagónica. 


\section{Scelidotheridæ}

Los animales de este grupo se distinguen por muelas elípticas con una marcada tendencia a la forma prismáticotriangular, todas de corona plana y sin que en ningún género tome la anterior la forma de canino o de incisivo. Todas las muelas son de forma bastante parecida e implantadas más o menos oblicuamente, menos la última de la mandíbula inferior que es más grande y bilobada en forma de 8 prolongado y con su diámetro dirigido de adelante hacia atrás. La parte del cráneo que se extiende adelante de las muelas es muy prolongada y la sínfisis de la mandíbula muy estrecha y muy larga. La abertura posterior externa de canal alveolar se abre sobre el lado externo de la rama ascendente.

Los géneros de esta familia mencionados hasta ahora se distinguen por los siguientes caracteres:

I. Primera muela inferior prismáticotriangular.

A. Húmero con perforación epitrocleana.

a. Intermaxilar muy largo.

aa. Primera muela superior prismáticotriangular: Scelidotherium.

b. Intermaxilar muy corto, casi rudimentario.

aa. Primera muela superior de contorno ovóideoalargado:

Scelidodon.

bb. Primera muela superior elipticocomprimida: Stenodontherium.

B. Húmero sin perforación epitrocleana.

a. Cinco dedos adelante y tres atrás. Platyonyx.

II. Primera muela inferior de contorno elíptico o subcircular.

a. Intermaxilar corto y de punta libre. Nephotherium.

b. Intermaxilar corto y con la punta reunida por un arco óseo a la punta de los nasales. Glossotherium.

\section{SCELIDOTHERIUM OWE}

OwEn: Zoology of the eBeagle», tomo I, página 73, laminas XX-XXII.

El género Scclidotherium fué fundado por Owen sobre algunos restos de un esqueleto recogido por Darwin en Punta Alta, cerca de Bahía Blanca, describiéndolo por primera vez en la parte zoológica del viaje del «Beagle». 
El cráneo del Scelidotherium tiene una conformación particular que io distingue inmediatamente del de todos los demás gravígrados; es muy pequeño en proporción del tamaño del cuerpo, de forma general cilínćricoaplastada, muy angosto y excesivamente largo, tanto que su diámetro longitudinal es tres veces mayor que el diámetro transversal. Hacia la mitad de su largo, haciendo abstracción del arco cigomático, el cráneo del Scelidotherium se angosta de una manera notable, dividiéndose en dos partes: una posterior, sumamente baja; y la otra anterior, que comprende la región dentaria, notablemente más elevada.

El llano occipital es más pequeño que en los demás gravígrados, de gran diámetro transverso, pero muy bajo, casi vertical y limitado por una fuerte cresta occipital. La parte posterior, que es la más maciza, presenta a los lados, entre las apófisis cigomáticas de los temporales, grandes fosas temporales, limitadas hacia arriba por crestas temporales muy desat rolladas, pero que en vez de unirse para formar una cresta sagital como en Lestodon o Megalonyx, permanecen separadas, limitando un espacio o plano sagital estrecho y largo, que se extiende desde el borde del occipital hasta la región media de la frente. La parte posterior se ensancha un poco hasta unirse con el occipital, donde en la juventud tiene un interparietal bien visible. El llano sagital se ensancha hacia adelante también gradualmente hasta ocupar todo el ancho del cráneo encima de las órbitas. Los frontales son muy largos y angostos, ensanchándose gradualmente de atrás hacia adelante.

Los huesos nasales son igualmente muy largos y angostos; la parte posterior penetra entre ambos frontales por un largo trecho y la parte anterior se ensancha en forma de clava, sobresaliendo bastante adelante de los bordes laterales de los maxilares, terminando en punta anterior redondeada.

El arco cigomático difiere del Mylodon por estar interrumpido, sin que la apófisis posterior del cigomático se ponga en contacto con la apófisis cigomática del temporal.

El hueso lacrimal es de tamaño mayor que en los demás gravígrados, con sus suturas visibles durante toda la vida y situado mucho más arriba que en los demás géneros, encontrándose en su mayor parte fuera de las órbitas.

Los maxilares son elevados y largos, pero en la delimitación de la abertura nasal anterior toman una parte menor que en la mayor parte de los demás géneros.

El paladar es una de las regiones más particulares del cráneo del Scelidotherium. Toda la parte del paladar limitada por las muelas y los palatinos es sumamente angosta y de ancho casi uniforme, presentando en vez de una superficie cóncava o más o menos plana, como en la generalidad de los mamíferos, una superficie fuertemente convexa acribi- 
lliada de surcos y perforaciones vasculares, que desciende gradualmente hasta los bordes alveolares. La parte anterior del paladar está completamente desprovista de dientes, presentando una longitud tan sólo en la parte formada por los maxilares, mayor que la extensión ocupada por las muelas. Adelante de esta región sin muelas, del paladar, formada por los maxilares, se articulan los intermaxilares, que están bien des. arrollados, pero que siguiendo la conformación general del cráneo, son muy estrechos y de un largo proporcionalmente extraordinario, pero no están unidos por suturas como en la generalidad de los mamíferos sino simplemente yuxtapuestos, quedando entre ambos una cavidad que representa las perforaciones incisivas y terminando adelante en borde espeso y redondeado. La extremidad anterior de los intermaxilares se extiende mucho más adelante que la abertura nasal, dejando también muy atrás la punta anterior de los nasales.

De acuerdo con esta conformación de la parte anterior del cráneo, l.t mandíbula inferior es delgada y prolongada, terminando hacia adelante en una sínfisis angosta, delgada y muy larga.

Las muelas del Scelidotherium son de un tipo especial; sin presentar entre si el gran parecido que distingue a las del género Megatherium, se parecen mucho más unas a otras que en los géneros Mylodon y Pseudolcstodon. Hay cinco muelas en cada lado de la mandíbula superior y cuatro en cada lado de la inferior. Todos estos dientes están colocados en el fondo de la boca, a continuación y a igual distancia unos de otros, formando dos series casi paralelas, que observando con atención se nota convergen un poco hacia adelante. Todas estas muelas son del mismo alio, truncadas transversalmente $y$ un poco gastadas en el centro, donde presentan una pequeña cavidad. Las cuatro primeras muelas superiores sun casi de la misma forma y tamaño, elipticotriangulares e implantadas oblicuamente, pero la última superior es más triangular, más pequeña y no implantada en dirección tan oblicua. De las cuatro muelas irferiores, las tres anteriores son elipticoprismáticas, casi iguales entre si y colocadas oblicuamente; pero la última inferior es mucho más grande, bilobada por dos surcos opuestos, presentando la forma de un 8 y colocada longitudinalmente.

El cuello consta de siete vértebras, como en la generalidad de los mamíferos, y de una conformación muy parecida a las del Megatherium. Las vértebras dorsales son igualmente muy parecidas a las del Megatherium, pero en vez de ser en número de 16 como en este género y en (-1) Mylodon, el Scelidotherium tiene 18 vértebras dorsales. Las vértebras lumbares son 3 , el sacro se compone de 6 vértebras soldadas y la cola de 18 a 20 o 22 vértebras. El esternón se compone de 7 piezas.

El húmero es parecido al del Mylodon, pero presenta sobre el cóndilo interno una gran perforación que falta en aquel género. El cúbito y 
radio, 10 mismo que el omoplato, son igualmente parecidos a los del Mylodon.

El pie anterior termina en cuatro dedos bien desarrollados, permaneciendo el pulgar o interno rudimentario, representado sólo por el metacarpo que está soldado al trapecio y probablemente por una pequeña falange rudimentaria. El dedo segundo y tercero son completos, terminando en grandes falanges ungueales, muy largas, anchas y deprimidas. Los dedos tercero y cuarto son imperfectos, sin falanges ungueales, terminando cada dedo en un pequeño huesecillo de cara anterior rugosa y redondeada.

La cadera es proporcionalmente tan fuerte como en el Megatherium. E1 fémur es un hueso muy robusto, no muy grueso, pero corto y casi del mismo ancho en todo su largo, afectando una forma rectangular. La tibia y el peroné son parecidos a los mismos huesos del Mylodon. E1 tarso está formado de seis huesos faltando un cuneiforme. El calcáneo difiere completamente por la forma del de los géneros Megathcrium, Lestodon y Mylodon, acercándose, por el contrario, a la forma que es propia del calcáneo de Megalonyx y Cœlodon, particularmente por el fuerte estrechamiento de la parte tuberosa que se extiende hacia atrás y por su forma general comprimida y elevada. La parte anterior presenta tres facetas articulares como el del Megathcrium y el del Lestodon, en vez de dos como el del Mylodon. El pie termina por tres dedos bien desarrollados, uno solo de los cuales es armado de uña. Estos dedos corresponden al tercero, cuarto y quinto. Del dedo primero no queda el más Fequeño vestigio, faltando por completo hasta el mismo metatarsiano correspondiente. El dedo segundo está representado por un metatarsiano rudimentario de extremidad anterior delgada y redondeada. E1 dedo tercero, que es el único armado de uña, no tiene más que una gran falange que sigue al metatarsiano, que corresponde a las dos primeras falanges de los demás mamíferos, ahí soldadas en un solo hueso, como en el Megatherium; a esta falange sigue la falange ungueal, que es de un desarrollo extraordinario. Los dedos cuarto y quinto están formados cada uno por un metatarsiano, al que siguen dos falanges, la última rudimentaria y de extremidad anterior irregularmente redondeada.

E1 Scclidotherium carccía de los pequeños huesecillos que cubrían el cuerpo del Mylodon, el Pseudolestodon y el Coelodon.

Las diferentes especies del género Scelidotherium son difíciles de distinguir; y generalmente han sido confundidas unas con otras. Bajo el nombre de Scelidotherium leptocephalum se han confundido por lo menos tres especies diferentes. Para la distinción del Scelidotherium leptocephalum y de las especies que más se le parecen, sigo a Lydekker, que habiendo tenido ocasión de examinar los originales típicos que sirvieron para fundar el Scelidotherium leptocephalum, constituye auto- 
ridad, concordando, por otra parte, su manera de ver con los materiales que personalmente he tenido ocasión de examinar.

\author{
SCELLDOTHERIUM LEPTOCEPHALUMA OWen

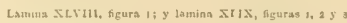

Scelidotherium leptocephalum. OwEx: Voyage of the \&Beagle», Zool., tomo I, página 73 . - Idem: «Ann. and. Magaz. nat. History», tomo II, página 249, I857. - Idem: «Philosoph. Transact. of the year», 1857 , página Ior, lámina VIII. - Idem: Odontography, página 337. Atlas, lámina INXX, figuras i a $4,1840-1845$.

Picter: Traité de Paléontologie, tomo I, página $27 \mathrm{r}$.

P. Gervars: Recherches sur les mammifères fossiles de l"Amórique Méridionale, Dág. 48 , lámina XT, figura $\mathrm{I}$.

GIEBEL: Fauna der Forsu., tomo I, página rzo.

Burmeister: ๔.Anales del Museo Público de Buenos Aires》, tomo I, página 79. - Idem; Description physique, etc., página 377.

H. Gervais y AMEghino: Los mamiferos fósiles, etc, página I44, I880.

LYDEkkra: Proceed. Zool. Soc., 1886 , página 493, lámina XLVI. - Idem: Catal. of Foss. Mamm., etc., parte $\mathrm{T}$, página 92,1887 .

Lydekker resume los caracteres distintivos de esta especie en los siguientes términos: «El perfil facial es fuertemente arqueado y presenta una protuberancia frontal muy pronunciada detrás de las órbitas; el cráneo es de un ancho moderado y los nasales son de largo relativamente considerable; siendo éstos, cuando enteros, iguales por lo menos a una mitad del largo total de la superficie superior del cráneo. En correlación con el largo considerable de los nasales, la porción facial de los maxilares es alargada y una parte considerable de ellos aparece visible en la vista superior del cráneo. El lacrimal no es muy prominente; y la abertura de su canal se dirige directamente hacia afuera. El borde anterior de la parte cigomática descendente del maxilar es inclinado hacia atrás: las crestas frontoparietales están muy separadas y la región interdentaria del paladar no es demasiado angosta.

«La mandibula que acompaña a este cráneo tiene una sinfisis alargada, siendo la porción que sigue adelante de las muelas casi el doble más iarma que la longitud total de la serie dentaria y el borde superior de la parte anterior de la rama horizontal casi derecho.

«Las principales medidas de este cráneo son las siguientes:

DLMENSIONES

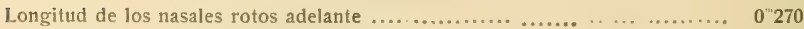

Longitud de la parte facial de los maxilares .......................... 0 170

Ancho de ámbos cóndilos occipitales .............................. 0108

Distancia desde el cóndilo hasta la îltima muela ...................... 0242

Longitud de la serie dentaria ..................................... 0113

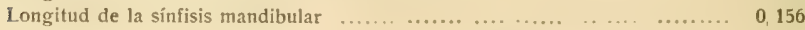

«La sola otra parte del esqueleto sobre la cual deseo llamar la atención. es el astrágalo que muestra la cresta troclear externa para la ar- 
ticulación con la tibia no prominente, proyectándose apenas encima del nivel de la tuberosidad interna. Esta forma de astrágalo es muy diferente de la del Megatherium (en el cual la cresta troclear externa es extremadamente prominente) y aparentemente indica que la reversión del pie no ha sido tan grande como en aquel género».

Según Lydekker, el tipo de esta especie, además del cráneo algo incompleto, del Museo Británico, está bien representado por el cráneo con mandíbula inferior publicado por Gervais en sus «Recherches», etc., como procedente de Buenos Aires, cuyo dibujo reproduzco en la lámina XLVIIl, figura 1, haciendo observar que la región facial no parece presentar la protuberancia frontal postorbitaria tan desarrollada como parece indicarlo la descripción transcripta del mencionado autor, cuyo grabado (lámina XLIX, figura 3) de la vista frontonasal del cráneo por él descripto reproduzco asimismo.

Agregaré que según los dibujos de las muelas del ejemplar figurado for Gervais y los publicados por Owen del ejemplar típico de la especie, la primera muela de la mandibula superior parece presentar una fcrma decididamente más triangular que en las otras especies.

Procedencia: - Los primeros restos de esta especie fueron descubiertos por Darwin en Punta Alta cerca de Bahía Blanca; pero sus restos existen en toda la llanura argentina.

Horizonte:- Pisos bonaerense y lujanense de la formación pampeana.

SCeLidotherium Iiravardi Lydekkst

Lamma XLVilt, hiegrass,$y$ t

Scclidotherium Bravardi. LYDEKKER: Proceed. Zool., Soc., 1886, pág. 494.-Idem: Catal. of Foss. Mamm., parte V, página 96, IS87.

Scelidotherium leptocephalum. OWEN (parte): «Philosoph. Trans.\$, $1 \$_{57}$, lámina VIII, figura 2 y lámina $I X$, figura $I$.

BurMeIster: Monats d. $k$. preuss. Ak. d. Wiss., I881, página $380 .-1$ dem: Ostcologia de los Gravigrados, Atlas, lámina XIV, figuras I a 4 , 1886.

Lydekker se expresa sobre esta especie en los siguientes términos: «Esta especie está fundada sobre un esqueleto imperfecto conservado en el Museo Británico, mandado por Bravard de la República Argentina, cue presenta una conformación que demuestra claramente no puede pertenecer a la especie típica a que hasta ahora ha sido referido. El cráneo, en el cual falta toda la dentición y la mayor parte de los nasales, ha sido figurado por Owen en «Phylos. Transact.» del año 1857, visto por su superficie palatina y referido a la especie típica.

«Es verdaderamente una desgracia que falten los nasales; pero por la conformación de los huesos adyacentes puede demostrarse que ellos eran seguramente mucho más cortos que en Scelidotherium leptocepha- 
lum, puesto que, en primer lugar, el borde superior de la región facial de los maxilares forma una curva mucho más corta que en éste, mientras que si los nasales hubieran tenido el mismo largo que en esta última especie tendrían que extenderse mucho más adelante que los premaxilares. Que los nasales fueron de un tipo más corto es también evidente por una comparación con el Scelidotherium chiliense, por la que puede verse que la región facial del maxilar no es desemejante en ambas especies. Todo el cráneo es, por otra parte, relativamente más angosto que el del Scelidotherium leptocephalum; y el perfil frontal es casi recto; escasamente una mitad de la parte facial de los maxilares aparece visible en la vista frontal; el lacrimal es caracterizado por ser excesivamente prominente y por la abertura de su canal dirigida en parte hacia arriba. El borde anterior de la parte cigomática descendente del maxilar es casi vertical, las crestas frontoparietales son muy aproximadas y la región interdentaria del paladar (como lo muestra muy bien la figura de Owen) es excesivamente angosta. Puede igualmente verse por la siguiente lista de dimensiones que, mientras el ancho de los cóndilos occipitales es menor que en el Scelidotherium leptocephalum, el intervalo entre los cóndilos y la última muela es considerablemente mayor, 10 que indica grandes diferencias en las proporciones relativas de amcos cráneos. Los premaxilares son bien desarrollados.

«En la mandíbula que acompaña a este cráneo, mientras el largo de la sinfisis es mayor que en el Scelidotherium leptocephalum, el intervalo entre el borde posterior de la sinfisis y el primer diente es considerablemente menor. El borde superior de la parte anterior de la mandíbula que se extiende adelante de los dientes es, además, fuertemente inclinado hacia arriba.»

\section{DIMIENSIONES}

Largo aproximado de la parte facial del maxilar ...................... 0 . 135

Ancho de ámbos cóndilos occipitales ............................... 0095

Distancia desde los cóndilos hasta la última muela ..................... 0258

Longitud de la serie dentaria superior $\ldots \ldots \ldots \ldots \ldots \ldots \ldots \ldots \ldots \ldots \ldots \ldots \ldots \ldots \ldots$

Longitud de la sinfisis mandibular $\ldots \ldots \ldots \ldots \ldots \ldots \ldots \ldots \ldots \ldots \ldots \ldots \ldots \ldots$

Esta especie, a pesar de los detalles dados por Lydekker, que dej) transcriptos, parece muy difícil de distinguir, y, o existen varias especies parecidas, o las dos especies mencionadas son muy variables, pues el conjunto de caracteres mencionados no los he encontrado en ningún cráneo de los que se aproximan al que ha servido de tipo para la fundación de esta especie y que sin duda se separan del Scelidotherium lepto. cephalum. Lydekker atribuye a esta especie el esqueleto y el cráneo completo dibujado por Burmeister en el Atlas de la «Descripción Fí- 
sica» (lámina XIV, figuras 1 a 4), de cuyo cráneo reproduzco las vistas frontonasal y palatina (lámina XLVIII, figura 5), que muestra realmente el angostamiento excesivo del cráneo y de la región interdentaria del paladar, así como también el acortamiento de los nasales, pero la vista de perfil no presenta la línea superior casi recta que menciona Lydekker sino que muestra detrás de la órbita una protuberancia frontal acentuada, ni tampoco el borde anterior del cigomático es casi vertical, sino fuertemente inclinado hacia atrás.

En la lámina XLVIII doy el dibujo de lado exacto de otro cráneo con la mandíbula inferior, que concuerda muy bien con el ejemplar figurado por Burmeister, pero presenta los nasales cortos, la región interdentaria estrecha, el conjunto del cráneo muy angosto y la parte anterior de la mandibula inferior fuertemente inclinada hacia arriba, que son carac. teres que según Lydekker distinguen al Scelidotherium Bravardi.

Entre todos estos cráneos y los atribuidos al Scelidotherium lepto. cephalum, encuentro la verdadera constante diferencia en la conformación del aparato dentario, y particularmente en la forma de la primera muela superior, que es de contorno triangular en la especie típica y simplemente elíptica en todos los otros que se aproximan al descripto por Lydekker como Scelidotherium Bravardi.

Este género necesita sin duda una nueva revisión con materiales más completos y mejor seleccionados que los que por ahora se poseen, pues es casi seguro que la mayor parte de los esqueletos de Scelidotherium que se conservan en los Museos están formados por restos de diversos individuos provenientes de especies diferentes.

Procedencia: - Los restos de Scelidotherium que se aproximan más o menos al tipo descripto como Scelidotherium Bravardi se encuentran con frecuencia en las toscas del fondo del río de la Plata, en el municipio de Buenos Aires, en las excavaciones del puerto de La Plata y en la base de las barrancas del rio Paraná en la provincia Buenos Aires.

Horizonte: - Piso ensenadense y piso belgranense de la formación pampeana.

Scelidothertum, Frowert Ameghino

AMertixo: La antigïedad del hombre, etc., tomo II, página 307, I88r.

He fundado esta especie sobre una rama horizontal de la mandíbula inferior y un maxilar superior, ambas piezas con casi toda la dentadura, provenientes de un individuo adulto, pero a pesar de eso, tan pequeñas, que indican que el animal alcanzaba apenas un tercio de la talla del Scelidotherium leptocephalım, más pequeño todavia, y de mucho, que el Scelidodon patrius. Las muelas son prismáticotriangulares, con una mar- 
cada tendencia a la forma oblonga rectangular, todas con un surco perpendicular sobre el lado externo, menos la última de cada mandíbula. La rama horizontal de la mandíbula es corta, alta y muy gruesa. Las piezas originales en que fué fundada esta especie se encuentran en el Museo de La Plata, por cuyo motivo no puedo dar más datos sobre ellas. Agregaré sólo que es la especie más pequeña del género Scelidotherium, hasta ahora conocida.

Procedencia:- He recogido los restos de esta especie cerca de la Villa de Luján.

Horizonte: - Piso belgranense de la formación pampeana (plioceno medio).

? ScElidotheriuar ReiluzuM Ameghino

Lamme XL figura is

ANEGrino: «Boletin de ta Academia Nacional de Ciencias», tomo IX, página $18 \mathrm{I}, \mathrm{I} 8 \mathrm{S6}$.

Fundé la especie en una muela superior que parece corresponder a la última superior del Scelidotherium, pero con bastantes diferencias para que no haya seguridad completa de que provenga del mismo género. Es de figura general prismáticotriangular, de ángulos redondeados y un poco arqueada. Sobre el lado más ancho, que parece ser el externo, hay un surco longitudinal ancho pero poco profundo y de fondo cóncavo. Ctro surco, también de fondo cóncavo, pero más angosto y más profundo, se ve sobre la cara interna posterior, mientras que la interna anterior es de superficie convexa, con algunos surcos longitudinales muy pequeños. La corona es un poco más gastada en el centro que en la periferia y tiene 18 milimetros de largo por 11 de ancho. El trozo existente tiene cerca de 5 centimetros de largo, pero la rotura de la base muestra el diente completamente macizo, de modo que cuando entero era bastante más largo.

Procedencia: - Ha sido descubierta por el profesor Scalabrini en las barrancas de los alrededores de la ciudad del Paraná.

Horizonte:- Piso mesopotámico de la formación patagónica (oligoceno inferior).

? SCELidothtiRIUM ELEGANS Moreno

Moreno: Informe preliminar, etc., Julio de $18 S S$ (nomen nudun).

? SCELIDOTHERTUM PozzII Moreno

Trabajo ? citado (nomen nadum). 
Además de las especies del género Scclidotherium mencionadas, hay varias otras poco conocidas y hasta ahora confundidas en una sola, y algunas de ellas hasta con el mismo Scelidotherium leptocephalum, pero que no obstante se distinguen por un conjunto de caracteres que demuestran que forman un grupo especial que debe distinguirse con un nombre genérico propio, para el que adopto el de Scelidodon, que empleé hace 8 años para distinguir una especie de este grupo.

Los primeros restos de un animal de este género fueron encontrados en Tarija por Weddell, y descriptos y figurados por Gervais en 1855, aunque incluyéndolos en el género Scelidotherium y sin separarlos como especie distinta del Scelidotherium leptocephalum.

En el Catálogo de los mamíferos fósiles sudamericanos que en 1889 publiqué en colaboración con el doctor $\mathrm{H}$. Gervais, reconocimos en el cráneo del Scelidotherium de Tarija llevado por Weddell y dibujado por P. Gervais, una especie distinta que designamos con el nombre de Scelidotherium tarijense, caracterizada sobre todo por un tamaño mayor, una parte anterior más corta y una mandíbula inferior de rama horizontal más alta y con la sínfisis levantada hacia arriba.

Además, pudinıos examinar una mandíbula inferior procedente de Buenos Aires, que presentaba caracteres algo parecidos, pero de tan:año un poco menor y con la parte sinfisaria al parecer menos elevada hacia arriba que en la especie de Tarija, por lo cual fundamos con ella una nueva especie que designamos con el nombre de Scelidotherilum Capellinii.

Según Burmeister parece que esta especie ya había sido conocida por Bravard, que la había denominado Scelidotherium magnum, cuyo nombre acepta el ilustre Director del Museo Nacional, uniendo en una sola especie a aquélla con el Scelidotherium tarijense. Pero si el nombre aplicado por Bravard se refiere a esta especie, sólo fué publicado formando parte de una lista de nombres de especies, sin el más insignificante carácter diagnóstico que permitiera reconocerlas; entran en la categoría de los nombres de nomina nuda y por las leyes de la nomenclatura no pueden preferirse a los que le son posteriores acompañados de caracteres diagnósticos, de manera que la especie en cuestión debe llevar el nombre de Scelidotherium Capellinii, con que la di a conocer conjuntamente con el doctor $\mathrm{H}$. Gervais.

Tampoco me parece posible, a lo menos hasta ahora, identificar esta especie con la de Tarija, que denominé Scelidotherium tarijense, pues for los mismos dibujos publicados for el doctor Burmeister bajo el nombre de Scelidotherium magnum, que es el Scelidotherium Capellinii, 
comparados con el dibujo del cráneo del Scelidotherium de Tarija dads por Gervais, se distingue fácilmente que éste es de tamaño un poco mayor; que el hueso cigomático es más simple, de una forma bastante diferente, y con su rama inferior más ancha; la mandibula inferior es de rama horizontal más alta, con la parte sinfisaria más elevada hacia arriba y la punta dada vuelta hacia adelante, formando su borde superior una especie de $\mathrm{S}$ prolongada.

Ambas formas se acercan, sin duda, por caracteres de mayor importancia, pero éstos tienen probablemente el valor de caracteres de un subgénero; y las diferencias mencionadas, que cuando se conozca mejor el Scelidotherium tarijense se encontrarán acompañadas de otras de no menor importancia, no permiten identificarla en una misma especie con la que designé con el nombre de Scelidotherium Capellinii.

En el yacimiento de Monte Hermoso existe una tercera forma, que si bien presenta los caracteres principales de las dos anteriores, es de tamaño todavía más reducido que el Scelidotherium leptocephalum y con caracteres secundarios tan diferentes que no se puede dudar ni un instante que constituye una especie distinta de las anteriores, al mismo tiempo que prueba que los caracteres principales comunes a los dos Scelidotherium antes mencionados no sólo son de valor específico, sino que también pueden servir para separarlos como género distinto del Scelidotherium, lo que ya hice desde 1881 con una especie muy pequeña de este mismo grupo que di a conocer bajo el nombre de Scelidodon Copei.

Los caracteres que distinguen al Scelidodon del Scelidotherium son numerosos y de importancia, manifestándose hasta en el mismo sistema dentario.

Las muelas del Scelidodon, son menos prismáticotriangulares y más elipticas que las del Scelidotherium, con el ángulo o columna perpendicular interna de las superiores y externa de las inferiores mucho menos acentuada que en este último género. La primera muela superior es más diferente todavia, pues en vez de la forma prismática que presenta en el Scclidotherium, en el Scelidodon es completamente elíptica, muy alargada de adelante hacia atrás y un poco más gruesa en la parte anterior que en la posterior.

El paladar presenta asimismo en la parte interdentaria particularidades que lo distinguen del Scelidotherium; en este género es constantemente más angosto entre las muelas anteriores que entre las posteriores, porque las series dentarias convergen hacia adelante; pero en el Scclidodon, a lo menos en la especie que me sirve de tipo, el Scelidodon patrius, las series dentarias convergen hacia atrás, como en el .11Ylodon; y supongo que debe suceder otro tanto en las demás especies del mismo grupo, o, por lo menos, que las series dentarias sean en ellas paralelas. 
Pero la parte más caracteristica del género Scelidodon es la conformación particular de la parte anterior del cráneo, que es muy diferente de la disposición que presenta en el Scelidotherium, pues la parte que se extiende adelante de las muelas es más corta y se dirige oblicuamente hacia arriba; presentando el intermaxilar completamente rudimentario y con dos alas ascendentes, una a cada lado, que faltan en el Scelidotherium. Los nasales son cortos y el lacrimal no es muy prominente. La mandíbula inferior presenta la región alveolar de la rama horizontal bastante elevada; y la parte que se extiende adelante de las muelas, de acuerdo con la conformación de la parte anterior del cráneo, es corta y fuertemente inclinada hacia arriba. El húmero presenta el mismo agujero epitrocleano que el del Scelidotherium.

\footnotetext{
SCELIDODON PATRIUS Ameghino

Lanias XLIII, Agurs olf $y$ Itmins XL2W, figuras 1,2 y a
}

Scelidotherium patrikm. AMEGHINo: Rápidas diagnosis de maniferos fósiles nuevos, etc., página 15 , número 23, Febrero de 1888, - Idem: Lista de los mamiferos fósiles de Monte Hermoso, página 17 , número 45 , Julio de 1888.

Scelidotherium australis. Moreno: Informe preliminar, etc., página II, Julio de I8s8 (nomen nudum).

Esta especie se distingue inmediatamente por su tamaño reducido, cuyo largo no excede de 32 a 33 centímetros, mientras el cráneo del Scelidotherium leptocephalum tiene de 52 a 55 centímetros de largo.

De los huesos nasales de esta especie no conozco más que la base que penetra en la parte anterior de ambos frontales, pero por la extensión de la parte existente de los maxilares se deduce que debían ser bastante largos y angostos y sin duda con punta libre en su parte anterior, como en las otras especies.

La parte superior del cráneo, desde la parte anterior de los frontales hasta el borde superior del occipital, se parece más al Scelidotherium leptocephalum que al Scelidodon Capellinii. Las crestas temporales son bajas y colocadas a una cierta distancia de la línea media, limitando un espacio superior largo y angosto, colocado sobre la línea media longitudinal del cráneo, pero casi completamente plano, sin surco longitudinal medio ni vestigios de los surcos laterales que muestra el Scelidodon Capellinii. Este espacio, limitado por las crestas temporales, tiene en casi toda la extensión de los parietales unos dos centímetros de diámetro transverso, pero se ensancha gradualmente hacia adelante en la región frontal hasta terminar en las apófisis postorbitarias que están separadas por un espacio algo mayor de 5 centimetros. La frente es bastante ancha y un poco convexa en su parte anterior.

La parte posterior del cráneo no es hundida en los lados, como en las otras especies, en la región de los temporales, sino más bien un poco 
hinchada, careciendo. por consiguiente, de verdaderas fosas temporales. Las crestas temporales forman hacia atrás un semicírculo que corre al lado de la cresta occipital, terminando en la base de la apófisis cigomática del temporal; y además toda la parte anterior es proporcionalmente más gruesa que en las demás especies.

El llano occipital no presenta nada de particular, a no ser su tamaño pequeño y su cresta superior, bastante fuerte, inclinada hacia atrás. En toda la extensión de su parte media existe bien marcada la cresta vertical, que va desde la parte superior del occipital hasta la parte superior del agujero occipital.

Si se mira de lado el cráneo, el llano superior forma una línea ondulada cuyas partes deprimidas corresponden: una a la parte posterior de los parietales, otra a la parte posterior de los frontales y una tercera a la parte media de los maxilares adelante de los lacrimales.

Sobre la parte inferior de la base del cráneo no se distingue ningún caracter peculiar a la especie, con excepción del plano horizontal formado por las apófisis cigomáticas del temporal, que es de un ancho considerable.

Los huesos pterigoides son muy descendentes y su borde inferior forma una curva de radio mucho menor que en las otras especies.

El hueso lacrimal es, en proporción, considerablemente más grande y particularmente más ancho sobre su costado interno, formando una prominencia apenas sensible con un agujero único y de tamaño relativamente considerable.

El hueso cigomático presenta caracteres distintivos más notables todavía. Su parte descendente inferior es mucho más ancha que en el SceItdodon Capellinii y con una prominencia posterior corta y ancha que lo distingue de esta especie, que sólo tiene una apófisis puntiaguda; y del Scelidodon tarijensis, que si bien presenta igualmente la apófisis descendente muy ancha, carece por completo de apéndice posterior, mientras en el Scelidotherium leptocephalum la misma apófisis se divide en tres puntas bien separadas.

La parte más superior del cigomático que se dirige hacia la apófisis temporal también difiere de las otras especies por su rama superior muy delgada y muy larga, que asciende hacia arriba de una manera anormal entre los desdentados conocidos y cuya punta posterior alcanza casi el nivel de la parte superior del cráneo; esta apófisis, a partir de su última bifurcación, tiene 47 milímetros de largo.

Los maxilares superiores se distinguen poco de los de las otras especies; pero la parte anterior que, delante de las muelas, forma la prolongación del paladar, difiere, sin embargo, de la parte correspondiente del Scelidodon Capellinii, por su ascensión hacia arriba, que está apenas indicada, mientras es muy pronunciada en la especie de Buenos Aires 
- Scelidodon Capellinii. Ambos maxilares se separan hacia arriba produciendo en ese punto un ensanchamiento del paladar, seguido hacia atrás de un estrechamiento considerable, inmediatamente adelante de la primera muela. La región del paladar comprendida entre ambas series dentarias, es más angosta en su parte posterior, donde sólo tiene 17 milímetros de ancho, ensanchándose un poco hacia adelante hasta alcanzar entre el primer par de muelas 50 milímetros de ancho.

El intermaxilar es sumamente corto, casi rudimentario, con sus dos mitades completamente separadas, muy angostas y casi puntiagudas adelante y más gruesas y anchas atrás, en donde se traban en una escotadura semicircular, ascendiendo un poco hacia arriba, de manera que contribuyen a forma en parte los bordes laterales de la abertura nasal. La superficie palatina del intermaxilar en vez de ascender un poco hacia arriba, como en el Scelidodon Capellinii, se dirige más bien un poco hacia abajo, como en el Scelidotherium leptocephalum.

La mandibula inferior es de rama horizontal relativamente gruesa y elevada, pero con el borde inferior poco arqueado. La parte sinfisaria es corta y delgada, levantándose un poco hacia arriba y angostándose hacia adelante, con sus ramas bien soldadas y formando en la punta anterior de la barba, en su cara anteroinferior, una cresta longitudinal media, bastante elevada, dirigida hacia adelante y hacia abajo. El ángulo de la mandíbula está fuertemente torcido hacia adentro.

Las muelas son, en su forma, algo diferentes de las del Scelidotherium leptocephalum, pero casi iguales a las del Scelidodon Capellinii, con la diferencia de que todas son un poco más pequeñas.

La primera muela superior es completamente eliptica e implantada con su eje mayor casi en la misma dirección que el eje de la serie dentaria.

Las tres muelas siguientes son elípticoprismáticas como las del Scelidotherium leptocephalum y el Scelidodon Capellinii. La última superio: es prismáticotriangular, muy pequeña, con un profundo surco perpendicular sobre el lado externo y otro menos marcado sobre el interno.

En la mandíbula inferior la primera muela es elípticoprismática; la segunda y tercera son elipticas e implantadas oblicuamente; y la cuarta, más grande, es bilobada con un surco interno angosto y profundo en su parte posterior.

\section{DIMENSIONES}

Diámetro anteroposterior de la primera muela superior ............ 0 "019

Longitud de la corona de la segunda muela ................. 0020

Longitud de la corona de la $\left\{\begin{array}{l}\text { tercera muela superior } \ldots \ldots \ldots \ldots \ldots \ldots \ldots \ldots \ldots \\ \text { cuarta muela superior }\end{array}\right.$ quinta muela superior ............................... 011 
Longitud del espacio ocupado por las cinco muelas superiores............. 07078

$\mid$ primera muela inferior........................... 0023

Longitud de la $\mid$ segunda muela inferior ............................ 0019

tercera muela inferior .............................. 0019

cuarta muela inferior .............................. 0025

Longitud de las cuatro muelas inferiores............................ 0080

Longitud del paladar, desde la parte anterior del intermaxilar hasta el agujero nașal posterior ................................................ 0164

Longitud de la parte del paladar adelante de la primera muela ........... 0075

Lon itud del intermaxilaı .................................... 0016

Longitud de la parte anterior libre del intermaxilar ..................... 0021

Longitud de la parte del críneo colocada adelante del agujero suborbitario ... 0 o 100

Longitud del maxilar en la parte superior del cráneo..................... 0093

Longitud de los frontales sobre la linea media ........................ 0092

Longitud de los parietales sobre la línea media ......................... 0082

Ancho de los intermaxilares en la punta libre anterior .................... 0014

Ancho de la parte superior del cráneo entre los lacrimales ................ 0067

Ancho de la parte superior del cráneo detrás de las órbitas ............. 0060

Ancho de la parte superior del cráneo entre los parietales ................ 0087

Diámetro transverso máximo del occipital .............................. 0096

Diámetro vertical desde la parte superior del occipital hasta el borde superior

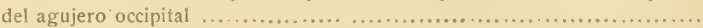

Diảmetro transverso máximo entre las puntas de las apófisis cigomáticas del

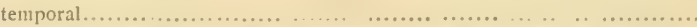

Dianctro tramberso máxino entre las extremidades inferiores del cigomático

Longitud del cráneo desde el cóndilo occipital hasta la parte anterior del intermaxilar .................................................... 0330

Longitud de la mandibula inferior ............................ 0275

Alto de la rama horizontal debajo de la primera muela... ................ 0045

Alto de la rama horizontal debajo de la cuarta muela ..................... 0063

Longitud de la parte sinfisaria delante de la primera muela ............... 0091

Longitud de la sutura mentoniana ............................... 0077

Diámetro transverso de la punta de la sínfisis...................... 0027

Procedencia: - He recogido los restos de esta especie en Monte Hermoso, a 60 kilómetros de Bahía Blanca; y en las excavaciones del puerto de La Plata.

Horizonte:- Piso hermósico de la formación araucana (mioceno superior); y piso ensenadense de la formación pampeana.

SCet,idodon tariJensis (II. Gervais y Ameghino) Ameghino

Latnina LXIrt, fieura a

Scelidotherium tarijense. II. GERVAIS y AMEGHiNo: L.os mamfferos fósiles de la América Meridional, página $148,1880$.

LYYEKKER: Catal. of Fossil Mamm., parte V, página 102, I887.

Swintherirta, procedente de Tarija. 1'. Gravars: Recherches sur les mammiferes fosshes de P'Amérique Méridionale, página 50, lámina XI, figura 2, 1855 .

Scclidotherium magnum (Bravard). BuRMEISTER: Atlas de la \&Description physique, etc.», página 103, $1 \$ 86$.

Fundé esta especie, en colaboración con H. Gervais, sobre el dibujo de una cabeza casi completa, publicado por P. Gervais en su primera 
Memoria sobre los mamíferos fósiles de la América Meridional, como procedente de Tarija, conjuntamente con otra de Scelidotherium leptocephalum procedente de Buenos Aires. P. Gervais puso de relieve las diferencias que entre sí presentaban ambos cráneos, pero sin separarlos específicamente, dejando hasta cierto punto entrever que quizá podrian ser en parte producidas por la edad. Los materiales de que pude disfoner más tarde, demostraron, no obstante, que se trataba de dos especies diferentes, a las cuales el aumento de mis conocimientos debía conducirme después a colocarlas en dos géneros distintos.

El Scelidodon tarijensis era un animal bastante corpulento, por 10 menos tres veces mayor que el Scelidodon patrius, con el cual también presenta algunas diferencias de conformación bastante notables.

El cráneo del Scelidodon tarijensis es muy ligeramente abovedado en sti región frontal y de superície deprimida, formando una ligera concavidad en la región parietal. El llano sagital es muy elevado, limitando a uno y otro lado fosas temporales bastante profundas; y la cresta occipital es gruesa y elevada.

En el ejemplar de referencia está destruida la parte anterior del críneo, pero se conoce que no debia ser tan larga como en el Scelidutherium leptocephalum, pues delante de las muelas la misma región de los maxilares es de largo absoluto menor y un poco inclinada hacia arriba. El intermaxilar está destruido, pero por la parte anterior de la mandíbula inferior se puede deducir que era más corto que en el Scelidotherium, aunque quizá no tanto como en el Scelidodon patrius, pero seguramente se dirigía oblicuamente hacia arriba de una manera mucho más pronunciada, lo que se demuestra por la forma de la parte anterior de la sínfisis de la mandíbula. Los huesos nasales parecen haber sido bastante largos y el lacrimal prominente.

Una parte característica que distingue "muy bien al Scelidodon tarijensis de las otras especies del mismo género, es el arco cigomático, cuya apófisis descendente es mucho más ancha que en los demás animales parecidos y sin bifurcaciones o ramificaciones en su parte posterior.

La mandíbula inferior también presenta algunos caracteres particulares, siendo en toda su conformación mucho más fuerte que la del Scelidotherium, pero de sínfisis delgada y dirigida hacia arriba. La región alveolar de la rama horizontal es muy elevada y de borde inferior más convexo, sobre todo en su parte anterior debajo de las tres primeras muelas. El borde superior o alveolar es horizontal en la región dentaria, pero delante de la primera muela desciende inmediatamente hacia abajo formando como una pequeña escotadura y de alli se levanta cblicuamente hacia arriba de una manera muy pronunciada, hasta que a! llegar a la parte anterior vuelve a dirigirse horizontalmente hacia 
adelante, constituyendo una especie de pico que describe una $\mathrm{S}$ prolongada. La mitad anterior de la parte sinfisaria es muy delgada, o deprimida de arriba hacia abajo, presentando un solo agujero mentoniano a cada lado, de tamaño mediano y cerca de la extremidad anterior.

No puede determinarse con seguridad el largo del cráneo por estar destruido en su parte anterior, pero puede evaluarse de una manera muy aproximada entre 58 y 60 centímetros.

Según Gervais, el plano occipital tiene 170 milímetros de diámetro transverso. La mandibula inferior tiene 45 centímetros de largo.

Según el dibujo, reducido en un tercio, la rama horizontal en la región aentaria tendría de 109 a 110 milimetros de alto; y la parte sinfisaria sin dientes que se extiende delante de la primera muela tiene 157 milimetros de largo.

Procedencia:- Los restos de esta especie se encuentran con frecuencia en el yacimiento fosilifero de Tarija; y Lydekker atribuye a la misma especie algunos restos procedentes de las cavernas de Brasil y otros de la provincia Buenos Aires; sin embargo no seria imposible que estos útlimos provinieran del Scelidodon Capellinii; cuya especie es comparable por su talla al Scelidodon tarijensis.

Horizonte: - En Tarija, los restos de esta especie se encuentran en la base de la formación fosilifera de esa localidad, que parece corresponder al piso ensenadense o pampeano inferior de Buenos Aires.

\footnotetext{
Scelidodon Capellinix (1f. Getvais y Ameghino) Ameghino

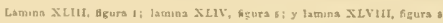

Seclidotherium Cafcllinii. II. Gervais y Ameghivo: Los mamiferos fósiles, ele., pág. 748 , afio 1880 .

Scolidotherium tarijense : CAPELLint: en Congrès Géologique International, deuxième session, Bologne, figura $x$, página 205, 1882 .

Scelidotherium magnum? Bravard: Registro estadistico de Buenos Aires, 1857 , tomo I, parte II (nomen nudum).

Burmerster: Atlas de la abescription physique de la République Argentine», página ro3. lámina XV, 1886.
}

Fundé esta especie en colaboración con $\mathrm{H}$. Gervais sobre una mitad de mandibula inferior con las cuatro muelas, pero con la sinfisis algo destruída, que indica un animal de talla algo más considerable que el Scclidotherium leptocephalum, y de muelas un poco diferentes; esta pieza procedia de Buenos Aires, donde fué recogida por F. Seguin y forma parte de las colecciones del Museo de París.

Nuevos restos han venido a demostrar que el animal tuvo grandes afinidades con la especie de Tarija y que, por consiguiente, debe entrar en el género Scelidodon. 
Burmeister identifica la especie de Tarija con la de Buenos Aires, reuniéndolas bajo el nombre de Scclidotherium magnum de Bravard, que es simplemente un nomen nudum que no puede ser rehabilitado porque hay nombres posteriores acompañados de diagnosis o que acompañan a las piezas depositadas en colecciones públicas.

Por otra parte, la especie de Buenos Aires no me parece idéntica a la de Tarija, sino bastante diferente, pues los caracteres que presentan en común son los que distinguen al género Scelidodon y de consiguiente son comunes a todas las especies del grupo.

El Scelidodon Capellinii es de talla un poco mayor que el Scelidotherium leptocephalum y sobre todo considerablemente más robusto, pero de tamaño algo menor que el Scelidodon tarijensis, pues ya se ha visto que el cráneo de éste debía tener aproximadamente 60 centimetros de largo y el de Scelidodon Capellinii sólo tiene 55, que es el tamaño que también alcanzan algunos cráneos del Scelidotherium leptocephalum, aunque son siempre considerablemente más delgados.

El plano occipital es menos inclinado hacia adelante que en el Scelidodon tarijcnsis y la región anterior de los parietales menos deprimida.

El llano occipital es de una conformación particular, más angosto que en el Scelidotherium y con tres surcos longitudinales bien acentuados, tno sobre la línea media o sagital y los dos otros laterales, uno a cada lado.

Los nasales son relativamente cortos pero con una punta libre prolongada hacia adelante.

El intermaxilar es corto y rudimentario como en Scelidodon patrius, pero con sus alas laterales posteriores no tan desarrolladas, de manera que casi no toman parte en la formación de las paredes laterales de la abertura nasal posterior. La región del paladar, que, en el Scelidodon Capellinii se extiende delante de las muelas, es mucho más inclinada hacia arriba que en el Scelidodon tarijensis y en toda su extensión, lo que constituye una diferencia notable con esta última especie. En efecto: en ésta la región del paladar que se extiende adelante de las muelas y' que forma parte de los maxilares, es horizontal, y la inclinación hacia arriba sólo se pronuncia en el intermaxilar, mientras que, como acabo de decirlo, en el Scelidodon Capellinii, se extiende a toda la región del paladar colocada delante de la primera muela. La parte anterior del intermaxilar, al contrario de lo que sucede en el Scelidotherium, no se prolonga más adelante de la punta de los nasales, o sólo se prolonga en una proporción apenas perceptible.

El arco cigomático del Scelidodon Capellinii, según el dibujo de Burrreister, es también de una forma muy distinta de la que presenta en el Scelidodon tarijensis. La apófisis descendente del arco cigomático es muy ancha en esta especie, y desciende hacia abajo con una muy pe- 
queña inclinación hacia atrás, terminando en un borde ancho y redonceado, sin que presente en toda su extensión ningún otro prolongamiento o ramificación. La apófisis descendente del arco cigomático es más angosta en el Scelidodon Capellinii, más fuertemente inclinada hacia atrás, con su extremidad inferior angosta y terminando en punt? dirigida hacia atrás y además con una segunda ramificación muy corta y puntiaguda en la misma dirección, en su borde posterior, que es fuertemente cóncavo y no convexo como en el Scelidodon tarijensis.

La mandíbula inferior es proporcionalmente más delgada que la del Scelidodon tarijensis, sobre todo por ser menos elevada en la parte posterior de la rama horizontal, aunque el borde inferior de la región dentaria es igualmente descendente y convexo. La parte sinfisaria se dirige oblicuamente hacia arriba, hasta en su misma extremidad, sin que la punta cambie su dirección oblicua en horizontal, como en el Scelidodon tarijensis, lo que da a esta región una forma bastante distinta. Además, ia parte anterior de la sínfisis presenta en Scelidodon tarijensis un solo agujero mentoniano a cada lado, mientras que en la del Scelidodon Cafrellinii hay dos, uno pequeño colocado más adelante y más cerca del rorde superior y el otro algo más grande, un poco más abajo y más atrás, lo que constituye una conformación más parecida a la del Scelidodon patrius, con el cual presenta grandes analogías el Scelidodon Capcllinii, aunque entre uno y otro media una gran diferencia de tamaño.

[DIMENSIONES

Longitud del cráneo ........................................... 01550

Longitud de los.huesos nasales ...................................... 0240

Longitud del intermaxilar .......................................... 0060

Longitud del espacio ocupado por las cuatro muelas superiores ............ 0125

Longitud del espacio ocupado por las cuatro muelas inferiores............. 0120

Procedencia:-Municipio de Buenos Aires, Ensenada, San Nicolás, etcétera, en la provincia Buenos Aires.

Harizonte:- Piso ensenadense de la formación pampeana.

Scezrdodon Coper Aneghino

Lamuna XLIt. figura o

AMEgItino: La antigüedad del hombre en el Plata, tomo II, página 307, $188 \mathrm{r}$.

Esta es la especie que me sirvió de tipo para fundar el género; y se distingue de todas las demás por su tamaño reducido, que es un tercio menor que el del Scelidodon patrius. Hasta ahora sólo me es conocida 
por un fragmento de maxilar superior izquierdo, al que se encuentra pegado el lacrimal del mismo lado y muestra además la apófisis cigomática del maxilar con el agujero interorbitario, la primera muela rota en el fondo del alvéolo, la segunda muela casi entera, la tercera bastante destruída y los alvéolos de las dos últimas.

El lacrimal es muy prominente, de gran tamaño y con una perforación elíptica enorme, alargada de arriba hacia abajo, de 13 milímetros de diámetro vertical y 5 milímetros de ancho.

En proporción del tamaño del animal el agujero suborbitario es de dimensiones considerables, pues tiene 17 milimetros de diámetro vertical y 9 milimetros de ancho.

La primera muela, muy eliptica, era de la misma forma que en el Scelidodoi patrius, pero notablemente más pequeña, pues sólo debía tener unos 16 milímetros de diámetro mayor por 7 milímetros de diámetyo transverso. La segunda muela tiene 14 milimetros de diámetro mayor; y las cinco muelas juntas ocupaban un espacio longitudinal de un poco menos de 6 centímetros. La textura del hueso, la sutura del maxilar con el lacrimal y la forma de las muelas, que presentan el mismo ancho en la base que en la corona, demuestran que se trata de un individuo adulto y que su pequeñez sólo es debida a la diferencia específica.

Procedencia: - He recogido esta pieza en las toscas del fondo del río de la Plata, en el municipio de Buenos Aires.

\section{Harizonte:- Piso ensenadense de la formación pampeana.}

E1 Scelidotherium chiliense de Lydekker, de la provincia Tarapacá, cn Chile, entra en este género; y se distingue claramente por su talla considerablemente mayor que la de los Scelidodon patrius y Scelidodon Copei e inferior a la de los Scelidodon tarijensis y Scelidodon Capellinii.

\section{STENODONTHERIUNI Ameghino}

Stenodon. Amegrino: «Boletín de la Acatemia Nacional de Cienciass, tomo VIII, página 116,1885 .

Este género, bastante cercano del Scelidotherium, está caracterizado por la primera muela superior muy comprimida, más todavía que en el Scelidodon patrius, con un corte transversal en forma de losange cuyas dos extremidades fueran redondeadas. Las muelas inferiores son más triangulares, con una tendencia a la forma oblonga. Designé al género primeramente con el nombre de Stenodon, pero como resulta que cste nombre ya ha sido empleado, lo cambio por el de Stenodontherium. 
Sterodon modicrs. Amegrno: «Boletin de la Academia Nacional de Ciencias», tomo VIII, página $116,1885 .-1$ dem: tomo IX, página $180,1886$.

Fundé la especie en la primera muela superior de un animal parecido al Scclidotherium; esta muela es muy comprimida, con una sección trans:ersal que representaría una figura muy alargada, de igual ancho en todo su largo, pero de extremidades redondeadas. En la corona los hordes están en parte más elevados que en el centro de la superficie masticatoria. La superficie del prisma está formada por una delgada capa de cemento que cubre una segunda capa intermedia de dentina que encierra la vásculodentina que constituye casi toda la masa principal del diente. Una de las caras anchas longitudinales de la muela ¿E plana y casi aplastada; y la opuesta, ligeramente convexa. El diámetro mayor de la corona es de 21 milímetros y el diámetro menor, casi isual en todas partes, es de sólo 9 milímetros. Es difícil saber cuál de cstos dos diámetros correspondía al eje de la serie dentaria, pero me inclino a creer que debió estar implantada en la mandibula con su diámetro mayor dispuesto oblicuamente sobre el eje longitudinal de la rama horizontal de la mandíbula.

Atribuyo al mismo género dos muelas inferiores cuya posición exacta €s difícil determinar. Una de ellas, larga y estrecha, ancha en una extremidad y angosta en la otra, tiene 19 milimetros de diámetro mayor, 12 nilímetros de grueso en el lado más ancho y sólo 9 milimetros en el más angosto. De las dos caras perpendiculares anchas, una tiene una depresión perpendicular muy ancha y bastante profunda en el fondo de la cual se ve una pequeña columna longitudinal muy angosta, y poco elevada: la otra cara ancha tiene también una depresión perpendicular, Fero menos profunda y con dos pequeñas columnitas longitudinales. De las dos caras perpendiculares más angostas, opuestas, la más ancha tiene un surco longitudinal bastante ancho y de fondo cóncavo, siendo la más angosta en forma de columna redondeada. La muela ha estado cubierta por una capa de cemento de menos de un milímetro de espesor, que sólo se conserva en uno que otro punto. La corona es de superficie desigual, sin formar cavidad en ninguna parte. El diente está quebrado en la parte inferior teniendo el trozo existente 4 centímetros de largo, pero cuando entero debía tener casi el doble.

La otra muela es de forma más triangular, más angosta en una extremidad que en la otra, con una corona de 22 milímetros de largo, 15 milimetros de ancho en el lado más grueso y 10 milimetros en el lado más delgado.

Una de las caras anchas muestra dos columnas anchas y aplastadas formadas por los bordes anterior y posterior y otras dos columnas me- 
dias igualmente aplastadas separadas por tres pequeños surcos longitudinales. En la cara opuesta vense también dos columnas medias y tres columnas perpendiculares, más una gran columna perpendicular convexa hacia el lado más grueso del diente. De las dos caras opuestas más angostas, la más ancha presenta un gran surco perpendicular ancho $\mathrm{y}$ profundo.

Procedencia:- Estos restos han sido descubiertos por el profesor Scalabrini en las barrancas de los alrededores de la ciudad del Paraná.

Horizonte:-Piso mesopotámico de la formación patagónica (oligoceno inferior).

\section{PLATYONYX Lund}

LuND: K. Danske, Vid. Selsk. Skr., tomo IX, página 345, 1842.

Este género ha sido, hasta por su mismo fundador el doctor Lund, considerado como idéntico al Scelidotherium, pero debido únicamente a un conocimiento incompleto de los caracteres que distinguen al esqueleto de ambos géneros. Ahora que se conoce el esqueleto completo del Scclidotherium, se notan tan considerables diferencias con las partes descriptas por Lund como del Platyonyx, que no es permitido dudar que se trata de dos géneros distintos.

El cráneo del Platyonyx es más corto, más ancho y más grueso que el cel Scelidotherium. La mandíbula inferior es menos prolongada y más maciza. La última muela inferior bilobada muestra el lóbulo posteriorinterno en forma de columna más pronunciada, limitando una escotadura interna ancha pero más profunda que en la misma muela del Scelidotherium. El húmero carece del agujero sobre el cóndilo interno, que siempre está presente en el mismo hueso del Scelidotherium.

El pie anterior del Platyonyx tiene cinco dedos en vez de cuatro como єn el Scclidotherium; y el pie posterior tiene los tres dedos, o por lo menos dos, armados de uñas, mientras en el Scclidotherium sólo un dedo de cada pie tiene uña. El Platyonyx estaba cubierto por una infinidad de huesecillos compactos e irregulares, como sucedía en los géneros Mylodon, Pseudolestodon y Colodon, pero el Scclidotherium no presentaba nada parecido.

Platyonyx Oliverae Ameghino

Rabdiodon Oliverae. Aménino: Catálogo de la sección de la prozincia Buenos Aires, etc., año 1883 (nomen nudum).

Este animal, del cual he recogido varias piezas (entre ellas algunas muelas y un miembro anterior casi completo) es más robusto que el Scelitotherium leptocephalum y con los huesos del miembro anterior 
de tamaño algo mayor. No puedo dar más detalles sobre esta especie, que parece tuvo alguna relación con el Platyonyx Bucklandi, de Brasil, porque los únicos restos que he recogido se encuentran en el Museo de La Plata.

Pracedencia: - He recogido los restos de esta especie en las barrancas del río Luján, cerca de la estación Olivera, en la provincia Buenos Aires.

Horizonte: - Piso bonaerense de la formación pampeana.

El doctor Lund menciona como encontrados por él en las cavernas de Brasil, seis especies diferentes, denominadas por él: Platyonyx $\mathrm{Cu}$ vieri, Platyonyx Bucklandi, Platyonyx minutus, Platyonyx Blainvillei, Platyonyx Agassizi y Platyonyx Brongniarti; pero algunas de esas especies, como ocurre con el Platyonyx Cuvieri, entran seguramente en el género Scelidotherium.

\section{NËPHO'THERIUM Ameghino}

AMrgmino: «Boletin de la Academia Nacional de Ciencias», tomo IX, página 18 , I 886 .

Este género es de caracteres que son mixtos en casi todo el grupo de los Scelilotherida, pero particularmente intermedio entre el Scelidotherium y el Glossotherium. La primera muela inferior es pequeña y eliptica. Las muelas inferiores segunda $y$ tercera son grandes y subprismáticas. La cuarta inferior es grande y bilobada, como en los demás géneros del mismo grupo. La rama horizontal de la mandibula es muy angosta y prolongada hacia adelante.

Nephotherius ambtguem Ameghino

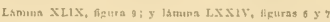

Nepliofheriun ambigunm. Axeguino: «Boletin de la Academia Nacional de Ciencias», tomo IX, página 182,1886 .

Grypotherium Darwinii ( 9 ) (Owen). Ameghino: \&Boletín de la Academia Nacional de Ciencias», tomo $\mathrm{V}$, página $300, i S 8_{3}$.

Mylodon (?) ambiguts. Aarenino: «Bol. de la Academia Nacional de Cienciass, t. VIII, página 120,1885 .

Este animal me fué primeramente conocido por una sola muela aislada, tan parecida a las del género Glossotherium que la consideré como proveniente del Glossotherium Daruini. Poco tiempo después recibí del señor Scalabrini parte de la mandibula inferior sin dientes de un animal aparentemente parecido al Mylodon, pero con algunos caracteres diferenciales que no me permitian colocarlo con seguridad en el mismo género, haciéndolo sólo provisoriamente, por lo cual describí la pieza con el nombre de Mylodon (?) ambiguus. Comparando más tarde aquella 
muela que al principio crei fuese de Glossotherium y otras parecidas con los alvéolos del fragmento de mandíbula mencionado, comprendí que provenía del mismo animal, en realidad muy parecido al Glossotherium, pero también muy parecido al Mylodon y al Scelidotherium y con un conjunto de caracteres diferenciales que no me permitieron identificarlo con ninguno de los mencionados géneros, por lo cual lo separé con el nombre de Nephotherium.

Los restos que conozco de este animal son:

Parte considerable de la mitad izquierda de la mandíbula inferior, incluyendo la mayor parte de la rama horizontal con los alvéolos de las tres primeras muelas y parte del alvéolo de la cuarta.

La rama horizontal es baja y prolongada, con alvéolos que, a excepción del primero, denotan la existencia de muelas de gran tamaño en proporción de la mandíbula, aunque no tanto como en el Interodon crassidens.

El primer alvéolo, separado del segundo por un tabique de 5 milímetros de espesor, es bastante más pequeño que los que siguen. Tiene una figura eliptica, con su mayor diámetro dispuesto en sentido anteroposterior. La parte anterior, posterior y externa del alvéolo es redondeada, pero el lado interno es más plano y con una cresta longitudinal muy grande. Tiene 21 milímetros de diámetro anteroposterior y 15 milímetros de diámetro transverso, pareciéndose mucho al mismo alvéolo del Interodon.

El segundo alvéolo es de sección prismáticotriangular, aunque tam. bién de ángulos redondeados. El lado interno es el costado más ancho; y el externo más redondeado es el más angosto. El tabique del alvéolo presenta en el costado interno una arista longitudinal más elevada que lí del alvéolo de la primera muela. Tiene 25 milímetros de diámetro anteroposterior en su costado interno más ancho y 28 milimetros en su mayor diámetro transverso, que es oblicuo a la dirección del eje de la serie dentaria.

El tercer alvéolo forma una elipse prolongada con dos diámetros muy diferentes, el mayor de los cuales corresponde a una línea oblicua a la serie dentaria. Este alvéolo muestra igualmente en su interior una cresta perpendicular, pero situada en la parte anterior sobre el tabique que la separa del segundo molar hacia el lado interno. Tiene 19 milímetros de diámetro anteroposterior y 31 milimetros de diámetro transverso.

Del alvéolo del cuarto diente sólo existe una pequeña parte del lado anterior o interno, de modo que no se puede determinar su forma, aunque es de creer que fuera como para recibir una muela bilobada.

La distancia que separa a la parte anterior del borde del alvéolo del frimer molar de la parte posterior del borde del alvéolo del tercero, es de 83 milimetros. 
El alto de la mandibula es de 46 milímetros al nivel de la primera muela, de 57 milimetros al nivel de la segunda y de 65 milímetros al nivel de la tercera.

El borde inferior de la mandibula en la parte existente es sensiblemente horizontal y se ve que, reposando sobre esta base, el borde alveolar va bajando gradualmente desde el cuarto hasta el primer alvéolo, que es el punto más bajo de la rama horizontal, para volver a subir hacia adelante; pero no se puede conocer exactamente la forma de la farte anterior porque la mandíbula está rota a unos 6 centímetros adelante del primer alvéolo, aunque parece que se prolongaba hacia adelante como en el Scelidotherium.

La mandíbula tiene en la parte anterior dos agujeros mentonianos, el primero situado a unos 20 milímetros adelante de la parte anterior del alvéolo del primer molar y a 8 milímetros debajo del borde superior de la mandíbula, siendo doble, o con dos aberturas: una posterior de 4 milímetros de diámetro y otra anterior de 6 milímetros, separadas por un tabique que desaparece unos cuantos milímetros hacia el interior. $\mathrm{El}$ otro agujero, situado unos 15 milímetros más adelante y más abajo, es bastante más grande.

Una mucla aislada muy pequeña, que considero la primera superior. Es de forma casi cilíndrica, de 18 milímetros de diámetro mayor y 15 milímetros de diámetro menor, con dos surcos perpendiculares casi opuestos y poco profundos, siendo además un poco curva.

Una muela bastante parecida a la precedente, que supongo sea la primera inferior del lado derecho, pues se adapta perfectamente al alvéolo de la mandíbula. Es de figura elíptica, con un surco perpendicular en su cara interna, que correspondería a la cresta longitudinal que se ha visto presenta el alvéolo sobre la misma cara. La corona no forma un plano horizontal; la delgada capa de cemento que envuelve a la muela y la capa de dentina gruesa de unos dos milímetros que envuelve a la vásculodentina, han resistido más que ésta a la masticación, de modo que la corona está gastada en el centro más profundamente que en la periferia y en un espacio que corresponde exactamente al área que la vásculodentina ocupa en la corona. La corona tiene 18 milímetros de diámetro anteroposterior y 11 milímetros de diámetro transverso. La delgada capa de cemento que envuelve a la muela está cubierta en casi toda sti superficie por un crecido número de crestas perpendiculares muy finas.

Una muela inferior de gran tamaño, que supongo sea la tercera inferior del lado derecho; es de forma muy elíptica, como en el Glossotherium, pero se implantaba en la mandíbula en dirección más transversal al eje de la serie dentaria, con un surco perpendicular en su zaria anterointerna y una depresión ancha y poco profunda en la cara poste- 
rior. La corona tiene 29 milimetros de diámetro mayor y 18 milímetros de diámetro menor, mostrando el centro de la superficie masticatoria correspondiente a la vásculodentina muy gastado y formando una especie de pozo rodeado por la capa intermedia de dentina; la delgada capa de cemento externo se levanta formando un borde periférico, elevado como en la primera muela.

Procedencia: - Los restos de este animal han sido descubiertos por el frofesor Scalabrini en las barrancas de los alrededores de la ciudad del Paraná y pertenecen al Museo provincial de Entre Ríos.

Horizonte: - Piso mesopotámico de la formación patagónica (oligoceno inferior).

OWeN: Zoology of the \&Beaglc», Foss. Manm., página 57 , lámina XXVI, 1840.

Los primeros restos de este género, consistentes en un cráneo imperfecto con la mandibula inferior, fueron descubiertos por Darwin en Punta Alta, cerca de Bahía Blanca, y llevados a Inglaterra, en donde fueron descriptos por Owen en la parte zoológica del viaje del «Beagle», fundando sobre esos restos dos géneros distintos; la parte posterior del cráneo fué descripta bajo el nombre genérico de Glossotherium, considerándoselo como un desdentado cercano del Orycteropus; y la mandibula inferior está descripta un poco más adelante, como proveniente de un género distinto, bajo el nombre de Mylodon Darwini, a cuyo género refiere asimismo una especie norteamericana: el Mylodon Harlani, que hasta entonces había sido considerado como un Megalonyx. Pero poco tiempo después, en su magistral descripción del Mylodon robustus reconoció la identidad del Glossotherium con el Mylodon Darmini, conservándolos en el mismo género por cuanto las partes de que disponía no eran realmente de naturaleza tal que bastase para revelar las diferencias profundas que existen entre Mylodon y Glossotherium.

Esta misma especie, o por lo menos otra muy parecida, fué descubierta por Bravard y considerada por dicho naturalista no como un $\mathrm{My}$ lodon sino como un Scclidotherium, al cual designó en sus catálogos con el nombre de Scelidotherium ankilosopum, en lo que no anduvo muy desencaminado, pues dicho animal presenta en realidad mayores analogías con el Scelidotherium que con el Mylodon.

Más tarde, el doctor Laussen, súbdito dinamarqués residente en Buenos Aires, envió al Museo de Copenhague, en calidad de regalo, un cráneo casi completo que fué estudiado por el profesor Reinhardt, quien publicó sobre él, en 1877, una notable Memoria, reconociendo en dicha 
pieza la especie descripta por Owen como Mylodon Darwini; pero la conformación del cráneo y el número y la disposición de las muelas, tan distinto de como se presenta en Mylodon, lo obligaron a establecer para el mencionado animal un nuevo género, al cual designó con el nombre de Grypotherium, sin duda por no haber notado que ya existía el nombre de Glossotherium aplicado precisamente al mismo animal.

Burmeister combatió en 1879 esta manera de ver, sosteniendo que debe formar parte del género Mylodon; y en su último trabajo sobre la «Osteología de los Gravigrados», ha descripto y dibujado un cráneo incompleto, persistiendo en la misma creencia.

Una vez más tengo el pesar de no encontrarme en concordancia de iceas con el ilustre paleontólogo. Para mí las diferencias entre el Glos. sotherium y el Mylodon son tan grandes como las que separan al Mylodon del Scelidotherium, y hasta mayores; y después de haber leído con la mayor atención la disertación del autor, me he convencido de la habilidad con que ha sabido hacer resaltar los muy pocos caracteres que acercan el Glossotherium al Mylodon, pasando por alto, sin agregar una palabra, sobre los más numerosos y de mayor importancia que separan netamente a ambos animales como géneros distintos.

Ya la vista general del cráneo demuestra en sus proporciones que no tiene ninguna relación inmediata con el Mylodon, pues el cráneo de éste es corto, ancho y grueso y el del Glossotherium, al contrario, largo, angosto y delgado como en el Scclidotherium, cuyos principales carac. teres muestra, acompañados de otros que tampoco permiten identificarlo con éste, como lo hacía Bravard, debido exclusivamente a un conocimiento incompleto de su organización. La única región que parece presentar una ligera analogía con la del Mylodon es el occipital, que es un poco más elevado y menos vertical que en el Scelidotherium, pero teda la parte posterior del cráneo que se extiende detrás del paladar es tanto o más larga y angosta que en el Scelidotherium, no presentando absolutamente ningún parecido con la misma parte corta y ancha del Mylodon, por supuesto exceptuando los caracteres de construcción fundamentalmente idénticos, que distinguen a todos los gravígrados.

La parte superior del cráneo detrás de las órbitas no presenta tampoco en toda su extensión ningún parecido con la región correspondiente del Mylodon: dicha parte es muy ancha y un poco abovedada en este género, con las crestas temporales poco desarrolladas y muy separadas de la línea media; en el Glossotherium, al contrario, esta región del cráneo, de acuerdo con su conformación general, es más larga y más estrecha, con las crestas temporales bien desarrolladas y acercándose a la línea media, limitando un llano sagital de superficie casi plana, largo y angosto, que se extiende desde la cresta occipital casi hasta la parte anterior de la frente, cuyo carácter es propio del Scelidotherium, el Platyonyx 
y el Scelidodon y probablemente de todos los demás representantes de la familia de los Scelidotheridoe.

El arco cigomático, al contrario, tal como lo describe y dibuja Burmeister, presenta analogías con el Mylodon, pero eso no basta para reunir a ambos géneros cuando casi todos los demás caracteres están en contradicción con dicha unión.

La parte anterior del cráneo, delante de la abertura nasai posterior, difiere por sus proporciones tanto del Mylodon como del Scelidotherium, presentándose como un poco más larga y más delgada que en el Mylodon, pero algo más corta y más ancha que en el Scelidotherium, con el cual, sin embargo, presenta un notable parecido, que es todavía mayor comparándolo con el Scelidodon.

Hasta el día no se conoce completa en ningún ejemplar, la punta anterior del cráneo del Glossotherium, lo que es tanto más de sentir cuanto que en esta parte reside uno de los caracteres genéricos distintivos de mayor importancia, puesto que separa por completo a este ani. mal de todos los demás gravígrados. Por los restos conservados en distintos ejemplares parece que el vómer, cartilaginoso o sumamente delgado en los otros géneros, se osificaba ahi formando una pared que divide la abertura nasal anterior en dos partes; hacia adelante, el vómer se ensanchaba de un modo extraordinario, formando un arco óseo sólido que se unía arriba con la punta de los nasales y abajo con la extremidad del intermaxilar, presentando así dos grandes aberturas nasales casi circulares, que se abren lateralmente, una a cada lado, en vez de la gran abertura anterior única de los demás gravígrados. Esta conformación particular y casi podría decirse que extraordinaria entre los Brutos, bastaría por sí sola para separar genéricamente al Glossotherium de todos los demás representantes del mismo grupo.

A causa de esta conformación particular, los huesos intermaxilares no son largos y delgados como en el Scelidotherium, sino más cortos y más robustos, considerablemente más anchos en su punto de unión con los maxilares y ascendentes hacia arriba sobre los lados para tomar parte en la formación de las paredes laterales que circunscriben las aberturas nasales; esta conformación presenta un cierto parecido con la conformación del intermaxilar del Scelidodon, pero difiere en absoluto del Mylodon, en el cual los huesos intermaxilares son pequeños, completamente rudimentarios, muy cortos y limitados a la región central del paladar, sin que sus alas laterales alcancen hasta los bordes externos del paladar.

El paladar del Glossotherium presenta también algunos caracteres particulares que lo separan completamente del Mylodon, a pesar de la opinión de Burmeister que cree encontrarle, precisamente ahí, en qué basar su opinión de que el Glossotherium no es más que una especie de 
Mylodon. Observa el distinguido paleontólogo que la reconstrucción del cráneo descripto por Reinhardt debe ser errónea en lo que se refiere al paladar. cuyo ancho no debe ser igual en todo el largo ocupado por las series dentarias, sino un poco más angosto atrás, como sucede en el $M y$ ludon, en lo que ve una prueba de la identidad genérica de ambos animales. Pero aun admitiendo que la reconstrucción del paladar del cráneo del Museo Nacional de Buenos Aires sea exacta y errada la del cráneo estudiado por Reinhardt, la convergencia hacia atrás de las series dentarias no es tan pronunciada como en la generalidad de las especies del género Mylodon, mientras que existen especies de este género, como el Mylodon Wieneri, cuyas series dentarias son casi paralelas. Pero lo que quita todo valor a este carácter como distintivo genérico exclusivo del Mylodon, es que en algunas especies del género Scelidodon, las series dentarias son un poco convergentes hacia atrás. Ahora la afinidad de este género con el Scelidotherium no puede ser negada, puesto que tanto yo como Bravard. Gervais y el mismo Burmeister, lo habiamos confundido hasta ahora con el mencionado género.

Pero si la pequeña convergencia hacia atrás de las series dentarias del Glossotherinm no tiene importancia alguna para sostener su afinidad con el Mylodon, la conformación de todo el resto del paladar, está en completa oposición con esa pretendida afinidad. En el espacio limitado por las series dentarias el paladar del Glossotherium es proporcional. mente mucho más angosto que en el Mylodon, lo que lo acerca más al Scelidotherium y al Scelidodon.

En el Mylodon los dientes ocupan siempre toda la extensión del paludar, que es corto y ancho; y la primera muela se encuentra implantada constantemente en la parte anterior del maxilar, de manera que el paladar no se extiende hacia adelante, o si lo hace es sólo en una extensión sumamente corta, formada por los intermaxilares rudimentarios. La conformación del Glossothcrium es completamente distinta; en este género el paladar es mucho más largo y relativamente más angosto, $v$ las muelas se encuentran colocadas en la parte posterior, de manera que los maxilares se extienden hacia adelante de la primera muela por un espacio considerable, al que sigue luego el que comprende los intermaxilares, de donde resulta que en el Glossotherium la región del paladar que se extiende adelante de la primera muela es más larga que la parte del paladar ocupada por las muelas. Esta conformación es parecida al tipo que presentan el Scelidotherium, el Scelidodon, el Megatherilum, el Colodon, etc. y no permite suponer ninguna afinidad próxima con el Mylodon.

La mandíbula inferior concuerda en su conformación mucho más con is del Scelidotherium que con la del Mylodon, pues en vez de terminar er una sínfisis corta y ancha como en este género, presenta una parte 
sinfisaria muy larga y delgada como en el Scclidotherium, completamente desprovista de dientes, pero que se dirige hacia arriba como en el Scelidodon.

Tanto por su conformación como por el número de los dientes, el sistema dentario confirma asimismo la separación genérica del Glossotherium.

Por lo que concierne al número, el Glossotherium tiene cuatro dientes cn cada lado de la mandibula superior e igualmente cuatro en cada lado de la inferior, lo que no permite establecer una identificación genérica con el Mylodon, que, de acuerdo con la fórmula dentaria de la generalidad de los gravígrados, tiene cinco muelas en cada lado de la mandíbula superior. Burmeister dice que no presta mucha importancia a la particularidad de no existir más que cuatro muelas superiores, porque ello es debido a que la primera muela situada más adelante en la parte anterior del maxilar debia ser sin duda pequeña y caediza; y le pareció ver un resto del alvéolo de dicho diente en el dibujo publicado por Reinhardt. Pero ninguno de los tres ejemplares de que tengo conocimiento presenta vestigio alguno de dicha muela; $y$, por otra parte, lo que el autor tomó por un alvéolo es una gran perforación vascular que se encuentra en la parte anterior de cada maxilar y que también existo en el cráneo del Scelidodon.

En la forma y disposición de las muelas encuentra Burmeister, igualmente sin razón, afinidades con el Mylodon. Dice que las muelas del Glossotherium difieren en su colocación de las del Scelidotherium por no encontrarse colocadas oblicuamente como en este género, sino en sentido longitudinal, pero aquí tampoco aparece afinidad con el Mylodon, en el cual las muelas prismáticas intermedias están siempre colocadas en sentido transversal.

En cuanto a la forma tampoco existe ninguna relación entre ambos géneros, representando el Glossotherium un tipo particular, distinto tinto del Mylodon como del Scclidotherium, pero con algún parecido con las del Lestodon, abstracción hecha, naturalmente, de la primera muela caniniforme de este último.

En el Glossotherium, todas las muelas están colocadas unas a continuación de otras sin que la anterior esté más separada de la que le sigue que las otras entre sí, siendo todas del mismo alto y con la corona truncada horizontalmente y el centro más gastado que la periferia.

La primera muela superior es elíptica y las dos siguientes elípticoovaladas, un poco más anchas adelante que atrás. La última muela superior es de contorno más triangular y mucho más pequeña que las otras tres.

En la mandíbula inferior, la primera muela es más pequeña que las siguientes y de sección elíptica; las dos siguientes son elípticoovaladas 
como las correspondientes de la mandibula superior; y la última inferior es más grande y bilobada, afectando una forma parecida a la del Lestodon.

Hasta el dia no se conoce ninguna pieza del esqueleto del Glossotherium, con excepción de los dos pies posteriores, recogidos por mí, completos, cerca de Luján. El pie es más parecido al del Scelidotherium que al de ningún otro mamífero, terminando como en éste en un solo dedo armado de uña, que es el tercero, y cuya falange ungueal tiene un tanıaño extraordinario. Las dos falanges de este dedo, que siguen al metatarso, están soldadas en un solo hueso como en el Megatherium; de los dedos primero y segundo no quedan más vestigios que los metatarsos. F1 dedo cuarto, muchísimo más pequeño que el tercero, termina en un sclo hueso, largo, grueso en la base y de extremidad casi cónica y rugosa; esta pieza representa las tres falanges ungueales soldadas. El dedo quinto es una mitad más pequeño todavía y formado por dos pieZís: la hase corta y gruesa que representa la primera falange y la terminal que concluye en punta cónica, que representa las dos falanges terminales soldadas.

La tibia y el peroné son separados como en el Mylodon y' el Scelidothicrium, pero mas parecidos a los de este último género que a los del primero.

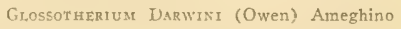

Grypotherium Darcini (Owen). Rernarar: k., Danske Vid. Selsks, skr., volumen XII, página 353,1879 .

Mylodon Darvinii. OWEN: Zoology of the vorage of the \&Beagles, tomo 1 , paiginas 68 y 73, láminas XVII-XIX.

Pictet: Traité de Paléontologie, tomo I.

Burmeister: «Anales del Museo Público de Buenos Aires», tomo I, página $1706 .-$ Idem: Description physique, etc., tomo III, página 359, 1879. - Iden: Atlas de la sDescription physique, etc.\$, página 1 s9.

LYDEKRER: Catal. of Foss. Mammal., parte V, página I04, I887.

Mylodon robustus intermedins. Biainvid.te: Ostéographie, Gen. Megatherium, tomo IV, lámina I, figura 15 .

Scelidotheriun ankilosopum? Bravard: Catalogue des fossiles, etc. (nomen nudum).

Glossotherium. Owex: Zoology of the «Beagle», página 57, lámina XXVI, $1840 .-$ Idem: Descr. of the slelcton of a cxtinct gigantic sloth tribe, etc., pagina 58,1855 .

Según Burmeister, el paladar es, en esta especie, un poco más angosto atrás que adelante.

La primera muela superior es de contorno elíptico e implantada con su eje mayor en la misma dirección del eje de la serie dentaria. La seginda muela superior es un poco más ancha, particularmente adelante, pero no más larga, e implantada un poco oblicuamente, dividida en dos lóbulos desiguales, el anterior un poco más ancho y el posterior más angosto y más pequeño. La tercera muela superior es de la misma forma 
que la precedente y la cuarta o última es un poco más pequeña y de contorno más triangular.

En la mandíbula inferior, la primera muela es de contorno elíptico, con su eje mayor en dirección del eje de la serie dentaria y de tamaño mucho menor que la segunda; la segunda muela inferior, de casi doble tamaño que la primera, es muy ancha adelante, mucho más angosta atrás, convexa sobre la cara externa y un poco deprimida sobre la interna; la tercera muela, más o menos del mismo tamaño que la segunda, es bilobada por dos pequeños surcos perpendiculares opuestos, con el lóbulo anterior muy ancho y más grande y el lóbulo posterior mucho más pequeño y muy angosto, estando además implantada un poco oblicuamente; por fin, la última muelą inferior, de tamaño mucho más considerable, está dividida en dos lóbulos iguales en forma de 8 prolongado, por dos grandes depresiones perpendiculares opuestas, sin surcos ni columnas accesorias.

DIMENSIONES

de la primera muela superior $\ldots \ldots \ldots \ldots \ldots \ldots$. 032

Diámetro anteroposterior de la segunda muela superior $\ldots \ldots \ldots \ldots \ldots \ldots . \ldots 028$

de la tercera muela superior ................... 0025

de la cuarta muela superior.................... 0020

de la primera muela inferior .................. 00195

de la segunda muela inferior .................. 0025

de la tercera muela inferior................. 0027

de la cuarta muela inferior ................... 0040

de la primera umela inferior ................ 0014

de la segunda muela inferior ............... 0018

de la tercera muela inferior ................ 0021

de la cuarta muela inferior ................ 0015

Longitud del espacio ocupado por las cuatro muelas inferiores........... 0123

Longitud total del cráneo .................................... 0620

Longitud del paladar ......................................... 0270

El cráneo y la mandíbula descriptos y figurados por Burmeister son de dos individuos distintos; y la mandibula inferior, sin duda alguna de una especie diferente de la que ha figurado Owen y debe considerarse como el tipo de la especie. La mandíbula inferior descripta por Burmeister pertenece al Glossotherium Zeballosi, pero por ahora no puede afirmarse que suceda otro tanto con el cráneo, al cual continúo conside. rándolo (cuando menos provisoriamente) como del Glossotherium Darwini.

Procedencia:- Distintos puntos de la provincia Buenos Aires.

Horizonte:-Piso bonaerense de la formación pampeana. 
Mriodon robustus intermedius, en DE BLATNviLLE: Ostéographie, etc.

Mylodon Zeballosi. H. Gervars y AMEghino: Los mamiferos fósiles, etc., nágina 156, i\$SO.

Mesodon. Zeballosi. AMEghro: Catalogo de la sección de la prozincia Buenes dires en la Exposición Continental Sud Americana, ete., página 4r, 1882.

Mylodon Darwini (parte). Burmerster, Atlas de la «Description pliysique, etc. lám. Xi, figura 6.

Esta especie es de la misma talla que la precedente, pero de una conformación general un poco más delgada; y a juzgar por la mandibula inferior, que es la única parte que de ella se conoce hasta ahora, con una diferencia notable en la conformación de las muelas.

La primera muela inferior es proporcionalmente mucho más pequeña que en la especie precedente. La segunda muela inferior difiere de la correspondiente en el Glossotherium Darwini, por ser mucho más angosta en su parte anterior y colocada en la misma dirección que el eje de la serie dentaria. La tercera muela inferior presenta mayores diferencias todavía, pues en vez de estar implantada un poco oblicuamente, cumo en el Glossotherium Darmini, presenta su eje mayor en la misma dirección que el eje de la serie dentaria, es mucho más angosta en su parte anterior $y$ apenas presenta vestigios perceptibles del surco perpendicular externo. La cuarta muela inferior no parece presentar diferencias con la correspondiente de la otra especie.

La mandibula descripta y figurada por Burmeister en el Atlas de la «Description physique», etc., lámina XV, figura 6 , pertenece a esta especie y no al Glossotherium Darwini.

\section{DIMENSIONES}

Diámetro anteroposterior $\left\{\begin{array}{l}\text { de la primera muela inferior } \ldots \ldots \ldots \ldots \ldots \ldots \ldots \\ \text { de la segunda muela inferior } \ldots \ldots \ldots \ldots \ldots \ldots \ldots \ldots\end{array}\right.$

Procedencia:- Distintos puntos de la provincia Buenos Aires.

Horizonte:-Piso lujanense de la formación pampeana.

Glossothrortum nonariense, Imeghino

Lanina XeIV, figurs:

Quatriodon bonariensis. AMEGrINo: La antigitedad del hombre en el Plata, tomo II, página $307,288 \mathrm{I}$.

Tetrodon bonariensis. Amecirno: Catálogo de la Sección de la provincia Buenos Aires e" la Exposiciön Continental Sud Americana, página 4, 1882.

Indiqué este animal por primera vez a principios de 1881; e ignorando en esa fecha el trabajo de Reinhardt sobre el Grypotherium, que 
se caracterizaba por la presencia de sólo cuatro muelas superiores, consideré este número menor de muelas como distintivo de un nuevo género, al cual designé con el nombre de Quatriodon; mas siendo éste un nombre de composición híbrida, lo cambié al año siguiente por el de Tetrodon, sin recordar que Linneo ya había empleado el mismo nomtre para un género de pescados; hubiera sido, por consiguiente, necesario cambiarlo por tercera vez; pero afortunadamente al someter a nuevo examen la pieza original, he visto que ella entra en el género Glossotherium, en el cual representa una especie de tamaño diminuto, cuya talla no alcanzaba a la mitad de la del Glossotherium Darwini.

La pieza más completa de que dispongo es un maxilar superior derecho con las cuatro muelas y la parte palatina correspondiente.

La primera muela es de sección completamente elíptica, un poco inclinada hacia atrás y hacia afuera, cón su eje mayor de adelante hacia atrás, de 12 milímetros de diámetro anteroposterior y 8 milímetros de diámetro transverso máximo, separada de la muela que sigue por un diastema de 6 milímetros de ancho.

La segunda muela superior es de sección alargada de adelante hacia atrás, colocada un poco oblicuamente, muy ancha en su parte anterior $y$ angosta en la posterior, y presenta un surco perpendicular angosto y profundo sobre la cara interna y una depresión apenas acentuada sobre la externa; tiene 13 milímetros de diámetro anteroposterior, 9 milímetros de diámetro transverso adelante y 6 atrás.

La tercera muela superior es de forma parecida a la precedente, pero colocada un poco más oblicuamente en la mandíbula; tiene 13 milíme. tros de diámetro anteroposterior oblicuo, 7 milímetros de diámetro transverso en la parte anterior externa y sólo 5 milímetros en la posterior interna.

La cuarta muela superior o última es de tamaño mucho menor y de sección triangular, presentando un aspecto casi igual al de la misma muela del Scelidotherium, con un pequeño surco perpendicular sobre su cara posterior interna; tiene sólo 8 milímetros de diámetro anterofosterior y 7 milímetros de diámetro transverso.

Las cuatro muelas superiores juntas ocupan un espacio longitudinal de sólo 55 milímetros. La mitad existente del paladar tiene un ancho de 20 a 22 milímetros, 10 que prueba que el paladar entero presentabit entre las muelas un ancho variable entre 40 y 45 milimetros y era, como 1. ha demostrado Burmeister para el del Glossotherium Darvini, un poco más ancho adelante que atrás.

Procedencia: - He recogido esta pieza cerca de la Villa de Luján.

Horizonte: - Piso belgranense de la formación pampeana. 
Los más antiguos representantes de los Scelidotherium conocidos hasta ahora, son el Stenodontherium y el Nephotherium. El Stenodontherium es un aliado muy cercano de Scelidodon, cuyo antecesor es, $\sin$ duda, así como es incuestionable que el Scelidodon es el antecesor del Scelidotherium.

El Nephotherium, por los restos que hasta ahora se conocen, parece más próximo del Glossotherium; y como es de talla más pequeña y de énoca mucho más remota, es natural considerarlo, a lo menos por ahora, como su antecesor.

No parece probable que el Nephotherium y el Stenodontherium desciendan uno de otro; y es posible que remonten a un antecesor común en la forma que lo indican las siguientes líneas:

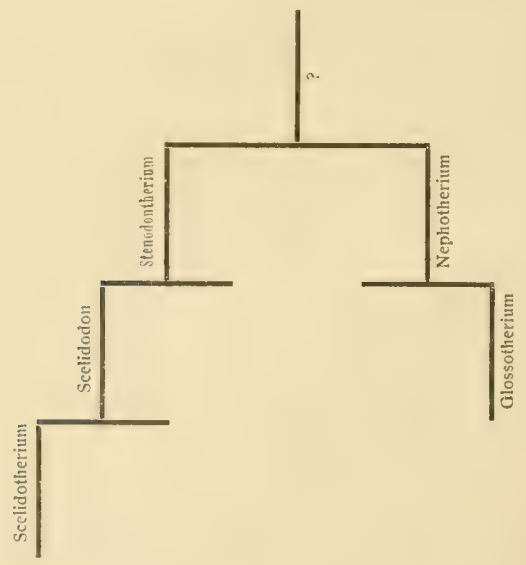

Mylodontidæ

Los representantes de este grupo se distinguen inmediatamente de los demás gravígrados, por la última muela superior, que es un poco más grande que las demás y bilobada. La primera muela anterior, tanto de arriba como de abajo, puede ser elíptica o más o menos prismática. La tercera y cuarta muela superiores y la segunda y tercera inferiores son siempre más o menos prismáticas con una tendencia a la forma triangular y colocadas constantemente en la mandíbula en posición transversal. La última inferior es considerablemente más grande que las otras 
y bilohada. La sínfisis mandibular es corta; y el intermaxilar es siempre rudimentario.

La abertura posterior externa de la rama externa del canal alveolar se abre siempre en el lado externo de la base de la rama ascendente de la mandíbula inferior. La forma general del cráneo es cilíndrica, con el mismo ancho o casi el mismo, adelante y atrás.

Los cuatro géneros de este grupo que hasta ahora me son conocidos se distinguen de este modo:

1. Primera muela de cada mandibula truncada horizontalmente.

a. Capa intermedia formada por una capa de dentina lomogénea entre la vásculodentina y el cemento. Mylodon.

b. Capa intermedia doble, entre la vásculodentina y el.cemento, o sea formada por una capa de dentina homogénea y otra de substancia vítrea. Promylodon.

II. Primera muela de cada mandíbula truncada oblicuamente.

a. Segunda muela superior, elíptica y subelíptica. Pseudolestedon.

b. Segunda muela superior triangular. Nematherium.

MYLODON Owen

OWEN : Zoology of the woyage of the \&Beaglen, tumo I, paigina 67, 1840. - Idem: Description of the skeleton of an cxtinct gigantic sloth., etc., 1842 .

E1 cráneo del Mylodon se distingue por su forma corta, ancha y gruesa, lo que le da un aspecto completamente distinto del que presenta el del Scclidotherium, del Scelidodon y del Glossotherium. Su aspecto general es el de un cilindro algo deprimido, truncado en sus dos extremidades, presentando casi el mismo ancho adelante y atrás, pero menos elevado perpendicularmente que en el Megatherium y el Megalonyx. La parte anterior del cráneo está como truncada perpendicularmente, mostrando una abertura nasal anterior ancha y alta, horizontal abajo y fuertemente abovedada arriba. Los huesos nasales apenas sobresalen un poco más adelante que las paredes laterales de la abertura nasal formadas por los maxilares. Los intermaxilares son muy pequeños, completamente separados entre sí y simplemente yuxtapuestos uno al lado del otro, articulados con los maxilares por suturas casi sueltas, por lo cual dichos huesos faltan en casi todos los cráneos; cada uno de estos huesos presenta dos ramas imitando casi la forma de un martillo, la del lado interno. que formaría la cabeza. dirigida de adelante hacia atrás y opuesta por su cara longitudinal a la del otro lado, y la rama externa que repre- 
senta el mango, dirigida hacia afuera y articulada en todo su largo con el maxilar, pero sin alcanzar al borde del paladar. De esta conformaciór particular resulta que ambos intermaxilares constituyen el borde anterior del paladar en su parte céntrica, entre el primer par de muelas anteriores, formando una pequeña punta ancha, convexa y poco prolongada, sobre 1. parte media. El llano occipital es bastante ancho y elevado, pero muy inclinado de adelante hacia atrás y de arriba hacia abajo. El arco cigomático es completo, tocando la apófisis posterior media del cigomático la apófisis cigomática del temporal, pero sin soldarse como en el Megatherium; la apófisis superior de las tres apófisis posteriores del cigomático es notablemente más larga que la del medio. El paladar es corto y muy ancho, un poco más angosto en la parte posterior que en la anterior, pero de una manera poco sensible y con las muelas ocupando toda la extensión del paladar, estando colocado el primer par en la parte anterior de los maxilares, lo que distingue profundamente a este género del Glossotherium y los demás géneros que poseen maxilares muy prolongados adelante de las muelas. La mandíbula inferior tiene una sínfísis muy ancha pero corta y como truncada hacia adelante, prolongándose muy poco adelante de las muelas anteriores.

- Los dientes son en número de $\frac{5}{4}:$ los dos primeros superiores más o menos elípticos; el tercero y cuarto superiores prismáticos y colocados transversalmente; y el quinto superior siempre bilobado, con el lóbulo anterior notablemente más grande que el posterior. En la mandíbula inferior, el primer diente es elíptico; el segundo y el tercero prismáticos y colocados transversalmente; y el cuarto de tamaño mucho mayor y bilobado. E1 par de dientes anterior de cada mandibula están truncados horizontalmente como los demás, sin estar separados del que sigue por un espacio mayor que los siguientes entre sí, o si lo están, ic están de una manera poco notable, sin tomar nunca el aspecto de verdaderos caninos. Las series dentarias son casi paralelas o muy poco convergentes hacia atrás.

La columna vertebral tiene 16 vértebras dorsales. La región lumbar consta de 3 vértebras unidas entre si y al sacro, que está formado por 7 vértebras, formando así un solo hueso constituído por la soldadura ¿̇ 10 vértebras. La cola tiene de 20 a 24 vértebras. El esternón consta dc 7 piezas. El miembro anterior es más corto y más grueso que en el Scelidotherium, pero termina en un pie bastante más pequeño. El húmero es corto y grueso y sin perforación sobre el cóndilo interno. El pie anterior termina en cinco dedos bien desarrollados, pero sólo los tres del medio, segundo, tercero y cuarto, con uña. La cadera es menos ancha y no $\tan$ fuerte como la del Scelidotherium. El fémur es igualmente un poco menos fuerte y no tan rectangular. La tibia y el peroné están separados. El calcáneo, que tiene su parte posterior menos des- 
arrollada que el de Lestodon y el de Megatherium, se articula con el astrágalo por medio de una sola superficie articular. El pie posterio; termina en cuatro dedos bien desarrollados, quedando el interno, o pulgar, atrofiado; los dedos segundo y tercero terminan en uña, y sus falanges son en número completo; los dedos cuarto y quinto carecen de uña; y el cuarto carece también de la falange ungueal correspondiente.

El Mylodon estaba cubierto por una espesa capa de huesecillos calcáreos, compactos, implantados en el espesor de la piel, formando una coraza rudimentaria que se extendía por sobre toda la superficie del cuerpo, como en el Colodon y el Platyonyx.

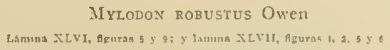

OweN: Description of the skeleton of an extinct gigantic sloth., etc., I $\$ 42$.

Burmerster: «Anales del Museo Público de Buenos Aires», 1omo I, página 164, - Idem: Description plujsique, etc., página $362,1879$.

LYDEKKER: Catal. of Foss. Mammal, parte V, página 107, 1887.

Esta es la especie típica del género, conocida en casi todos los detalles de su conformación osteológica gracias a la admirable descripción que de ella ha publicado Owen sirviéndose de un esqueleto completo que se conserva en el Museo del Colegio de Cirujanos de Londres, encontrado en 1841 a unas 12 leguas al Norte de Buenos Aires.

Indudablemente, este es el más robusto de los representantes del género Mylodon.

El cráneo es relativamente grueso y corto y con la parte anterior muy ancha. El arco cigomático es muy fuerte y tiene la apófisis descendentes muy ancha. La mandíbula inferior se distingue por la región que se extiende adelante de las muelas, que es relativamente más larga que en las especies de Pseudolestodon, y por el ángulo mandibular más agudo y prolongado hacia atrás; en la parte anterior, adelante de la primera muela, tiene tres agujeros mentonianos en cada lado, de tamaño desigual, uno más grande colocado cerca del borde superior adelante de la primera inuela; otro mucho más pequeño colocado bastante más abajo y un poco más adelante; y el tercero más pequeño todavía, debajo y delante del precedente.

El paladar es muy angosto atrás y muy ancho adelante, con las series dentarias muy convergentes hacia atrás en toda su longitud.

La primera muela superior es de contorno oval, sin surcos ni depresiones perpendiculares en su superficie y con su parte más angosta dirigida hacia adentro y hacia atrás; su tamaño es casi igual al de la segunda muela, pero está separada de ésta por una pequeña barra considerablemente mayor que los pequeños diastemas que separan entre sí a las demás muelas. 
La segunda muela superior es de sección eliptica, igualmente sin surco alguno y con su mayor diámetro de adelante hacia atrás.

La tercera muela superior es un poco más grande y de sección triangular, pero con los tres ángulos anchos y redondeados, con la cara interna más ancha, figurando la base del triángulo y la externa la cúspide, 1 resentando un surco perpendicular bastante acentuado sobre el lado interno.

La cuarta muela superior es de la misma forma y tamaño que la tercera, pero con una pequeña depresión perpendicular sobre su cara posterior.

La quinta muela superior es un poco más prolongada hacia atrás, más ancha adelante, más angosta atrás, con un surco interno y otro opuesto externo menos acentuado.

En la mandibula inferior, el primer diente es mucho más pequeño que el segundo, de sección elíptica, con su diámetro mayor de adelante hacia atrás, sin surcos perpendiculares y separado del segundo por un diastema pequeño, no mayor que el que separa al segundo del tercero.

La segunda muela inferior es de sección triangular, de ángulos anchos y redondeados, más ancha en el lado interno que en el externo y con un surco perpendicular interno bastante ancho y profundo.

La tercera muela inferior es de sección rectangular, con las caras interna y externa angostas, la anterior y posterior anchas, los ángulos redondeados y colocada un poco oblicuamente; las caras más anchas, anterior y posterior, son un poco deprimidas perpendicularmente en el centro.

La cuarta muela inferior es de tamaño mucho mayor y bilobada; sobre el lado externo no presenta más que una depresión ancha y poco acentuada; sobre el lado interno, al contrario, muestra un gran surco ancho, profundo y de fondo cóncavo que divide a la muela en dos partes, la anterior de las cuales presenta otro surco también bastante an sho pero menos profundo, colocado sobre el lado anterointerno.

\section{DIMENSIONES}

Longitud del cráneo, desde los cóndilos occipitales hasta el borde anterior de

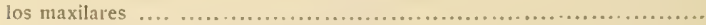

Longitud desde los cóndilos occipitales hasta el borde anterior de la base de la apófisis descendente del malar ............................. 0330

Diámetro mayor de la primera muela superior ...................... 0020

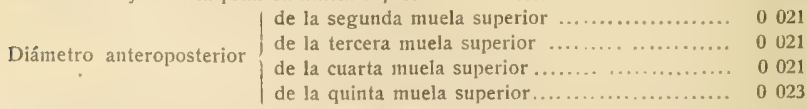

Largo del diastema entre la primera y segunda muela superiores ............ 0014

Ancho de la region interdentaria del paladar entre la primera muela de cada lado. 
Ancho de la region interdentaria del paladar entre la última muela de cada lado .................................................... 0057

Longitud del espacio ocupado por las cinco muelas superiores ............. 0137

Diámetro de la primera muela inferior $\int$ antero posterior.................. 0020

Diámetro de la primera mutela inferior ; transverso .................... 0016

Diámetro de la segunda muela inferior $\mid$ anteroposterior ................. 0023

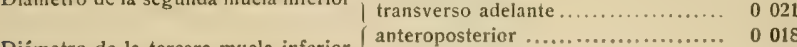

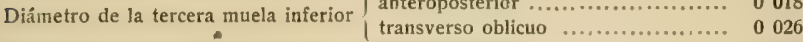

Diámetrior ................. 0050

transverso máximo ................... 0020

Longitud del espacio ocupado por las cuatro muelas inferiores ............ 0127

Longitud de la parte de la mandibula inferior que se extiende adelante de la primera muela................................................. 0900

Alto de la rama horizontal de la mandíbula inferior debajo de la primera muela ........................................................... 0067

Procedencia:- Distintos puntos de la provincia Buenos Aires.

Horizonte:- Piso bonaerense y piso lujanense de la formación pampeana.

Irylodon Sauvager H. Gervais y Ameghino

H. Gz̈Rvais y Ameghivo: Los mamíferos fósiles, etc., página 156, 1880 .

Es la especie más pequeña del género Mylodon que yo conozca hasta ahora. El paladar es menos triangular que en el Mylodon robustus y, por consiguiente, las series dentarias son menos convergentes hacia atrás.

El carácter distintivo más notable de esta especie consiste en la forma de las dos primeras muelas superiores, de las cuales la primera o anterior es mucho más pequeña que las otras, inclinada hacia atrás y de sección casi circular, mientras que la segunda, notablemente más grande c igualmente inclinada hacia atrás, es de sección sumamente elíptica, con su eje mayor dirigido de adelante hacia atrás y sumamente comprimida transversalmente.

La primera muela inferior es elíptica, sin surcos perpendiculares y no tan pequeña como la primera de la mandíbula superior.

De esta especie yo poseía una parte considerable del cráneo y muchos lutuesos del esqueleto, entre ellos los cuatro pies completos; pero siendo hoy esos objetos propiedad del Museo de La Plata, no puedo dar acerca de ellos más detalles ni dibujos.

Procedencia:- He recogido los restos de esta especie cerca de la estación Jáuregui, en la provincia Buenos Aires.

Horizonte:-Piso lujanense de la formación pampeana. 
II. Gervais y Amíghino: Los mamíferos fósiles, etc., página 256, I880.

Conjuntamente con $\mathrm{H}$. Gervais, fundé esta especie sobre parte considerable de un esqueleto de un animal de talla apenas un poco menor que la del Mylodon robustus, pero de formas igualmente macizas.

Los caracteres distintivos más notables de esta especie consisten en la forma de la primera muela de cada mandíbula, tanto arriba como abajo, que es de sección elíptica y más pequeña que la segunda, de la cual se encuentra separada por un pequeño diastema; y en la forma del paladar, que no es triangular sino rectangular, presentando casi el mismo ancho adelante $y$ atrás, debido a las series dentarias que son casi paralelas, exceptuando en la parte anterior entre la primera muela de cada lado, que son un poco divergentes.

La segunda muela superior es de tamaño un poco mayor que la primera, pero de sección igualmente elíptica y con su eje mayor de adelante hacia atrás, estando separada de la anterior por un diastema considerable que casi afecta la forma de una barra.

La tercera muela superior es mayor que la segunda, de sección elípticoprismática, implantada oblicuamente y con un prolongamiento $o$ fuerte columna perpendicular sobre lá cara anterointerna.

La cuarta muela superior es también de contorno subelíptico, angosta en el lado externo y ancha en el interno, con un fuerte surco perpendicular sobre el lado interno y una columna ancha y convexa sobre la cara anterointerna.

En la mandíbula inferior, la primera muela elíptica y de superficie flana está separada de la segunda por un diastema menor que en la superior; la tercera es de contorno menos rectangular que en la generalidad de las especies, afectando más bien un contorno triangular, angosta en el lado interno y ancha en el externo, donde presenta un fuerte surco perpendicular.

Procedencia:- He descubierto los restos de esta especie en los alrededores de Mercedes, en la provincia Buenos Aires.

Horizonte:-Piso lujanense de la formación pampeana.

MyLodon intermedius Ameghino

Latmina XLVI, figuras o 5 s

AMEghino: La antigüedad del hombre, etc., tomo II, página 308, $188 \mathrm{r}$.

Esta especie es de caracteres intermedios entre las de los verdaderos Mylodon y las del grupo de los Pseudolestodon; y de una confor- 
mación general más grácil que la de los Mylodon robustus y Mylodon Wieneri. El paladar es de aspecto un poco más triangular que en las mencionadas especies, pero no tanto como en las del género Pseudolestodon, es menos convexo en su parte interdentaria posterior que en el Pseudolestodon y más cóncavo en la parte anterior. Los intermaxilares son un poco más prolongados hacia adelante que en las otras especies de Mylodon, formando una ligera protuberancia en su parte miedia. La primera muela de cada mandibula es de sección elíptica, más pequeña que la segunda y sin aspecto caniniforme; su superficie masticatoria no es tampoco completamente horizontal como en el Mylodon robustus, sino un poco en declive hacia atrás en las superiores y hacia adelante en las inferiores, pero sin tener la forma oblicua tan pronunciada que distingue a las especies del género Pseudolestodon. La segunda muela superior es de sección elíptica y muy comprimida transversalmente. La última muela superior es bilobada de un modo imperfecto, con el lóbulo posterior afectando la forma de un prolongamiento posterior del anterior. El paladar tiene una longitud de 208 milímetros, 11 centímetros de ancho entre el par de muelas anteriores y 56 milimetros entre el par de muelas posteriores. Las cinco muelas superiores ocupan un espacio longitudinal de 148 milímetros. La longitud total del cráneo es de 49 centímetros.

Procedencia:- He descubierto los restos de esta especie sobre las barrancas del río Luján en el municipio de Mercedes.

Horizonte:- Piso bonaerense de la formación pampeana.

Moreno, en el «Informe preliminar», etc., ya repetidas veces mencionado, cita una especie de Mylodon de Monte Hermoso, a la cual la considera como nueva y la denomina Mylodon Martinii, representada por una parte de la columna vertebral que, según dice, indica un animal de formas más corpulentas que el Mylodon robustus. En el estado actual de la parte de la Paleontología que se refiere a este grupo, se necesita un exceso de buena voluntad para exponerse a fundar especies nuevas sobre restos de la columna vertebral, sólo conocida hasta ahora en un limitadísimo número de especies y que hasta parece no presenta diferencias en géneros afines.

PROMYIODON Ameghino

Amegrino: «Boletin de la Academia Nacional de Cienciass, toma V, página $298, x 883$.

Este género se distingue por sus muelas de composición interna compleja y de sección triangular elongada, con ángulos muy redondeados. 
Promytodon paraneNisis Ameghino

Lamma LXXI, ffeura 3 ; y lanuma L.XXU, histurs 3

Mylodon (\%) parancusis. Amegrino: «Boletín de la Academia Nacional de Ciencias», t. V, página 114,1883 .

Promylodon parancrsis. Amegrivo: «Boletin de la Academia Nacional de Ciencias», t. V, púgina 114 - - Idem: tomo IX, página $184,1886$.

Sólo conozco hasta ahora dos dientes de esta especie. Una muela que me ha facilitado el profesor Scalabrini, y es la segunda de la mandíbula inferior y denota una especie algo más pequeña que los Mylodon procedentes del terreno pampeano, pero de ángulos más redondeados y surcos menos profundos. La corona tiene 10 milímetros de diámetro mayor y 15 milimetros de diámetro transverso máximo. En su parte inferior, que está rota, la sección transversal muestra una delgadísima lámina de substancia vitrea, interpuesta entre la dentina y la vásculodentina.

La segunda muela, que me ha sido facilitada por el señor Lelong, sólo tiene la corona completa, que es de sección prismáticotriangular, rero de ángulos redondeados, de 23 milímetros de largo, 15 de ancho en la parte inás gruesa, formada por la base del triángulo, y sólo 7 milímetros en la parte más angosta, que forma la cúspide. La superficie masticatoria de la corona presenta una cavidad de la misma forma que el prisma, bastante profunda, limitada por una cresta periférica elevada, formada por la capa de substancia interna, de aspecto vítreo. Toda la superficie externa formada por la capa de cemento está finamente estriada en sentido perpendicular. Examinando el corte transversal se ve

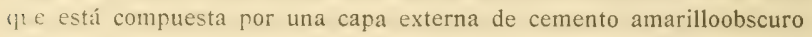
de un milímetro de espesor, al cual sigue una capa más o menos del niis mo grueso de substancia de color obscuro y aspecto vítreo que cubre a otra capa también del mismo espesor de dentina dura de color blancoamarillento, la que envuelve a su vez a la masa interna de vásculodentina, que representa en menor escala la forma general de la muela.

Procedencia:- Estas piezas han sido recogidas en las barrancas de los alrededores de la ciudad del Paraná.

Horizonte:-Piso mesopotámico de la formación patagónica (oligoceno inferior).

\section{DSEUUDLLISTODON II. Gervais y Ameghino}

H. Gervits y Amremino: Los mamiferos fósiles, etc., página i 58 , is8o.

Este género es sin duda muy cercano del precedente; y en este caso, apoyado en la conformación general del esqueleto, podría realmente sostenerse que es idéntico al Mylodon. Pero aunque las diferencias en- 
tre ambas divisiones no sean muy considerables, ellas existen; y precisamente los caracteres diferenciales más notables son constantes y comunes a un cierto número de especies que constituyen así un grupo bien definido, para el cual me parece apropiada y conveniente su separación con un nombre genérico distinto.

La conformación del cráneo es, en su configuración general, idéntica en ambos géneros; las diferencias de importancia sólo se presentan en los dientes y en la configuración del paladar.

Los dientes, en número igual a los del Mylodon, presentan también una conformación casi parecida; pero el primer diente de cada mandibula toma el aspecto de un canino, estando siempre más separado de los demás y colocado más afuera del eje de la serie dentaria y en la mandibula inferior dirigido oblicuamente hacia afuera y hacia adelante. La superficie de estos dientes caniniformes, en vez de estar truncada transversalmente como en el Mylodon, está cortada en declive oblicuo, de arriba abajo, pero concluyendo en ápice triangular; estas caras oblicuas lisas miran hacia atrás en los caninos superiores y hacia adelante en los inferiores, adaptándose perfectamente las superficies oblicuas de los inferiores con las de los superiores. Las series dentarias son muy convergentes hacia atrás, delimitando un paladar de aspecto triangular, muy angosto en su parte posterior y de casi doble ancho en la anterior. El arco cigomático está conformado como en el Mylodon, pero las dos ramas superiores de las tres en que se divide el hueso cigomático hacia atrás, son con poca diferencia del mismo largo, mientras en el Mylodon la superior es casi doble más larga que la del medio.

En la columna vertebral la única diferencia de importancia se encuentra en la conformación del hueso sacro, que consta de sólo seis vértebras en vez de siete. Los miembros son un poco más delgados que los del Mylodon; y el fémur particularmente es más delgado y más largo, acercándose a la forma característica del mismo hueso del Lestodon.

E1 Pseudolestodon tuvo la misma cubierta de huesecillos cutáneos calcáreos y compactos que he mencionado en el Mylodon.

La distinción de las diferentes especies del género Pseudolestodon es muy difícil, pues son muy parecidas unas a otras y han sido a menudo confundidas. En un principio todas fueron identificadas con el Mylodon robustus, luego fueron separadas bajo el nombre específico de Lestodon myloides, que incluía a todas las formas de este grupo, mientras otros autores las consideraban como una especie distinta del género Mylodon, hasta que últimamente se ha reconocido que ellas forman un grupo aparte al cual he designado con el nombre de Pseudolestodon, pero qui para otros autores, y en particular Burmeister, forman simplemente uni sección del género Mylodon. Agréguese a esto, que casi todas las espe. cies descriptas hasta hace poco, lo fueron sin estar acompañadas po: 
caracteres diagnósticos precisos, ni figuras, y se comprenderá las dificultades que se presentan para su distinción.

Los materiales que sobre esta sección habia reunido eran bastante numerosos y me habrían permitido realizar un trabajo, si no exento de errores, por lo menos bastante perfecto; pero, por desgracia, como esos materiales son hoy propiedad del Museo de La Plata, de cuyo personal ya no formo parte, no me es posible aprovecharlos. De modo, pues, que la enumeración que de los representantes de esta sección presento, queda sujeta a una nueva revisión, que puede alterar en parte los términos adoptados.

Pseudotestodon MYloides P. Gervais

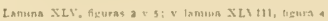

Psendolestodon myloides (P. Gervais). H. Gervais y Aarghino: Los namiferos fósiles, etcétera, página I60.

Mvlodon robustus (Owen). DE BLAINviLLE: Ostégraplie, etc.

Lestodon myloides. P. Gervais: Recherches sur les mammifères fossiles de i’Amérique Méridionale, página 47,1855 .

Mylodon gracilis. Burmeister: «Anales del Museo Público de Buenos Aires», tomo I, página 166. - Idem: Description pllysique de la République Argentune, tomo III, pág. 364 .

LYDEKKER: Catal. of Fossil Mammaliu, parte V, página III, 1887.

Psendolestodon gracilis (Burmeister). II. GERvals y AMEGino: Los mamifcros fósilcs, etcétera, página 164,1880 .

Esta especie fué indicada primeramente por P. Gervais bajo el nombre de Lestodon miloides, pero sin dibujos de ella y describiéndola de una manera sumamente rápida, aludiendo únicamente a los caracteres principales, tales como el aspecto caniniforme de la primera muela y su corona cortada en bisel, que son caracteres comunes a todo el grupo.

Más tarde, Burmeister, sobre un animal que, a buen seguro, era de la misma sección, constituyó una nueva especie que designó con el nombre de Mylodon gracilis, pero sin dar igualmente nada más que los caracteres generales que distinguen a la sección, a los cuales, como Gervais, tomó por específicos; hace igualmente alusión al Lestodon myloides de Gervais, que identifica con su Mylodon gracilis y atribuye a la misma especie un cráneo figurado por de Blainville en su «Ostéographie», genre Megatherium, lámina I, figura 8.

En 1880, al hacer conjuntamente con $\mathrm{H}$. Gervais, nuestra revisión general de las especies de mamíferos fósiles sudamericanos, separamos los representantes de esta sección como género distinto del Mylodon y del Lestodon, con el nombre de Pseudolestodon, incluyendo en él varias especies hasta entonces inéditas y otras dudosas cuya identificación no podía establecerse por falta de materiales de comparación.

Tomamos como tipo de esta sección al Pseudolestodon myloides dc Gervais (Lestodon myloides), al cual, sobre restos conservados en el 
Museo de París, lo distinguimos por los siguientes caracteres: talla aproximada a la del Mylodon robustus; diente caniniforme superior triangular v sin ninguna canaleta o surco perpendicular; caniniforme inferior con cos surcos perpendiculares, colocados, uno sobre la cara anterior y el otro sobre la cara externa; los dos pares de dientes caniniformes implantados un poco hacia afuera de la serie dentaria y separados de la segunda muela por un espacio bastante grande.

En cuanto al Mylodon gracilis de Burmeister, si bien reconocimos que se trataba de un Pscudolestoton, como resultaba haber varias especies de este grupo, no pudimos identificarlo con ninguna por falta de figuras o descripción detallada de las muelas y lo conservamos como especie distinta bajo el nombre de.Pseudolestodon gracilis, pero sin pretender que fuera realmente una especie diferente, teniendo cuidado de agregar: «El animal llamado por Burmeister Mylodon gracilis, entra en ruestro género Pseudolestodon. El esqueleto completo y montado se encuentra en el Museo de Buenos Aires, pero es de sentir que el sabio Director del Museo no haya dado de él una descripción más detallada, la cual nos hubiera permitido decir si es idéntica a algunas de las que acabamos de mencionar». (Los mamiferos fósiles, etc., página 174).

Lydekker no tiene, pues, razón al identificar el Mylodon gracilis con el Lestodon myloides sobre la autoridad de Burmeister, no para agregar que ello no es dudoso aunque no sea aceptado por nosotros (Catálogo, parte $V$, página 111 ), puesto que en realidad nunca hemos pretendido que fuera distinta. Lo único que hicimos fué no hacer identificaciones prematuras; y al hacerlo así procedimos sin duda juiciosamente, pues For lo inismo que está pasando con esta especie me estoy convenciendo cada vez más que no se puede establecer identificaciones sin buenas ilustraciones o caracteres diagnósticos no de un orden general sino de ąquellos que dan esos caracteres al parecer de pequeña importancia, que son los que realmente permiten las distinciones o identificaciones específicas.

En efecto, entre los caracteres que Lydekker asigna a esta especie, menciona el del caniniforme inferior que tiene dos surcos, uno adelante y otro sobre la cara posterior externa? (aft) como lo he establecido conjuntamente con Gervais en nuestro trabajo ya citado; pero al enumerar los restos que se conservan en el Museo Británico, menciona un esqueleto casi completo, cuyo cráneo concuerda precisamente con el cráneo típico figurado por de Blainville en su «Ostéographie», genre Megatherium, lámina I, figura 8.

Ahora Burmeister, precisamente sobre esta misma figura de la «Ostéographie» de de Blainville, que antes había identificado con su Mylodon gracilis, y, por consiguiente, con el Lestodon myloides de Gervais, pretende reconocer una especie distinta para la que resucita el nomen 
nudum de Bravard, si bien los restos que describe pertenecen evidentemente al Psendolestodon debilis ( Osteografía de los gravígrados», página 118 año 1886). Agréguese a esto la circunstancia probable de que el original de este mismo cráneo figurado por de Blainville es el que sirvió de tipo a Gervais para la fundación de su Lestodon myloides y se tendrá una idea de la confusión a que han conducido la falta de descripciones fundadas en pequeños detalles, la ausencia de ilustraciones y las identificaciones prematuras.

A propósito de esta misma especie. Burmeister me hace un cargo por fundar especies sobre pequeñas diferencias, como ser el contorno más o menos triangular de un diente o la ausencia o presencia de un surco, agregando que rehusa como innecesarias las obras de esta naturaleza y que tampoco está dispuesto a dar su garantía (que nadie le exige) a las once especies que dice hemos incluído en este género, porque no puede odnitir la fundación de especies sobre algunos dientes sueltos, aunque immediatamente a continuación reconoce que el Lestodon trigonidens ac Gervais fundado sobre un solo diente triangular es una buena especie.

Hace bien el ilustre sabio en no ocuparse de estas nimiedades; 10 harán otros que tienen tiempo que perder: pero en tođo caso será conveniente que cuando describa especies nuevas pase revista a esas especies fundadas sobre piezas sueltas para no exponerse a describir las ya nombradas con otros nombres, como acaba de sucederle con el Mylodon omeni, pues tengo para mí que hay mayor mérito para quien es capaz de distinguir una especie por algunas muelas, que no en quien para hacer el mismo trabajo dispone de un esqueleto.

Pienso también que es de mayor importancia y de mayor precisión dar los caracteres precisos, los contornos exactos y todos los detalles de algunas muelas que no los caracteres generales de un cráneo, que pueden servir para una determinación genérica pero de ninguna manera para establecer las distinciones específicas.

Así sucede en este caso, en que, aunque da el dibujo del esqueleto montado del Mylodon gracilis, la vista del cráneo en distintas posiciones y las muelas de tamaño natural, no me es posible reconocer con precisión la especie, pues no veo en los caniniformes inferiores vestigios de surcos perpendiculares, ni el caniniforme superior aparece de forma triangular como se presenta en el Pseudolestodon myloides; y como, según declaración del autor, no presta mucha importancia a estos detalles, no sé si realmente el dibujo es correcto o si esos caracteres han sido omitidos, cuya duda es tanto más justificada en quien, como yo, ha tenido ocasión de cerciorarse de que en los dibujos del ilustre sabio se ve a menudo lo que no existe.

De cualquier modo, es evidente que tanto Gervais bajo el nombre de l.cstolun myloides, como Burmeister bajo el de Mylodon gracilis, han 
confundido al principio más de una especie, pero como la designación específica de myloides es la primera aplicada a una especie de este grupo, ella debe conservarse para el ejemplar típico cuyos caracteres específicos hayan sido definidos primero. Esos caracteres, tomados de la conformación de los dientes en las distintas especies, los di por primera vez conjuntamente con $\mathrm{H}$. Gervais; y los del Pseudolestodor myloides son los mismos que menciona Lydekker, los cuales deben conservarse como distintivos de la especie, sea ella o no idéntica con la de Burmeister. Lydekker cita además como caracteres distintivos, su construcción general más débil que la del Mylodon robustus, lo que es un carácter distintivo de todas las especies de esta sección: el plano del occipital menos inclinado; y la última muela inferior muy alargada, a lo que puedo agregar la forma del paladar muy triangular, muy angosto atrás y muy ancho adelante.

Es posible, y lo admito cuando menos hasta que se pruebe lo cuntrario, y sobre la autoridad de Lydekker y Burmeister, que el Mylodon sracilis sea especificamente idéntico al Pseudolestodon myloides, pues no dispongo por el momento de materiales originales para poder decidir definitivamente la cuestión.

Reproduzco la figura del cráneo, visto de lado y por su base, conjun. tamente con las muelas de tamaño natural. El cráneo, según Burmeister, tendria 49 centímetros de largo; la longitud del paladar sería de 20 centimetros; la de la serie dentaria superior, 13 centímetros; y la de la inferior, 12 centímetros.

Según los dibujos, el ancho del paladar, entre las dos últimas muelas superiores, sería de 43 milímetros; y entre el par de caniniformes anteriores, de 85 milímetros.

Por los dibujos reproducidos, que dejo mencionados, el caniniforme superior es de tamaño mucho mayor que el diente que sigue y no de sección completamente triangular, sino más bien elípticotriangular, bastante más estrecho adelante que atrás. La segunda muela superior sería nucho más pequeña y elíptica. El caniniforme inferior seria igualmente elíptico y no triangular y sin surcos perpendiculares en ninguna de las caras, pero como en el caso correspondiente de la mandíbula superior, de tamaño mucho más considerable que el diente que le sigue.

Estos dibujos no concuerdan a buen seguro con los caracteres del Pseudolestodon myloides, cuyo caniniforme superior es decididamente triangular, con la cara posterior más ancha y algo deprimida, mientras que el caniniforme inferior, igualmente triangular, tiene un surco perpendicular en la cara anterior y otro en la cara posterior externa.

Por consiguiente, si el dibujo de Burmeister es exacto, mi opinión es que se trata de una especie distinta para la cual deberá conservarse el nombre de Pseudolestodon gracilis. 
Procedencia: .. Distintas localidades de la provincia Buenos Aires y de la República Oriental del Uruguay.

Horizonte:- Piso bonaerense y piso lujanense de la formación pampeana.

Pseudotestodon RFinhardir 11. Gervais y Ameghino

II. Gervais y Amechino: Los maniferos fosiles, etc., página ío.

Conjuntamente con H. Gervais fundé la especie sobre una mandibula inferior completa, cuyas proporciones indican que el animal a que pertenecia era de una talla por lo menos igual a la del Pseudolestodon myloides. El diente caniniforme inferior es proporcionalmente más grtteso e igualmente triangular, con dos surcos perpendiculares como en el de la especie precedente, pero colocados de distinta manera, uno sobre la cara anterior y el otro sobre la cara interna. La altura de la rama horizontal de la mandíbula debajo de la última muela es de $17 \mathrm{mi}$ límetros menor que la altura de la mandibula de la especie precedente tomada en el mismo punto; y esto, a pesar de que ambas tienen el mismo largo, de donde se sigue que la rama horizontal de la mandibula C’el Pseudolestodon Reinhardti es más baja que en la otra especie, pero con dientes relativamente más fuertes y especialmente con el primer diente de aspecto más decididamente caniniforme.

En la mandibula superior el caniniforme es igualmente muy fuerte y de contorno triangular y más echado todavía hacia afuera que en el Psendolestodon myloides, más grueso que el diente siguiente, cortado en bisel muy inclinado y terminando en cúspide muy puntiaguda; la barra que separa el caniniforme de la segunda muela es de 16 milimetros. La última muela superior no es claramente bilobada como en la otra especie sino que tiene tan sólo una especie de prolongamiento posterior que sigue hacia atrás la dirección de la serie dentaria.

La serie dentaria superior ocupa un espacio longitudinal de 144 milimetros. El paladar tiene 57 milimetros de ancho entre el último par de muelas superiores y 117 milimetros en la parte anterior entre ambos caniniformes.

No pudiendo disponer de los materiales reunidos sobre esta especie, por la misma razón que en los casos anteriores, no puedo dar más detalles ni dibujos.

Procedencia: - He recogido los restos de esta especie en distintas localidades de la provincia Buezos Aires.

Horizonte:- Piso lujanense de la formación pampeana. 
Especie establecida igualmente en colaboración con $\mathrm{H}$. Gervais, sobre una mandíbula inferior que difiere a primera vista de la misma parte cie las otras especies por la forma de su parte anterior, que es más elevada, y cuya superficie sinfisaria interna es más cóncava. El diente caniniforme es igualmente triangular, pero con un solo surco perpendicular colocado en la cara anterior, estando el diente implantado en una dirección muy inclinada hacia afuera.

No me es posible dar más detalles ni dibujos por la misma causa que en los casos precedentes.

Procedencia:- Parte Norte de la provincia Buenos Aires.

Horizonte:- Piso lujanense de la formación pampeana.

Pseudolestodon debilis II. Gervais y Ameghino

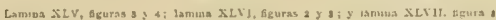

Psendolestodon debilis. II. Gervais y AMeghrno: Los maniferos fósiles, etc., página i6a. aก̃o 1880.

Mylodon Otceni? Bravard: Catalogue des collections, etc., (nomen nudum).

Burmeister: Ostcografia de los Grazigrados, pág. 115, lám. XVI, fig. I, 2, 6 y 8, IS86.

Esta es la especie más pequeña de este género que hasta ahora se conozca de las que proceden de la formación pampeana; y se distingue fácilmente de las otras por los caracteres particulares de la dentadura. El caniniforme y el diente que sigue hacia atrás, tanto en la mandíbula superior como en la inferior, sobresalen fuera de los alvéolos mucho más que en todas las otras especies.

El caniniforme superior no es tan grueso como en las otras especies, n1 $\tan$ fuertemente inclinado hacia atrás, pero es más largo y con la corona cortada en bisel muy pronunciado, terminando en cúspide aguda; es de sección elíptica, un poco más ancho atrás que adelante y de superficie lisa, siendo todo el prisma del diente fuertemente arqueado hacia atrás; tiene 17 milímetros de diámetro anteroposterior y 13 milímetros de diámetro transverso.

La segunda muela superior es de sección elíptica y de corona truncada horizontalmente, con la parte que sobresale fuera del alvéolo muy larga pero fuertemente arqueada hacia atrás, como en el diente anterior; tiene 21 milímetros de diámetro anteroposterior y 14 milímetros de diámetro transverso. E1 diastema que separa a los dos primeros dientes tiene 15 milimetros de ancho.

La tercera muela superior es triangular y con sus tres caras fuertemente deprimidas en sentido perpendicular. 
La cuarti muela superior es igualmente triangular, angosta en el lado externo y ancha en el interno, donde muestra igualmente un fuerte sturco perpendicular.

La quinta muela superior es alargada de adelante hacia atrás, con dos depresiones perpendiculares opuestas, una interna y otra externa, y cun el lóbulo anterior considerablemente más ancho que el posterior. Tienc 21 milimetros de diámetro anteroposterior, 15 milímetros de diámetro transverso adelante y 10 milimetros atrás.

l.ongitud del espacio ocupado por las muelas superiores: 12 centímetros.

El primer diente de la mandíbula inferior o caniniforme, es pequeño pero muy elevado, colocado bastante hacia afuera de la línea dentaria, de sección elíptica y de superficie completamente lisa, sin surcos perpendiculares en ninguno de los costados. Tiene 20 milimetros de diámetro anteroposterior y 13 milimetros de diámetro transverso; se eleva unos 35 milímetros fuera del borde alveolar de la mandíbula, estando un poco inclinado hacia adelante y hacia afuera.

La segunda muela inferior es triangular, fuertemente excavada en sus lados interno y externo, pero de una manera más débil en el anterior. Tiene 21 milímetros de diámetro anteroposterior y la corona está gastada en declive hacia atrás. La altura de la muela es, sobre el borde alveolar, de 24 milimetros y está separada del caniniforme por un diastema de 15 milímetros de ancho.

La tercera muela inferior es subrectangular y está colocada oblicuamente, con su lado externo más ancho que el interno. Presenta una gran depresión perpendicular sobre su cara ancha anterior y una mucho más estrecha en forma de surco sobre el lado angosto interno. Tiene 26 milinetros de diámetro anteroposterior oblicuo y 14 milímetros de diámetro transverso.

La última muela inferior es muy alargada de adelante hacia atrás, con el lado externo ocupado en casi toda su extensión por una depresión muy ancha y bastante profunda que contiene una segunda depresión apenas acentuada en su parte posterior. Sobre el lado externo ticne una depresión menos ancha pero mucho más profunda, que ocupa casi toda su parte posterior, limitada por dos columnas salientes, muy pronunciadas. Esta muela tiene 45 milímetros de largo.

Las cuatro muelas juntas de la mandibula inferior ocupan un espacio longitudinal de un poco más de 12 centímetros.

Burmeister describe y dibuja un cráneo perfecto de esta especie bajo el nombre de Mylodon Oweni, que pretende le ha aplicado Bravard. Según el dibujo, el cráneo es relativamente corto, pero de superficie superior convexa o abovedada, particularmente en la región frontal.

La mandíbula inferior presenta en su parte anterior, delante de la 
Frimera muela, tres agajeros mentonianos, más o menos del mismo tamaño y colocados sobre la misma línea longitudinal. La longitud del cráneo es de 44 centimetros, 19 de los cuales corresponden al palada:. El alto de la rama horizontal de la mandibula, debajo de la segunda muela, es de 74 milímetros.

Procedencia:- He recogido los restos de esta especie en las barancas del río Luján, a poco más de una legua de Mercedes, en el punto conocido por Paso del Cañón.

Horizonte:- Piso bonaerense de la formación pampeana.

I'seudolestodon bisulcarus II. Gervais y Ameghino

II. Gervats y $\Lambda$ Megrino: Los maniferos fosiles, etc., págira 162, 1880 .

Fundé la especie, conjuntamente con H. Gervais, sobre restos de un rsculolestodon, cuyos caniniformes inferiores son de figura triangular, de cara perpendicular anterior lisa, pero que presentan, en cambio, un surco perpendicular sobre la cara interna y otro sobre la externa, ambos muy pronunciados.

No predo dar más detalles, dibujos ni medidas. por la misma razón que en los casos precedentes.

Procedencia: - He recogido los restos de esta especie en el municipio de Buenos Aires.

Horizonte:- Piso bonaerense de la formación pampeana.

Pseudolestodon trisul,catus H, Gervais y Ameghino

Laminn XLIX, gururas

H. Gervais y Aarenino: Los mamiferos fosiles, etc, página i64.

Fundé la especie, conjuntamente con $\mathrm{H}$. Gervais, sobre un caniniforme inferior del lado derecho, de sección triangular y de corona cortada . en bisel muy pronunciado, dirigido oblicuamente de arriba hacia abajo, de atrás hacia adelante y de adentro hacia afuera. El prisma del diente ¿s ancho adelante y angosto atrás; y la superficie masticatoria es ancha abajo y adelante, estrechándose gradualmente hacia atrás y hacia arriba hasta terminar en cúspide aguda; esta superficie masticatoria, completâmente lisa, tiene 21 milímetros de ancho en su parte anterior y $29 \mathrm{mi}$ límetros de largo de abajo hacia arriba y de adelante hacia atrás. El prisma del diente tiene 25 milímetros de diåmetro anteroposterior y 21 milimetros de diámetro transverso. La cara anterior, de 20 milímetros de ancho, presenta un surco perpendicular cóncavo y profundo, situado niás hacia el lado interno que al externo. La cara externa del prisma, 
ac 25 milimetros de ancho, es convexa en forma de columna hacia adelante y presenta un surco perpendicular cóncavo y profundo hacia su parte posterior. La cara interna, de 24 milimetros de ancho, es un poco deprimida perpendicularmente en el centro, formando como un tercer surco muy ancho pero poco profundo.

Procedencia: - Parte Norte de la provincia Buenos Aires.

Horizonte:-Piso bonaerense de la formación pampeana.

P'si:LDOR,ESTODon LeTtSomt (Owen) H. Gervais y Ameghino

tamina XLYTH, Wenras a

Mylodon Lelisomi (Owen) en H. Gervais y AMEghino: Los mamiferos fósiles, etc, página 164,1880 (escrito Leptsomi por error).

LYDEKKER: Catal. of Fossil Mammalía, parte V, página 108, 1887.

Pseudolestodon Lettsomi. H. Gervars y Amegurno: Obra citada.

Esta especie fué simplemente indicada en nuestro catálogo de los mamíferos fósiles de Sud América según el marbete que ostentaba un cráneo de Pseudolestodon que vi expuesto en las galerías del Museo Británico durante mi visita a Londres en 1879; y Lydekker da ahora de ella los jirincipales caracteres distintivos, acompañándolos de un grabado que reproduzco (lámina XLVII, figura 4). En la introducción del mismo traliajo ( Catálogo», etc., parte $V$, página 16), manifiesta Lydekker que éta especie puede ser idéntica con la que acababa de describir Burmeister, bajo el nombre de Mylodon OHeni, que es mi Pseudolestodon debilis, pero esta identificación no es posible, pues el cráneo del Pseudolestodon dehilis es notablemente más pequeño, bastante más corto y relativamente más ancho; el paladar es más corto, más ancho y menos trianSular; y las muelas diferentes, particularmente la primera, que está separada de la segunda por un diastema bastante ancho.

Los caracteres distintivos que asigna Lydekker a este especie, son: «el paladar muy estrecho y convexo, la elevación excesiva de la pared interna de los alvéolos de los dientes posteriores y el intervalo más angosto entre los pterigoides».

Según el grabado que acompaña a la enumeración de los restos de esta especie, puedo agregar que todo el cráneo es en su conformación más alargado y relativamente más estrecho que en todas las demás especies, siendo esta particularidad bien visible en todas las regiones del cráneo. L! paladar es de un aspecto triangular muy característico, siendo su ancho, entre el par de dientes anteriores, casi dos veces y media mayor que entre el par de dientes posteriores, cuya desproporción no se nota en ninguna otra especie.

Desgraciadamente faltan en este cráneo todos los dientes, pero los alvéolos bien conservados proporcionan preciosas indicaciones. La pri- 
mera muela superior era de contorno oval y no más grande que la segunda, aunque más corta: estaba colocada en una situación más anterior que en las otras especies, sobre el mismo borde anteroexterno del paladar, pero no estaba separada de la segunda por un diastema ancho como en las demás especies de Pseudolestodon, siendo el diastema todavía más corto que en los verdaderos Mylodon; pero la gran separación entre ambos dientes superiores y la divergencia enorme de las series dentarias en la mitad anterior de su largo, no dejan duda alguna de que se trata de un verdadero Pseludolestodon.

La segunda muela superior es de sección eliptica, muy alargada de adelante hacia atrás y muy comprimida transversalmente, como la muela correspondiente del Mylodon Sauvagei.

El largo de este cráneo es de $0^{\mathrm{m}} 465$, pero como le faltan los intermaxilares, su largo total debía ser superior a 48 centimetros, to que indica un animal de talla relativamente considerable.

Procedencia: - Este cráneo ha sido enviado a! Museo Británico por el señor W. G. Lettsom, como procedente de la barranca de Santa Lucía, cerca de Montevideo; y Lydekker atribuye a la misma especie algunos restos procedentes de la República Argentina. La especie ha existido seguramente en la provincia Buenos Aires, pues he recogido un cráneo entero, aunque también sin muelas, cerca de la Villa de Luján, que concuerda por completo con el grabado publicado por Lydekker. Esta pieza forma parte de las colecciones del Museo de La Plata.

Horizonte: - Piso belgranense y piso ensenadense de la formación pampeana.

Pseudozestodon AzQualis Ameghino

Pseudolestodon acqualis. AMEGHino: «Boletin de la Academia Nacional de Ciencias», tomo $1 \mathrm{X}$, página 186 , año 1886 .

Pserdolestodon, ST.? AMFGHINn: \&Bol.s, etc, tono VIII, página I23, 1885 .

Este desdentado, de una época mucho más antigua que los prececentes, ha tenido casi la misma talla y la misma conformación que las grandes especies pampeanas, pero hasta ahora sólo me es conocido por dientes aislados, de modo que el cráneo o las otras partes del esqueleto pueden presentar caracteres distintivos más perceptibles que los que es dado percibir en la dentadura.

Además, es muy difícil distinguir los dientes aislados que corresponden a una especie cuando ella no es conocida ya por partes completas que permitan determinar las pequeñas variaciones de cada una de las muelas. Es, pues, casi seguro que las numerosas muelas de Pseudolestodon de las formaciones antiguas del Paraná, provienen de más de un. 
especie, rere an 1. imposibilidad de pouler referirlas con seguriuad a calla unn do las especies alli representadas, me parece preferible refeJirlis provisoriamente a una sola especie que ya anteriormente he menLivilulo cunt el nombre de Psendolestoton atqualis, hasta que nuevos materiales puedan permitir un conocimiento mis exacto de las espe. cies alli representadas.

Les diunies aisludes son numerosos, pero sólo mencionaré algunos cie los principales.

Un caniniforme superior, que es el que me sirvió de base para la fimticicial th 1. especie; us bastante rodado pero muy característico por su inma triungular, su curva muy pronunciada y la corona cortada en IS 1. Este dientu ha perdido la capa de cemento externo que se conserva sulu en un peyueño trecho con un espesor de cerca de un milimetro. Fl prisma del diente es completamente liso, sin ningún surco ni ranura lingitudinal: tiene 17 milimetros de diámetro anteroposterior, 13 milínetros de dímetro transverso y un largo en linea recta de unos 8 centímetrus. La silperficie tritoria de la corona cortada en bisel tiene 22 milímetros de largo y 13 de ancho.

Lin caninifonac inferior (lamina XL, figura 9) de dimensiones proforcionalmente mis pequeñas que el superior, de sección eliptica y cortado en bisel solure la cara mis ancha. El prisma del diente tiene 1.t milimetres it Ámetro mayor, 10 milímetros de diámetro menor y 5 centímetros de largho. La superficie cortada en declive tiene 18 milimetros de largo.

Lna muela que fatece corresponder a la tercera superior izquierda del Pseudolestodon myloides y con poca diferencia del mismo tamano (lámina XL. figura 3). Muestra una depresión ancha en el lado externo, poco profunda y de fondo cóncavo; y dos depresiones en el lado interno, vona liacia adelante y otra hacia atrás, que limitan una columna perpendicular estrccha y prolongada hacia adentro y hacia adelante. La corona tiene 24 milimetros de diámetro anteroposterior y 16 milímetros de diametro transverso al nivel de la columna interna. El largo del trozo existente es de 5 centímetros, pero está roto en la base. La columna interna forma una cúspide más elevada que el resto de la corona.

Una muela parecida a la anterior, pero que parece corresponder a la cuarta superior derecha (lámina $\mathrm{XL}$, figura 4); se distingue de la anterior por el surco externo menos marcado y la columna interna no tan acentuada. La corona tiene 25 milimetros de largo y 15 de ancho; y el trozo existente, roto en la base, 55 milimetros de largo.

Otra muela superior, que parece igualmente la cuarta superior (lámina XL, figura 7), pero de tamaño un poco menor que la precedente y con algunas pequeñas diferencias; presenta igualmente una depresión externa bastante ancha y dos internas más angostas, pero el lóbulo ante- 
rior es muy grande y regularmente cóncavo, mientras el posterior y la co'umna interna son más estrechos. La corona está gastada en declive siendo más baja en el lóbulo posterior; tiene 23 milímetros de diámetro anteroposterior por 16 milímetros de ancho y 65 milimetros de largo.

Un trozo de muela, quinta superior (lámina XL, figura 5), roto en la base y en la corona, pero que se conoce era de tamaño relativamente considerable. Presenta un surco perpendicular externo muy ancho y otro interno situado más hacia atrás, angosto y profundo, de manera que la muela queda dividida en dos lóbulos desiguales, el anterior más grande y el posterior más pequeño. Tiene $2 S$ milímetros de diámetro anteroposterior, 15 milimetros de diámetro transverso en el lóbulo anterior y 11 en el posterior.

Una muela inferior que supongo sea la segunda del lado derecho (lámina XL, figura 6). Tiene una depresión perpendicular interna relativamente angosta y otra externa más angosta y profunda en la parte fosterior, de manera que la corona envia un prolongamicnto posterior Instante parecido al de las muelas de las especies pampeanas, sólo que 1: falta el surco de la cara anterior, al parecor siempre presente en los últimos. La corona tiene 23 milímetros de largo y 13 de ancho. E1 trozo existente, roto en la base, tiene 4 centímetros de largo.

Otra muela inferior, que supongo sea igualmente la segunda (lámina XL, figura 8); es bastante parecida a la anterior, pero con tres surcos perpendiculares como en las especies más modernas: uno interno, otro externo y el tercero sobre la cara anterior. La corona tiene 14 milimetros de largo por 13 de ancho. Probablemente proviene de una especie distinta.

Una tercera muela inferior, de forma rectangular y de tamaño relativamente considerable. La corona, un poco excavada en el centro, tiene 2.3 milímetros de largo y 17 de ancho. En cada una de las cuatro caras longitudinales hay un surco perpendicular de fondo cóncavo, dos de ellos bastante profundos y los otros dos poco marcados. La parte existente tiene 55 milímetros de largo, estando roła alli donde empezaba la cavidad nasal faltándole, por consiguiente, tres o cuatro centímetros en la base.

Proccdencia: - Los restos de esta especie han sido descubiertos por el profesor Scalabrini en las barrancas de los alrededores de la ciudad del Paraná.

Horizonte:- Piso mesopotámico de la formación pampeana (oligoceno inferior). 
Oligodon freudolestoides. AnECHrno: «Boletin de la Academia Nacional de Ciencias», tonı $\mathrm{V}$, página $299,1883$.

Este animal está representado por un solo diente, el primero de la mandíbula superior, de aspecto caniniforme como el diente correspondiente de todas las especies de Pscudolestodon, pero de tamaño muy pequeño. Es de sección transversal eliptica, con su eje mayor en dirección anteroposterior $y$ fuertemente arqueado en todo su largo. La corona está gastada en declive muy inclinado, como la correspondiente del Pscudolestodon, formando una elipse muy alargada de 15 milímetros de largo y 6 de ancho máximo. Esta corona así gastada y perfectamente pulida por el frotamiento representa una especie de corte en el cual se ven varias capas concéntricas que corresponden a las distintas capas de stibstancias diferentes que constituyen la muela. La primera capa externa, gruesa en la esquina posterior, cóncava y muy delgada en la anteror convexa, representa el cemento. Sigue a ésta una muy delgada lámina de color verdoso o azulado, de aspecto vítreo, que encierra otra figura elipsoidal de dentina de unos dos milimetros de grueso, en el centro de la cual se ve una especie de núcleo igualmente elipsoidal, de vásculodentina, de cuatro mílímetros de largo y dos de ancho.

Este diente proviene, a buen seguro, de un género distinto, al que hahín designado desde el principio con el nombre de Oligodon pseudolestoides: $\sin$ embargo, como resulta que el nombre de Oligodon ya ha sido empleado, habría que substituirlo por otro. Pero como desde entonces tio he vuelto a encontrar otros restos que puedan dar más indicios sobre sus afinidades, prefiero por ahora, antes que crear un nuevo nombre, dejarlo provisoriamente en el género Psendolestodon, con el cual sin duda presenta grandes afinidades.

Procedencia: Ha sido descubierto por el profesor Scalabrini en las barrancas de los alrededores de la ciudad del Paraná.

Horizonte:- Piso mesopotámico de la formación patagónica (oligoceno inferior).

(?) PSEUdOLESTODON INJUNCTUS, n. $s p$.

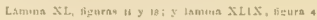

Dos muelas inferiores del tamaño de las de un Mylodon o un Pseudolı stodon, presentan suficientes diferencias para ser separadas como de una especie distinta, que probablemente pertenece a un género nuevo, pero al cual coloco provisoriamente en el género Pseudolestodon, hasta 
que nuevos materiales me proporcionen datos más seguros sobre sus caracteres distintivos como género.

Una de estas muelas (lámina XL, figura 18), la más grande, de contorno triangular, presenta a primera vista un gran parecido con una de Pscudolestodon, pero examinándola con más detención se perciben bastantes diferencias para que no sea posible determinar con precisión la posición que ocupaba en la serie dentaria, aunque el prisma completamente recto no deja duda que se trata de una muela de la mandíbula inferior, que, según las analogias con los otros géneros, no puede ser ni la primera ni la última, sino la segunda o la tercera. Supongo sea la tercera inferior; una de sus caras laterales, la más ancha, muestra varias ondulaciones perpendiculares, visibles también sobre la cara opuesta, en la que se levanta además una fuerte columna perpendicular, detrás de la cual, en el costado más angosto, que puede considerarse como la base del triángulo, hay un fuerte surco perpendicular, ancho, profundo y de fondo cóncavo. La corona tiene 23 milímetros de largo y 14 milimetros de ancho máximo. El trozo existente tiene 55 milímetros de largo, pero está roto alli donde empieza la cavidad pulpal, de manera que entero debía ser bastante más largo.

La otra muela, que, por sus caracteres, proviene sin duda del mismo animal, es también completamente recta, de manera que pertenece igualmente a la mandíbula inferior, pero como es algo más pequeña que la precedente debe ser la segunda. Es de sección transversal también algo triangular o subelíptica (lámina XL, figura 11), con dos caras principales opuestas, una con una ancha y profunda depresión perpendicular, que divide a la muela en dos partes; en el fondo de esta depresión y precisamente en el medio, se ve una pequeña arista longituclinal que recorre la muela en todo su largo. La cara opuesta es casi flana, con algunas pequeñas ondulaciones perpendiculares poco sensibles. La cara perpendicular tercerą, que forma la base del triángulo, muestra también un surco longitudinal, pero no tan profundo como en la muela precedente. La corona está gastada de un modo desigual, elevándose en el medio en forma de cresta transversal oblicua y en declive adelante y atrás. Todo el prisma ha estado cubierto de una capa muy delgada de cemento amarillento, de la cual se conservan todavía vestigios en algunos puntos. El prisma es un poco más grueso en la base disminuyendo gradualmente de tamaño hacia la cúspide. La corona tiene 18 milímetros de diámetro anteroposterior y 11 milímetros de diámetro transverso máximo; el trozo existente tiene unos cuatro centímetros de largo, pero está roto precisamente allí donde empieza $1 \lambda$ cavidad pulpal.

Atribuyo a la misma especie, a lo menos provisoriamente, un caniniforme inferior aislado del lado izquierdo, de una forma muy diferente 
de la glie prünta el mismo diente de las demás especies que me son conouilas. Es de sccuión triangular muy pronunciada, con todo el prisma ciel diente fuertemente encorvado con la concavidad hacia el lado t': : nno y la convexidad hacia el interno, terminando en corona cortada (1) Sed con tha superficic oblicua piramidal de 26 milímetros de alto $\because$ I. de ancluo en la base. La cara longitudinal del lado interno, que es ia mais ancha, es casi plana, con una muy pequeña ondulación longitudinat cara de su horde posterior y presenta un ancho de 22 milímetros. La cara lonsitudinal anterion ticne 18 milimetros de ancho y es fuertemente axcavada un sentido longitudinal formando un surco cóncavo bastanti ancho pero poco profundo. La cara longitudinal externa es mucho r.ri: angosial pues sólo tiene 13 milímetros de ancho; y es fuertemente convia afectando la forma de una columna longitudinal; además pres.ntir sobre sii lido interno una ancha excavación longitudinal bastante "wranda $y$ de fondo cónciro, que corre paralela a la arista longitudinal preterio:. Trulo el prisma del diente cstí cubierto por una capa de ce.

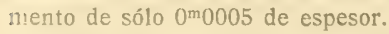

Pruchicita: - Estas piezas han sido descubiertas por el profesor Scalahrini en las barrancas de los alrededores de la ciudad del Paraná y pertenecen al Museo provincial de Entre Ríos.

Horizonie: -.- Piso mesopotámico de la formación patagónica (oligoceno inferior).

\section{NEMATTHEIRIUAL Ameghino}

Axecritio: Enumeración sistesnática de los mamiferos, etc., página 22,1887 .

Este género se distingue de todos los demás de las antiguas formaciones eocenas del río Santa Cruz por sus muelas, que en vez de ser todas iguales $y$ de forma más o menos rectangular, excepto, naturalmente, el caniniforme, son de forma desigual y todas más o menos prismáticas, farecidas a las de los géneros Mylodon y Pseudolestodon. La perforación de la rama externa del canal alveolar se abría probablemente sobre el lado externo de la base de la rama ascendente.

Nematheritim anculatum Ameghino

Arregrino: Enumeración sistemática de los mamfferos, etc., página 22 , número 102,4887 .

Esta especie está representada por dos pequeños fragmentos de los maxilares superiores, uno derecho y el otro izquierdo, con vestigios de los cuatro dientes anteriores, un pequeño fragmento de mandibula inferior $y$ dos o tres dientes sueltos. 
Los fragmentos de maxilares stperiures muestran que el primer diente ara elíptico, poco separado del segundo y de aspecto caniniforme muy poco acentuado. Desgraciadamente sólo existe la base de uno de ellos, que si. no otra cosa, proporciona cuando menos su diámetro, que es de unos 6 milimetros. El diastema que separa a este diente del que le sigu sólo tiene 6 milímetros de largo.

El diente que sigue hacia atrás, o segundo, es de sección triangular con sus tres caras dispuestas de modo que una mira hacia adentro, otra adelante y la tercera atrás, mirando al lado externo la arista que forma la cúspide del triángulo. Los ángulos son redonduados y cada una de las tres caras es un poco deprimida verticalmente en el centro, particularmente la interna que muestra un verdadero surco perpendicular. El diente tione 10 nilimetros de diámetro anteroposterior y 9 milimetros de diámetro transverso.

La tercera muela superior es elipticoprismatica, de ángulos más redondeales, mís parecida a la de Scclitotherimm y como las de este género con su mayor diámetro colocado oblictamente al eje de la serie dentaria. Este diente tiene 12 milimetros de diámetro mayor y 6 milimetros de diámetro transverso.

De la muela que sigue, o cuarta, existen pequeños vestigios, que pueden hacer suponer que era de la misma forma que la tercera. Las muelas superiores segunda $y$ tercera ocupan juntas un espacio longitudinal de 22 milimetros.

E1 fragmento de naxilar derecho muestra encima de la parte anterior del diente tercero y a sólo pocos milímetros del borde alveolar, el agujero suborbitario, de tamaño relaívamente considerable, e inmediatamente encima se ve una parte del lacrimal separada del maxilar por situra bien visihle y con una perforación elíptica de gran tamaño en su parte superior.

El fragmento de mandibula inferior consiste tan sólo en un trozo de la pared externa de la parte media de la rama horizontal del lado derecho, en el cual se ve la parte externa de los alvéolos de las tres últimas muelas. Los dientes segundo y tercero parecen haber sido elípticoprismáticos, prohablemente parecidos a los del Scclidotherium; el diente cuarto ha sido de tamaño mayor y con un principio de división en dos lóbulos sobre su cara externa.

Uno de los dientes sueltos es probablemente el primero de la mandibula inferior; es asimismo de sección triangular, con sus tres caras in poco deprimidas perpendicularmente y de sólo 6 a 7 milímetros de diámetro. Este diente está todavía adherido a un pequeño fragmento de mandíbula en el cual se ve parte del alvéolo del que le sigue, de manera que el primer diente estaba colocado inmediatamente adelante del segundo. 
Otro diente suelto es el primero de la mandíbula superior, con la corona intacta. Este diente es notablemente más pequeño hacia la corona cue en la base y de sección bastante elíptica, con un diámetro mayor de 3 milimetros y 6 milimetros de diámetro transverso en su parte posterior, que es la más ancha. La corona está cortada en bisel en su cara pesterior, formando un plano inclinado elíptico de 10 milimetros de largo por 5 de ancho.

Procedencia: - Los restos de esta especie han sido descubiertos por Carlos Ameghino en las barrancas del río Santa Cruz, en Patagonia austral.

Horizonte:- Piso santacruceño (eoceno inferior).

\author{
Nematuertuat sinuatum Ameghino \\ AMEGntwo: Enumeración sistemálica de los mamiferos, etc., página 22, numero 103, 1887.
}

Esta especie sólo esta representada por un fragmento de mandibula inferior de la parte posterior de la rama horizontal del lado izquierdo, en el cual está implantada la base o parte inferior de la última muela. observándose también la base del alvéolo de la penúltima.

Se distingue inmediatamente de la especie precedente, por sı tamaño hastante mayor y por la forma particular de la última muela inferior. Esta muela es de tamano hastante más considerable que las anteriores y de forma cuadrangular, con su cara anterior notablemente más ancha cue la posterior y con sus cuatro ángulos bien pronunciados. Las caras anteriores interna $y$ posterior son un poco deprimidas perpendicularmente, pero la cara externa es deprimida y con un verdadero surco perpendicular, angosto y profundo. Tiene 18 milimetros de diámetro anteroposterior, 12 milimetros de diámetro transverso en la cara anterior y \& milímetros en la posterior. La rama horizontal de la mandibula debajo de esa misma muela tiene 34 milimetros de alto y 21 milimetros de espesor.

Procedencia: - Los restos de esta especie han sido descubiertos por Carlos Ameghino en las harrancas del río Santa Cruz, en Patagonia austral.

Horizonte: - Piso santacruceño (eoceno inferior).

De estos géneros, los de caracteres más primitivos son los de dientes anteriores truncados horizontalmente, esto es: el Mylodon y el Promylodon. El Promylodon es un antecesor del Mylodon en el tiempo y lo es también por sus caracteres más primitivos, entre otros, el de las muelas con una capa de substancia interna vitrea que corresponde al esmalte. 
El Pseudolestodon, no es más que una modificación del Mylodon, al cual se liga por una serie completa de tipos intermedios. El Nematherium, a su vez también es próximo aliado đel Mylodon, pero no puede ser su antecesor por sus muelas truncadas oblicuamente, ni tampoco su descendiente puesto que se remonta a una época mucho más lejana, debiendc ligarse probablemente con uno de los antecesores del Mylodon y del Promylodon, más o menos en esta forma:

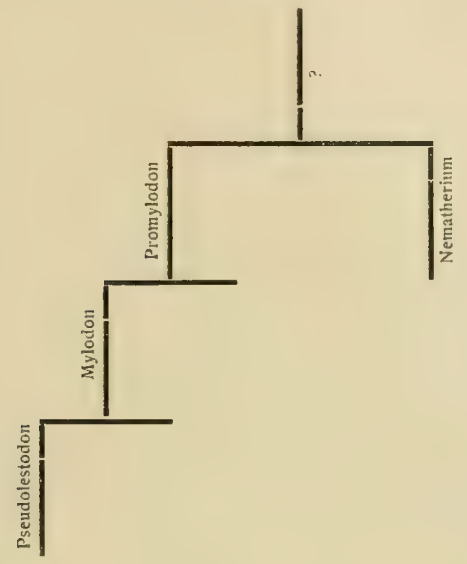

Tampoco son difíciles de establecer las relaciones de parentesco y descendencia de los distintos grupos de los gravígrados.

El mayor número de dientes observado entre los gravígrados, excepto los casos de la presencia de dientes anormales, es de cinco arriba y cuatro abajo; luego esta es la fórmula del tipo más primitivo. Es evidente que ese tipo primitivo tuvo por antecesores otras formas que tenian un número de dientes bastante mayor; y como más cercano al tipo antecesor de los homalodontes, todos los dientes debían ser de igual forma, de donde puede deducirse que aquellos que presentan dientes de formas más heterogéneas descienden de los que presentan dientes de formas riás homogéneas. Considerados según estos principios, la primera diferencia notable que salta a la vista es la que existe entre los animales que presentan todas las muelas truncadas horizontalmente y aquellos que tienen la primera muela de cada mandíbula truncada oblicuamente o de aspecto caniniforme más o menos pronunciado; estos últimos, de acuerdo con las leyes de la evolución, deben descender de los primeros; pero 
dicho carácter, que no es más que el resultado de una especialización nás o menos avanzada, está distribuido de una manera muy irregular, siendo en unos casos propio de grupos o familias enteras y en otros tan sólo de ciertos géneros. El grupo en el que esta especialización ha alcanzado su más elevado desarrollo, es el de los Lestodontide, todos cuyos representantes son de talla considerable y con la primera muela de cadi mandibula constantemente truncada oblicuamente o en bisel.

El otro grupo, en el cual el carácter mencionado se encuentra más desarrollado es el de los Megalonychidu, pero en éstos el caniniform เ: a menudo pequeño o truncado horizontalmente y sus representantes son casi siempre de dimensiones mucho menores que los Lestodontidu.

Por estos caracteres podrian ser antecesores de los Lcsiodontida, pero la forma de las muelas es muy distinta, ligándose por ella los $M e$ galonychidae a los Orthotheridae y a los Megatheridae.

El aspecto caniniforme de la primera muela es mucho menos pronunciado en los Orthotherida que en los Lestodontidu y en los Mcgalonychilli, presentando además, en todos los demás caracteres de la dentición una transición entre ambos grupos. Todos los Orthotheridix son, además, de talla muy pequeña; y como remontan a los primeros tiempos terciarios, en los cuales aún no se han encontrado representantes de los Lestoduntide, es claro que tienen forzosamente que ser los antecesores de éstos. La diferencia principal entre los Orthotheridu y los Lestodontide' se encuentra en la posición de la abertura externa del canal alveolar, en la base de la rama ascendente en los primeros y sobre el lado externo de la misma en los segundos; pero la forma que distingue a los Orthotherido es más parecida a la que se encuentra en los Megatherida, que es el grupo de gravígrados más primitivo. Una diferencia igualmente de consideración entre los Orthotherida y los Lestodontida, aparece en la forma de la ultima muela inferior, siempre simple en los Orthotheride, carácter primitivo y de antecesor, pero siempre bilobada en los Lestodontida, carácter de evolución más avanzada. En cuanto a la forma de las muelas, en los Orthotheride, se manifiestan desviaciones evidentes a la forma que caracteriza a los Lestodontida, formando el género Hapa. lops la transición entre ambos grupos, no siendo dudoso que constituye entre los Orthotherida el verdadero antecesor de los Lestodontida.

Los Megalony'chide' no pueden descender de los Lestodontida por oponerse a ello su tamaño bastante menor y la última muela inferior, que siempre es simple. Por la forma de las muelas se ligan evidentemente a los Orthotheridu, de los cuales puede decirse se distinguen únicamente por la posición de la abertura de la rama externa del canal alveolar, colocada en los Megralonychide sobre el lado externo de la base de la rama ascendente, de manera que no es dudoso que desciendan de los Orthotheridce. 
Por la forma de las muelas, los Orthotherida se acercan a los $M$ egli . theride, diferenciándose de ellos por la posición de la abertura externa del canal alveolar colocada un poco más hacia afuera, cuyo carácter indica una modificación hacia el tipo de los Megalonychide y de los Lestodontidx y también por la forma distinta de la primera muela, más o menos caniniforme, que es un carácter evidente de evolución más avanzada, siendo de consiguiente muy natural la descendencia de los Orthotherida de una forma de los Megatherida.

Los Mylodontide no pueden reclamar por antecesores ni a los Urthotheride, ni a los Megalonychida, ni a los Lestodontidac, pues la primera muela de cada mandíbula es en ellos de un carácter más primitivo o, si se quiere, menos especializado; $\sin$ embargo, en los demás caracteres constituyen un tipo de evolución más avanzada, pues tiene la abertura de la rama externa del canal alveolar colocada en la misma posición que en los Megalonychide y en los Lestodontida, presentan el intermasilar: completamente atrofiado y la última muela de cada mandibula, tanto arriba como abajo es bilobada. La distancia que los separa de los Megatheridu es asi verdaderamente enorme, pero entre ambos grupos se colocan los Scclidothcrida, que son de un carácter más primitivo y más cercano de los Megatheride, por su intermaxilar muy largo y la última muela superior no bilobada, presentando igualmente las muelas una forma intermedia entre la subcuadrada de los Megathcrida y la triangular de los Mylodontida; éstos tienen, por consiguiente, que haber pasado por una forma o etapa parecida a la de los Scelidotherida, los que serían descendientes directos de los Megatherida. Los Megatheride serian de consiguiente, entre los gravígrados, el tipo de caracteres más primitivos y el tronco antecesor de todos los demás, 10 cual concuerda con sus caracteres dentarios, con el gran desarrollo que prescnta el intermaxilar, con su remota antigüedad y con la talla diminuta de sus más antiguos representantes.

Las relaciones de los tres grandes grupos de los Anicanodonta, son igualmente fáciles de establecer entre los Gravigrada y los Tardigrada, pero más difíciles en lo que concierne a los Vermilinguia. Los Tardistada, por la atrofia de la cola y la forma craneana, son los Anicanodonta de evolución más avanzada, lo cual está de acuerdo con su aparición relativamente reciente y pueden considerarse como descendientes de los Gravigrada. El grupo con el que presentan un mayor parecido, tanto por su tamaño relativamente pequeño, como por la forma de las muelas, la disposición de la mandíbula, etc., son los Orthotheride, cuyos verdaderos descendientes son.

Los Vermilinguia se unen, por la forma alargada del cráneo, a los Scelidotherida, con los cuales seguramente están estrechamente emparentados y pueden considerarse como sus descendientes. 
Estas vistas pueden expresarse en la siguiente forma:

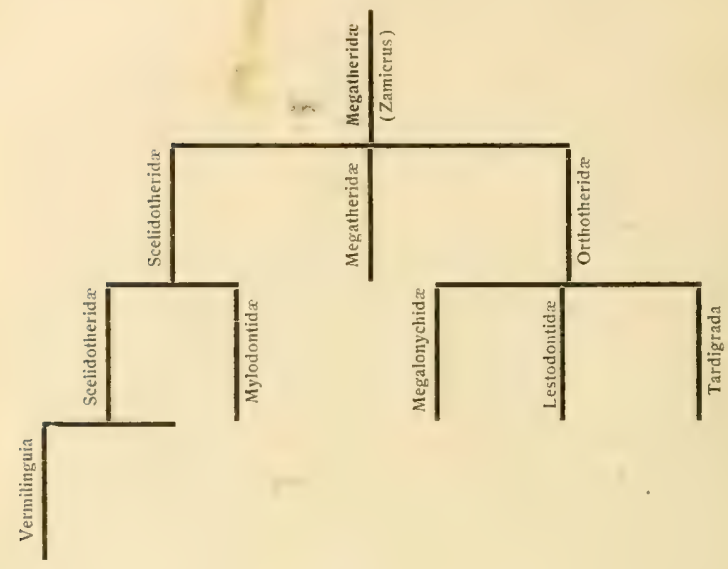

HICANODONTA

Incisivos generalmente ausentes o rudimentarios. Muelas numerosas, no menos de $\frac{8}{8}$, alcanzando hasta ${ }_{24}^{25}$, todas de la misma forma o con variaciones de forma poco sensibles. Un exoesqueleto más o menos ferfecto, siempre divisible en tres partes: una cefálica, que protege al cráneo; una dorsal, que protege al tronco; y una caudal, que envuelve a la cola.

Los representantes de esta tribu se dividen en tres órdenes que se distinguen por los siguientes caracteres:

a. Coraza dorsal sin fajas transversales movibles en el centro. Glyptodontia.

$b$. Coraza dorsal con fajas transversales movibles en el centro. Dasypoda.

$c$. Coraza dorsal formada por placas todas movibles, dispuestas por fajas transversales e imbricadas. Peltateloidea. 


\section{GLYPTODONTIA}

RESEÑA HistóRICA. - Las primeras noticias sobre un animal del grupo de los Gliptodontes se encuentran en Falkner (4), quien a mediados del siglo pasado encontró una gran coraza de un animal desaparecido, que a pesar de su enorme tamaño fué por él comparada a la de los armadillos actuales, reconociendo que ambos animales debian ser muy afines. Esto no impidió que años más tarde, cuando se encontraron nuevos fragmentos de corazas de Gliptodontes mezclados con los huesos del esqueleto de Megatherium que actualmente se conserva er. Madrid, se atribuyeran a una coraza que hubiera pertenecido a este tiltimo coloso. De este modo, la clasificación de los Gliptodontes y su sinonimia se encontraba embrollada desdé el primer momento; y a medida que los nuevos descubrimientos se suceden y se adquieren nociones prsitivas sobre su conformación y afinidades, la sinonimia se enreda cada vez más. A principios de este siglo, un ilustrado clérigo oriental, autor de varios trabajos, desgraciadamente inéditos, cuyos manuscritos se encuentran en poder del doctor Andrés Lamas, encontró diversos trozos de coraza de un Gliptodonte, acompañados de algunas vértebras caudales y atribuyó esos restos al Megatherium, comunicande su descubrimiento a Augusto de Saint-Hilaire, que dió cuenta de ello en el «Bulletin de la Société Philomatique», 1823 (página 23). Cuvier cita esta comunicación en sus «Ossements fossiles» (tomo V, página 179. año 1823), asintiendo a la opinión de que la mencionada coraza pertenece probablemente al Megatherium. Pero en la edición póstuma de las obras de Cuvier publicada por Laurillard, en 1836, ese distinguido naturalista se pronuncia en contra de la prematura atribución al Megatherium de los fragmentos de corazas que se encuentran en Sud América en. las mismas formaciones que éste.

Sellow, viajero prusiano que por aquella misma época recorría la República Oriental, envió a Berlín algunos trozos de la coraza de un Glyptodon, acompañados de algunos huesos del esqueleto y la extremidad de un tubo caudal, evidentemente de un Panochtus. Estos restos fueron mencionados por el mineralogista Weiss en un trabajo sobre las petrificaciones de la Banda Oriental, dando la figura de la extremidad del mencionado tubo caudal, que atribuyó al Megatherium ( Abland1. de: Kon. Akad. Wissensch. zu Berlin», correspondiente al año 1827, Berlín 1830, páginas 218,278 y 282). El autor inglés Clift, en una Memori. sobre los primeros restos de Megatherium llevados a Inglaterra por

(4) FalKen: Description des Terres magellaniques. Idaussanne, I787, 2 volúmenes. - La eclición original apareció en 1724 . 
Woodbine Parish reproduce la opinión de Weiss atribuyendo al Megatherium una coraza ósea, de la cual creia poseer fragmentos en la colección mencionada, pero que en realidad eran de un Gliptodonte. (Clift: "Notice of the Megatherium», en «Transact. Geolog. Soc.», 1832, publicadas en el año 1835).

Mientras tanto. el célebre anatomista alemán D'Alton, catedrático en la Universialad de Halle, se ocupaba del estudio de los restos enviados i Alemania por Sellow; y en 1833 publico la descripción del miembro anterior incompleto $y$ de algunos huesos del pie, probando que el animal tuvo afinidad con los armadillos y que a él debian atribuírsele los icstos de coraza repetidas vices mencionados y no al Megutherium, que eta mucho más cercano de los perezosos. («Abland. etc. zu Berlin», ลท๊̄ 1833).

Woodbine Parish y Carlos Darwin enriquecian al mismo tiempo al Colegio de Cirujanos de Londres con numerosos restos de Megatherinmi de Gliptodontes; tan pronto como llegaron esos restos a Inglaterra, tanto para Clift como para Owen fué evidente que se habian confundido dos animales distintos y que los fragmentos de coraza atribuídos al . Heguth rum eran en realidad de un animal muy distinto: se moldearon algunos huesos y un fragmento de coraza que, enviados al Museo de París, fueron reconocidos por Laurillard. Pentland y de Blainville como pertenecientes a un armadillo gigantesco.

Entre esos restos figuraban una coraza completa, partes del esqueleto lan tubo caudal, comprados a Pedro de Angelis, de Buenos fires, que fueron restaurados bajo la dirección de Owen, quien publicó sus primeras investigaciones en la obra de Woodbine Parish, «Buenos Aires and la Plata», página $178, b$, año 1838 (cierto numero de ejemplares llevan la fecha de 1830), designando al animal con el nombre senérico de Glyptoton y llamando a la especie Glyptodon clavipes, a causa de la forma maciza de los pies.

En ese mismo año, Bronn, en la entrega segunda de su «Lethæa seognostica» (1838), proponía para los restos descriptos por D'Alton, dos nombres: el de Orycterotherium para el caso de que el animal no hubiera sido acorazado, y el de Chlamydotherium para el caso contrario, nombre este último que, en el mismo año empleó igualmente Lund para designar un armadillo gigantesco fósil en Brasil, pero mucho más farecido a los armadillos actuales que al Glyptodon. Conjuntamente con los restos del Chlamydotherium, descubrió Lund en las cavernas fosiliferas de Brasil los restos de un verdadero Gliptodonte, aplicándole en ese mismo año (1838) el nombre genérico de Hoplophorus y designando a la especie con el de Hoplophorus euphractus y agregando sucesivamente el conocimiento de nuevas partes, que después resultaron pertenecer a dos especies distintas. El nombre de Hoplophorus fué general- 
mente considerado, hasta una época relativamente reciente, como sinónimo de Glyptodon.

D'Alton que hasta entonces no se habia apresurado a denominar al animal, volvió a disertar acerca de él en la reunión del Congreso de naturalistas alemanes reunido en Erlangen, en Septiembre de 1839, designándolo con el nuevo nombre de Pachypus, mientras Lund designaba en el mismo año, con el nombre de Pachytherium algunos restos de un animal acorazado que parece ser genéricamente idéntico al Glyptodon.

Comparando Lund algunos huesos de los pies de su Hoplophorus cuphractus con los que habia figurado D'Alton, reconoció quie son de un: especie diferente, a la cual designó con el nombre de Hoplopitoris Scllowi, reconociendo como fósil en las cavernas de Brasil una tercara especie más pequeña a la cual denominó Hoplophorus minor.

En 1839 y 1810 publicó Owen sus observaciones completas sobre cl Glyptodon clizipes ( Proceed. Zool. Soc.», February 1839, página 90. «Transact. Geolog. Soc.», serie $2^{\mathrm{a}}$, volumen $6^{\circ}$, página $81 .-\ll Z o o l$ of the «Beagle», I, página 106). Desgraciadamente, el esqueleto que se conserva en el Mușeo de Cirujanos de Londres, ha sido mal reconstruido, pues Owen creyó que todos esos huesos provenían de un solo individuo, mientras que provienen no sólo de individuos distintos, sino también de especies diferentes. La coraza dorsal es de un verdadero Glyptodon, mientras que el tubo cónicocilíndrico que constituye la cola es de un animal muy diferente, para el que se ha adoptado el nombre genérico de Hoplophorus. Por otra parte, esos restos tampoco fueron encontrados juntos, pues me consta por las informaciones que me han sido proporcionadas en el partido Cañuelas, donde los mencionados restos fueron descubiertos, en las barrancas del río de la Matanza, que el tubo caudal fué recogido a unos 5 kilómetros de distancia de la coraza, pero acompañado a su vez de algunas placas de la coraza, que son probablemente las que más tarde publicó Owen bajo el nombre de Glyptodon ornatus, pues proceden de la misma localidad.

Otro carácter que no sospechó Owen es que entre las colas que terminan por un tubo cilíndrico y las corazas a que estos tubos se adaptan, debian existir varios anillos movibles que existen en los armadillos actuales pero que faltan en la restauración del Glyptodon clavipes, auncue era fácil sospechar su existencia por analegía y además por la desproporción de tamaño entre la abertura caudal de la coraza y la extremidad proximal del tubo caudal que se le quería adaptar. Desde esa época, el dibujo del Glyptodon clavipes, así restaurado, figura en todos los tratados de paleontología y otras obras científicas, produciendo una confusión que todavia continúa y que continuará quizá por muchos años. Nunca se ha vuelto a encontrar otro ejemplar igual al descripto por 
Owen, ni podri encontrarse, puesto que, 10 repito, se halla restaurado con restos de dos géneros distintos: Glyptodon y Hoplophorus.

En 1840, en la parte zoológica del viaje del «Beagle», figuró el mismo autor algunas placas, a las cuales designó con el nombre de HoplophoIIIS cuphractus de Lund, pero no pertenecen a dicha especie, sino probablemente al Hoplophorus elegans de Burmeister.

Mientras tanto, Lund, continuando sus investigaciones, descubrió nueios restos que le permitieron conocer que bajo el nombre de Hoplophorus éluphractus habia confundido a dos especies distintas, conservando el nombre frimitivo para los primeros restos descriptos, que son en verdad de un verdadero Glyptodon, y designando a los restantes, ya figuralos con el mismo nombre de Hoplophorils euphractus, con el nuevo numbre de Hoplophorus Meveri (1843), constituyendo estos restos el tipo del género Hoplophorus, que desde un principio fué dificil separarlo del Glyptodon, a causa de lo parecida que es la dentadura en ambos animales. El Hoplophorus minor parece ser no un Hoplophorus, sino un verdadero Glyptodon y probablemente la especie más pequeña del género hasta ahora conocida.

Hacia esa misma época, el doctor Vilardebó, de Montevideo, envió al Jardín de Plantas de París, la coraza de un Glyptodon gigantesco, al cual designó primero con el nombre de Dasypus antiquus y después con el de Dasypus maximus. Dicha coraza fué clasificada en París como de Glyptudon claripes, aunque erróneamente, constituyendo una especie diferente, a la cual, más tarde, conjuntamente con $H$. Gervais, designé con el nuevo nombre de Glyptodon principalis. A esta coraza hace alusión Pictet en su «Tratado de Paleontología», cuando dice que el Dasypus antiquus y el Dasypus maximus de Viladerbó, deben ser reunidos al Glyptodon clavipes de Owen.

Owen agregó en 1845 algunos nuevos datos al conocimiento del Glyptodon clavipes, introduciendo al mismo tiempo tres nuevas especies, a las cuales designó con los nombres de Glyptodon ornatus, Glyptodon reticulatus y Glyptodon tuberculatus («Cat. Foss. Mamm. Aves Mus. R. Coll. Surg.», año 1845).

E! Glyptedon ornatus es caracterizado for un tamaño bastante menor que el del Glyptodon claripes y actualmente es considerado como un Hoplophorus.

El Glyptodon reticulatus parece ser la misma especie a la cual más tarde designó Nodot con la denominación de Schistopleurum typus y Burmeister con la de Glyptoton asper, pero mal caracterizada por Owen, de manera que no fué posible reconocerla. En efecto: dicho autor da como caracteres distintivos de la especie, el de que la eminencia centra! angulosa de cada placa es del mismo tamaño que las eminencias marginales, que son, por lo general, en número de seis y el de que toda la 
superficie exterior de la coraza presenta esta misma disposición, con sólo la probable excepción de los bordes o sus proximidades, lo que evidentemente importa un error, pues sólo en el centro de la coraza y en un trecho de escasa extensión se confunden las figuras periféricas con la figura central de cada placa y digo, desde luego, que no en todos los ejemplares.

El Glyptodon tuberculatus es el que sirvió mucho tiempo después como tipo del género Panochtus.

Un año después (1846), el mismo Owen introdujo una nueva especie con el nombre de Glyptodon clavicaudutus («Rep. Brit. Assoc.», 1846), muy diferente de las otras por la extremidad del tubo caudal ensanchada en forma de clava, cuyo tipo fué separado más tarde por Burmeister, como género distinto, bajo el nombre de Doedicurus.

En ese mismo año (1846) regresó a Francia de una misión al Río de la Plata, el almirante francés Dupotet, llevando consigo una rica colección de huesos fósiles recogidos por el doctor Francisco Javier Muñiz, en la Villa de Luján, y rcgaluda por éste a aquél por orden del dictador Rosas. Esa colección fué entregada en su mayor parte al Museo de París, y el resto, entre lo que iba la pieza más completa, consistente en una coraza de Glyptodon casi entera, al Museo de Dijón. En esa colección iban a E*ropa los primeros restos de colas anilladas y con tubérculos, caracteristicas del verdadero Glyptodon, siendo algunos fragmentos, así como también algunas otras partes de Gliptodontes, figurados por de Blainville en su «Ostéographie». El autor falleció antes de que hubiera redactado la descripción correspondiente.

La coraza regalada al Museo de Dijón estaba acompanada de la mayor parte de la cola, en fragmentos como la coraza, pero una y otra fueron reconstruídas bajo la dirección de Nodot, Director del Museo, naturalista de mérito, a quien llamó inmediatamente la atención la enorme diferencia que existía entre la cola cónicocilindrica y de una pieza que acompañaba a la coraza del Glyptodon clavipes de Londres y la cola formada por anillos separados que obraba en su poder. No sospechó que Fudiera habcr un error en la reconstrucción del Glyptodon clavipes; y aunque las corazas de Londres y de París eran bastante parecidas en sus caracteres generales, las diferencias que presentaban las colas le parecieron suficientes para referirlas a dos géneros distintos. En 1855 , en una breve comunicación que hizo a la Academia de Ciencias de París, aesignó su pretendido nuevo animal con el nombre de Schistopleurum typus, describiéndolo detalladamente un año después, pasando al mismo tiempo en revista todo el grupo de los Gliptodontes, en el cual admite unas doce especies diferentes, repartidas en dos géneros: Glyptodon y Schistopleurum ( Description d'un nouveau genre d'animaux fossiles», etcétera, 1857). 
Distingue el género Schistuplcurum por la cola compuesta de un ciert.s númcro de anillos movibles colocados unos en otros y armados de fuertes tuhérculos espinosos y por la presencia de hendeduras perpendiculares en los bordes laterales de la coraza, que son, ambos, caracteres erróncos, puts las hendeduras perpendiculares laterales también las tiene el Cipptodun clarip's, aunque poco acentuadas, y la diferencia en la forma de la cola es debida al injerto del tuho caudal de Hoplophorus en 12. coraza existente en el Museo de Cirujanos, pues la cola de esta coraza lebia estar formada por anillos espinosos como la del Museo de Dijon, no existiendo, por consiguiente, caracteres que permitieran separarlas como representantes de dos géneros distintos.

Las especies que Nodot colocó en el género Schistopleurum son en número de tres, y las designó con los nombres de Schistopleurum typum, Schistopleurum gemmatum y Schistopleurum tuberculatum.

El Schistopleurum typum, constituye, como su nombre 10 indica, la especie tipica del pretendido nuevo género y corresponde, según Lydekker, al Glyptodun reticulatus de Owen. El Schistopleurum gemmatum Es sin duda in verdadero Gluptodun muy cercano del precedente; pero El Sinistoplorum tuberculutium, fundado sobre el Glyptodon tuberculains de Owen, es un animal sumantente diferente de los dos precedentes y de un género que es tan distinto del Glyptodon como de su pretendido Schistupleurum, separado más tarde como género distinto por Burmeister con el nombre de Panochtus tuberculatus.

Las otras nueve especies, que colocó en el género Glyptodon, son:

F1 Glyftudun clumipes de Owen, que no conoció que estaba formado con restos de dos especies.

El Giyftutun Oneni, que parece ser una simple variedad del Glyptodon clavipes.

El Glyptodon ornatus de Owen, del que no conoció más restos que los descriptos por el fundador de la especie.

El Glyptodon reticulatus de Owen, que no conoció, era el mismo animal que el acababa de describir con el nombre de Schistopleurum typum, aunque también es verdad que la breve descripción dada por Owen no habia permitido tampoco reconocerlo con seguridad. Nodot tomó la especie descripta por Owen for otra muy parecida, pero que se distingue por presentar un cierto número de grandes agujeros en el fondo de los surcos que rodean a las figuras centrales de las placas, que designé últimamente con el nombre de Glyptodon perforatus.

Fl autor fundó el Glyptodon elcratus sobre una porción considerable do la coraza de un animal muy particular y muy diferente de los otros Gliptodontes. Nodot no se dió cuenta de que las placas que componen esta coraza, a pesar de ser simétricas, no se traban unas a otras por suturas fijas como en los otros Gliptodontes, sino que están simplemente 
yuxtapuestas unas al lado de otras; y que si en dicho ejemplar permanecen unidas es a catisa de un cemento calcáreo que ha penetrado por las hendeduras uniendo a las placas entre si. Sobre esa misma coraz? fundé más tarde, conjuntamente con H. Gervais, el género Thoracuphorus.

E1 Glyptodon subcleratus de Nodot, parece ser, en efecto, una especie distinta, de tamaño no muy considerable y aliada del Glyptodon clavipes.

El Giyptodon gracilis es otra especie muy pequeña que entra en el género Lomaphorus.

Nodot fundó el Glyptodon quadratus en un pequeño fragmento lateral de la coraza de un verdadero Glyptodon, que probablemente proviene del Glyptodon reticulatus. Tanto en esta especie, como en el Glyptodon elongatus, en los lados laterales de la coraza hay trechos en los cuales las placas presentan la misma disposición que las figuradas por Nodot y que observadas aisladas podrían dar lugar al mismo error.

El Glyptodon retricosus fué fundado por Nodot sobre el dibujo de una placa que figura en la «Ostéographie» de de Blainville. Busqué dicha placa en el Museo de Paris, donde debia encontrarse, pero en vano. En cambio vi en él una porción considerable de una coraza de un Panochtus que se encuentra alli desde hace más de 40 años y que me reveló lo que debía ser el Glyptodon verrucosus. Este Panochtus, cuyo dibujo de una placa doy en la lámina LXXXVIII, figura 2, tuvo una enfermedad en la región superior de la coraza; la parte afectada por la enfermedad muestra un gran número de verrugas irregulares más grandes que los pequeños tubérculos que adornan las placas de los Panochtus normales y colocadas en sentido longitudinal, es decir: siguiendo el mayor largo de las placas que, en la coraza, es de adelante hacia atrás. La figura del pretendido Glyptodon verrucosus de Nodot presenta absolutamente el mismo aspecto, por lo cual no dudo que 10 que de Blainville hizo figurar es una placa de la misma coraza enferma. Así el Glyptodon verrucosus es un Panochtus tuberculatus enfermo.

Nodot mencionó, además, las grandes colas claviformes designada, por Owen con el nombre de Glyptodon clavicaudatus bajo el nombre genérico de Hoplophorus.

En orden de antigüedad vienen los trabajos de Bravard, hasta hoy en su mayor parte inéditos. Este distinguido naturalista, reunió entre los años de 1852 a 1856 una numerosa colección de fósiles que en parte sc conserva actualmente en el Museo Nacional de Buenos Aires. En ella clasificó siete especies de Gliptodontes, denominándolas: Glyptodon gigas, Glyptodon geometricus, Glyptodon tuberculatus, Glyptodon Oveni, Glyptodon D'Orbigny y Glyptodon radiatus. Antes de salir de Europa para Buenos Aires, Bravard habia visitado detenidamente las colecciones de fósiles argentinos conservadas en los Museos de Londres, por 10 
cual es de interés conocer la relación de sus especies con las que ya se conocian entonces y con las que se descubrieron después. Publicó él repetidamente la lista de sus especies, aunque no sus caracteres diagnósticos, pero hizo algunos buenos dibujos de las placas de las corazas y de las colas. acompañados de algunas explicaciones que se encuentran en mi poder y me permiten reconocer las mencionadas especies.

El Glyptodon gigas es un Gliptodonte de placas lisas en sus dos caras y con grandes agujeros que las perforan completamente. Entra, pues, en el género Doedicurus.

El Cilyptodon geometricus corresponde al Glyptodon elongatus de Burmeister.

El Glyptodun tuberculatus, no corresponde al Panochtus tuberculatus, sino al Glyptodon reticulatus de Owen.

El Glyptodun reticulutus de Bravard corresponde al Glyptodon tuberculatus de Owen y al Panochtus tuberculatus de Burmeister.

El Glyptodon Oncrni es un Hoplophorus, si no idéntico, muy parecido n! ornatus.

FI Glyptulun DO Orbignyi es de placas lisas, sin figuras o adornos en la superficie externa, pero como no da dibujos de él no puedo reconocerlo con seguridad. A juzgar por el carácter de tener placas lisas y sin adornos en la superficie externa, supongo que es una especie del género Euryurus.

El Gluptudon ratiatus corresponde al Hoplophoras clegans de Burmeister.

Desde dicha fecha, no apareció ningún otro trabajo sobre los Gliptodontes, hasta el año 1863, en que el profesor Huxley dió algunas noticias sobre el esqueleto incompleto de un Gliptodonte, atribuyéndoselo al Clyptodon claripes, pero que Burmeister, y creo que con razón, duda que pertenezca a la mencionada especie.

Al año siguiente empezó Burmeister sus laboriosas y sabias investigaciones sobre este grupo. En la entrega primera de los «Anales del Museo Público de Buenos Aires» (1864), sólo reconoció la existencia de cuatro especies distintas: a la primera la designó con el nombre dz Glyptudon spinicaulus como especie nueva, pero corresponde evidentemente al Schistoplcurum typum de Nodot y de consiguiente al Glyp. tolon reticulatus de Owen; la segunda es el Glyptodon tuberculatus de Owen; la tercera es el Glyptodon clavipes del mismo autor; y la cuarta, es una especie nueva, muy pequeña, que designó con el nombre de Glyptodon pumilio. No se pronunció sobre la cuestión de saber si los Gliptodontes constituyen uno o más géneros; y aunque reconoció que el Glyptodon clavipes del Museo de Cirujanos de Londres está mal restaurado, puesto que entre la base del tubo cilíndrico de la cola y la abertura caucial de la coraza debían existir un cierto número de anillos movibles, no 
sospechó que el mismo tubo caudal fuera de otro individuo, otra especie y otro género.

En 1865, Serres, describió una nueva especie de Glyptodon, bajo el nombre de Glyptodon giganteus, fundada sobre una enorme cadera llevada a París por Séguin, acompañada de algunas placas de la coraza sin adornos y con grandes agujeros que pasan de parte a parte, como he podido cerciorarme de ello en el Jardín de Plantas, lo que demuestra que entra en el género Doedicurus. En aquel mismo año, en una corta comunicación al Instituto, mencionó una coraza casi completa de un pequeño Gliptodonte, que identificó con el Glyptodon ornatus de Owen. Al año siguiente, el profesor Pouchet describió la misma coraza bxjo el nombre de Hoplophorus euphractus de Lund. Dicha coraza es realmente de un Hoplophorus, pero no es idéntica al Hoplophorus Meyeri de Lund, sino probablemente al Glyptodon ornatus de Owen, que resuita así ser i'n verdadero Hoplophorus.

En 1866, en la Entrega tercera de los «Anales del Museo de Buenos Aires», Burmeister dividió a los Gliptodontes en tres grupos diferentes. Dió a su primer grupo el nombre genérico de Panochtus, tomando por tipo de este nuevo género al Glyptodon tuberculatus de Owen, conociendo así, aun antes de tener el esqueleto completo de este animal, su forma particular, muy diferente de los otros Gliptodontes; pero identificó erróneamente al Glyptodon giguntens de Serres con su Panuchths tuberculatus, incluyendo en el género al Glyptodon clavicaudutus de Owen, que figura así con el nombre de Panochtus clavicaudatus.

Su segundo grupo, el Glyptodon, no comprende más que una sola especie: el Glyptodon clavipes de Owen (cuyo tipo es el ejemplar del Museo de Cirujanos de Londres) y lo distinguió del grupo precedent: tan sólo por la parte terminal de la cola en forma de tubo cónicocilíndrico, que es precisamente la referida parte injertada.

Al tercer grupo lo identificó con el Schistopleurum de Nodot y erró. neamente con el Hoplophorus de Lund. Incluyó en este grupo a su Glyptodon spinicandus, al que dió el nuevo nombre de Glyptodon asper, con la singularidad de que reconoció que su pretendido nuevo animal corresponde al que había descripto Nodot diez años antes bajo el nombre de Schistopleurum typum. Introdujo además dos nuevas especies, que denominó Glyptodon elongatus y Glyptodo laevis.

A la otras especies no des dió colocación en esta clasificación. Al Glyptodon ornatus de Owen 10 consideró un Glyptodon clavipes joven; dice no haber visto ningún pedazo del Glyptodon reticulatus de Owen, que es su propio Glyptodon asper; y reunió en una misma especie al Glyptodon clevatus y el Glyptodon subeleratus de Nodot que son dos animales com. plelamente diferentes. El autor enunció también por primera vez en dicha Entrega la peregrina idea de que los Gliptodontes estaban protegidos 
for un escudo ventral o plastrón o manera del de las tortugas, independiente de la coraza dorsal: y hasta creyó haber encontrado los vestigios de dicho plảstrón consistentes en placas lisas en sus dos caras y con grandes agujeros que las perforaban por completo y que no conoció feitenecian al mismo animal de cola en forma de clava que habia deno. minado Panochtus cluricaudatus, ocurriéndosele (no sé por qué razón) que debian provenir de un plastrón ventral que supuso debian tener tóóos los Gliptodontes. A causa de la supuesta existencia de este plastrón dividió a los desdentados cavadores y acorazados de Sud América en đos familias distintas: a una la denominó de los Loricutu cingulatu provistos de una sola coraza, y la forman los armadillos; y a otra la designó con el nombre de Biloricatu, por suponer que tenían además de la coraza dorsal el plastrún ventral aludido, formado por placas lisas $y$ con agujeros, que son precisamente caracteristicas de la coraza dei género Dúdicurus (en esa época su Panochilus claviculadutus). Es soiprendente que conociendo Burmeister la cola del mencionado animal no se diera cuenta de que las placas de su pretendido escudo ventral co1respondian perfectamente a las placas que formaban la parte anterior de la coraza del tubo de la mencionada cola y que, por consiguiente, podían pertenecer a la coraza dorsal del mismo animal, en vez de inventar la existencia de un plastrón ventral que, sobre ser de un pes.) enorme en un animal terrestre de tanta corpulencia, no estaba tampoco en conexión con la coraza dorsal ni con ninguna otra pieza del esqueleto, lo que desde el punto de vista puramente teórico basta para nega: la posibilidad de su existencia.

En las Entregas siptima y uctava (1870-1871) de los citados «Anales», describió Burmeister la coraza y el esqueleto completo del género Panochtus, sobre un ejemplar que acababa de ser exhumado en las cercanías de Mercedes; quiso la desgracia que, conjuntamente con este esqueleto, se encontrara un cierto número de placas de la coraza del Dóticurus, que, naturalmente, fueron por él atribuídas al supuesto plas. trón ventral del Panochtus, dando una restauración completamente imaginaria de él, puesto que nunca existieron Gliptodontes con plastrón ventral. Reconoció una nueva especie de Panochtus, que denominó Punnchtus bullifer, e identificó el Glyptodon giganteus de Serres con el Glyptodon claricaudatus de Owen bajo el nombre de Panochtus claricaudutus. Dió algunos restos dibujados por Lund como de Hoplophorus euphructus y luego adscriptos al Hoplophorus Meyeri, como los de un Panochtus al cual denominó Panochtus Lundi, y persistió en creer que el Glvptodon ornatus de Owen y el Hoplophorus euphractus de Pouchet pertenecen al Glyptodon clavipes joven; e insistió nuevamente, y con razón, en que no hallaba diferencias fundamentales entre el SchistoFleurum de Nodot y el Glyptodon de Owen, con excepción de la cola. cuyo tubo ya se sabe que no es del Glyptodon. 
En la Entrega novena (1871), disponiendo ya de un mayor acopio d: materiales, pudo reconocer la distinción del Hoplophorus y del Glypto. don, admitiendo el primero como género perfectamente distinto. Reconoció que el pretendido Panochtus Lundi es realmente un Hoplophorus, asi como también el Glyptodon ornatus de Owen, cuya coraza y partz considerable del esqueleto describió bajo el nombre de Hoplophorus ornatus, añadiendo una nueva especie bajo el nombre de Hoplophorus clcgans, que corresponde a la especie que Bravard habia denominado Glyptudon radiatus, y a una parte de las placas figuradas por Owen en el viaje del «Beagle» como de Hoplophorus euphractus. Reunió el Glyptoaon gracilis de Nodot con el Hoplophorus cuphrictus de Lund, que es el Hoplophorus Meyeri, e incluyó en el mismo género a su antiguo Glyptodon pumilio.

En la Entrega décima (1872) empezó la descripción completa y comparada de los préendidos géneros Schistopleurum y Glyptodon, insistiendo siempre en que la única diferencia entre ambos consiste en la forma de la cola. En la Entrega undécima continuó esa descripción, que concluyó en la duodécima (1874), haciendo en ella esfuerzos inauditos para encontrar una separación natural entre el Schistoplcurum y el Glyptodon, pero en vano; la sola diferencia de importancia es constituida siempre por la cola; y concluyó por declarar que se sentía incapaz de reconocer las especies del subgénero Glyptodon, aunque colocó en él, además del Glyptodon clavipes, al Glyptodon reticulatus, que es precisamente su mismo Glyptodon asper y el tipo del género Schistopleurum de Nodot, puramente nominal, puesto que el carácter único importante que parecia distinguirlo también es propio del Glyptodon clavipes. Describió una coraza incompleta y varios tubos caudales cónicocilindricos, que basándose sobre el esqueleto del Museo de Cirujanos de Londres, atribuyó al Glyptodon clavipes, pero todos esos tubos son, como el de Londres, de especies del género Hoplophorus, tal como resulta fácil cerciorarse comparándolas con las colas cilindricas de las especies de este uiltimo género. En cuanto a la coraza que describe como de Glyptodon clavipes tampoco es de esta especie sino de Glyptodon reticulatus.

Entre las láminas que acompañan a esa última Entrega hay una en la que el autor ha dado la restauración del Glyptodon clavipes, según los materiales, dice, conservados en el Museo de Buenos Aires. La coraza de esta restauración es completamente diferente de la del Glyptodon clavipes de Londres, tanto por su curva como por su forma general, y tampoco existe en el Museo de Buenos Aires. A esta coraza se adaptan siete anillos caudales planos, a los que sigue un tubo caudal cónicocilínd́rico de Hoplophorus, constituyendo así una cola cuyo largo iguala casi a la longitud del tronco. Tal animal no ha existido, y es pertinente recordar que dicha reconstrucción es puramente ideal y fantástica. 
En la segunda parte de esta última Entrega, fundó el autor el nuevo género Dadicurus, sobre una parte considerable del esqueleto, incluso la cabeza, recogidos por don José Pacheco en su estancia de Salto, atribuvendo al mismo género las colas en forma de clava como la del Glyptodon claricaudatus de Owen, e identificó la especie con el Glyptodon grganteus de Serres, que es el Glyplodon gigas de Bravard, llamándolo Dúdicurus giganteus. No da ninguna descripción de la coraza, lleváncolo su preocupación infundada del plastrón ventral, a decir: «Desgracladamente, nada se ha encontrado de la coraza externa, sea del tronco, sea de la cola, sino solamente la del pecho, que no muestra caracteres diagnósticos». En efecto, conjuntamente con los restos del esqueleto mencionado, el senor Pacheco habia recogido varios cajones de placas Isas y perforadas, que formaban parte de la coraza dorsal del animal, pero que Burmeister, guiado por suposiciones sin fundamento, atribuía a un escudo ventral, del que carecían tanto el Diedicurus como los demás Gliptodontes.

En dicha Entrega concluyó Burmeister su monografía de los Gliptodentes, obra colosal que quedará como un monumento de la paleontología argentina. En ella dió la descripción e ilustración completa de un nuevo género, el Panuchtus; fundó otro género no menos interesante, del cual describió partes considerables del esqueleto, el Dodicurus; describió el género Hoplophorus separándolo de los otros Gliptodontes; y dió la descripción casi completa de tres especies de Glyplodun: El Glyptodon asper, el Glyptodun elongatus y el Glyptodon lerris, advirtiénlose de la estrecha unión del pretendido género Schistopleurum con el (:lytulen, aunque sin conseguir unirlos en uno solo, a causa de la falsa restauración del Glyptodon clavipes de Londres.

En 1872, el profesor Cornalia, en su trabajo sobre los fósiles de la Pampa regalados al Museo de Milán, adoptando la primera identificación de Burmeister del Schistoplcurum con el Hoplophorus, designó a los Glyptedon asper, clongatus y livis de Burmeister, con los nombres de Hoplophorus asper, Hoplophorus clongatus y Hoplophorus lavis, incluyendo, con la misma denominación de Hoplophorus, al Glyptodon reticulatus.

En 1875 designé bajo el nombre de Hoplophorus Burmeisteri a una parte considerable de un escudo cefálico, que resultó proveniente de un Hoplophorus ornatus.

En el mismo año, el profesor Reinhardt refirió al género Schistopleurum o Glyptodon, las primeras piezas originales en que Lund habia fundado el Hoplophorus cuphractus, designándolo con el nombre de Schistopleurum euphractum y fundó una nueva especie bajo el nombre de Glyptodon dubius, la que probablemente no se diferencia de la precedente. 
En 1878 el profesor Gervais introdujo dos nuevas especies, a las cuales las designó con los nombres de Glyptodon rudis y Hoplophorus discifer. El primero es realmente un Gliptodonte muy diferente de los demás, que separé más tarde como género distinto; pero el segundo es un armadillo del género Propraopus. En dicho mismo año, en mi Catúlogo de la Sección Paleontológica Argentina, en la Exposición Universal de Paris (página 63), manifesté por primera vez mi opinión de que las placas lisas y agujereadas atribuídas por Burmeister al plastrón ventral de los Gliptodontes, provenían de la coraza dorsal del Dodicurus.

Al año siguiente, 1879, Burmeister, en el tercer volumen de la «Descripción física de la República Argentina», pasó en revista sus trabajoj anteriores sobre los Gliptodontes, concluyendo por admitir la separación de los géneros Schistopleurum y Glyptodon. Identificó el Glyptodon gracilis de Nodot con el Hoplophorus euphractus (que es el Hoplophorus Heyeri) y el Glyptodon rudis de Gervais con el Dodicurus gigantcus, pero erróneamente, pues son dos animales muy diferentes. Se extendió algo más sobre el Doedicurus, del que se ocupó más extensamente todavía en una comunicación publicada en aquel mismo año, en las Actas de la Academia de Ciencias de Berlín, insistiendo en atribuir al plastrón ventral las placas de la coraza dorsal. Estableció que nunca se ha encontrado junto con los huesos de Dodicurus más que las placas perforadas mencionadas; y esto, conjuntamente con el magnífico ejemplar de tubo caudal, cuyo dibujo dió y cuya parte anterior consta de placas lisas y perforadas, cualquiera creería que habría podido inducir a Burmeister a pensar que sus pretendidas placas del escudo ventral bien habrian pocido pertenecer a la coraza dorsal. Pues nada de eso; el distinguido naturalista, para resolver la dificultad, más bien que renunciar a la idea de la existencia del plastrón ventral, prefirió creer que el Dodicurus (contra lo que es de regla en los Gliptodontes y armadillos) tenía un plastrón ventral óseo, pero carecía de coraza dorsal. Y a pesar de admitir que un género, el Hoplophorus, carecía de coraza ventral y que el Dodicurus carecia de coraza dorsal, continúa designando al grupo de los Gliptodontes con el nombre de Biloricata y al de los armadillos con el de Loricata cingulata.

En 1880, en Los mamiferos fósiles de la América Meridional, trabajo que publiqué en colaboración con Henry Gervais, pasamos en revista todo el grupo de los Gliptodontes, admitiendo en él seis géneros, a saber:

El Docdicurus Burmeister, en el cual colocamos cuatro especies: el Dadicurus clavicaudatus Owen, sobre la cola gigantesca conservada en el Museo Británico; el Dodicurus uruguayensis, fundado sobre un tubo caudal del Museo de la Escuela Normal de París, que nos pareció más pequeña que el de Londres, pero que según Lydekker es abso. 
lutamente idéntico; el Dódicurus Poucheti, sobre un tubo de menor tamano, de las colecciones del Museo de París; y el Dodicurus giganteus sólo de una manera provisoria, pues no conociéndose su cola, quizá podía ser idéntico con alguna de las especies precedentes.

El Euryurus, género nuevo, fundado sobre el Glyptodon rudis de Gervais.

El Panochtus de Burmeister con las dos especies que este sabio incluye en él.

El género Hoplophorus de Lund en el cual, además de los Hoplophorus urnatus Owen y Hoplophorus Meyeri Lund, introdujimos dos nuevas especies: el Hoplophorus perfectus y el Hoplophorus imperfectus, colocando tambien en el mismo género al Hoplophorns minor de Lund, que es un verdadero Glyptodon, como ya lo suponiamos entonces; e ítentiticanios el Gipptodun rudutus de Bravard con el Hoplophorus clegans de Burmeister.

El género ulypirion, yue reunimos en ese trabajo al Schistupleurum, por no encontrar entre ambos ninguna diferencia bastante importante que justificara su separacion. Discurriendo acerca del Glyptodon clavipes digimos lo siguiente: «Entre los, principales restos que se conocen de esta especie, citaremos la coraza que figura en las colecciones cel Colegio de Cirujanos de Londres, descripta por Owen; pero la cola adaptada a esta coraza pertenece a un individuo del género Hoplophorus; el animal así restaurado ha sido, desgraciadamente, reproducido de usa manera en un gran número de tratados de paleontologia, error que nos ha parecido útil indicar, tanto más cuanto que sobre él reposa la separación infundada del genero Glyptodon, en Glyptodon y SchistoIleurum» (página 202). Habia llegado a este resultado después de una visita que hice a Londres en el mes de Septiembre de 1879, durante la cual pude examinar el esqueleto conservado en el Museo de Cirujanos y convencerme de que la cola era de un Hoplophorus y que la coraza no se diferenciaba for ningún carácier de importancia de las que se atribuían al pretendido género Schistoplcurum. Incluimos en este género a Schistopleurum asperum de Burmeister bajo la denominación de Glyptodon typum, por ser este nombre 10 años más antiguo que el que le dió Burmeister. Al Schistoplcurum clongatum lo incluimos con el nombre de Glyptodon gemmatus, identificándolo con la especie de este nombre Uc Nodot, aunque quizá erróneamente. Identificamos el Glyptodon geometricus de Bravard con el Glyptodon asper de Burmeister y el Schistofleurum typum de Nodot, pero sin razón, pues deberíamos haberlo referido al Glyptodon clongutus. Identificamos bajo la fe de Pictet, el Dasypus antiquus y el Dasypus maximus de Vilardebó con el Glyptodon claripes, cuando dichos nombres habían sido aplicados, aunque sin diagnosis a un Glyptodon completamente diferente que en el mismo trabajo 
designamos con el nombre de Glyptodon principalis, por ser aparentemente el más corpulento de todos los verdaderos Glyptodon.

El nuevo género Thoracophorus, que fundamos sobre el antiguo Glyptodon elevatus de Nodot.

En 1881, en el segundo volumen de mi obra La antigïedad del Hombre en el Plata, agregué a esa ya larga lista varias nuevas especies: un Panochtus Morenoi del Uruguay; dos Gliptodontes: el Glyptodon rudimentarius y el Glyptodon Muñizi; y dos especies de Thoracophorus: el Thoracophorus depressus y el Thoracophorus minutus. Al año siguiente aumenté todavía ese número con el Glyptodon perioratus, cat ate: zado por una esculttra externa con grandes surcos profundos y agujeros enormes que absorben casi por completo la superficie central de cada placa; y dos Hoplophorus de talla muy pequeña: el Hoplopho. rus elevatus y el Hoplophorus compressus.

Hasta acá todos los representantes conocidos del grupo de los Gliptodontes procedian de los terrenos sedimentarios más modernos, o sea de la formación pamepana. Recién durante aquel año de 1881 empezaron a mencionarse los primeros restos del Gliptodontes prepampeanos; sobr: placas de coraza de los terrenos eocenos de Patagonia austral, fundó Moreno, sin caracterizarla, una nueva especie de Hoplophorus, a la cual designó con el nombre de Hoplophorus australis, que es el tino de mi géncro Propalahoplophorus; y sobre otros restos de los terrenos prepampeanos de Catamarca, fundó el Hoplophorus Ameghinoi, también sin caracterizarlo, y que forma parte de otro género igualmente distinto del Hoplophorus, que designé últimamente con el nombre de Plohophorus.

En 1883 publiqué una revisión general de los Gliptodontes. extendiéndome detenidamente sobre la identidad genérica del Glyptodon v del Schistopleurum, probando que el tubo caudal de la coraza del Glyptodon clavipes del Museo de Cirujanos de Londres es realmente de un Hoplophorus y que la cola de otros ejemplares de coraza de Glyptodon clavipes está en realidad constituida por una serie de anillos espinosos como en los otros representantes del género Glyptodon. A fines del mismo año agregué dos nuevas especies de Hoplophorus: el Hoplophoris paranensis y el Hoplophorns Scalabrinii, ambos de los terrenos terciarios antiguos del Paraná.

En 1884 introduje un nuevo representante de este grupo, procsdente de los terrenos pampeanos y algo parecido al Docdicurus, al que designé con el nombre de Plaxhaplus canaliculatus.

En 1885, estudiando los restos de vertebrados fósiles de los terrenos terciarios antiguos del Paraná recogidos por el profesor Scalabrini, fundé el género Palchoplophorus, tomando como tipo el Hoplophorus Scalabrinii, agregando una nueva especie, a la cual denominé Palahoplopho- 
rils pressulus. Fundé el nuevo género Protoglyptodon con una sola especie: Protogiyptodon primiformis; y di a conocer del género Eurýurus, el Euryurus interundatus. El año siguiente (1886) agregué a esa lista y de la misma procedencia, el Comaphorus concisus, aliado del género Dodicurus.

Durante el ano 1887 continué aumentando los representantes de este f.rupo con dos formas que descubri en el mioceno superior de Monte Tiermoso, una de ellas de un nuevo género que designé con el nombre de Plohophorus figuratus y la otra una especie más pequeña de Dodicurus, que llamé Docdicurus antiquus, pero que entra en realidad en el género Plaxhaplus. Al mismo tiempo estudié los restos de Gliptodontes de los terrenos eocenos de Patagonia austral que habian sido referidos al género Hoplophurus, llegando a la conclusión de que pertenecian a un género bastante diferente, que denominé Propalahoplophorus, tomando como tipo el Hoplophorus australis de Moreno y agregando una nueva especie bajo el nombre de Propaluhoplophorus incisivus.

En aquel mismo año apareció el tomo $\mathrm{V}$ del Catálogo de los mamiferos fósiles del Museo Británico, en el cual Lydekker da la enumeración de los restos que se conservan en dicho establecimiento. En el género Glyptudon menciona: el Glyptodon clunipes; el Glyptodon reticulatus, identificado por él con el Schistopleurum typum de Nodot y el Glyptodon usper de Burmeister: el Glyptodun cuphractus de Lund; y una especie inédita que por los caracteres que asigna a la escultura externa debe entrar en el género Plohophorus o en el Nopachtus.

En el género Duxdicurus, sólo menciona los restos de Dodicurus claviculudutus, al que refiere también el Dodicurus gigunteus de Burmeister y el Dedicurus uruguayensis de Gervais y Ameghino.

En el género Euryurus, la especie tipica del género, Euryurus rudis.

En el género Panochtus sólo menciona restos del Panochtus tuberculatus.

En cl géncro Hoplophorus menciona restos del Hoplophorus Heyeri, del Huplophorus ormatus, del Hoplophorus elegans y de cuatro especies más a las que no asigna nombre específico, algunas de ellas seguramente nuevas.

Darante el ano que acaba de transcurrir (1888), el naturalista alemán Koken, bien conocido por sus notables trabajos sobre los mamíferos fósiles de China, ha descripto un nuevo Gliptodonte de gran talla: el Eleutherocercos setifer: y por mi parte he agregado otro género no menos curioso al cual denominé Nopachtus coagmentatus; dos nuevas especies de Hoplophorus: Hoplophorus cordubensis y Hoplophorus lineatus, y una de Euryurus: el Euryurus antiquus, todas ellas procedentes del mioceno superior. 
Caracterfs. - Los Glyptodontic constituyen un orden de mamíferos acorazados de tamaño gigantesco, hoy completamente extinguido, pero que, conjuntamente con los gravigrados, da al conjunto de la fauna extinguida de Sud América, un aspecto peculiar, que la distingue de las de todas las demás regiones de la tierra.

Los Gliptodontes son próximos aliados de los armadillos existentes, pero se distinguen de éstos por un conjunto de caracteres çue no permite reunirlos en un mismo grupo. Los caracteres culminantes que separan a los Gliptodontes de los armadillos son:

La coraza dorsal, sólida, compuesta de placas soldadas en toda la extensión del dorso, sin presentar en el centro las bandas transversales movibles, que son características del grupo de los armadillos.

El cráneo corto, alto y truncado adelante, con el occipital inclinado y una apófisis descendente del cigomático, que son, todos, caracteres que faltan en los armadillos actuales.

La cavidad cerebral sumamente pequeña.

La rama ascendente de la mandibula inferior sumamente elevada e inclinada hacia adentro para formar con la rama horizontal un ángulo de menos de 90 grados.

La forma de las muelas, cada una de las cuales es constituída po: tres partes prismáticas soldadas.

La columna vertebral formada por tres o cuatro piezas largas, que representan las vértebras de los demás mamiferos, que en los Gliptodontes están soldadas entre si para formar las mencionadas piezas dorsales.

Los caracteres mencionados no sólo distinguen a los Gliptodontes de los armadillos, sino que los separan asimismo de todos los demás mamíferos, justificando su separación como orden distinto.

La coraza dorsal de los Gliptodontes, que es de forma más o menos esféricoalargada, está formada por la reunión de un considerable número de placas óseas, de un espesor considerable, de contornos poligonales. generalmente pentagonales o exagonales, especialmente en el centro de la coraza, pero que toman más bien una forma rectangular hacia cl centro de los costados laterales. Estas placas están reunidas entre sí por suturas fijas en el centro, pero que resultan más sueltas hacia la. periferia, especialmente en los costados laterales, donde, en el medio de la coraza, persisten hendeduras perpendiculares entre las filas transversales de placas, a cuyas hendeduras debe considerárselas como los últimos vestigios del estado primitivamente independiente de las filas de placas trans. versales del centro de la coraza, que formaban anillos movibles como en los armadillos existentes. Sobre la línea media longitudinal del centro de la coraza, y' especialmente en el medio de la región dorsal, las placas unidas por suturas más fijas concluyen por soldarse unas a otras formando una sola pieza al avanzar en edad el animal, pero en la periferia 
de la coraza las suturas permanecen visibles durante toda la vida. En los individuos jóvenes, todas las placas están separadas, completamente sueltas, como que las suturas se formaban con la edad, pero en ciertos géneros este estado era persistente durante toda la vida, conservando asi toda la coraza una especie de flexibilidad, de que carece en sus regiones fijas la de los actuales armadillos.

Las placas que componen la coraza están formadas por dos capas corticales compactas, pero muy delgadas, que limitan las dos superficies interna y externa, consistiendo todo el centro limitado por las mencionadas cortezas, en un tejido óseo sumamente esponjoso, atravesado por canales reticulares que se cruzan en varias direcciones, y además por algunas perforaciones de mayor tamaño que atraviesan las placas partıendo del centro sobre el lado interno, dirigiéndose al externo en dirección más o menos divergente. La superficie interna de las placas es siempre lisa y un poco cóncava, particularmente en los individuos jóvenes. La superficie externa es convexa, plana o cóncava, según los géneros, y casi siempre cubierta de rugosidades o tubérculos de formas defiridas y dispuestos según cierto orden, como si fueran esculpidos, imitando los dibujos de un mosaico, de aspecto distinto según los géneros I las especies, pero en otros casos la cara externa de las placas no presenta esculturas, sino una superficie simplemente rugosa o lisa, ora convexa ora cóncava, con un aspecto idéntico a la cara interna, mostrando como ésta un cierto número de agujeros que la atraviesan ya directamente, ya convergiendo hacia adentro a una perforación común. El tamaño y la forma de las placas, lo mismo que la disposición de los dibujos de la cara externa, varian en las distintas regiones de una misma coraza y de una manera diferente según las especies, pero el borde periférico está constantemente formado por una fila de placas, de forma distinta de las que constituyen el centro de la coraza.

La coraza, además de la gran abertura ventral que sirve para dar Sillida a los miembros, presenta otras dos aberturas semicirculares en sus extremos, una en la extremidad anterior, más pequeña, que da salida a la cabeza, y otra en la extremidad posterior, a la que sigue la cola. La parte superior y lateral de la coraza es muy convexa y sobre los tordes desciende hacia abajo, dando vuelta la curva hacia adentro, disminuyendo gradualmente de diámetro transverso hacia su parte inferior, llegando los bordes laterales más o menos hasta la mitad de la altura de las piernas.

El vientre quedaba a descubierto, cubierto de pelos, y en algunas especies con pequeños huesecillos irregulares y sueltos implantados en la fiel, como los que presentan en distintas partes del cuerpo los armadillos actuales, pero de ninguna manera formando una coraza, escudo o plastrón, como lo ha supuesto Burmeister, quien en mala hora confundió las 
placas de la coraza dorsal del Dodicurus con partes de un plastrón ventral, que él creía debían presentar todos los Gliptodontes (5).

La cabeza está igualmente protegida por un escudo óseo que cubría su parte superior desde el vértice hasta cerca de la nariz, formado por placas de formas distintas, según los géneros; estas placas, en unos géneros se articulaban entre sí formando un escudo sólido como la coraza dorsal, mientras que en otros presentaban formas más irregulares y estaban simplemente yuxtapuestas, sin suturas que las unieran unas a otras.

La cola estaba igualmente protegida por una coraza ósea que afecta las formas más distintas, estando compuesta en unos géneros por placas dispuestas por series transversales, formando anillos completos en todo su largo, mientras que en otros la extremidad está formada por un tubo óseo sólido, más o menos largo y que encierra en su centro las vértebras caudales.

La forma del cráneo es también sumamente variahle, según los géneros, pero se distingue constantemente del de los armadillos, por un alto mucho mayor, por un ancho considerable y por ser bastante más corto $y$ como truncado en su parte anterior, en vez de extenderse en hocico prolongado como en los armadillos; pero e: unos la abertura nasal anterior es muy ancha y en otros mucho más angosta. Del mismo modo la configuración general del cráneo, en unos aparece como muy comprimida en su parte superior y en otros sumamente convexa.

Los nasales son siempre muy pequeños; en unos, como el Glyptodon y el Dadicurus, son muy cortos y anchos; en otros como el Panochtus, un poco más largos y puntiagudos adelante.

El arco cigomático es siempre muy fuerte y completo, sin que por 10 general se perciban suturas que demuestren la parte que en su formación toman los distintos huesos; pero en ciertos géneros presenta una apófisis postorbitaria que se une a la del frontal, cerrando las órbitas con un círculo óseo completo, mientras en otros géneros las órbitas quedan anchamente abiertas hacia atrás, comunicando con las fosas temporales. La parte inferior del arco cigomático debajo de las órbitas sc prolonga en forma de una fuerte apófisis cigomática descendente como en los gravígrados, pero es considerablemente más fuerte y $\sin 12$ Livisión en varias ramas que presenta en estos últimos. Además, en los Eravígrados, esta apófisis cigomática descendente es formada exclusivamente por el malar o cigomático; y en los Gliptodontes únicamente

(1) Lydekker, en los caracteres que ciistinguen a los representantes del grupo de los Gliptchlontes (Cafal., etc., parte $V$, página 114 ), menciona a existencia general de un plastrón ventral, guiado sin duda por las afirmacicnes de Burmeister, quien hasta ha dado recons. trucciones imagirarias del plastrón completo. Iloy ya no se jodria sostener de buena fe 13 existencia de un plastrón vertral en ningún género de este grupo. 
por el maxilar superior que forma el borde anterior e inferior de las órbitas. La región frontal, es muy grande, ancha y deprimida en unos géneros y convexa en otros. La región parietal es siempre más pequeña y sobre todo más angosta que la frontal; unas veces es deprimida y rugosa. con una cresta sagital larga $y$ fuerte y otras veces es sin cresta sagital y de superficie lisa más o menos plana o convexa.

El occipital es muy pequeño y muy bajo y más o menos inclinado ohlicuamente de adelante hacia atrús, terminando en cóndilos occipitales muy separados, entre los cuales se abre el agujero occipital que, en vez de presentar un contorno mis o menos circular e infundibuliforme, como en la generalidad de los mamiferos, es aquí fuertemente elíptico y con su eje mayor en dirección transversal.

El temporal es fuerte y extendido sobre los costados, con su parte esamosa separała por sutura persistente de la región petrosa y con una apófisis cigomática fuerte que lleva en su parte posterior la faceta articular para el cóndilo de la mandibula inferior. cuya faceta se distingue por la singularidad de que en vez de estar dada vuelta hacia abajo como en la generalidad de los mamiferos, está, al contrario, dada vuelta hacia atrás.

El maxilar superior y el paladar forman la parte más notable del críneo de los Gliptodontes. Fl maxilar superior presenta un desarrollo en verdad extraordinario y que no tiene nada parecido en ninguno de los otros grupos de mamiferos conocidos hasta ahora, pues por sí solo forma cas i todo el alto de las paredes laterales del cráneo delante de las órbitas y da al cráneo entero la forma elevada y casi cúbica que presenta. Para dar una idea de este inmenso desarrollo, basta decir que la parte-del cráneo que comprende la dentadura es de un diámetro vertical casi tres veces mayor que la parte posterior sin dentadura constituida por el occipital, los farietales y temporales, que es una conformación verdaderamente extraordinaria entre los mamiferos. Toda la extensión vertical de los maxilares de los Gliptodontes está ocupada por los alvéolos de las muelas. cuyo largo, en proporción del tamaño del cráneo y del paladar, es verdaderamente excepcional.

Fl palaủar de los Gliptodontes es muy largo y extendido de adelante lacia atrás, pero relativamente angosto y con las series dentarias casi paralelas. La superficie del paladar es rugosa y con una cantidad sorprendente de agujeros vasculares: los bordes alveolares son un pocu más descendentes, formando asi un paladar un poco excavado, pero con ina cresta media longitudinal mís o menos desarrollada, según las especies. Otra particularidad del paladar de los Gliptodontes es su superficie que forma una curva ondulada, comparada a una $\mathrm{S}$ prolongada, de curvas poco acentuadàs. que se extiende de adelante hacia atrás; la parte posterior es un poco descendente, asciende hacia arriba en su ter- 
cio anterior, vuelve a descender hacia abajo formando una fuerte convexidad en su tercio superior para volver a levantarse luego hacia arriba de una manera más acentuada, en su parte posterior.

La parte anterior del paladar es sin dientes y está formada por el hueso incisivo, muy corto y ancho y fuertemente soldado a los maxilares.

La mandibula inferior, de acuerdo con la construcción del maxilar, tiene una rama horizontal muy elevada, destinada al desarrollo de los alvéolos que deben recibir las muelas que, como las superiores, son de un largo verdaderamente excepcional. La parte anterior es corta adelante de las muelas y termina en un reborde grueso y vuelto hacia abajo, pero la punta anterior sin dientes de este reborde se prolonga un poco más adelante de la punta del intermaxilar. Ambas ramas mandibulares están unidas en casi la mitad de su longitud, constituyendo una parte sinfisaria que se extiende debajo de las muelas anteriores. formando en el lado interno una concavidad profunda. La rama ascendente de esta mandibula constituye otra de las grandes particularidades de los Gliptodontes. Esta rama, en vez de extenderse hacia atrás de las últimas muelas como una prolongación de la rama horizontal, cual sucede en la generälidad de los mamiferos, se desprende del lado externo de ésta, al nivel de las dos últimas muelas y antes de llegar al borde alveolar, separándose de la rama horizontal y ascendiendo luego hacia arriba de modo çue quede en la base entre ambas ramas una cavidad longitudinal muy pronunciada. Como la faceta articular del temporal se encuentra en la parte más elevada del cráneo a una altura verdaderamente extraordinaria del paladar, la rama ascendente de la mandíbula inferior para articularse con dicha faceta presenta una elevación extraordinaria, que no §uarda ninguna proporción con el tamaño de la rama horizontal, terminando hacia arriba en un cóndilo transversal muy comprimido de adelante hacia atrás y en una apófisis coronoides más o menos redondeada Fiero no más elevada que el cóndilo. Como complemento de todas estas singularidades, la rama ascendente, en vez de estar más o menos inclinada hacia atrás, como es de regla en la generalidad de los mamíferos, se inclina, al contrario, fuertemente hacia adelante, tanto que su borde ascendente anterior forma con la rama horizontal un ángulo siempre agudo, a veces no mayor de 60 grados, cuya conformación debía dar a los músculos destinados a mover el aparato masticatorio una fuerza extraordinaria. La altura de la rama horizontal aumenta gradualmente de adelante hacia atrás.

La dentadura de los Gliptodontes no es menos particular que la conformación del resto del cráneo.

Por regla general carecen siempre de incisivos; y cuando ellos existen se reducen a unos dos pequeños dientes cilíndricos completamente rudimentarios, implantados en el intermaxilar y sólo presentes en la juven- 
tud. siendo luego reabsorbidos en edad más avanzada o caedizos en algunos casos.

Las muelas son siempre en número de 8 en cada lado de cada mandíhula, todas de la misma forma, menos la primera y a veces la segunda (i. cada mandibula, que pl:eden presentar algunas modificaciones, generalmente de fequena importancia. Las muelas estan formadas por la reunión de tres prismas, más o menos iguales, de figura romboide, separados for dos surcos perpendiculares opuestos a cada lado, muy profunLos; cada muela presenta asi dos aristas perpendiculares angostas a cada $1:$ do separadas por dos surcos que van desde la raíz a la corona, dando a la forma externa de las muelas el mismo aspecto en todo su largo. La base de las muelas es completamente abierta, mostrando tres cavidades que corresponden a cada uno de los prismas y se comunican por pequenas hendeduras que se abren entre los istmos formados por los surcos opuestos de cada lado. La parte inferior de las paredes de esta abertura tiene apenas el espesor de una hoja de papel, pero se engruesan pronto hacia la corona hasta que los prismas se hacen sólidos. En la corona, cada diente muestra en el centro de la superficie masticatoria una pequeña elevación muy angosta que se dirige de adelante hacia atrás, con dos prolongaciones transwersales en cada prisma, una en el lado externo y otra en el interno: estas crestas elevadas están formadas por una substoncia muy porosa compuesta de tubos perpendiculares, análoga a la vásculodentina. Estas crestas están rodeadas por una substancia más homogénea, pero probablemente más blanda, pues siempre se presenti más gastada que la substancia del centro, formando en la superficie masticatoria una cavidad muy pronunciada en la que sobresale de una manera muy perceptible la substancia céntrica que forma las crestas mencionadas. Por último, cada diente está envuelto por una capa externa muy delgada de una substancia compacta y muy dura que sobresale en la superficie masticatoria de la corona, formando un borde periférico elevado, pero que en ninguna parte se pone en comunicación con las crestas centrales, de las cuales está separada por la substancia intermedia más blanda. Todas las muelas están truncadas horizontalmente, $\sin$ que sobresalgan las unas sobre las otras y saliendo muy poco afuera del alvéolo. Todo el resto del prisma que constituyen las muelas, que son de un largo verdaderamente considerable, está incluído en los alvéolos que ocupan toda la extensión vertical de los maxilares superiores y descienden en la mandibula inferior hasta la misma base de la rama horizontal.

El cráneo de los Gliptodontes muestra un ejemplo notable del enorme desarrollo puramente vegetativo en detrimento del desarrollo cerebral. Casi todos los huesos que constituyen el cráneo están soldados en una sola pieza sin rastro de sutura; y la unión y soldadura precoz de los pa- 
rietales, occipitales y temporales, aprisionando al cerebro en una caja que ya no era susceptible de dilatarse, impidieron el aumento de volumen del encéfalo mientras continuaba el desarrollo de las otras partes cel cráneo y especialmente del aparato masticatorio, que tomó proporciones verdaderamente monstruosas. Lós Gliptodontes eran los mamíferos más estúpidos que sea posible imaginar, en quienes sólo se habian desarrollado los órganos destinados a la nutrición: eran máquinas que no tenían otro objeto que mascar y mascar.

En la conformación de los Gliptodontes, la columna vertebral es la Farte más notable de todo el esqueleto, pues en vez de estar formada por una sucesión de vértebras como es de regla en todos los demás mamíferos, está constituída por un tubo muy fuerte y arqueado y dividido en dos piezas principales articuladas por sincóndrosis, que comprenden las vértebras cervicales, las vértebras dorsales, las lumbares y las que constituyen el sacro, todas soldadas unas a otras, no quedando libres más que las vértebras caudales y unas pocas del cuello.

El atlas permanece libre, presentando un tamaño mediano y alas laterales pequeñas.

El axis y las tres o cuatro vértebras que siguen están reunidas en una pieza que lleva el nombre de hueso mesocervical. Es éste un hueso ccrto y ancho, con una cresta superior longitudinal más o menos pronunciada que corresponde a la apófisis espinosa; y dos fuertes prolongaciones laterales en forma de alas, una a cada lado, que representan las apófisis transversas soldadas, pero en cuyas bases se ven tres agujeros a cada lado que representan los pasajes intervertebrales y prueban la formación del hueso por tres vértebras primitivamente separadas. Hacia adelante se articula con el atlas por tres facetas articulares, uni central, a veces muy prominente, que corresponde a la apófisis odontoides del axis, y dos laterales: una a cada lado. La parte central de este hueso, arriba de la pared inferior, que representa el cuerpo de las vértebras, muestra una gran perforación circular longitudinal que representa el canal medular.

La sexta vértebra cervical es, según los géneros, unas veces libre y otras soldada a la quinta, formando parte del hueso mesocervical. Cuando se presenta suelta es un hueso muy corto y muy delgado, con apófisis espinosa corta y grandes apófisis transversas, de un contorno general triangular y con un gran agujero o canal medular igualmente triangular. Se articula, tanto adelante como atrás, por medio de cuatr, facetas articulares a cada lado, es decir: 8 adelante y 8 atrás. La base de cada apófisis transversal tiene una perforación para el pasaje de 1. arteria vertebral, pero este conducto falta en algunos géneros.

La séptima vértebra cervical está siempre separada del hueso mesocervical, pero se presenta soldada atrás con las partes que representa- 
rían las dos primeras vértebras dorsales, formando las tres un solo hueso que lleva el nombre de metacervical. Este es un hueso corto, ancho $y$ casi plano, en el cual es más visible que en el hueso precedente la composición por tres vértebras antes separadas, pues cada vértebra conserva sus contornos, que están bien delimitados por surcos acentuados entre unas y otras, existiendo en la base de las apófisis transversas dos perforaciones intervertebrales. Las apófisis espinosas de las tres vértebras están reunidas en una sola que forma una fuerte protuberancia en la parte superior. A cada costado existen tres articulaciones cóncavas destinadas a la articulación de los tres primeros pares de costillas. Hacia adelante, el hueso metacervical se articula con la sexta vértebra cervical por medio de 6 facetas articulares, tres a cada lado; hacia atrás se articula con el tubo dorsal por medio de cuatro caras articulares.

Al hueso metacervical sigue un hueso muy largo y delgado, un poco arqueado y perforado en todo su largo, que lleva el nombre de tubo dorsal; esta pieza representa todas las demás vértebras dorsales soldadas y el agujero que la atraviesa en todo su largo es el canal medular. La parte engrosada que en los otros mamíferos forma los centros vertebrales aqui se ha vuelto una lámina delgada, no más gruesa que el resto de las paredes laterales que limitan el canal medular. La parte superior de este hueso se divide en tres crestas longitudinales regularmente eleradas y bien separadas, que corresponden: la del medio a las apófisis espinosas de todas las vertebras soldadas y las laterales a las apófisis tıansversas. Una doble fila de agujeros intervertebrales a cada costado atestigua todavía la separación primitiva de las vértebras, permitiendo ceterminar su numero, que también es fácil de reconocer por las onduliiciones del borde superior de la cresta media longitudinal cuyas protuberancias convexas corresponden a otras tantas apófisis espinosas. Las crestas laterales muestran una serie de excavaciones articulares cóncavas destinadas a recibir las facetas articulares de las costillas. La farte posterior del tubo se unia a la región lumbar siguiente de una manera más fija, que sólo permitía una especie de movimiento de ginglimo.

A esta sección sigue otro hueso mucho mayor, igualmente perforado en todo su largo, que lleva el nombre de tubo lumbosacral, porque representa las vértebras lumbares y el sacro reunidos, estando además soldado con la cadera, no formando el todo más que un solo hueso de una mole extraordinaria comparativamente al tamaño de estos animales. La parte de este hueso que corresponde a la columna vertebral se divide en dos partes: una anterior, que representa las vértebras lumbares que es el tubo lumbar: y la otra posterior, que constituye el sacro propia. mente dicho.

El tubo también empieza en su parte anterior por un pequeño borde 
engrosado en oposición con otro igual de la parte posterior del tubo dorsal, articulíndose con éste hacia arriba por una pequeña articulación cóncava que recibe una convexa del tubo dorsal y hacia abajo se une por superficies rugosas que demuestran que ambas partes estaban fuertemente ligadas por tejido fibroso que no permitia un gran movimiento de una parte sobre la otra. La parte inferior del tubo es delgada y parecida a la parte correspondiente del tubo dorsal, pero las crestas laterales son rudimentarias; en cambio la cresta media se levanta de un modo extraordinario formando una pared ósea continua, perpendicular, cuatro veces más elevada que la parte correspondiente del tubo dorsal. Parece que esta región lumbar se compone de un número distinto de vértebras soldadas, según los géneros y las especies.

Al tubo lumbar, e íntimamente soldado a éste, sigue el sacro, que está formado por lo menos por la reunión de ocho vértebras soldadas que cunstituyen un tubo parecido al lumbar, redondeado y perforado en su parte inferior y provisto de una alta cresta vertical en la superior. Hacia adelante, el tubo del sacro es ancho y excavado en su parte inferior; hacia el centro se vuelve mucho más delgado y forma una curva convexa muy pronunciada hacia arriba volviendo a ensancharse en su partiz posterior, donde termina en una vértebra muy gruesa, parecida a las primeras caudales, pero separada del resto del sacro por una fuerte escotadura a cada lado que la separa de la vértebra siguiente. Esta última vértebra sacra está provista de grandes apófisis transversas que se dirigen horizontalmente hacia los lados hasta unirse con el isquion; la penúltima vértebra sacra también está provista de apófisis transversas, pero mucho más delgadas y más cortas, terminando en las apófisis transversas de la última con las que se unen formando un solo hueso. De las vértebras anteriores del sacro, sólo las dos primeras se ponen en comunicación con los iliacos (con los que se sueldan en una pieza). La región del medio del sacro, formada por las cinco o más vértebras intermedias, es la parte más delgada y más arqueada del tubo, encontrándose libre, suspendida en el medio de la cadera.

Las primeras vértebras de la cola que siguen al sacro son siempre libres y de gran tamaño, con un arco neural completo, grandes apófisis transversales de un largo considerable; y en la parte inferior un arco hemal igualmente completo y muy fuerte, pero formado a veces solamente por huesos en forma de $\mathrm{V}$ de gran tamaño.

El manubrio es un hueso cuadrangular muy grande pero muy delgado; y los demás huesos del esternón son piezas delgadas y pequeñas. Las clavículas no existen o son rudimentarias. Las costillas son anchas, planas y delgadas, las anteriores con huesos esternocostales, excepto las del primer par. Su número varía de 12 a 13 pares.

El omoplato es muy extendido, de figura casi circular tan sólo inte- 
rimpida en su parte inferior y sumamente delgada en la mayor parte ¿C su extensión, siendo más corto y más ancho que el de los armadillos. La cresta media superior es baja, pero el acromion es muy largo, arqueado, ensanchado y deprimido en su parte superior. La apófisis coracuides es bien desarrollada y la cavidad glenoides de tamaño mediocre.

El húmero se parece al de los armadillos, pero es un poco más esbelto y al veces carece de perforación epitrocleana. El cúbito y el radio, siemre separados, presentan con los mismos huesos de los armadillos las mismas analogias que el himero, pero son siempre considerablemente miás robustos.

El carpo ticne el número completo de ocho huesos, como en los armadillos, con el cual presenta grandes analogías; pero el trapecio y el trapezoides se encuentran a menudo soldados en un solo hueso. Los metacarpianos son de largo regular y gruesos; y las falanges primeras y segtindas cortas y gruesas. Las falanges ungueales son largas y gruesas, casi cilindricas en la base y falciformes en su extremidad distal. Debajo cel carpo y de la parte contigua del metacarpo existe un gran hueso sesamoides plano $y$ de contorno irregular. Los dedos son en número de tres o cuatro y cada uno tiene un fuerte hueso sesamoides debajo de la articulación de la falange ungueal con la que le sigue atrás. Todo el pie es ancho, corto y fuerte.

El miembro posterior es mucho más robusto que el anterior. La cadera, sobre todo, soldada al sacro y al tubo lumbar, constituye una especie de armazón de tamaño enorme y que difiere de lo que se observa en todos los demás mamíferos, con excepción de la misma parte de los armadillos, con los que $\sin$ duda muestra grandes analogías. Los huesos iliacos de gran tamaño están colocados en posición vertical, dirigidos lateralmente hacia afuera formando más o menos un ángulo recto con la columna vertebral y soldados sobre la línea media con el tubo de la columna vertebral, con cuya cresta longitudinal forman como una cruz. Los bordes de láminas óseas verticales que forman dicha cruz, que son las crestas superiores de los iliacos y el borde superior de la cresta del tubo dorsal, son irregulares, rugosos y con fuertes protuberancias que servían de punto de apoyo a la coraza, con la que también se soldaban formando una sola pieza, a edad muy avanzada. Los isquiones, se dilatan hacia los lados formando grandes alas isquiáticas ascendentes de cytremidades igualmente rugosas que se aplicaban contra la cara interna de la coraza a la que formaban dos fuertes puntos de apoyo suplementarios, con los cuales en edad muy avanzada también se unía por anquilosis completa. La cavidad cotiloides es grande y vuelta hacia abajo. La sínfisis pubis se presenta en unos cerrada, formando un arco continuo, quizá debido a la intercalación de un hueso intermedio, como en los armadillos actuales, que concluye por unirse con los otros en una sola 
pieza; pero en otras especies la sinfisis permanece abierta durante toda la vida. La cadera, como en la generalidad de los desdentados, present: dos puntos de unión con el sacro: uno adelante, donde los ilíacos se sueldan a la primera o a las dos primeras sacras; $y$ una posterior, en la que los isquiones se unen con la última sacra.

El fémur es también un hueso muy grande y muy fuerte, considerablemente más robusto que el de los armadillos, casi cilíndrico y relativamente delgado en el medio, pero muy grueso y excesivamente ancho en las extremidades, debido, en la extremidad proximal, al gran desarrollo del trocánter externo que se separa de la cabeza articular más que en ningún otro mamifero; y en la extremidad distal, a causa del trocánter tercero colocado en el tercio inferior del hueso, muy prominente y que se prolonga en forma de cresta hasta el cóndilo externo. La rótula es un hueso grueso y casi cúbico. La tibia y el peroné son dos huesos cortos y anchos, intimamente unidos en sus dos extremidades y separados en el medio, quedando entre ambos una perforación ancha y alargada, de gran tamaño.

El pie posterior es muy corto y muy ancho, de una construcción sumamente fuerte. El tarso está formado por siete huesos, todos separados. El calcáneo es grueso y con una fuerte prolongación posterior, articulándose con el astrágalo $\mathrm{y}$ el cuboides sin tocar el escafoides.

El pie se termina en cuatro o cinco dedos completos, con metatarsianos y falanges muy gruesos y cortos y terminados en falanges ungueales cortas, aplastadas y redondeadas adelante, que parecen adaptadas más bien para recibir un casco que una uña.

Los representantes del grupo de los Glyptodontia se dividen en tres familias, que se distinguen por los siguientes caracteres:

I. Cola corta y compuesta en toda su extensión por un cierto número de anillos armados de tubérculos espinosos, que se adaptan sucesivamente unos a otros.

a. Superficie externa de la coraza dorsal con esculturas o figuras en relieve. Glyptodontida.

II. Cola larga, compuesta de un cierto número de anillos movibles, seguidos de un tubo cónicocilíndrico aplastado.

a. Coraza dorsal de superficie externa con figuras o esculturas más o menos acentuadas.

Tubo caudal de extremidad distal más o menos puntiaguda.

Hoplophorida.

b. Coraza dorsal de superficie externa sin dibujos o esculturas.

Tubo caudal de extremidad distal generalmente más o mencs ensanchada en forma de clava. Dodicurida. 


\section{Glyptodontidæe}

Los representantes de la familia de los Glyptodontidu presentan una coraza de forma más esférica que la de los demás grupos. Cada una de las placas de la coraza dorsal tiene en la cara externa una figura central en relieve, más o menos grande, rodeada de un cierto número de figuras Feriféricas a veces rudimentarias. La cola es corta y cónica, muy gruesa en la base, formada por anillos movibles que entran los unos en los otros, y en su parte superior son adornados con fuertes tubérculos agudos.

El cráneo es de superficie superior plana y horizontal.

El himero carece de agujero epitrocleano y el pie posterior termina siempre en cinco dedos completos.

Conozco de esta familia dos generos bien distintos que se distinguen por los siguientes caracteres:

A. Coraza compuesta de placas grandes, grtuesas y unidas por suturas fijas.

a. Escultura externa de la coraza, regular y simétrica. Glyptodon.

B. Coraza compuesta de placas pequeñas, gruesas y simplemente yuxtapuestas, sin estar reunidas por suturas fijas.

a. Primera muela inferior muy pequeña y cónicopuntiaguda.

Neothoraphorus.

(;I.YITODON OWE

Glypodon Owen, en P’arisir: Buenos Aires and La Plata, página $1-8, b, 1838$.

Dructerotherium. Brons: Lecthaca geognestica, $1 \$_{3} 8$.

Chlanydotherium. Bronn: Obra citada, I 838 ,

Hoplophorus (Lund). Turseristri: « Inales del Museo Público de Duenos Aires», etc., entrega $3^{n}$, página $39 \overline{7}, 1886$.

Schistopleurum. Nonot: Description d'un nourecan gente d'ćdenté fossilc, I856.

Burmeistra: «inales del Mirseo Público de Buenos Aires», tomo I, página 197, IS66.

Los representantes del género Glyptodon son los más robustos de todos los Gliptodontes y rupresentan el último término de la evolución del grupo a que pertenecen, si bien en algunos caracteres han conservado un tipo primitivo notable.

La coraza dorsal es menos alargada, más gruesa y más esférica que en los otros géneros. No es tan alargada y deprimida en su parte supe. rior como en el Hoplophorus, ni presenta encima de la región sacro. lumbar, la convexidad o joroba que distingue a las corazas de los gé. neros Panochtus y Doxdicurlis, representando más bien la forma de un fran tonel que estuviera abierto en sus dos extremidades. Las placas 
que componen la coraza son muy gruesas, por 10 general pentagonales o exagonales, unidas unas a otras por fuertes suturas en el centro de la coraza, pero por suturas mis flexibles sobre los bordes laterales. Cada placa lleva en la superficie externa una figura central poligonal, generalmente más grande, rodeada de seis a siete figuras periféricas, dispuestas en una sola fila, igualmente poligonales y todas más o menos con la superficie sobre un mismo plano; estas figuras perifèricas concluyen sobre el mismo borde de la placa en una linea recta opuesta a la de otra figura de la placa contigua, constituyendo por su reunión en las placas soldadas una figura de mayor tamano. Todas estas figuras están separadas por surcos angostos y generalmente profundos, en cuyo fondo, particularmente alrededor de la figura central y de la convergencia de los surcos radiales con el periférico de la figura central, se encuentran agujeros de tamaño variable y a veces de dimensiones verdaderamente extraordinarias. Las placas se vuelven a menudo más grandes sobre los flancos laterales, pero más delgadas y casi siempre de superficie externa más rugosa. Todas las placas en el centro de la coraza están dispuestas como las piezas de un mosaico, sin presentar una disposición bien definida en filas transversales como en el Panochtus, pero en los costados se vuelven más rectangulares y se encuentran dispuestas en filas transversales más perceptibles; algunas de estas filas, colocadas en el centro o un poco más adelante del centro de la coraza, se separan al llegar al borde dejando entre unas y otras pequenas hendeduras perpendiculares, que daban una pequeña flexibilidad a los borcles de la coraza; pero no son tan largas y pronunciadas como en el Panochtus. Estas placas laterales semimovibles se articulaban unas a otras de adelante hacia atrás, pasando la parte anterior adelgazada de cada placa por debajo de la parte posterior de la placa correspondiente clel anillo situado adelante. Todo el borde periférico de la coraza está formado por una fila de placas más gruesas y de forma completamente diferente, pues en vez de ser planas y con figuras sobre la cara externa, afectan la forma de grandes tubérculos más o menos cónicos, de superficie rugosa y articulados con la coraza únicamente por la base; estos tubérculos son más grandes y más romos en el centro de la abertura cefálica y caudal, pero a los lados y en los ángulos inferiores toman la forma de mamelones cónicopuntiagudos.

La coraza o casco cefálico está formado por un gran número de pecueñas placas delgadas y deprimidas, generalmente con una sola figura plana en la superficie externa y terminando casi todas en bordes delgados, la mayor parte sin suturas que las unieran entre sí, de manera que su reconstrucción es muy difícil.

La coraza caudal se compone de la reunión de 9 o 10 anillos movibles que se adaptan los unos en los otros y disminuyen de tamaño del pri- 
mero al último, formando una cola corta cónicocilindrica, muy gruesa en su extremidad proximal y que disminuye rápidamente de diámetro, terminando en punta roma redondeada en la extremidad distal.

Cada anillo está formado por dos o tres filas de placas, a veces por tres filas en un costado $y$ dos en el otro; la fila anterior de cada anillo esti formada de placas alargadas, deprimidas y adelgazadas en la extremidad anterior, pero más gruesas en la extremidad posterior, donde presentan en la superficie externa una figura elíptica o subeliptica, casi siempre fuertemente acentuada; la fila posterior se compone de placas muy gruesas en su parte posterior, donde la superficie externa se levanta para formar tubérculos cónicopuntiagudos, parecidos a los de los bordes de la coraza, muy grandes, elevados y puntiagudos en la parte superior o dorsal, pero más pequeños y deprimidos en la cara inferior.

Los anillos anteriores más grandes son de contorno fuertemente eliptico, con su mayor diámetro en dirección transversal, pero se hacen mís redondos hacia atrás, hasta que los últimos son casi perfectamente circulares.

El primer anillo, que es el más grande, está formado por dos o tres filas de placas, según las especies, pero difiere siempre de los demás por las placas de la parte superior de la última fila que presentan en su parte posterior una figura deprimida, en vez de los fuertes tubérculos puntiagudos que hay en los demás anillos. Los anillos intermedios están formados casi siempre de tres filas de placas, pero una de ellas interrumpida, de manera que presentan tres filas de placas en un costado $y$ dos en el otro. Parece que los últimos anillos están siempre formados de dos filas de placas. Todas las placas que constituyen a estos anillos están reunidas por suturas muy flexibles o casi sueltas, de manera que se deshacen con la mayor facilidad, pero los dos últimos anillos están formados por placas reunidas por suturas más sólidas y a veces se presentan los dos anillos reunidos entre si por sutura entre las flacas contiguas. Todos los anillos articulados entre si forman una especie de tubo cónico cilindrico rodeado de filas transversales de tubérculos espinosos más altos en la parte superior que en la inferior, cerrado en st extremidad distal por una especie de escudo cóncavo adelante y convexo atrás, formado por la reunión de un corto número de placas dispuestas en dos filas y unidas por suturas más fijas que en el resto de la cola.

El cráneo del Glyptodon es proporcionalmente más pequeño que el cel Panochtus y el Hoplophorus y la parte anterior menos prolongada hacia adelante y como truncada verticalmente; así la abertura nasal, en vez de ser baja, angosta y dirigida hacia abajo, es de gran tamaño, bastante elevada, muy ancha y dirigida hacia adelante. La superficie superior del cráneo, tampoco es convexa como en los mencionados géneros, 
sino plana y en ciertas partes deprimida, con los nasales, frontales y parietales colocados en un mismo plano horizontal, dándole un aspecto completamente característico. Los huesos nasales son pequeños y cortos, casi rudimentarios, colocados en la parte anterior del cráneo, de manera que constituyen el borde que limita la parte superior de la abertura nasal, pero estos huesos se sueldan a los frontales en edad muy temprana, de manera que en los cráneos de individuos que han alcanzado su completo desarrollo no se ven vestigios de las suturas. La abertura nasal tiene una forma triangular, muy ancha arriba y angosta en su parte inferior. Los frontales forman entre las órbitas y hacia adelante un espacio ancho y corto, completamente plano o deprimido que se extiende hacia adelante hasta la abertura nasal y está limitado hacia atrás por dos líneas curvas o crestas que se desprenden de la cresta sagital y se dirigen a los lados terminando encima de las órbitas en las apófisis postorbitarias. Los huesos parietales son más largos y más estrechos cue los frontales y no forman un plano horizontal deprimido sino una convexidad en dirección transversal poco acentuada, levantándose sobre la línea media una cresta sagital elevada que parte del borde anterior del occipital y se dirige hacia adelante hasta penetrar en los frontales, donde se divide en las dos líneas curvas mencionadas. Casi toda la superficie superior del cráneo está cubierta por una gran cantidad de agujeros vasculares generalmente pequeños, que en la región posterior de los parietales y en la parte escamosa del temporal adquieren un desarrollo considerable, constituyendo verdaderas perforaciones a veces de varios milímetros de diámetro. El occipital es ancho, muy inclinado hacia adelante, deprimido y limitado arriba y a los lados por una fuerte cresta occipital.

El arco cigomático es mucho más fuerte adelante que el del Panochtus y con una apófisis descendente más gruesa; pero inmediatamente detrás de la cavidad orbitaria es, al contrario, sumamente delgado; mientras que en la misma región, en el Panochtus y el Hoplophorus es sumamente grueso; además, la cavidad orbitaria, más circular que en los mencionados géneros, se comunica hacia atrás libremente con las fosas temporales, por no existir el puente que en el Panochtus une la apófisis postorbitaria del frontal con el cigomático, ni existe tampoco en la parte superior de este hueso la apófisis postorbitaria o canto ascendente que se observa en el cráneo del Hoplophorus, de manera que la comunicación entre la cavidad orbitaria y la fosa temporal es más ancha que en el mencionado género. El distintivo más característico del Glyptodon en el paladar, es el ancho y la brevedad de la región que se extiende adelante de las muelas, lo que demuestra que el intermaxilar era más corto que en los demás géneros. Los agujeros incisivos son cortos y anchos y están colocados en la parte del paladar comprendida entre las extremi- 
dades anteriones de la primera muela de cada lado. La mandibula inferior es más maciza que la del Panochtus, la rama horizontal más alta $\because$ la parte sinfisaria que se extiende adelante de las muelas más corta.

Los dientes del Glyptulun se distinguen de los del Panochtus y el Hoplophorus, por la lámina interna de la vásculodentina, que presenta en la corona pequeñas ramificaciones que penetran en la masa de dentina que las envuelve. Estas muelas son, por otra parte, más parecidas untre sí tanto por la forma como por el tamaño, que en los demás géneros; la primera muela de cada mandibula es un poco más pequeña que las otras, pero no de una manera muy notable y sin que pierda la forma triprismática, cono sucele con la misma muela en los otros géneros.

El atlas carece de la apófisis superior presente en el Panochtus y el Hoplophorus y tiene las alas laterales más grandes.

E1 hueso mesocervical se compone de cuatro o cinco vértebras, según las especies y la edad de los individuos; la apófisis espinosa es pequeña Y la apófisis odontoides es muy prolongada hacia adelante, separada en su hase del resto del hueso por una depresión circular muy pronunciada.

La sexta vértebra cervical se presenta casi siempre separada, pero a veces también soldada a la parte anterior del hueso metacervical, to que se considera como un carácter particular de ciertas especies, que también puede ser el resultado de una anquilosis senil.

El hueso metacervical se compone de tres o cuatro vértebras, según que la sexta cervical esté unida a su parte anterior o separada.

El tubo dorsal, a juzgar por los ejemplares que hasta ahora se conocen, parece estar formado en todas las especies, por la reunión de once vértebras.

La parte lumbar del tubo sacrolumbar, se compone de seis a ocho vérthras soldadas. según las especies: y la parte del tuho que corresponde ¿ll sacro parece estar formada por la unión de nueve o diez piezas.

El número de las vértebras caudales es de 11 a 12 ; y en algunas especies la primera caudal se soldaba a la parte posterior del sacro.

Las costillas eran en numero de 13 pares, de los cuales el primero se unia por sinostosis con el manubrio. Los huesos de los miembros son notablemente más fuertes que en los otros géneros.

I:I humero tienc una cresta deltoides inás fuerte que en el Panochtus y 1 Hoplophorus, distinguicindose además por carecer del agujero epitrocleano, que se encuentra en el húmero de los mencionados géneros, asi como también en el del Doedicurus.

El carpo del Gilluptudu se compone de ocho huesos en unas especies; y en algunas otras de sólo siete, a causa de la unión del trapecio y del trapezoides en una sola pieza. El pie termina en cuatro dedos completos correspondientes al primero, segundo, tercero y cuarto, faltando por completo el quinto, del cual no existen ni vestigios del respectivo metacarpiano. 
E1 dedo primero o interno, aunque provisto de uña, es rudimentario, pues la falange ungueal, de tamaño mucho más pequeño que las otras, se articula directamente con el metacarpiano primero, que es de tamaño verdaderamente diminuto. Los metacarpianos de los dedos siguientes son cortos y gruesos, de aspecto casi cuboides. La primera falange de los dedos segundo y tercero es más corta todavia que los metacarpianos; y la falange segunda de los mismos dedos y la primera y segunda del cuarto, son tan cortas y altas que afectan casi una forma laminar. Las falanges ungueales de los tres dedos externos, son en cambio más largas que el metacarpiano y las dos falanges de cada dedo y muy deprimidas en todo su largo. La longitud de estos dedos disminuye del segundo al cuarto.

El pie posterior, sumamente corto $y$ ancho, termina en cinco dedos completos, todos con uña, el primero o interno bastante pequeño, el segundo y tercero mucho más grandes, el cuarto casi del mismo tamañc que el segundo y el quinto apenas un poco mayor que el primero. Las fitlanges ungueales son cortas, anchas y deprimidas, dispuestas como para llevar una pezuña en vez de uña.

Lydekker, en la diagnosis que da de este género ( Catal. of Foss. mammal.», parte $V$, página 115 ), afirma que tiene un escudo ventral, guiado, sin duda, por los trabajos de Burmeister, que es en los que se encuentra esta afirmación original pero errónea, pues ya he demostrado suficientemente en mis trabajos precedentes, que tanto el Glyptodon cumo los demás géneros de esta familia, carecían de plastrón ventral y que los fragmentos que Burmeister confundió por tales eran simplemente placas de la coraza dorsal del género Dodicurus.

El fragmento de coraza de placas perforadas dibujado por Burmeister en la lámina XLI, figura 1, del tomo segundo de los «Anales del Museo de Buenos Aires», atribuido por él al plastrón ventral del Glyptodon clavipes, pertenece al borde de la parte lateral de la coraza dorsal de una especie del género Doedicurus.

Las especies del género Glyptodon son muy numerosas, pero en su mayor parte poco conocidas y de difícil distinción entre sí. Agréguese a esta dificultad, que, cuando se trata de esqueletos montados en los Museos, lo son generalmente con restos provenientes de individuos distintos, que a menudo no provienen tampoco de la misma especie, y ser $i$ fácil darse cuenta de las dificultades que existen para dar una sinopsis de nuestros conocimientos sobre este grupo. Las especies nominales son considerables; y los sinónimos no siempre pueden ser establecidos con precisión.

Con todo, es probable que cuando se conozcan más materiales, sobre todo un mayor número de piezas del esqueleto, recogidas con más orden que no lo han sido hasta la fecha, esto es: que puedan en todos 
los casos mostrarse al lado de las piezas del esqueleto, los restos de corazas que provengan con seguridad de los mismos individuos, se podrán establecer distinciones más evidentes y fundamentales, suprimir algunas especies nominales y quizá también dividir el género en subgéneros.

En el estado actual de la ciencia, y es preciso no cesar de repetirlo, las diferencias específicas sólo pueden ser apreciadas sobre aquellas partes del esqueleto en las que sea menos probable que se hayan confundido restos de varios individuos en uno y además que sean las que se recogen con mayor frecuencia. En este caso se encuentran los restos de coraza.

Según la estructura externa de las placas que forman la coraza dorsal, las especies del género Glyptodon pueden agruparse en tres secciones: en una de ellas, la figura central de cada placa es siempre considerable. mente más grande que las figuras periféricas, de contorno circular o subeliptico y deprimida o excavada en el centro; en el otro grupo, la figura central de cada placa es relativamente más pequeña que en los representantes de la otra sección y en el centro de la coraza, la figura central se confunde a veces por su forma y tamaño, con las figuras periféricas, presentando siempre como éstas la superficie, plana o rugosa, pero nunca excavada en el centro o sólo de una manera accidental; en el tercer grupo, la figura central de cada placa es de tamaño siempre mayor que las periféricas y de superficie convexa o globulosa.

\section{GRUPO A}

Especies con la figura central de cada placa considerablemente más grmale que las periféricas, de contorno circular o subcircular y fuertemente deprimida o excavada en el centro.

\section{Giyptodon ciavipes Owen}

Lamin Lil, figuras

Gluplodon clavipes. Owen: Proceed. Geol. Soc., 1839 , página 238. - Idem: Trans. Geol. Soc., tomo VI, página 8r, 18.4. - Idem: Zoology of the $\alpha$ Beagle», tomo I, pág. 106, $18+n$. -Descr. Cat. of the coll. of the college of Surgeons, tomo I, numero 555, 1842.

W. Parish: Bucnos Ayres from the conquest, $2^{0}$ edición, páginas 217,220 y 433,1838 .

J. MUlLer: Abl. d. Kön. Akad. z. Berlin, Cl. phys., 1846.

Nodor: Description d'un nouveau genre d'ídenté fossile, etc., página $\mathrm{S}_{5}$. Atlas, lámina I, figura I.

PICret: Traité de Paléontologie, tomo I, página 27r, Atlas, lámina VIII, figuras 8-11.

GIEbel: Fauna der Vorwelt, tomo I, página 110.

HuXz,E: \&Philosoph. Transact. , etc., tomo CLV, I865.

BurMeister: «Anales del Museo Público de Buenos Aires», tomo I, páginas 76 y 195. -

Idem: tomo II, página 383.-Idem: Description physique, etc., tomo III, página 422, 2879.

II. Gervais y AMEghino: Los mamíferos fósiles, etc., página 200, i88o.

Amegrino: «Boletin de la Academia Nacional de Ciencias», tomo V.

LYDEKKER: Catal, of the Foss. Mammalia, parte V, página i15, 188\%.

Glyptodon Oweni? NoDor: Description d'un noureau genre d'édenté fossile, página 88 , lámina $\mathrm{X}$, figura 4,1857 .

Esta es la especie típica del grupo y lo fué también durante largo tiempo del género, tomándose como tipo el esqueleto reconstruído bajo 
la dirección de Owen, en el Museo del Colegio de Cirujanos de Londres; por desgracia, esa reconstrucción es híbrida, pues los diferentes restos que constituyen el mencionado esqueleto, provienen de individuos distintos y en ciertos casos de especies diferentes y de otros géneros. Asi, si bien la coraza es indisputablemente de un verdadero Glyptodon, la cola, formada por un tubo caudal cilíndricoaplastado, es evidentemente de una especie del género Hoplophorus; y nada prueba tampoco que la cabeza sea del mismo individuo que la coraza.

La coraza, comparada con la de los demás Gliptodontes, es más bien de tamaño pequeño que grande y de una forma oval, prolongada, semicilindrica.

Según Owen, las medidas del ejemplar del Museo del Colegio de Cirujanos de Londres, son:

\section{DIMENSIONES}

Diámetro anteroposterior siguiendo la curva superior del dorso ............ $1^{m} 700$

Diámetro anteroposterior en linea recta .... ......................... 1420

Diámetro transverso siguiendo la curva en el centro de la coraza . . ....... 2335

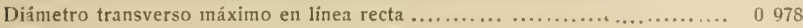

Diámetro transverso er la extremidad posterior ....................... 0508

«Las placas que formar esta coraza tienen en la superficie externa una figura central, grande, subpentagonal o subcircular, rodeada generalmente de cinco o seis figuras más pequeñas, unas y otras rugosas, pero particularmente las periféricas. En las placas próximas a los bordes de la coraza, la figura central es de mayor tamaño, mientras las periféricas disminuyen de tamaño y desaparecen completamente cerca del borde anterior; las figuras centrales del medio de la coraza, se dilatan Ce adelante hacia atrás formando figuras oblongas; al contrario, cerca del borde anterior, las figuras centrales avanzan hacia adelante en forma angulosa; las placas de la parte posterior son las más gruesas y de figura pentagonal.

«Tiene esta coraza 42 filas transversales de placas; las filas más largas, esto es: aquellas que corresponden a la parte más gruesa del animal, contienen cada una setenta placas distintas; pero este número disminuye gradualmente, de manera que sobre la fila anterior que forma el borde no hay más que diez y seis placas y en la parte posterior veinticinco; siendo de más de dos mil el número total de las placas del Glyptodon clavipes». (Owen).

En las partes periféricas de la coraza, la figura central de cada placa es no sólo más grande, sino también más elevada y con sus bordes levantándose a un nivel algo mayor que el de las figuras periféricas. Esa figura central es constantemente excavada en el centro, en dond: 
forma una depresión cúncava muy acentuada, mientras que las figuras periféricas son planas o casi planas, pero unas y otras de superficie relativamente lisa, con simples puntuaciones que no forman asperosidades; los surcos que separan a las figuras son anchos y poco profundos; y las placas de tamaño relativamente grande pero no muy gruesas. Las placas terminales en forma de tubérculos cónicos que constituyen el borde fieriférico de la coraza, son en toda su extensión más iguales entre sí çue no lo son en las otras especies del mismo género, a 10 menos en aquellas cuyos bordes se conocen.

La cola del Glyptodon clavipes estaba constituída por un cierto nümero de anillos con tubérculos espinosos, como en los demás Gliptodontes: y no por un tubo cónicocilindrico aplastado como el que se ha adaptado al ejemplar típico del Museo del Colegio de Cirujanos de Londres, que, ya lo he dicho, proviene del género Hoplophorus.

Las demás partes del esqueleto son poco conocidas o no han sido liasta ahora descriptas en presencia de ejemplares indiscutiblement 2 auténticos como provenientes del Glyptodon clavipes. Los miembros posteriores forman probablemente excepción, pues parece que los que fueron descriptos por Owen pertenecen realmente al mismo individuo que la coraza; estos restos demuestran que el pie de esta especie era muy corto, ancho y macizo.

En cuanto al cráneo, descripto por Owen como del Glyptodon clavipes. si realmente es del mismo individuo que la coraza, demostraría que difiere del correspondiente del Glyptuden reticulatus, por sus proporciones, siendo relativamente un poco más largo y más angosto, particularmente en su región anterior. que es muy prolongada hacia adelante $\because$ notahlemente más angosta. la apófisis cigomática es hacia abajo más estrecha, menos gruesa y fuertemente recurvada hacia atrís, siendo la distancia entre las extremidales de ambas apófisis un tercio menor que en Glyptodon reticulatus.

La parte de cráneo y esqueleto, descriptos por Huxley como de Glyptoldon clanipes, no estin de acuerdo con la descripción de Owen, ni por su forma, ni por su tamaño; y corresponde probablemente a otra especic mayor.

La suerte de esta especie, en las descripciones, ha siao verdaderamente desgraciada; y la confusión que reina a su respecto constituye un laberinto del cual casi no es posible salir sin destruir la mayor parte de Is que sobre ella se ha publicado.

A la primera restauración equivocada, dada por Owen, en la que la crraza figura con un tuho conicocilinurico aplastado del género Hoplophoms que se adapta a ella sin anillos intermedios (error excusable si se tiene en cuenta que fué el primer ensayo de reconstrucción de un animal de este grupol. siguió últimamente otra reconstrucción dada por 
Burmeister, destinada a corregir los errores de la primera, en la cua: éstos son aumentados de una manera considerable. Esta figura se encuentra en el tomo segundo de los «Anales del Museo Público de Buenos Aires» y en la lámina XXXVI, que representa la coraza entera, 1 a cola formada por siete anillos seguidos de un tubo cónicocilíndrico, la cabeza con su casco cefálico y los cuatro miembros.

Lydekker, al hablar del Glyptodon clavipes, dice: «The specimen figured by Burmeister in the «Anales del Museo de Buenos Aires》, vol. II, lam. XXXVI, under the present name has been referred by Gervais and Ameghino to Hoplophorus». (Catálogo, parte V, pág. 115); sin duda por error, pues con Gervais sólo hemos referido al Hoplophorus el tubo caudal adaptado a la coraza dorsal del Glyptodon clavipes de Londres.

Más adelante, a propósito de una especie de Hoplophorus (?) inédita, de gran talla, dice el mismo Lydekker: «The Glyptodon figured by Burmeister in the "Anales del MIuseo de Buenos Aires》, 1'ol. II, lam. XX.YVI, under the name of Glyptodon clavipes, differs from the type specimen of that species figured by Owen, inthe more elongated and less vaulted form of the carapace, and the straight inferior border of the same, and also in the more clongated scutes, in wich the central disks are mach less distinctly defined; in all of wich respects it has a much closer rescmllance to the carapace of Hoplophorus ornatus, to wich specics it is referred by Ameghino. The carapace and caudal sheath of that specimen may very probably belong to the same species as the specimens noticed bellow; but the cranium wich is like that of Glyptodon, may possibly belong to another form, and the margins of the carapace are perhaps incorrectly restorred. If this cranium really belong to the same individual as the carapace, it would apparently indicate that the species presents caracters intermediate betwen those of Hoplophorus ornatus and Glyptodon reticulatus.» (Catálogo, etc., parte V, página 133). Sin duda se refiere Lydekker a mi trabajo: Sobre la necesidad de borrar el gíncro Schistopleurum, etc., publicado en el tomo V del «Boletín de la Acade. mia Nacional de Ciencias», pero en este trabajo no refiero la coraza al Hoplophorus, contentándome con decir que ella no es tampoco del Glyptodon clavipes, refiriendo sólo con seguridad al Hoplophorus, la cola.

Los caracteres intermedios tan notables e imposibles que de tal manera llamaron la atención de Lydekker no lo hubieran sorprendido tanto si hubiera fijado su atención en el texto, alli donde, en la página 379, por ejemplo, del tomo II de los «Anales del Museo de Buenos Aires», dice Burmeister lo siguiente: «La coraza del Glyptodon clanipes figurada por Owen y repetida por Nodot, no ha sido completa, faltándole toda la orilla lateral y por consiguiente no puede esta figura representar el animal como ha sido durante su vida. Por esta razón he compuesto 
(lámina XXXVI) una nueva figura mejor, con asistencia de los restos conservados en nuestro Museo Público; pero esta figura tampoco es una representación exacta del objeto, sino una composición de la fantasia, con auxilio de algunos objetos positivos». Y para ser más explícito, agregaré que el tubo caudal de esta restauración es de Hoplophorus; que los anillos movibles que lo preceden no existen en el Museo de Buenos Aires, estando ellos reconstruídos según fragmentos de anillos caudales movibles de Hoplophorus; que la cabeza del Glyptodon clavires tampoco existe en el Museo, según declaración del propio Burmeistur en la misma obra, página 268; la coraza (página 384) según confesión del mismo autor es más incompleta que la figurada por Owen, pues se reduce a un pequeño fragmento del centro de la coraza, que tampoco rertenece al Glyptudun clanipes, sino que es de un individuo del Glyptiulun reticulutus. Esos son los materiales positivos con los cuales Burmeister ha reconstruido el $G$. clavipes representado en la lám. XXXVI, yue con razón ha calificado él mismo como una composición de la fantusia y que proporciona un cjemplo muy ilustrativo de la cautela con çte debemos servirnos de los dibujos del ilustre paleontólogo, sin duda muy hermosos, y representando siempre objetos intactos, en los que no se nota el más pequeño desperfecto, pero a menudo fantásticos.

Procedicncia: El ejemplar típico descripto por Owen fué descubierto sribie el río de la Matanza, en el partido Cañuelas; y según informe que he rodilo recoger personalmente sobre el terreno, el tubo de Hoplophoris adaptado a esta coraza procede de la misma localidad, pero fué recosido a una distancia de más de dos kilómetros del punto de donde fué extraida la coraza. Fragmentos de coriza parecidos, se descubren, aunqine no con mucha irecuencia, en las provincias Buenos Aires, Santa $\mathrm{Fe}$ Y. Córdoha; en la Rep. O. del Uruguay; y en la extremidad sud de Brasil.

Horizunte: Piso bonaerense y piso lujanense de la form. pampeana.

GLYPTODON EUPHRACTUS Lund

Lamira Lirt, tigura s

Hoplophorus cuphractus. LUND (parte): «Annales de Sciences Naturelles», serie 2n, volumen XI, página 21S, I 839 . - Idem: Overs. k. Danske Vid. Selsh, Forhandl., $18_{3} 8$, pág. 11. Hoplophoras Scllowi. Irund: Orers. k. Danske, Vid. Selsk. Forhundl. Gluptodon eupliractus (I,und). Rernirardt: Vil. Med. Nat. Foren. Köbenlavn, pág. 165.
año 1875.

LYDEKKER: Catal. of Foss. Mamm., parte V, pigina $121,1887$.

H. Gervais y AMegmino: Los mamiferos fósiles, etc., página 202, 1880.

Clyptodon dubiks. ReINIIARDT: Obra y página citadas.

Glyptodon Sellowi (Lund). II. Gerlais y AxEgirino: Los mamifcros fósiles, etc., página 202, año i 880 .

Schistopleurum euphractum Reinhardt.

Esta especie es todavía muy imperfectamente conocida; y parece ser tan cercana del Glyplodoin clavipes, que, por el momento, es difícil dis- 
tinguirla con seguridad. Según Lydekker es de tamaño apenas un poco mayor que el Hoplophorus ornatus; y los restos de que dispongo indican un tamaño algo menor que el Glyptodon clavipes. Las placas de la coraza son un poco más pequeñas y más delgadas que las de la mencionada especie, con la superficie externa ocupada por una figura central de gran tamaño, de contorno subcircular o poligonal y fuertemente deprimida o excavada en el centro, rodeada por seis o siete figuras poligo. nales más pequeñas, de superficie plana o un poco deprimida. La superficie de todas estas figuras parece ser un poco más rugosa que en Glyptodon clavipes y separadas por surcos poco profundos y de fondo casi liso. En el fondo del surco que rodea a la figura central existen de 4 a 6 perforaciones pequeñas (las más grandes son apenas de un poco más de un milímetro de diámetro) colocadas en el punto de reunión de los surcos radiales que separan las figuras periféricas. Una placa del centro de la coraza de este animal, en el punto donde presenta mayor espesor, tiene unos 45 milímetros de largo, otro tanto de ancho y sólo 19 milimetros de espesor. La figura central tiene 20 milímetros de diámetro.

Procedencia: - República Argentina, República Oxiental y parte Sud de Brasil.

Horizonte:- En la provincia Buenos Aires, los restos referibles a esta especie, que son bastante raros, proceden del piso bonaerense de la formación pampeana.

Glyptodon subetevates Nodot Laminn L.X, Agras o $y$ it

ToDox: Description d'un novecau genve d'édenté fossile, página 94, lámina II, figura I, año I 857 .

La especie fué fundada sobre un trozo de coraza formado por placas delgadas, exagonales, cuya superficie externa está ocupada en su mayor parte por una gran figura central, más elevada que las periféricas, de superficie irregular, con algunos agujeros en el centro, que es fuertemente deprimido como en el Glyptodon clavipes y el Glyptodon euphractus. Las figuras periféricas, en número de 6 a 8 , son relativamente muy pequenas y mal delimitadas, separadas por surcos poco profundos y presentando una superficie como radiada; en algunas placas, casi puede decirse que las figuras periféricas están reemplazadas por una serie de impresiones radiales, que van del surco que rodea a la figura central a los bordes de las placas, carácter particular que distingue muy bien a esta especie del Glyptodon clavipes. En el fondo del surco que rodea 
a la figura central, que es el único que está bien delimitado, hay en cada placa de 4 a 6 agujeros de tamaño relativamente considerable, pues tienen un diámetro de 2 a 3 milímetros. En las placas centrales de la coraza las figuras periféricas son mejor delimitadas, con las impresiones radiales poco marcadas, pero con la figura central igualmente grande y deprimida en el medio. Las placas tienen de 30 a 36 milímetros de largo, 28 a 32 de ancho y sólo de 15 a 20 de espesor. 10 que indica un animal bastante más pequeño que el Glyptodon clavipes.

Procedencia: - La pieza original sobre que fué fundada la especie ha sido recogida por Vilardebó en las cercanías de Montevideo; y se han recogido fragmentos iguales, evidentemente de la misma especie, en distintas localidades de la región Norte de la provincia Buenos Aires, pero la especie parece ser aqui bastante rara.

Horizonte:- Piso belgranense de la formación pampeana.

Giyptodon princtpalis 11. Gervais y Ameghino

Glyptodon principalis. H. Gervais y AMrciriso: Los mamífcros fósiles, etc., pág. 204, rS\$o.

Fundé la especie en colaboración con H. Gervais, expresándonos en los siguientes términos: «El Glyptodon principalis, a juzgar por las placas dérmicas, que son de doble tamaño que las de las otras especies que acabamos de estudiar, debía ser de dimensiones gigantescas. La superficie de las placas no es rugosa, sino simplemente puntuada; la figura central es mucho más grande que las que la rodean. El espesor medio de las placas es de 43 milimetros.»

No puedo dar más detalles ni dibujos porque las piezas de que disponía se halian en las colecciones del Museo de La Plata, pero será siempre fácil distinguir la especie por el tamaño y el espesor considerables de las placas, por el tamaño notable de la figura central de cada placa, por los surcos bien marcados y angostos pero no profundos, por la figura central un poco deprimida en el centro y por la superficie de todas las figuras, que es casi completamente lisa como la de algunos Hoplopho. rlts, presentando únicamente simples puntuaciones.

Procedencia: - Las piezas originales sobre que fué fundada la esFecie proceden de los alrededores de Montevideo, donde fueron descubiertas por Vilardebó; y se han recogido iguales en las toscas del fondo del río de la Plata, en el municipio de Buenos Aires.

Horizonte:- Piso ensenadense de la formación pampeana. 
AmegrrNo: La antigücdad del hombrc, etc., tomo II, página 309, IEsr.

Esta especie es también de gran tamaño, por lo menos igual al del Glyptodon reticulatus, pero la forma de la coraza es muy distinta, pues en vez de ser globulosa y casi esférica como en ésta, es mucho más alargada, oblongoovalada y relativamente angosta, pareciéndose en su forma general a la del Glyptodon clavipes. Las placas de la coraza son relativamente pequeñas, pero muy gruesas; cada placa tiene la superficie externa ocupada por una figura central mucho más grande que las periféricas hasta en el mismo centro de la coraza, de figura poligonal a veces con ángulos muy marcados, pero otras veces con una tendencia a la forma subcircular. Las figuras periféricas son siempre mucho más fequeñas, poligonales y angulosas y de superficie no más baja que la ce la figura central. La superficie de todas las figuras es muy rugosa y áspera, casi tanto como en el Glyptodon rcticulatus, pero se distingue netamente de esta especie por la figura central de cada placa, cuyo centro es excavado, formando como un hoyo a menudo profundo, aunque a veces está reemplazado por una depresión menos marcada y de mayor extensión, pero siempre de superficie muy rugosa. Este carácter, dz presentar la superficie de las placas sumamente áspero y rugoso, distingue igualmente con seguridad esta especie, del Glyptodon clavipes, cuya superficie es casi lisa.

Los surcos que separan a las figuras entre sí, son relativamente angostos, pero profundos; en el fondo del surco que delimita a la figur. central hay algunos agujeros piliferos, colocados como en las otras especies, pero de tamaño muy pequeño en proporción de la talla del animal, pues son muy raros los que tienen más de 2 milímetros de diámetro; además se encuentran algunos agujeros parecidos en los bordes periféricos de las placas, en el medio de los surcos que separan a las figuras periféricas y colocados de modo que se dividen en dos mitades que se reparten en las dos placas contiguas y forman, poniéndose en contacto, como en su posición natural, una sola perforación; constituye este último un carácter particular que por ahora puede considerarse como el distintivo más notable de esta especie, pues no lo he observado en ningún otro Glyptodon; estas perforaciones, que pueden ser denominadas periféricas, son siempre de doble tamaño que las otras, teniendo algunas más de 4 milímetros de diámetro.

Las placas del centro de la coraza, que son las más pequeñas pero las más gruesas, tienen un diámetro de 40 a 55 milímetros y de 25 a 28 milímetros de espesor. La figura central de cada placa tiene de 25 a 30 cenlímetros de diámetro, siendo un poco mayor en las placas laterales que en ias del centro. 
Procedencia:- Barrancas del Paraná, en la provincia Buenos Aires; toscas del fondo del río de la Plata, en el municipio de Buenos Aires; y excavaciones del puerto de La Plata, en la Ensenada.

Horizontc: - Piso ensenadense de la formación pampeana (plioceno inferior).

Glyptodon Minor (Lund) Ameghino

Iloplophorns minor. LUND: Blik, pac Bras. Dyr, etc.

II. Gervais y Aaregino: Los mamiferes fósiles, etc., página 192 , IS80.

Glyptodor minor (Lund). AMECHino: en «Boletín de la Academia Nacional de Ciencias», tomo $V$, página $=9$.

Entre las que se conocen hasła el día, esta es la especie más pequeña del género Glyptodon; pero desgraciadamente sólo está representada por fragmentos de coraza que indican grandes afinidades con el Glyptodon churipes. Las placas son de tamaño pequeño y sumamente delgadas, no más gruesas que las del Hoplophorus ornatus, pero con la escultura de la superficie externa con los caracteres del género Glyptodon. La superficie externa presenta una figura central muy grande, de contorno subcircular y fuertemente deprimida en el centro, rodeada por ocho o nueve figuras periféricas de tamaño muy desigual, algunas reducidas a pequenos segmentos de circulo y todas de superficie plana, poco rugosa, como también la figura central. Los surcos que separan a las figuras son anchos pero poco profundos $y$ con varios agujeros pilíferos pequeños en el surco que rodea a la figura central.

Una placa del centro de la coraza tiene 4 centímetros de diámetro anturoposterior, 4 centímetros de ancho y sólo de 10 a 11 milímetros de espesor; la figura central tiene 19 milímetros de diámetro.

El carácter distintivo más notable de esta especie consiste en el poco espesor de las placas y en el número de figuras periféricas, que no baja de ocho en cada placa, lo que constituye una disposición parecida a la de los Hoplophorus; pero la superficie de las placas es mucho más rugosa y los surcos son mucho más anchos, cuyos caracteres son distintivos de los representantes del género Glyptodon.

Procedencia:- Los primeros restos de esta especie fueron descubiertos por Lund en las cavernas de Brasil; y he recogido restos de la misma especie en las barrancas del valle del río de la Matanza, en los alrededores de Flores, dentro del municipio de Buenos Aires.

Horizonte:- Piso belgranense de la formación pampeana. 


\section{GRUPO B}

Especies cuyas placas tienen una figura central relativamente más pequeña, la que en el centro de la coraza se confunde con las figuras periféricas, sin que nunca sea deprimida en el centro o sólo lo sea de una manera accidental.

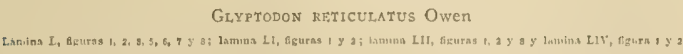

Glyptodon reticulatus. Owen: Descr. catal. of the Fioss, Mamm. Aves, ete, Mus. R. Coll. Surg., página 119, 1845 .

Nono's (parte): Description d'un nouvcau genre d'édenté fossile, etc., página 91, lám. X, figura $I$, lámina 2 , figura 0,1857 .

BurMeISTER: \&Anales del Museo Público de Ruenos Aires», tomo I, página 205. - Idem: tomo II, página 385 . - Idem: Descriptioit physique, etc., tomo III, página $422_{2} 1879$.

J TDEKKER: Catal. of Foss. Mamm., parte V, página 117,1887 .

Hoplophorus reticulatus (Owen). Cornalia: Sui fossili delle Pampas, etc, pág. 4i, i87z.

Hoplopliorus asper (Burmeister). Cornalia: Obra y página citadas.

Hoplophorus spinicaudus (Burmeister) Reinhardt.

Schistopleurum typum. NंODOT: Description d'un nouscaú geure d'ídenté fossile, página zI y siguientes, lámina I-III, 1857 .

Schistopleurum asperum. BurMEISTER: Description physique de la République Argentine, tomo III, página 424,1879 .

Glyptodon spinicaudus. Burmeister: «Anales del Museo Püblico de Duenos Aires», t. I, página 75. - Idem: en Arch. f. Anat. u. Phys., 1865, página 320, láminas VII y VIII.

Glyptodon asper. Burmerster: «Anales del Museo Público de Buenos Airesi, entrega $3^{n}$, página 200, 1866.

Glyptodon typus (Nodot). H. Gervars y Amecrino: Los mamiferos fósiles, etc., pág. 198.

Glyplodon tuberculatus. I3ravard: Catalogue des collections, etc., 1885 .

Glyptodon tubcrculatus (Owen). Eurareisrer: en Arch. für. Anat. atud phys., 1865, págins 325 .

Todos los autores que hasta ahora se han ocupado del estudio de los Gliptodontes, están acordes en reconocer que el Glyptodon reticulatus de Owen, según la descripción y dibujos que de él ha dado en el Catálogo del Museo del Colegio de Cirujanos de Londres, es un animal distinto del Glyptodon typum de Nodot. La verdad es que la descripción de Owen, en la cual dice: «La figura 1 representa un trozo de la superficie de la coraza del Glyptodon reticulatus cuyas placas tienen la figura central angulosa y del mismo tamaño que las figuras periféricas, que seneralmente son en número de seis; todo el exterior de la coraza ofrece esta disposición con la probable excepción de los bordes o cerca de ellos». no cuadra con la conformación del Schistopleurum typum de Nodot y el Glyptodon asper de Burmeister, que son, indudablemente, una misma especie; y en la cual sólo una muy pequeña parte de la coraza situada en el centro del dorso ofrece la disposición particular de que habla Owen y dígase que no de una manera tan acentuada como lo indica la figura por él publicada.

Nodot, que es el primer autor que reconstruyó la coraza de un individuo de esta especie, reconoce que la figura y la descripción de Owen no 
cuadraba con los caracteres de su Schistopleurum typum y conserva, por consiguiente, el Glyptodon reticulatus de Owen como especie distinta, aunque no puede establecer de una manera bien clara sus caracteres; inenciona trozos de coraza de una estructura externa parecida a la del trozo que dibuja Owen, pero con grandes agujeros piliferos cuyo diámetro llega a menudo a 7 milimetros. Y en vista de estos caracteres, yue en realidad no se encuentran en el Glyptodon asper de Burmeister ni en el Schistopleurum typum de Nodot, en mi trabajo sobre los mamiferos fósiles de Sud América conservé el Glyptodon reticulatus como especie distinta.

Pero Lydekker, en la última parte del Catálogo de los mamíferos fósiles del Museo Británico, recientemente publicada, identifica el Glypiodon typus de Nodot con el Glyptodon reticulatus de Owen, fundánlose para ello en una comparación directa del original de la descripción de Owen con el Glyptodon typum de Nodot, cuyos moldes de las piezas originales que sirvieron de base para la descripción existen en el Museo Británico. En tales condiciones no es posible dudar de la identida 1 de ambos animales, que acepto bajo la autoridad de Lydekker, pero me será permitido hacer notar una vez más, como descargo para los que liemos conservado las dos especies como distintas, que la descripción original hecha por Owen del Glyptodon reticulatus, en la que afirma que los caracteres del fragmento cuyo dibujo da son los mismos en casi toda la extensión de la coraza, es entonces un error, pues sólo existen iguales en un pequeño trecho del centro de la región dorsal.

Es tal la confusión que ha reinado en la denominación de esta especie, que hubo un momento en que, no teniendo a mano el trabajo original de Owen publicado en el primer Catálogo del Museo del Colegio de Cirujanos de Londres, crei posible que el Glyptodon reticulatus de Owen fuera mis bien el Panochtus tuberculatus y no un verdadero Glyptoiton («Boletín de la Academia Nacional de Ciencias», tomo V, página 8): pero hoy, leyendo las descripciones originales de Owen, veo que fué realmente un error de mi parte, en el cual han incurrido también otros autores, incluso el mismo Owen, pues en 1879, época de mi visita al Museo Británico, podian verse restos de Panochtus tuberculatus rotulados como Glyptodon reticulatus, mientras que ostentaban el mismo nombre restos de verdaderos Glyptodon, en realidad específicamente idénticos al Schistopleurum typum de Nodot y al Glyptodon asper de Burmeister. Esta confusión de rótulos (?) que mencioné en esa ocasión es, sobre todo, la que me indujo en error.

El Glyptodon reticulatus se distingue por un tamaño considerable, de corpulencia casi dos veces mayor que el Glyptodon clavipes, y por una coraza menos alargada y mucho más globulosa hacia el centro, afectando una forma mucho más esférica. 
Las placas de la coraza son relativamente más pequeñas que las del Glyptodun claripes, pero más gruesas, con un espesor hacia el centro que a menudo pasa de 4 centímetros. En el centro del dorso de la coraza, la figura central de cada placa es casi de la misma forma y tamaño que las figuras periféricas, de manera que resulta difícil distinguit el límite de las placas entre si sobre el lado externo; pero a medida que se alejan del centro, las figuras centrales se hacen más grandes y las periféricas más pequeñas. Sobre la parte superposterior, las figuras centrales se vuelven todavia mayores, afectando cerca del borde posterior una forma elipsoidal y volviéndose algo convexas. En el centro de la región dorsal existe, alrededor de las figuras centrales de cada placa, un cierto número de perforaciones pilíferas colocadas en el fondo de los surcos, cuyo diámetro varia entre 2 y 3 milímetros. Esas perforaciones se hacen cada vez más raras y de menor diámetro hacia los bordes. En la región central los surcos son angostos y profundos, pero en la periferia son más anchos y más bajos. Toda la superficie de la coraza es fuertemente rugosa, a causa de un sinnumero de asperosidades que se encuentran encima de las figuras, pero muy poco acentuadas en el centro de la coraza, donde todas las figuras afectan una forma angulosa más o menos parecida, adquiriendo, al contrario, una mayor elevación y un aspecto más áspero o más espinoso en los bordes.

El cráneo, de acuerdo con el tamaño mayor del animal, es más voluminoso que el del Glyptodon claripes, pero apenas un poco más pequeño que el del Glyptodon elongatus, del cual se distingue por la parte anterior formada por los frontales, que es notablemente más angosta y la apertura nasal anterior un poco más estrecha.

El hueso mesocervical está formado por cuatro vértebras. E1 tubo dorsal consta de 11 vértebras y el lumbar de 7 . El sacro está formado por la reunión de 9 vértebras y la cola presenta 11 vértebras. De los trece pares de costillas, el primero se articula con el manubrio, desde el segundo al séptimro se unen al esternón, desde la octava a la décima se unen unas a otras y los dos o tres últimos pares quedan libres.

De los esqueletos de esta especie de que tengo conocimiento el más completo es el del Museo de Buenos Aires, cuyas medidas de la coraza y del cráneo doy a continuación, repitiendo a Burmeister:

\section{DIMIENSIONES}

Longitud de la coraza siguiendo la curva superior del dorso.............. 2040

Longitud de la coraza en linea recta ............................... 1650

Anclio transversal de la coraza con la curva .............................. 2730

Diámetro transverso máximo de la coraza en línea recta ................. 1180

Diámetro transverso de la abertura posterior ......................... 0660

Diámetro perpendicular de la abertura posterior ....................... 0400

Longitud de la cola. ............................................ 0800 
Longitud del cráneo, desde la punta anterior del paladar hasta los cóndilos occipitales

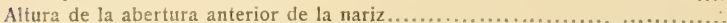

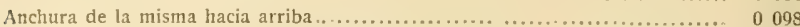

Anchura de la frente en el ángulo anterior de la órbita $\ldots \ldots \ldots \ldots \ldots \ldots \ldots \ldots . \ldots \quad 0 . \ldots 6$

Anchura de la misma entre los ángulos posteriores ..................... $0 \quad 140$

Anchura del cráneo en el medio de la fosa temporal....................... 0100

Anchura del cráneo entı e las apófisis cigomáticas....................... 0256

Anchura del mismo entre los arcos cigomáticos ....................... 0225

Anchura entre las caras articulares para la mandibula inferior............. 0 193

Anchura entre los luuesos petromastoides ......................... 0160

Anchura de los dos cóndilos occipitales unidos........................ 0118

Anchura del agujero occipital ..................................... 0037

Altura del cráneo, desde el vértice hasta el plano del paladar .............. 0162

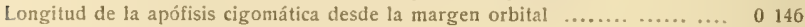

Longitud de la fosa temporal con la órbita ........................ 0108

Anchura máxima de la misma ...................................... 0050

Longitud del paladar ........................................... 0216

Longitud de la fila de las muelas................................... 0196

Anclura del paladar entre las muelas ................................ 0050

Altura del plano occipital sobre el agujero occipital........................ 0016

Longitud de la mandibula inferior ............................... 0305

Longitud de la rama horizontal de la mandibula inferior................. 0255

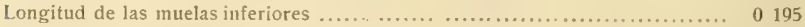

Longitud de la parte de la sinfisis delante de las muelas ................... 0037

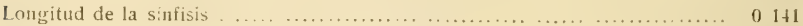

Alto de la rama perpendicular sola ............................. 0006

Procedencia:- Los restos de esta especie se encuentran con frecuencia en toda la llanura argentina al Norte del río Colorado y en la República Oriental del Uruguay.

Horizonte: - Pisos belgranense, bonaerense y lujanense de la formación pampeana.

Gitytodon enongatus Rurmeister

Lathuna LII, Agura?

Glyptodon clongatus. Burmerster: «Anales del Museo Público de Buenos Aires», tomo I, entrega $3^{\mathrm{n}}$, página 202, 1866 . - Idem: tomo 1I, página 389 .

Hoplophorns elongatus (Burmeister). Convalia: Sui fossili delle Pampas, páginas 26 y 41,1872 .

Schistoplenrum elongatum. Burmerster: Description physique de la Republique Argentine, tomo III, página 424,1879 .

Esta especie es de tamaño un poco mayor aún que la precedente, distinguiéndose de ella sobre todo por su coraza, que es un poco más larga y menos esférica y por su superficie externa, que no es tan rugosa.

Las placas son de tamaño un poco mayor, pero no más gruesas que en sl Glyptodon reticulatus; y la figura central de cada placa es relativa- 
mente mayor que en esta especie, siendo siempre más grande que las periféricas aun en el mismo centro de la coraza, donde las figuras no afectan las formas angulosas que presentan en la especie precedente, siendo siempre bien visible la separación de las placas en el lado externo. Toda la superficie externa de la coraza es menos rugosa que en la otra especie, presentando impresiones de diferentes tamaños, pero sin que estén separadas por asperosidades, como en el Glyptodon reticulatus, con excepción de cerca de los bordes, donde existen algunas, pero no tan acentuadas como en las especies anteriores. Los surcos que separan entre sí a las placas son más angostos, pero igualmente profundos. Los tubérculos cónicos que forman el borde periférico de la coraza y los que adornan los anillos de la cola son también de superficie más lisa que en el Glyptodon reticulatus.

Los agujeros pilíferos colocados en el surco que rodea a la figura central de cada placa son pequeños y no muy numerosos.

El cráneo es de tamaño un poco mayor que el del Glyptodon reticulatus y con la región frontal un poco más ancha, asi como también 12 abertura nasal anterior. Las apófisis cigomáticas descienden un poci más perpendicularmente y son menos encorvadas hacia atrás, pero están algo más hacia adentro y son bastante más anchas. El hueso mesocervical consta de cuatro vértebras, el tubo lumbar de ocho y el sacro de nueve.

Medidas de la coraza y de la cabeza, según Burmeister:

\section{DIMENSIONES}

Diámetro anteroposterior de la coraza siguiendo la curva superior del dorso.... 2"150

Diámetro anteroposterior en línea recta.............................. 1 s00

Ancho en el medio siguiendo la curva.............................. 2400

Diámetro transverso máximo en línea recta $\ldots \ldots \ldots \ldots \ldots \ldots \ldots \ldots \ldots \ldots \ldots, 1600$

Diámetro transverso de la abertura posterior $\ldots \ldots \ldots \ldots \ldots \ldots \ldots \ldots \ldots \ldots . \ldots 60$

Diámetro perpendicular de là misma................................ 0320

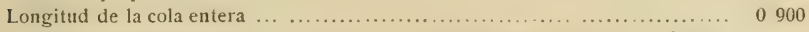

Longitud del cráneo desde la punta anterior del paladar hasta los cóndilos

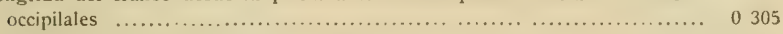

Altura de la abertura anterior de la nariz....................... 0072

Anchura de la misma hacia arriba ............................... 0107

Anchura de la frente, en el ángulo anterior de la órbita ....... ........ 0184

Anchura de la misma entre los ángulos posteriores ................. 0171

Anchura del cráneo en el medio de la fosa temporal ..................... 0101

Anchura del cráneo entre las apófisis cigonáticas ....................... 0300

Anchura del mismo entre los arcos cigomáticos ........................ 0254

Anchura entre las caras articulares para la mandibula inferior ............. 0178

Anchura entre los huesos petromastoides ............................ 0170

Anchura de los dos cóndilos occipitales unidos......................... 0 114

Anchura del agujero occipital ..................................... 0044

Altura del cráneo desde el vértice hasta el plano del paladar............... 0186

Longitud de la apófisis cigomática desde la margen orbital.............. 0215

Longitud de la fosa temporal con la órbita ............................... 0114 


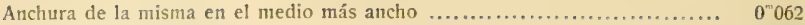

Longitud del paladar.......................................... 0216

Longitud de la fila de las muelas ................................. 0204

Anchura del paladar entre las muelas.............................. 0056

Altura del plano occipital sobre el agujero occipital ................... 0046

Longitud entera de la mandíbula inferior en dirección horizontal ........... 0331

Longitud de la rana horizontal de la mandibula inferior $\ldots \ldots \ldots \ldots \ldots \ldots \ldots .6284$

Longitud de lis tilas de las muelas inferiores ....................... 0203

Longitud de la parte anterior de la mandibula situada delante de las muelas... 0050

Longitud de la sinfisis ........................................ 0150

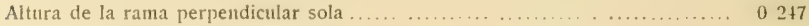

Procedencia:- Los restos de esta especie se encuentran con frecuencia en toda la provincia Buenos Aires.

Horizunte: - Piso honaerense y piso lujanense de la formacion pamjeana.

\section{Giyptodon LaEvis Durmeister}

Laroutis LII, Gicuras 4, 5, a y 10

Glypiodon lactis. DURMEistar: «Anales del Museo l’úblico de Duenos Aires» entrega $3^{2}$, página 204, I $\$ 66$.

H. Gervais y INeghino: Jos mamiferus fósiles, etc., página 200, 1880 .

Amegrino: Lista de los mamiforos fósiles de Monte Hermoso, página 17 , número 47 , Julio de I888.

Hoplophoris laceis (Iurmeister). Cornalu: Sui fossili delle Pampas, página 41, 1872.

Schistapleurum lace. lyurmerster: Description physique, etc., tomo 11I, página 425, I879.

Esta especie, de tamaño un poco menor que las dos precedentes, se distingue por la coraza muy convexa y aglobada en el medio, más todavía que en el Glyptodon reticulatus, que le da un aspecto casi completamente esférico.

La figura central es mis grande que las periféricas en todas las placas; y las placas son bien distintas en el lado externo sobre el mismo cuntro de la coraza. Todas las figuras son bien delimitadas, planas y de superficie lisa, sin rugosidades ni asperosidades, sino con simples punquaciones o impresiones de tamaño diferente, pero sin elevaciones que sohresalgan fuera del plano general. A este respecto, es de superficie mucho más lisa todavia que la del Glyptodon clongains. Todos los tubérculos cónicos que forman el borde de la coraza y los anillos de la cola son igualmente lisos, de superficie simplemente puntuada, pero más puntiagudos que en las otras especies. Los surcos que separan a las figuras son relativamente anchos y no muy profundos, de fondo casi liso $y$ con algunas perforaciones piliferas muy pequenas en el fondo de los surcos que delimitan a las figuras centrales.

Dimensiones de la coraza, según Burmeister: 
Longitud de la coraza siguiendo la curva superior del dorso $\ldots \ldots \ldots \ldots \ldots \ldots .2$...... 000

Diámetro longitudinal en línea recta ................................. 1590

Ancho en el centro, siguiendo la curva .................................. 2480

Diámetro transverso máximo en línea recta ............................ 1280

Longitud de la cola ........................................... 0600

Procedencia:- Los restos de esta especie parecen ser mucho más raros que los de las dos precedentes. La coraza incompleta, sobre la cual Burmeister ha fundado la especie, fué descubierta por Bravard en su viaje a Bahía Blanca; y se han recogido restos de la misma especie en Monte Hermoso y en los trabajos del puerto de La Plata en la Ensenada.

Horizonte:- Piso hermósico de la formación araucana (mioceno superior) hasta el piso ensenadense de la formación pampeana (plioceno inferior).

GLYPTODON PERFORATUS Ameghino

Ltmios LIV, figura $\mathrm{a} ; \mathrm{y}$ lamina LXXXi, firurh

Amectrino: «Boletín de la Academia Nacional de Ciencias», tomo V, páginas 23 y 29, año 1883, - Idem: Catálogo de la Sección de la provincia de Buenos Aires, etc., página 4I, año 1882 (nomen nudum).

Entre las especies que se conocen hasta el día, ésta es una de las más grandes especies del género y se caracteriza por una forma general de la coraza, que es más esférica todavía que la del Glyptodon reticulatus y por la escultura externa de la coraza. Las placas del centro de la coraza tienen un diámetro de 5 a 6 centímetros y un espesor de 40 a 45 milimetros. Cada placa tiene en la cara externa una figura central angulosa, rodeada generalmente por siete figuras igualmente angulosas y casi siempre del mismo tamaño que la figura central. La superficie de estas figuras es poco rugosa, casi lisa, por lo general un poco convexa en el medio, estando ellas mismas separadas por surcos profundos y angulosos que afectan un aspecto reticular. En el fondo del surco que rodea a cada figura central y en los puntos de convergencia de los surcos radiales, existe un cierto número de perforaciones, que varían de 2 a 6 , de gran tamaño, profundas y de fondo cóncavo; las mayores de estas perforaciones tienen hasta 7 y 9 milímetros de diámetro, penetrando en parte en la figura central, cuya superficie es absorbidx casi por completo en algunas placas por las mencionadas perforaciones.

Las muelas de esta especie se distinguen por la vásculodentina que no envía ramificaciones a la masa de dentina que la rodea.

Procedencia:-Distintos puntos de la provincia Buenos Aires.

Horizonte:- Piso lujanense de la formación pampeana. 
Esta especie pareçe haber sido del mismo tamaño que el Glyptodon luvis, pero no puedo determinar la forma de la coraza por no conocerse todavia ninguna completa.

Sin embargo se distingue inmediatamente de todas las otras especies for la superficie externa de la coraza, de aspecto rugoso y áspero y por las figuras muy poco elevadas y separadas por surcos anchos, poco profundos y de fondo igualmente rugoso, con algunos agujeros pilíferos colocados sin orden alguno. La figura central de cada placa es de tamaño mayor que las periféricas y a veces un poco deprimida en el centro. Las figuras periféricas son bastante más pequeñas, pero de tamaño desigual y de forma irregular, uniéndose casi siempre las de dos placas contiguas para formar figuras más grandes, de superficie áspera y de contornos mal delimitados.

Otra particularidad distintiva de esta especie consiste en los surcos que separan a las placas, que son mucho más anchos que en todas las demás especies; y este mismo ancho es muy desigual, siendo mucho mayor entre ciertas figuras que entre otras, siempre poco hondos y de fondo desigual.

Los agujeros pilíferos que se encuentran en el fondo de estos surcos están repartidos de una manera muy desigual y presentan tamaños muy diferentes, siendo unos excesivamente pequeños y otros de 2 a 3 milímetros de diámetro.

En un trozo del centro de la coraza, las placas tienen un diámetro de 4 centímetros y sólo 20 o 21 milimetros de grueso, siendo la figura central de cada placa de 18 a 20 milímetros de diámetro. El ancho de los surcos varía entre 4 y 9 milímetros.

Procedencia: - - He recogido restos de esta especie en distintos puntos de la región Norte de la provincia Buenos Ares; y en Paraguarí, en Paraguay, a 15 leguas de Asunción.

Horizonte:- Pisos bonaerense y lujanense de la formación pampeana.

GLYPTODON FALKNERT, $n$. $s p$.

Lamisa L, Ggurn ti $y$ inmuia LIII, figura ?

Esta es la especie más pequeña del género Glyptodon, que yo conozca, puesto que su talla era bastante inferior a la del Hoplophorus ornatus, aunque la coraza era mucho más espesa. Además, presenta caracte- 
res tan particulares que, probablemente, cuando se conozca el esqueleto, habrá que constituir con ella un género especial.

Las placas de las corazas son pequerias y muy gruesas, un poco más chicas en el centro, en donde presentan constantemente una forma exagonal o pentagonal, pero en los bordes laterales alcanzan un tamaño un poco mayor, aunque son algo más delgadas, afectando una forma subcuadrada, con una marcada tendencia a formar filas transversales. Todas las placas de la coraza son además menos trabadas entre sí que en las demás especies, unidas por suturas muy flojas que dejan entre las placas pequeñas hendeduras bien visibles tanto en el lado interno como en el externo. La superficie externa de las placas tiene varias figuras, una central y las otras periféricas, con su superficie sobre el mismo plano, pero en la cara interna son fuertemente cóncavas terminando hacia el centro en uno o varios agujeros de tamaño considerable, que penetran en el interior de las placas.

Una particularidad notable de esta especie, que permite distiıguirla con seguridad, es la disposición de las figuras periféricas, bien separadas todas, sin que se pongan en contacto las de las placas contiguas para formar figuras de mayor tamaño, como sucede con los demás represenlantes del mismo género.

En el centro de la coraza, las placas tienen de 25 a 30 milímetros de diámetro por 20 a 22 milímetros de espesor; la cara interna es fuertemente cóncava, terminando en el centro en una gran perforación infundibuliforme. Sobre la cara externa, cada placa tiene una figura central un poco más grande y seis o siete figuras periféricas muy pequeñas, todas muy elevadas, planas o ligeramente convexas y de superficie casi lisa; todas las figuras periféricas son bien separadas, sin que, como ya lo he dicho más arriba, se pongan nunca en contacto las de dos placas contiguas. Las figuras centrales tienen un diámetro de 8 a 10 milímetros y las periféricas de 5 a 8 milímetros. Los surcos que separan a las figuras son profundos y muy anchos y existen en el fondo del que rodea la figura central dos o tres perforaciones pilíferas de tamaño considerable. Los contornos de las figuras centrales son ya irregularmente circulares o más o menos angulosos.

Las placas afectan una forma más rectangular y su tamaño aumenta un poco en los bordes laterales; y el tamaño de las figuras centrales de cada placa aumenta también al mismo tiempo, se vuelven de contorno circular más regular y son a menudo un poco deprimidas en el centro; pero las figuras periféricas, al contrario, se hacen más pequeñas, disminuyen de numero o afectan a veces una forma rudimentaria, estando siempre colocadas sobre los mismos bordes de las placas y separadas entre sí y de las placas centrales por surcos muy anchos, que a menudo afectan más bien la forma de grandes depresiones. Los 
agujeros piliferos se conservan en igual número y casi con el mism? tamaño que en las placas del centro de la coraza.

Esta especie que dedico a Falkner, que es el primer autor que mencionó el hallazgo de una coraza de Glyptodon, a la cual comparó con la de los armadillos actuales, parece formar una especie de transición al género Neothoracophorus.

Procedencia:- He recogido los restos de esta especie en las cercanías de la Villa de Luján, en la provincia Buenos Aires.

Horizonte:- Piso bonaerense de la formación pampeana.

Giyptodon Fiorinit, n. $s p$.

LAmins LXXY, Geura o

Esta especie, de la cual dispongo de un trozo del centro de la coraza, era de tamaño considerable, casi comparable al del Glyptodon principalis, pues las placas que la componen presentan un espesor de cerca de 4 centímetros, aunque en proporción no son muy grandes, como que las mayores no alcanzan a tener un diámetro de 5 centímetros. Cada placa tiene en la cara externa una figura central subcircular, plana o casi plana, nunca deprimida, de superficie fuertemente rugosa, rodeada por un cierto número de figuras periféricas mucho más pequeñas, más o menos angulosas, de superficie plana o ligeramente convexa, también fuertemente rugosa. Los surcos que separan a todas estas figuras son muy profundos pero no muy anchos y más angostos en el fondo que en la boca. Todas las figuras permanecen separadas por los mencionados surcos, siendo muy raro que algunas de las figuras periféricas se pongan en contacto con las de las placas contiguas para formar figuras de mayor tamaño. Alrededor de cada figura central, en el fondo del surco que 1a delimita, hay cinco o seis perforaciones circulares profundas, de 4 a 6 milímetros de diámetro, colocadas como en las demás especies. Lo que sobre todo distingue con seguridad a ésta de las otras especies más o menos parecidas del mismo grupo, es:

$1^{\circ}$ El tamaño considerable de la figura central, que ocupa la mayor parte de la superficie de la placa y el tamaño relativamente pequeño de las figuras periféricas;

$2^{n}$ El número considerable de figuras periféricas, que es de nueve alrededor de cada figura central, el mayor número que hasta ahora he observado en las especies del género Glyptodon, pues no pasan de siete en la generalidad de las especies y muy rara vez alcanzan a ocho.

Procedencia: - El trozo de coraza que me ha servido de tipo para la fundación de esta especie es propiedad del señor Angel Fiorini y procede de la provincia Córdoba. 
Horizonte:- No es posible determinar su horizonte; pero el estado de conservación de la pieza indica a las claras que no puede procede: de una formación prepampeana.

\section{GRUPo C}

Especies con la figura central de cada placa más grande que las periféricas y de superficie muy convexa afectando una forma más o menos globulosa.

\footnotetext{
GiYPTONON GEMMATUS Nodot

Latrina LH, Agura g: y lamana LXXV, Ggurn +
}

Nopor: Description d'un nonveau genre d'édentś fossile, etc., página 78 , lám. VIII, fig. I.

En un principio creí que esta especie podía ser idéntica con el Glyptodon elongatus, de cuya creencia también participaba, hasta cierto punto, Burmeister, reuniéndolas en mi Catálogo de los Mamíferos fósiles de América Meridional en una sola especie, bajo el nombre específico de Nodot, por ser el más antiguo. Pero ahora, comparando con detención la descripción de Nodot y las figuras que la acompañan, así como también algunos trozos de coraza, con las del Glyptodon elongatus de Burmeister, veo que es absolutamente imposible reunir en una a las dos especies.

El Glyptodon gemmatus difiere muchísimo de los demás Gliptodontes conocidos: primero, porque presenta en el borde de la abertura caudal una doble fila de tubérculos cónicos, que no he visto en ninguna otra especie; esta segunda fila de tubérculos cónicos se presenta inmediatamente delante de los que forman el borde marginal, con los cuales se articulan, pero son un poco más pequeños que los posteriores, algo más circulares, menos cónicos y más globulosos. El segundo carácter que distingue al Glyptodon gemmatus consiste en la forma particular de la figura central de cada placa, que es siempre convexa y globulosa. Transcribo a continuación los párrafos principales de la descripción que de las piezas originales da Nodot y la reproducción de la figura que la acompaña:

«El primer fragmento triangular (figura 9, lámina LII), presenta sobre la parte arqueada que corresponde a la abertura caudal una serie de once tubérculos gruesos y desiguales, de iguales forma y tamaño que los de la especie precedente (Glyptodon reticulatus); pero son algo comprimidos lateralmente, Io que les da una forma más alargada. Presentan la superficie igualmente rugosa y muestran una punta obtusa en el centro de su masa, que no tiene la forma piramidal subtetragonal de las del Glyptodon clavipes.

«Las placas que componen esta coraza muestran una figura central muy grande, rugosa, siempre globulosa o subhemisférica, cuyo tamaño 
y convexidad aumentan al acercarse al borde posterior de la abertura caudal. La figura central de esta última fila de placas se hace tan considerable que adquieren el aspecto de gruesos tubérculos globulosos y desiguales que se articulan inmediatamente con los tubérculos cónicos, constituyendo así una doble fila de tubérculos marginales en el borde posterior de esta coraza.

«El segundo fragmento, de forma asimismo triangular, tiene unos 30 centímetros de largo y es de superficie muy rugosa. La figura central Ce las placas es siempre circular, más o menos convexa y ocupa la mayor parte de la superficie, mostrando también algunas cavidades que recivian los bulbos de los pelos. Las placas son de forma extremadamente variable y las suturas tienen una disposición muy pronunciada a formar lineas rectas; la rotura de uno de los lados corresponde a esta disposición. Este fragmento proviene de los costados, lo que se prueba por su espesor mucho menor que en el fragmento anterior.»

La cola se componía de una serie de anillos con tubérculos cónicos, como en todas las demás especies del mismo género.

Procedcncia: - Las piezas originales sobre las cuales fué fundada esta especie fueron regaladas al Museo de París por el Vicealmirante Dupotet, como procedentes de los alrededores de Buenos Aires; y el señor Angel Fiorini ha encontrado restos de la misma especie en los alrededores de La Plata.

Horizonte:-Formación pampeana. Piso ensenadense?

NE,OTHORACOPHORUS Ameghino

Thoracophorus. H. Gervais y Amegrino: Los mamiferos fósiles, etc., página 206, x88o.

En 185i, en su Memoria sobre el Schistopleurum typum, describió Nodot un animal que colocó en el género Glyptodon con el nombre de Glyptodon elevatus. Los materiales que sirvieron de fundamento para esta descripción, conservados en el Museo de París, examinados más târde por mí y por H. Gervais, resultaron presentar diferencias fundamentales con las partes correspondientes del género Glyptodon, constituyendo con ellos, por consecuencia, un nuevo género al cual lo designamos con el nombre de Thoracophorus. Pero como este nombre ha sido empleado con anterioridad (1840) para designar un género de coleópteros, cambio ahora el nombre del animal del grupo de los Gliptodontes en Neothoracophorus.

Los representantes de este género parecen haber sido todos de tamaño kastante menor que el de los del género Glyptodon y de una conformación bastante diferente, sobre todo en la estructura de la coraza, por la que difieren de todos los demás géneros del grupo de los Glyptodontia. 
La coraza del Neothoracophorus se distingue por estar formada por placas muy pequeñas y relativamente muy gruesas, de forma pentagonal o exagonal y con sus paredes perpendiculares laterales desprovistas de suturas, presentando superficies o caras casi lisas, de modo que las placas estaban simplemente yuxtapuestas una junto a otra, reunidas por tejido conjuntivo, sin formar suturas, conservando una cierta movi-

- lidad que daba un poco de flexibilidad a toda la coraza. Las placas del centro son un poco más grandes y más gruesas que las laterales y la superficie externa de cada placa es plana o con una sola figura central más o menos elevada, que ocupa la mayor parte de la superficie de la placa, siempre sin figuras periféricas, ni surcos alrededor, pero a menudo con perforaciones piliferas bien desarrolladas. Debido a esta conformación particular, las piezas que constituian las corazas se disgregaban fácilmente, por lo que no se encuentran placas articuladas sino accidentalmente y debido a circunstancias especiales.

La cola se componía de anillos con tubérculos espinosos como los del Glyptodon.

Del esqueleto no conozco más que la mandíbula inferior, construida sobre el tipo de la de ios demás Gliptodontes, pero con algunas diferencias genéricas bien acentuadas; entre éstas, las más notables son la dirección de la rama ascendente, que no se inclina hacia adelante como en los demás Gliptodontes y la forma de la primera muela inferior, que, en vez de ser triprismática, se reduce a un diente cilíndrico muy pequeño y puntiagudo, de aspecto cónicopuntiagudo o estiliforme.

NEOTHORACOPHORUS miEVATUS (Nodot) Ameghino

Lamins Liv, agurs a

Glyptodon elevatus. Nodot: Description d'un nouveau genre d'édenté fossile, página 95. lámina $X$, figuras 6 y 7, I 857 .

Thoracophorus elevatus (Nodot). H. Gervats y AMEgrino: Los mamijeros fósiles, etc., página 208, 1880.

Esta especie fué descripta por Nodot sobre una gran parte de la coraza reunida en un solo trozo que se encuentra en el Museo de París y cuyas placas se han conservado en su posición gracias a una fuerte incrustación calcárea que cubre casi toda la coraza, impidiendo restaurarla ni estudiarla en sus pequeños detalles; en algunas partes, sin embargo, las placas se encuentran fuera de posición, cuyas dislocaciones ya había observado Nodot, pero cuyas causas no comprendió, creyendo que fueran simplemente quebraduras accidentales. Si no existiera la incrustación calcárea mencionada todas las placas se separarian unas de otras, pues carecen absolutamente de todo vestigio de suturas, presentando los lados perpendiculares completamente planos. Las placas son bastante más grandes en el centro y mucho más pequeñas en los bordes 
laterales; las más grandes tienen de 15 a 18 milímetros de diámetro y 17 a 18 milimetros de espesor. La cara interna de las placas es cóncava; la cara externa está ocupada en su mayor parte por una figura circular o elíptica, fuertemente convexa y de superficie un poco rugosa, con puntuaciones bien acentuadas. La parte periférica que rodea a esta figura es simplemente plana, sin surco alrededor de la figura central, aunque con algunas perforaciones piliferas irregularmente repartidas; el resto . Cie la superficic es un poco rugoso y sin vestigios de figuras periféricas.

La talla de este animal era comparable a la de una de las más peque. ñas especies del género Hoplophorus.

Procedencia: - Los primeros restos sobre los cuales fué fundada esta especie proceden de las orillas del río Das Velhas, en el Sud de Brasil; pero he recogido restos de la misma especie en las toscas del fondo del río de la Plata, en el municipio de Buenos Aires.

Horizonte:-Piso ensenadense de la formación pampeana.

NéthoracophorUS DE,PUESSUS Ameghino

Lamino LIV, figuras $7 \mathrm{~g}$.

Toracophorns depressus. ANEgrivo: La antigiedad del hombre en el Plata, tomo II, página $310,188 \mathrm{r}$.

Esta especie era de tamaño mucho más considerable que la precedente y de una conformación bastante distinta.

Las placas que forman la coraza son asimismo pequeñas y sumamente gruesas, todas sueltas sin estar unidas por suturas, pero con las caras perpendiculares contiguas un poco más rugosas. Las placas del centro de la coraza tienen un diámetro de 18 a 22 milímetros y un espesor de 15 a 19 milímetros. La cara interna es fuertemente cóncava. La superficie externa presenta una figura central, circular o subcircular más elevada que la parte periférica, pero en vez de ser convexa o globulosa como en Neothoracophorus elevatus, la superficie de esta figura es plana y un poco deprimida en el centro y con dos o cuatro agujeros pequeños; esta figura central tiene un diámetro de 10 a 11 milimetros. No existe surco periférico que delimite a esta figura, pero hay alrededor de 6 a 7 perforaciones pilíferas de gran diámetro, separadas por elevaciones radiales que se unen a la figura central y corresponden a las figuras periféricas de los verdaderos Gliptodontes.

Procedencia: - He recogido los restos de esta especie por primera vez en los alrededores de la ciudad de Mercedes; y últimamente Carlos Ameghino ha recogido en un arroyo cerca de la estación Jáuregui, algunos otros restos, y entre ellos la mandíbula inferior con la rama ascendente no inclinada hacia adelante y la primera muela pequeña, cónico- 
juntiaguda y estiliforme, pero como esta pieza forma parte de las colec. ciones del Museo de La Plata, no puedo dar acerca de ella ni otros datos ni su dibujo.

Horizonte:- Piso bonaerense de la formación pampeana.

NeOTHORACOPHORUS MINUTUS. Ameghino

Lamino Liv, agures a g 10

Thoracophorus minutus. Amegriso: La antigüedad del hombre en el Plata, tomo II, página $310,188 x$.

Fundé la especie sobre placas sueltas de cerca de los bordes de la coraza, que me hicieron creer que la talla del animal era mucho más pequeña que la de la especie precedente, pero el descubrimiento de placas de la región central de la coraza me han demostrado que la talla era muy poco inferior a la que alcanzaba el Neothoracophorus depressus.

Las placas de esta especie se distinguen con facilidad por la cara externa, que no tiene figura central distinta y saliente, apareciendo toda la superficie de la placa deprimida o ligeramente convexa, un poco rugosa o con puntuaciones poco perceptibles, acompañadas de pequeñas perforaciones piliferas distribuidas $\sin$ orden alguno. Las superficies Ferpendiculares por donde las placas se ponen en contacto, son casi completamente planas. Las placas centrales tienen de 18 a 20 milímetros de diámetro y de 16 a 20 milímetros de espesor y las de cerca de los bordes de 14 a 16 milímetros de diámetro y de 6 a 10 de espesor.

Procedencia:- He recogido los restos de esta especie en las barrancas del río Luján, en la Villa del mismo nombre.

Horizonte: - Piso lujanense de la formación pampeana.

\section{COCHLOFS, $n$, gen.}

Conozco este género por placas provenientes de distintas regiones de la coraza, que indican algunas afinidades con los verdaderos Gliptodontes, pero con algunas particularidades que lo distinguen claramente de todos los demás representantes del mismo grupo. La coraza dorsal está formada de placas de tamaño bastante notable, de contorno Fentagonal o exagonal, pero de una forma general subcuadrada, muy delgadas en proporción de su tamaño; cada placa tiene una figura central convexa, que a menudo se levanta en forma de pezón, rodeada de figuras periféricas pequeñas, que, en las placas en las cuales la figura central se levanta en forma cónica, afectan la forma de pequeños 
tubérculos puntiagudos. La cola está formada por una sucesión de anillos movibles, armados de tubérculos elevados en forma de puntas comprimidas. El escudo cefálico está formado por placas de tamaño y formas muy distintas, delgadas, cóncavas en el lado interno y con una fi. sura central en el lado externo, más o menos elevada y de forma diferente, según las placas, pero limitada siempre por una depresión ancha y profunda en algunos de cuyos puntos se ven grandes perforaciones pilíferas.

Cocirlops MURICATUS, $n$. sp.

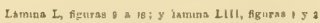

Las placas que forman la región superior de la coraza tienen de 35 a 45 milímetros de largo, de 30 a 36 de ancho y sólo de 7 a 8 de espesor, siendo todas de cara interna fuertemente cóncava y de cara externa un poco convexa. Estas placas se dividen en dos categorías: unas muestran una figura central elíptica de 15 a 18 milimetros de largo, de superficie convexa, más levantada en la parte posterior que en la anterior, rodeada por nueve o diez figuras periféricas poligonales, planas en la región anterior de la placa y más o menos convexas en la posterior, separadas for surcos angostos y poco profundos, con pequeños agujeritos en el fondo del surco que rodea a la figura central: toda la superficie externa de esas placas, hasta en el mismo fondo de los surcos, está completamente cubierta de puntuaciones muy perceptibles, que le dan un aspecto áspern o poroso muy particular. Las placas de la segunda categoría presentan una figura central elíptica que se levanta en el medio en forma de una fuerte protuberancia en forma de pezón, casi puntiaguda, rodeada por diez o doce y a veces más figuritas periféricas, las posteriores de las cuales, separadas unas de otras por fuertes depresiones, se levantan en forma de tubérculos cónicopuntiagudos, pero las anteriores son menos elevadas y más planas; toda la superficie de las placas presenta el mismo aspecto esponjoso o poroso, ya mencionado en las placas anteriores.

Las placas de los anillos movibles de la cola y las del escudo cefálico presentan demasiada variación de forma para que puedan ser descriptas, sobre todo no conociéndose todavía la forma completa de esas partes, pero las figuras 9 a 18 de la lámina $\mathrm{L}$, darán una idea de su conformación y de las variedades que presentan.

El animal parece haber tenido un tamaño comparable al del Hoplophorus ornatus.

Procedencia: - Barrancas del río Chico, en Patagonia austral.

Horizonte:-Piso santacruceño (eoceno inferior). 


\section{Hoplophoridæ}

La coraza de los Hoplophoride es, en general, más alargada y menos convexa que la de los Glyptodontida y siempre está provista de dibujos externos de formas variadas.

La cola está formada por un cierto número de anillos movibles angostos y planos, cuyo tamaño disminuye de adelante hacia atrás, terminando en un tubo largo, cónicocilíndrico, a menudo aplastado en sentido perpendicular, que concluye en una extremidad siempre más delgada 0 más angosta que el resto del tubo, cuya punta está formada por dos grandes placas laterales, una por cada lado, que cierran la extremidau como las dos valvas de una concha. El cráneo es de superficie superior siempre más o menos convexa y el húmero está provisto de agujero epitrocleano.

Los seis géneros que conozco de esta familia se distinguen por los siguientes caracteres:

I. Placas del centro de la coraza con una figura central y una sola fila de figuras periféricas, reemplazadas a veces por una simple zona rugosa.

A. Con incisivos en el intermaxilar: Propalchoplophorus.

B. Sin incisivos en el intermaxilar.

a. Figuras periféricas de las placas de la coraza bien delimitadas. Tubo caudal cónicocilindrico y puntiagudo.

aa. Tubo caudal con grandes figuras rugosas, sin figuras periféricas pequeñas, pero con una fila de grandes perforaciones periféricas: Palchoplophorus.

$a b$. Tubo caudal con dos filas de figuras periféricas pequeñas entre cada dos figuras centrales: Zaphilus.

ac. Tubo caudal con una sola fila de figuras periféricas pequeñas entre cada dos figuras centrales: Hoplophorus.

$b$. Figuras periféricas de las placas de la coraza rudimentarias o reemplazadas por una zona rugosa.

$a b$. Tubo caudal sin figuras periféricas entre cada dos figuras centrales: Lomaphorus.

II. Placas del centro de la coraza con una figura central y dos filas de figuras periféricas.

a. Tubo caudal cónicocilíndrico, casi recto, y sin verrugas laterales salientes: Plohophorus.

b. Tubo caudal ancho, deprimido y con grandes verrugas laterales salientes: Nopachtus. 
III. Placas del centro de la coraza adornadas con un considerable número de figuras pequeñas iguales, que pueden alcanzar hasta el número de cincuenta en cada placa. Tubo caudal aplastado, adornado con las mismas figuras pequeñas y con grandes verrugas laterales:

Panochtus.

IV. Coraza con figuras centrales de gran tamaño y dos tipos de figuras periféricas, unas más grandes y otras más pequeñas, dispuestas a su vez alrededor de las primeras y todas rodeadas de grandes agujeros. Tubo caudal ancho, deprimido y con todas las figuras igualmente rodeadas de perforaciones: Protoglyptodon.

PROPALAEHOPIOPHORUS Ameghino

AMEchino: Enumeración sistemática de los mamiferos, etc., página 24, 1887.

Los primeros restos de este animal fueron recogidos por el doctor Moreno durante su exploración del río Santa Cruz (1876-1877) y atribuídos por él a una especie del género Hoplophorus, a la cual designó con el nombre de Hoplophorus alstralis. Esos restos consistian en varias placas aisladas de la coraza, que ofrecen, en efecto, una similitud casi completa, con las del género Hoplophorus. En la colección recogida por Carlos Ameghino hay una gran cantidad de placas, que presentan igual parecido con las del mencionado género, acompañadas de otras muy diferentes, cuya colocación no es fácil determinar, ni es tampoco seguro que provengan del mismo animal. Pero el gran parecido de las placas no es tampoco una razón bastante para afirmar la identidad genérica, pues la forma de la coraza puede haber sido muy diferente en su conjunto, así como también pueden haber tenido una forma distinta algunas de sus partes.

Las placas, aunque numerosas, son de individuos distintos y no permiten dar una idea de la configuración general de la coraza, pero las partes del esqueleto que las acompañan, particularmente restos de cabeza, prueban que se trata de un animal muy diferente del Hoplophorlls y de los demás géneros de Gliptodontes conocidos hasta el día, quiz: con excepción del Plohophorus, con el cual parece presentar algunas afinidades, particularmente por la forma de las muelas.

La fórmula dentaria no ha sido tampoco idéntica a la de los verdaderos Gliptodontes, pues el Propalchoplophorus ha tenido uno o dos pares de incisivos superiores aunque muy pequeños y caedizos, de manera que el animal cuando joven tenía $\frac{1}{0}$ o $\frac{2}{0} \mathrm{i} \cdot \frac{8}{8}, \mathrm{~m}$.

Las dos primeras muelas, tanto superiores como inferiores, son com. fletamente elípticas; las demás están divididas en prismas, presentando algunas de ellas una complicación mayor que las de los Glyptodontido. 
Del esqueleto, se conoce el fémur, que es de una forma intermedia entre la del de los Gliptodontes y la del de los armadillos, pero más esbelta y más delgada que en ambos.

De la cola se conocen algunos trozos que prueban estaba formada por un tubo cónicocilíndrico constituído por varios anillos que se articulaban unos a continuación de otros, cada uno formado por dos filas de placas.

PropalaEHOPLOPHORUS AUSTRALIS MOTENo

LAmuas LI, flguras o a $10 ;$ y lamina Llit, flguran o, o y 10

Hoplophorus australis. Moreno: Patagonia, restos de un continente hoy sumergido, pá. gina 26,1882 (nomen nudum).

Propalaeloplophorus australis (Moreno). Ameghro: Ënumeración sistemútica de los mamiferos etc., página 24 , número 110,1887 .

De esta, que parece ser la especie más abundante, hay una gran canudad de placas de la coraza, parte del tubo caudal, la región anterior de rin cráneo con la mayor parte de la dentadura y algunos fragmentos de mandibulas con dientes. La talla del animal era bastante pequeña, quizá ri una mitad de la del Hoplophorus ornatus.

Las placas de la coraza son pentagonales, con una tendencia a adquirir una forma rectangular muy acentuada, sobre todo en las que provienen de las regiones laterales, conservándose la forma pentagonal o exagonal más marcada en las que provienen de la región del centro del dorso.

Las placas más grandes del centro de la coraza parecen ser más delgadas, de unos 38 a 42 milímetros de diámetro anteroposterior, de 30 a 35 milímetros de diámetro transverso y sólo de 7 a 8 de grueso. La cara interna es un poco lisa y la externa algo convexa, con una figura central circular de 16 a 17 milímetros de diámetro, un poco levantada en el centro y rodeada por 10 u 11 figuritas pentagonales más pequeñas, separadas por surcos angostos, con pequeños agujeros en el punto de reunión de los surcos periféricos con el que rodea a la figura central. En la parte posterior de la placa se ven a menudo algunas figuritas suplementarias incompletas y atrofiadas, que corresponden a la segunda fila de figuritas apenas indicada, de las placas de la coraza del Plohophorus. La superficie de la figura central y de la periférica es casi lisa, apenas in poco puntuada.

Las placas de los costados, que tienden a tomar una forma rectangular, tienen, término medio, unos 25 milímetros de largo, de 15 a 18 milíme. tres de ancho y de 8 a 10 milímetros de grueso. La cara externa muestra una figura central eliptica, que adquiere una forma ovoidea en las placas próximas a los bordes, rodeadas por figuras periféricas, chicas adelante y en los costados y más grandes en la parte posterior, donde también cstán seguidas de otras más o menos desarrolladas. 
Hay algunas placas más grandes, pentagonales o exagonales, de unos 25 a 30 milímetros de diámetro y bastante gruesas, que se distinguen por la figura central más grande y elevada hacia un lado casi en forma de pezón, rodeada por entre 10 y 12 figuritas más pequeñas. Supongo que algunas de estas placas provienen de cerca de la abertura anterior y otras de la posterior.

Hay también algunas placas marginales, de unos 20 a 25 milímetros de largo y sólo de 10 a 15 de ancho, con rudimentos de dibujos en uno de los dos costados mayores y terminando el resto en un borde redoncieado, presentando un aspecto casi idéntico a las placas marginales de !a coraza del género Hoplophorus.

For último, se encuentran mezcladas con las precedentes, otras placas d. tamaño mucho mayor, que pueden alcanzar un diámetro de cinco centímetros, de formas variadas y a menudo irregulares, que frecuentemente tienen un borde libre. Estas placas son muy gruesas en el centro y delgadas en las extremidades, con cara interna muy cóncava y cara superior muy convexa, sin dibujo, con toda la superficie puntuada y €l centro levantado hasta formar a menudo un tubérculo áspero y casi s:empre con una depresión en el centro. Supongo que estas placas provienen del escudo cefálico.

De la coraza de la cola hay muchas placas sueltas, el último anillo que forma la punta de la cola y el antepenúltimo.

El anillo que constituye la extremidad terminal es un cono de 35 milimetros de diámetro en la base y 37 milimetros de largo, con una punta cónica obtusa un poco convexa. Este anillo está compuesto por dos filas de placas, una que sólo forma un arco de círculo en la parte superior formado por 4 placas y otra, que es la posterior y forma el anillo cumpleto con 8 placas. La punta del tubo formada por la parte posterior del anillo está cerrada por cinco o seis placas irregulares y rugosas. Las piacas que forman las filas son más o menos elipticorombóideas y las de l. parte superior con una pequeña protuberancia longitudinal en la parte media, más elevada hacia atrás que en la parte anterior. La superficie de las placas es casi lisa, apenas un poquito punteada.

El anillo penúltimo se encuentra intacto, compuesto por dos filas de placas, cada una de ellas formando un cínculo completo. La fila anterior consta de 9 placas, más grandes que las de la fila pusterior y con un prolongamiento anterior en declive, destinado a engastarse en la abertura posterior del anillo que seguía hacia adelante. La fila posterior consta igualmente de 9 placas un poco más pequeñas que las de la fila anterior y más elípticas. Todas las placas son de superficie casi lisa, separadas por surcos bien definidos, con algunos agujeros de distancia cn distancia repartidos irregularmente en el fondo de los surcos y en aigunos puntos, particularmente en la parte anterior, con una o dos figu- 
ritas periféricas rudimentarias. El tamaño de estas placas varía de $20 \ell$ 25 milímetros de largo por de 12 a 20 de ancho. El anillo o segmento tiene 42 milimetros de diámetro y 5 centímetros de largo.

Estos anillos se articulaban unos a otros sin dejar espacio vacío intermedio, de manera que formaban un tubo largo cónicocilíndrico, de aspecto general igual al tubo caudal del Hoplophorus, del cual, en realidad, sólo se distinguía por sus segmentos, que se conservaban separados, sin soldadura entre sí.

La parte anterior de cráneo existente de esta especie está demasiado destrozada y deformada para que sea posible formarse una idea de su conformación, que, por otra parte, no podía diferir mucho de los otros Gliptodontes conocidos. La bóveda superior del cráneo falta por completo, menos una pequeñísima parte al nivel de las órbitas, que parece demostrar no era aplastada como en el Glyptodon sino convexa como en el Hoplophorus. La apófisis cigomática de los maxilares ha tenido el mismo proceso descendente que en los demás géneros de esta familia y el agujero suborbitario en la misma posición.

De los nasales existe la parte anterior en contacto a ambos lados con los maxilares; por la parte existente se conoce que permanecían separalos por sutura visible sobre la línea media longitudinal, que eran más largos y prolongados hacia adelante que en el Glyptodon y con su parte anterior un poco encorvada hacia arriba. La abertura nasal anterior es bastante parecida a la del Glyptodon, pero relativamente más pequeña y más baja.

Toda la parte del rostro situada adelante de la órbita es también más frolongada hacia adelante que en el Glyptodon, pues a pesar del tamaño pequeño de este cráneo la distancia existente entre el agujero suborbitario y la abertura nasal es de 35 milímetros.

El paladar, àunque bastante deformado, parece que presentaba la misma curva que el del Glyptodon, estrechándose un poco adelante entre las dos primeras muelas.

El intermaxilar es relativamente un poco más desarrollado que en el Glyptodon y tiene a cada lado adelante de la primera muela un pequeño agujerito de menos de un milímetro de diámetro, que supongo es el alvéolo de un incisivo atrofiado y caedizo.

La primera muela, más pequeña que todas las demás, está implantada en la parte anterior del maxilar y es de sección elípticocilíndrica, sin surco ni aristas perpendiculares, parecida a una muela de armadillo $y$ con su eje mayor en dirección transversal al eje de la serie dentaria; tỉene 5 milímetros de diámetro mayor y 4 de diámetro menor.

La segunda muela, un poco más grande que la primera, es también más cilíndrica, igualmente $\sin$ surcos ni aristas perpendiculares y de 6 milímetros de diámetro. 
La muela tercera es más grande que la segunda y de sección elíptica, ccn su eje mayor dirigido de adelante hacia atrás en dirección del eje de la serie dentaria. La cara externa es convexa y con un pequeño surco Ferpendicular en el medio. La cara interna es deprimida, un poco excavada y con una pequeña arista perpendicular rudimentaria en el centro. Tiene 10 milímetros de diámetro transverso.

La muela cuarta es más grande que la tercera y más alargada en sentido anteroposterior. Sobre el lado externo forma dos columnas perpendiculares colocadas más hacia el centro que las extremidades externas anterior y posterior de la muela, quedando entre ambas columnas y ocupando el centro de la cara externa de la muela un surco perpendicular ancho y profundo. La cara interna es deprimida, con dos surcos perpendiculares poco profundos separados por una columna perpendicular media opuesta al surco perpendicular externo. La corona tiene ¡3 milimetros de diámetro anteroposterior por 5 milímetros de diámo tro transverso.

La muela quinta es un poco más grande todavía, de corona relativamente más larga y más angosta y con un principio de división en tres prismas. Sobre el lado externo muestra dos columnas perpendiculares principales, formadas por los prismas anterior y posterior, cada una de ellas dividida a su vez en dos columnas secundarias por un surco perpendicular poco profundo; entre las dos columnas principales queda un vacío ancho y profundo en cuyo fondo se ve una columna perpendicular más pequeña, con un surco a cada lado, de manera que, entre grandes Y pequeñas, la muela muestra sobre el lado externo cinco columnas perpendiculares, separadas por cuatro surcos. El lado interno es más simple, mostrando sólo tres columnas perpendiculares, separadas por dos surcos. La columina media del lado externo es perfectamente opuesta a la del medio del lado interno, pero como la columna externa es mucho más pequeña que las que se encuentran sobre el mismo lado, resulta que el prisma del medio es mucho más pequeño que el anterior y posterior, quedando, por decirlo asi, rudimentario. La corona tiene 14 milímetros de diámetro anteroposterior por 5 a 6 de ancho.

La muela sexta ha tenido casi el mismo tamaño y probablemente la misma forma, pero ello no se puede determinar con exactitud por estar destrozada en los dos lados. El alvéolo tiene 14 milímetros de diámetr? anteroposterior y 5 milímetros de diámetro transverso.

La muela séptima es un poco más pequeña y dividida en tres prismas más iguales. Sobre el lado externo muestra tres columnas perpendiculáres correspondientes a los tres prismas que componen la muela, el posterior subdividido a su vez en dos columnas por un surco perpendicular externo, angosto y profundo. El lado interno está bastante destrozado, pero parece presentar tres columnas separadas por dos surcos. 
E! prisma anterior parece ser un poco más grande que el posterior y el del medio un poco más pequeño. Tiene 12 milímetros de diámetro anteroposterior, 7 de diámetro transverso adelante y 6 atrás.

La última muela u octava está completamente destrozada, no pudiéndose determinar exactamente sus contornos, pero se conoce que es bastante más pequeña, el prisma anterior más grande y el posterior más pequeño, separados por dos surcos opuestos, uno interno y otro externo. Tiene 10 milímetros de diámetro anteroposterior y 8 milimetros de ancho en el prisma anterior. Como se ve, de las 8 muelas, las dos anteriores son completamente elipticocilindricas, la tercera es elíptica con un principio de división al lado externo, y la cuarta un poco más complicada, sin presentar aún distintamente la separación en prismas, que recién empieza a acentuarse en la quinta, presentándose más definida en las siguientes. El tamaño aumenta gradualmente de la primera a la quinta y disminuye de la quinta a la octava. Las dos filas dentarias son perfectamente paralelas en todo su largo, menos en la parte anterior, en donde se aproxima la una a la otra en el espacio comprendido entre las dos primeras muelas.

Las 8 muelas ocupan un espacio longitudinal de 80 milímetros y el ancho del paladar es de 19 milimetros entre el primer par de muelas anteriores y de 25 milimetros en casi todo el resto de su extensión.

De la mandibula inferior hay un trozo de la parte anterior con cuatro muelas algo destrozadas, que supongo sean la segunda, tercera, cuarta y quinta.

La muela segunda es elíptica, dividida al lado externo en tres columnas perpendiculares, una anterior convexa, una media muy pequeña casi rudimentaria y una posterior mucho más grande que la primera y más sobresaliente hacia afuera. Entre las dos columnas principales, anterior y posterior, hay una profunda depresión dividida a su vez en dos surcos por la columna media rudimentaria que se levanta en su fondo. Sobre el lado interno está dividida por un surco perpendicular poco marcado, en dos lóbulos desiguales, uno anterior pequeño y otro posterior más grande. Tiene 12 milímetros de diámetro anteroposterior y 5 milímetros de diámetro transverso.

La muela tercera, de sección elíptica más prolongada y de tamaño un poco mayor, está dividida al lado externo en tres columnas perpendiculares separadas por dos surcos, la anterior y la posterior más grandes y la del medio más pequeña. Sobre el lado interno muestra un surco anterior ancho y bastante profundo y una depresión posterior apenas marcada. Tiene 14 milímetros de diámetro anteroposterior por 5 milímetros de ancho.

La muela cuarta, de tamaño un poco mayor, presenta ya más acentuada una división en tres prismas formando tres columnas externas se- 
paradas por dos surcos, el anterior más ancho y menos profundo, y la columna anterior igualmente interna menos distinta que las dos posteriores. Tiene 15 milímetros de diámetro anteroposterior por 6 milímetros de ancho.

De la muela quinta sólo existe una parte, pero parece que con muy escasa diferencia tuvo la misma forma que la precedente.

Las tres muelas enteras o casi enteras, segunda, tercera y cuarta, ocupan un espacio longitudinal de 41 milímetros. El alto de la rama horizontal debajo de la cuarta muela es de 38 milímetros.

Otro fragmento de mandibula inferior comprende la parte posterior de la muela sexta y las dos últimas, o séptima y octava, aunque un poco gastadas. Estas tres muelas presentan una conformación triprismática bien acentuada, con tres columnas externas angostas separadas por dos surcos profundos y tres internas, la anterior de las cuales es más ancha $y$ poco delimitada, pareciéndose más bien a una prolongación anterior del prisma medio. La cara posterior de cada una de las tres ultimas muelas presenta la particularidad de tener una depresión que forma en el centro un surco perpendicular. La muela séptima tiene unos 15 milímetros de diámetro anteroposterior, y otro tanto la octava o última. La rama horizontal debajo de la penúltima muela tiene 38 milímetros de alto.

Procedencia: - Los restos de esta especie han sido descubiertos por Carlos Ameghino en las barrancas del río Santa Cruz, en Patagonia austral.

Horizonte:- Piso santacruceño (eoceno inferior).

\footnotetext{
Propalazhoplopitorus incisives Ameghino

Lamoa LI, figuras a as ; y lamina LXIV, figuran o a is
}

Axegrino: Enumeración sistemática de los :namiferos, etc., págína 24 , número I11, 1887.

Esta especie está representada por fragmentos de coraza, por un cráneo destrozado pero con el paladar y la dentadura en bastante buen estado y por una mitad de mandíbula inferior casi intacta. Estos restos indican una especie de tamaño un poco menor que la precedente y relativamente más delgada.

Las placas de la coraza de esta especie se distinguen por una forma más rectangular y por su espesor poco considerable. El tamaño de las placas centrales es de unos 25 milimetros de largo por 18 a 20 de ancho, teniendo tan sólo 5 a 6 milímetros de espesor. Cada placa presenta al lado externo una gran figura central más o menos elíptica, de 12 a 16 1.1ilimetros de diámetro, rodeada por una fila única de 9 a 10 figuritas periféricas, todas de superficie casi lisa y plana. 
Existe una pequeña parte del intermaxilar del lado derecho que demuestra que este hueso era considerablemente más desarrollado que en los Gliptodontes más modernos, pues ocupa toda la parte anterior del paladar y envía un prolongamiento hacia arriba, de manera que toma parte en la formación de las paredes laterales de la abertura nasal, conservándose perfectamente visible la sutura que los separa del maxilar. Sobre la superficie palatina y en la parte anterior, cerca del borde de la abertura nasal, tiene el intermaxilar dos pequeñas perforaciones de apenas un poco más de un milímetro de diámetro; son dos alvéolos en los cuales se implantaban un par de pequeños incisivos, que caían luego cuando el animal llegaba a su estado adulto.

Inmediatamente detrás de la sutura del intermaxilar con el maxilar viene el alvéolo de la primera muela de forma elípticocilíndrica y term.nando hacia abajo en forma de embudo. Este alvéolo tiene 5 milímetros de diámetro mayor y en él se implantaba un diente elípticocilíndrico sin surcos ni columnas perpendiculares como el correspondiente de la especie precedente.

El diente que sigue, o segundo molar, es de sección más elíptica todavía, con su eje mayor en dirección oblicua al eje de la serie dentaria y también sin surcos ni aristas perpendiculares. Tiene 6 milímetros de diámetro mayor y 4 de diámetro menor.

La muela tercera es de tamaño bastante mayor, elíptica, presentando una sección transversal larga y estrecha con su diámetro mayor de adelante hacia atrás y una pequeña curva hacia adentro. La cara interna es deprimida y con una pequeña arista perpendicular, completamente rudimentaria. Tiene 10 milímetros de diámetro anteroposterior y 4 milímetros de diámetro transverso.

La muela cuarta está completamente destrozada en los dos lados, no pudiéndose, pues, determinar su forma, pero se conoce que se acentuaba en ella la división en prismas distintos. Tiene 12 milímetros de diámetro anteroposterior y $0^{\mathrm{m}} 0045$ de diámetro transverso.

La muela quinta presenta una forma triprismática bien caracterizada, con el prisma anterior más grande que el posterior y el del medio, al contrario, más pequeño. La cara externa muestra una columna anterior bien desarrollada correspondiente al prisma anterior, una segunda columna (o media) pequeña y rudimentaria correspondiente al prisma más pequeño del medio y una columna posterior grande y ancha correspondiente al prisma tercero y dividida ella misma en dos columnas secundarias por un pequeño surco perpendicular. Sobre el lado interno tiene tres columnas bien desarrolladas separadas por dos surcos. Sobre la cara perpendicular anterior hay un pequeño surco perpendicular colocado sobre el lado externo. La muela tiene 12 milímetros de diámetro anteroposterior y 6 milimetros de diámetro transverso. 
La muela sexta está construida sobre el mismo tipo que la precedente, con la única diferencia del prisma anterior que tiene un diámetro transverso más considerable con su ángulo interno más prolongado hacia adentro y hacia adelante. Tiene 12 milimetros de diámetro anteroposterior, 7 milimetros de diámetro transverso en el lóbulo anterior y $0^{\mathrm{m}} 0055$ en el posterior.

La muela séptima se distingue por un tamaño un poco menor, por la cara anterior del primer prisma, que tiene la depresión perpendiculai más al medio y por el prisma intermedio, que es un poco más grande. Tiene 11 milímetros de diámetro anteroposterior, 6 milimetros de diámetro transverso en. el prisma anterior y 5 milímetros on el posterior.

La muela octava, que es la última, se distingue por los dos prismas posteriores sensiblemente de un mismo tamaño y más pequeños que el anterior, y por la división perpendicular en dos columnas del último prisma, menos acentuado sobre el lado externo que en las muelas precedentes. Tiene diez milímetros de diámetro anteroposterior, seis milímetros de diámetro transverso en el lóbulo anterior y cinco en el posterior.

Las ocho muelas superiores ocupan un espacio longitudinal de $88 \mathrm{mi}$ límetros y el ancho del paladar es de 24 milimetros entre las últimas dos muelas, de 19 milímetros entre el quinto par de muelas y notablamente más angosto todavia entre los dos primeros pares de muelas anteriores, que están implantados desviándose hacia la línea media.

En su configuración general, la mandíbula inferior se parece a la da Glyptodon, con ocho muelas separadas por diastemas regulares. El tamaño de estas muelas aumenta gradualmente desde la primera, que es muy pequeña, hasta la quinta, que es la más grande; y disminuyen u: poco desde la quinta a la octava, ocupando casi toda la extensión del borde superior de la rama horizontal, de manera que el diente primero está colocado casi en la parte anterior de la mandíbula, a sólo 5 milímetros del ángulo anteroexterno de la sínfisis y a 15 milímetros del ángulo interior sobre la línea media. La parte sinfisaria anterior de cada rama mandibular está dada vuelta hacia abajo de una manera más pronunciada que en el Glyptodon, formando un borde grueso y redondeado de 14 milímetros de ancho, sin dientes y en el cual no se perciben tampoco vestigios de alvéolos que estén en correspondencia con los que se observan en el intermaxilar.

La primera muela inferior es muy pequeña y elíptica, con su diánfietro mayor en dirección oblicua al eje de la serie dentaria dirigido de atrás hacia adelante y de afuera hacia adentro. Este diente no presenta vestigios ni de surcos ni de aristas perpendiculares, presentando absolutamente el mismo aspecto que un diente de armadillo: tiene 5 milímetros de diámetro mayor y tres milímetros de diámetro menor. 
El diente segundo es absolutamente de la misma forma e implantado del mismo modo, pero de tamaño un poco mayor; tiene 7 milímetros de diámetro mayor y 4 de diámetro menor.

La muela tercera, de tamaño mucho mayor y de corona más estrecha y alargada, está implantada con su eje mayor en la misma dirección que el eje de la serie dentaria y presenta un principio de división en tres prismas apenas marcado, particularmente sobre el lado interno. Tiene 11 milímetros de diámetro anteroposterior y $0^{\mathrm{m}} 0045$ de diámetro transverso.

La muela cuarta, de tamaño un poco mayor, presenta la división triprismática un poco más visible, particularmente sobre el lado externo. Tiene 12 milimetros de diámetro anteroposterior y 4 milímetros de diámetro transverso.

La muela quinta, que es la más grande, presenta los tres prismas bien marcados, el anterior un poco más angosto y el posterior más ancho. Tiene 14 milímetros de diámetro anteroposterior y 5 milímetros de diámetro transverso en el último prisma.

La muela sexta es un poco más pequeña y con la cara posterior del último prisma un poco deprimida perpendicularmente. Tiene 13 milímetros de diámetro anteroposterior.

La muela séptima tiene 12 milímetros de diámetro anteroposterior, distinguiéndose tan sólo por la cara posterior del último prisma, que es un poco más deprimida perpendicularmente en el medio.

La muela octava presenta la depresión perpendicular de la cara posterior del último prisma más acentuada aún, tomando la forma de un surco; y tiene también 12 milímetros de diámetro anteroposterior.

Las ocho muelas juntas ocupan un espacio longitudinal de 95 milímetros.

La rama horizontal tiene 33 milímetros de alto debajo de la muela cuarta y 37 milímetros debajo de la séptima.

Los agujeros mentonianos son dos, uno muy pequeño adelante, debajo de la parte posterior de la segunda muela, a 17 milímetros debajo del borde alveolar, y el otro apenas un poco más grande debajo de la parte posterior de la tercera muela.

Parece que la rama ascendente, cuya parte basal existe, presentaba una forma parecida a la de los demás Gliptodontes, aunque es probable que la línea anterior no se inclinara hacia adelante y, por consiguiente, no formara con la rama horizontal un ángulo agudo, sino más bien recto o quizá un poco abierto.

El largo total de la mandíbula inferior, desde la parte anterior de la sínfisis hasta la parte posterior de la rama ascendente es de 148 milimetros. 
Procedencia: - Los restos de este animal han sido descubiertos por Carlos Ameghino en las barrancas del río Santa Cruz, en Patagonia austral.

Horizonte:-Piso santacruceño (eoceno inferior).

PALAEHOPIOPIORUS Ameghino

AMEGHINO: «boletín de la Academia Nacional de Ciencias», tomo VIII, página 131, 1885.

La coraza de este género se distingue por placas con una figura central de tamaño considerable, rodeada de otras más pequeñas y de agujeros grandes y profundos. La cola está provista de un tubo terminal compuesto de grandes placas ovaladas, cada una de las cuales tiene e! redor una línea periférica de grandes perforaciones o agujeros, y de figuritas periféricas muy chicas, en forma de pequeños tubérculos.

\footnotetext{
Palaemoplophorus Scalabrinit Ameghino

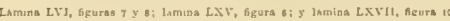

Amegrrno: «Boletín de la Academia Nacional de Ciencias», tomo V, página $30 \mathrm{r}, 183_{3}$. - Idem: torno IX, página 193, 1886.

Los restos de esta especie son bastante escasos aún y por ahora no permiten formarse una idea exacta del animal, que, a juzgar por los pocos restos conocidos, era bastante diferente de los verdaderos $\mathrm{Ho}$ plophorus.

Las placas del centro de la coraza tienen de 3 a 4 centímetros de diámetro y sólo de 16 a 18 de espesor. La cara externa de cada placa tiene una figura central de contorno circular o subcircular, de unos 15 milímetros de diámetro, fuertemente deprimida en el centro, presentando una superficie cóncava un poco rugosa. Alrededor de esta figura central hay un considerable número de figuras periféricas pequeñas, dispuestas en dos filas o círculos concéntricos seguidos a menudo de una tercera fila incompleta. Estas figuras periféricas son rugosas, poco marcadas, separadas por surcos imperfectamente delimitados, poco profundos y de fondo rugoso; en el fondo de estos surcos, distribuidos sin orden alguno, se encuentra un considerable número de perforaciones circulares de $0^{\mathrm{m}} 001$ a $0^{\mathrm{m}} 0015$ de diámetro.

Sohre los flancos, cerca de los bordes, las placas toman una forma más rectangular, modificándose por completo el aspecto de la cara externa. Una de estas placas tiene 45 milímetros de largo, 22 milímetros de ancho y sólo 8 a 9 de espesor. La cara externa muestra en el centro una figura elípticocircular de 18 a 20 milímetros de diámetro, de superficie muy poco rugosa y casi plana, rodeada por una especie de surco 0 depresión ancha pero poco profunda, en cuyo fondo se ven varios 
agujeros que penetran en el interior de la placa, existiendo sólo dos o tres figuritas periféricas en sus extremidades anterior y posterior.

Las placas de la parte anterior de la coraza que siguen inmediatamente a las marginales, tienen una figura cuadrangular con un diámetro de 20 a 22 milímetros por cada lado y un espesor relativamente considerable que varía de 10 a 14 milimetros. La cara externa está ocupada casi por completo por una sola figura central de superficie algo rugosa y de 16 milímetros de diámetro. El perímetro de esta figura está limitado por un surco poco marcado, de fondo igualmente rugoso y con un número considerable de agujeros circulares profundos de uno o dos milímetros de diámetro.

Conozco muchas placas sueltas de los anillos movibles, varias articuladas y un fragmento bastante considerable de uno de los primeros anillos. Este fragmento está formado por dos filas de placas. Las de la fila anterior son rectangulares, de cuatro centímetros de largo por dos y medio de ancho; la cara externa de cada placa ostenta en su parte posterior una gran figura elíptica, de 13 a 16 milímetros de diámetro, rodeada de una fila de figuras periféricas pequeñas, rudimentarias en su parte posterior, pero mucho más grande hacia adelante, en donde están seguidas de otras dos filas transversales de figuritas más pequeñas, siguiendo luego una parte rugosa y en declive que se extiende hasta el borde anterior. En el fondo de los surcos que separan entre sí a las figuritas y a éstas de las figuras centrales, hay en casi todos los puntos de convergencia un agujero circular profundo, cuyo diámetro varía de uno a tres milimetros. La fila de placas posteriores, está formada por placas más cortas y más anchas, casi cuadradas, con una figura central subesférica, rodeada de una fila de figuras periféricas bien delimitadas, más grandes adelante, muy pequeñas o rudimentarias a los lados, faltando por completo en el borde posterior. En el fondo de los surcos se ven los mismos agujeros que en las placas de la primera fila. El ancho del anillo es de un poco más de 6 centímetros.

Otros dos fragmentos de la coraza de la cola, muestran que ésta terminaba en un tubo cónicocilíndrico como en el Hoplophorus, pero con una escultura externa muy distinta.

Uno de los dos fragmentos, que debe provenir de la mitad del largo del tubo, más o menos, está formado por tres placas, cada una con una gran figura elíptica u ovalada, deprimida en el centro y rodeada de figuritas muy pequeñas en forma de tubérculos, separadas entre sí y de la figura central por surcos profundos. La figura central de cada placa está rodeada de un considerable número de agujeros profundos y de gran diámetro, colocados en el fondo del surco que separa a la figura central de las figuras periféricas.

El segundo fragmento comprende la mitad de la extremidad posterior 
del tubo caudal correspondiente al lado izquierdo, de manera que puede examinarse muy bien la forma de las placas laterales. En una extensión longitudinal de 12 centímetros, esa parte del tubo se compone de placas de tamaños diferentes, cada una de las cuales contiene una sola figura externa de la misma forma de la placa; todas estas figuras son de contorno más o menos elíptico, unas de superficie áspera y más o menos deprimidas y otras de superficie convexa. Ahí no existen figuras periféricas, o son excesivamente raras, afectando la forma de pequeños tubérculos. Las placas están separadas unas de otras por surcos anchos pero poco acentuados, presentando en cambio en su fondo una fila continua de perforaciones o agujeros circulares cuyo diámetro varía de 2 a 6 milímetros. Puede decirse que esta figura de filas periféricas, forma la verdadera separación entre las distintas placas.

$\mathrm{Al}$ examinar esta parte lateral de la cola, empezando por su extremidad posterior, se encuentra una figura elíptica colocada oblicuamente sobre su parte superior, a la cual corresponden dos figuras más pequeñas en su parte inferior, todas convexas y separadas sobre la linea media lateral por una depresión con perforaciones que se ensanchan en la misma punta del tubo conteniendo varios tubérculos. Hacia adelante, a continuación de esta depresión viene una gran figura elíptica de 5 centímetros de largo y $0^{\mathrm{m}} 035$ de ancho, de superficie áspera y rugosa. Más adelante siguen a esta figura otras dos placas, igualmente elípticas, entre las cuales en su extremidad posterior se coloca la extremidad anterior de la placa o figura más grande ya mencionada. A cada lado, tanto arriba como abajo, siguen placas igualmente elípticas, todas de gran tamaño y con la misma fila de perforaciones periféricas. A los 12 centimetros de la extremidad posterior, el espesor de la coraza es, en los lados, de poco más de 3 centímetros; y en su parte superior, de sólo 2 centímetros. En ese mismo punto, el ancho del tubo no debía sei mayor de 10 centimetros y su alto o diámetro vertical era aproximadamente de 8.

Procedencia:--Los primeros restos de esta especie fueron descubiertos por el profesor Scalabrini en las barrancas de la ciudad del Paraná; y el fragmento de tubo caudal descripto fué recogido en la misma localidad por el señor Lelong Thévenet.

Horizonte:-Piso mesopotámico de la formación patagónica.

PALAEHoplopitorus pRESSUlus Ameghino

LAmina LXIX, Ggura 10

Amecrino: «Boletin de la Academia Nacional de Ciencias», tomo VIII, página 132, I885.

Esta especie parece representar un tipo más primitivo que la precedente; pero, por desgracia, sólo está representada por dos pedazos ḋ 
coraza de individuos distintos y de región muy diferente, como qua uno de ellos pertenece a la coraza dorsal y el otro a uno de los anillos de la cola.

El primer fragmento, perteneciente a la coraza dorsal, consta de cuatro placas; éstas son de forma más o menos pentagonal y bastante grandes, puesto que tienen de 30 a 35 milímetros de diámetro, pero relativamente muy delgadas, presentando un espesor que varía entre 7 y $10 \mathrm{mi}-$ límetros. El centro de la superficie externa de cada placa está ocupado por una roseta o figura circular de diámetro variable, formada en su perímetro por un reborde bastante elevado y en el centro por una depresión pronunciada. Esta figura central está delimitada, no por un surco como en los Hoplophorus pampeanos, sino por una depresión ancha, poco profunda y no muy bien marcada, en cuyo alrededor, ocupando el contorno de la placa, se ven otras figuras más pequeñas, todas ellas muy mal delimitadas y separadas por surcos poco perceptibles, unas más rugosas y otras más lisas y de tamaños distintos. No se ven ni en estas depresiones ni alrededor de la figura central esos pequeños agujeros que se encuentran en las placas de los otros Gliptodontes y de los Hoplophorlus pampeanos. Lo que más caracteriza a este fragmento es 1o rudimentario de sus dibujos y la poca fijeza de los caracteres que presentan sus distintas partes.

El segundo fragmento proviene de uno de los anillos movibles de la cola y también consta de cuatro placas, pertenecientes, dos a la fila anterior y dos a la posterior.

Las placas de la fila posterior tienen un diámetro de 18 milímetros y 7 de espesor. Casi toda la figura externa está ocupada por una roseta o figura central de unos 12 milimetros de diámetro que en su parte posterior constituye el borde mismo de la placa, pero en la parte anterior forma hacia adelante una pequeña protuberancia de la cual está separada la roseta por un surco bastante ancho y profundo en el que se ven algunos agujeros de 2 a 3 milímetros de diámetro y de fondo cóncavo.

Las dos placas de la fila anterior son, como de costumbre, de figura más rectangular, de 28 milímetros de largo y de 16 a 18 de ancho, siendo más anchas y gruesas en la parte posterior, delgadas y más angostas en la anterior, de modo que el anillo no sólo formaba ahí un borde anterior delgado, sino que si la particularidad observada en estas placas se repetía en las demás, como hay motivos para creerlo, presentaba también una serie de escotaduras correspondientes a la parte anterior de las suturas de las placas. En las placas existentes, esa escotadura tiene 7 milímetros de largo por 4 milímetros de ancho.

La parte posterior de cada una de esas placas está ocupada por una figura elíptica bastante elevada, de unos 10 milímetros de diámetro, rodeada en sus dos costados laterales y en el anterior por un surco o, más 
bien, depresión ancha y poco profunda, pero con unos cuantos agujeros anchos y de fondo cóncavo. Más adelante se presenta una protuberancia elevada, rodeada igualmente por algunos grandes agujeros, terminando la placa en su parte anterior por una especie de plano inclinado, rugoso e irregular.

Ya en algunos Hoplophorus pampeanos se notan algunos de estos detalles que pueden determinarse como irregulares, pero no con los caracteres de una irregularidad o imperfección tan acentuada como en la especie del Paraná descripta.

Procedencia: - Estos restos han sido descubiertos por el profesor Scalabrini en las barrancas de los alrededores de la ciudad del Paraná y pertenecen al Museo provincial de Entre Ríos.

Horizonte: Piso mesopotámico de la formación patagónica (oligoceno inferior).

l'ALAEHOPLOPHORUS DISJUNCTUS, $\mu$. $s p$.

Lamina LV, ligura o

El centro de la coraza dorsal de esta especie se distingue por placas proporcionalmente más pequeñas y más gruesas que en las especies precedentes y reunidas entre si por suturas menos fijas. Estas placas tienen una figura casi cuadrada, de unos tres centímetros por cada lado y de 10 a 13 milímetros de grueso. Cada placa tiene en la cara externa una figura central circular de 16 a 17 milímetros de diámetro, de superficie un poco rugosa y deprimida en el centro. Alrededor de esta figura central hay una fila de figuritas periféricas en número de 9 a 10 , muy pequeñas, casi en forma de tubérculos y algunas completamente rudimentarias. Esta fila está seguida de otras figuritas periféricas atrofiadas e interrumpidas, que en algunos casos afectan la forma de simples rugosidades; como consecuencia de esta conformación, los surcos que separan a las figuras son muy anchos, pero poco profundos y de fondo rugoso. En el fondo del surco que rodea a la figura central existen de distancia en distancia pequeñas perforaciones.

Procedencia: - Los restos de esta especie han sido descubiertos por Carlos Ameghino en Monte Hermoso, a 60 kilómetros de Bahía Blanca.

Horizonte:-Piso hermósico de la formación araucana.

HOPLOPHORUS Lund

Luno: en Overs, $K$. Danske, Vid. Selsk. Forhandl., 1838, página r1.-Idem: «Annales des Sciences Naturelles

Las especies de este género son, en general, de tamaño inferior a la mayor parte de los demás Gliptodontes y la coraza es de una conforma- 
ción bastante diferente; en vez de ser casi esférica como en el Glyptodon o alargada, ancha, elevada y convexa en el medio como la del $P a$ nochtus, es, al contrario, más angosta, menos ensanchada en el medio, más baja y más alargada, tomando una forma oblongoalargada casi subcilíndrica, lo que le da algún parecido con la de algunos armadillos, especialmente con la de las especies del género Tatusia. Otra particularidad de la coraza del Hoplophorus reside en el distinto tamaño de sus dos mitades anterior y posterior, siendo esta última más ancha y más elevada y la anterior más estrecha y más baja, con toda la región superior más aplastada que en el Panochtus, formando de atrás hacia adelante una línea que desciende regularmente abajo. La abertura cefálica es pequeña y elevada y la posterior o caudal notablemente mayor pero más deprimida. En la abertura anterior o cefálica de este género, que lo distingue de todos los demás, hay una particularidad consistente en las paredes laterales de la abertura, que se dirigen hacia adelante en forma de dos aletas laterales muy prolongadas, completamente libres arriba y abajo y terminan adelante en un borde redondeado; esas aletas están formadas por un considerable número de placas muy pequeñas, de distinta forma de las que comprende el resto de la coraza y dispuestas por fajas perpendiculares.

Otra particularidad que distingue a la coraza del Hoplophorus de la de los demás Gliptodontes, es la de no presentar sobre los flancos de su mitad anterior ningún vestigio de las hendeduras perpendiculares que en los otros géneros existen en los bordes y separan las extremidades de las hileras transversales. Si este carácter no es común a todos los Hoplophorus, cuando menos ha sido hallado en las dos o tres especies cuya coraza completa se conoce.

Aun tomando en cuenta el tamaño menor del animal, la coraza del Hoplophorus es bastante más esbelta que la del Glyptodon y el Panochtus, formada por placas relativamente de gran tamaño, pero delgadas. Cada placa tiene en la cara externa una figura central poligonal de gran tamaño que afecta una forma más o menos circular, rodeada de una fila de siete a doce o más figuras periféricas más pequeñas colocadas en parte sobre los bordes, de manera que uno de sus lados se une con otra figura igual de la placa opuesta formando otra de mayor tamaño. Todas estas figuras son por lo general casi lisas, planas y la del medio deprimida en el centro, separadas por surcos angostos y poco profundos, en los cuales se ven, de distancia en distancia, pequeños agujeros. En algunas especies no existe en cada placa más que la figura central, rodeada de una pequeña depresión, de la que parten un sinnúmero de rayos que van a los bordes de las placas, reemplazando a las figuras periféricas. Esta es la forma de las placas de la región central, pero ella cambia un poco cerca de los bordes. En las dos alas laterales las placas son muy 
pequeñas y con la cara externa casi por completo ocupada por la figura central de contorno elípticocircular, rodeada por una depresión y uı borde rugoso.

El borde anterior de la coraza está formado por una fila de placas pequeñas, adelgazadas hacia adelante, por lo general con una sola figura estrecha, pero con varios agujeros circulares, grandes, poco profundos y de fondo cóncavo. En los lados laterales el borde está formado poi placas pequeñas, con una figura externa generalmente única, de contorno distinto, según provengan de más adelante o de más atrás, o según las especies. En la abertura posterior el borde está formado por placas con una gran figura elípticocircular en su parte posterior, que termina en un borde libre muy engrosado; las placas que sobre la región superior de la coraza siguen inmediatamente detrás del borde periférico son las más grandes de toda la coraza, casi siempre con una figura central muy grande, elevada pero deprimida en el centro, acompañada de figuras periféricas parecidas a las del resto de la coraza.

Proporcionalmente, el escudo cefálico ha sido más grande que el de todos los demás Gliptodontes, pues cubria toda la parte superior de la cabeza, extendiéndose desde la parte anterior de la abertura nasal hasta más atrás de los cóndilos occipitales. Este escudo es muy convexo, redondeado en su parte anterior, de forma general un poco alargada y fuertemente descendente a los lados, pero con una fuerte entrada o escotadura cóncava en cada costado, que empieza inmediatamente encima del borde orbitario anterosuperior. Las placas que forman este escudo son variables, según las especies, pero por lo común presentan la superficie externa ocupada en su mayor parte por una figura eliptica central de gran tamaño, rodeada de otras más pequeñas o simplemente de una banda rugosa con pequeñas perforaciones. Las placas que forman el casco cefálico del Hoplophorus son entre sí de tamaño menos desigual que en el Panochths y todas ellas reunidas por suturas fijas bien dentadas, formando una resistente coraza enteramente distinta de la del Panochtus, cuyas partes periféricas anteriores y de los lados externos anteriores estaban formadas por placas casi sueltas; y más todavía del casco del Glyptodon, cuyas piezas, más pequeñas aún, estaban casi todas simplemente yuxtapuestas sin trabarse por suturas.

El número de anillos de la parte movible de la región caudal no es conocido con precisión, aunque en algunas especies parece ser de cinco.

Estos anillos están formados por dos filas de placas muy diferentes. La fila anterior está constituida por placas con una gran figura elípticocircular en su parte posterior y cuya parte anterior se prolonga hacia adelante en declive inclinado, con varias perforaciones de gran tamaño $y$ de fondo cóncavo sobre la cara externa, concluyendo en un borde anterior muy delgado, en línea transversal oblicua casi recta; cada una de 
estas placas se articula con dos de las de la fila posterior. La segunda fila está constituída por placas pentagonales o exagonales alargadas con los dos bordes laterales opucstos más largos y casi rectos como en los de la fila que la precede; estas placas son muy gruesas en su borde posterior y presentan una gran figura subcircular que ocupa la mayor parte de la placa y llega hasta el mismo borde, pero hacia adelante se extiende un pequeño espacio casi en forma de segmento de círculo con tres o cuatro figuras más pequeñas.

La parte posterior de la cola está formada por un tubo cilindricn aplastado que se ensancha bastante en su extremidad anterior, terminando en punta roma formada por dos grandes tubérculos laterales, convexos, uno a cada lado, convergentes hacia su extremidad posterior, pero que a menudo no alcanzan a ponerse en contacto, quedando separados por una ranura perpendicular estrecha y profunda. Toda la superficie del tubo está cubierta de figuras elípticocirculares o subcirculares dirigidas cen su mayor diámetro de adelante hacia atrás y rodeadas de un considerable número de figuritas o tubérculos mucho más pequeños, tcdos separados por surcos angostos y profundos. Sobre los costados se encuentra a cada lado una fila de verrugas subcirculares mucho más gruesas, colocadas unas a continuación de otras y que aumentan de tamaño de las primeras a las últimas; en la parte anterior del tubo no son más grandes que las demás, pero hacia el tercio posterior de su longitud, el tamaño de las que forman esta línea lateral empieza a aumentar gradualmente, hasta que la última de cada lado constituyen el par de grandes verrugas terminales que forman la extremidad terminal del tubo.

Un tubo de este tipo y, por consiguiente, de una especie de Hoplophorus, es el que fué colocado en la abertura caudal del Glyptodon clavipes reconstituído en el Museo del Colegio de Cirujanos de Londres.

El esqueleto del Hoplophorus se acerca por muchos caracteres al dei género Panochtus.

La parte superior del cráneo es fuertemente convexa, aunque no tanto como en aquel género; y la curva de los huesos de la nariz, así como la abertura nasal, son también inclinados hacia abajo, pero de una manera menos pronunciada que en el Panochtus. La convexidad de la región superior del cráneo es debida, como en este género, al desarrollo de grandes cavidades o sinus en el espesor de los frontales y parietales. Las órbitas difieren de las del género Panochtus por estar abiertas atrás y en comunicación con las fosas temporales, limitadas hacia atrás por una fuerte apófisis postorbitaria ascendente del arco cigomático, que se acerca mucho a la apófisis opuesta del frontal, formando un estrechamiento que interrumpe el círculo de la órbita. Los parietales son más deprimidos que en el Panochtus, más descendentes hacia los lados y 
cubiertos de asperosidades y numerosas perforaciones vasculares. E1 occipital es un poco más extendido que en el Glyptodon, con crestas occipitales laterales más pronunciadas y por consiguiente con el llano occipital más excavado y dividido por una cresta perpendicular media, que son caracteres que no se observan ni en el Glyptodon ni en el Panochtus.

El arco cigomático, a pesar de no presentar el puente que lo une al frontal, como en el Panochtus, se parece más al de este género que al del Glyptodon, particularmente por el ensanchamiento considerable que presenta detrás de la órbita, producido en parte por el desarrollo de la apófisis postorbitaria. El paladar es parecido al del Panochtus. La mandibula inferior presenta la rama ascendente más corta y más ancha que en la generalidad de los Gliptodontes; y los agujeros mentonianos parecen ser por lo menos en número de dos.

Las muelas están construídas sobre el mismo tipo que las de los otros Gliptodontes, pero la lámina de vásculodentina central más elevada no presenta en la superficie masticatoria las pequeñas ramificaciones que penetran en la masa de la dentina, visibles en las especies del género Glyptodon, cuyo carácter las acerca a las del Panochtus, aunque el tamaño relativo de algunos de los dientes es un poco diferente. El tamañ s de las muelas aumenta en la mandibula superior desde la primera a la quinta; la quinta, sexta y séptima son casi iguales y la octava es bastante más pequeña. Las anteriores son también bastante pequeñas en la mandíbula inferior. La primera de cada mandibula no es triprismática sino más o menos elíptica, sin indicación de las aristas perpendiculares, o indicadas de una manera completamente rudimentaria.

El hueso mesocervical se compone de cuatro vértebras y presenta una forma parecida a la del Panochtus.

La. sexta vértebra cervical unas veces es libre y otras soldada a la parte anterior del hueso metacervical, probablemente según las especies. De acuerdo con esta variación, el hueso metacervical consta algunas veces de tres vértebras, según es de regla en todos los demás Gliptodontes, y otras veces de cuatro.

El tubo dorsal está formado por lo menos de doce vértebras reunidas.

Los huesos largos del miembro anterior son parecidos a los del $\mathrm{Pa}$ nochtus, presentando el húmero un agujero epitrocleano, como en este último género. En el carpo sólo existen siete huesos, porque el trapecio y el trapezoides están reunidos en uno. Toda la conformación del pie anterior es parecida a la del Panochtus, terminando como el de este género en cuatro dedos completos, correspondientes al segundo, tercero, cuarto y quinto. El pie nosterior presenta con el mencionado género la misma analogía, terminando asimismo en cuatro dedos, de los cuales e! externo o quinto es un poco más fuerte que en el Panochtus. 
HOPLOPHORUS MEYERI Lund

Latmina LX, figuras $z y$,

Hoplophorus cuphractus. Lund (parte): Bhk pas Bras. Dyrev, etc.

BURMeister: \&Anales del Museo Público de Buenos Aires», tomo II, páginas 219 y 224.

-Idem: Description physique, ete., tomo III, página 4I0, 1879.

Hoplophorus gracilis (Nodot). H. Genvars y AMEGruno: Los mamíferos fósiles, etc., página 196,1880 .

Glyptodon euphractus (Lind), Lisis (parte).

Panochtus Lundi. Burmerster: «Anales del Afuseo Público de Buenos Aires», tomo II, página $103,1870$.

Hoplophorus Meyeri. Lund, según I,ydekrin en Oters, $K$. Danske, Vid. Selsh. Forhandl. de 2843 , página $79,(1844)$, texto LÜTKEN ( 11 . S.)

II. Gervats y Amegrino: Los mamiferos fósiles, etc., página 190 , numero 247,1880 .

LYDEKKER: Catal. of Foss. Mamm., parte V, página $127,1887$.

Los restos de esta especie fueron en un principio descriptos por Lund bajo el nombre de Hoplophorus euphractus, pero confundidos bajo la misma denominación con los de un verdadero Glyptodon; más tarde, percatándose de su error, conservó el nombre especifico de euphractus para los restos del verdadero Glyptodon y cambió el nombre de la que él suponía una especie más pequeña del mismo género por el de Hoplophorus Meyeri.

La talla del Hoplophorus Meyeri era un poco menor que la del Hoplophorus ornatus; y las placas se distinguen fácilmente de las correspondientes en la especie mencionada por la figura central de cada placa, que es relativamente más pequeña, apenas un poco mayor que las figuras periféricas y a veces más pequeñas que algunas de éstas y de un contorno más o menos subcircular. Las figuras periféricas varían de 6 a 8 , son de contorno generalmente anguloso y están separadas unas de otras por surcos bien marcados, con perforaciones pilíferas en el fondo del que rodea la figura central, aunque en número variable, pero colocadas siempre como en los Gliptodontes en el punto de convergencia con los surcos radiales. La superficie de todas las figuras es un poco áspera o rugosa y cubierta con puntuaciones muy acentuadas, lo que las distingue fácilmente de las correspondientes del Hoplophorus ornatus que son siempre mucho más lisas. Todas las figuras se encuentran sobre el mismo plano; y las placas del centro de la coraza tienen un diámetro de 18 a 22 milimetros, bastante menor que el de las correspondientes del Hoplophorus ornatus. Cada placa del Hoplophorus Meyeri, tiene, por lo general, una figura periférica menos que las placas de la misma región de la coraza en el Hoplophorus ornatus.

Lydekker menciona como probablemente perteneciente a esta especie, un pequeño fragmento del tubo caudal, en el cual la figura central de cada placa es más pequeña y más rugosa que en la porción correspondiente del Hoplophorus ornatus, lo que está en buena relación con las partes conocidas de la coraza dorsal. 
E] cráneo, según Burmeister, se distingue por el arco cigomático que carece de la apófisis descendente suborbitaria del borde inferior, que se encuentra en el Hoplophorus ornatus; y por la apófisis descendente del arco cigomático, que es bastante más delgada que en la mencionada especie.

Procedencia: - Los restos de esta especie fueron primeramente descubiertos por Lund en las cavernas de Brasil, de donde se han extraido sucesivamente numerosos restos que se conservan en los Museos de Copenhague $y$ de Londres. No he visto hasta ahora ningún fragmento procedente de nuestro territorio que pueda atribuirse a este animal; Burmeister, sin embargo, cita la especie como habiendo existido igualmente en la República Argentina ( Description physique», etc., tomo III, página 410, Hoplophorus euphractus); y bajo su autoridad incluyo la especie entre las argentinas.

Horizonte:-Formación pampeana (?).

JOPLOPIIORUS ORNATUS (Owen) Burmeister

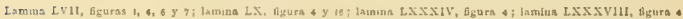
y tanuma detil higurus $b_{2} 2 y$ s

Glyptodon ornatils. Owen: Catal. Fioss. Mamm. Aves. Mus. R. Coll. Surg., pág. 149, 1845. Nodor: Description d'un nouveau genre d'édenté fossile, pág. 90, lámina II, fig. 6, 1857. SERRES: Compte-Rendu, etc., Septiembre de 1865.

Glyptodon Oweni. BRAVARD: Catalogue des collections, etc. (nomen nudum).

Glyptodon clazipes (Owen). Burmerstre: aArales del Miuseo Público de Buencs Aires», tomo I, entrega $3^{2}$, página 205, 1866. - Idem: tomo II, página 56, 1870.

Hoplophorus euphractus (Lund). Poucrer: en «Journal de l'Anatomie et Physiologie», Julio de $1 \$ 66$.

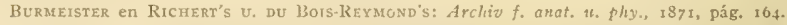
Hoplophorus ornatus (Owen). Burmistra: «Anales del Museo Público de Buenos Aires», tomo II, página 219, lámina XVII, 1871 , - Itemi: Description physique, etc, tomo III, página $140,1879$.

H. Gervais y Ameghino: Los namiferos fósiles, etc., página 116, 1880.

LYDEKkER: Catal. of Foss. Mamm., parte V, página 128, I887.

Esta especie es de tamaño un poco mayor que el Hoplophorus Meyeri, del cual se distingue fácilmente por la superficie de las placas que es siempre mucho más lisa, apenas ligeramente puntuada, con las figuras más planas, las placas de tamaño un poco mayor, la figura central de cada placa siempre de tamaño notablemente mayor que las periféricas y porque cada placa tiene una o dos figuras periféricas más que las placas correspondientes del Hoplophorus Meyeri.

El tamaño de las placas es sumamente variable, teniendo las más grandes en el centro del dorso, encima de la cadera, un diámetro de 4 centímetros, que disminuye hacia la periferia, hasta que en los bordes de las alas laterales de la abertura anterior las hay que no tienen 
más de 4 a 5 milímetros de diámetro. En e! centro del dorso, la figura central de cada placa es relativamenic más pequeña que en la periferia, pero siempre notablemente más grancle que las figuras periféricas, de superficie plana y casi completamente lisa, pero a menudo un poco deprimida o más baja que las figuras periféricas, siendo por lo general de contorno subcircular o subeliptico. Las figuras periféricas son angulosas, comúnmente pentagonales, de superficie plana pero puntuada y separadas por surcos bien marcados pero bajos y angostos. En el surco que delimita a la figura central se ven pequeñas perforaciones que penetran en el interior de la coraza; el espesor máximo de las placas no pasa de 16 a 18 milímetros.

La cola de esta especie es la que ha figurado Burmeister en el tomo segundo de los «Anales del Museo», lámina XL, figuras 7 y 8 , como de Glyptodon clavipes. Es un tubo cónicocilindrico aplastado, relativamente muy largo, cuya anchura disminuye gradualmente de adelante hacia atrás de una manera considerable; y es un poco arqueado hacia arriba en toda su longitud, terminando en punta muy delgada. Tiene 435 milimetros de longitud; y en la base una circunferencia de 34 centímetros.

Inmediatamente hacia atrás empieza a deprimirse en su cara superior, presentando 26 centimetros de circunferencia hacia la mitad de su largo y sólo 21 centímetros en su extremidad posterior en el espacio comprendido entre las verrugas laterales última y penúltima. El diámetro transverso es de 107 milímetros en la extremidad anterior, de 89 milímetros hacia la mitad de su largo y de sólo 70 milímetros en la parte anterior del último par de verrugas terminales que constituyen la punta.

La fila de figuras laterales está formada por siete placas o figuras en cada lado, todas más o menos elípticas y sucesivamente más grandes hacia atrás, con excepción de la primera o anterior, colocada más o menos en el primer cuarto de la longitud del tubo, que es casi circular. La desproporción entre el tamaño de las placas laterales penúltima $y$ última, es muy grande, siendo ésta de tamaño mucho mayor y convexa y la antepenúltima mucho más pequeña y un poco deprimida en sentido transversal.

La última figura lateral tiene 68 milímetros de diámetro anteroposterior y 49 milimetros de diámetro transverso, sin tener en cuenta la curva; la penúltima tiene 52 milimetros de diámetro anteroposterior y 38 milímetros de diámetro transverso; y la antepenúltima 41 milímetros de diámetro anteroposterior y 28 milimetros de diámetro transverso. Las seis últimas figuras laterales ocupan, aproximadamente, un espacio longitudinal de 30 centímetros, extendiéndose hacia adelante hasta el borde anterior del tubo cinco filas transversales de figuras subcirculares.

La cara superior está adornada con figuras subcirculares, algunas un poco ovaladas, de tamaño desigual y dispuestas en filas transversales 
regulares de ocho placas en cada fila en la parte anterior y en filas transversales irregulares hacia atrás, cuyo número de placas o figuras disminuye gradualmente hasta la parte posterior de la penúltima placa lateral de cada lado, en donde sólo es de tres placas o figuras, siguiendo luego una fila de dos iiguras y al fin una figura terminal aislada. Todas estas figuras están rodeadas por una fila periférica de figuritas más pequeñas separadas por surcos profundos. La cara inferior está cubierta por figuras elípticas de tamaño desigual, las posteriores de mayor tamaño que las anteriores, de superficie lisa, a veces un poco deprimida y rodeadas por una fila de figuras periféricas bien desarroliadas. Un carácter distintivo de esta especie, que permite reconocerla con facilidad, consiste en existir siempre dos filas de figuritas periféricas pequeñas entre los espacios que separan entre si a las grandes placas o figuras laterales, incluso el espacio comprendido entre la última y la penúltima.

El tubo que me ha servido para la precedente descripción es el mismo ejemplar que en dos partes distintas ha figurado Burmeister como de Glyptodon clavipes, y en ambas de una manera equivocada, que altera completamente su forma. En la lámina XL del tomo segundo de los «Anales del Museo de Buenos Aires», está figurado de lado y visto por la cara superior, reducido a un cuarto. Pero si bien la reducción es exacta en cuanto al largo no lo es en cuanto al ancho, pues la extremidad anterior (figura 7) aparece como teniendo un diámetro transverso de 120 milimetros mientras que en el original no tiene más que 107, lo que le da un aspecto completamente distinto, pues el ancho resulta exagerado en todo su largo y hasta la misma extremidad terminal que parece notablemente más gruesa, que en realidad no lo es.

Por último, el mismo tubo está dibujado en la fantástica restauración del Glyptodon clavipes que se encuentra en la lámina XXXVI del mismo tomo de los «Anales del Museo», como reducido a un décimo de la escala natural, apareciendo acá, según dicha reducción, como teniendo unos. 60 centímetros de largo en vez de 43 que tiene el original y como teniendo 17 centímetros de diámetro vertical en su extremidad anterior, mientras que el original sólo tiene 10 centímetros.

Lydekker sugiere que sería bueno tomar como tipo de la especie el ejemplar descripto por Burmeister en los «Anales del Museo», pero no está de más tener presente que ese ejemplar ha sido restaurado con restos de varios individuos que no está probado pertenezcan a la misma especie. En cuanto al tubo caudal que describe y dibuja con la coraza, es en su casi totalidad de yeso, existiendo de él sólo un pequeñisimo fragmento de la extremidad distal, de manera que lo restante debe haber sido reconstruido sobre el modelo de algún otro ejemplar que podría provenir de otra especie, o quizá, lo que es más probable, según el 
dibujo del tubo caudal atribuido al Glyptodon clavipes ya mencionado, pues la parte terminal es idéntica.

La coraza y la cabeza presentan, según Burmeister, las siguientes dimensiones:

\section{DIMENSIONES}

Longitud de la coraza siguiendo la curva superior del dorso.............. 1"335

Longitud de la coraza en línea recta ................................. 1240

Diåmetro transverso en el medio, siguiendo la curva de la coraza ........... 1400

Diámetro transverso máximo elı línea recta ......................... 0735

Diámetro transverso de la abertura anterior ........................ 0305

Diámetro transverso de la abertura posterior .......................... 0510

Longitud del cráneo desde la punta anterior del paladar laasta los cóndilos occipitales ...... ................................................... 0268

Longitud del paladar ............................................. 00177

Longitud de la serie dentaria ..................................... 0152

Altura del cráneo desde ia cresta sagital hasta el llano del paladar............ 0165

Ancho de la frente entre las apófisis postorbitarias ......................... 0127

Anchura entre los arcos cigomáticos ................................ 0216

Longitud de la apófisis cigomática, desde el margen de la órbita ............ 0152

Longitud de la rama horizontal de la mandibula inferior ................... 0210

Longitud de la sinfisis............................................. 0115

Altura del ramo perpendicular .................................. 0178

Altura desde el llano occipital hasta el margen superior del agujero occipital... 0063

Procedencia:- Los restos de esta especie se encuentran con frecuencia en toda la llanura argentina y en la República Oriental del Uruguay. Lydekker refiere a la misma especie algunos restos procedentes de las cavernas fosiliferas de Brasil.

Horizonte: - Piso ensenadense de la formación pampeana.

IOPLOPHORUS PSEUDOTKATUS, $n, s p$.

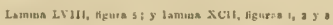

Hoflophorts, sp. a. ? LYDEKkER: Catal. oj Fossil Mamm, parté V', página 130, 1887.

Esta especie era de coraza delgada, pero probablemente de tamaño igual o mayor que el del Hoplophorus ornatus. Las placas son de superficie externa más lisa todavía que en la especie precedente, con la figura central relativamente más pequeña y las periféricas más grandes pero menos numerosas, siendo generalmente de 7 a 8 en la parte central de 1a coraza.

Las placas del centro de la coraza tienen un diámetro de 30 a 35 milímetros y sólo 10 milímetros de grueso. La figura central de cada placa representa un polígono de un considerable número de lados, de un contorno irregularmente sutcircular, de tamaño no mucho más grande que 
las figuras periféricas y de superficie completamente lisa, pero no deprimida como a menudo se observa en el Hoplophorus ornatus; estas figuras centrales tienen un diámetro de 14 a 16 milímetros. Las figuras periféricas son bien delimitadas, de tamaño considerable, siempre poligonales, de contornos angulosos formados por lineas rectas, por lo general pentagonales, rara vez exagonales y de superficie plana y lisa, 110 más elevada que la de la figura central. Una particularidad de estas figuras periféricas consiste en que son de muy desigual tamaño, como que en una misma placa las hay muy pequeñas, de sólo 5 o 6 milímetros de diámetro, y las hay muy grandes, de 10 a 15 milímetros de diámetro; pero a menudo, no siempre, estas figuras periféricas más grandes son formadas por la reunión y soldadura de dos figuras periféricas de dos placas contiguas. Los surcos que delimitan las figuras son angostos $y$ profundos, mucho más marcados que en el Hoplophorus ornatus; y las perforaciones que se encuentran en el fondo del surco que rodea a la figura central son sumamente pequeñas y en corto número.

El tamaño de la figura central de cada placa aumenta hacia la periferia, tomando un contorno más elíptico; y las figuras periféricas resultan un poco menos angulosas.

El tubo caudal de esta especie, cuya parte posterior conozco, es notablemente más delgado que el del Hoplophorus ornatus, bastante más deprimido y casi recto. Su anchura disminuye gradualmentè de adelante hacia atrás, aunque no de una manera muy acentuada, y termina en punta much $৩$ más aguda que en las otras especies. El diámetro transverso del tubo es de 95 milimetros en el espacio entre la antepenúltima figura lateral y la que le sigue hacia adelante, de 91 milimetros en el espacio entre la penúltima y la antepenúltima y de 83 milimetros entre la última y la penúltima, disminuyendo desde ahi hasta la punta de una manera sumamente rápida. Sobre el lado más completo del tubo las figuras laterales son en número de cinco, la anterior incompleta, cuyo tamaño aumenta gradualmente hacia atrás, todas de una forma elipsoidal muy regular, colocadas con el eje mayor en dirección del eje longitudinal del tubo, formando una linea casi recta. Las figuras laterales penúltima y antepenúltima de cada lado son fuertemente deprimidas en sentido transversal, pero con su parte posterior prominente afectando casi la forma de una silla de montar. El último par de figuras laterales son muy gruesas, fuertemente convexas y de superficie rugosa. La antepenúltima figura lateral tiene 58 milímetros de largo por 38 de ancho, la penúltima 60 milímetros de largo por 49 de ancho y la última 76 milimetros de largo por 52 de grueso, sin tener en cuenta la curva.

La cara superior está cubierta por figuras circulares planas o un poco deprimidas alrededor de la parte céntrica, afectando una forma anular. Estas figuras principales están rodeadas por una fila de figuritas peri- 
féricas pequeñas, poligonales, angulosas y bien delimitadas. En la parte posterior, en el espacio comprendido entre el penúltimo par de figuras laterales, hay tres filas transversales de estas figuras mayores, formadas cada una de dos figuras, seguidas atrás por una figura impar colocada entre la parte anterior del último par de figuras terminales. Hacia adelante el tubo está destruído, pero se conoce que las figuras centrales o principales eran relativamente pocas, probablemente en número de tres o cuatro en cada fila.

La cara inferior es notablemente más convexa que la superior y con figuras centrales igualmente poco numerosas, pero de tamaño un poco mayor, de forma menos circular y más elíptica, más rugosas y hacia atrás un poco deprimidas en el centro. En el espacio comprendido entre el antepenúltimo par de figuras laterales, cada fila transversal consta de tres figuras; entre el penúltimo par sólo de dos como en la cara superior, terminando también con una figura aislada impar. Las figuras periféricas forman a los lados filas bien desarrolladas, pero poco marcadas o casi atrofiadas en el mismo centro o eje longitudinal medio de la cara inferior.

Todas las figuras laterales están separadas entre si por una sola fila de figuritas periféricas pequeñas bien marcadas.

Procedencia: - He recogido los restos de esta especie en las toscas del fondo del río de la Plata, en el municipio de Buenos Aires; y en las excavaciones del puerto de La Plata, en la Ensenada.

Horizonte: - Piso ensenadense de la formación pampeana (plioceno inferior).

IIOPLOPHORLS LINEATUS Ameghino

Lamina LXIV, Aguns 5 Y T

Hoplophorus lineatus. AnEGHa: Rúpidas diagnosis de mamiferos fósiles mevos, ete., página 17 , númera 26 , Febrero de 1888 , - Idem: Lista de los maniferos fósiles de Monte Hermoso, página 18 , numero $4 \mathrm{I}$, Junio de $\mathrm{r} 888$.

Hoplophorus formosus. MoRENo: Injorme plelminar, etc., página 8 , Julio de I8S8.

Esta especie es bastante cercana de la precedente y más o menos de la misma talla, pero con algunos caracteres particulares que desde luego la distinguen de ella. La coraza es delgada como en el Hoplophorus pseudornatus. La figura central de cada placa es mucho más grande que las periféricas, pero éstas son también de tamaño mayor que en la generalidad de los Hoplophorus, todas bien delimitadas y en el centro de la coraza más angulosas todavía que en el Pseudornatus.

Las placas del centro de la coraza tienen un diámetro anteroposterior de 32 a 35 milimetros y un diámetro transverso de 18 a 20. La figura 
central es de gran tamaño, de 15 a 20 milimetros de diámetro, representando un poligono de aspecto general subcircular, de superficie lisa, apenas ligeramente puntiaguda, pero deprimida, aunque sin formar concavidad en el centro y con los bordes periféricos más elevados. Las figuras periféricas son por lo común en número de ocho, de tamaño muy desigual y con una disposición particular que permite distinguir con facilidad los restos de esta especie; generalmente hay tres figuras adelante y tres atrás de tamaño mayor y dos en el medio, una a cada lado, de tamaño mucho menor y alargadas de adelante hacia atrás. Todas estas figuras periféricas se distinguen por unirse con las figuritas opuestas de las placas contiguas, formando figuras de mayor tamaño y de formas distintas. Las figuras más pequeñas son las que se encuentran en el medio sobre los bordes laterales, siempre compuestas de dos mitades $y$ de una forma que, por lo general, es rectangular. Las mayores se encuentran en los ángulos y están formadas por tres figuritas periféricas de aspecto triangular, pertenecientes a tres placas cont guas, formando por su reunión grandes figuras poligonales que alcanzan a veces hasta 12 centimetros de diámetro y son casi siempre un poco deprimidas en el centro. Esta disposición es tal que entre cada dos figuras centrales no se interpone más que una sola figura intermedia formada por la unión de dos o tres figuras periféricas, lo que le da a esta parte de la coraza un aspecto particular que no permite confundirla con la parte correspondiente de ninguna otra especie. La superficie de las figuras periféricas es lisa y ur poco puntuada como las figuras centrales. Los surcos que separan a todas estas figuras son muy angostos pero bien acentuados.

La forma de las placas y su tamaño se conserva casi igual cerca de los bordes laterales, pero la disposición de la escultura externa cambia por completo. Estas placas de aspecto general subcuadrado o rectangular tienen unos 3 centimetros de largo por entre 20 y 25 milimetros de ancho.

La figura central es proporcionalmente mucho mayor, ocupando la mayor parte de la superficie de cada placa, pero aunque asimismo es poligonal, su contorno se ha cambiado de subcircular en elíptico; cada una de estas figuras tiene de 20 a 22 milímetros de diámetro mayor por de 16 a 18 de diámetro transverso, con la superficie puntuada o plana y en algunas un poco deprimida.

Las figuras periféricas son en número de 7 a 9 , pero mucho más fequeñas que en las placas del centro de la coraza y sobre todo muy angostas, representando casi segmentos de círculo y sin que se pongan en contacto las opuestas de las placas contiguas, de manera que esta farte de la coraza presenta un aspecto muy distinto de la región central, existiendo siempre entre dos figuras centrales dos figuras periféricas separadas. 
Procedencia: - He recogido los restos de esta especie en Monte Hermoso, a 60 kilómetros de Bahía Blanca.

Horizonte:- Piso hermósico de la formación araucana (mioceno superior).

HoplopHorus PERFEctus 11. Gervais y Ameghino

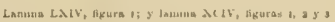

II. Gervats y $\Lambda$ Megrixo: Los mamiferos fúsiles, etc., página I64, 1880 .

Esta especie era de tamaño relativamente considerable. Las placas del centro de la coraza son poligonales, afectando en sus contornos una disposición subcircular, con un diámetro de 4 centímetros más o menos y un espesor de 16 a 18 milímetros. Las figuras centrales de cada placa son muy grandes; y aunque de contorno poligonal, presentan una forma general subcircular con un diámetro de 22 a 25 milímetros, un poco deprimidas en el centro, pero de superficie casi completamente lisa, mostrando solamente pequeñas puntuaciones. Cada una de estas figuras centrales está rodeada por de 11 a 13 figuras periféricas mucho más pequeñas, de tamaño menos desigual que en la generalidad de las especies, de contorno poligonal y anguloso, todas bien delimitadas, de superficie plana y lisa como la figura central, aunque las mayores son a veces un poco deprimidas; estas figuritas tienen un diámetro de 5 a 8 milímetros y todas se presentan sobre un mismo plano entre sí y con la figura central. Las figuras periféricas de cada placa no se unen con las opuestas de las placas contiguas, quedando, al contrario, bien separadas, de manera que entre cada dos figuras centrales hay siempre dos filas de figuras periféricas bien acentuadas.

Los surcos que separan a todas estas figuras son relativamente anchos, pero poco profundos; y las perforaciones en el fondo del surco que rodea a la figura central son numerosas, pero muy pequeñas.

El tubo caudal es de tamaño considerable, un poco más largo que el del Hoplophorus ornatus y casi otro tanto más grueso. El ejemplar de quz dispongo es incompleto adelante, teniendo la parte existente 43 centímetros de largo; pero le faltan unas dos o tres filas transversales, de manera que el tubo completo tuvo seguramente más de 45 centímetros de largo. En la parte anterior rota tiene 35 centímetros de circunferencia y debía tener aproximadamente unos 40 centímetros en el borde ant:rior; tiene 31 centímetros hacia la mitad de su largo y 27 en su extremidad posterior, en el espacio comprendido entre la última y la antepenúltima figura lateral. Es fuertemente deprimido en todo su largo, particularmente en su parte superior, regularmente encorvado hacia arriba y su tamaño disminuye gradualmente de adelante hacia atrás. Tiene 113 milímetros de diámetro transverso en el borde anterior de la parte exis- 
tente, 109 milímetros hacia la mitad de su largo y 95 milimetros en la parte posterior en el espacio comprendido entre las figuras laterales última y penúltima.

Sobre los costados sólo hay tres grandes verrugas laterales elipticas a cada lado, la segunda o penúltima fuertemente deprimida en sentido transversal, afectando la forma de una silla de montar. La última figura lateral tiene 80 milimetros de largo y 59 de ancho, sin tener en cuenta la curva; la penúltima tiene 71 milimetros de largo y 50 de ancho; y la antepenúltima, sólo 56 milímetros de largo y 41 de ancho, siguiendo a esta figura hacia adelante un par de figuras elípticas más pequeñas colocadas en fila transversal.

La escultura está formada en la cara superior por grandes figuras elípticas sobre los lados y figuras circulares o subcirculares mucho más péqueñas en el centro, todas muy elevadas pero a menudo un poco de. primidas en el medio. En la extremidad posterior, en el espacio triangu lar limitado por los dos tubérculos o verrugas laterales, hay tres figuras, una posterior impar y dos anteriores un poco más grandes, precedidas adelante por un par de grandes figuras ovoides de unos 4 centímetros de diámetro, de superficie lisa, levantadas en la periferia y fuertemente cxcavadas en el medio. Todas estas figuras están rodeadas por una fila de figuras periféricas pequeñas, planas y angulosas, pero bien determinadas.

La cara inferior está adornada con figuras elípticas, de superficie casi lisa, muy próximas unas a otras, con figuras periféricas rudimentarias y completamente ausentes en la parte media longitudinal. El tamaño de estas figuras resulta hacia atrás mucho más considerable, ocupando de a dos en filas transversales el espacio comprendido entre las dos iltimas verrugas laterales, terminando por una figura impar mucho más ผequeña.

Estas figuras de la parte posterior son de contorno más irregular, fuertemente deprimidas en el centro, separadas por pequeños surcos sin vestigios de figuras periféricas pequeñas.

Procedencia:- He recogido los restos de esta especie en el fondo del cauce del rio Luján, en la Villa del mismo nombre; y en las toscas del fondo del río de la Plata, en el municipio de Buenos Aires.

Horizonte:- Piso belgranense y piso ensenadense de la formación pampeana (plioceno inferior).

IIOPLOPHORUS IVIDENS, $n$. $s p$.

Lamina LXXV, figura a; $y$ lamins LXXXIV, fgurso 2 y

Esta especie, a juzgar por los fragmentos de coraza de que dispongo, ha tenido una talla mucho mayor que el Hoplophorus ornatus, compa- 
rable a la del Hoplophorls cordubensis, al que se acerca por el gran espesor de las placas, pero se distingue de él por la escultura externa bien definida y parecida a la del Hoplophorus ornatus. El fragmento más importante de que dispongo es un trozo de la parte posterior comprendiendo algunas de las placas marginales de la apertura caudal y placas de las filas que siguen hacia adelante.

Las placas marginales son de forma casi cuadrada, de $0^{\mathrm{m}} 037$ de largo por $0^{\mathrm{m}} 027$ a $0^{\mathrm{m}} 032$ de ancho; cada placa tiene una gran figura elíptiz. de 27 milimetros de diámetro mayor, con su eje mayor dirigido de adelante hacia atrás y deprimida longitudinalmente en el centro siguiendo - la misma dirección; esta figura forma hacia atrás el borde mismo de la coraza, pero adelante está seguida de una fila transversal de figuras periféricas, dispuestas en arco de círculo, en número de 5 a 6 , de 5 a 8 milímetros de diámetro, separadas por surcos muy angostos pero bien delimitados.

Las placas de las filas que siguen inmediatamente hacia adelante, son todavía más cuadradas, de unos tres a tres centímetros y medio por cada lado; cada placa tiene una figura elíptica de 20 a 26 milímetros de diá. metro mayor, con su eje mayor dispuesto no longitudinalmente, sino transversalmente, fuertemente excavada en el centro, donde forma una concavidad muy pronunciada, presentando una superficie casi lisa, apenas un poco ligeramente puntuada; estas figuras centrales tienen alrededor una fila de figuritas periféricas mucho más pequeñas, en número de 11 a 12 , de superficie plana y casi lisa y separadas por surcos bien marcados. El espesor de todas estas placas, es, término medio, de $24 \mathrm{mi}$ limetros, grueso considerable que distingue fácilmente a la especie de todas las demás conocidas del mismo género.

Atribuyo a esta especie, aunque con las reservas del caso, el tubo caudal que acompaña a la coraza del Glyptodon clavipes del Museo del Colegio de Cirujanos de Londres, pues por su tamaño relativamente considerable corresponde muy bien con las dimensiones de las placas de la coraza de esta especie. Este tubo, según Owen, tiene 457 milimetros de largo, es casi circular en la base y resulta algo deprimido en la extremidad posterior. Todo el tubo es un poco ligeramente encorvado hacia arriba. Según los dibujos de Owen, reproducidos por Nodot, cada una de las filas de placas laterales, parece componerse de seis placas o figuras elípticas cuyo tamaño aumenta de adelante haciu atrás, siendo las dos últimas de un tamaño relativamente considerable. L.a última placa de cada lado es muy convexa, de 89 milímetros de largo : 76 milimetros de ancho. La penúltima placa lateral de cada lado, un foco menor que la última, no es convexa sino cóncava, pero con la depresión no en sentido longitudinal, sino en sentido transversal, de arriba habia abajo. Las placas intermedias que forman las caras superior e 
inferior, son entre las dos últimas grandes figuras laterales de cada lado, en corto número tanto arriba como abajo, cada placa con una figura eliptica mayor. rodeada por una fila de figuritas periféricas pequeñas. De estas figuras elipticas mayores hay en la cara superior una sola, aislada en la extremidad posterior entre el par de placas laterales terminales, dos en fila transversal regular al nivel del espacio compren. dido entre las placas laterales última y penúltima de cada lado y tres más pequeñas y dispuestas en serie transversal irregular entre el penúltimo par de placas laterales. En la cara inferior hay una figura terminal aislada como en la cara superior y luego hacia adelante dos filas transversales de dos figuras cada una. La circunferencia de la base de la cola es de 355 milimetros, pero cerca de la extremidad, en el intervalo entre la última y la penúltima placa laterales sólo tiene 254 milímetros de circunferencia.

Procedencia:- Los restos de esta especie proceden de Santa Cruz de la Sierra, en Bolivia; y de la provincia Buenos Aires, en la República Argentina.

Horizonte:- Formación pampeana.

IIorLOFIORLS CORDUBENSIS Ameghino

Lemina LVib, Hguras y

Amegnino: Ráridas diagnosis de mamiferos fosiles nueros, ete., página 16 , numero 25 , lebrero de 1888 .

Esta especie parece haber sido, cuando menos aparentemente, de tamaño mayor y más robusta que las demás y presenta caracteres intermedios entre las demás especies del género Hoplophorus y los representantes del género Glyptodon. Las placas son relativamente pequeñas pero muy gruesas, con un corto número de figuras periféricas $\mathrm{y}$ de superficie externa muy rugosa. Las placas del centro de la coraza soil de figura subcuadrada o rectangular de 35 a 38 milimetros de largo por 28 a 30 de ancho y 16 a 17 de grueso. Cada placa tiene una figura central circular de 18 a 20 milímetros de diámetro, de superficie plana, pero fuertemente rugosa y con algunas fuertes puntuaciones. Alrededor de esta figura central hay 7 u 8 figuras periféricas mucho más pequeñas y de tamaño desigual, las más grandes de las cuales no tienen más de 7 a 8 milímetros de diámetro; estas figuras son de contornos irregulares y mal definidos y de superficie áspera y rugosa con fuertes puntuaciones. Los surcos que separan a las figuras son muy anchos, poco profundos, de fondo igualmente áspero y de contornos mal definidos, lo que acerca notablemente esta especie al género Glyptodon. Las figuras peri- 
féricas más pequeñas de las placas contiguas se unen a menudo entro sí con los lados laterales.

Las placas se hacen más pequeñas y más definitivamente rectangulares en los bordes laterales, pero conservan el mismo espesor, y a veces hasta mayor, que en el centro de la coraza. La figura central de cada placa se hace proporcionalmente más grande y adquiere una forma fuertemente elíptica, aunque conservando su superficie igualmente rugosa. Las figuras periféricas han desaparecido o son rudimentarias en los bordes laterales conservándose sólo delante y atrás, aunque también en parte atrofiadas, sin formas definidas, mal delimitadas y de superficie muy áspera. Los surcos que separan a estas figuras son poco.acantuados, aunque anchos y rugosos.

Procedencia: - Los restos de esta especie han sido descubiertos por Francisco P. Moreno en los valles de la sierra de Córdoba.

Horizonte:- Piso puelche de la formación araucana (miozeno superior).

IIOPLOPHORES PAKANENSIS Ameghino

Lamina LXIS, figura a

AmentiNo: «Boletin de la . Icademia Nacional de Ciencias», tomo V, página i $6,{ }_{1} 88_{3}$.

Fundé esta especie en un fragmento bastante considerable de coraza, proveniente de hacia el centro de la región dorsal, lo que permite determinar sus caracteres con bastante precisión. Este trozo indica una especie del tamaño del Hoplophorus ornatus, del cual se distingue por el dibujo de la escultura externa de las placas; la figura central de cada placa es relativamente de tamaño más considerable y las figuras periféricas son más pequeñas y en mayor número que en las demás especies. El espesor de la coraza en este fragmento es de sólo 11 milimetros y el diámetro de las placas de unos 3 centímetros. Cada placa presenta en su superficie externa una gran figura circular de unos 21 a 22 milimetros de diámetro, de superficie casi plana, ligeramente convexa y un poco rugosa; cada figura central está rodeada de 12 a 13 figuritas pequeñas de forma pentagonal irregular, pero de superficie igualmente un poco rugosa y separadas entre sí y de la figura central por surcos que, aunque angostos, son bien delimitados; estas figuras periféricas tienen un diámetro que varía entre 4 y 6 milimetros.

Después he podido examinar varios otros restos del mismo animal, particularmente un trozo de coraza de cerca del borde, formado por rueve placas dispuestas en dos filas, una de cinco y otra de cuatro. Desgraciadamente el trozo está envuelto en arenisca dura que en parte cubre la escultura externa, rellenando todos los huecos, ocultando asi a la 
vista una parte de los surcos y todos los agujeros que se encuentran en el fondo de éstos.

Las placas son bastante parecidas a las correspondientes del Hoploihorus ornatus, de forma rectangular, con poca diferencia de 27 milímetros de largo, 20 de ancho y de 10 a 12 de espesor, cada una. La forma elípticocircular de unos 18 a 20 milímetros de diámetro, de superficie plana y ligeramente puntuada, rodeada por un surco angosto y bastante hondo, que conjuntamente con la figura central ocupa en el medio todo el ancho de la placa, de modo que sólo se presentan figuras periféricas en las extremidades anterior y posterior, en número de tres a suatro en cada una.

Estas figuras periféricas son siempre bastante más grandes en una extremidad que en la otra, separadas por surcos angostos y bastante bajos. La superficie de las figuras perıféricas es también poco rugosa y casi lisa.

Una placa aislada, que por la textura del hueso proviene de un individuo adulto y del centro de la coraza, se encuentra perfectamente intacta y libre de toda incrustación, de manera que permite determinar con toda exactitud sus caracteres específicos.

Es de forma exagonal, con un diámetro mayor de 36 milimetros, 30 milimetros de diámetro transverso y 10 milímetros de grueso. El. centro de la cara externa está ocupado por una gran figura circular, un poco elíptica, de 21 milimetros de diámetro, casi plana y lisa, con un considerable número de pequeños agujeritos, que no forman asperosidades en la superficie. Alrededor de esta figura central, hay catorce ؟iguras más pequeñas, más o menos de la misma forma y tamaño, bien delimitadas e igualmente de superficie plana y no rugosa. Estas arealitas periféricas están separadas de la gran figura central por un surco bastante ancho pero poco profundo, del cual salen surcos radiales que se dirigen a la periferia separando a las figuras periféricas entre sí. En el punto de partida de cada surco radial del surco central hay un agujero circular. no muy grande pero profundo que se pierde en el interior de la placa, de modo que en el surco central que rodea a la gran figura interna hay catorce de estos agujeritos, todos con la misma colocación indicada.

Procedencia: - Estos restos han sido descubiertos por el profesor Scalabrini en las barrancas de los alrededores de la ciudad del Paraná y pertenecen al Museo provincial de Entre Ríos.

Horizonte: - Piso mesopotámico de la formación patagónica (oligoceno inferior). 
Hoplophoris pumilio. BurMeIster: \&Anales del Museo P'úblico de Buenos Aires», tomo II, páginas 222 y 224. - Idem: Description physique, etc., tomo 1II, página 413.

Glyptodon pumilio. IUrmerster: «Anales del Museo Público de Buenos Aires», tomo I, páginas $77 \mathrm{y} 204$.

Esta especie, probablemente nominal, fué establecida por Burmeister sobre parte de una mandíbula inferior y es mencionada en la «Description physique de la République Argentine», del mismo autor, en los siguientes térninos: «La mitad izquierda de una mandíbula inferior muy pequeña, conteniendo los alvéolos de las seis muelas posteriores, conservada en nuestro Museo, me ha servido de base para el tipo de lina especie particular, a causa de su pequeñez y de la conformación de los dientes. Comparando este fragmento con la mandíbula completa del Hoplophorus ornatus, encuentro que la rama horizontal del Hoplophorus pumilio es más baja y sin embargo más gruesa que en la otra especie. El alto de ésta con los dientes es de 3 pulgadas y en el Hoplophorus Fumilio es apenas de $21 / 2$ pulgadas. La longitud de las seis muelas que quedan es de $41 / 2$ pulgadas en el Hoplophorus pumilio y de $53 / 4$ en el Hoplophortus ornatus. En fin, los lóbulos de cada muela son un poco más gruesos en el Hoplophorus pumilio que en el Hoplophorus ornatus. Por último, la sínfisis de la barba es mucho más corta en el Hoplophorus pumilio, pues ella no pasa hacia atrás más allá de la segunda muela, y en el Hoplophorus ornatus llega hasta más allá de la tercera. Me parece, a causa de esas diferencias, que el Hoplophorus pumilio era un animal más pequeño, pero de una conformación más robusta que la otra especie con la que lo he comparado».

Esta mandibula proviene sin duda de una de las especies enumeradas, representadas por restos de coraza, pero no es posible determinar a cuál de ellas, hasta que no se encuentre una pieza idéntica acompañada de fragmentos de coraza.

\section{Procedencia:- Provincia Buenos Aires.}

Horizonte:-Formación pampeana (?).

HOPLOPHORUS VERUS, $n$. $s p$.

Lamina LXIX, Agura is

Esta especie se distingue por las placas del centro de la coraza, de contorno poligonal regular, no oblongas como en la mayoría de las especies, con un diámetro de cerca de 4 centímetros y 12 milímetros de espesor. La cara externa presenta una figura central de gran tamaño, de contorno circular, de 18 milímetros de diámetro, completamente plana y de superficie casi lisa. Esta figura central está rodeada por una fila 
de figuras periféricas pequeñas, en número de nueve, de tamaño desigual, todas de superficie plana y casi lisa, separadas entre si por surcos bien marcados pero poco profundos. En el surco que rodea la figura central existe un cierto número de perforaciones.

Las diferencias que distinguen a esta especie son muy difíciles de explicar por medio de palabras, pero saltan inmediatamente a la vista cuando se examinan las piezas originales.

Procedencia: Barrancas de los alrededores de la ciudad del Paraná.

Horizonte: Piso mesopotámico de la formación patagónica (oligoceno inferior).

IJopt,opllores (?) L,YuKkERi, n, sp

\section{LAmitun LXXXW, feure a}

Hoplophorts (?), sp. c. LrDEkKer: Catal. of the Fossil Manm, in the British Mnscum, parte $V$, página 13.3, figura 2.4, 1887.

Esta especie está representada en el Museo Británico por la extremidad de un tubo caudal y un trozo de la parte anterior de la coraza, caracterizándola Lydekker en los siguientes términos:

The following specimens indicate a species apparently nearly or quite as large as Glyptodon reticulatus. The large terminal disks on the latera! surfaces of the tube of the caudal sheath are separited from one another ly a row of small disks, and are followed laterally by a series of enlarged disks, which decrease gradually in size as they reced from the tip. The disks on the dorsal aspect of the tube are subcirculur in shape, fre. quently concave, and present great variation in size, but those on th:" ventral surface are more regular in this respect. The scutes of the fragment of carapace are oblong, with the grooves very indistinctly marked. and with a series of hair-pits in the groove surraunding the central disk.

Although the present form is aparently distinct from all described species, with the exception of the so-called Glyptodon clavipes of Burricister, the writer thinks it inexpedient at present to assign to it a distinct specific name.

The extremity of the terminal tube of the caudal sheath; from the Pleist'cene of Uruguay. This specimen, although of considerable larger size, cpparently agrees very closely with the terminal tube figured by Bur-

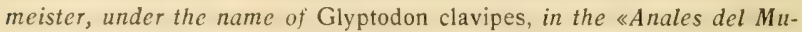
seo de Buenos Aires», vol. II, pl. XL, figs. 7, 8, showing the irregular arrangement of the disks on the ventral surface (fig. 7), and the large sub-circular lateral ones (fig. 8), which decrease regulary in size from the hindmost one. In the terminal tube of a caudal sheath referred by Owen to Glyptodon clavipes, but which, as already mentioned, probably 
belongs to Hoplophorus, the lateral disks are oval, and the two last ar, riluch larger than the others, while on the ventral and dorsal aspects the disks are less numerous and of a decidedly oval form. The upper surface of the present specimen is represented in the accompanying woodcut, where the form of the disks is wel shown. Its transverse diameter ist $0^{m} 144$, against $0^{m} 075$ in the corresponding element of Hoplophorus ornatus.

Fragment from the anterior region of a carapace, showing nine scutes, which agrees in relative size with the preceding specimen. The scutes are nearly smooth, their central disks being mainly defined by a circle of hair-pits, and the peripheral ones scarcely differentiated. The scutes form oblong hexagons, and in this respect, as well as in the absence of rugosity, agree with those of Hoplophorus ornatus and differ from those of Glyptodon. Their longer diameter is $0^{m} 052$, and their thickness $0^{m} 031$.

Lydekker no da nombre a este animal por creer que puede ser idéntico al denominado por Burmeister Glyptodon clavipes, ignorando siı duda çue el dibujo de esta especie dado por el ilustre Director del Museo de Puenos Aires, es, como el mismo autor lo reconoce, completamente fantástico y el tubo caudal es del Hoplophorus ornatıs y por cuanto concierne a sus verdaderas proporciones incorrectamente dibujado.

La extremidad de la cola descripta por Lydekker, de la que acompañ t un grabado que he reproducido en la lámina LXXXIV, figura 8, es indudablemente muy parecida a la de las especies del género Hoplophorus, pero sobrepasa en más del doble el tamaño de los más grandes tubos dz Hoplophorus que hasta ahora me son conocidos; y constituye con toda seguridad una especie distinta de las descriptas hasta el dia, y que quizá ni entra en el género Hoplophorus, pues su enorme tamaño no concuerda con el de las especies de este género, todas ellas de una conformación más delgada que las de los verdaderos Gliptodontes.

Procedencia: - Las piezas descriptas por Lydekker proceden de la Banda Oriental; pero dada la vecindad de ambas regiones y la gran uniformidad que en ellas presenta tanto la fauna actual como la extinguida, es casi seguro que también habitó en la República Argentina.

Horizonte:-Formación pampeana.

Hoplopitorus BERCI, $n . s p$.

Latnona xi, hzuras i, 2 y.

Esta especie me es conocida por tubos caudales de una conformación particular, que se desvía del tipo común de una manera más notabl z todavía que el del Hoplophorus Heusseri. Desgraciadamente por el momento no dispongo más que de la extremidad posterior de uno de estos 
tubos, aunque basta para dar una idea de la conformación particular de la especie.

El tubo entero parece haber sido casi del mismo ancho en todo su largo, pero es muy aplastado en su cara superior, convexo en la inferior y casi recto, arqueado hacia arriba y de una manera poco sensible, tan sólo en su parte posterior.

El trozo de la parte posterior de que dispongo tiene 20 centímetros de largo, que es más o menos la mitad del largo total del tubo entero. Su ancho en la parte anterior, donde está roto, es de unos 9 centímetros, conservándose casi igual hasta el principio del último par de figuras laterales en donde recién empieza a angostarse rápidamente para formar la punta.

La extremidad terminal está formada, como en las demás especies, por un par de grandes figuras laterales, elipticas, convexas y de superficie casi lisa, de 75 milímetros de largo por 55 de ancho (naturalmente, como en todo los demás casos, sin tomar en cuenta la curvatura).

La figura que sigue hacia adelante a cada lado, o sea el penúltimo par de figuras laterales, son de tamaño relativamente muy pequeño, muy alargadas y muy angostas, bastante elevadas pero casi planas; tienen 59 milimetros de largo y sólo 35 de ancho.

Hacia adelante falta la figura elíptica lateral de cada lado que constituye el antepenúltimo par, o está colocada más adelante, interponiéndose entre ésta y la penúltima, dos figuras elipticas más pequeñas, separadas por dos filas de tubérculos periféricos pequeños colocados precisamente en el punto por donde deberia pasar el eje longitudinal de la antepenúltima figura lateral si ocupara el mismo lugar que en todas las cremás especies del mismo género que me son conocidas, singularidad que demuestra que realmente se trata de una especie bien distinta. Sigue a estas dos figuras hacia adelante una figura elíptica única, de tamaño no muy grande, pero que no existe entera en ninguno de los dos lados; esta es la que parece corresponder al antepenúltimo par de figuras laterales de los demás Hoplophorus.

La cara superior deprimida de la parte existente del tubo está adornada con figuras elevadas, casi lisas y deprimidas en el centro, pero de forma y tamaño muy diferente; sobre la línea media longitudinal son figuras relativamente pequeñas y circulares o subcirculares; sobre los lados son figuras doble o triple más grandes y de contorno elíptico u ovoide. Todas estas figuras mayores están rodeadas por una fila de figuritas periféricas muy pequeñas y de una forma particular, que parece exclusiva de esta especie, pues en vez de ser planas, poligonales y angulosas como en los demás Hoplophorus, son de tamaño más pequeño, circulares, elevadas y muy convexas, estando separadas unas de otras no por surcos angostos y profundos como en las otras especies, 
sino por depresiones anchas en el fondo de las cuales se levantan en forma de pequeños tubérculos convexos.

Las figuras principales son de tamaño considerable en la cara inferio: y todas elípticas, de superficie lisa y casi plana y separadas unas de otras por filas de tubérculos periféricos pequeños, planos y bien desarrollados a los lados, pero rudimentarios o poco aparentes en el medio.

Esta pieza es propiedad del Museo provincial de Entre Rios, en el Paraná.

Dedico la especie al doctor Carlos Berg, catedrático de Zoología en la Universidad de Buenos Aires.

Procedencia:- El ejemplar mencionado procede de los valles de la sierra de Córdoba, pero se han encontrado iguales en distintos puntos de la provincia Buenos Aires.

Horizonte:-Formación pampeana.

HOPLOPHOKUS MEUSSER, n. sp.

Lamina t.xxxy, figiras i, a y

Esta especie me es conocida por un tubo caudal casi completo, al cual sólo le falta un pequeño trozo de la parte proximal; e indica una especie de tamaño considerable, probablemente bastante mayor que el del $\mathrm{Ho}$ plophorus ornatus.

Este tubo se distingue de los demás por ser un poco más cilíndrico en casi toda su extensión, por ser fuertemente curvado hacia arriba en su mitad posterior y por presentar un ancho casi uniforme en todo su largo, lo que le da una forma muy característica, completamente distinta de la de los tubos de todas las demás especies que me son conocidas.

La parte existente del tubo tiene 41 centimetros de largo, pero adelante le falta más de 4 centímetros, de manera que el tubo completo tuvo por lo menos unos 45 centímetros de largo. En su parte anterior es casi completamente cilíndrico, pero hacia los tres cuartos de su longitud es ligeramente deprimido en su cara superior, mientras que la inferior permanece convexa en toda su extensión.

La circunferencia del tubo caudal es de 286 milímetros en la región anterior de la parte existente, de 275 milimetros hacia el medio y de 263 milimetros en el medio del penúltimo par de placas elípticas laterales.

El diámetro transverso del tubo es, en la parte anterior, de 95 mili. metros, cuyo ancho se conserva igual hasta entre el antepenúltimo par de figuras laterales, disminuyendo apenas un poco entre el penúltimo par, donde tiene 91 milímetros de diámetro transverso, disminuyendo luego rápidamente hasta formar la punta. Este ancho uniforme en casi todo su largo y la fuerte curvatura hacia arriba de la parte posterior 
constituyen el distintivo más característico de esta especie, pero existen también particularidades bien visibles en la disposición de la escultura que la adornan.

Las figuras laterales que se siguen en fila ininterrumpida de adelante hacia atrás, son en número de seis, todas elípticas y de superficie casi lisa, pero muy pequeñas en proporción del tamaño del tubo; todas, a excepción de la última de cada lado, son un poco deprimidas en sentido transversal en el medio, pero de una manera poco acentuada. La antepenúltima figura tiene 50 milímetros de largo y 36 de ancho, la penúltina 59 milímetros de largo y 42 de ancho y la última 66 milímetros de largo por 53 de ancho. Entre la última y la penúltima y entre ésta y la antepenúltima no hay más que una sola fila de figuras periféricas pequeñas.

La cara superior está adornada con figuras circulares o subcirculares muy elevadas pero más o menos deprimidas en el centro y de tamaño muy desigual; unas más pequeñas y más circulares están colocadas sobre la linea longitudinal central y las otras de tamaño bastante mayor y más ovoides, están colocadas sobre los costados al lado de las figuras laterales mayores. Todas estas figuras están rodeadas por una fila de figuritas poligonales y angulosas más pequeñas, separadas por surcos bien marcados, pero casi siempre un poco más bajas que los bordes de las figuras mayores o centrales. Debido a este tamaño desigual las figuras no están dispuestas por filas transversales regulares, sino alternadas, colocándose cada figura más pequeña enfrente del espacio que separa a dos de las más grandes.

La cara inferior es muy convexa en toda su longitud e igualmente vuelta hacia arriba en su parte posterior. Las figuras que la adornan son también de tamaño desigual, pero no circulares o subcirculares sino fuertemente elípticas, todas con su eje mayor dirigido de adelante hacia atrás, no tan elevadas como las de la cara superior, de superficie casi lisa pero un poco deprimidas en el centro. Las figuras periféricas que rodean a esas figuras mayores o centrales son generalmente muy pequeñas, poligonales y poco acentuadas, y casi desaparecen sobre la línea media longitudinal. En la extremidad posterior las figuras principales son de tamaño mayor pero de contorno más irregular y separadas unas de otras por surcos anchos bien acentuados, sin interposición de la fila de figuras periféricas que han desaparecido ahí, con excepción de una que otra de tamaño muy pequeño.

Esta pieza es propiedad del doctor Christian Heusser, que me la ha facilitado para su estudio y a quien dedico la especie.

Procedencia:- Municipio de Buenos Aires.

Horizonte:- Formación pampeana. 
Esta especie sólo me es conocida por un tubo caudal incompleto en su parte anterior, dibujado por Lydekker («Catalogue of the Fossil Mammalia», etc., tomo $\mathrm{V}$, página 132 , figura 23 ) sin darle nombre específics particular. No puedo identificar esta pieza con ninguna de las especies que me son conocidas y constituyo, por consiguiente, con ella una nueva especie, a la cual designo con el nombre de Hoplophorus Clarazianus, en honor del señor Jorge Claraz, que, en colaboración con el doctor Heusser, es autor del primer ensayo geognóstico físico sobre la provincia Buenos Aires. Este tubo es más o menos del mismo tamaño que el del Hoplo-. phorus ornatus, pero proporcionalmente es más robusto, disminuyendo menos de adelante hacia atrás y por consiguiente con su extremidad posterior proporcionalmente más ancha. Según la reducción de la figura, tiene: entre el penúltimo par de figuras laterales, 88 milímetros de diámetro transverso; y en su parte anterior, más o menos a la distancia de un cuarto del borde proximal, 110 milímetros. Las figuras mayores de la cara superior son numerosas, subelípticas, de tamaño más igual que en la generalidad de las especies y dispuestas en filas transversales regulares, en número de 5 a 6 en cada fila en la mayor parte de su extensión. Las figuras laterales más grandes son en número de cuatro por cada lado. y el último par de gran tamaño. Las del penúltimo par son convexas en el medio en vez de excavadas perpendicularmente; y en el espacio comprendido entre la última y la penúltima no existe la fila de figuras periféricas más pequeñas que se encuentran en las otras especies, carácter particular que permite distinguirla con facilidad.

Procedencia: - Esta pieza se conserva en el Museo Britániço, donada por el señor W. G. Lettsom, como procedente de los alrededores de Montevideo; pero es indudable que la especie debe haber existido igualmente en la República Argentina.

Horizonte:-Formación pampeana.

IIOPLOPHORUS SCROBICULATUS Burmeister Laràtua LXXXY, f̈gura *

Esta especie me es conocida por algunos pequeños trozos de coraza que he recogido en las excavaciones del puerto de La Plata, pero existe una coraza casi intacta en el Museo Nacional, que lleva el nombre de Hoplophorus scrobiculatus Burmeister, aunque creo no ha sido publicada. Y si lo ha sido, no ha llegado a mi conocimiento. Segregado el grupo de especies que constituyen el género Lomaphorus, esta es la 
especie de Hoplophorus más pequeña que conozco y presenta caracteres de transición a las especies del género Lomaphorus. Las placas de la coraza son oblongocuadrangulares, término medio de 3 centímetros de diámetro anteroposterior por 24 milímetros de ancho y sólo 6 a 7 milímetros de espesor. En el centro y adelante esta forma oblonga de las placas es más acentuada, ostentando cada placa una figura eliptica, un poco deprimida en el centro, rodeada por ocho o más figuras periféricas no muy bien delimitadas, de superficie casi plana y separadas por surcos anchos y poco profundos. En la parte posterior de la coraza la figura central de cada placa se hace más elevada, con bordes salientes, pero es fuertemente deprimida en el centro, mientras que las figuras periféricas concluyen por desaparecer, reemplazadas por una zona rugosa un poco radiada.

La coraza existente en el Museo de Buenos Aires está acompañada de un tubo caudal que, visto su tamaño sumamente pequeño, es probable provenga de esta especie.

El tamaño de este tubo disminuye fuertemente de adelante hacia atrás, presentando al fin de la penúltima figura lateral de gran tamaño un diámetro transverso que no debe exceder de 6 centímetros. Las figuras mayores de la cara dorsal o superior son generalmente ovales, convexas, de tamaño desigual y dispuestas en filas regulares. Las figuras mayores de la cara inferior son fuertemente elípticas. Las figuras elípticas laterales, particularmente las últimas, son de un gran tamaño, que, gradualmente, disminuye hacia atrás; y la penúltima y antepenúltima son un poco deprimidas en sentido transversal, afectando una forma parecida a la de una silla de montar.

Procedencia:- He recogido restos de esta especie en las excavaciones del puerto de La Plata; y en las toscas del fondo del río de la Flata, en el municipio de Buenos Aires.

Horizonte:- Piso ensenadense de la formación pampeana.

IIOPLOPHORUS MigoYanus, n. sp.

Lomua LXXxis, figuras is as ?

Esta especie me es conocida por el tubo caudal en varios ejemplares más o menos completos, presentando una forma completamente distinta de la que muestra en las otras especies, pues es más corto y más grueso, del mismo ancho en casi toda su longitud, muy aplastado en su cara superior, convexo en la inferior y recto o casi completamente recto.

El tubo completo tiene sólo 40 centímetros de largo y 97 milimetros de ancho en casi toda su extensión. con excepción de su borde proximal (en donde alcanza unos pocos milímetros más) y de su extremidad 
distal formada por el par de grandes verrugas elipticas laterales en donde disminuye gradualmente hacia atrás.

El par de figuras o verrugas terminales son sumamente grandes, muy convexas y muy extendidas sobre las dos caras superior e inferior, en donde sólo están separadas por un surco angosto y profundo, sin tubérculos intermedios en la cara inferior, pero con una hilera de tubérculos muy pequeños en la superior.

Visto el tubo de lado, presenta en su mitad posterior una fila de sólo tres verrugas laterales elípticas, cuyo tamaño aumenta de la anterior a la posterior. La posterior o terminal ya mencionada, muy convexa y de superficie rugosa, tiene 87 milímetros de largo y 67 milímetros de diámetro transverso máximo sin tener en cuenta la curva. La penúltima figura lateral, mucho más pequeña, de superficie más lisa y un poco deprimida en sentido transversal, tiene 62 milímetros de largo y 53 milí metros de diámetro transverso máximo. La antepenúltima figura, un poco más pequeña y más elíptica todavía, tiene 50 milímetros de largo por 40 milímetros de diámetro transverso máximo. Entre una y otra de estas tres figuras laterales, hay una sola fila de figuras periféricas muy pequeñas, alargadas y comprimidas.

Adelante de la antepenúltima verruga lateral, la fila longitudinal está interrumpida por la interposición de un par de figuras de la misma forma, pero más pequeñas y colocadas una junto a la otra en fila transversal; ambas tienen casi el mismo tamaño, de 38 milímetros de largo por 31 milímetros de ancho. Más adelante, en la parte anterior del tubo, adelante del par de verrugas mencionadas, sigue otra fila lateral de tres verrugas elípticas cuyo tamaño disminuye de la posterior a la anterior y forman como la continuación de la fila constituída por las tres verrugas laterales posteriores, que fuera interrumpida por la interposición del par de figuras dispuestas en serie transversal, ya mencionadas.

Visto por la cara superior, el tubo es muy deprimida y adornado con figuras centrales de contorno elipticoirregular, de tamaño muy desiguales, las posteriores y las laterales muy grandes y las que se encuentran en el medio mucho más pequeñas. Cada una de estas figuras centrales está rodeada por una fila de figuras periféricas bien determinadas y de contorno poligonal en la parte anterior, pero más pequeñas y en forma de tubérculos irregulares hacia atrás.

Las figuras no son de tamaño tan desigual en la cara inferior; son más regularmente elípticas y de tamaño mayor sobre la línea longitudinal media, con una fila de figuras periféricas bien determinadas, pero de tamaño desigual. Las figuras principales adquieren hacia atrás una forma irregular y su tamaño aumenta considerablemente, desapareciendo entre ellas las figuras periféricas o presentándose en estado rudimentario en algunos puntos. 
Dedico la especie al señor Julio Migoya, a quien debo la comunicación de varios fósiles interesantes.

Procedencia: - Distintos puntos de la provincia Buenos Aires.

Horizonte:- Piso bonaerense de la formación pampeana.

El número de especies de Hoplophorus enumeradas es verdadera. mente sorprendente; y como algunas sólo se conocen por trozos de coraza y otras únicamente por tubos caudales, podría creerse que muchas de ellas son nominales; mas no obstante, una breve reseña de los horizontes y localidades de que proceden basta para demostrar 10 contrario.

Seis especies: los Hoplophorus Meyeri, Hoplophorus ornatus, Hoplothurus scrobiculatus, Hoplophorus cvidens, Hoplophorus pseudornatus y Hoplophorus perfectus se conocen por la coraza y por los tubos caudales más o menos conmpletos, que con mayor o menor seguridad han sido referidos a las mencionadas especies, todas las cuales proceden de la formación pampeana.

Cinco especies son conocidas tan sólo por tubos caudales: los Hoplophorus Migoyanus, Hoplophorus Heusseri, Hoplophorus Lydekkeri, Hoplophorus Bergi y Hoplophorus Clarazianus; y las cinco proceden igualmente de la formación pampeana, de manera que con las precedentes constituyen indiscutiblemente once formas de colas distintas.

Quedan cuatro especies que sólo se conocen por fragmentos de coraza: Hoplphorus lineatus, Hoplophorus cordubensis, Hoplophorus paranensis y Hoplophorus verus, que son decididamente prepampeanas, pues faltan en la formación pampeana y no pueden por consiguiente identificarse con ninguna de las especies pampeanas que sólo son conocidas por tubos caudales.

Queda el Hoplophorus pumilio, que, siendo la única especie conocida tan sólo por la mandibula inferior, es más que probable que habrá más tarde que identificarla con alguna de las mencionadas especies pampeanas.

\section{LOMAPIIORUS, $n$ gen.}

Este género es bastante cercano de Hoplophorus, con el cual ha sido confundido hasta ahora, distinguiéndose de él sobre todo por la escultura externa de la coraza y la forma de la cola.

La coraza dorsal es delgada como en el Hoplophorus y compuesta de placas exagonales y pentagonales en el centro de la coraza, pero que adquieren una forma subcuadrada o rectangular en los planos y son siempre menos soldadas entre sí que en las especies del género Hoplo- 
phorus. Cada placa tiene una figura central, circular o subcircular, más o menos elevada y siempre deprimida o excavada en el centro; las figuras periféricas son poco acentuadas, rudimentarias, sin estar separadas por surcos bien marcados, pero presentando una superficie estriada por un cierto número de impresiones que desde el surco que rodea a la figura central se dirigen a la periferia. Las figuras periféricas faltan a menudo por completo, y se encuentran reemplazadas por una zona periférica bastante ancha, cubierta de impresiones radiales que van desde la figura central, o desde el surco que la limita, a los bordes periféricos.

La cola se compone de un cierto número de anillos movibles a los cuales sigue un tubo caudal cónicocilíndrico aplastado, por lo común más corto y más ancho que en el Hoplophorus, asimismo un poco encorvado hacia arriba, pero formado de placas trabadas entre sí por suturas más flojas; y cada placa con una sola figura central de contorno elíptico, sobre el lado externo, rodeada por una faja periférica más o menos ancha, de superficie rugosa o con impresiones radiales, pero sin vestigios de figuras periféricas. Todas esas placas están dispuestas en fajas transversales bien acentuadas. Sobre los lados laterales se encucntran las mismas grandes verrugas elípticas que en el género Hoplophorus, pero igualmente carecen de figuras periféricas, tal como sucede con las demás partes de la coraza. La extremidad del tubo es relativamente muy ancha y formada por un par de grandes tubérculos laterales, el último de cada lado, separados en su extremidad posterior por una fuerte hendedura vertical.

Casi todas las especies del género Lomaphorus son notablemente más pequeñas que las del género Hoplophorus.

LoMAPHoRUS imperfectus (H. Gervais y Ameghino) Ameghino

Lamana Litll, figurus i, a y s; y lamas Lx, figira 6

Hoplophorns imperfectus. II. Gervars y Axegrrmo: Los mamiferos fósiles de la América Meridional, página 192, 1880.

Esta es la especie más grande del género y aproximadamente ha tenids la talla del Hoplophorus ornatus. Las placas del centro de la coraza tienen un diámetro de 30 a 35 milímetros y de 12 a 15 milímetros de espesor. Cada placa tiene una figura central más o menos circular de 12 a 13 milímetros de diámetro, no más elevada que el resto de la superficie de la placa, pero fuertemente deprimida o excavada en el medio. El surco que limita a esa figura es poco acentuado, con impresiones distintas y de distancia en distancia con pequeñas perforaciones. Las figuras periféricas son en número de 8 a 9 , pero poco marcadas, pues los surcos radiales que las dividen son poco visibles, formados por un cierto número de impresiones radiales. La superficie de esta figura está igualmente 
cubierta de impresiones radiales que constantemente se dirigen de adentro hacia afuera contribuyendo a ocultar aún más la división en figuras distintas ya poco acentuadas. Todas las figuras periféricas se encuentran sobre un mismo plano entre sí y con los bordes de la figura central, pero la superficie de las placas es un poco más rugosa y áspera que en Hoplophorus ornatus y con puntuaciones mucho más perceptibles.

El tubo caudal tiene 42 centímetros de largo, 108 milimetros de ancho en su extremidad proximal y 65 milímetros en la distal; está formado por 14 filas transversales de placas, disminuyendo el número de placas de cađa fila de adelante hacia atrás. Cada placa ostenta en la cara externa una figura subelíptica de tamaño variable, en medio de una zona periférica con impresiones radiales más o menos acentuadas. Las grandes verrugas elípticas laterales empiezan a pronunciarse hacia la mitad del largo de la cola; y su tamaño aumenta gradualmente hasta la última de cada lado, que es dos veces mayor que la penúltima y mucho más prominente.

Procedencia:- He recogido restos de esta especie en diferentes puntos de las provincias Buenos Aires, Córdoba y Santa Fe.

Horizonte: Piso belgranense y piso ensenadense de la formación pampeana.

Lomapitorus compressus Ameghino

Latuina $L X \mid X$, agurs Is

Hoplophorus compressus. Amegrino: Catálogo de la sección de la proźnecia de Buenos Aires, etc., página 4t, 1882. - Idem: alsoletin de la Academia Nacional de Ciencias», $t . V$, página 32,1883 (nomen nudum).

Esta especie es de tamaño un poco menor que la precedente; y la coraza se compone de placas subcuadradas y más rectangulares en casi toda su extensión.

Las placas tienen de 25 a 40 milímetros de largo en el centro de ia coraza, de 20 a 23 milímetros de ancho y sólo de 7 a 9 milimetros de espesor, lo que es muy poco en proporción del tamaño de las placas. Cada placa tiene en la superficie externa una figura subcircular o subelíptica, según la región de la coraza, de un diámetro de 14 a 15 milímetros y fuertemente deprimida o excavada en el centro, pero de superficie completamente lisa, apenas ligeramente puntuada, lo que permite distinguirlas con facilidad de las del Lomaphorus imperfectus.

Las figuras periféricas son en numero de ocho, menos marcadas que en los Hoplophorus, pero un poco menos acentuadas que en Lomaphorus imperfectus y de superficie lisa un poco puntuada. Los surcos no son muy perceptibles, con excepción del que rodea a la figura central, el cual 
muestra en su fondo y en la posición de costumbre, numerosas perforaciones bien visibles y de tamaño relativamente notable.

Las placas adquieren una forma más alargada y más estrecha a los lados y las figuras centrales un contorno más elíptico; las figuras periféricas no están tan bien delimitadas, mostrando impresiones radiales que las hacen menos visibles, con surcos poco perceptibles que también tienen impresiones rađiales en su fondo, pero la superficie de toda la placa permanece constantemente mucho más lisa que en el Lomaphorus imperfectus.

Las placas son casi completamente planas en la cara interna, pero con los bordes de las suturas longitudinales levantándose en forma de pequeñas aristas; y cada placa con uno o dos agujeros de tamaño bastante considerable en el centro.

Procedencia: - He recogido los restos de esta especie en las toscas del fondo del río de la Plata, en el municipio de Buenos Aires; y en las excavaciones del puerto de La Plata, en la Ensenada.

Horizonte:- Piso ensenadense de la formación pampeana.

LOMAPHORUS Fi.LVATUS Ameghino

Damina $L X$, figurah is a

Hoplophorus elez'atus. Amegnno: «Boletin de la Academia Nacional de Cienciass, t. T, página 32,1883 (nomen nudum).

Esta especie es de tamaño un poco menor aún que el Lomaphoris compressus; y a juzgar por la coraza, de una forma bastante distinta. Las placas del'centro de la coraza son de tamaño un poco menor, pero no más delgadas, de forma menos cuadrada y regularmente exagonal o pentagonal. Cada placa tiene un diámetro de 25 a 28 milímetros, con la cara interna fuertemente cóncava y con una o dos grandes perforaciones en el centro. Cada placa tiene en la cara externa una figura central más o menos circular y muy elevada, pero fuertemente deprimida en el centro, donde presenta fuertes puntuaciones que adquieren un aspecto de pequeñas perforaciones. Alrededor de la figura central falta completamente todo vestigio de figuras periféricas, que están reemplazadas por una zona notablemente más baja que la figura central, en la que se encuentra el surco que delimita la figura central representado por una pequeña depresión, en cuyo fondo se ve un considerable número de perforaciones de tamaños distintos pero todas muy pequeñas, la mayor parte de las cuales se prolongan en forma de impresiones hasta los mismos bordes periféricos, intercalándose entre ellas numerosas impresiones pequeñas que siempre se dirigen del centro a la circunferencia, dando a esta zona un aspecto sumamente característico. Las suturas que 
separan entre sí a las placas son más abiertas que en la generalidad de las demás especies de Hoplophorus y Lomaphorus. En las placas del centro de la coraza, en la depresión poco acentuada que rodea a la figura central, se ven algunas perforaciones de diámetro bastante grande, aunque en muy corto número. Tres, cuando más, en cada placa.

Procedencia: - He recogido restos de esta especie en los alrededores dé La Plata y en la estación Olivera, en las barrancas del río Luján.

Horizonte:- Piso bonaerense y piso belgranense de la formación pampeana.

Lomaptrores rLEGANS (Butmeister) Ameghino

Lamuna LX, figtirs s; $y$ thmuan LXIS, fipuea 17

Hoplophorns clegans. Burmeister: «Anales del Miseo Público de Buenos Aires», tomo Il, página 219, 18j1. - Idem: Descriptiost fhysique, etc.. tomo III, página $413,1879$.

LYDEKKER: Catal. of Foss. Mamm, parte V, página $532,1887$.

Hoplophorus cupliractus (Lund). OwEN (parte): Zool. of the aBcagle».

Glyptodon radiatus. Bravard: Catalogue des collcctions, etc., 1854 (nomen nudum).

Hoplophorus radiaits (Bravard). II. Gervats y AMFGrino: Los maniforos fósiles, etc., página $194,1880$.

Esta especie es muy cercana del Lomaphorus clevatus, del cual se distingue principalmente por su talla un poco menor aún y por la escultura externa, que es un poco diferente. Las placas son exagonales y pentagonales en el centro del dorso y subcuadradas o rectangulares en los flancos, de 22 a 27 milímetros de largo, 18 a 20 de ancho y 8 a 9 de espesor. Cada placa presenta en la cara externa una figura subcircular o subelíptica, un poco deprimida en el centro y fuertemente puntuada, pero que difiere de la del Lomaphorns clevatus, porque no es elevada como en esta última especie, levantándose apenas un poco encima de la zona periférica; esta última es radiada por impresiones de diferente tamaño, algunas bastante grandes, y corresponden a los surcos periféricos que separan las figuras en las especies en que ellas existen, aunque sea en estado más o menos rudimentario. Alrededor de la figura central hay una depresión más acentuada con perforaciones de diferente tamaño; toda la zona periférica es bastante rugosa a causa de las muchas impresiones radiales que la cubren.

Procedencia: - He recogido restos de esta especie en las cercanías de Mercedes, en la provincia Buenos Aires; y en los alrededores de la ciudad Córdoba.

Horizonte:- Piso bonaerense de la formación pampeana (plioceno medio). 
Esta especie es de la talla del Lomaphorus elegans, con el cual presenta una analogía tan grande que es dificil explicar bien sus diferencias ni aun con dibujos, aunque ambas especies se distinguen inmediatamente con facilidad cuando se tienen los originales a la vista. Las placas del centro del dorso son rectangulares, de $0^{\mathrm{m}} 030$ y $0^{\mathrm{m}} 035$ de largo por $0^{\mathrm{m}} 025$ de ancho y 8 milimetros de espesor. La cara externa muestra una figura central circular que no forma relieve, estando indicada únicamente por una depresión circular poco visible, que la delimita, pero con su parte central un poco deprimida. Toda la superficie de la placa está cubierta con impresiones radiales bien marcadas, que parten del medio de la figura central, pasan por encima de la depresión circular que delimita la figura central y se dirigen a la periferia dándole a la placa una figura particular.

Procedencia: - Los restos de esta especie han sido descubiertos por el señor León Lelong Thévenet en las barrancas de las cercanías del Paraná.

Horizonte:- Piso mesopotámico de la formación patagónica.

LoMapiorus Gracilis (.rodot) Ameghino

Lnmima Lx, Aguras 5, 10, 11 y 15

Glypodon gracilis. NoDot: Description d"un nonzcan gene d'édenté fossile, página 97, lámina XI, figuras 3,4 y 5,1857 .

Hoplophorus gracilis. H. Gervars y AMestuko: Los mamiferos fósiles, etc., pág. I96, 1880.

Esta especie, descripta primeramente por Nodot, sobre fragmentos de coraza procedentes de Brasil, fué considerada por Burmeister como fundada sobre fragmentos de una de las alas laterales de la abertura cefálica de la coraza del Hoplophorus Mejeri, opinión a la que luego me adheri; pero hoy, en posesión de nuevos materiales, veo que hubo error de nuestra parte y que la especie es perfectamente distinta, tanto que hasta forma parte de un género diferente de aquel en que se coloca el Hoplophorus Meyeri. En realidad no se trata de un Hoplophorus sino de un Lomaphorus, pues si bien es cierto que el fragmento original sobre que fué fundada la especie es realmente un trozo de una de las alas laterales, las placas difieren de las correspondientes de los Hoplophorus, por carecer de figuras periféricas, que están reemplazadas por una zona rugosa, que es lo que precisamente caracteriza al género Lomaphorils. La identificación del Glyptodon gracilis de Nodot con el Hoplophorus Meyeri de Lund es tanto más imposible si se consideran los caracteres completamente opuestos de la escultura externa de la coraza en ambas especies, pues el Hoplophorus Meyeri se distingue por el tamaño relati- 
vamente pequeño de la figura central de cada placa y su superficie muy rugosa, casi granulosa, mientras que el Glyptodon gracilis de Nodot, presenta la figura central de tamaño mucho mayor y de superficie plana y casi completamente lisa.

Sobre la parte superior de la coraza, las placas del Lomaphorus gracilis, son de figura regularmente exagonal, con un diámetro de unos 25 milímetros y 8 a 10 milímetros de espesor. Cada placa tiene una figura central de gran tamaño, de contorno subcircular o poligonal, bastante elevada, pero plana y completamente lisa, rodeada por un surco angosto y bien delimitado. Alrededor de esta figura central se extiende la zona periférica, baja y rugosa, dividida por algunos surcos radiales en figuras periféricas incompletas y rugosas, que desaparecen completamente, alejándose del centro de la coraza. En el fondo del surco que rodea a la figura central existen (generalmente en los puntos de convergencia de los surcos radiales) perforaciones circulares, de un poco más de un milímetro de diámetro.

Procedencia:- Los primeros restos de este animal fueron encontrados en las cercanias del valle del río das Velhas, en Brasil; pero la especie ha existido también en la provincia Buenos Aires.

Horizonte:-Piso belgranense de la formación pampeana.

ASTFROSTEMML, n. gen.

- Recibo los restos de este género al concluir la parte de este trabajo destinada a los Gliptodontes, de manera que no se encuentra citado en el cuadro sinóptico de los géneros. Sólo me es conocido por partes de coraza, que indican afinidades con el Palwhoplophorus y el Propalahoplophorus. No sería difícil, sin embargo, que el conocimiento de la cola y del esqueleto obligara a formar con él un nuevo grupo, pues la coraza dorsal presenta mayores afinidades con la de los Dasypoda que con la d: cualquiera de los demás géneros de Gliptodontes hasta ahora conocidos.

Las placas son de contorno subcuadrado o subrectangular y dispuestas en filas transversales más regulares que en los demás Gliptodontes. Cada placa tiene una figura de tamaño mucho mayor, de contorno subelíptica u ovoide, pero que en vez de estar colocada en el centro de la placa, como es de regla en los demás géneros, se encuentra colocada más hacia atrás, no dando lugar a la formación de figuras periféricas en la parte posterior de la placa o ellas son completamente rudimentarias o de tamaño diminuto. Alrededor de esta figura central ovoide (cuya extremidad más angosta está siempre dirigida hacia adelante y la más ancha hacia atrás) hay una fila de figuras periféricas más pequeñas, de tamaño relativamente considerable en la parte anterior, un poco más 
pequeñas sobre los costados laterales y más pequeñas todavia y a veces completamente ausentes en el borde posterior; las figuritas laterales de cada placa se unen a las correspondientes de las placas contiguas para formar figuras de mayor tamaño. En la parte anterior de cada placa hay a menudo delante de la fila de figuras periféricas una segunda fila transversal de figuras pequeñas más o menos desarrolladas. Cada placa tiene un cierto número de agujeros cuya mayor parte están colocados en el fondo del surco que rodea a la figura central, en el punto de convergencia con los surcos radiales, pero hay también algunos colocados en la periferia o entre las figuras periféricas. El aspecto de estas placas, con la figura central ovoide colocada hacia atrás y las figuras periféricas más desarrolladas adelante, presenta un notable parecido con las placas de la coraza de los armadillos del grupo de los Praopidae. Todos los representantes de este género han sido animales muy pequeños, de tamaño apenas algo mayor que el Eutatus Seguini.

ISTrROSTEMMA DEPRLSSA, $n$. sp.

Lamena LXiv, ficturth 2, 6

Las placas de la coraza son de un contorno subcuadrado regular, con una pequeña tendencia a la forma rectangular, de 22 milímetros de largo, 19 a 20 de ancho y sólo 6 milímetros de espesor, término medio. Cada placa tiene en la cara externa una gran figura ovoide, de 18 a 20 milímetros de largo, de superficie casi completamente lisa, con algunas pequeñas puntuaciones poco perceptibles, un poco deprimida en el centro y a veces deprimida en toda su extensión, de manera que se muestra a un nivel inferior al de las figuras periféricas. Alrededor de esta figura principal hay tres o cuatro figuras periféricas más grandes, de superficie plana y puntuada, colocadas en la parte anterior de la placa; y una o dos más pequeñas a cada lado, que se unen con las de las placas contiguas, faltando las mencionadas figuras en la parte posterior o presentándose sólo en una forma completamente rudimentaria. Los surcos que separan a las figuras son angostos pero bien marcados, encontrándose en el fondo del surco que rodea a la figura central cuatro o seis agujeros pequeños, de un diámetro comparable al grueso de un alfiler, colocados en la confluencia de los surcos periféricos con el surco central.

Procedencia:- Barrancas del río Chico, en Patagonia austral.

Horizonte:- Piso santacruceño (eoceno inferior).

ASTEROSTEMMA GRANATA, $n$, sp.

Latrat Lixir, Gigtira,

El tamaño de esta especie es comparable al de la precedente, pero probablemente era un poco más robusta, pues las placas de la coraza 
son proporcionalmente más gruesas, diferenciándose por su aspecto externo algo diferente. Las placas tienen de 21 a 22 milímetros de largo, de 18 a 20 de ancho y 7 de espesor, término medio. Cada placa tiene en la cara externa una figura subcircular o subovoide, proporcionalmente más pequeña que en la especie precedente, menos ovoide y nunca deprimida sino más bien un poco convexa y de superficie no tan lisa, mostrando puntuaciones más marcadas, que le dan un aspecto más áspero, casi granuloso; esta figura central tiene un diámetro de 9 a 12 milimetros. Alrededor de ella hay seis a siete figuras periféricas más pequeñas, cuya superficie es también un poco áspera o granulosa, las dos o tres anteriores más grandes, las laterales más pequeñas y separadas de las figuras de las placas contiguas por surcos bien visibles y las posteriores rudimentarias y a menudo completamente ausentes. Los surcos que separan a las figuras son más anchos que en la especie precedente; y los agujeros que se encuentran en el fondo del surco que rodea a la figura central son de tamaño mucho mayor, encontrándose también entre los surcos que separan a las figuras periféricas.

Procedencia: - Barrancas del río Chico, en Patagonia austral.

Horizonte:- Piso santacruceño (eoceno inferior).

ASTEROSTEMMA LAEVATA, $n$, sp.

Lamata LXIV, Agura o

Esta especie parece no haber sido de tamaño mayor que las demás, pero es considerablemente más robusta, pues las placas de la coraza, sin ser de tamaño mayor, son casi doble más gruesas que en la especie precedente. Las placas son de figura más rectangular, con sus bordes laterales paralelos y dispuestas en fajas transversales regulares; el tamaño de las placas es de 20 a 22 milimetros de largo, de 15 a 16 de ancho y de 8 a 11 de espesor. Cada placa tiene en la cara externa una figura central más grande, de contorno oval o subelíptico, de 10 a 12 milímetros de diámetro mayor, un poco convexa y casi completamente lisa, con algunas pequeñas puntuaciones, apenas visibles, menos acentuadas todavia que en el Asterostemma depressa. Alrededor de esta figura central hay una fila de 8 a 10 figuras periféricas pequeñas, todas de superficie plana y casi lisa, las dos anteriores más grandes, las laterales más pequeñas y las posteriores rudimentarias, casi en forma de pequeños tubérculos; en la parte anterior de cada placa, delante de la fila de figuras periféricas, hay una segunda fila transversal de figuras de tamaño desigual, la mayor parte rudimentarias; en cada uno de los bordes laterales de cada placa, casi completamente rectos, hay tres o cuatro figuritas que se unen a las opuestas de las placas contiguas. Los surcos que separan a las figuras son angostos pero bien delimitados; y los agu- 
jeros que se encuentran en el fondo de estos surcos, la mayor parte de ellos en el que delimita la figura central, son de tamaño bastante mayor que en Asterostemma depressa.

Procedencia:- Barrancas del río Chico, en Patagonia austral.

Horizonte:- Piso santacruceño (eoceno inferior).

\section{PLOHOPIIORUS Ameghino}

Amecrino: Apunes proliminares sobre maniferos crtinguidos de Montc Hermoso, pá$\operatorname{gin} 317,1887$.

Este género es de caracteres intermedios entre el Hoplophorus y el Panochtus, particularmente por la escultura externa de la coraza, qua es de un tipo suficientemente distinto para separarlo netamente de ambos géneros. Las placas de la coraza del Hoplophorus, generalmente delgadas, presentan en su superficie externa una figura central más o menos circular, rodeada de una sola fila de figuras periféricas más pequeñas; pero en el Plohophorus, cada placa tiene una figura externa central siempre considerablemente más grande y dos filas o círculos concéntri$\cos$ de pequeñas figuras periféricas. Examinando un trozo algo grande de coraza se nota que las figuras centrales más grandes están desparramadas en una superficie cubierta de pequeños tubérculos, estando separadas unas de otras por tres o cuatro filas de tubérculos o figuritas pequeñas, mientras en las corazas de los verdaderos Hoplophorus, las figuras centrales están separadas unas de otras, cuando más por dos filas de figuritas periféricas pequeñas.

La cola se compone de una serie de anillos movibles terminando en un tubo cónicocilíndrico, no aplastado como en el Hoplophorus, en algunas especies completamente recto, de extremidad casi puntiaguda y sin los grandes tubérculos laterales que distinguen al de aquel género.

Las muelas superiores se distinguen por un surco perpendicular colocado en la parte externa del último prisma. El cráneo muestra un occipital menos oblicuo que en el Hoplophorus, con una cresta occipital menos desarrollada y dirigida hacia atrás y parietales muy deprimidos acompañados de una larga y elevada cresta sagital.

\footnotetext{
Prohopizorus Figurates Ameghino

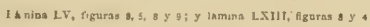

Plohophorus figuratus. Amegrino: Lista de las especies de mamíferos fósiles del mioceno superior de Monte Hermoso, número 52, página 18, Junio de 1888.

Moreno: Informe preliminar, etc.; página 8 , Julio de 1888.

Panochtus Tronessarti. Moreno: Informe preliminar, etc., página 9, Julio de 1888 .

Este animal tenía la talla del Hoplophorus ornatus, pero era considerablemente más robusto y de coraza más espesa. Las placas de la coraza 
son en su mayor parte de forma subcuadrada, teniendo las del centro del dorso, unos 35 milimetros de largo por 25 de ancho y de 15 a 17 de grueso. Cada placa tiene en la cara externa una figura central subcircular o subeliptica, de 13 a 16 milímetros de diámetro, de superficie plana, rara vez deprimida, pero fuertemente puntuada. Alrededor de esta figura central hay una primera fila de figuras periféricas, en número de 9 a 10 , seguida de otra segunda fila externa compuesta de 16 a 17 figuras, todas de tamaño poco desigual, de contornos irregularmente poligonales con la superficie sobre un mismo plano, fuertemente puntuada como la figura central, lo que da a la superficie de las placas un aspecto áspero bastante pronunciado. Todas estas figuras están separadas entre sí y de la figura central por surcos angostos y bastante profundos, en cuyo fondo se encuentran numerosas perforaciones, las que, en vez de encontrarse, según es de regla en el Hoplophorus y el Glyptodon, sólo en el fondo del surco que rodea a la figura central, se encuentran en el Plohophorus figuratus desparramadas por sobra toda 1a superficie de las placas.

El tubo caudal es cilindrico, formado en unas partes por placas con una figura más o menos circular, rodeada de 7 u $S$ figuras más pequeñas, todas separadas por surcos profundos en cuyo fondo se abren de distancia en distancia pequeños agujeritos. Estas placas pasan gradualmente a otras ocupadas por una gran figura alargada, dispuestas todas con el eje mayor en dirección al eje longitudinal de la cola, ostentando en torno 4 o 5 figuritas más pequeñas, particularmente adelante y atrás, que separan entre sí a las figuras mayores, pero a menudo se tocan por sus ejes menores, estando entonces separadas sólo por el surco divisorio, en cuyo fondo tiene siempre pequeños agujeritos. El largo de los distintos ejemplares que he podido examinar varia entre 46 y 48 cen. tímetros.

Procedencia: - He recogido los restos de esta especie en Monte Hermoso, a 60 kilómetros de Bahía Blanca.

Horizonte: - Piso hermósico de la formación araucana (mioceno superior).

PLOHOPIIORt'S AMEGIINOT Moreno

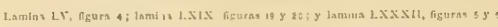

Hopiophorts Ameghinoi. Moreno: Patogonia, resto de un contincute, etc, página 26, I\$82 (nonen nudum).

Amennivo: Informe sobre el Musco Palcontológico de la Unizersidad Nacional de Córduba, página 4,1885 .

Esta especie fué fundada por Moreno sobre fragmentos procedentes de los terrenos terciarios antiguos de Catamarca, considerándola 
como un representante del género Hoplophorus, pero sin acompañar ninguna descripción que permitiera reconocerla. He podido, no obstante, examinar un cierto número de fragmentos y las mismas piezas originales que demuestran que realmente se trata de una especie diferente porque forma parte del género Plohophorus. Las piezas más importantes que conozco son:

Un trozo de coraza que parece proviene de uno de los costados aunque de lugar un poco distante del borde; está formado por placas subcuadradas de 27 milimetros de largo y 22 de ancho con un espesor de 11 a 13 milimetros. La superficie externa presenta un dibujo formado por figuras centrales más o menos circulares, de aspecto casi liso, un poco puntuadas, planas o un poco deprimidas en el centro y de 12 a 15 milimetros de diámetro. Estas figuras centrales más grandes están rodeadas de figuritas pequeñas, casi en forma de tubérculos, del mismo alto, de sólo 2 a 3 milimetros de diámetro, separadas entre sí y de las figuras centrales más grandes por ranuras angostas y profundas. Entre una y otra de las figuras centrales, en los puntos donde más se aproximan, existen tres filas de estas figuritas periféricas más pequeñas. La primera fila de figuritas que rodea a la figura central se compone de 11 a 13 tubérculos y la segunda de 15 a 17 .

Otro fragmento un poco más pequeño, también de uno de los lados, pero más cercano del borde que el fragmento precedente. Las placas son algo más rectangulares y un poco más pequeñas ( 26 milímetros de largo por 15 a 16 de ancho), con la cara externa ocupada por una figura central casi lisa, un poco mảs ovalada, rodeada por una fila de figuritas periféricas mucho más pequeñas, de sólo 2 a 3 milímetros de diámetro y una segunda fila incompleta, de la cual sólo existen vestigios en los bordes anterior y posterior de cada placa, encontrándose interrumpida en los costados.

Un pedazo que parece provenir del centro de la región dorsal; las placas que forman este trozo son de tamaño algo mayor y relativamente más anchas $\left(0^{\mathrm{m}} 037\right.$ de largo por $0^{\mathrm{m}} 034$ de ancho), con un espesor de 12 a 15 milímetros. Cada placa presenta en su cara externa una figura central casi circular, apenas un poco más elevada que el resto de la superficie de la placa, de superficie casi lisa en unas, pero en otras fuertemente excavadas en el centro y de un diámetro de 16 a 18 milímetros. Cada una de estas figuras centrales está rodeada por una primera fila de figuritas periféricas en número de 12 a 13 , de forma poligonal y de superficie plana y casi lisa, apenas un poco puntuada, seguida de una segunda fila externa formada por 16 a 18 tubérculos absolutamente iguales a los precedentes.

Un trozo de la parte posterior de la coraza, con parte del borde de la atertura caudal; este borde está formado por una fila de placas muy 
gruesas atrás y delgadas adelante, cada una con una gran figura elíptica fuertemente aglobada o convexa. Sigue hacia adelante una segunda fila transversal de plazas de una forma particular; cada una de estas placas presenta igualmente una gran figura que ocupa toda la parte posterior hasta el mismo borde de la placa, pero un poco menos convexas y no tan elipticas como las de la fila posterior; sin embargo, como ahí también el espesor máximo de cada placa es en su parte posterior e inmediatamente detrás de la gran figura mencionada, la placa se adelgaza rápidamente, resulta que entre el límite de ambas placas se forma una gran depresión transversal, ancha, profunda y de fondo cóncavo, que sin duda corría paralela a lo largo de toda la abertura posterior de la coraza. Cada una de las grandes figuras convexas que ocupan las placas de esta fila están rodeadas por un círculo casi completo de pequeñas figuras periféricas, en forma de pequeños tubérculos, más o menos en número de veinte, de sólo unos dos milímetros de diámetro, un poco más grandes hacia adelante, pero considerablemente más pequeñas hacia atrás, hasta que se pierden por completo en un pequeño trecho hacia el medio del ancho de la parte posterior de cada placa. Hacia adelante, en cada placa, siguen a este arco de figuritas o tubérculos periféricos, dos otras filas incompletas de tubérculos parecidos, dispuestos alrededor de la primera en forma de arco de círculo.

La cola estaba formada, como en el Hoplophorus, por una serie de anillos movibles, seguidos de un tubo más o menos cónicocilindrico.

De los anillos movibles conozco un pequeño fragmento, que demuestra eran parecidos a los de los verdaderos Hoplophorus. Está constituido, como en éstos, por dos filas de placas. La fila posterior está formada por placas rectangulares de 30 milímetros de largo por 54 de ancho; en la cara externa cada placa tiene una gran figura un poco elíptica, de 20 a 22 milimetros de diámetro mayor que ocupa casi toda la superficie de la placa, menos un pequeño espacio de la parte anterior en donde hay de 4 a 6 figuritas periféricas dispuestas alrededor de la gran figura central en forma de arco de círculo. Las placas de la segunda fila o anterior son un poco más largas y relativamente más angostas (37 a 38 milímetros de largo por 20 a 22 de ancho) ; la cara externa presenta en su parte posterior una figura principal casi circular y más pequeña que las de la otra fila de placas, de sólo 15 milímetros de diámetro, rodeada de una fila de figuras periféricas en número de 10 a 12 , pequeñas hacia atrás y más grandes hacia adelante, en donde sigue otra fila transversal de figuras parecidas en número de 3 a 5 , siguiendo después una superficie en déclive más delgada, de 12 a 15 milímetros de ancho, sin dibujos, pero con unos cuantos agujeros irregulares.

Del tubo caudal conozco la parte anterior más o menos en una mitad de su largo y de una forma general tan distinta del tubo caudal de los 
Hoplophorus que sólo esta parte del esqueleto bastaría para justificar la separación genérica del Plohophorus. En efecto: en el Hoplophorus, el tubo caudal disminuye de tamaño de adelante hacia atrás y ofrece un corte o sección transversal con el eje mayor en dirección horizontal, mientras que en el Plohophorus Ameghinoi, bien que igualmente de sección elíptica, tiene su eje mayor en dirección vertical, es decir, que en vez de estar el tubo caudal deprimido de arriba hacia abajo, como es de regla en los Gliptodontes, en esta especie parece estar comprimido en sentido lateral. La parte proximal del tubo está formada por dos filas de placas que representan un anillo pegado a la parte anterior del tubo, formando con éste una sola pieza, pero del cual se distingue fácilmente por un diâmetro considerable que disminuye inmediatamente hacia atrás formando un desnivel como en forma de escalón. El borde anterior de la abertura del tubo caudal, formada por el anillo mencionado, está constituído por una fila de placas pequeñas, algunas con rudimentos de figuras externas en su parte posterior, terminando hacia adelante en un plano en declive hacia el interior, de superficie rugosa. El resto del tubo se compone de placas poligonales, cada una de las cuales tiene en su superficie externa una figura central principal, muy grande y de forma eliptica, rodeada por una fila de figuritas o tubérculos periféricos pequeños, más grandes adelante y atrás, pero más pequeños hacia el medio en donde en algunos puntos llegan hasta desaparecer, poniéndose entonces en contacto por sus lados laterales las figuras principales separadas unas de otras tan sólo por el surco intermedio que marca la división de las placas entre sí. Estas figuras centrales son más circulares y más pequeñas hacia adelante y más grandes y más elípticas hacia atrás. Obsérvese también que son más pequeñas abajo y arriba y más grandes a los lados. Las figuras centrales son, como en el resto de la coraza, un poco convexas y de superficie casi lisa. El diámetro mayor de las figuras centrales varía de 18 a 35 milímetros y sin duda era todavía mayor en la extremidad. El trozo existente de la cola tiene, unos 24 centímetros de largo y calculo que el largo del tubo entero no debía sobrepasar unos 40 centímetros. La abertura anterior del tubo tiene un diámetro mayor (vertical) de 113 milímetros y 95 milímetros de diámetro menor o transverso. En la extremidad opuesta, donde está roto, tiene 80 milímetros de diámetro mayor y 72 de diámetro menor.

En poder de un coleccionista he visto hace tiempo la extremidad de una cola de esta especie, que es más cilíndrica y mucho más delgada que en el Hoplophorus.

El animal era de tamaño un poco menor que el Hoplophorus ornatus.

Procedencia:- Los restos de esta especie se han encontrado en al valle de Santa María, en la provincia Catamarca, donde parece no son 
escasos; y casi todos los fragmentos figurados me han sido facilitados por el señor Angel Fiorini.

Horizonte: - Piso araucano de la formación araucana (mioceno interior).

PLOITOPIORUS (?) ORIENTALIS, $n$. sh.

IAmua X('T. figura 2

Esta especie, que sólo de una manera provisoria coloco en el género Plohophurus, pues quizá puede provenir de un género nuevo, está representada por un trozo de la parte posterior del tubo caudal, en el cual $f{ }^{t}{ }^{t}$ la la extremidad terminal, e indica un animal diferente de todos los que hasta ahora me son conocidos del mismo grupo y de tamaño muy pequeño, comparable a una de las más pequeñas especies del género Hoplophorus. El tubo caudal se parece al del Plohophorus figuratus por ser casi exactamente cilíndrico, con excepción de la extremidad terminal, que era un poco más ancha que alta dando un corte transversal ligeramente elíptico.

El trozo existente tiene un poco más de 8 centímetros de largo, estando roto en su parte posterior hacia la mitad o el tercio de una gran verruga elíptica lateral que creo probable sea la terminal, de manera que sólo le faltaría la punta en una extensión de 5 centímetros a lo sumo.

En su parte anterior la rotura da un corte casi circular de 66 milímetros de diámetro transverso y 62 de diámetro vertical; en la parte posterior el diámetro tranverso es de 60 milimetros y el vertical de 51 , con las paredes de un grueso de 14 a 20.

Toda la superficie del tubo está ocupada por figuras elipticas regulares, pero con una disposición diferente, según las distintas regiones de él.

A cada lado existe una fila de figuras elípticas mayores cuyo tamaño aumenta de la anterior a la posterior como en el Hoplophorus. Sobre uno de los lados existen vestigios de tres de estas figuras, la parte posterior de la antepenúltima, la penúltima completa y la parte anterior de la última. La parte existente de la antepenúltima tiene 21 milimetros de ancho y es convexa y de superficie lisa. La penúltima figura lateral era apenas un poco mayor que la precedente, también de superficie casi lisa y algo convexa; tiene 36 milímetros de diámetro anteroposterior por 25 milímetros de diámetro transverso máximo. La última figura lateral o terminal era muy convexa, de superficie lisa y de tamaño mucho mayor que la penúltima, pues la pequeña parte anterior existente, tiene, sin tomar en cuenta la curva, 38 milimetros de diámetro transverso.

La cara inferior está cubierta por figuras elipticas dispuestas en filas transversales, cada fila, entre el penúltimo par de figuritas laterales, está 
formada por cuatro figuras que casi se tocan, poco elevadas, casi lisas y alyo convexas, separadas por surcos muy angostos, poco hondos y con algunas figuritas periféricas pequeñas que alternan con pequeñas perforaciones, afectando el conjunto un aspecto casi igual al que presenta el tubo caudal del Plohophorus figuratus.

La curva superior está adornada con figuras elípticas todavía mejor deprimidas y dispuestas en filas transversales regulares, cada fila compuesta de cuatro figuras; estas figuras son elevadas, un poco convexas y de superficie completamente lisa, separadas unas de otras por espacios o surcos poco hondos pero muy anchos, particularmente los que separan entre sí a las filas transversales. En estos surcos o espacivi existen algunas figuritas periféricas muy pequeñas, en forma de tubérculos pequeños, redondeados y convexos, presentando un aspecto granular. Cada una de estas figuras elípticas de la cara superior, así como también las figuras laterales mayores, están rodeadas por una fila de perforaciones circulares profundas, de un diámetro de 1 a 2 milímetros, que alternan con los pequeños tubérculos periféricos mencionados.

Procedencia:- Esta pieza me ha sido facilitada por la señora Eloisa G. de Andrade, viuda del malogrado poeta argentino Olegario V. Andrade, como procedente de la República Oriental del Uruguay, pero es casi seguro que la especie ha vivido igualmente en la Repriblica Argentina.

Horizonte:-Indeterminado; pero por el estado de conservación del hueso es seguro que procede de una formación prepampeana, probablemente de la formación araucana.

Este género se distingue por poseer un tubo caudal cónicocilindrico adornado de figuras subelípticas periféricas poligonales pequeñas, dispuestas de modo que entre cada dos grandes figuras centrales giobulosas hay siempre dos filas de figuras periféricas pequeñas.

Todas las figuras están separadas por surcos bien marcados, angostos y profundos, existiendo siempre en todos los ángulos o en los puntos de convergencia de dos surcos una perforación circular bastante grande.

ZAPHILUS LARRAÑAGAE, $n, s p$. Lamina EXXXI1t, Aguras $1 y_{3}$

La especie sólo me es conocida hasta ahora por el dibujo de un tubo caudal ejecutado por su descubridor el presbítero Dámaso Larrañaga, antiguo cura de Montevideo, y hoy en poder del doctor Andrés Lamas, 
quien posee todos los manuscritos dejados por aquel ilustre ciudadano oriental.

Según este dibujo, èl tubo caudal estaba dividido en dos trozos y debía tener entero un largo de 45 centimetros. En su parte anterior tenía un ancho de cerca de 11 centímetros que disminuye gradualmente poco a poco de manera que en la mitad de su largo tiene todavía 9 centímetros cle ancho, pero en su extremidad posterior se angosta con mucha mayor rapidez terminando en una punta muy acentuada.

Las figuras globulosas que adornan el tubo varían mucho de forma $y$ de tamaño, habiéndolas casi completamente circulares y otras, al contrario, muy elípticas; las más pequeñas sólo tienen 14 milímetros de diámetro, las medianas tienen de 2 a 3 centímetros y las muy grandes colocadas sobre los lados laterales, tienen 5 centímetros de diámetro.

Las figuras periféricas pequeñas, siempre poligonales y angulosas, tienen de 3 a 5 milímetros de diámetro. siendo su número alrededor de cada figura central muy numeroso.

Procedencil: $\quad$ Esta pieza fué descubierta en la República Oriental del Uruguay, pero es casi seguro que la especie debe encontrarse también en la República Argentina.

Horizonte:-Formación pampeana.

NOP $\lambda$ CHTUS Ameghino

Axremino: Ráfidas diagnosis de mamiferos fósiles nucios, etc., pág. I6, Febrero de IS8s.

Este animal es algo parecido a Pluhophorus por la coraza dorsal, pero por el tubo caudal constituye un tipo muy distinto, más parecido al del Panochtus. Casi toda la extensión de la coraza está formada por placas cuya cara externa tiene una gran figura central subcircular o elíptica, más elevada que el resto de la placa, de superficie unas veces convexa y otras excavadas en el centro. Esta figura central está rodeada de una primera fila de figuras periféricas en número de 10 a 12 , pentagonales y exagonales, de ángulos bien marcados y de superficie plana. A ésta sigue una segunda fila de figuras periféricas que rodea a la primera, formada por 20 o más figuras, también de superficie plana; cada una de estas figuritas periféricas que rodea a la primera, está soldada por sutura poco visible a otra más o menos parecida, de la placa contigua, formando figuras más grandes, de manera que entre una y otra figura central se interponen tres filas de figuras periféricas, de las cuales la figura del medio está formada por figuras de mayor tamaño que resultan de 1a unión de dos partes pertenecientes a dos placas contiguas. El tamaño de estas figuras periféricas es muy variable, pero siempre mayor que las de Plohophorus y Panochtus, de superficie plana o ligeramente depri- 
mida y de contornos bien definidos y angulosos. Los surcos son bien marcados, angostos y profundos; y con pequeñas perforaciones en su fondo desparramadas sobre toda su superficie. Hacia la parte posterior las figuras centrales de las placas se vuelven más grandes y más globulosas, formando filas transversales separadas por depresiones transversales, terminando el borde posterior en una fila de figuras elípticoglobadas. Sobre los costados laterales se vuelven de más en más pequeñas, tomando una forma rectangular y una disposición en fajas transversales muy aparente, que se prolonga en una extensión considerable, formando filas de placas imbricadas de adelante hacia atrás, que daban a los bordes laterales de la coraza una movilidad mayor que en todos los demás Gliptodontes conocidos por mi hasta hoy.

La cola se compone de anillos parecidos a los del Plohophorus, terminando en un tubo largo y muy deprimido de arriba hacia abajo, más todavía que en el Panochtus, con una escultura externa más parecida a la del Plohophorus, pero con grandes verrugas laterales salientes en su parte posterior; estas verrugas, de contorno elíptico, son convexas, de superficie un poco rugosa y mucho más salientes que las del Panochtus. Toda la superficie superior e inferior del tubo está formada por placas con una figura central elíptica, alargada de adelante hacia atrás y de tamaño bastante notable, rodeada de una fila de figuras periféricas mucho más pequeñas y dispuesta de manera que por lo general no con? stituyen más que una sola fila entre cada dos figuras grandes; todas estas figuras son planas, de superficie apenas un poco puntuada y separadas por surcos bien marcados aunque angostos y poco hondos.

Nopachrus coagmentatus Ameghino

L.mina LV, Aguras I $y$ a

Nopachus coagmentalus. AmzGrsvo: Rápidas diagnosis de alguros maniforos fósiles nuevos, etc., página 16 , número 24 , Febrero de 1888 . - Idem: Lista de los mamifcros fósiles de Monte Hermoso, página 18 , número 50 , Junio dé 1888.

Panochtus Brocheri? MORENo: 1. c. (nomen nudum).

Era éste un animal de talla considerable, aproximada a la del Panochtus tuberculatus, pero de coraza un poco más delgada, aunque compuesta de placas de tamaño relativamente mayor. Las placas del centro del dorso de la coraza tienen entre 5 y 6 centímetros de diámetro y sólo 18 milimetros de espesor. La figura central de cada placa, de contorno subcircular, es bastante más elevada que las figuras periféricas, de superficie un poco convexa y casi lisa, pero a menudo un poco excavada en el centro, que entonces es generalmente un poco áspero; estas figuras tienen un diámetro de 20 a 25 milímetros. Las figuras periféricas son de forma y de tamaño muy variables; las hay de sólo 5 milímetros de diámetro, mientras que otras tienen hasta 12 milimetros; en cuanto 
a la forma, unas son cuadradas, subcuadradas o rectangulares y romboidales, algunas pocus triangulares y la mayor parte, entre las que se cuentan las más grandes, son pentagonales y exagonales. Todas estas figuras son bien delimitadas, sin que unas sean más elevadas que otras, casi todas planns, excepto las más grandes que son un poco deprimidas en el centro de una manera apenas perceptible. La superficie de todas las figuras es lisa o casi lisa, mostrando sólo pequeñas puntuaciones que no forman asperosidades. Los surcos que separan a las figuras, bicn marcacios en toda la extensión de la coraza, apenas tienen un poco más de um milimetro de ancho, pero son relativamente hondos y de fondo igual. Las perforaciones que se encuentran en el fondo de estos surcos son sumamente pequeñas.

Procedencia: - Se han recogido restos de esta especie en los valles de la sierra de Córdoba y en el yacimiento de Monte Hermoso.

Horizonte: - Piso hermósico y piso puelche de la formación araucana (mioceno superior).

\section{PANOCHTUS Burmeister}

Burmatster: «Anales del Miseo Público de Buenos Aires», tomo II, página I90, I867.

Las especies que entran en este género son todas de tamaño considerable y se distinguen por caracteres comunes en su construcción general, que no permiten confundirlas con las de los otros géneros.

La coraza se compone de placas exagonales y pentagonales de un espesor consilerable, que adquieren en los flancos una forma rectangular o subcuadrada. Cada placa tiene en la superficie externa un adorno o escultura formada for un considerable número de tubérculos o figuras más o menos poligonales y de superficie flana y casi lisa, separadas por surcos foco profundos, en cuyo fondo, de distancia en distancia, se ven algunos pequeños agujeritos; el número de estos tubérculos o figuritas que hay en cada placa es muy variable, según la posición de las placas; en las más grandes del centro y de la parte posterior de la coraza pasa de 50 , mientras que no llega a una docena en las placas más pequeñas de los flancos. Pero al acercarse a los lados laterales de la coraza, sobre todo en el medio, uno de los tubérculos de la escultura de cada placa, el que ocupa el centro, alcanza un desarrollo más considerable que los otros, hasta que en las últimas placas ocupa casi la mitad de la superficie, con un contorno más o menos circular o elíptico y rodeado por una o dos filas de tubérculos más pequeños.

Las verruguitas o tubérculos que adornan la superficie externa son un poco más grandes en el centro de la coraza, más planas y más angulosas, a menudo un poco deprimidas en el medio y separadas por surcos 
más profundos que se entrecruzan como el tejido de una red. Una particularidad del género Panochtus, que lo distingue tanto del Glyptodon como del Hoplophorus y del Nopachtus, consiste en que todos los tubérculos o figuras que adornan cada placa son completas, sin que haya una sola que esté colocada en el borde de las placas, completándose: por dos mitades colocadas en dos placas contiguas, como en los géneros arriba mencionados.

Casi todas las placas de la coraza del Panochtus afectan una forma más rectangular que en los demás Gliptodontes, con su mayor diámetro dirigido de adelante hacia atrás y por eso mismo formando hileras o filas transversales más regulares, que se pueden seguir con más facilidad a través de toda la coraza, cuya disposición o construcción típica se aproxima en cierto modo a la disposición que presenta en los armadillos. Es cierto que el Panochtus no tiene fajas movibles en el centro, pero las hileras transwersales del centro o de cerca del centro en la parte anterior de la coraza, al llegar a los bordes laterales se separan de las filas anteriores y posteriores correspondientes, dejando entre ellas hendeduras perpendiculares más anchas sobre los mismos bordes de la coraza pero que se angostan gradualmente hacia arriba hasta que desaparecen pol' medio de suturas de las placas del centro de cada faja, con las placas correspondientes de los anillos contiguos. Estas hendeduras transversales, que también existen en casi todos los demás géneros de este grupo, aunque no tan desarrolladas, le daban a los bordes de la coraza una puqueña flexibilidad; y las fajas transversales así separadas en sus extremos corresponden perfectamente a las fajas transversales de los armadillos, que en el Panochtus y en los demás Gliptodontes han perdido en el centro su carácter movible. Una particularidad que demuestra la correspondencia que hay entre las fajas transversales soldadas del $\mathrm{Pa}$ nochtus y las de los demás armadillos se presenta en la disposición de las últimas placas de las extremidades de cada una de las hileras transversales separadas en los bordes por hendeduras perpendiculares. Estas placas, en vez de terminar en su parte anterior por un borde transversal, se prolongan en una parte sin adornos y en declive, que se dirige hacia adelante para colocarse debajo de la parte posterior de la placa que la precede, que presenta en dicho punto un plano en declive en sentido contrario, disposición, aparte los pequeños detalles, fundamentalmente idéntica a la que presentan entre si las placas de una de las fajas movibles de los armadillos, con respecto a las del anillo igualmente movible que las precede.

Las series o hileras transversales de placas que forman la coraza dorsal parece que son de 38 a 40 , según las especies.

Todo el borde periférico de la coraza está formado por una fila de placas que llevan sobre la cara externa una figura elípticocircular de 
gran tanaño, acompañada casi siempre de un cierto número de figuritas pequeñas alrededor como las que forman la escultura de las demás placas. Sobre los costados laterales estas placas periféricas son muy pequenas y precedidas por 10 menos de otras dos filas de placas con verruga central más desarrollada; sobre el borde anterior son un poco más granles $y$ en el borde de la abertura posterior todavía mayores, tomando particularmente en el centro la forma de grandes tubérculos con una verruga central de gran tamaño seguida atrás de verruguitas pequeñas como en el resto de la coraza.

La figura general de la coraza dorsal representa, como dice muy bien Burmeister, un gran óvalo corto y grueso, truncado en sus dos extremidades, pero con la parte anterior más pequeña que la posterior y con la región dorsal que se eleva considerablemente encima de la pelvis, formando casi como una joroba, que corresponde exactamente a la elevación súbita hacia atrás de la alta cresta del tubo sacrolumbar y de la cresta transversal que la cruza formada por la parte superior de los ilíacos.

El casco cefálico está formado por veinte a treinta placas de gran tamaino, de contorno poligonal, pero afectando formas y tamaños variables, que se articulan entre si por suturas fijas y constituyen el centro y la parte posterior del casco, siguiendo a los lados y adelante un cierto número de placas más pequeñas, casi libres, que completan el contorno de la coraza cefálica.

Las placas más grandes, unidas por suturas fijas, son muy cóncavas en la cara interna, y convexas en la externa, en la que presentan una gran figura elípticocircular elevada pero deprimida en el centro y rodeada de una a tres filas de figuras o tubérculos periféricos pequeños. La forma general del casco es casi triangular o puntiaguda hacia adelante, ensanchándose gradualmente hacia atrás, volviéndose a angostar otro poco al llegar a su parte posterior; todo el casco es muy cóncavo en su parte interna y convexo en la externa, siguiendo la fuerte convexidad general del cráneo.

La coraza caudal anterior esta formada por seis anillos movibles, completamente separados, que disminuyen del primero al último, y un anillo séptimo más pequeño, que en edad avanzada se suelda a la parte anterior del tubo caudal, pero conservando siempre visible la hendedura transversal que lo separa de éste. Los anillos, disminuyen de diámetro de adelante hacia atrás, pero las placas aumentan de espesor en la misma dirección; cada anillo está formado por una fila de placas principales que forman el borde posterior, cada placa con una gran figura elipticocircular convexa en su parte posterior y otra fila secundaria de placas más pequeñas hacia adelante, con su superficie externa adornada con las mismas verruguitas pequeñas que presentan las placas de la 
coraza dorsal; esta fila anterior es a veces interrumpida ofalta en algur.os anillos.

El tubo caudal es un estuche óseo muy grueso de placas completamente soldadas entre las que han desaparecido las suturas que las unían. Este tubo es ancho y muy aplastado de arriba hacia abajo, con un diámetro casi igual en su mitad anterior, pero que disminuye de una manera poco sensible de adelante hacia atrás en su mitad posterior, terminando en una extremidad bastante roma. Presenta a cada costado una fila de figuras o verrugas elípticas muy rugosas y con una protuberancia en el centro, colocadas unas a continuación de otras con su eje mayor en dirección del eje longitudinal del tubo y aumentando gradualmente de tamaño desde las anteriores a las posteriores, presentando estas últimas un tamaño cinco o seis veces mayor que las anteriores. Esta fila de verrugas principales está acompañada a ambos lados de figuras elípticas más pequeñas, cuyos espacios intermedios están adornados con verruguitas pentagonales o exagonales casi planas. La superficie superior, así como también la inferior, casi planas, están adornadas en toda su ex. tensión (con excepción de los bordes laterales, en donde se presentan las mencionadas figuras elípticas más pequeñas) por figuras o verrugas igualmente pentagonales o poligonales separadas por pequeños surcos estrechos, presentando un aspecto casi absolutamente igual a la escultura que adorna la superficie externa de las placas del centro de la coraza. Este tubo está anquilosado con la apófisis de las vértebras caudales que encierra. La longitud total de la región caudal es con poca diferencia igual a la longitud del tronco.

En su conformación general el esqueleto es más alargado que el del Glyptodon, con la parte posterior más robusta y con el cráneo mucho más grande.

La parte superior del cráneo del Panochtus, en vez de formar un plano casi horizontal como en el Glyptodon y el Docdicurus, es fuertemente convexa, particularmente en la región frontal comprendida entre ambas cavidades orbitarias; toda la parte del cráneo que se extiende delante de las órbitas forma una curva convexa que desciende hasta la abertura nasal, la que en vez de dirigirse hacia adelante se abre hacia abajo. Los nasales son anchos atrás y angostos adelante, donde terminan en punta, y fuertemente convexos en su parte superior, donde constituyen una superficie semicircular. La cavidad nasal muestra un septum muy fuerte que forma una pared perpendicular que divide la fosa nasal en dos partes hasta su misma extremidad anterior.

La elevación sorprendente del cráneo y su tamaño considerable haría creer a primera vista que el Panochtus tuvo una cavidad cerebral considerable, pero no es así: la caja encefálica no es mayor que la del Glyptodon; y el tamaño enorme del cráneo y su gran convexidad se 
debe a un laberinto de cavidades irregulares, de diferentes formas $y$ tamainos, currespondientes a los simus frontales del hombre y excavadas en el espesor de los frontales y de los parietales.

Los parietales también son un poco más convexos que en el GlyptoLun, reuondeados, sin cresta sagital y con las líneas temporales poco marcadas y muy distantes de la linea media, limitando fosas temporales más pequeñas que en el Glyptodon y menos rugosas.

El occipital es pequeño y bajo como en los demás Gliptodontes, pero un poco menos inclinado; y las perforaciones condiloides mucho más pequeñas que en el Glyptodon, estando limitado el llano occipital hacia arriba y a los costados por una cresta occipital no muy alta pero muy gruesa.

E1 arco cigomático es completo y sumamente fuerte, muy corto y muy ancho y con sus partes constituyentes soldadas sin huella de suturas cuando adultos, de manera que es difícil reconocer la parte que en su formación toman los distintos huesos; la parte posterior que representa la apófisis cigomática del temporal se estrecha hacia atrás, extendiendose en forma de protuberancia lateral hasta el llano occipital. En la parte anterior del arco cigomático, se forma hacia arriba una fuerte apólisis postorhitaria que asciende hasta tocarse con la apófisis corresrondiente del frontal, con la que se suelda formando una cavidad orbitaria regularmenti elíptica y de arco completamente cerrado. Inmediatamente detrís de la orbita, el ancho del arco cigomático es enorme, sobre todo comparado con el del Glyptodon que ahi es muy angosto. La apólisis descendente del mismo arco es también un poco más fuerte y más largu que en los demás Gliptodontes. Sin embargo, parece que en algunas especies las órhitas qucdaban abiertas atrás como en el Glyptodon.

Los maxilares superiores tienen un desarrollo extraordinario, pues forman todos los costados laterales del cráneo delante de las órbitas, desde la parte alveolar (que es muy descendente hacia abajo) hasta su unión con los nasales.

El paladar es largo y angosto, con las series dentarias casi paralelas pero un poco más aproximadas entre ellas en el medio y algo más divergentes en la parte posterior, en donde la abertura nasal posterior penetra en el paladar entre el último par de muelas, formando una pequeña escotadura transversa. El intermaxilar es muy corto pero bastante ancho; y la superficie del paladar parecida a la de los otros Gliptodontes.

La mandibula inferior es un poco más robusta que en el Glyptodon y con la parte que se extiende adelante de las muelas un poco más prolongada y más delgada.

Las muelas del Panochtus se distinguen de las del Glyptodon sobre todo po: la estructura de la superficie masticatoria, en la cual la cresta 
central formada por la substancia vascular más dura, no envía a la masa de la dentina que la rodea, la cantidad de pequeñas ramificaciones que se observan en las muelas del Glyptodon.

Las muelas anteriores y posteriores son un poco más pequeñas y las del medio más grandes, en la mandibula superior. La primera de la mandíbula inferior es casi elipticoprolongada a causa de que las aristas perpendiculares son poco pronunciadas y tiene un tamaño notablemente menor que la segunda.

El tamaño de las muelas aumenta en la mandíbula inferior desde la primera a la cuarta, siendo las cuatro posteriores de tamaño casi igual. La primera inferior es también bastante más pequeña que la segunda y de sección elíptica, implantada oblicuamente, con una cara convexa y la otra con las aristas perpendiculares apenas indicadas.

Los tres prismas que componen cada muela son también casi siempre de tamaño un poco diferente; el prisma anterior en las superiores y el posterior en las inferiores es de tamaño un poco mayor y sobre todo más ancho, mientras que el prisma del medio es, al contrario, un poco más pequeño.

E1 atlas, en proporción del cráneo, es bastante pequeño.

E1 hueso mesocervical está formado por cuatro vértebras como en la mayor parte de los Gliptodontes, pero se distingue del de éstos por una fuerte apófisis odontoides, que es más pequeña, no tan prolongada, ni separada en su base por una escotadura tan marcada como en el Glyptodon.

El tubo dorsal está formado por la reunión de diez vértebras; y el lumbar de 8 . El sacro consta de 8 vértebras soldadas.

La cola se compone de una primera serie de 7 grandes vértebras completamente separadas y movibles que corresponden a la región basal de la cola rodeada por los anillos movibles y de una segunda serie compuesta de 12 a 14 vértebras más pequeñas encerradas en el tubo caudal, todas soldadas entre sí y. con el tubo.

Las costillas son 11 pares, uniéndose la primera al manubrio por articulación flexible, en vez de unirse en una pieza con éste, como sucede en el Glyptodon.

El húmero es un poco menos robusto que el del Glyptodon, relativamente más largo y con una fuerte perforación epitrocleana.

El trapecio y el trapezoides están soldados en una pieza en el pie anterior y no existen más que cuatro metacarpianos, faltando el primero o interno con todo el dedo correspondiente. Cada uno de los cuatro metacarpianos correspondientes a los cuatro dedos externos, tienen un dedo completo, compuesto de tres falanges, la ungueal inclusive, cuyo tamaño y largo disminuyen del segundo o interno al quinto o externo, que es muy pequeño. 
El pie posterior es más fuerte, más corto y más ancho, terminando en cuatro dedos perfectos, faltando, como en el pie anterior, el interno o primero, del cual no existen ni vestigios del metatarso.

Panochtus Tuberculatus Owen

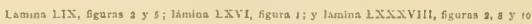

Glyptodon tuberculatus. Owz: Trans geolog. Soc., a serie, tomo II, página 82. - Idem: Descript catal. 'of the collec. of the $R$. College of Surgeons, tomo I, numeros 558-559, 1845. Burmerster: «Anales del Miseo Público de Buenos Aires», tomo I, páginas 77 y 192. Glypiodon verrucosus. BUrmeIster: Zeitsclirift fur die gesommten Naturwissenschaften, Bd. XXVIII, pág. I46, I886. - Idem: «The Annals and Magazin of natural hystory», I886. -Idem: «Anales del Museo Público de Buenos Aires», entrega $3^{0}$, página 194, 1866. Glyptodon reticulatus. Bravard: Catalogue des collections, etc., 1855 (nomen nudum).

Glyptodon gigantens (Serres). Burmerster: «Anales del Museo Público de Buenos Aires», tomo I, páginas 194 y 216 (identificación errónea), 1866.

Glyptodon robustus. Bunmerster: en «Arch. f. Anat. u Phys.», r865, página 320.

Glyptodon cerrucosus. Nodor: Description d'un nouvean gcure d'édenté fossile, pág. 1oo, aก̃o 1857 .

Schistoplewrum tuberculatum. Nodor: Description d'un nousean gente d’édenté fossile, página $8 \mathrm{x}$, láminas VIII y $1 \mathrm{X}, \mathrm{I} 856$.

Panochtus tuberculatus. Burderster: «Anales del Museo Público de Buenos Aires», t. II, páginas 147 y 22.. - Idem: Description physique, etc., tomo III, página 416.

Rydìr J. A.: «The popul, scient, monthly Journ.», volumen XIII, número 10, página I42. H. Gervais y Amegmino: Los mamíferos fósiles, etc., página 188, I880.

LYDEKKER: Catal. of Foss. Mamm, parte V, página 185, I8S7.

Ha sido este uno de los más grandes animales de este orden, pues su volumen igualaba al de un gran rinoceronte. La coraza es muy ancha y muy convexa, con una joroba pronunciada encima de la parte anterior de la pelvis y del tubo lumbar. Se compone de placas subcuadradas, de tamaño considerable en el centro, pero más pequeñas sobre los costados. En casi toda la extensión de la coraza, las placas están cubiertas por un considerable numero de figuras externas poligonales, de superficie plana o deprimida pero fuertemente puntuadas formando asperosidades más o menos pronunciadas, sin figura central de mayor tamaño, con excepción de la primera fila anterior, de las dos últimas posteriores y las tres o cuatro últimas placas de cada fila en los bordes laterales.

Las placas del centro de la coraza tienen de 5 a 6 centímetros de largo (habiéndolas todavía algo más grandes) por 4 centímetros de ancho. Cada una de estas placas tiene en la cara externa de 40 a 50 o más figuras poligonales, de superficie relativamente lisa, separadas por sur$\cos$ angostos en los que se ven pequeñas perforaciones.

El tubo caudal empieza adelante con una forma casi circular, que se cambia en deprimida, adornado por dos filas de tubérculos laterales, elípticos, salientes y rugosos, cuyo tamaño aumenta desde el primero al penúltimo, siendo el último de cada lado un poco más pequeño; este par de tubérculos terminales forma, como es de regla, la extremidad de la cola. Estos grandes tubérculos laterales están acompañados a uno v otro lado por figuras elípticas más pequeñas y de tamaño distinto; y los. 
cspacios intermedios están ocupados por pequeños tubérculos irregulares generalmente poligonales. Toda la parte media longitudinal inferior y superior del tubo está cubierta por una escultura compuesta de figuras poligonales, de ángulos bien marcados y separadas por un sistema reticular de surcos bien pronunciados, pero en la parte anterior, inmediatamente detrás del borde, hay entre estos tubérculos, una fila transversal de figuras elipticas mayores, seguida hacia atrás de otra fila menos acentuada, separada de la anterior por una zona bastante ancha adornada únicamente con los mencionados tubérculos más pequeños.

El escudo cefálico está formado por la unión de unas 20 a 25 placas de gran tamaño (y no de 70 como supuso Burmeister) que constituyen la parte central y posterior del casco, a las que se unían sobre los bordes una cierta cantidad de placas más pequeñas, cuyo número es desconocido, pero que no es de creer sobrepasara mucho el de las placas de gran tamaño.

Lydekker, en la diagnosis de este género, dice que posee un escudo ventral, guiándose sin duda, como en el caso del Glyptodon, por la desgraciada ocurrencia de Burmeister. El Panochtus, siguiendo la regla de los demás Gliptodontes, carecía de plastrón ventral.

\section{DIMENSIONES SEGÚN BURMEISTER}

Longitud del cráneo desde la punta anterior del paladar hasta los cóndilos occipitales

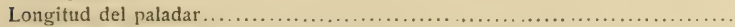

Longitud del espacio ocupado por las ocho muelas superiores ................

Altura del cráneo desde la cresta lambdoides hasta el llano del paladar .......

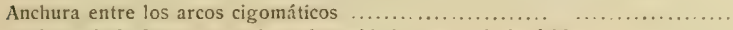

Anchura de la frente entre las tuberosidades antes de la órbita ...............

Anchura de las apófisis cigomáticas descendentes entre sus puntas más sobresalientes

Longitud de la misma apófisis desde el margen inferior de la órbita .........

Anchura entre las puntas externas de las superficies articulares para la mandi-

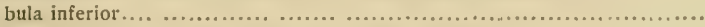

Longitud de la rama horizontal de la mandibula inferior ....................

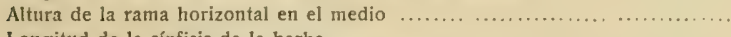

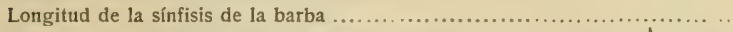

Anchura de las dos ramas horizontales unidas.

Altura de la rama ascendente, desde la escotadura que la separa de la rama horizontal, hasta el final de la apófisis coronoides.

Distancia de las puntas internas de los cóndilos entre si ....................

Altura de la parte occipital del cráneo desde la cresta lambdoides hasta la base

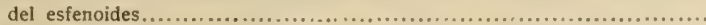

Anchura de la pelvis entre las esquinas externas de los acetábulos..............

Diámetro transversal del acetábulo

Distancia de las esquinas externas de los huesos iliacos $\ldots \ldots \ldots \ldots \ldots \ldots \ldots$

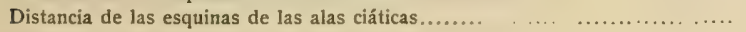

Diámetro longitudinal de la cavidad cotiloides $\ldots \ldots \ldots \ldots \ldots \ldots \ldots \ldots \ldots . . . \ldots \ldots$ 
Diámetro transversal de la misma bajo las apófisis transversales del sacro .... 0 0 061

Longitud del arco sacral con la curva .............................. 0580

Longitud de la coraza siguiendo la curva superior del dorso ... ......... 1900

Longitud de la coraza en linea recta ................................ 1640

Circunferenc'a transversal de la coraza, en el medio, siguiendo la curva de ella ........................................................ 2900

Diámetro transverso máximo en línea recta .......................... 1320

Altura máxima de la coraza ...................................... 1050

Anchura de la abertura ventral ................................... 1030

Diámetro transverso de la abertura anterior ......................... 0380

Diámetro transverso de la abertura posterior .......................... 0770

Longitud del tubo caudal .......................................... 0910

Ancho del tubo caudal adelante .................................... 0240

Longitud total del animal desde la punta de la nariz hasta la extremidad de la cola ................................................... 3450

Procedencia:- Los restos de esta especie se encuentran con frecuencia en toda la llanura argentina y en la República Oriental del Uruguay.

Horizonte:- Piso lujanense y piso bonaerense de la formación pampeana.

Panochtus Morenot Ameghino

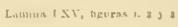

AMEcrrtivo: La antighedad del hombrc, etc., tomo II, página $310,189 \mathrm{r}$.

Esta especie es muy cercana de la precedente, de la cual se distingue sobre todo por su tamaño general bastante menor. La coraza es un poco más delgada y compuesta de placas más pequeñas, pero con la misma escultura externa, con la única diferencia de los tubérculos que son menos deprimidos y un poco más ásperos y cerca de la periferia menos distintos, con rugosidades que los unen entre si, por cuya catisa los surcos son entonces menos acentuados.

La configuración del cráneo en sus rasgos generales es la misma que en el Panochtus tuberculatus.

La cola se distingue por un tamaño bastante menor y algunas pequeñas diferencias en la forma y en la escultura que ostenta. El tubo caudal tiene de 75 a 80 centimetros de largo y no más de 18 de ancho en su extremidad proximal, terminando en punta bastante más estrecha que en el Panochtus tuberculatus. Toda la parte central de las superficies inferior y superior está cubierta por las mismas figuritas poligonales que en la otra especie, sin interposición de figuras más grandes, faltando igualmente hacia adelante las dos filas transversales de figuras elípticas más grandes, visibles en la parte anterior del tubo del Punochtus tuberculatus. 
Procedencia: - He recogido los restos de esta especie por primera vez en los alrededores de la ciudad Montevideo; y luego en distintos puntos de la provincia Buenos Aires.

Horizonte:-Piso bonaerense de la formación pampeana.

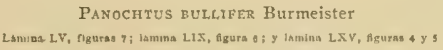

Burmerster: \&Anales del Museo Públicu de Buenos Aires», tomo II, páginas 5, 103, 149 y 224. - Idem: Descripción physique, etc., tonı III, página 417 .

Por su tamaño, esta especie es comparable al Panochtus Morenoi, pero es de una conformación bastante distinta. diferenciándose igualmente mucho del Panochtus tuberculatus.

El distintivo característico más notable es el de que cada placa tiene sobre la cara externa, en el medio de las figuritas que la adornan, una figura de mayor tamaño, de contorno subcircular o subelíptico, que so eleva en forma de ampolla; esta figura central, de mayor tamaño en las placas de la circunferencia, disminuye gradualmente hacia el medio hasta que desaparece en el centro mismo de la coraza, que está formada por placas con la cara éxterna de figuras poligonales pequeñas, como en el Panochtus tuberculatus, sin figura central de mayor tamaño. Por esta conformación particular de casi toda la extensión de la coraza el Panochtus bullifer presenta una transición notable al Plohophorus y al Nopachtus.

El borde caudal de la coraza está formado por placas con una gran verruga, no muy elevada pero un poco rugosa y ocupando cada una la mayor parte de la placa; adelante vienen 8 o 9 filas transversales de placas adornadas con la mencionada verruga central de gran tamaño y elevada en forma de ampolla, rodeadas por tres o cuatro filas de figuras periféricas, perdiéndose las figuras centrales recién encima de la parte media de la pelvis. Sobre los lados laterales, cerca de la periferia, las figuras centrales de las placas ocupan la mayor parte de la superficie de éstas, presentando una forma regularmente elíptica, disminuyendo gradualmente de tamaño hasta desaparecer en la parte central del dorso, reemplazadas poco a poco por las pequeñas figuritas periféricas, que concluyen por ocupar toda la superficie de la placa. La superficie de estas figuritas es por lo general un poco deprimida y más lisa que en ¿i Panochtus tuberculatus.

Según Burmeister, la forma general de la coraza es también algo diferente, siendo un poco más prolongada, menos esférica y más oval que la del Panochtus tuberculatus.

El tubo de la cola muestra las diferencias específicas de una manera más acontuada todavía, siendo bastante más corto y más angosto que el 
del Panochtus tuberculatus, angostándose un poco hacia atrás cerca de la punta, pero la extremidad misma de la cola vuelve a ensancharse, aunque no tanto como para alcanzar el ancho que presenta inmediatamente adelante del estrechamiento. Sobre los costados laterales presenta una fila de grandes verrugas elípticas salientes muy parecidas a las mismas del Panochtus tuberculatus y dispuestas más o menos de la misma manera, pero las verrugas elípticas secundarias que se extienden a uno y otro lado de las filas principales son más pequeñas y con una disposición diferente; además, en toda la extensión de la superficie inferior y superior del tubo, existen figuras elípticas centrales de mayor tamaño y más elevadas, alrededor de las cuales se agrupan las figuras periféricas como en las placas de la coraza; y para completar el parecido, estas figuras centrales son más acentuadas o aparentes en los costados que sobre la linea media longitudinal; estas figuras elípticas de mayor tamaño están siempre dispuestas en filas transversales bien perceptibles y con su eje mayor siempre dirigido de adelante hacia atrás. El tubo caudal completo tiene 30 pulgadas de largo y 6 pulgadas de ancho en su parte anterior.

Procedencia: - Los restos de esta especie se encuentran con frecuencila en los valles de la sierra de Córdoba.

Horizonte:- Piso puelche de la formación araucana (mioceno superior).

Panochtus Frenzeltanus, $\pi$. $s p$.

Lamina ItX, figurne t, a y a y lamina Lxxxvill, figurak 3, e, 7 y

Esta especie tenia la talla del Panochtus Morenoi, pero se distingue inmediatamente, tanto de él como del Panochtus tuberculatus, por las órbitas abiertas atrás, que comunican libremente con las fosas temporales, en vez de estar cerradas, como en las mencionadas especies, por un-arco óseo sompleto. La frente es muy ancha y convexa; y toda 1a parte superior del cráneo forma una superficie lisa que se extiende desde la sutura parietoccipital hasta la extremidad anterior de la nariz. Esta superficie lisa empieza atrás con un llano sagital bastante ancho cue se ensancha todavia hacia adelante limitado por dos líneas curvas parietales que terminan en las apófisis postorbitarias, donde la superficie superior del cráneo adquiere su ancho máximo, angostándose luego gradualmente hacia adelante hasta la punta de los nasales, los que en su extremidad anterior están separados por una hendedura perpendicular. Los nasales se unen atrás con los frontales por una sutura transversal colocada un poco más adelante de las hendeduras laterales, formando un espacio triangular, ancho atrás y angosto adelante. 
Las apófisis postorbitarias de los frontales son muy pronunciadas, pero no se unen al arco cigomático, terminando en extremidad libre. El arco cigomático carece por completo de apófisis postorbitaria ascendente y es, en consecuencia, mucho más delgado hacia atrás que en el Panochtus tuberculatus y el Panochtus Morenoi, presentando un mayor parecido con las especies de Glyptodon.

La mandibula inferior es de rama ascendente un poco más ancha que en el Panochtus tuberculatus; la rama horizontal presenta en su parte inferior una curva descendente regular en toda la extension ocupada por la dentadura; y en la parte anterior tiene a cada lado tres o cuatro perforaciones mentonianas en vez de la perforación única que muestra la mandíbula del Panochtus tuberculatus.

E1 casco cervical del Panochtus Frenzelianus era bastante parecido al del Panochtus tuberculatus, compuesto como en este último de un cierto número de piezas o placas de gran tamaño, a las que seguian sobre los bordes laterales y anterior un cierto número de placas pequeñas, perdidas en los ejemplares que hasta ahora se han descubierto. Las placas de mayor tamaño que cumponen la casi totalidad de la extensión del casco, son un poco más pequeñas que las que componen el escudo de la otra especie y articuladas de una manera algo distinta; la figura central de cada placa es además más rugosa y alrededor no tiene más que una sola fila completa de figuras o tubérculos periféricos, mientras que en la mayor parte de las placas grandes del casco cervical del Panochtus tuburculatus, hay dos filas completas.

La coraza se compone de grandes placas subcuadradas con la superficie externa cubierta de pequeños tubérculos poligonales como en el Panochtus tuberculatus y el Panochtus Morenoi, sin las figuras elípticas más grandes y convexas que distinguen al Panochtus bulifer. La abertura posterior de la coraza está formada por una fila de placas alargadas con una verruga elíptica y rugosa en su parte posterior, seguida hacia adelante de un espacio cubierto de pequeños tubérculos poligonales parecidos al resto de la coraza; sobre los lados laterales estas placas carecen de las mencionadas figuras y se adelgazan, formando entre una y otra placa una depresión con cara muy pronunciada que hace resaltar más todavía la forma elevada de las verrugas de la orilla libre de ta abertura. La penúltima fila de placas no presenta más que los pequeños tubérculos que adornan toda la superficie de la coraza, lo que constituye una diferencia notable con el Panochtus tuberculatus, en el cual las Flacas de la penúltima fila tienen en el medio una figura subcircular de mayor tamaño, rodeada por los pequeños tubérculos que cubren el resto de la superficie de cada placa.

Dedico la especie al distinguido zoólogo doctor Juan Frenzel, mi sucesor en la cátedra de Zoología en la Universidad de Córdoba. 
Procedencia: - Se han encontrado restos de esta especie en la provincia Buenos Aires y en los alrededores de Montevideo.

Horizonte:- Piso bonaerense y piso belgranense de la formación pampeana.

Panocheres Vogti, 21. sp.

Lamun LT1t, figurs:

Esta especie parece muy distinta de las demás, pero desgraciadamente sólo dispongo de una vista fotográfica del cráneo que me ha sido obsequiada por su descubridor, el señor Santiago Roth, quien me ha comunicado que se distingue principalmente del Panochtus tuberculatus, por su tamaño bastante menor y por el tubo caudal, que es más corto pero más grueso, aunque de una conformación general muy parecida.

El cráneo parece ser relativamente más corto y más elevado que el del Panochtus tuberculatus y de una forma bastante distinta. La parte anterior que se extiende adelante de las órbitas es relativamente más larga y la posterior más corta, encontrándose así las órbitas situadas más atrás que en el Panochtus tuberculatus y presentan un tamaño proporcionalmente mayor. Las hendeduras laterales de la abertura nasal anterior son más extendidas y la superficie frontonasal del cráneo más convexa y más inclinada hacia abajo. El arco cigomático es más corto y más delgado que en el Panochtus tuberculatus; y la apófisis descendente está colocada considerablemente más hacia atrás, descendiendo hacia abajo de una manera más perpendicular, con la mitad inferior menos arqueada hacia atrás y dejando visible adelante las cuatro primeras muelas en vez de sólo tres como en el Panochtus tuberculatus. La mandibula inferior presenta una rama ascendente muy angosta pero muy elevada y en cambio una rama horizontal muy alta, con un solo agujero mentoniano a cada lado y con el borde inferior con fuertes protuberancias formadas por la base de los alvéolos de las muelas.

He designado esta especie con el nombre de Panochtus Vogti, en honor de Carlos Vogt, que es uno de los más ilustres naturalistas suizos contemporáneos.

Procedencia: El cráneo mencionado, conjuntamente con una parte considerable del esqueleto, ha sido encontrado por el señor Santiago Roth en el arroyo Pergamino, en la parte Norte de la provincia Buenos Aires y se conserva actualmente en el Museo de Historia Natural de Ginebra, en Suiza.

Horizonte: - Formación pampeana. 
En la «Ostéographie» de de Blainville, se encuentra el dibujo de la extremidad de una cola sin indicación alguna, reproducido luego por Nodot, acompañándolo de una descripción según el molde de un original, pero sin dar al animal ningún nombre especial. Según Burmeister, esta pieza provendría del Panochtus tuberculatus, pero bastará tomarse la molestia de comparar esta figura, con las de la cola del Panochtus tuberculatus, para llegar inmediatamente a la persuasión de que tal identificación es absolutamente imposible, pues por su conformación difier más del Panochtus tuberculatus que el mismo Panochtus bullifer descripto por Burmeister como especie idistinta.

Es evidente que esta pieza proviene, si no de una especie del género Panochtus, a lo menos de un género muy cercano, pero la extremidad de la cola formada por dos enormes verrugas elipticas separadas en su extremidad posterior por una hendedura perpendicular y muy poco divergentes adelante, no permiten identificarla con ninguna de las especies de Panochtus, constituyendo evidentemente una especie distinta, a la cual designo con el nombre de Panochtus (?) Nodotianus en honor de Nodot, que es quien nos la ha dado a conocer.

La parte existente de este fragmento tiene 26 centimetros de largo; y es descripta por Nodot en los términos siguientes:

«La superficie superior de la extremidad obtusa de esta cola se compone de dos discos casi elípticos de un decímetro de largo por siete centímetros de ancho, que se articulan juntos como una concha bivalva sobre el eje medio, cubriendo la extremidad de las vértebras caudales. La superficie superior de estos dos discos está cubierta de asperosidades y láminas muy salientes y onduladas que se extienden desde la parte media, de donde existe una elevación subcónica, hasta la circunferencia, que toma la forma de un fuerte reborde. Sobre la parte media de esta cola e intercalada en el ángulo entre las dos placas mencionadas, se encuentra otro disco de 45 milímetros de diámetro, de forma subcircular, muy cóncavo y cubierto de rugosidades en toda su superficie; después, adelante de éste, vienen dos otros discos más grandes, elípticos, cuyos ejes mayores paralelos al eje de la cola tienen 8 centimetros de largo y se articulan juntos; estos discos están cubiertos, como los de la extremidad de la cola, de asperosidades onduladas y salientes que irradian del centro, un poco convexo, a la circunferencia, que toma la forma de un fuerte reborde. En fin, en la extremidad de la parte que queda intacta sobre el lado derecho, se encuentra todavia otra gran impresión de 9 a 10 centimetros de largo, igualmente elíptica y que se parece en un todo a las que terminan la cola, de las cuales está separada por un intervalo de sólo 5 centímetros. Una multitud de pequeñas eminencias, todas igual- 
mente salientes, pero que varían considerablemente en sus formas poliédricas, rodean y ocupan todos los vacios entre las figuras elípticas mencionadas.»

Procedencia: - Esta pieza ha sido recogida en las cercanias de Montevideo, por Vilardebó, y se conserva en el Museo de Historia Natural de Paris, pero dada la vecindad de la mencionada localidad se pued asegurar que la especie debe también haber habitado la República Argentina.

Horizonte:-Formación pampeana.

PROTOGLYPTOLON Ameghino

Amentivo: «Doletin de la Academia Nacional de Ciencias», tomo VIII, página 135, 1885.

La coraza de este género se distingue por placas con dibujos externos rudimentarios y rugosos, formados por figuras pequeñas dispuestas por grupos alrededor de otras apenas un poco más grandes, con surcos rudimentarios y grandes agujeros alrededor de las figuras centrales, presentándose de distancia en distancia figuras centrales de gran diámetro rodeadas igualmente por figuritas pequeñas y rugosas y agujeros anchos y profundos. La cola termina en un tubo caudal adornado con los mismos dibujos que la coraza.

Protoglyptodon primiformis Ameglino

Lamua LVIII, figura 7 i g thmus LIF, figgre 6

Amegrino: «Boletín de la Academia Nacional de Ciencias», tomo V'III, página $x_{3.5}$, $1 \$ 8_{5}$; idem, tomo IX, página 200, I886.

Fundé la especie sobre un trozo de coraza de unos 12 centímetros de largo, compuesto de un cierto número de placas cuyas suturas no era posible reconocer, cubiertas en su superficie externa de dibujos irregulares, que variaban de forma y disposición de un punto a otro, tanto que hubiera podido tomarse este fragmento por una anomalía individual. Pero varios otros fragmentos parecidos de distintos individuos, encontrados más tarde, han venido a demostrar que esa aparente irregularidad de la estructura externa de la coraza era constante y perfectamente característica de este animal, cuyas dimensiones parecen haber sido bastante considerables, pues las placas del centro de la coraza tienen unos 5 centímetros de largo por 4 centímetros de ancho y de 15 a 20 milímetros de grueso.

Comparando los varios fragmentos que ahora conozco se pueden establecer con bastante exactitud los caracteres generales de los dibujos externos de la coraza de este género.

Dada la irregularidad en la distribución de las distintas figuras externas que adornan a la coraza, 10 primero que salta a la vista es que 
no hay relación alguna entre la escultura cxterna y la división por placas, pues hay trechos considerables ocupados tan sólo por figuras pequeñas y otros en los cuales predominan las grandes.

La parte principal de la escultura externa está formada por pequeñas figuras o verruguitas parecidas a las que adornan las placas del género Panochtus, pero más rugosas e irregulares y dispuestas por grupos de siete u ocho figuras cada uno. Cada grupo está formado por una figura o verruguita central algo más grande, de 7 a 8 milímetros de diámetro, a cuyo alrededor están colocadas las otras seis o siete más pequeñas, de sólo dos a cuatro milimetros de diámetro. Esta figura central está separada de las periféricas por un surco poco aparente y de fondo desigual. presentando el mismo carácter los surcos que separan entre sí a las figuras periféricas. Alrededor de cada una de las figuras centrales se encuentran cuatro o seis agujeros anchos de dos a cuatro milímetros y profundos, unas veces distantes unos de otros y otras veces al lado, separados sólo por aristas delgadas y elevadas que unen la figura central a la periférica. Cada uno de estos grupos ocupa un espacio circular más o menos de dos centimetros de diámetro.

Estos grupos de figuras o verruguitas pequeñas se reunen a su vez en número de siete $u$ ocho para formar otros grupos princ:pales, colocados alrededor de una figura mucho más grande, de unos dos centímetros de diámetro, muy parecida a la figura central de las placas del Glyptodon. Esta figura central más grande es también de superficie rugosa y está rodeada por 12 a 15 figuras más pequeñas parecidas a las ya descriptas y por un considerable número de agujeros.

Este es el carácter de la escultura externa; pero, como ya lo dije antes, él no es completamente uniforme, variando más bien de un punto a otro, presentándose bajo una forma ora más regular, ora más irregular. confundiéndose las verrugas unas con otras, no formando más que una superficie rugosa atravesada por aristas y acribillada de agujeros, o bien levantándose en forma de tubérculos aislados.

Me parece inútil entrar en la descripción detallada de la escultura de cada uno de los fragmentos, pues la descripción general que acabo de dar basta. Uno de ellos tiene la cara interna intacta, de modo que permite medir el espesor de la placa, que es de 20 a 25 milímetros, lo que demuestra que el animal alcanzaba un tamaño considerable.

Conozco un trozo de la parte anterior del tubo caudal en el cual ni sobre el lado interno ni sobre el externo se ven vestigios de las suturas de las placas que lo forman, apareciendo como de una sola pieza. Hacia adelante hay un pequeño trozo del borde anterior, donde el tubo tiene sólo un centímetro de espesor, aumentando muy poco hacia atrás, de manera que a 13 centímetros del borde anterior sólo tiene un centímetro y medio de grueso. 
La escultura externa está formada por filas transversales de figuras circulares de un poco más de un centímetro de diámetro, muy ásperas y rugosas, rodeadas por varias filas de figuras periféricas pequeñas en forma de tubérculos ásperos e irregulares, dispuestos ellos mismos en grupos alrededor de un tubérculo central algo más grande, todos separados por surcos anchos, pero de fondo y contornos rugosos e irregulares, dando a toda la escultura externa una gran irregularidad y aspecto casi igual al que presenta la superficie externa de la coraza dorsal, presentando, como en ésta, en el fondo de los surcos y distribuídos sin crden alguno, un considerable número de agujeros circulares, de uno a tres milimetros de diámetro, que penetran en el interior de la coraza.

Procedencia:-L Los primeros restos de este animal fueron descuhiertos por el profesor Scalabrini en las barrancas de los alrededores de la ciudad Paraná. El fragmento de cola descripto y figurado ha sido recogido en la misma localidad por el señor León Lelong Thévenet.

Horizonte: - Piso mesopotámico de la formación patagónica.

ELEUTHEROCERCUS Kioken

E. KокеN: Ein neur Glyptodont aus Uruguay, en Abhandl, der Kön. preus. Akad. der Wis. $z u$ Berlin, 1888 .

Este género se distingue por el tubo caudal ancho y aplastado perpendicularmente como en el Panochtus, y con la extremidad posterior más angosta y redondeada. Los lados laterales están formados por una fila de verrugas o figuras elípticas rugosas y de gran tamaño, cada una de ellas rodeada por una fila de pequeñas perforaciones circulares. A cada lado de esta fila de verrugas longitudinales laterales hay una fila de figuras elipticas más pequeñas, colocadas una sobre la esquina de la cara dorsal y la otra en la esquina de la cara ventral; las figuras de estas filas son igualmente rugosas y rodeadas por una fila de agujeros circulares profundos pero no muy grandes.

Toda la parte central de la superficie dorsal está adornada por figuras elipticas mucho más pequeñas, cada una de ellas rodeada a su vez de una fila de figuras periféricas más pequeñas, poligonales y angulosas y de tamanio muy variable, todas separadas por surcos angostos y bien marcados. Cada una de estas figuras centrales está rodeada por una fila de agujeros periféricos colocados en el fondo del surco que limita a la figura, extendiéndose igualmente a menudo en el fondo de los surcos que separan a las figuras periféricas.

La superficie de la cara ventral está cubierta por figuras elípticas pequeñas, unas más grandes en los lados laterales y las más pequeñas en el medio, todas de superficie áspera y deprimidas en el centro en 
dirección de su eje mayor, sin figuras periféricas más pequeñas, pero cada una con una fila de surcos periféricos de mayor tamaño que los que rodean a las figuras centrales de la superficie dorsal. La conformación del tubo caudal muestra una mezcla de los caracteres que distinguen a los géneros Panochtus, Plaxhaplus, Palcchoplophorus y Zaphilus.

ËLEUTHEROCERCUS SETIFER Koken

Lamina LXV1, figura ?

KOKEN: Obra citada, láminas I y II.

Ei animal ha tenido una talla comparable a la de un gran Panochtus, pues el tubo caudal, del cual existe más o menos la mitad posterior, tiene hacia la mitad de su largo, a 36 centimetros de su extremidad posterior, 18 centímetros de ancho y cerca de 8 centímetros de grueso o diámetro vertical. El ancho del tubo empieza a disminuir en su último cuarto posterior, angostándose gradualmente hasta terminar en una punta rugosa, de 10 a 12 centímetros de ancho, formada por la unión de cuatro placas en forma de figuras irregularmente subcirculares, colocadas de a dos en sentido transversal, dos arriba y dos abajo, encerrando entre ellas algunas más pequeñas o rudimentarias.

Procedencia: - La pieza mencionada, sobre la cual se han fundado el género y la especie, procede de la República Oriental del Uruguay, pero es más que probable que la especie habitó igualmente en la República Argentina.

Horizonte:- Piso hermósico (?).

\section{Dœedicurida}

Los representantes de este grupo se distinguen por un conjunto de caracteres tan particulares y tan distintos de los que presentan los demás Gliptodontes, que permiten distinguirlos con la mayor facilidad a primera vista. La coraza dorsal se distingue por carecer completamente de los dibujos externos que presentan los representantes de las dos familias precedentes; y la cola termina en un tubo muy aplastado, particularmente en su parte posterior, con la punta terminal siempre más o menos ensanchada en forma de clava.

Los cuatro géneros de este grupo que hasta ahora me son conocidos se distinguen por los siguientes caracteres:

I. Placas de la coraza de superficie externa plana y rugosa.

a. Cada placa con un considerable número de perforaciones sumamente pequeñas, que le dan un aspecto esponjoso:

Neuryurus. 
II. Placas de la coraza de superficie externa lisa pero con grandes agujeros:

a. Placas de cara externa levantada en el medio en forma de ampolla y con agujeros de tamaño mediano en todo su contorns, que no perforan directamente todo el espesor de la placa:

Comaphorus.

b. Placas de superficie externa deprimida y con agujeros de gran tamaño:

aa. Los agujeros de las placas en corto número, reunidos en el centro y de gran tamaño, atraviesan las placas de parte a parte. Tubo caudal con grandes verrugas y figuras más pequeñas sólo en su extremidad:

Dodicurus.

$b b$. Los agujeros de las placas, en mayor número, se presentan en casi toda la superficie, son de tamaño más pequeño y se pierden en el interior esponjoso de las placas, sin atravesarlas de parte a parte. Tubo caudal adornado con dibujos o figuras en toda su extensión:

Plaxhaplus.

\section{NEURYURUS}

Euryurus. II. Gervars y Amegrino: Los mamiferos fósiles, etc., página I85, I880.

Fundé este género, conjuntamente con H. Gervais, sobre restos de un Gliptodonte particular que ya Paul Gervais había designado con el nombre de Glyptodon rudis, aplicándole el nombre genérico de Euryurus, pero como este nombre ha sido empleado con anticipación (1864) para designar un género de crustáceos, lo cambio ahora por el de Neuryurus.

Este género, presenta en su conformación una mezcla de caracteres de los géneros Panochtus, Doedicurus y Hoplophorus.

La coraza dorsal es de un espesor relativamente considerable, formada por placas pentagonales y exagonales, de aspecto general subcuadrado y que se distinguen fácilmente de las de todos los demás Gliptodontes por la superficie externa que es simplemente más o menos rugosa, en vez de presentar esas figuras simétricas a menudo tan complicadas que adornan la superficie externa de la armazón dérmica de los Gliptodontes.

A los lados y en la parte posterior las placas se vuelven un poco más pequeñas, de una forma rectangular constante y casi perfecta y dispuestas en filas transversales bien perceptibles. El borde posterior de la coraza está formado por una fila de placas cuya parte posterior se levanta un poco en forma de verruga, de superficie igualmente rugosa, 
terminando en un borde libre redondeado.Cada fila transversal termina a los lados en una placa del mismo tamaño o apenas un poco más pequeña que la penúltima, pero de superficie externa más convexa, formando un principio de elevación y terminando en borde libre arqueado, con la convexidad hacia afuera. En la cara interna las placas son un poco cóncavas, y con un cierto número de perforaciones pequenas distribuidas sin orden sobre toda la superficie de cada placa. Las placas permanecen unidas por suturas bien visibles en toda la extensión de la coraza, sin que se soldaran en una sola pieza, como sucede a menudo en los demás Gliptodontes.

El casco cefálico es muy parecido al del Panochtus, compuesto como en éste de un cierto número de piezas de tamaño relativamente considerable, muy cóncavas en la cara interna y convexas en la externa, con una figura externa muy elevada y cubierta de asperosidades, rodeada de una zona periférica rugosa o con tubérculos periféricos pequeños poco marcados.

La región caudal está formada por un cierto número de anillos casi circulares, compuestos de dos filas de placas de tamaño y forma bastante diferente; la fila anterior de cada anillo está formada por placas subcuadradas o rectangulares que, adelante, donde constituyen el borde libre son delgadas y más gruesas atrás, con la superficie externa simpl:mente rugosa; la fila posterior está formada por placas cuya superfici externa se levanta en su parte posterior formando verrugas o tubérculos elípticos con una elevación cónica y mayor en el medio; cada uno de esos anillos tiene sobre los costados laterales un par de placas más grandes, una a cada lado, que adquieren la forma de verrugas elipticas salientes más pronunciadas en los anillos posteriores que en los anteriores.

El tubo caudal es largo y muy deprimido en sentido perpendicular, formado por una serie de placas de formas muy distintas, unas subcuadradas o rectangulares y las otras pentagonales o exagonales, de tamaño relativamente pequeño pero muy gruesas y unidas unas a otras por suturas casi sueltas, de manera que todas las piezas son visibles y se separan unas de otras; estas placas son de superficie externa igualmente rugosa, pero un poco convexa en el centro, levantándose en algunas una zona periférica rugosa como en el Lomaphorus. Cada uno de los costados laterales del tubo caudal está adornado por una fila de grandes verrugas elípticas, con su eje mayor en dirección longitudinal, con su parte central elevada en forma de cono puntiagudo muy saliente y de superficie muy áspera.

El cráneo presenta su superficie superior o frontonasal un poco inclinada hacia abajo, pero no abovedada como en el Panochtus, sino plana, aunque no tanto como en el Glyptodon. La región parietal es semicilíndrica y cubierta de grandes perforaciones vasculares, estrechándose un 
poco el plano superior del cráneo hacia adelante para volver a ensancharse de una manera notable entre ambas órbitas, las que están limitadas hacia arriba y hacia atrás por un fuerte callo o apófisis postorbital muy rugosa formada por el hueso lacrimal; este hueso forma todo el borde superior y anterior de las órbitas con exclusión completa de los frontales, siendo continuado el arco óseo hacia abajo por el cigomático. El espacio del rostro que se extiende delante de las órbitas es ancho pero corto, estrechándose hacia adelante hasta la abertura nasal anterior, que era pequeña comparativamente a la del Glyptodon. El llano occipital es muy ancho y excesivamente bajo, con una fuerte cresta media perpendicular en el medio que lo divide en dos mitades y limitado hacia arriba por un reborde ancho pero no muy saliente. Las órbitas están colocadas muy adelante y completamente abiertas hacia atrás. El arco cigomático atrás de las órbitas es más delgado que en el Panochtus y el Hoplophorus, pero presenta en su parte superior un fuerte callo postorbital. El cráneo, visto de perfil, muestra que su superficie stuperior desciende gradualmente hacia abajo de atrás hacia adelante formando más bien que una convexidad un fuerte plano inclinado que le da un aspecto particular, presentándose excesivamente elevado en su parte posterior y muy bajo en la anterior.

Las muelas tienen la lámina de vásculodentina interna muy delgada y $\sin$ ramificaciones secundarias en la dentina. Las dos primeras muelas de cada mandíbula son mucho más pequeñas, la primera elíptica, muy pequeña y sin vestigios de los surcos perpendiculares; la segunda igualmente elíptica, pero más grande, mucho más alargada y con la división triprismática poco acentuada. Las demás muelas son de tamaño casi igtial, distinguiéndose las superiores por un pequeño surco perpendicular colocado sobre el canto externo del último prisma y las inferiores por pressntar el mencionado surco sobre el canto interno del prisma anterior.

Este animal, por la coraza sin escultura externa se acerca evidentemente al Dœdicurus; por la forma del escudo cervical está más cerca del Panochtus; y por la conformación general del cráneo, del Hoplophorus.

NEURYuRUS RUdis (P. Gervais) Ameghino

Lamina LX1, figuras $t$ a is: $y$ lamina LXZt, Bruras a as

Glyptodon rudis. P. Gervais: Comptes-rendus, volumen LXXXVI, página $136 \mathrm{r}, 1878$.

Euryurus rudis. H. Gervais y AmEGirno: Los mamiferos fósiles, etc., página 186, 1880. IYDEKKER: Catal. of Foss. Mamm, parte $V$, página I24, I880.

Esta es la especie típica del género y también la de talla más considerable, pues por los restos que se conocen parece que era un poco mayor todavía que la del Panochtus tuberculatus. Las placas de la coraza no son muy grandes, pero relativamente son muy espesas. Las placas 
mayores tienen entre 4 y 5 centímetros de diámetro y de 25 a 30 milímetros de espesor. La superficie externa de cada placa es áspera, de aspecto esponjoso, plana en el centro de la coraza y muy ligeramente convexa cerca de los bordes. En medio de las asperosidades de la superficic externa se ve un cierto número de perforaciones de mayor tamaño, generalmente dispuestas en una zona alrededor de la parte central, que penetran en el interior de la placa dirigiéndose oblicuamente hacia el centro. La cara interna muestra un considerable número de perforaciones pequeñas, con prolongaciones radiales hacia la periferia.

En el escudo cervical, las placas centrales más grandes presentan alrededor de la figura central una o dos filas de figuras periféricas rudimentarias.

En los anillos de la cola, las placas posteriores que tienen la verruga elevada terminan en bordes libres redondeados. separados unos de otros por escotaduras profundas, 10 que les da a los anillos un aspecto muy distinto del que presentan en el Panochtus y el Hoplophorus.

Las placas que componen las superficies superior e inferior del tubo caudal son más grandes en su parte anterior, de forma rectangular y dispuestas en fajas transversales, con la cara externa de aspecto esponjoso, con puntuaciones bien perceptibles y un poco convexas; mas hacia atrás se cambia la forma rectangular en pentagonal o exagonal, alterándose la disposición en filas transversales, mientras que la parte media de la cara externa se levanta para formar una figura más o menos elíptica, cuya superficie es igualmente rugosa. El tubo caudal no tuvo menos de 80 centímetros de largo.

Procedencia: - Los restos de esta especie no son abundantes, encontrándose en las provincias Buenos Aires y Santa Fe, a lo largo de las barrancas del río Paraná. Los restos más completos que hasta ahora me son conocidos fueron encontrados por F. Seguin no lejos de Rosario de Santa Fe y se conservan en el Museo de Historia Natural de París.

Horizonte:- Piso ensenadense de la formación pampeana.

\footnotetext{
Nevryurus antiques Ameghino

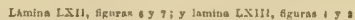

Euryurus antiquus. AmEGHino: Lista de los maniferos fósiles de Monte Hermoso, păgina 77 , número 49 , Junio de 1888 .

Esta especie era mucho más pequeña que la precedente, pues su tamaño no era mayor que el del Hoplophorus ornatus. La cara externa de las placas es más elevada en el centro y toda su superficie es más rugosa que en Neuryurus rudis, pero de un aspecto general menos esponjoso; las pequeñas perforaciones que penetran en el centro de las placas son, 
en cambio, de diámetro un poco mayor, habiéndolas también a menudo en la parte central más elevada de las placas. Sobre la cara interna las placas son un poco cóncavas y en vez de las numerosas pequeñas perforaciones que existen en las del Neuryurus rudis, no hay más que un pequeño número de agujeros, por 10 general de 3 a 6 , de tamaño conside. rable, casi tan grandes como en el Dodicurus, pero que se pierden en el interior de la masa en vez de perforar las placas por completo, como sucede en este último género. Las placas de la parte anterior de la coraza están dispuestas por filas transversales regulares, presentando un diámetro anteroposterior de 3 centímetros, 2 centímetros de ancho y 15 milímetros de espesor. Las placas terminales de la abertura posterior (?) son de mayor ancho o diámetro transverso que largo, terminando en borde libre rugoso.

Las placas resultan más pequeñas a los lados, pero apenas un poco más delgadas, con la cara externa todavía más elevada en el centro y rodeada de perforaciones muy acentuadas, lo que les da un aspecto algo parecido a las del Lomaphorus.

El cráneo tiene el tamaño del de un Hoplophorus.

La primera muela superior, muy pequeña, es elíptica sin surco interno ni externo. La segunda muela superior, es de corona mucho más prolongada, presentando las tres columnas internas rudimentarias; $y$ de las externas sólo la anterior y la posterior, estando reemplazada la del medio por una depresión plana perpendicular. Las demás muelas superiores tienen los tres prismas bien desarrollados, el posterior con un surco perpendicular sobre el lado externo, apenas indicado en la última muela. En la mandibula inferior la primera muela, todavía más pequeña que 1 a correspondiente de la mandibula superior, es de circunferencia subelíptica con una fuerte depresión perpendicular sobre el lado externo. La segunda muela inferior, mucho más grande y de sección más alargada, es angosta adelante, más ancha atrás y con la división triprismática apenas acentuada. Con la cuarta muela inferior empieza a acentuarse el surco de la esquina interna del prisma anterior de cada muela.

El paladar es un poco más ancho adelante que en el medio y con una fuerte cresta longitudinal media en su parte posterior.

\section{DIMENSIONES}

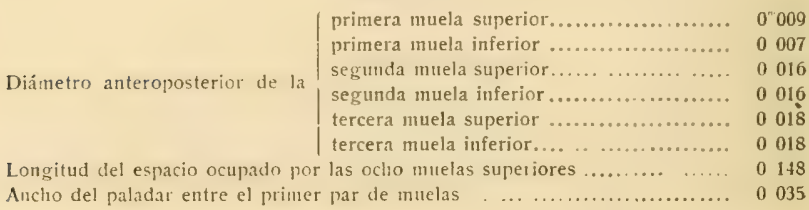


Ancho del paladar entre el quinto par de muelas ...................... $0^{0} 029$

Ancho de la parte superior del cráneo desde una lasta otra apófisis postorbitaria. $0 \quad 117$

Longitud total del cráneo ...................................... 0250

Diámetro vertical encima de la úitima muela .............................. 0120

Diámetro vertical encima de la primera muela.......................... 0054

Ancho del arco cigomático detrás de la órbita ............................ 0029

Diámetro transverso máximo entre los arcos cigomáticos................. $0 \quad 170$

Procedencia: - He recogido por primera vez los restos de esta especie en Monte Hermoso, a 60 kilómetros de Bahía Blanca.

Horizonte: - Piso hermósico de la formación araucana (mioceno superior).

\section{Neuryerus interundatus Ameghino

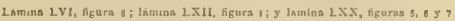

Euryurus interundatus. AMEGHNo: «Bol. de la Academia Nacional de Ciencias», t, VIII, página $134,1885 .-$ Idem: tomo IX, página I99, 1886.

Las placas del centro de la coraza del Neuryurus rudis son algo parecidas a las del Panochtus, diferenciándose, sobre todo, por la faita de esculturas o tubérculos externos, que están reemplazados por una superficie cubierta de asperosidades que convergen hacia un centro que se encuentra en el medio de cada placa; alrededor de este centro, vénse en la superficie pequeños agujeritos que se dirigen oblicuamente hacia el interior y hacia el centro de la placa.

El Neuryurus antiquus se distingue del anterior por las asperosidades de la superficie externa, que son much menos pronunciadas y por 103 agujeros, que son de tamaño un poco mayor.

Las placas del Neuryurus interundatus se distinguen de las de los dos precedentes por la ausencia completa de asperosidades externas, presentando una superficie casi lisa, algo más elevada en el centro, con una zona anular bastante ancha alrededor con muchos agujeros algo más grandes que los de las placas de las dos especies anteriores, que se dirigen igualmente hacia el interior y hacia el centro de la placa. La superficie interna algo cóncava muestra cuatro agujeros dispuestos por pares. La figura general de las placas es algo rectangular, de 52 milimetros de largo, 40 milímetros de ancho y 15 de grueso. Su talla debia aproximarse a la del Panochtus.

Estas placas presentan evidentemente una notable tendencia hacia la forma de las del género Dodicurus.

Las placas de las regiones laterales, cerca de los bordes anteriores, son de una forma más poligonal y pequeña, de 20 a 25 milímetros de diámetro y 11 milímetros de grueso, con la superficie cubierta de perforaciones de tamaño relativamente considerable. 
Procedencia: - Ha sido descubierta por el profesor Scalabrini en las barrancas de los alrededores de la ciudad del Paraná.

Horizonte: - Piso mesopotámico de la formación patagónica (oli. goceno inferior).

COMAPHORUS Ameghino

Amegrino: «Boletin de la Academia Nacional de Ciencias», tomo 1X, página 197, 1886.

Las placas son rectangulares, sin dibujo ni esculturas externas, pero con un considerable numero de agujeros grandes y colocados alrededor y al pie de una elevación central de la placa. Los agujeros penetran en la coraza sin atravesarla por completo perdiéndose en la masa esponjosa.

Comaphorus concisus Ameghino

Lamuna $L X_{1}$ Hguras $19 y 13$

Amemino: Obra y página citadas.

Fundé este género y la especie sobre una placa de la coraza, de una forma muy particular, completamente distinta de las que forman las corazas de todos los otros géneros que hasta ahora me son conocidos. Es una placa rectangular de 40 milímetros de largo, 27 milímetros de ancho y 13 milímetros de espesor. La cara interna, algo cóncava y lisa, muestra varios agujeros repartidos sin orden alguno, unos de 2 a 4 milímetros de diámetro y otros muchísimo más pequeños. En la cara externa no presenta dibujos ni esculturas, acercándose por este carácter a los géneros Neuryurus y Plaxhaplus Ameghino y Doedicurus Burmaister, pero se distingue de todos ellos por su parte central que se levanta formando una especie de ampolla o elevación de varios milímetros de alto y superficie convexa. Esta cara externa muestra una veintena de perforaciones, unas de diámetro considerable y otras más pequeñas que penetran en la placa dirigiéndose hacia el centro de ésta. Por el crecido número de estos agujeros se parece al Plaxhaplus, pero se diferencia de éste porque los agujeros están colocados simétricamente hacia el centro, no existiendo en el Plaxhaplus la elevación central que muestra la placa del Comaphorus. Por el tamaño y la profun lidad de las perforaciones se parece al Dodicurus, pero en las placas de éste los agujeros sólo son en número de tres o cuatro como regla general o cinco o seis a lo sumo, mientras que en la placa en cuestión son en número de veinte. Además, en el Dœdicurus los agujeros perforan completamente la coraza, mientras que en el Comaphorus se pierden en la masa esponjosa interna de la placa. Un cierto número de estos agujeros están colocađos en el Comaphorus encima mismo de la elevación central y los demás en la base de ésta simétricamente alrededor. Estas par- 
ticularidades no dejan duda de que el Comaphorus es un género particular, distinto de los conocidos, que entra en la misma división que las formas pampeanas Dodicurus y Plaxhaplus. Otra particularidad de esta placa es la de presentar indicios evidentes, como distintos otros loricados del Paraná, de estar formada por dos partes primitivamente distintas, como si fueran dos placas que se hubiesen unido y que sobre su línea de contacto se hubiera formado la elevación mencionada. La huella de esta antigua división en dos se observa en la cara externa en forma de una pequeña ranura transversal interrumpida a trechos, últimos vestigios de una antigua sutura, y en la cara interna por una elevación transversal, especie de costura formada por la osificación y anquilosis sobre esa línea de las dos placas primitivamente distintas.

Procedencia: - Esta pieza la he recogido personalmente en un pequeño arroyo de las inmediaciones de la ciudad Paraná, conjuntamente con restos de Chlamydotherium, Promegatherium, etc.

Horizonte:- Piso mesopotámico de la formación patagónica (oligoceno inferior).

\section{DOFDICURUS Burmeister}

Burmeister: «Anales del Museo Público de Buenos Aires», tomo II, página 393, i\$74, Idcn: Description physique, etc., tomo III, página 418, 1879. - Idem: Nere beobaciutungen an «Doedicturus giganteus», en Abhandl. der Kön. Akad. de Wissensch. z. Berlin, 1879 .

II. Gervais y AMEgino: Les mammifères fossiles de l'Amérique Méridionale, página izg. aก๊̃o 1880 .

Amecrino: Exposition Uniwerselle de 1878 . Catalogue special de la section anthropologique et paléonlologique de la République Argentine, páginas 47 y 62. - Idem: La antigüedad del hombre en el Plata, tomo II, páginas 260 y 330, 1881. - Idem: Sobre la necesidad de borrar el género Schistopleurum, etc., en «Boletin de la Academia Nacional de Ciencias». tomo V, página 29, I883. - Idem: Excursiones gcológicas y paleontoíbgicas, en «Boletin de la Academia Nacional de Ciencias», tomo VI, página 200, 1884.

L,YDEKKFR: Catal. of Foss. Mammalia, parte V, página 122, 1887.

En su forma general, la coraza del Dodicurus participa de los caracte. res que distinguen a las de los géneros Glyptodon y Panochtus; es corta. sumamente gruesa en el medio, casi esférica como la del Glyptodon y sumamente alta, con una elevación o joroba que asciende bruscamente hacia atrás por encima de la región sacrolumbar, como en el Panochtus, pero de una manera todavía mucho más pronunciada, lo que le da a la coraza una forma completamente especial. A cada lado de la región posterior, en el punto donde la coraza descansa encima de las alas ciáticas, existe la misma depresión que se encuentra en la coraza del $\mathrm{Pa}$ nochtus.

Toda la coraza dorsal se compone de placas, cuya superficie externa es casi igual a la interna, por carecer de los adornos, esculturas o rugosidades que presentan en la cara externa, las placas de la coraza de casi todos los otros géneros. Las placas de la coraza del Dodicurus son de 
superficie lisa tanto en el lado interno como en el externo, pero de cara interna un poco más cóncava que la externa y algo radiada por un considerable número de estrias muy finas que convergen hacia el centro, que desaparecian en edad muy avanzada. Cada placa presenta un cierto número de agujeros, generalmente de gran diámetro, que la perforan completamente de parte a parte; el número de estas perforaciones, su tamaño y su colocación, son muy variables, según las distintas regiones de la coraza y según las especies; por lo común son en número de tres a cinco en la cara externa, colocados en la región central y dispuestos de modo que penetran convergiendo hacia el centro de la placa, reuniéndose a menudo en dos o tres en la cara opuesta, por lo que se observa que el número de perforaciones es mayor sobre el lado externo que sobre el interno. Las placas tienen la misma figura pentagonal y exagonal que en los demás Gliptodontes, pero asemejándose más por sus contornos a las del Panochtlls, tomando sobre los costados, como en este género, una forma más rectangular y una disposición en filas transversales más acentuada que en el Glyptodon; estas filas transversales de la parte posterior de la mitad anterior de la coraza terminan como en el Panochtus separadas por hendeduras perpendiculares bastante acentuadas. E1 espesor de las placas es variable, asi como su tamaño: en los costacios laterales, cerca de la periferia, son muy pequeñas y muy delgadas, mas hacia el centro de la coraza y en su parte anterior son un poco más grandes y de un espesor medio, en el centro de la coraza y particularmente encima de la pelvis son mayores todavía y de un grueso extraordinario que alcanza hasta siete y ocho centímetros. Todo el borde de la coraza está formada por una fila de placas parecidas a las del resto de ella, pero generalmente son más pequeñas, siempre más delgadas, igualmente perforadas y con un borde libre delgado y muy irregular. Las placas de la coraza del Dudicurus estaban unidas entre sí por suturas más flexibles que en los demás géneros, excepción hecha del Ncothoracophorus; por eso es que no se encuentran corazas completas de este animal aunque abundan sus restos, pues las placas que las componian se desarticulaban con facilidad, quedando sólo fijas las de la región que cubría la cadera, que se unían por suturas más imbricadas, las que desaparecian en edad avanzada para soldarse entre sí las placas.

La coraza del género Dedicurus no formaba la superficie externa del animal como en los demás géneros, sino que estaba implantada en el espesor del cutis; $y$ encima de éste se extendía una segunda coraza externa, de naturaleza córnea, que formaba al exterior una superficie áspera por una multitud de pequeños tubérculos parecidos a los que adornan la coraza del Panochtus, pero sin ninguna relación en su disposición con la coraza ósea subyacente, de la que estaba separada por 
un espacio de 5 a 6 milímetros, rellenado por substancia conjuntiva elástica; los grandes agujeros que perforan la coraza ósea estaban destinados a dar paso a los vasos sanguíneos destinados a nutrir este tejido externo y a renovar de continuo la cubierta córnea que lo envolvía, formada por los tubérculos mencionados, constituidos a su vez. por una sucesión de capas finas superpuestas, que se sucedian del interior al exterior a medida que se desprendian las más superficiales.

El escudo cefálico estaba formado por pequeñas placas en su mayor parte sueltas, sin estar unidas por suturas, de superficie irregular y con numerosas perforaciones vasculares.

La cola se componía de una sucesión de anillos semimovibles, cuyo número es desconocido, pero que no debia pasar de seis a siete, formados por dos o tres filas de placas más o menos rectangulares, de bordes muy irregulares y con perforaciones parecidas a la que presentan las placas de la coraza dorsal. A estos anillos sigue un tubo caudal de tamano enorme. sumamente aplastado en sentido vertical; la parte anterior de este tubo se ensancha como la boca de un embudo, para adaptarse al último anillo separado, disminuyendo luego rápidamente de diámetro hacia atrás, tomando una forma casi cilíndrica para volver a ensanciarse a veces de una manera extraordinaria en su parte posterior en forma de clava o de una cabeza de mano de mortero fuertemente deprimida. Esta cxtremidad ensanchada transversalmente y deprimida verticaimente, está adornada en los costados y sobre las partes laterales de las caras superior e inferior con algunas grandes verrugas elipticas de tamaño enorme, de borde periférico elevado y superficie excesivamente rugosa y deprimida en cuyo centro se levanta una prominencia con numerosás rugosidades que parten como radios de este centro a la periferia; se supone que en estas verrugas se adaptaban fuertes tubérculos córneoespinosos. Estas grandes verrugas están acompañadas de otras más pequeñas igualmente elípticas o subcirculares, de una estructura idéntica a la de las grandes. En las caras planas inferior y superior de la extremidad caudal, el espacio comprendido entre las verrugas mencionadas está cubierto por una seric ininterrumpida de pequeños tubérculos rugosos, de contorno poligonal y separados por surcos más o menos bien marcados, presentando un aspecto parecido a la escultura externa de la coraza del Panochtus. Hacia adelante, en donde desaparece el ensanchamiento de la extremidad posterior, estos tubérculos desaparecen poco a poco, apareciendo en cambio pequeños agujeros vasculares que se vuelven más numerosos hacia adelante, hasta que en la parte ensanchada antcrior la superficie de la coraza de la cola es casi lisa, sin tubérculos o rugosidades, pero con numerosas perforaciones como en la coraza dorsal, aunque mucho más pequeñas y siempre dispuestas con su mayo: diámetro de adelante hacia atrás, acompañadas en la superficie de in:- 
presiones dispuestas en la misma dirección. La parte anterior del tubo cnsanchada en forma de embudo se compone de placas muy delgadas cuyas stuturas permanecen visibles entre ellas hasta edad bastante avanzada, pero la extremidad posterior claviforme no presenta vestigios de suturas, mostrándose como de una sola pieza ósea, sólida y maciza, con filas regulares de perforaciones vasculares alrededor del borde perifé. rico de las grandes verrugas elipsoidales.

El cráneo del Dodicurus, como sucede con la coraza, presenta caracteres de Glyptodon y de Panochtus; se parece al del Glyptodon por su superficie superior, que presenta los nasales, frontales y parietales sobre un mismo plano casi horizontal, como en este género, en vez de formar una fuerte convexidad como en el Panochtus, pero los nasales se prolongan en punta anterior y la órbita forma un circulo completo cerrado atrás como en el mencionado género. La apertura nasal está dirigida hacia adelante como en el Giyptodon, pero es más alta y no de figura triangular sino casi del mismo ancho arriba y abajo. Los huesos nasales se extienden delante de la abertura nasal y de los maxilares en una punta libre bastante larga. Detrás de la órbita, el hueso cigomático es casi tan grueso y ancho como el del Panochtus y con una prolongación de la apófisis postorbitaria que se une por soldadura completa con la apófisis postfrontal formando un puente que separa la cavidad orbitaria de la fosa temporal. La mandibula inferior es de rama ascendente un poco más baja que la del Panochtus, pero de rama horizontal muy alta y parecida a la del Glyptodon. Las muelas carecen de las pequeñas ramificaciones secundarias de la lámina interna de dentina vascular que presentan las del Glyptodon; y la primera de cada mandibula es bastante más pequeña que las otras y de sección transversal semielíptica.

El atlas presenta los mismos caracteres intermedios que las demás partes del esqueleto; la apófisis espinosa es baja y casi rudimentaria como en el Glyptodon; y las alas o apófisis transversales tan pequeñas como en el Panochtus.

E] hueso mesocervical está compuesto de cuatro vértebras. La sexta vértebra cervical es libre, pequeña y triangular como en el Panochíus. El hueso metacervical es parecido al del mismo género.

El húmero tiene el agujero epitro leano como en el Hoplophorus y el Punochtus; y el pie anterior no tiene más que tres dedos completos correspondientes a los tres del medio, o sea segundo, tercero y cuarto, pero existe de cada uno de los dedos laterales, primero y quinto, un ru dimento del metacarpiano.

La pelvis es sumamente fuerte y de un ancho sorprendente. El fémur y los demás huesos del miembro posterior son igualmente robustos y parecidos a los del Glyptodon. El pie posterior termina en cuatro dedos completos, faltando el primero o interno. 


\section{Doedicurus clavicaudatus Owen}

Lamina LXXX11, figurn $\nu_{;}$y lamins LXXXV, figura

Glyptodon clavicaudatus. OwEN: Reprort of the British Asociat. for the advanc. of scienc., año 1846 , tomo 11 , página 67 .

Nodor: Description d'un nouzean genre d'édenté fossile, etc., página 133, 1856.

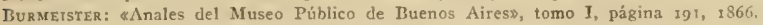

Glyptodon gigas. Bravard: Catalogue des collections, etc., (nomen nudum).

Glyptodon giganteus. SERRE: Compte-rendu hebdomadaire des sciences, etc., 23 Oct. 1865.

G. Poucuer: «Journal de l'Anatomies, etc., de Crr. Ronin, Marzo de 1866.

Hoplophorus clavicaudatus. NoDot: Description d'un nouvean genre d'édenté fossile.

Panochtus gigantcus (Serres). Bukmerster: «Anales del Museo Público de Buenos Aires», tomo II, páginas $9 \mathrm{I}, 140 \mathrm{y} 223$.

Doedicurus giganteus (Serres). Buranister: «hnales del Museo Público de Buenos Aires», tomo II, pág. 394 y 404 . - Idem: Abliandl. d. Kön. Akad. d. Wissensch. z, Berlin, pliys. Cl., año 1878. - Idem: Description physique, etc., tomo III, página 420, 1879.

Doedicurus clavicaudatus (Owen). H. Gervais y AMEgrrino: Los mamiferos fósiles, etc., página 180,1880 .

L.YDEKKER: Catal. of Foss. Mamm., parte V, página I22, I887.

Panochtus tuberculatus. Burmeister: «Anales del Museo Público de Buenos Aires», \&. I, página 77 , linea 29.

Hoplophorus clavicandafus. Nonor: Description d'un nourcau gcnre d'édenté fossile, página 106.

Doedicurus Urmgnayensis. H. Gervals y Amegrixo: Los mamiferos fósiles, etc., pág. 182, ano 1880 .

El ejemplar tipo de esta especie es la extremidad de un tubo caudal, descripto primeramente por Owen de una manera sucinta y sin dibujos, bajo el nombre de Glyptodon clavicaudatus. Posteriormente, fundé en colaboración con Gervais una nueva especie bajo el nombre de Daid:curus uruguayensis sobre un tubo caudal figurado por Nodot y procedente de la Banda Oriental, pero Lydekker, en posesión de un molde de este ejemplar, ha podido compararlo con la pieza original mencionada por Owen y cerciorarse de que ambas provienen de una misma especie. La cadera y el tubo caudal más completo, descriptos por Burmeister en 1879, bajo el nombre de Dodicurus giganteus, pertenecen sin duda a la misma especie, que ha sido de tamaño verdaderamente gigantesco y considerablemente mayor que las otras especies que luego se han citado como del mismo género.

Todos los tubos figurados hasta el día son incompletos, pero tengo conocimiento de algunos más enteros que se hallan en poder de particulares y que tienen de $1^{\mathrm{m}} 10$ a $1^{\mathrm{m}} 30$ de largo, lo que puede dar una ide 1 del tamaño enorme que alcanzaba.

Lo que distingue al tubo caudal de esta especie, además de sus grandes proporciones, es el ensanchamiento enorme de su parte posterior. cuyo diámetro transverso sobrepasa en más del doble al ancho que presenta el tubo en su parte más angosta, más o menos hacia la mitad de su largo. Este ensanchamiento empieza a acentuarse poco a poss, aumentando luego bruscamente alli donde empiezan el par de granics verrugas huecas laterales, alcanzando su mayor diámetro transverso hasta 35 centímetros. 
Toda la superficie del tubo que se extiende delante de la parte más ensanchada determinada por el par de grandes verrugas laterales mencionadas, es casi lisa, sin esculturas, pero con numerosas perforaciones vasculares en forma de agujeros pequeños que se hacen cada vez más grandes hacia adelante.

La parte terminal ensanchada transversalmente y aplastada vertica!monte, está adornada con diez enormes verrugas, colocadas, cuatro en la superficie superior, cuatro en la cara inferior y dos laterales, una a cada lado, situadas más adelante de las anteriores.

Las verrugas laterales empiezan con el ensanchamiento brusco de la parte claviforme; son de contorno elíptico, cóncavas, de fondo áspero $y$ rugoso y de un tamaño positivamente enorme, alcanzando hasta 25 centimetros de largo, ocupando más o menos la mitad anterior del largo total de la parte ensanchada o claviforme.

Vista desde abajo, la parte ensanchada es un poco convexa y presenta cuatro grandes figuras subcirculares, excavadas, de fondo rugoso, con aristas radiales que parten del centro a la periferia. De estas cuatro verrugas, las dos más grandes son terminales y las dos más pequeñas están colocadas adelante pero sobre los lados y todas en declive, ocupando la mitad inferior del borde lateral que se extiende detrás de las grandes verrugas elípticas laterales mencionadas.

En la cara superior hay otras cuatro grandes verrugas subcirculares opuestas a las inferiores, pero más grandes. Estas verrugas son de tamaño muy desigual, las dos posteriores colocadas en la extremidad, más pequeñas y las dos anteriores colocadas a los lados, mucho más grandes, las cuatro en posición oblicua como las inferiores, ocupando la parte superior de los costados que se extienden detrás de las dos enormes verrugas laterales. Toda esta parte superior comprendida entre las seis grandes verrugas mencionadas, es muy deprimida, ligeramente excavada en sentido longitudinal hacia el medio, con algunas verrugas subcirculares más pequeñas colocadas en el lado interno de las grandes y todo el resto de la superficie está cubierto por fuertes asperosidades que afectan casi la forma de pequeños tubérculos.

Atribúyese a esta especie una cadera enorme conservada en el Museo de Paris y descripta por Serres y Pouchet bajo el nombre de Glyptodon gigas. Las dimensiones de esta pieza son las que siguen:

\section{DIMENSIONES}

Anchura de la pelvis entre las esquinas externas de los acetábulos ........ $0^{m} 85$

Diámetro transversal del acetábulo ............................... 019

Distancia de las esquinas externas de los huesos iliacos ............. 080

Distancia de las esquinas de las alas ciáticas ........................ 105

Diámetro longitudinal de la cavidad cotiloides $\ldots \ldots \ldots \ldots \ldots \ldots \ldots \ldots \ldots \ldots . \ldots 60 . \ldots \ldots$

Diámetro transversal de la misma, debajo de las apófisis transversas del sacro. 067

Longitud del arco sacral con la curva... ............................. 0 72 (?) 
Procedencia: - Los restos de esta especie se encuentran con frecuencia en la provincia Buenos Aires y en la República Oriental del Uruguay.

Horizonte:- Piso lujanense de la formación pampeana.

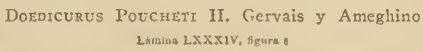

II. Gervais y AMEghino: Los mamíferos fósiles, etc., página 182, I880.

Fundé esta especie en colaboración con el doctor H. Gervais, sobre un tubo caudal de las colecciones del Museo de París, figurado anteriormente por de Blainville y por Nodot, que indica un animal de proporciones bastante menores.

El tubo, aunque igualmente deprimido en su parte superior, es proporcionalmente más cilíndrico, de tamaño más pequeño y bastante menos ensanchado en su parte posterior, donde el diámetro transverso múximo no pasa de 25 centímetros y no excede a una mitad más del ancho del tubo en la parte más angosta, que se encuentra hacia la mitad de su largo. La parte posterior claviforme tampoco se ensancha bruscamente como en la especie precedente, sino de una manera más gradual; y el par de grandes verrugas laterales, no son tan salientes. Las grandes verrugas principales de la parte terminal son en número de diez como en el tubo de la otra especie y con la misma disposición general, pero bastante más pequeñas, de acuerdo con el tamaño menor de todo el tubo. Las grandes figuras elípticas laterales, son de tamaño enorme, en proporción no más pequeñas que en la otra especie, pues tienen hasta 20 centímetros de largo, pero son proporcionalmente más angostas y cada una está precedida adelante por una verruga subcircular mucho más pequeña. La cara superior presenta al lado de las verrugas principales otras verrugas más pequeñas; y todo el resto de la superficie es fuertemente rugoso y con asperosidades que se pierden adelante de las grandes figuras laterales, siendo reemplazadas por perforaciones vascu. lares de diferentes tamaños.

El largo total del tubo entero parece que no pasaba de un metro.

Procedencia: - Se han encontrado tubos caudales parecidos en distintos puntos de la provincia Buenos Aires y en la República Oriental del Uruguay.

Horizonte:- Piso bonaerense de la formación pampeana.

Doeptcurus Kokentanus, $n$, $s p$.

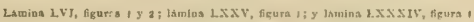

Esta especie era de conformación parecida a la precedente, pero más delgada aún y con algunos caracteres que la acercan al género 
Plaxhaplus. Las placas de la coraza son relativamente delgadas, con suturas sueltas y perforadas por grandes agujeros.

El tubo caudal es muy largo, pero poco grueso y con la extremidad claviforme menos ensanchada todavía que en el Dædicurus Poucheti, pudiéndose calcular el ensanchamiento máximo en una tercera parte más que el ancho de la parte más angosta colocada hacia la mitad del largo del tubo. El ejemplar más completo que conozco tiene unos 90 centímetros de largo, pero está roto en su parte anterior, por lo que es probable que su largo total no bajara de un metro.

La parte claviforme ensanchada, a partir del borde anterior de las grandes verrugas laterales, tiene unos 30 centímetros de largo, con Ln diámetro transverso máximo de 20 centímetros, que permanece casi igual en la mayor parte del largo de esta región.

Las grandes verrugas elipticas laterales forman una línea longitudinal casi recta de 16 centimetros de largo. La cara superior es igualmente deprimida y con cuatro grandes verrugas terminales, pero en vez de ser como en las otras especies las dos anteriores muy grandes y las posteriores mucho más pequeñas, ahí las posteriores son mucho más grandes y las dos anteriores muy pequeñas. En el espacio terminal limitado por esas cuatro grandes verrugas, existen otras dos más pequeñas y poco acentuadas, sin vestigios en todo el resto de la cara superior de otras verruguitas más chicas, con toda la superficie menos áspera y rugosa que en las otras especies, presentando hacia adelante las mismas impresiones o agujeros vasculares, pero más acentuados.

En los costados del tubo, delante de las dos gran'des verrugas laterales, se extiende una doble fila de impresiones elípticas o subcirculares, poco acentuadas, como en forma de verrugas rudimentarias, que se extienden casi hasta la parte anterior, hasta perderse gradualmente. Tal carácter distingue muy bien de las demás a esta especie, como que la aproxima al género Plaxhaplus.

El cráneo, los pies y otras partes del esqueleto descripto por Burmeister en el tomo segundo de los «Anales del Museo» y dibujadas en 1a lámina XLII bajo el nombre de Dadicurus giganteus, presentan dimensiones relativamente pequeñas, que demuestran que no pueden provenir del Dodicurus clavicaudatus. Por el examen personal que he hecho de esas piezas y de los fragmentos de coraza que los acompañaban, me creo autorizado para atribuírselas al Dœdicurus Kokenianus.

Procedencia: - He recogido restos de esta especie, y entre ellos parte considerable de un esqueleto, que está actualmente en el Museo de La Plata, en los alrededores de la Villa Luján.

Horizonte: - Pisos ensenadense y belgranense y base del piso bonaerense de la formación pampeana. 
Amegrino: «Boletín de la Academia Nacional de Ciencias》, tomo VI, página 199, $18+4$.

Este género está caracterizado por placas lisas, sin adornos externos, pero con agujeros como en las del género Dœdicurus, aunque no dispuestos en grupos; y con toda la parte posterior de la coraza con depresiones transversales profundas y de fondo cóncavo, más pronunciadas a medida que se acercan a la abertura caudal.

Toda la coraza es menos esférica y no tan elevada como la del Docdicurus, pero sí más baja y más alargada, presentando un mayor parecido con la del Hoplophorus.

El tubo caudal es de una forma muy particular, intermedia entre la que presentan los tubos caudales del Panochtus y del Nopachtus por una parte y los del Dedicurus por la otra, muy parecido en la disposición de la escultura externa al del Eleutherocercus, pero con su extremitad distal un poco ensanchada, aunque de una manera apenas sensible. Su parte proximal es comprimida, hacia la mitad es casi cilíndrica y su extremidad distal ensanchada es fuertemente deprimida. Toda la superficie del tubo está adornada por figuras más o menos elípticocilíndricas fuertemente excavadas en el medio y rodeada cada una por una fila de agujeros periféricos de gran tamaño. Las figuras que cubren las dos caras superior e inferior son de tamaño moderado, pero las laterales son algo mayores, aumentando gradualmente hacia atrás hasta que la punta de la extremidad distal está cubierta por un corto número de grandes verrugas con una disposición parecida a la que presentan en Dœdicurus.

Plaxitartes caxal,ictiatus Ameglino Lamina LVI, fieura a

AMFGrino: Obra y página citaclas.

La talla de esta especie, a juzgar por los pocos restos que de eila me son conocidos, era comparable a la de una de las más grandes especies del género Dodicurus, pues las placas de la parte posterior de la coraza no tienen menos de 7 a 8 centímetros de largo, por 5 a 6 de ancho, con un grueso proporcionado. La superficie externa de las placas es un poco convexa y con un considerable número de agujeros; pero éstos no están dispuestos en grupos regulares como en las placas del género Dodicurus, ni tampoco perforan por completo la coraza, como sucede en este último género; están repartidos sin ningún orden por sobre toda la superficie de las placas, presentando tamaños muy variados, pues unos son tan pequeños que apenas puede penetrar en ellos la 
punta de un alfiler, mientras que otros alcanzan un diámetro de 12 a 15 milimetros. Las placas son fuertemente soldadas entre sí por suturas fijas muy fuertes y dispuestas en fajas transversales. La línea de sutura de cada faja transversal con la que le sigue hacia atrás forma en la superficie externa una ancha y profunda depresión transversal, de fondo cóncavo, que corresponde a una prominencia de la superficie interna. Estas depresiones o canales transversales debian darle a la coraza un aspecto raro, sumamente distinto del que presentan los demás Gliptodontes, con excepción de la región más posterior de la coraza dorsal del Nopachtus; pero la coraza de éste, adornada de dibujos, es sumamente distinta de la del Plaxhaplus, que es lisa y perforada como en el Doedicurus.

Proccdenciu: He recogido restos de la coraza de esta especie pro. venientes del centro del dorso y de los bordes, en la Villa de Luján; pero como las piezas recogidas son hoy propiedad del Museo de La Plata, no puedo dar a su respecto otros datos ni dibujos, con excepción del croquis de una de las placas del centro del dorso.

Horizonte:- Piso lujanense de la formación pampeana.

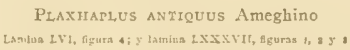

Doedicurus antiquns, AMEgHก⿻: Apuntes preliminarcs sobre algunos namiferos cxtinguidos de Monte Hermoso, página 18, 1887. - Idem: Lista de los mamiferos fósiles de Monte HerMoso, página 17 , número 48 , Junio de 1888.

Doedicuras Copei. Mforeno: Informe preliminar, etc., página ro, Julio de r 888 .

Esta especie era de tamaño mucho menor que la precedente, más pequeña todavia que el Dadicurus Kokeniunus. La coraza es baja y oblonga; y por los trozos que se conocen parece no tuvo más de $1^{m} 60$ a $1^{\mathrm{m} 70}$ de largo por 90 a 95 centímetros de ancho máximo.

Las placas del centro de la coraza son rectangulares, alargadas, de 5 a 6 centímetros de diámetro anteroposterior por 3 a 4 de diámetro transverso y 2 a 3 centímetros de espesor, estando reunidas unas a otras por suturas más cercanas y más fijas que en las especies del género Doedicurus.

La cara interna de cada placa es apenas un poco cóncava y casi lisa, con un cierto número de agujeros pequeños, generalmente de 5 a 8 , cuyo diámetro varía de 1 a 2 milímetros, dispuestos sin orden alguno, pero por lo general de manera que dejan libre la parte central, perdiénclose en el interior de la masa esponjosa. La cara externa es un poco levantada en el medio y algo deprimida adelante y atrás, con una cantidad de agujeros cuyo número puede alcanzar hasta 20 , la mayor parte 
agrupados en una zona alrededor de la parte céntrica de la placa, penetrando oblicuamente al interior todos en dirección al centro para perderse en la masa esponjosa.

El tamaño de estos agujeros es sumamente variable, habiéndolos que tienen menos de un milímetro de diámetro, mientras otros tienen 304 , pero sin que ninguno de ellos atraviese directamente las placas, como sucede en Dodicurus.

El tubo caudal tiene cerca de un metro de largo, siendo más grande en su extremidad proximal y comprimido verticalmente, más delgado en su segundo tercio posterior y de sección más cilindrica, volviendo a ensancharse un poco en la extremidad distal, aumentando igualmente su espesor, siendo ahí un poco convexo en su cara superior y deprimido en la inferior. En su parte más angosta, antes de empezar el ensanchamiento distal, tiene aproximadamente unos 14 centímetros de ancho por 10 de espesor vertical, alcanzando hacia atrás en su parte más engrosada, de 10 a 17 centímetros de ancho por 12 a 13 de diámetro vertical.

Toda la superficie del tubo está cubierta de dibujos.

Visto por la cara superior aparcec cubierto por una cantidad de figuras elipticas, fuertemente excavadas en el medio y rodeadas por una fila de profundos agujeros periféricos de uno a dos milímetros de esFesor; estas figuras tienen un diámetro mayor de 3 a 4 centímetros. La parte superior de la extremidad distal está formada por cuatro grandes figuras excavadas y rugosas en el centro, dispuestas por pares transversales y de contorno casi circular. Las dos anteriores son mucho más pequeñas que las posteriores, de un diámetro de 6 centimetros, pero profundamente excavadas. Las dos posteriores tienen aproximadamente unos 9 centímetros de diámetro, siendo menos excavadas pero de fondo más rugoso. Cada una de estas cuatro grandes figuras está rodeada por una fila de agujeros periféricos de 1 a 3 milimetros de diámetro.

La cara opuesta, que supongo sea la inferior, está cubierta por las mismas figuras elípticocirculares pequeñas, excavadas en el centro y rodeadas por una fila de perforaciones, extendiéndose hasta la misma extremidad distal, en donde sólo existen dos figuras laterales, una a cada lado, de tamaño bastante mayor, separadas por una más pequeña y seguidas por otras dos, igualmente pequeñas, que forman la parte terminal.

Vista de lado, la misma extremidad distal formada por la parte comprendida entre la última gran figura superior y la opuesta inferior es delgada. A un decímetro más o menos de la extremidad se encuentra la primera figura lateral, que es la mayor, de contorno elíptico, de 10 centimetros de diámetro mayor, por un poco más de 7 centímetros 
de diámetro transverso, fuertemente excavada en el centro, de super. ticie rugosa y rodeada de una gran fila de perforaciones periféricas.

Hacia adelante siguen a esta figura lateral única dos figuras más pequeñas y desiguales en tamaño, un poco menos elípticas pero más profundamente excavadas en el centro y más rugosas y también rodeadas por una fila de agujeros periféricos. De estas dos figuras, la más grande, de unos 8 centimetros de diámetro mayor, está colocada mirando hacia la cara inferior; y la menor, de sólo 7 centímetros de diámetro, está colocada sobre la cara superior.

A estas dos figuras siguen hacia adelante otras dos figuras laterales, más o menos de la misma forma e igualmente de tamaño desigual, pero colocadas la más grande hacia la cara superior y la más pequeña hacia la inferior.

Procedencia:- He recogido los restos de esta especie en Monte Hermoso, a 60 kilómetros de Bahia Blanca. El tubo caudal que me ha servido de base para la descripción procede de otro yacimiento cercano del precedente y es propiedad del doctor Christian Heusser.

Horizonte:- Piso hermósico de la formación araucana (mioceno superior).

PSEUDOFURYURUS, $n$ gen.

Este género no está incluido en el cuadro sinóptico por haber reci. bido sus restos cuando dicho cuadro ya estaba impreso. Por los caracteres de la cara dorsal, de la cual conozco placas de las distintas regiones, es un tipo intermedio entre Plaxhaplus y Neuryurus.

Las placas del centro de la coraza dorsal son de forma rectangular, con la cara interna casi plana. Cada placa tiene en la cara externa una figura central subcircular, muy elevada, casi lisa y deprimida en el centro. Todo el resto de la superficie de cada placa forma una zona mucho más baja y de superficie irregular, conteniendo una serie de depresiones cóncavas dispuestas alrededor de la elevación central en filas periféricas concéntricas, que se pierden en los bordes de las placas en forma de rugosidades. Algunas de estas depresiones tienen en su fondo perforaciones circulares o elipticas que penetran en el interior de la placa, dirigiéndose oblicuamente hacia el centro.

Las placas próximas a los bordes laterales de la región anterior presentan en la superficie externa, en un punto que no corresponde exactamente al centro, una figura central en forma de tubérculo o protubelancia elevada, de cuya periferia parten en todas direcciones aristas o crestas elevadas que como radios de un círculo se dirigen al borde de 
1a placa, no sin antes ser interceptadas por una cresta que corre a alguna distancia de la figura central, trazando alrededor de ésta una curva o círculo, cuyo entrecruzamiento da origen a la formación de dos series de profundas cavidades colocadas en dos círculos alrededor del tubérculo central.

Pseudoeuryures I,rioncianus, $n . s p$.

EAmita LXY, fikura ;

Es la única especie de este género que por ahora me es conocida y ha tenido una talla considerable, comparable a la de un Panochtus; pero probablemente era mucho más débil, pues la coraza es proporcionalmente muy delgada. Las placas de la región central, que son làs más grandes, tienen 6 centímetros de largo por 4 a 5 de ancho y 15 a 16 milímetros de espesor. Las de los flancos son un poco más irregulares, de 4 centímetros de largo por 3 de ancho y 10 a 12 milimetros de grueso.

Procedencia: - Los restos de esta especie han sido descubiertos por el señor Lelong Thévenet en las barrancas de los alrededores del Paraná.

Horizonte:- Piso mesopotámico de la formación patagónica.

\section{DASYPODA}

Los representantes de este orden se distinguen desde luego por la coraza dorsal, que en vez de estar constituida en toda su extensión por placas unidas por suturas, presenta en el centro varias bandas transversales movibles, cada una de ellas compuesta de una sola fila de placas rectangulares, largas y angostas, cuya parte anterior pasa por debajo de la parte posterior de las placas de la fila que la precede hacia adelante. Las partes anterior y posterior forman dos secciones separadas por los anillos o bandas mencionadas; cada una de estas secciones se compone de placas pentagonales o exagonales unidas por suturas como en los Gliptodontes y presentando en la cara externa, lo mismo que las placas de los anillos movibles, esculturas o dibujos de aspecto diferente, según los géneros. Carecen de plastrón ventral como los Gliptodontes. pero tienen un casco cefálico y la cola está envuelta en una coraza, anillada en la base como en algunos Gliptodontes, cuando es larga, o envuelta en otros géneros por placas imbricadas o tuberculosas.

El cráneo no es corto y truncado adelante como en los Gliptodontes, sino alargado y puntiagudo, con un intermaxilar bien desarrollado, provisto en algunos géneros de incisivos en función y en otros de dos 
pequeños prenasales. El occipital es vertical, limitado por una pequeña cresta, las órbitas son siempre abiertas atrás y los arcos cigomáticos, no muy fuertes, pero siempre completos y $\sin$ la gran apófisis descendente que distingue a los Gliptodontes. Los maxilares superiores son más pequeños y más bajos y de consiguiente el cráneo entero, notahlemente menos elevado que en el otro grupo. La mandibula inferior es menos maciza y más puntiaguda que en los Gliptodontes y con la rama ascendente que no se levanta al lado de la parte posterior de la rama horizontal, sino que forma la continuación de ésta detrás de la última muela y presenta el borde ascendente anterior inclinado hacia atrás como en la generalidad de los mamíferos.

Los dientes son relativamente pequeños y bien separados unos de otros, por lo común cónicocilíndricos muy rara vez elípticos y nunca, salvo muy rarísimas excepciones, en menor número de ocho en cada lado de cada mandíbula.

El axis y las dos o tres vértebras que siguen se reunen para formar un hueso mesocervical como en los Gliptodontes: pero las demás vértebras, con excepción de las que toman parte en la conformación del sacro, son libres.

El sacro es un tubo parecido al de los Gliptodontes, formado por la reunión de 8 a 12 y hasta 13 vértebras; pero en el caso de que haya un número $\tan$ considerable, las dos o tres anteriores son verdaderas lumbares soldadas al sacro y la ultima de atrás es la primera caudal. E1 sacro de los armadillos se pone en contacto con la cadera por dos puntos distintos como en los Gliptodontes, pero por medio de un número de vértebras bastante mayor, generalmente por medio de 3 vértebras adelante con los iliacos y por 3 o 4 atrás con los isquiones.

La sinfisis del pubis por lo general está cerrada por el desarrollo de Inn hueso interpubiano que con la edad se une a las dos puntas de los luesos pubis, desapareciendo toda huella de sutura, pero en algunos casos la sinfisis del pubis queda completamente abierta. El omoplato posee un acromión sumamente desarrollado y presenta un supraescapular representado por un cartílago osificado que se une a la base del omoplato. El húmero es menos fuerte que en los Gliptodontes y provisto siempre de agujero epitrocleano. El trapecio y el trapezoides están a menudo unidos y el magno se suelda a veces al metacarpo del dedo tercero. El fémur posee un trocánter mayor de tamaño enorm: y un trocánter tercero no menos desarrollado, pero que no se prolonga en cresta hacia abajo como en los Gliptodontes. La tibia y el peroné son más largos que en los Gliptodontes, pero como en éstos completamente soldados en sus dos extremidades, dejando en el medio una larga y ancha abertura oval o elíptica. El calcáneo es un hueso muy fuerte y con una gran prolongación posterior. Los dedos son en número varia- 
ble en los pies anteriores, pero siempre de cinco en los posteriores; los del medio bastante largos, particularmente en los pies anteriores y con enormes uñas falciformes dispuestas para cavar, de donde vieno el nombre de Effodiontiı con que a menudo se designa a este grupo. En ciertos géneros las falanges de algunos dedos se sueldan entre sí, como sucede en algunos megateroides.

Los representantes conocidos del orden de los Dasypoda se reparten en cuatro familias que se distinguen por los siguientes caracteres:

I. Coraza dorsal formada en parte por bandas movibles que ocupan casi siempre el centro y por secciones fijas colocadas generalmente adelante y atrás:

a. Muelas elípticas y bilobadas: Chlamydotherida.

$b$. Muelas cilíndricas o subcilíndricas.

aa. Escudos córneos que cubren las placas de forma distinta de las figuras de las mismas: Praopidx.

$b b$. Escudos córneos de la misma forma que las figuras de las placas que cubren: Dasypodida.

II. Coraza dorsal compuesta de bandas transversales en toda su extensión y con un escudo pélvico perpendicular independiente: Chlamydophoridee.

\section{Chlamydotheridæ}

Los Chlamydotherida son los representantes del grupo de los Dasypoda, que tanto por su conformación como por la talla, se acercan mís a los Glyptodontia, pero conservando los rasgos principales de los da. sipódidos.

La coraza dorsal se compone de un escudo anterior $y$ otro posterior. separados por varias fajas movibles en el centro de la coraza, como en los verdaderos armadillos. E1 cráneo no es truncado como el de los Gliptodontes, sino puntiagudo. La forma de la mandibula inferior es intermedia entre la de los armadillos y la de los Gliptedontes, con la rama ascendente no tan alta como en estos últimos e inclinada hacia atrás. Las muelas son de sección eliptica, bipartidas sobre un lado y sobre el opuesto con un vestigio rudimentario de la forma tripartida de la de los Gliptodontes. La cola es muy larga, anillada en la base y cubierta de placas pequeñas imbricadas en la parte posterior. La columna vertebral se compone de vértebras separadas en casi toda la totalidad de su extensión, como en los armadillos actuales. 
CHLAMYDOTHERIUM Lund

Chlunydotherimt. LUND: \&Ann. des Sciences Naturelles», XI, 1839 .

Dasypus. Nodot: Descriftion d'un nowzean genre d'édenté fossile, página ixi, lám. XII, figuras 8 a $13, \pm 856$.

Pampatherium. IMEghivo: en đJournal de Zoologie», tomo $V$, página $52 \%, 3875$.

Las placas que componen la coraza son grandes pero muy delgadas; las que constituyen la parte anterior del escudo dorsal anterior, son exagonales y pentagonales, con la superficie externa casi lisa, un poco puntuada y ligeramente levantada sobre los bordes; las que constituyen la parte posterior son de forma rectangular, estrechas y largas, de superficie igualmente plana y un poco levantada en los bordes. Las placas que constituyen los anillos movibles son las más grandes de toda la coraza, de una forma rectangular muy prolongada, con una parte anterior lisa o casi lisa, a la que sigue hacia atrás una depresión transversal ancha y rugosa y luego la parte libre o cuerpo de la placa, que es la más considerable, de forma rectangular, casi plana, un poco levantada en los bordes, gruesas adelante y delgadas en la parte posterior. La mandibula inferior es de rama ascendente con el borde anterior inclinado hacia atrás y la rama horizontal baja y puntiaguda adelante, con nueve dientes, el último a menudo muy pequeño, los cincu intermedios mucho más grandes y los dos anteriores igualmente muy pequeños y colocados en la parte anterior de la mandíbula tomando casi la forma de incisivos.

I.as muelas son alargadas de adelante hacia atrás, de sección eliptica, con la corona un poco excavada longitudinalmente en el centro; sobre el lado externo hay una depresión perpendicular profunda y cóncava que divide a cada muela en dos columnas perpendiculares convexas; la cara perpendicular interna es ligeramente deprimida, con dos depresiones perpendiculares poco aparentes, una anterior algo más grande y la posterior mucho más pequeña.

Todas las placas de la coraza, incluso las de las secciones fijas anterior : posterior, no están unidas por suturas fijas, sino simplemente yuxtapuestas, con un principio de trabazón, pero sin que nunca se soldaran unas a otras.

El húmero posee el agujero epitrocleano, que siempre está fresente en todos los Dasypoda.

Chlamydotitrien typuar Ameghino

Lames LXV1:, figurat $9,11,12$ is 17,18 y 10

l'ampatherium typus. AMfGino: en \&Journal de Zoologie», tomo V. página 527.

Chlamydotherim typus (Ameghino). H. Gervais y Amecmivo: Los mamiferos fósiles, etc., página 210.3880.

El húmero estả provisto de agujero epitrocleano.

Era éste un animal de talla considerable, un poco mayor que la del Hoplophorus ornatus. 
Las placas del escudo dorsal anterior, exagonales y pentagonales, tienen un diámetro de 3 a 4 centímetros y sólo de 5 a 7 milímetros de espesor. La cara interna es un poco cóncava, lisa y con algunos pequeños agujeros dispuestos sin orden alguno. La cara externa es lisa, apenas un poco ligeramente puntuada, con la parte central algo más levantada, aunque de una manera poco sensible; esta parte más elevada cstá seguida de una depresión poco acentuada limitada por el borde periférico más elevado que la region central; alrededor de este borde periférico se ven, de distancia en distancia, algunas pequeñas perforaciones que penetran en el interior de las placas.

Las placas de la parte posterior del mismo escudo son rectangulares, de 4 a 6 centímetros de largo y de 20 a 25 milímetros de ancho, son la cara externa más elevada en la parte central, la misma depresión intermedia y el borde periférico igualmente elevado; adelante presentan una zona rugosa transversal muy angosta y sobre el borde periférico algunas perforaciones pequeñas distribuídas sin orden alguno; el grueso máximo de estas placas no pasa de 9 milímetros.

Las placas más grandes de toda la coraza son las de los anillos movibles, entre las cuales las hay que tienen entre 9 y 10 centímetros de largo y 3 centímetros de ancho, pero la mayor parte son un poco más pequeñas; estas grandes placas tienen una parte anterior lisa, que es la que penetra debajo de la parte posterior de la placa que la precede, una zona transversal rugosa y luego la parte posterior rectangular de la misma forma que las placas precedentes, pero con la parte posterior siempre muy delgada.

Procedencia:- He recogido restos de esta especie en distintas localidades de la provincia Buenos Aires.

Horizonte:-Pisos ensenadense, belgranense y bonaerense de la formación pampeana.

\footnotetext{
CHLANYDOTIERIUTA PARANENSE Ameghino
}

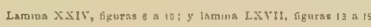

Amegrino: «Doletín de la Academia Nacional de Ciencias», tomo V, páginas Ir y 300 , afio I883.- Idem: tomo VIII, página 139, I885. - Idem: tomo IX, página 203, 1886.

Esta especie es la del desdentado acorazado cuyos restos se encuentran con mayor frecuencia en las formaciones terciarias antiguas de las barrancas del Paraná, pero ellos consisten casi siempre en placas de la coraza, que, como no estaban reunidas por suturas fijas, se encuentran aisladas, de modo que es muy difícil determinar de qué región del cuerpo provienen. 
Las placas de la coraza del Chlamydotherium del Paraná ofrecen, sin embargo, diferencias notables, comparadas con las correspondientes del Chlamydotherium typum de la formación pampeana.

Estas diferencias, en su carácter general, son: un tamaño algo más pequeño, el espesor de las placas relativamente menor y la figura central de cada una de ellas de forma distinta y mejor delimitada en el Chlamydotherium paranense que en el Chlamydotherium typum.

Estas placas sueltas pueden dividirse en tres categorías: unas pentagonales o exagonales, que formaban parte de las secciones fijas de la coraza; otras rectangulares, no muy largas, que debian formar parte de las secciones de la coraza inmediatas a los anillos movibles; y otras rectangulares muy largas con su parte anterior en forma de tecla, que constituian las fajas movibles.

Dispongo de varios ejemplares de las primeras o pentagonales: uno muy pequeño, de 24 milimetros de largo, 21 milímetros de ancho y 6 milimetros de espesor, tiene la cara interna cóncava y la externa con tna figura central de forma circular, limitada por una depresión algo profunda que a su vez está limitada por el borde periférico de la placa más elevada en forma de cordón. Otra placa de tamaño mucho mayor tiene unos 33 milímetros de largo y 7 de espesor. La cara interna es cóncava y la externa muestra igualmente en su superficie una figura circular rodeada por cuatro de sus lados por una depresión ancha y profunda, limitada a su vez por un reborde periférico ancho y elevado. Estas placas difieren de las correspondientes del Chlamydotherium typum por esta figura central, la depresión que la rodea y el surco que 1a limita, pues en la especie pampeana la figura central de superficie lisa es poco perceptible a causa del surco que la rodea, que está apenas indicado.

De las placas rectangulares fijas conozco muchos ejemplares, algunos muy pequeños y otros bastante más grandes.

El ejemplar más pequeño tiene 26 milímetros de largo y 20 milímetros de ancho. Otro un poco más grande tiene 28 milímetros de largo y 22 milímetros de ancho. Estos dos ejemplares son algo cóncavos en su cara interna, presentando en la externa una figura central larga y angosta, de superficie convexa, limitada en sus dos lados laterales por dos depresiones anchas y profundas.

Una tercera placa más grande tiene 34 milímetros de largo por 26 milímetros de ancho; es igualmente cóncava en su cara interna y con una figura central en la externa, angosta y elevada, limitada también por dos surcos anchos y profundos. La figura central tiene 20 milímetros de largo y 6 milímetros de ancho; y los surcos que la rodean más o menos el mismo largo y ancho. Una cuarta placa es proporcionalmente más ancha, pues tiene 37 milímetros de largo y 29 de ancho. 
La figura larga central es también de mayor diámetro transverso; y los surcos que la rodean son relativamente más hondos y angostos. Estas placas difieren de las correspondientes del Chlamydotherium typum de la formación pampeana, por presentar las de esta última especie la cara externa casi lisa y plana sin la figura central longitudinal que caracteriza a las de la especie antigua, figura que está reemplazada por otra más ancha que ocupa casi toda la superficie de la placa y es limitada por una depresión periférica apenas perceptible.

El ejemplar más pequeño de las placas movibles es incompleto, faltándole la prolongación en forma de tecla. La parte existente, que comprende todo el cuerpo de la placa, tiene 34 milímetros de largo, sólo 16 milímetros de ancho y apenas 5 de espesor. La cara externa presenta, como en las placas precedentes, una elevación longitudinal convexa más elevada en el centro que en las extremidades, limitada por dos depresiones angostas y profundas rodeadas a su vez por dos cordones laterales elevados.

Otra placa de los anillos movibles, mucho más grande e intacta, tiene $55^{\prime}$ milímetros de largo, 28 milímetros de ancho y 6 milimetros de espesor. La cara interna es muy cóncava y la externa con una figura longitudinal larga, ancha y convexa rodeada por dos depresiones laterales bastante profundas.

Comparadas estas últimas placas con las de igual forma del Chlumydotherium typum de la formación pampeana, difieren también, como las precedentes, por la presencia de estas figuras centrales dispuestas en sentido longitudinal, largas, convexas y separadas por surcos profundos, pues las mismas placas de la especie pampeana presentan la cara externa deprimida, casi plana, con una figura rectangular apenas marcada que ocupa casi todo el cuerpo de la placa, limitada por depresiones apenas perceptibles. De modo que las figuras centrales de forma circular en las placas pentagonales y de forma alargada y estrecha en las rectangulares, delimitadas unas y otras por surcos bien marcados, son el distintivo característico de la especie del Paraná, que sirve para distinguirla no sólo del Chlamydotherium typum de la formación pampeana de Buenos Aires, sino también del Chlamydotherium Humboldti Lund, de las cavernas de Brasil, cuya coraza presenta placas de superficie externa casi absolutamente iguales a la especie pampeana de aqui.

Del esqueleto conozco la parte posterior de la rama horizontal del lado derecho de la mandibula inferior, en el que están implantados los últimos cuatro dientes molares.

Las muelas son de un tipo distinto de las de los Gliptodontes, pero difieren igualmente de las de los armadillos actuales, presentando a ese respecto una verdadera forma intermedia entre las muelas de 
los representantes de ambos grupos. Son de corona larga $y$ angosta, esto es: de forma muy eliptica, con dos fuertes columnas longitudinales separadas por un surco ancho, profundo y de fondo cóncavo en el lado externo y tres columnas apenas visibles separadas por dos surcos poco perceptibles en el interno. En este lado las muelas de Chlamydotherium parecen representar el primer esbozo de las muelas triprismáticas de los Gliptodontes, pues hubiera bastado que los dos canales o depresiones longitudinales indicadas hubieran adquirido mayor profundidad para que en el lado interno las muelas del Chlamydotherium presentaran los dos surcos longitudinales profundos y las tres aristas que los delimitan, que son los caracteres propios de los Glyptodontia. Asi, a causa de esta conformación, resulta que las muelas del Chlamydotherium son más estrechas en el centro de la corona que en sus extremidades.

También estas muelas en proporción del tamaño sobresalen fuera de los alvéolos mucho más que las de los Gliptodontes.

Las muelas elipticas del Chlamydotherium paranense tienen su diámetro mayor de adelante hacia atrás en dirección del eje de la serie dentaria como en los Gliptodontes, pero no tienen como éstos en el centro de la superficie masticatoria de la corona las láminas duras de dentina que sobresalen en forma de aristas o crestas que atraviesan las muelas en su mayor diámetro de adelante hacia atrás con prolongaciones a las columnas laterales. La base de las muelas, que llega hasta el fondo mismo de la mandíbula, está abierta, presentado una ancha cavidad única como en los armadillos y no subdividida como en los Gliptodontes. Las paredes de esta cavidad están formadas en su parte más inferior por una muy delgada capa de dentina, que es apenas un poco más gruesa que la hoja de un papel; el interior del hueco se estrecha poco a poco hacia su parte superior. La corona de cada una de las muelas, más gastada en el centro que en la periferia, muestra una hendedura en su parte media dirigida de adelante hacia atrás como último vestigio en la parte superior de la prolongación hacia arriba de la cavidad de la base, pero en ciertos ejemplares aislados la cavidad está ocupada por un depósito de dentina más dura, que sobresale en el fondo gastado del centro de la corona en forma de lámina elevada, dirigida longitudinalmente, pero $\sin$ que ninguna de sus dos extremidades toque en la periferia de la corona; a la vista no aparece más que la vásculodentina rodeada por una delgada lámina de dentina más dura, que constituye el borde periférico más elevado de la corona, pero toda la superficie perpendicular está cubierta por una delgadísima capa de cemento amarillo.

Las muelas del Chlamydotherium paranense están bien separadas entre si por espacios intermedios de 2 a 3 milimetros de largo, concor- 
dando un poco con los Gliptodontes en este modo de implantación, pero por el tamaño relativo de las muelas, los Gliptodontes típicos y el Chlamydotherium constituyen dos tipos completamente opuestos. En el Glyptodon las muelas van aumentando gradualmente de tamaño desde la primera hasta la última, que es de dimensiones apenas mayores que las dos o tres que la preceden. Las cuatro muelas existentes en el fragmento de mandíbula del Chlamydotherium, que son las cuatro posteriores, disminuyen de tamaño de adelante hacia atrás. La última muela inferior es mucho más pequeña que las otras, desviándose también en su modo de implantación de la linea perpendicular, de manera que aunque la corona se encuentra sobre el eje longitudinal de la serie dentaria, la base se desvia hacia el lado externo varios milímetros afuera de la línea media longitudinal. La corona es también un poco distinta de la forma que presenta en las otras muelas, siendo algo más ancha adelante y más angosta hacia atrás.

En el lado interno de la mandibula, más o menos a la mitad de la altura de la rama horizontal, corre un canal ancho y poco profundo, que pasa por sobre las muelas, de las que está separađo por una delgada lámina ósea; es el canal alveolar colocado algo más abajo en las mandibulas de los Gliptodontes. En el fragmento de mandibula de Chlamydotherium que describo, este canal se encuentra casi por todas partes a descubierto, debido prohablemente a un desgaste del hueso producido post mortem.

De la rama ascendente de la mandíbula no existe más que la parte de la base cercana al borde alveolar en donde empezaba a levantarse hacia arriba, conociéndose por ella que no formaba un ángulo agudo como en los Gliptodontes, sino un ángulo más abierto, mayor de 90 grados; ni tampoco estaba situada tan adelante como en éstos, pues que, vista la mandíbula de lado, la rama ascendente sólo alcanza a ocultar la última muela, mientras en los Gliptodontes típicos, vista la mandíbula en la misma posición, la rama ascendente oculta por completo las dos últimas muelas y la mitad posterior de la antepenúltima.

\section{DIMENSIONES}

Alto de la rama liorizontal debajo de la antepenúltima muela ............. 0032

Espesor de la mandibula en el mismo punto ............................. 0015

Espesor de la mandíbula debajo del borde alveolar de la primera nuela existente 0012

Diámetro de la primera muela existente $($ anteroposterior ................. 0012 (la sexta de la serie dentaria) | transverso ................... 0007

Diámetro de la antepenúltima muela ( anteroposterior................ 0012 (la séptima de la serie dentaria) | transverso ................... 00065

Diámetro de la penúltima muela ....... | anteroposterior .............. 00115

Diámetro de la última muela...........

i transverso ....................... 0004 
Conozco también una muela aislada, sin duda de otro individuo, de la misma forma que las que se encuentran implantadas en la mandíbula, pero por el tamaño no corresponde a ninguna de ellas, teniendo la corona más corta y proporcionalmente más ancha: era probablemente una de las muelas anteriores.

La talla del Chlamydotherium paranense era comparable a la de una de las más pequeñas especies del género Hoplophorus.

Procedencia: - Los restos de esta especie han sido descubiertos pimeramente por el profesor Scalabrini en las barrancas de los alrededores del Paraná, donde después han recogido restos del mismo animal varios coleccionistas, habiendo también encontrado algunas piezas personalmente en una de mis visitas a aquella localidad.

Horizonte: - Piso mesopotámico de la formación patagónica (oligoceno inferior).

Cillamyothemium ? Extremum Ameghino

Lamins $\mathrm{XL}$. Aizura is

AMEghro: «Boletín de la Academia Nacional de Ciencias», tomo 1X, página 20\%, 1886.

La gran diferencia de tamaño que presentan las numerosas placas de coraza de Chlamydotherium recogidas en los yacimientos del Paraná me hicieron sospechar que podrían provenir de más de una especie y así lo manifesté en uno de mis trabajos sobre fósiles del Paraná ( «Boletín», etc., tomo VIII, página 137). Parece que mis dudas no cran completamente infundadas, pues entre las nuevas piezas del Museo del Paraná que he podido posteriormente examinar hay una muela de un gran desdentado, tan parecida a las muelas del Chlamydotherium antes descriptas, que estoy dispuesto, cuando menos provisoriamente, a considerarla como proveniente del mismo género, pero de una especie de tamaño gigantesco en proporción de la precedente. La corona, algo destruída, es más angosta en el medio que en las extremidades y más ancha en una de las extremidades que en la otra. El angostamiento del medio de la corona es producido, como en las muelas del Chlamydotherium paranense antes descripto, por un gran surco longitudinal externo, ancho y profundo, pero las tres columnas y los dos surcos longitudinales internos de las muelas del Chlamydotherium paranense son aquí todavía menos perceptibles, de modo que la muela presenta una cara interna ancha y casi plana. Estuvo cubierta de una capa de cemento amarillo de un milímetro de espesor que ha desaparecido casi por completo, conservándose vestigios en el fondo del surco externo y en la cara perpendicular anterior. La corona tiene 22 milímetros de diámetro anteroposterior, 9 milímetros de diámetro transverso en el 
medio, 14 milímetros en su parte anterior más ancha y 11 milimetros en la posterior. El largo no se puede determinar, pues sólo existe la parte superior; pero debía ser muy considerable, pues el trozo existente tiene unos 4 centímetros de largo y su parte inferior es todavía maciza, sin vestigios de la cavidad basal.

La talla de este animal, a juzgar por el tamaño de esta muela, debía ser comparable a la de las grandes especies del género Panochtus Burmeister.

Procedencia: - Esta especie ha sido descubierta por el profesor Sca. labrini en las barrancas de los alrededores de la ciudad del Paraná.

Horizonte:- Piso mesopotámico de la formación patagónica (oligoceno inferior).

Cithamydothertum intermedium Ameghino

Chlamydotherium, sp. ? Aar EGrixo: Apuntes preliminares sobre maniferos extinguidos de Monte Hermoso, página 19, 1887.

Chlamydotherium internediun. AMEGHro: Lista de los mamiferos fósiles de Monte Hermoso, página 13 , número 53 , Junio de 1888.

Tanto por su forma como por su talla, esta especie parece ser intermedia entre el Chlamydotherium paranense y el Chlamydotherium typum. Las placas de las secciones fijas, que son las unicas de las cuales hasta ahora conozco algunos ejemplares, son un poco más pequeñas que las correspondientes del Chlamydothcrium typum; la superficie externa de estas placas no es casi plana o ligeramente ondulada como en las de la especie pampeana, sino un poco excavada alrededor de la elevación central, pero no tanto como en Chlamydotherium paranense. Las diferencias entre la configuración externa de las placas de estas tres especies son difíciles de distinguir en los dibujos, pero se perciben con la mayor facilidad en el examen de las piezas mismas.

Procedencia: - He recogido los restos de esta especie en Monte Hermoso, a 60 kilómetros de Bahía Blanca.

Horizonte:- Piso hermósico de la formación araucana (mioceno superior).

Chlamydotheriuar (?) Australe Ameghino

Aseghino: Enmeración sistemática de los mamiferos, etc., página 25 , numero $42, \mathrm{I} \$ 87$.

Este animal sólo está representado por una placa de la coraza y un pequeño fragmento de mandíbula inferior, piezas que muestran algu- 
nos de los caracteres de las correspondientes del Chlamydotherium, pero con algunas diferencias notables que es posible indiquen una diferencia genérica, que, por ahora, sin otros materiales, no es posible determinar.

La placa es de figura exagonal, con dos lados más largos, opuestos y paralelos; y luego dos más pequeños y no tan bien definidos en cada tino de sus extremos. La placa tiene 39 milimetros de largo y 36 de ancho. La cara superior presenta un aspecto casi idéntico a una placa cel mismo tamaño de Chlamydotherium. El borde periférico, de 3 a 4 milímetros de ancho, es un poco rugoso y completamente cubierto de pequeñas perforaciones como en las especies conocidas del mismo género. Todo el resto de la superficie superior es casi completamente lisa, apenas ligeramente puntuada, presentando una ancha depresión periférica parecida a la que muestran las placas del Chlamydotherium jurunense, pero con una elevación central más irregular, menos larga y más ancha, más extendida hacia un extremo (en donde interrumpe la depresión periférica) que hacia el otro, bastante convexa y con una pequeña depresión circular y rugosa en el centro. La cara inferior presenta la particularidad de ser también convexa en vez de cóncava, de manera que la placa presenta su mayor espesor en el centro, donde alcanza unos 7 milímetros, mientras es sólo de 3 a 4 en la periferia. Los bordes no muestran tampoco rastros de suturas que sirvieran para la articulación de las placas, de manera que también en esta especie estaban unas al lado de otras, tocándose simplemente por sus bordes.

El fragmento de mandibula inferior es un pedazo de la pared externa de la rama izquierda, al nivel de la rama ascendente, conteniendo la impresión externa de los alvéolos de tres muelas y pequeñísimos fragmentos de éstas, que suponiendo que el animal tuvo nueve de ellas como las especies conocidas, supongo que esos alvéolos corresponden a las muelas sexta, séptima y octava. Cada una de esas muelas, presentaba en el lado externo una depresión perpendicular, ancha y relativamente más profunda que en las muelas de los Chlamydotherium typum y paranense.

Cada alvéolo tiene unos 11 milímetros de diámetro anteroposterior; y los tres juntos ocupan un espacio longitudinal de 33 milimetros.

La rama ascendente, cuya base existe, parece se inclinaba hacia atrás como en las especies ya conocidas; y la rama horizontal parece haber sido baja y muy espesa.

Procedencia: - Ha sido descubierta por Carlos Ameghino en las ba. rrancas del río Santa Cruz, en Patagonia austral.

Horizonte:- Piso santacruceño (eoceno inferior). 
Este es un género particular, conocido por un gran número de placas de la coraza, que ofrecen un pequeño parecido con las de la coraza del Chlamydotherium y caracteres hasta cierto punto intermedios entre los de este último género y los del actual género Priodon.

Las placas son más o menos rectangulares o cuadrangulares, en general más cortas y más anchas que las de los demás armadillos. Parece que casi toda la coraza ha sido anillada transversalmente, pues la casi totalidad de las placas recogidas, presentan la prolongación anterior lisa y en forma de tecla que caracteriza a las placas que provienen de los anillos movibles. Esta parte anterior lisa, que entra debajo de la parte posterior de la placa que la antecede, es más corta y más gruesa que en todos los demás armadillos, tomando casi la forma de un reborde redondeado. La superficie externa del resto de la placa es muy rugosa, con una pequeña elevación longitudinal en el centro que no llega hasta el borde posterior y limitada a ambos lados por una depresión ancha y poco profunda. La parte anterior del cuerpo de la placa forma una depresión transversal bastante ancha y profunda, que la separa de la parte anterior en forma de tecla. Esta depresión transversal es rugosa y con dos grandes perforaciones circulares en el medio, que penetran en el interior de la placa, colocadas en línea transversal. El grueso máximo de cada placa se encuentra precisamente al nivel del surco transversal, en cuyo punto sobre el lado interno forma una convexidad muy pronunciada, disminuyendo gradualmente el espesor hacia adelante hasta terminar en borde delgado, pero de una manera brusca hacia atrás, formando como un escalón, de manera que casi la mitad posterior de la placa es muy delgada, concluyendo en borde posterior fino y sin perforaciones para la implantación de pelos.

Las placas de las secciones fijas son relativamente más cortas y más anchas, más deigadas y de espesor uniforme, con los bordes ásperos y rugosos y una figurita longitudinal en el centro limitada por una depresión a uno y otro lado como en las placas de los anillos movibles; en la parte anterior, a unos dos o tres milimetros del boride se encuentran también las dos perforaciones circulares ya mencionadas. En el borde posterior se ven algunas perforaciones pequeñas, en las que quizá se implantaban pelos. En realidad, estas placas no presentan suturas que indiquen que se trabaran unas con otras y probablemente se encontraban simplemente yuxtapuestas, formando así una coraza de tipo primitivo, en la que las placas afectaban la forma de las escamas de los cocodrilos. 
Peltephilus strepens Ameghino

Lamins LXIX, Ggurag i *

Ameghiso: Emumeración sistemática de los mamferos, etc., página 25, número Ir 3, I88\%.

Este animal ha tenido la talla de un Hoplophorus pequeño. Una de las placas más grandes de los anillos movibles tiene 25 milimetros de largo, 17 de ancho y 6 de espesor máximo; y la parte anterior lisa en forma de tecla sólo tiene 5 milímetros de ancho. Pero otras tienen el mismo largo y son más angostas; y algunas son más anchas y más cortas.

Una de las placas más grandes, sin la prolongación en forma de tecla, tiene 23 milimetros de largo, 20 de ancho y 4 de espesor.

Las dos perforaciones que se encuentran en la parte anterior de cada placa alcanzan un diámetro de dos milímetros.

Procedencia: - Los restos de esta especie han sido descubiertos por Carlos Ameghino en las barrancas del río Santa Cruz, en Patagonia austral.

Horizonte:- Piso santacruceño (eoceno inferior).

Pertephilus pumiles Ameghino

Lamina LXIX, figuras $q$ a 9

AMEGHINO: Enumeración sistemática de los mamiferos, etc. página 25, número II4, I837.

Esta especie era de tamaño mucho más pequeño, pero a juzgar por las placas de la coraza presentaba absolutamente los mismos caracteres. Parece, sin embargo, que algunas placas presentan la figura longitudinal media mejor acentuada y el par de agujeros de la parte anterior es sin duda más acentuado en todas.

Una placa media de esta especie tiene 12 milímetros de largo pos 8 de ancho y $0^{\mathrm{m}} 0016$ de espesor, pero hay algunas un poco más grandes y otras considerablemente más pequeñas.

Procedencia: - Los restos de esta especie han sido descubiertos por Carlos Ameghino en las barrancas del río Santa Cruz, en Patagonia austral.

Horizonte:-Piso santacruceño (eoceno inferior).

\section{Praopida}

Coraza dorsal dividida en tres secciones bien separadas, una anterior y otra posterior, en forma de escudos formados por placas poligonales unidas por suturas más o menos fijas y una central constituida por un cierto número de fajas movibles, compuestas de placas rectangulares. Las placas que componen los dos escudos: anterior y posterior, son de 
contornos poligonales, la mayor parte pentagonales y exagonales, unidas entre sí por suturas poco fijas, con la cara interna lisa, un poco cóncava o deprimida y con uno o tres agujeros bastante grandes en el centro; la cara externa de cada placa presenta en el centro una figura de gran tamaño, poligonal o subcircular, rodeada de seis o siete más pequeñas, de forma irregular, parecidas en su mayor parte a segmentos de círculo, separadas por surcos bien marcados, tanto entre sí como de la figura central; la superficie de todas estas figuras es un poco convexa, rara vez plana, pero nunca rugosa. Las figuras periféricas son de tamaño muy distinto en una misma placa y se reunen con la opuesta de una o dos de las placas contiguas, formando figuras intermedias compuestas de dos o tres segmentos, cada uno de una placa distinta, pero que durante la vida del animal estaban cubiertas por un escudo córneo único; la figura central lleva otro escudo córneo que no se extiende a las figuras periféricas. De esta conformación particular resulta que los escudos córneos no son completamente simétricos con las figuras que cubren, a excepción de la figura central de cada placa; y que las figuras o tubérculos óseos de las placas son en número bastante mayor que los escudos córneos externos que las cubren. Las placas rectangulares de los anillos movibles presentan en la superficie externa de su parte posterior libre tres figuras en forma de $\mathrm{V}$, la del medio con el vértice de la $\mathrm{V}$ hacia adelante y las laterales con el vértice hacia atrás. El sistema pilífero es poco desarrollado.

La cola es muy larga, con la mitad por lo menos de su parte basal formada por una sucesión de anillos y la parte posterior cubierta por placas óseas simplemente imbricadas.

El cráneo es muy puntiagudo adelante; y la mandíbula inferior presenta la parte anterior de la base de la rama ascendente en el mismo eje longitudinal que el de la serie dentaria. Los dientes varían en número de siete a nueve en la mandíbula superior y de siete a ocho en la mandibula inferior, los anteriores más pequeños y comprimidos.

\section{TATUSIA F. Cuvier}

Tatusia, F. Cuvıre: Histoire Naturelle des Mammifères, I 822 .

Praopus. Burmetster: Syst. Uebers. Thier 73 rasiliens, página 295, 1854.

Muelas en número de $\frac{7}{7}$ a $\frac{8}{8}$, las anteriores muy pequeñas y comprimidas y la posterior de tamaño menor que la penúltima. Las fajas moribles del centro de la coraza varian de 6 a 8 . La cola tiene en la base por 10 menos seis anillos distintos, que se elevan hasta 10 o 12 en a!gunas especies. El pie anterior no tiene más que cuatro dedos perfectos, correspondientes al primero, segundo, tercero y cuarto, faltando el quinto, del cual sólo queda un rudimento del metacarpo; de estos 
cuatro dedos los dos internos son más largos que los externos. El pie posterior tiene cinco dedos completos, pero el primero y el quinto son muy pequeños.

\section{TATUSTA Iy BRIDA (Desmarest) Lesson}

Dasypus hybridus. Desmarest: Mammalogie, página 368.

DARW1N: Zoology of the \&Bcngles, tomo II, páginz 92.

Wagner-Schreber: Säugcth. Suppl, tomo IV, rágina Igr.

Dasypus septemcinctus. Schreber: Säugcth., página 220.

Mulctia septemcincta. GraY: Proceed. Zool. Soc., I874, página 244, lámina XLI.

Praopus hybridus. Burmeister: Reise durch die La Plata Staatch, tomo II, página 428 , numero 42. - Idem: Descriplion fhysique, etc., tomo III, página 432.

Tatusia hybrida. Lesson: Mast. de mammal.

Martin: Proceed, Zool. Soc., i $\$ 37$, página 13.

Turner: Procced. Zool. Soc., $185 x$, página 213.

Gray: Proceed. Zool. Soc., I865, página 373.

La mulita. AzAra: Afuntaciones, etc., tomo II, página 156 , número 58 .

Es la especie más pequeña de este género. La coraza tiene generalmente siete bandas transversales movibles y la base de la cola seis $\omega$ siete anillos. Los dientes son casi siempre en número de ${ }_{8}^{7}$. Habita las provincias Buenos Aires, Santa Fe y Entre Rios y gran parte del territorio de la Pampa.

\section{'IATUSTA IYYRIDA FOSSILIS}

Praopus aff. hybridus. H. Gervas y AMEGIINo: Los mamiferos fósiles, etc., página 2 r6, año 1880.

Praopus hybridus. Amechixo: La antigüedad dol hombre en el Plate, tomo I, paigina 625. año 1880. - Idem: tomo II, página $8 \mathrm{r}$, $188 \mathrm{r}$.

He encontrado con frecuencia restos de coraza en estado fósil, que, cuando menos por el momento, no es posible distinguir de la especie viviente en el pais, aunque no sería difícil que los restos más antiguos provinieran de una especie distinta, lo cual sólo se podrá determinar disponiendo de mayores materiales.

Procedencia:- Alrededores de Mercedes, Luján y La Plata, en ín provincia Buenos Aires.

Horizonte:- Piso lujanense de la formación pampeana hasta la época actual.

\section{TATUSIA Nove'MCINCTA (Linneo) Lydekker}

Dasypus nouencinctus. L,iNnzo: Systema Naturae, edic. $12^{\mathrm{a}}$, volumen I, página 54,1766 . Dasypus peba. DésMAREST: Mammalogic, página 368 , I\$22.

Dasypus septemcinctus. LINNeO: Amoenitat. Acad., $3^{a}$ edición, volumen I, pág. 281,1785 . Dasypus octocinctus. Scrreber: Säugctle, volumen II, lámina IXXIII, I775.

Praopus longicandatus. Burserster: Syst. Ubersicht Thicr Brasilicns, página 295, 1854 .

Es de tamaño bastante mayor que la precedente. En esta especie el sacro está formado por ocho vértebras y su unión con la cadera se 
verifica adelante por dos vértebras solamente. Las vértebras caudales son entre 29 y 30 . Habita en la República Argentina los territorios del Chaco y de Misiones.

TATUSLA NOVZMCINCTA FOSSILIS

Dasypus aff. octocincta. I,Und: $K$. Danske, Viil. Sclsk. Skr, volumen IX, pág. 197, 1842, Praopus aff. longicaudatus. II. Gervats y AMEghivo: Les mammifèrcs fossiles de l'Amé. rique Mćridionale, página $257,1880$.

Tatusia novemcincta. LYDEKKER: Catal. of Foss. Mammalia, parte V, página I4I, I887.

La especie ha sido encontrada en estado fósil en las cavernas de Brasil por Lund y Claussen; y parece que también ha existido en la República Argentina, pues Lydekker menciona como existentes en las colecciones del Museo Británico placas de los anillos movibles de esta especie que supone proceden de la República Argentina y de las colecciones recogidas por Bravard.

Procedencia: - Indeterminada, pero probablemente dentro de los límites de la provincia Buenos Aires.

Horizonte:-Formación pampeana.

\section{PROPRAOPUS Ameghino}

Amegrino: La antigïedad del hombre en el Plata, volumen II, página 3ir, $188 \mathrm{I}$.

Este género presenta una construcción fundamental idéntica a la de los representantes del género Tatusia actual, pero sobrepasa de mucho el tamaño de las más grandes especies existentes, presentando algunas particularidades distintivas bastante notables, que obligan a separarlo como género distinto. El animal ha sido de coraza alargada y estrecha, pero muy convexa y con no menos de 9 anillos movibles, construídos por el mismo tipo que los del género Tatusia. Las placas exagonales y pentagonales de las secciones fijas se distinguen por la posición de ios agujeros que rodean la figura central, colocados siempre en el fondo del surco entre la figura central y una figura periférica, mientras en los Tatusia los surcos se encuentran, salvo rarísimas excepciones, entre la figura central y dos figuras periféricas, por encontrarse siempre en el punto de convergencia del surco que rodea a la figura central, con uno de los surcos radiales que separan a las figuras periféricas. Las placas de los anillos movibles son grandes y gruesas, con algunos agujeritos bastante grandes en el fondo de los surcos que forman los triángulos de su superficie y con pequeñas rugosidades en su borde anterior. Las placas de las secciones fijas son generalmente exagonales, de cara interna cóncava y con uno o dos grandes agujeros en el centro, separadas unas de otras por surcos profundos; la superficie 
externa de cada placa ostenta una figura central de gran tamaño, de contorno poligonal, algo convexa, de superficie casi completamente lisa, en la cual se distinguen varios agujeritos muy pequeños y roćeada de 5 a 6 figuritas mucho más chicas, en forma de segmentos de círculo, igualmente lisas y separadas unas de otras y de la figura central por surcos anchos y profundos; estas figuras periféricas son rudimentarias en la parte posterior y más desarrolladas en la anterior. Los bordes de las secciones fijas están formados por placas imbricadas, que se cubren unas a otras y presentan una punta libre dirigida hacia abajo y hacia atrás. La cola es fuertemente comprimida en su parte posterior no anillada.

ProfraOPUS GRANDIS Ameghino

Lamina LXVII, Reguras 1 o 8

Axecmino: La antiguicdad del hombre en el Plata, tomo I1, página 3II, IS8I. - Idem: «Boletín de la Academia Nacional de Ciencias», tomo IX, página 2 II y siguientes, 1886.

Esta especie, que es la única de este género que hasta ahora me es conocida, ha tenido una talla superior a la del Eutatus Seguini y comparable a la del Lomaphorus elegans.

Las placas de los anillos movibles de la coraza, largas y angostas, tienen un tamaño superior a las de los más grandes Eutatus conocidos, pues las placas más grandes de los anillos del medio, alcanzan hasta cerca de 8 centímetros de largo y 14 o 15 milimetros de ancho. La parte anterior lisa, en forma de tecla, ocupa a menudo casi la mitad del largo total de la placa; la otra mitad, o posterior, de superficie externa libre, presenta en su superficie dos surcos bastante profundos que parten de la depresión transversal que separa la parte anterior de la posterior; estos surcos se acercan adelante casi hasta tocarse y terminan atrás en los dos ángulos posteriores del rectángulo que forma cada placa. El espacio comprendido entre estos dos surcos representa la figura de un triángulo cuya base es formada por el borde posterior de la placa y la cúspide termina en la parte anterior del cuerpo de la misma. A los lados laterales de esta figura y de los surcos que la limitan se ve la figura de otros dos triángulos, pero invertidos, con las bases hacia la parte anterior y las cúspides formadas por los dos ángulos posteriores de las placas. La superficie de las figuras laterales, más pequeñas e invertidas, está cruzada en todo su largo por un cierto número de ranuras o entaliaduras transversales e irregulares. La figura central y de mayor tamaño, muestra una superficie más convexa, con filas longitudinales de agujeritos muy pequeños, dispuestos la mayor parte en dos filas paralelas. Los surcos longitudinales que separan a las tres figuras triangulares de cada placa son profundos, mostrando en su fondo una 
fila de perforaciones o puntuaciones sumamente pequeñas y de uno a tres agujeros circulares más grandes; en el borde posterior de cada placa hay uno o dos agujeros parecidos.

La sección fija anterior está compuesta de placas exagonales unidas por suturas muy sueltas, cada placa con una figura central subcircular limitada por un surco profundo y rodeada por tres o cuatro figuras periféricas colocadas en la parte anterior y lateral de las placas, que tienen un diámetro de 9 a 10 milímetros y sólo 2 o 3 de espesor. La figura central de cada placa, de superficie lisa y bastante convexa, tiene de 6 a 7 milímetros de diámetro y muestra en el medio un grupo de agujeritos muy pequeños. Las figuras periféricas tienen la forma de un segmento de círculo, siendo igualmente de superficie lisa y convexa y separadas unas de otras y de la figura central por surcos profundos. En el fondo del surco periférico que rodea a la figura central, en la parte anterior, hay dos o tres agujeros profundos, colocados, salvo rarísimas excepciones, entre la figura central y una de las periféricas, mientras que en las placas de los Tatusia, los mismos agujeros, relativamente mucho más pequeños, están siempre colocados entre la figura central y dos periféricas, por encontrarse siempre en el punto en donde se reune uno de los surcos radiales al surco periférico. Sobre los lados laterales de la sección anterior, y particularmente hacia atrás, las placas toman una forma más alargada y una disposición en fajas transversales mucho más visible que en la región central; las figuras periféricas son pequeñas, casi rudimentarias y la figura central aumenta hasta ocupar casi toda la superficie de la placa tomando una forma elíptica prolongada; son muy convexas, de superficie casi lisa y con dos filas paralelas longitudinales de pequeños agujeritos. Las placas que forman los bordes laterales de esta sección son igualmente alargadas, con la cara externa ocupada por una sola figura elíptica, cubriéndose unas a otras de adelante hacia atrás formando un borde casi derecho.

Las placas de la sección fija posterior son igualmente pentagonales o exagonales, de tamaño un poco mayor y afectando siempre una figura subcuadrangular más pronunciada. Las placas de la región central tienen 13 milímetros de largo por 11 a 12 de ancho, con la figura central subcircular, de 8 a 9 milimetros de diámetro, más deprimida que en las placas de la sección anterior y con las figuras periféricas más pequeñas pero más salientes.

Sobre los lados laterales, la forma de las placas es un poco diferente; son de mayor tamaño y más alargadas en sentido longitudinal, de 12 a 16 milímetros de largo y de 11 a 12 milímetros de ancho. La figura central de cada una de estas placas es ovalada, bastante convexa, más angosta adelante, ancha, redondeada y más abierta atrás y con dos 
filas longitudinales de pequeñas impresiones en la superficie. Las placas que forman los bordes tienen de 17 a 20 milímetros de largo y 10 a 12 de ancho, con la superficie externa convexa, lisa y puntuada, el borde libre delgado y un poco arqueado y con el borde externo posterior saliente en forma de punta dirigida hacia atrás y hacia abajo.

De la cola, además de algunos fragmentos de anillos incompletos, conozco casi toda la parte posterior que sigue al último anillo caudal. Esta pieza difiere notablemente de la misma de los Tatusia, por presentar una forma muy comprimida en vez de ser cilindrica como en el género existente, teniendo así dos diámetros muy diferentes, de 25 milimetros el mayor y de sólo 19 el menor, disminuyendo gradualmente hasta la punta, que es muy delgada, pero conservando siempre ambos diámetros la misma relación. Esta parte de la coraza está formada por placas romboidales, grandes, ásperas, colocadas como un tejado, cubriendo la parte posterior de cada placa la parte anterior contigua de las dos que la siguen hacia atrás y disminuyendo de tamaño desde las anteriores, que tienen unos 15 milímetros de diámetro, hasta las posteriores, que son de tamaño verdaderamente diminuto. Sólo esta parte terminal de la cola tiene 14 centímetros de largo.

Aunque poseo corazas dorsales casi completas, las dificultades de la reconstrucción, que exige mucho tiempo, no me han permitido armar una, pero los anillos y los fragmentos sueltos, permiten calcular el tamaño de una manera muy aproximada; la coraza dorsal debía tener de 70 a 75 centímetros de largo; 10 que demuestra que, comparado con los representantes del género existente, era el Propraopus grandis un animal de talla relativamente considerable.

Procedencia: - He recogido restos de esta especie en Mercedes, en la laguna de Lobos, en La Plata, en las toscas del fondo del río de la Plata en Buenos Aires y en los alrededores de Córdoba.

Horizonte: - Piso ensenadense, piso belgranense y base del piso honaerense de la formación pampeana.

\section{Dasypodidæ}

Los representantes de este grupo afectan formas muy variadas, pero en general puede decirse que se distinguen por la escultura de las placas de la coraza, en las que nunca se ponen en contacto dos figuras de dos placas contiguas para formar figuras de mayor tamaño, como sucede en los Pranpida, de donde resulta igualmente que cada uno de los escudos córneos que recubren a las placas, corresponde exactamenie a una figura de la escultura de la placa más o menos de la misma forma. 
La forma de las placas de las secciones fijas es poligonal con tendencia a la forma subcuadrada. Las placas de los anillos movibles son rectangulares, largas y angostas. Las bandas transversales varian en número desde 3 hasta 12 y a veces más. La cola generalmente es más corta que en los Praopida y a menudo sin base anillada.

\section{DASIPUS Linneo}

Linneo: Systema naturae, edición $12^{\mathrm{a}}$, tomo I, página 53, 1766.

Coraza con seis o siete bandas movibles, formadas por placas rectangulares largas y angostas, cuya superficie externa libre presenta en el medio una figura longitudinal larga y estrecha, rodeada de figuras laterales más pequeñas y más 0 menos perceptibles, terminando hacia atrás en un borde muy delgado ocupado en toda su extensión por una serie de agujeros grandes y profundos que penetran en el interior de las placas, destinados a recibir los bulbos de los fuertes pelos que cubren la coraza en series transversales. Las placas de las secciones fijas son subcuadrangulares, con una figura eliptica, elevada y alargada de adelante hacia atrás, rodeada de figuras periféricas más pequeñas e irregulares y con el borde posterior ocupado por grandes agujeros pilíferos. La cola es larga, cilíndrica y anillada en la base. Los dientes son en número de $\frac{9}{10}$, cónicos y con una cresta transversal en la corona que la divide en dos caras oblicuas; el primer par de dientes superiores 'stá implantado en el intermaxilar; los dos dientes anteriores de cada mandíbula son mucho más pequeños y un poco comprimidos, pero los demás son de tamaño sensiblemente igual. Rama ascendente de la mandíbula inferior muy elevada y con la base levantándose al lado de la última muela. Cinco dedos en cada pie. En los miembros anteriores los cinco dedos son desiguales, comprimidos oblicuamente, el pulgar delgado y corto, el índice mucho más largo y los siguientes sucesivamente más cortos. En los pies posteriores todos los dedos son más cortos y el del medio más largo que los laterales. Todas las vértebras cervicales están separadas. El sacro es formado por nueve vértebras. La sinfisis del pubis es abierta; y tiene once pares de costillas, seis articuladas con el esternón, las tres siguientes unidas unas a otras y las dos últimas libres.

DAsypus SEXcinctus Linneo

Dasypus sexcinctus. I 3 NNEO: Systcma naturae, edición $12^{3}$, volumen I, página 53 , 1766 . Euphractus sercinctus. Wagler: Sy'st. d. Amphibien, etc., página $36,1830$.

Es la especie más grande del género. Habita la parte más septentrional de la República. 
Euphractus affinis scxcinctus. P. GERvals: Recherches sur les mammiferes fossiles de l'Amérique Méridionale, página 55, lámina XXIIII, figuras $x$ y 2, 1855 .

H. Gervais y AMEgirino: Los mamiferos fósiles, etc, página 214, i8so.

P. Gervais describió con este nombre parte de un cráneo de una especie fósil, si no idéntica, por lo menos muy parecida a la actual, de la cual, según el autor, sólo se distinguiría por las placas del escudo. cefálico, que son algo más pequeñas, y por la primera muela superior implantada en el intermaxilar, que se encuentra más separada de la segunda que en la especie viviente; el paladar parece igualmente un poco más estrecho en la especie fósil y las series dentarias menos paralelas. El autor figura la región anterior del cráneo de este animal, con algunas placas del escudo cefálico y las seis primeras muelas de cada lado o los alvéolos correspondientes, que ocupan un espacio longitudinal de 34 milímetros. El ancho del paladar entre el primer par de muelas anteriores es de cerca de 9 milímetros y de 13 milímetros entre el sexto par.

Procedencia: - Los restos de esta especie, primeramente descriptos por Gervais, fueron descubiertos por Weddell en Tarija, antes provincia argentina, hoy boliviana, pero se encuentran restos atribuibles a la misma especie en la provincia Buenos Aires.

Horizonte:- Piso bonaerense de la formación pampeana.

DAsypus viliosus Desmarest

Dasypus villosus. Desmarest: Nourean Dicionnaire d'Histoire Naturelle, volumen XXIl, página 489, 1819. - Idem: Mammalogie, página 370.

Griffith: Anim. Kingd., tomo III, jágina 292.

WAGner-Scirreber: Surpl., tomo IV, página 175.

Burmerster: Reise durch die La Plata Staaten, tomo II, página 427,-1dem: Description physique, etc., tomo III, página 438,7879 .

Grax: Proceed. Zool. Soc., 1865, página 376.

Esta especie es de tamaño apenas un poco menor que la precedente y habita en la actualidad casi toda la región oriental de la República, desde Bahía Blanca al Norte.

DAsYpus vil.tosus fosstr.IS

LAmina LXVII1, fieura 9 s

Eupliractus villosus (Desmarest). AMEgrino: La antigücdad del hombre en ol Plata, vo. lumen I, página 625,1880 . - Idem: tomo II, jágina $81,188 \mathrm{I}$.

Los restos de la especie actual son comunes en estado fósil en las capas sedimentarias más superficiales de la provincia Buenos Aires.

Horizonte: Piso querandino y platense de la formación pampeana hasta la época actual. 
DASYPUS AFFINIS VIILOSUS

Dasypus villosus fossilis. Burmetster: «Anales del Museo Público de Buenos Aires», t. I, entrega $3^{n}$, página 232,1866 . - Idem: Description physiguc, etc., tomo III, página 440, 1879 .

Dasypus villosus. L, yDEKkER: Catal. of Foss. Mamm., parte V, página 138, 1887.

Euphractus affinis villosus. II. Gervars y AmEGHno: Los mamiferos fósiles, etc, página 216,1887 .

Los restos de Dasypus, muy parecidos si no idénticos a los de la especie existente que es común en el país, son muy abundantes en todos los horizontes de la formación pampeana, pero como no conozco cráneos completos en buen estado, sino fragmentos de esqueleto, no puedo afirmar que sean absolutamente idénticos a los de la especie actual, como aparentemente parecen indicarlo los. fragmentos de coraza. Así, me parece prudente conservar en suspenso su determinación definitiva. pues la época a que remontan es realmente demasiado alejada de nos. ctros, para suponer que la especie se haya conservado sin variación hasta ahora.

Procedencia: - He recogido restos de este animal en distintas localidades de las provincias Buenos Aires, Santa Fe y Córdoba.

Horizonte:-- Todos los niveles de la formación pampeana, encontrándose placas de coraza aparentemente iguales hasta en el mismo. yacimiento de Monte Hermoso.

\section{DASYrts MAJor Ameghino}

Lamina LXith, theren at $y$ an

Euphractus major. AMegmino: Catálogo de la Sccción de la prorincia de Buenos Aires c1s la Euposición Continental Sudamericana, página 4t, I882 (nomen nudum).

Esta especie se distingue fácilmente por su tamaño dos veces mayor que el de las especies actuales: Dasypus sexcinctus y Dasypus villosus, igual a una de las más pequeñas especies del género Eutatus.

Las placas de las secciones fijas, son relativamente grandes y delgadas, de 15 a 18 milímetros de largo, por 10 a 12 de ancho y 3 a 5 de grueso; las que forman la úitima fila de la sección fija anterior alcanzan un largo de hasta 23 a 25 milimetros. Estas placas presentan en la cara externa una figura longitudinal oblicua, muy estrecha y convexa, con cinco o seis figuras laterales más pequeñas e irregulares, separadas por surcos anchos, poco profundos y a menudo mal definidos. Toda la superficie de las placas es lisa o casi lisa, pero con puntuaciones bien perceptibles, faltando las perforaciones del fondo de los surcos, que en las otras especies penetran en el interior de la coraza. Los agujeros pilíferos del borde posterior son muy desarrollados. Las placas de mayor tamaño provenientes de las bandas movibles alcanzan a tener hasta unos 4 centímetros de largo. 
Procedencia:- He recogido los restos de esta especie en los alrededores de la Villa de Luján.

Horizonte:- Piso platense de la formación cuaternaria.

DASYPUS PLATENSIS, $u, s p$,

Lamtan LXi IIt, tiguras as a 42

Esta especie es del tamaño del Dasypus villosus, pero se distingue fácilmente de él por la estructura de la escultura externa de la coraza. El tamaño de las placas que componen la coraza es sensiblemente igual al de las mismas placas de la coraza de la especie existente antes mencionada. Las placas de las secciones fijas presentan la cara externa rugosa y áspera, en vez de las figuras elevadas que se observan en ias otras especies, notándose en algunas apenas rudimentarios vestigios de la figura central estrecha y alargada de cada placa; entre estas rugosidades se encuentran, generalmente distribuidas sin orden alguno, un cierto número de perforaciones o agujeros de diámetros distintos; los agujeros piliferos del borde posterior son escasos y poco desarrollados. Las placas de los anillos movibles son de superficie externa igualmente áspera y rugosa y con las mismas puntuaciones 0 agujeros de las secciones fijas, pero la figura longitudinal del centro es a menudo más visible; las perforaciones piliferas del borde pos. terior son numerosas pero pequeñas. Las placas de las secciones fijas tienen de 10 a 15 milímetros de largo, 6 a 7 milímetros de ancho y 2 a 5 de espesor; las placas de las bandas movibles tienen de 20 a 25 milimetros de largo y 6 a 8 de ancho.

Procedencia: - He recogido los restos de esta especie en las barran. cas del río Luján en el pueblo del mismo nombre y en los alrededores de La Plata.

Horizonte:- Piso querandino y piso platense de la formación cuaternaria.

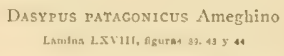

Euphractus patagonicus. Amegrivo: Enumeración sistcmálica de los mamiferos, etc, pá. gina 26 , número 120 , 1887 .

Esta especie parece haber sido un poco más robusta que el Dasypus rillosus; y aunque los restos de coraza, que son las únicas partes que hasta ahora conozco, son muy parecidos a los de la especie siguiente, es casi seguro que el conocimiento de corazas completas y de partes del esqueleto han de revelar importantes diferencias de conformación, pues remonta a una época demasiado lejana para suponer que pueda ser una especie idéntica o muy parecida a la existente. 
Las placas de las bandas movibles tienen de 18 a 20 milimetros de largo por 6 a 8 de ancho; y las de las secciones fijas de 6 a 9 de largo por 6 a 8 de ancho y 3 a 5 de espesor.

Las placas de las secciones fijas se distinguen por la figura elíptica central de cada placa, que no es muy larga, pero es siempre más elevada que en la especie actual y rodeada adelante y sobre los costados laterales por un surco relativamente muy profundo, particularmente adelante y en el cual se ven algunos agujeros de tamaños diferentes; en el borde posterior de cada placa difiere de las demás especies mencionadas, por presentar un corto número de agujeros pilíferos, a veces no más de cuatro o cinco, pero siempre de tamaño considerablemente mayor.

Las placas de los anillos movibles se distinguen por la figura longitudinal del medio de la placa, igualmente más elevada y convexa, con los surcos laterales bien marcados y con algunos agujeros; las figuras periféricas están reemplazadas por dos elevaciones laterales largas y angostas, una a cada lado, forman to los bordes laterales de las placas, $\sin$ las entalladuras transversales que los dividen en figuras distintas más pequeñas, como sucede en los otros Dasypus, o si hay algunas, se reducen a dos, una a cada lado y apenas indicadas. En el borde posterior presentan la misma diferencia característica que distingue a las placas de las secciones fijas; cada placa tiene sólo tres o cuatro perforaciones, pero muy grandes, de manera que ocupan todo el borde posterior; en las mismas placas del Dasypus villosus, los agujeros son en número considerable pero mucho más pequeños.

Procedencia:- Los restos de esta especie han sido descubiertos por Carlos Ameghino en las barrancas del río Santa Cruz, en Patagonia austral.

Horizonte:-Piso santacruceño (eoceno inferior).

ZAEDYUS, 3t. gcn.

Este género, cuyo tipo es el Zaedyus minutus (Dasypus minutus) ha sido hasta ahora confundido con el precedente, por presentar, sólo aparentemente, una conformación externa muy parecida; pero la extructura interna muestra diferencias tan considerables que no permite conservarlos unidos. En la misma coraza, que son las partes que en ambos géneros se parecen más, se notan también algunas diferencias notables; las placas de la coraza del Zaedyus presentan la escultura externa más elevada, pero de superficie más lisa; y las placas de las bandas movibles muestran la figura longitudinal central, más larga, más estrecha y más elevada, con superficie fuertemente convexa. El 
horde posterior de las placas movibles es muy delgado y con sólo uno o dos agujeros pilíferos, situados uno en cada ángulo, raramente tres, estando entonces situado el tercero en el medio del borde de la placa; estos agujeros, además de ser en escaso número, difieren por su tamaño excesivamente pequeño, de manera que sólo ocupan un muy pequeño trecho del borde, lo que constituye una diferencia considerable con el Dasypus, que presenta todo el borde posterior de cada banda ocupado por agujeros piliferos, ya de tamaño mediano pero en número considerable como en el Dasypus villosus, ya en corto número pero de tamaño enorme como en el Dasypus patugonicus. Las placas de las secciones fijas presentan con el Dasypus la misma diferencia: cada placa no tiene en el borde posterior más que una o dos perforaciones piliferas sumamente pequeñas. Las bandas movibles de la coraza son en número de siete a ocho y dispuestas de manera que no permiten a la coraza tomar la forma de bola.

El cráneo del Zaedyus es más puntiagudo que el del Dasypus; y el sistema dentario bastante diferente, pues no tiene ningún diente imFlantado en el intermaxilar, mientras que en el Dasypus la primer. muela de cada lado de la mandíbula superior está constantemente imFlantada en el mencionado hueso. El número de dientes es también distinto y constante; el Dasypus tiene siempre nueve superiores y diez inferiores en cada lado; y el Zuedýus sólo ocho arriba y nueve abajo.

ZAEDYL'S MiNutus (Desniarest) Ameglino

Dasyrus minurus. DesMarest: Mammalogie, página 37 .

DARWrN: Zoology of the $\&$ Beagle», tomo If, página 93 .

Gay: Faura chilena, tomo 1, página 131 .

Burmetster: Reise durch die La Pluta Staaten, tomo II, página 428. -- Idem: Description physique, etc., tomo III, página $\$ 40$.

Grax: Procced. Zool. Soc., 1865, página 376.

Dasypus patagonirus. Desmaress: Nonveau Dictionnaire d'Histoire Naturelle, tomo XXX. página $49 \mathrm{I}$.

Tatusia minuta. Lesson: Mon, etc.. página $\$ 47$.

Es la especie típica del género y la única existente ahora, cuyo tamaño es aproximadamente un tercio menor que el del Dasypus villosus. Habita la región occidental de la República, en las provincias San Luis y Mendoza, el territorio de la Pampa, la región austral de la provincia Buenos Aires y Patagonia.

ZaEDYUS BINUTUS FOSSILIS

He encontrado sus restos en estado fósil en distintos puntos de las provincias Buenos Aires y Córdoba, en las capas sedimentarias más superficiales.

Horizonte:- Piso platense de la formación cuaternaria hasta nuestra época. 


\section{ZaEdYUS PROXIMSUS Ameghino}

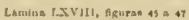

Euphracius proximus. Aмegrino: Enumeración sistemática de los mamiferos, etc., pjgina 26 , número 121,1887 .

Este animal me es conocido por numerosas placas de la coraza, que indican una talla comparable a la del Zaedyus minutus; las placas de los anillos movibles tienen de 12 a 16 o 17 milímetros de largo por 5 a 6 de ancho y las de las secciones fijas de 5 a 7 milimetros de largo por 4 o 5 de ancho.

La escultura externa es muy parecida a la de la especie actual, con la única diferencia de la figura central longitudinal de las placas de las bandas movibles, que es más angosta, más larga, más elevada y más lisa que en la especie existente. Las placas de las secciones fijas, muestran esa misma figura central rodeada por figuritas periféricas más pequeñas y casi circulares que están separadas por surcos muy profundos. Es casi seguro que, cuando se conozcan partes más completas, se encontrarán diferencias más acentuadas todavia, pues data de una época demasiado remota para que pueda ser en todos sus detalles tan cercana a la especie existente, como parecen indicarlo las placas sueltas de la coraza.

Procedencia: - Los restos de este animal han sido descubiertos por Carlos Ameghino en las barrancas del río Santa Cruz, en Patagonia austral.

Horizonte:- Piso santacruceño (eoceno inferior).

PROEUPHRACTUS Ameghino

Lamana Lxitut, figuras as y 43

Euphractus crilis. AMEGrino: Enumeración sistemática de los mamíferos, etc., yágina 26 , пúmero 122,1887 .

Esta especie se distingue de la precedente y de la actual por su tamaño notablemente menor, que no permite identificarlas. Las placas de las secciones fijas tienen de 4 a 6 milimetros de largo por 3 a 5 de ancho; la figura central alargada de cada placa es muy angosta y está rodeada adelante y a los lados por de 6 a 8 figuritas muy pequeñas, pero muy elevadas, terminando casi en punta dirigida hacia atrás; estas figuras periféricas están separadas por surcos profundos en los que se encuentran pequeños agujeritos. Las placas de las bandas movibies tienen de 8 a 12 y hasta 14 milímetros de largo por 2 a 4 de ancho y sólo $!$ de espesor; la cara superior libre muestra una figura longitudinal que la recorre en todo su largo, muy estrecha y del mismo tamaño en 
toda su extensión, limitada por dos surcos longitudinales con algunos pequeños agujeritos de los cuales salen pequeñas hendeduras transversales que dividen de un modo más o menos perceptible a las figuras longitudinales laterales.

Procedencia: - Los restos de esta especie han sido descubiertos por Carlos Ameghino en las barrancas del río Santa Cruz, en Patagonia austral.

Horizonte:- Piso santacruceño (eoceno inferior).

Zafdyus minimus Ameghino

Lsmua L.xvi1, seura so

Euphractus minimus. AMEgino: La antigüedad del hombre en cl Plato, tomo 1I, pág. 310, aก๊ $188 \mathrm{I}$.

Esta especie es del tamaño del Zaedyłus cxilis o quizá todavía más pequeña; pero la escultura externa de las placas es más parecida a la del Zaedyus minutus. Las placas de las bandas movibles tienen sólo de 8 a 11 milímetros de largo, de $0^{\mathrm{m}} 002$ a $0^{\mathrm{m}} 0035$ de ancho y no más de un milímetro de espesor máximo. La figura longitudinal del centro de la cara externa es angosta pero no muy elevada; y las dos elevaciones laterales están divididas por pequeñas hendeduras o surcos transversales, en tres o cuatro figuras regulares, partiendo cada rama transversal de una pequeña perforación en el fondo de los surcos que limitan a la figura central. La parte posterior de cada placa termina en un borde sumamente delgado, en el cual en la casi totalidad de los ejemplares no se ven absolutamente vestigios de agujeros pilíferos.

Procedencia: - He recogido los restos de esta especie en el arroyo Frías, no lejos de Mercedes, en la provincia Buenos Aires.

Horizonte:- Piso bonaerense de la formación pampeana.

\section{PROEUPHRACTUS Ameghino}

AMEgrino: «Boletín de la Academia Nacional de Ciencias», tomo IX, página 208, 1886.

La talla de los representantes de este género es comparable a la de los representantes del género Eutatus. Las placas de los anillos movibles llevan tres figuras longitudinales y paralelas en el cuerpo, regulares $y$ en forma de columnas, separadas por dos surcos longitudinales paralelos, sin agujeros en el fondo de los surcos, pero con agujeros profundos sobre los bordes longitudinales. Las placas de la sección fija ostentan una figura central muy elevada, con figuritas periféricas bien destacadas, convexas y con agujeros en los bordes laterales. 
ANEGHiNo: Obra y página citadas.

Hasta hace poco no se había encontrado en los terrenos terciarios antiguos del Paraná ningún resto de verdadero armadillo, hecho que no dejaba de preocuparme, pues según mis vistas filogenéticas, los armadillos constituyen un tipo de evolución menos avanzado, es decir: más primitivo que el de los Gliptodontes; y de consiguiente deben haberlos precedido en su aparición.

Pero como la duración de una forma animal es continua desde el primer momento de su aparición hasta su desaparición, que es definitiva, resultaba que existiendo en los terrenos antiguos del Paraná, Gliptodontes que tienen que haber tomado origen en un tipo inferior parecido a los armadillos y existiendo aún éstos en la actualidad, forzosamente deben también haber existido conjuntamente con los Gliptodontes del Paraná. Basado en estos principios invariables pude decir en uno de mis últimos trabajos que si aún no se habian encontrado sus restos fósiles en esos yacimientos, se encontraríar (6); y pocos meses bastaron para confirmar mi deducción, cumpliéndose la previsión científica; poco tiempo después encontraba personalmente restos de armadillos en los yacimientos del Paraná.

Conozco del mencionado yacimiento, una placa de la sección fija y ctra de los anillos de un animal bastante cercano al género Dasypus actual, pero de un tamaño mucho mayor y con algunos caracteres bastante distintos para autorizar su separación como género diferente.

La placa de la sección fija es de figura general rectangular, aunque en su parte anterior el borde forma dos caras distintas que hacen de la placa un pentágono irregular y muestra en su superficie externa una figura principal rodeada de varias menores que ocupan toda la superficie de la placa, como sucede con las correspondientes de los Dasypus, pero en el fondo de los surcos no tiene agujeritos que dividen a las figuras, existiendo éstos, al contrario, sobre los dos bordes laterales de la placa.

La figura principal parte de los dos tercios anteriores de la placa y se extiende hasta su parte posterior en forma de carena muy elevada, de casi un centimetro de largo. Rodean a esta figura principal seis más pequeñas, desiguales en tamaño, las tres más grandes sobre la parte anterior, dos de las más pequeñas sobre el borde lateral derecho y la otra sobre el izquierdo, no existiendo ninguna sobre la parte posterior a donde va a concluir la figura principal con su máximo desarrollo. El surco que aisla a la figura principal es ancho y profundo, rodeándola

(6) «Boletín de la Acađernia Nacional de Ciencias», tomo VIII, página I73, I885. 
sólo en sus dos tercios anteriores por tres de sus lados. Los surcos menores que van de éste a la periferia son angostos y poco marcados. En los Dasypus estos surcos radiales son angostos y profundos y terminan en el punto de unión con el surco central en un agujero que falta en Procuphractus. Examinando, sin embargo, el fondo del surco central con un lente, se ve que está ocupado por una serie de agujeritos muy pequeños, en número considerable y colocados en línea, pero tanto for su tamaño diminuto como por su número y colocación no corresponden seguramente a los agujeritos de las placas de los verdaderos Dasypus. En cambio tiene el Prouphractus agujeros bastante grandes sobre los bordes laterales, aunque sólo en número de tres o cuatro en cada lado. En la parte posterior se ven tres grandes y profundos agujeros destinados a recibir los bulbos de las cerdas, colocados, uno en el medio y los otros dos uno en cada ángulo lateral, habiendo entre cllos otros agujeritos muy pequeños y apretados unos a otros en serie continua. La cara interna de la placa, ligeramente cóncava, presenta entre 10 y 12 agujeritos distribuídos $\sin$ orden alguno. La superficie de la placa es muy lustrosa y lisa, particularmente encima de las figuras externas convexas. Tiene 16 milímetros de largo, 12 de ancho y sólo dos de espesor alli donde no presenta engrosamiento debido a las figuras externas. Esta pieza ha sido recogida por el señor don Luis Lélong Thévenet.

La placa de la sección movible debe ser del centro de uno de los anillos, pues presenta la forma rectangular característica de estas placas perfectamente regular, con su parte anterior en forma de tecla, corta, muy gruesa y de superficie lisa y la parte posterior que forma el cuerpo libre de la placa, más larga, más delgada, pero de una conformación externa bastante distinta de la de los Dasypus, sin que tampoco presente analogía decidida con ningún otro de los géneros conocidos de csta familia. En el centro de la placa se ve una figura elevada, muy larga y angosta, de superficie convexa muy lisa, perfectamente recta, que parte de la hase de la parte anterior en forma de tecla y recorre el cuerpo por su parte media longitudinal, en la mayor parte de su largo, terminando varios milimetros antes de llegar al borde posterior. Esta columna longitudinal media existe también en los Dasypus, pero no es tan regular y llega siempre hasta el borde posterior de la placa. Está limitada por dos surcos longitudinales bastante profundos y de fondo cóncavo, uno a la derecha y otro a la izquierda, perfectamente rectos, que difieren igualmente de los correspondientes del Dasypus for no alcanzar hasta el borde posterior, terminando naturalmente al nivel de la parte posterior de la figura longitudinal central. En el fondo de estos surcos no existen agujeros que penetren en el interior de la flaca, que es un carácter particular que distingue al Prouphractus tanto 
del Dasypus como del Eutatus y del Propraopus. En fin, estos dos surcos están limitados a su vez por otras dos columnas o figuras longitudinales que constituyen al mismo tiempo, a derecha e izquierda, los bordes laterales de la placa; estas figuras son, como la central, bastante elevadas, de superficie convexa y continuada sin interrupción de uno a otro extremo, diferenciándose así mucho de las columnas o figuras longitudinales que ocupan la misma posición en las placas de los $D a$ sypus y también de los Eutatus, que siempre están divididas por surcos transversales que parten generalmente de uno de los agujeros que en dichos géneros presenta en su fondo y se dirigen a la periferia dividiendo las columnas externas en dos o tres trozos. Esta diferencia del Prouphractus está acompañada por otra bastante notable: la presencia de una fila de agujeros relativamente grandes y profundos en cada uno de sus bordes laterales, colocados con corta diferencia a la misma distancia unos de otros y disminuyendo de tamaño desde atrás hacia adelante hasta que desaparecen hacia la mitad del largo de la placa. El borde angosto posterior está ocupado por varios agujeros grandes y profundos destinados a recibir los bulbos de las cerdas. El largo de la placa es de 21 milímetros, pero como está algo gastada en su borde posterior y quebrado el borde anterior delgado de la parte en forma de tecla, pienso que entera debía tener más o menos unos 25 milímetros de largo.

Procedencia:- He recogido los primeros restos de esta especie en las barrancas de los alrededores de la ciudad del Paraná.

Horizonte: - Piso mesopotámico de la formación patagónica (oligoceno inferior).

Proevpitracturs recFins Ameghino

Lamina $2 X 1 X$, AEYTRS in A 14

AMEGHiNo: Apuntes preliminarcs sobre mamiferos extinguidos de Monte Hermoso, página 19, I887. - Idem: Lista de los mamiferos fósiles de Mlonte Hermoso, No. 56, pág. 19, Junio de 1888 .

Esta especie se distingue de la precedente por su tamaño algo mayor y una conformación algo distinta de las placas.

Las placas de las secciones fijas tienen de 15 a 18 milímetros de largo por de 10 a 12 de ancho. La figura longitudinal central es muy elevada, oblicua y extendida hasta el borde posterior; en el fondo del surco que rodea a esta figura se ven a menudo algunos agujeritos sumamente pequeños y sobre los bordes sólo existen perforaciones pilíferas en parte del borde posterior, pero en corto número y pequeñas.

Las placas de las secciones movibles tienen de 28 a 38 milímetros de largo por entre 10 y 12 de ancho. La figura longitudinal media es 
casi siempre mucho más elevada que en la especie precedente, presentando a menudo el aspecto de una arista; siempre es muy oblicua y se extiende hasta el mismo borde posterior. Las figuras longitudinales laterales son, al contrario, mucho más bajas que en la otra especie, casi planas y siempre sin entalladuras transversales. En el fondo de los dos surcos longitudinales que delimitan a la figura longitudinal central existen a menudo algunas perforaciones pero sumamente pequeñas, apenas visibles. El borde posterior, que es muy delgado, está ocupado por una fila de agujeros pilíferos de menos de un milímetro de ancho, fila que se continúa sobre uno solo de los bordes longitudinales laterales, perdiéndose antes de alcanzar la mitad del largo de las placas.

Procedencia:- He recogido los restos de esta especie en Monte Hermoso, a 60 kilómetros de Bahía Blanca.

Horizonte:- Piso hermósico de la formación araucana.

\section{MACROEUPHARACTUS Ameghino}

AMEGirino: Apuntes proliminares sobre mamiferos extinguidos de Monte Hermoso, pág. r9, a tio I887. - Idem: Lista de los maniferos fósiles de Monte Hermoso, página 19, número 57 , Junio de 1888 .

Talla comparable a la de un Hoplophorus, con las placas de la coraza de las secciones fijas de figura cuadrangular y una fila de perforaciones pilíferas en todo el borde de las placas.

MaCroeupuractus retusus Ameghino

AMEgrino: Obra y página citadas.

De este armadillo gigantesco, sólo conozco hasta ahora placas de las secciones fijas de la coraza, todas de forma rectangular y con la superficie externa cubierta con los mismos dibujos que las placas correspondientes de la coraza de los Dasypus, pero con figuras más planas; y además de los pozos profundos para la inserción de los pelos que llevan en el borde posterior, como en los Dasypus, aunque en menor número, presentan una fila de agujeritos pequeños en toda su periferia. Estas placas tienen 35 milímetros de largo y 24 o 25 de ancho, lo que indica un animal de la corpulencia de un pequeño Hoplophorus y del Chlamydotherium typum.

Procedencia:- He descubierto los restos de esta especie en Monte Hermoso, a 60 kilómetros de Bahía Blanca; y se conservan en el Museo de La Plata, por 10 que no puedo dar otros datos ni dibujos.

Horizonte:- Piso hermósico de la formación araucana (mioceno superior). 


\section{EUTATUS P. Gervais}

P. Gervais, en los Comptes-rendus, volumen LXV, página 280, 1867.

Este género comprende especies de mayor tamaño que los Dasypus existentes, algunas de bastante mayor tamaño que el Priodon giganteus, que es el más grande de los armadillos actuales. Toda la coraza está formada por placas rectangulares dispuestas en filas transversales, formando bandas movibles, menos en la parte posterior, en donde cada fila transversal está soldada a la que la sigue. Todas las placas presentan en la cara externa una escultura mal definida, con una figura central elíptica y como hundida, rodeada adelante y a los costados por figuras periféricas más elevadas pero poco distintas. El borde posterior de cada placa está ocupado en toda su extensión por una fila de agujeros pilíferos de tamaño enorme que reunidos forman como una gran ranura transversal.

La cola es larga, cilíndrica y cubierta de pequeñas placas yuxtapuestas.

El cráneo es deprimido, muy prolongado hacia adelante y de hocico muy puntiagudo, presentando un pequeño parecido con el de los Tatusia, pero es relativamente más ancho en su mitad posterior.

Los dientes son en número de 8 a 9 en la mandíbula superior y 10 - 9 en la inferior, según las especies, todos subelípticos y de corona plana un poco excavada en el centro, sin que ninguno de ellos esté implantado en el intermaxilar, extendiéndose, al contrario, el maxilar todavía bastante más adelante de la primera muela. El intermaxilar es muy largo; y los nasales, más largos todavía, sobresalen considerablemente adelante del intermaxilar. La mandibula inferior es de rama horizontal baja y de sínfisis muy prolongada.

El axis y las dos vértebras siguientes están soldadas en una sola pieza. Tiene 11 vértebras dorsales y tres lumbares; y cinco dedos en cada pie, el interno más delgado y el tercero y cuarto más fuertes.

\footnotetext{
Eutatús Secuini P. Gervais

Lamina LVIl, Agurna s s s; y lamina LXziv, Bgura s
}

P. Gravars: Comples-rendus, volumen $\mathrm{LXV}$, página $280,1867 .-$ Mémoire sur plusicurs espèces de mammifères fossiles propres à l'Amérigue Méridionale, pág. 36, láminas XXVIII y XXIX, 1875 .

BuRMeISTER: Description pltysique, ete, tomo 1I, pág. 443, 1879. - Idem: Sits. k. preuss. $A k$. Wiss., I883, volumen II, página 1045, lámina XIII.

H. Gervais y Amegirno: Los mamíferos fosiles de la América Meridional, pág. 214, is8o.

L,YDEKKER: Catal. of Foss. Mamma, parte V, página 140, 1887.

Es la especie típica del género y la de mayor tamaño. El cráneo tiene 26 centímetros de largo y 11 de diámetro transverso máximo. El maxilar superior tiene 9 muelas, todas subelípticas y más o menos parecidas. La mandíbula inferior tiene 10 muelas a cada lado, la anterior mucho más pequeña que las demás. 
Las placas de la sección fija, o posterior, son rectangulares, de 20 a 25 milímetros de largo por de 12 a 15 de ancho, con la figura central poco acentuada y sin perforaciones en su parte superior, o apenas visibles. El borde posterior tiene 3 o 4 perforaciones piliferas de gran tamaño.

Las placas de las bandas movibles tienen de $0^{\mathrm{m}} 035$ a $0^{\mathrm{m}} 045$ de largo por de 11 a 13 de ancho, con la figura central media también poco indicada e igualmente sin perforaciones en el fondo de la parte anterior del surco que delimita dicha figura o apenas visibles. Los agujeros del borde posterior son en corto número pero muy grandes.

El húmero tiene $0^{\mathrm{m} 130}$ de largo y $0^{\mathrm{m}} 060$ de ancho en su extremidad distal.

El fémur es mucho más robusto, pues mide 21 centímetros de largo y cerca de 7 centímetros de ancho, presentando un trocánter tercero de un desarrollo verdaderamente enorme.

Procedencia:- Provincias Buenos Aires y Santa Fe.

Horizonte:-Piso ensenadense de la formación pampeana.

EUTArus erFvis Ameghino

Lamina LAritl, figaras i y a

Eutatus brexis. AMEgmino: La antigücdad del hombre en cl Plata, tomo II, pág. 310, 188r.

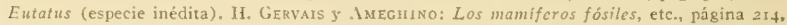
número 279, 1880 .

Esta especie es un tercio menor que la precedente y de una conformación general bastante más esbelta. El cráneo es mucho más pequeño y no tiene más que 8 muelas en la mandibula superior y 9 en la inferior.

Las placas que constituyen la coraza presentan la misma escultura externa que en la especie anterior, pero son notablemente más pequeñas. y proporcionalmente más gruesas. Las placas que siguen inmediatamente a los anillos movibles tienen de 20 a 24 milímetros de largo por 12 o 13 de ancho; las que siguen unas tres o cuatro filas más atrás sólo tienen unos 18 o 20 milímetros de largo, pero de 12 a 15 de ancho y 7 u 8 milímetros de espesor. Los agujeros pilíferos del borde posterior están dispuestos formando una doble fila bien visible. La figura central es muy deprimida, con dos o tres perforaciones muy pequeñas en su parte posterior y toda la superficie de las placas es un poco rugosa y como de aspecto granular.

Procedencia: - He recogido restos de esta especie en distintos puntos de las provincias Buenos Aires, Santa Fe y Córdoba.

Horizonte:- Piso bonaerense y piso lujanense de la formación pampeana. 
En el yacimiento de Monte Hermoso existe un Eutatus que sólo me es conocido por restos de coraza, que presentan el mismo tamaño y el mismo aspecto que los del Eutatus brevis, con el que en un principio lo identifiqué (Lista de los mamíferos fósiles de Monte Hermoso, página 19, número 54); pero me parece difícil que una especie abundante en el pampeano superior y de la que aún no se conocen restos en el pampeano inferior pueda ser hallada en un horizonte considerablemente más antiguo todavía, tal como lo es el de Monte Hermoso. Me parece más probable que los restos de Eututus procedentes de este último punto sean de una especie distinta, probablemente nueva, pero que los restos de coraza hasta ahora conocidos no me permiten caracterizar.

Eutatus punctatus Ameghino

Lawins LXII.L, Meuras a $y$ \&

ANeGnino: La antigïedad del hombre es et Plata, tomo II, página 310, $183 \mathrm{~s}$.

Esta especie era de tamaño superior al del Eutatus brevis, igualando casi al del Eutatus Seguini. Las placas que forman la coraza se distinguen fácilmente por la figura central más alargada y del mismo alto que las figuras periféricas. Esta figura central está limitada por dos surcos laterales anchos y profundos y presenta en su parte superior dispuestos en arco de círculo, o simétricamente a ambos lados, 3 a 6 agujeros circulares de gran diámetro que penetran en el interior de las placas; estos agujeros presentan un aspecto muy distinto del que muestran las pequeñas perforaciones que se ven en el mismo punto en las nlacas de las otras especies y dan a la coraza un aspecto especial. Las placas de las bandas movibles tienen de 4 a 5 centímetros de largo; y las de la parte fija tienen de 20 a 27 milimetros de largo por 12 a 15 de ancho.

Procedencia:- He recogido restos de esta especie en las barrancas del río Salado y en los alrededores de La Plata.

Horizonte:- Piso belgranense y base del piso bonaerense de la formación pampeana.

\section{Eutatus mintrus Ameghino}

Lemเna LXVtIt, Aguras ai y az

Ameghino: Catálogo de la Sección de la provincia de Buenos Aires en la Exposición Continental Sud Americana, página 41, 1882 (Homen nulum).

Esta especie era de tamaño mucho menor que todas las precedentes, comparable al del Dasypus sexcinctus. Las placas más grandes de las bandas movibles no tienen más de 25 milimetros de largo por 8 milímetros de ancho, pero la mayor parte son un poco más pequeñas. 
La figura elíptica del centro de cada placa está bien marcada y presenta en su parte anterior dos o cuatro agujeros de gran tamaño como en el Eutatus punctutus, siempre dispuestos por pares simétricos, en número de uno o dos a cada lado. Por este carácter se acerca al Eutatus punctatus, pero se distingue fácilmente de éste por su tamaño mucho menor y además por la conformación del borde posterior, que en el Eutatus punctatus presenta los agujeros piliferos dispuestos en una doble fila, de los cuales los anteriores son notablemente más pequeños que los posteriores, mientras que las placas del Eutatus minutus no presentan más que una sola fila de agujeros piliferos, pero de gran tamaño, todos de contorno subrectangular y dispuestos con su eje mayor dirigido de adelante hacia atrás, colocados unos a continuación de otros y separados por láminas óseas muy delgadas.

Toda la superficie de las placas es áspera, como granulada y con puntuaciones finas irregulares.

Procedencia: - He recogido los restos de esta especie en los alrededores de La Plata.

Horizonte:- Piso belgranense de la formación pampeana.

Eutatus oenopiorus Ameghino

LAmina LXVIU, Rigures 5 a 20 y as $y$ st

AMEGHiNo: Enumcración sistemática de los maniferos, etc., página 25, número I16, 1889 , incluyendo el Eutatus bipuratatus, numero Itg.

Esta especie alcanzaba próximamente el tamaño del Eutatus Seguini. Las placas de las bandas movibles tienen de 28 a 38 milímetros de largo por de 10 a 13 de ancho, y las placas de la sección fija de 20 a 28 milimetros de largo por de 12 a 16 de ancho. La superficie externa de las placas tiene un aspecto bastante distinto del que distingue a los Eutatus pampeanos.

Las placas de las handas movibles presentan en la parte libre de la superficie externa una figura longitudinal media, estrecha y convexa, que recorre la placa de un extremo a otro de su parte libre; a cada lado de esta figura central hay una depresión longitudinal; en la parte posterior de la placa, a cada lado de esta depresión, hay otra clevación más corta, seguida a cada lado de un surco longitudinal situado sobre el mismo borde periférico, que se dirigen adelante, y hacia la mitad del largo de la parte libre dan vuelta hacia adentro formando ángulo más o menos abierto hasta las depresiones laterales que limitan a la figura central, dirigiéndose ahí hacia adelante en el fondo de los surcos longitudinales laterales como una prolongación de éstos, limitando así una forma muy ancha atrás y mucho más angosta adelante, 
que imita la figura de una botella. En el borde posterior los agujeros piliferos son de tamaño mediano y bastante numerosos, pero dispuestos sobre una línea simple. Toda la superficie de las placas es más lisa que en las especies anteriores, de aspecto menos granulado, pero más puntuado.

Las placas de la sección fija muestran en la cara externa la misma figura en forma de botella, pero no tan bien definida como en las placas de las bandas movibles; en la parte anterior lo que representa el gollete de la botella, está rodeado por cuatro figuras pequeñas; y a menudo entre éstas, en el fondo de los surcos, hay algunos pequeños agujeritos. En el borde posterior los agujeros pilíferos son siempre en corto número, pero de gran tamaño y dispuestos constantemente en una sola fila.

Procedencia: - Los restos de esta especie han sido descubiertos por Carlos Ameghino en las barrancas del río Santa Cruz, en Patagonia austrai.

Horizonte:- Piso santacruceño (eoceno inferior).

Eututus Lagena Ameghino

Lamina Lxrill, Gguras at a so

AMEGHiNo: Enumeración sistemática de los mamiferos, etc., página 26, número $117,1887$.

Esta especie es sumamente parecida a la precedente; las placas de 1a coraza presentan la misma escultura externa, siendo la figura en forma de botella todavía mejor definida; pero la escultura es más suave, las figuras menos elevadas, los surcos y depresiones menos profundos y toda la superficie de las placas más lisa, no granulada sino simplemente puntuada. Los agujeros pilíferos del borde posterior son en corto número, no muy grandes y siempre dispuestos en una sola fila. El tamaño era por lo menos una mitad más pequeño que el del Eutatus anophorus, pues las placas de las bandas movibles sólo tienen de 18 a 22 milímetros de largo por de 8 a 10 de ancho y las plazas de las secciones fijas de 12 a 15 milímetros de largo por de 8 a 10 de ancho.

Cuando se conozcan corazas completas, $\mathbf{u}$ otras partes del esqueleto, esta especie y la precedente presentarán sin duda caracteres suficientes para separarlas como género distinto.

Procedencia: - Los restos de esta especie han sido descubiertos por Carlos Ameghino en las barrancas del río Santa Cruz, en Patagonia austral.

Horizonte: - Piso santacruceño (eoceno inferior). 
Amegrino: Enumeración sistemática de los mamíferos, etc., página 26, número 118, 1887 .

Esta especie, que sólo me es conocida por numerosas placas de las bandas movibles, era de tamaño muy pequeño, comparable al de la especie anterior, pero de una conformación bastante distinta; las placas son relativamente más largas, pero más angostas y más gruesas, variando su tamaño entre 20 y 25 milímetros de largo por 6 y 8 de ancho.

De la figura en forma de botella que adorna la cara externa de las placas de las especies precedentes, no existen vestigios en las del Eutatus distans. En esta especie, cada placa presenta en la cara externa una figura longitudinal media angosta y muy elevada, pero que no recorre todo el largo de la placa, perdiéndose, al contrario, en la parte posterior mucho antes de llegar al borde que contiene los agujeros pilíferos. Esta figura central está limitada por dos surcos. laterales muy angostos y profundos, que también se pierden hacia atrás, limitados a su vez por otras dos figuras largas, estrechas y elevadas, como la del centro, colocadas una en cada borde, casi siempre sin presentar interrupciones en toda su longitud. La parte posterior, antes de llegar al borde, es elevada y plana. Los agujeros pilíferos son en corto número, grandes y dispuestos en una sola fila.

Procedencia: - Los restos de esta especie han sido descubiertos por Carlos Ameghino en las barrancas del río Santa Cruz, en Patagonia austral.

Horizonte:- Piso santacruceño (eoceno inferior).

TOLYPLUTES Iliger

ILIGER: Prodromus Syst. Mamm, et avium, página III, I8II.

Este género es muy distinto de los precedentes y presenta caracteres verdaderamente particulares, que permiten reconocer todas sus. partes con igual facilidad; por la forma de la coraza es entre los armadillos actuales, el que más se acerca a los extinguidos Gliptodontes.

La coraza dorsal está formada por dos grandes secciones fijas, una anterior y la otra posterior, separadas por sólo tres bandas movibles que, sin embargo, permiten que la coraza tome la forma de una bola completa. Las placas de las secciones fijas son poligonales, la mayor parte de aspecto subcuadrangular, con la cara externa cubierta por un cierto número de protuberancias o tubérculos cónicos y lisos, de los cuales de uno a tres forman el centro de la placa y los demás están 
dispuestos alrededor, presentando todos un aspecto parecido. Las placas de las bandas movibles son de tamaño mucho mayor, largas y angostas como en todos los demás armadillos y con la cara externa cubierta por los mismos tubérculos que adornan las de las secciones fijas, pero en mayor número y más puntiagudos, presentando un aspecto granular.

La cola es corta y cónica, muy gruesa al principio y cubierta de grandes placas óseas tuberculosas.

Las muelas son en número de 9 , muy raramente de ocho, en cada lado de cada mandíbula, todas subcilindricas y las anteriores y posteriores un poco más pequeñas que las intermedias. La mandíbula tiene la rama ascendente arrancando del lado externo de la rama horizontal y ascendiendo casi perpendicularmente. El cráneo es cónico, puntiagudo adelante y con el arco cigomático muy delgado. Las cinco vértebras cervicales intermedias están soldadas en una sola pieza.

Los pies anteriores no tienen más que cuatro dedos, faltando el quinto; los dos dedos internos son más grandes que los externos; y el tercero tiene una uña sumamente larga. Las dos primeras falanges de los dedos tercero y cuarto están soldadas en un solo hueso. Los pies fosteriores tienen cinco dedos, con uñas cortas y anchas, siendo los dedos externos muy pequeños.

\section{TOLypeutes conurus I. Geoffroy Saint-IIilaire}

Dasypus conurus. Is. Geoffroy SaINT-IliLAire: Comptes-rendus, volumen XXIV, pág. 575, año 1847 - Idem: «Revue Zoologique», année 1847 , página 135 .

WAGNER-SCHREBER: Suppl., tomo V, página i78, 5 .

Burmerster: Reise durch die La Plata Staaten, tomo 1I, página 426, 39. - Idem: Description physique, etc., tomo III, página $4 \mathrm{II}$.

GIEBeL: Zeitschr. f. d. gesamt. Naturw., I $\$ 61$, tomo XVIII, láminas III-V, figura 3.

Gray: Proceed. Zool. Soc, 1865, página 380. - Idem: 1874, página 244.

MURIE: Trans, Linn. Soc., tomo XXX, página $7 \mathrm{r}$, láminas 20-26.

Habita casi toda la extensión de la República al norte del río Colorado.

TOLYPEUTES CONURUS FOSSILIS

Laruina LXYI, Aguran 7 a 8

Dosyth conurus, Burmeisterr: «Anales del Museo Público de I3uenos Aires», tomo I, entrega $3^{\natural}$, página 232, 1866 . - Idem: Description physique, etc., tomo III, página $4+3$.

Dasyipus apareoides. Bravard: Catalogue, etc.

Tolypeutes aff. conurus. H. GERVAIS y AMEGHiNo: Los mamiferos fósiles, etc. página 216.

Tolypeutes conurns. AMEghiNo: La antigüedad del hombre en el Plata, tomo I, pág. 625. año I880. - Idem: tomo II, página $8 \mathrm{r}, \mathrm{I} 88 \mathrm{r}$.

LYDEKKER: Catal. of Foss. Mamm., parte V, página $\mathrm{r}_{3} 8,1887$.

Los restos de esta especie se encuentran con frecuencia en las capas sedimentarias más superficiales de la provincia Buenos Aires.

Bravard y Burmeister mencionan restos de Tolypeutes procedentes Le la formación pampeana, que el primero de esos autores consideró 
como de una especie distinta de la actual y el segundo como de la especie existente; y Lydekker identifica con la especie actual, restos fósiles de la misma procedencia. Por mi parte he encontrado repetidas veces restos fósiles de Tolypeutes en los distintos niveles de la formación, consistentes, sobre todo, en restos de coraza, que cuando menos aparentemente parecen idénticos a los de la especie actual, aunque es posible que el descubrimiento de corazas completas o de partes del esqueleto, pruebe lo contrario, por lo que creo que la identificación de la especie fósil con la actual debe admitirse tan sólo de un modo provisorio.

Procedencia: - Los restos de esta especie se encuentran con frecuencia en las provincias Buenos Aires, Santa Fe y Córdoba.

Horizonte: - Todos los niveles de la formación pampeana hasta la época actual.

PRIODON F. Cuvier

T. CUVIER: Dents des manmifères, 1825 .

Este género es, entre los armadillos, todavía más singular y de formación más anómala que el Tolypeutes.

La coraza se compone en toda su extensión de placas rectangulares de superficie externa casi lisa dispuestas en toda su extensión en filas transversales, formando tres partes distintas, una anterior con 10 filas transversales y la otra posterior con 16 filas transversales unidas y la tercera central formada por bandas movibles, generalmente en número de doce. La cola es larga, cilindrica, acorazada en toda su extensión, encerrando de 20 a 25 vértebras.

El sistema dentario se compone de un considerable número de dientes, pues varia entre las fórmulas $\frac{20-21}{16-17}, \frac{24}{22}, \frac{25}{24}$, que no es difícil caractericen variedades o especies hasta ahora confundidas en una sola. Estos dientes son comprimidos lateralmente, particularmente los anteriores, y todos más o menos parecidos entre sí.

Las vértebras cervicales segunda y tercera y a veces también la cuarta están soldadas en un solo hueso. Las vértebras dorsales varian en número de 12 a 13 . Las vértebras lumbares son en número de 5 , o de 4 cuando hay 13 dorsales, las dos últimas unidas con los huesos ilíacos. El sacro consta de 12 vértebras soldadas, contando las dos últimas lumbares y la última del sacro que es una vértebra caudal todavía separada en parte. 
Sinfisis del pubis abierta. Cinco dedos en cada pie, los tres externos de los anteriores con grandes uñas falciformes y los dedos tercero y cuarto con las dos falanges que preceden a la falange terminal unguilifera, soldadas en una sola pieza.

\section{PRIODON GIGAS}

Dasypus gigas, G. Cuvier: Recherches sur les ossements fossiles, tomo V, parte I, página 120 , lámina $X I$, figuras $I, 3$ y 10.

PR. DE NeW WIED: Beitr. z. Naturg. Bras., tomo II, página 516, I.

WAGNER-SCHREBer: Suppl, tomo IV, página 169 , $x$.

BURMerster: Syst, Ubers, d. Thiere Brasil, tomo II, página 277. - Idem: Actas de la So. ciedad Paleontológica, tomo I, pág. 32. - Idem Description physique, etc, tomo III, pág. 436.

Dasypus giganteus (Geoffroy). DESMAREST: Mammalogie, página 368.

GrIfFIT: Anim. Kingd., tomo III, página 290.

LEsSON: Mamm., página 309.

Priodontes gigas. OWEN; Odontographie, lámina LXXXV, figura I.

Gervais: Voyage de F. de Castelnait, Mammifères, tomo XVIII.

RAPP: Edentaten, tb. 4 .

Prionodus gigas. Gray: Proceed. Zool. Soc., 1865, página 374.

Es el más gigantesco de los armadillos existentes. Habita los territorios del Chaco y de Misiones y toda la región septentrional de la República. Al principio de este siglo se encontraba en las provincias de Córdoba y Santa Fe y hasta en la parte Norte de la provincia Buenos Aires.

PrIODON GIGAS FOSSILIS

Priodon giganteus, Irais: Clinats, Géologie, faune du Brésil, página 366, 1872.

Hasta ahora no se han encontrado restos fósiles de esta especie en 1a República Argentina, pero Liais cita en su trabajo la existencia de restos fósiles en las cavernas de Brasil, particularmente placas sueltas de la coraza, que le han parecido idénticas a las de un individuo actual de gran talla.

\section{XiNuRUS Wagler}

WAGIER: Natürliches systen d. amphibien, etc., página 36,1830 .

Curaza formada por 12 o 13 bandas movibles centrales, seguidas adelante y atrás por secciones fijas compuestas de placas poligonales trabadas entre sí y de superficie externa irregularmente granular, con pequeñas cavidades hacia el centro que desaparecen con la edad. Cola muy corta y casi desnuda o con coraza incompleta, formada por algunas placas aisladas y tuberculosas.

Dientes en número de $\frac{8}{8}$ a $\frac{9}{9}$, subcilíndricos, los anteriores y posteriores más pequeños que los intermedios. Pie anterior con cinco dedos, el tercero corto pero con una uña enorme; el segundo, más largo, 
pero con una uña más corta; primero, cuarto y quinto mucho más pequeños; dedos tercero, cuarto y quinto, con las dos falanges que preceden a la unguilífera, soldadas en una sola pieza. Pie posterior con cinco dedos cortos, el tercero más largo y el primero y el quinto más pequeños.

\section{Xenurus unicinctus (Linneo) Wagler}

Dasypus unicinctus. LinNeo: Systema naturae, edición $12^{\mathrm{a}}$, volumen I, página $53,1766$. Dasypus duodecincinctus Linneo.

Dasipus gymnuтus Illiger.

M. DE NEW WIED: Beitr. Nat. Bras., volumen II, página 529,1832 .

Dasypus tatouaj. Desmarest: Mammalogie, página 369,1822 .

Xenurus nudicaudus Lund.

Habita en la República Argentina el territorio de Misiones.

XENURUS UNICINCTUS FOSSILIS

Xenurus aff. nudicaudo. Lund: Kön. Danske, Vid. Selsk. Skr., vol. IX, pág. I97, 1842.

Xenurus antiqurts. LUND: Obra citada, volumen VIII, página 227, 1841 .

Xenurus unicinctus. I.XDEKKER: Catal. of Foss. Mammal., paite V, página I39, 1887.

No se conoce hasta ahora fósil en la República Argentina, pero ha sido encontrado en las cavernas de Brasil por Lund y Claussen. Lund, separó la especie fósil de la actual, pero según Lydekker son absolutamente idénticas, o por lo menos, los restos conservados en el Museo Británico no difieren de las partes correspondientes de la especie existente.

\section{Chlamydophoridæ}

Esta familia se distingue muy bien por la coraza dorsal compuesta de bandas movibles transversales en toda su extensión y por la existencia de un escudo pélvico formado por placas trabadas entre sí por suturas, de una forma general semicircular, que cubre la parte posterior del tronco, descendiendo perpendicularmente hacia abajo. La cabeza no está protegiđa por un casco cervical separado, estando éste reemplazado por la parte anterior de la coraza dorsal que se extiende adelante hasta encima de la frente.

\section{CHLAMYYDOPIIORUS Harlan}

HARLAN : «Annals of the New-York Lyceun of nat. hist.», tomo I, lámina IV, 1825.

La coraza dorsal está formada por placas rectangulares dispuestas en bandas transversales, todas libres, sin que las placas tampoco estén soldadas con las laterales del mismo anillo; la superficie de estas placas es casi lisa, presentando un ligero parecido con las del género Zaëdyus, aunque están dispuestas de una manera completamente dis- 
tinta. La coraza dorsal, que empieza encima de la frente, consta de 28 bandas transversales, empezando las bandas anteriores con sólo 3 o 4 placas, aumentando sucesivamente hacia atrás el número de placas de cada banda, hasta que hacia el centro alcanzan hasta el número de 24 , disminuyendo luego de algunas placas en el borde posterior. El escudo pélvico es cóncavo en el lado interno y está formado por cinco filas de placas ovaladas. La cola es acorazada en toda su extensión, terminando en una extremidad fuertemente ensanchada y deprimida perpendicularmente como en el género Dœdicurus entre los Gliptodontes.

El cráneo es corto, ancho atrás y de hocico puntiagudo, con ocho dientes en cada lado de la mandíbula superior y ocho o nueve en la inferior. Cinco dedos en cada pie, los tres externos de los anteriores con grandes uñas falciformes, los de los posteriores con uñas pequeñas y puntiagudas.

\section{Chlamydophorus truncatus IIarlan}

HarLAN: eZool. journ.», tomo II, página 154, lámina VI. - Idem: Isis., v. 1830,424, tb. 4 . YARREL: «Zool. journ.», tomo III, página 544, lámina XVI.

WAGNER-SCFREBER: Suppl., tomo IV, página I87.

IIYRTt: Abh. der Kais. Akad. d. Wissenscli. z. Wient, phys. Cl., tomo IX, I855.

Gilltss: Un. st. nav. astr. Eirped., tomo II, página 158, lámina II.

Burmeister: Reise durch die La Plata Staaten, tomo I, página 297.- Idem: tumo II, página 429. - Idem: Description physique, etc., tomo-III, página 445.

GraY: Proceed. Zool. Soc., 1865 , página 381 .

Este es el más pequeño de los armadillos actualmente existentes. Habita la llanura argentina al Norte del río Negro, hasta las provincias Mendoza y San Luis y la parte austral de la provincia Buenos Aires hasta unas 20 leguas al Norte de Bahía Blanca, aunque muy raro.

\section{ChLAMYdophorus truncatus (?) FOSSILIS}

Una especie de este género ha dejado sus restos en la formación pampeana y me es conocida por placas de coraza que en un principio creí provinieran de una especie muy pequeña del género Dasypus, pero que un nuevo examen me ha probado pertenecen a una especie de Chlamydophorus, que por las placas no me es posible separar de la especie existente, aunque ello no es una prueba de identidad específica, reuniendo la especie fósil a la actual sólo de una manera provisoria, pues sin partes del esqueleto, o por lo menos sin el dérmatoesqueleto casi completo, me parece que no es posible determinar con seguridad si se trata de la misma especie actual o si representa una especie extinguida.

Procedencia:- He recogido los restos fósiles de este animal en el arroyo Frías, no lejos de Mercedes, en la provincia Buenos Aires.

Horizonte:-Piso bonaerense de la formación pampeana. 


\section{PELTATELOIDEA}

Toda la coraza compuesta de placas simplemente imbricadas. Cola, muy larga, cilíndrica y cubierta de placas imbricadas. Cráneo muy largo y puntiagudo adelante. Mandíbula inferior larga, con rama horizontal baja y rama ascendente poco elevada. No menos de ${ }_{25}^{25}$ dientes cónicocilíndricos y pequeños. Intermaxilar bien desarrollado y provisto de incisivos. Vértebras cervicales todas separadas. Sacro de no más de 5 vértebras. Húmero con agujero epitrocleano. Tibia y peroné separados. Todas las articulaciones de las extremidades distintas. Cinco dedos en cada pie, con uñãs largas y acuminadas.

Grupo teórico, antecesor de Glyptodontia y Dasypoda, en el cual coloco a la familia de los Stegotherido.

\section{Stegotheridx}

Coraza no dividida por secciones, compuesta en toda su extensión de placas rectangulares o subcuadradas, de superficie externa lisa o casi lisa, dispuestas en filas transversales, sin trabarse por suturas, pero imbricadas en toda la extensión de la coraza, cubriéndose unas a otras de atrás hacia adelante como el tejado de una casa.

\section{STEGOTHERIUM Ameghino}

AmeGrino: Enumeración sistemática de los mamíferos, etc., página 25,2887 .

Este es un género de armadillos extinguidos completamente, diferentes de todos los conocidos, tanto actuales como fósiles, caracterizado por placas rectangulares, pequeñas, muy gruesas y con una fila de perforaciones para la implantación de pelos que da vuelta todo alrededor, pasando adelante en el fondo de la pequeña depresión transversal que separa a la parte anterior en forma de tecla del cuerpo de la placa.

STEGOTHERILAT TESSELI.ATUM Ameghino

Lamans LAIS, figuras 10 y 11

AmegHiNo: Enumeración sistemática de los mamiferos, etc, página 25, número 115,1887 .

El animal ha sido de tamaño muy pequeño, comparable al del peludo (Euphractus villosus) pero su forma debió ser sin duda muy distinta, pues todas las placas presentan una prolongación anterior lisa, lo que hace suponer que toda la coraza era anillada; pero esta parte anterior lisa no es larga y sobre un plano más elevado que el cuerpo de la placa, sino corta y en declive hacia abajo, separada del cuerpo de la placa por una pequeña depresión transversal poco profunda. La cara opuesta 
o interna, está, al contrario, cortada en bisel o declive en su parte posterior y en dirección opuesta al declive externo anterior, esto es: dirigiéndose hacia arriba. De esto se deduce que las placas del Stegotherium tessellatum se cubrian unas a otras en toda la extensión de la coraza, tapando la parte posterior de cada placa la anterior de la que sigue, como las tejas del techo de una casa.

La parte externa de cada placa que quedaba libre, esto es: que no era cubierta por la que la precedía, representa un rectángulo, cuyo perímetro está limitado por una línea de perforaciones profundas, colocadas unas a continuación de otras, que ocupan los tres bordes de la placa y dan vuelta adelante siguiendo el pequeño surco transversal que separa el cuerpo de la placa, de la parte anterior en declive. La superficie de la placa limitada por la fila de perforaciones periféricas mencionadas conserva la forma rectangular, siendo poco áspera, un poco puntiaguda y deprimida o un poco excavada en el centro.

Las placas de este animal tienen de 7 a 11 milimetros de largo, 5 a 6 de ancho y 3 a 4 de grueso.

Procedencia: - Los restos de este animal han sido descubiertos por Carlos Ameghino en las barrancas del río S. Cruz, en Patagonia austral.

Horizonte:- Piso santacruceño (eoceno inferior).

\section{OBSERVACIONES GENERALES}

SOBRE LOS MAMÍFEROS DEL GRUPO DE LOS HICANODONTES

Los mamíferos Hicanodontes fueron durante las épocas geológicas pasadas, por lo menos en Sud América, uno de los grupos predominantes, el que después de haber alcanzado un desarrollo nada común, se ha ido restringiendo, desapareciendo poco a poco la mayor parte de sus representantes, encontrándose hoy en vía de rápida extinción.

Mucho falta todavía para que pueda trazarse un cuadro completo del parentesco y grandes líneas de filiación de sus representantes, a pesar de lo cual los materiales conocidos permiten trazar un bosquejo bastante aproximado de la descendencia de los distintos géneros y de las diversas familias en que se agrupan. De los tres grandes grupos en que se dividen los mamíferos hicanodontes, el de los Peltateloidea, el de los Glyptodontia y el de los Dasypoda, sólo el último conserva todavía representantes vivos; los dos primeros han desaparecido por completo.

El grupo extinguido de los Glyptodontia es el que parece haber alcanzado un mayor desarrollo y sus representantes un tamaño más gigantesco. Generalmente se ha considerado a los Gliptodontes como los antecesores de los armadillos actuales, que serían sus descendientes 
degenerados. Repetidas veces me he pronunciado contra esta opinión que parecía tener en su favor la gran antigüedad de los Gliptodontes y la edad relativamente reciente, a lo menos en apariencia, de los armadillos. En mi Filogenia, basándome en los principios y reglas en ella expuestos, llegué a un resultado completamente contrario, expresáncome al respecto en los siguientes términos: «En cuanto al dérmatoesqueleto que caracteriza a diversos animales, presenta estados de evolución muy distintos, según los géneros, las familias, los órdenes y aun los grandes grupos. Compuesto de placas sueltas sin ninguna trabazón en la mayor parte de los reptiles escamosos, las mismas placas se unen en una coraza sólida, que se une a su vez a la columna vertebral en las tortugas. Casi existe la misma relación en los mamíferos, comparando entre sí a los Megatéridos de huesos dérmicos informes y sueltos y a los armadillos de placas unidas por suturas fijas, formando una sólida coraza que se une a su vez en distintos puntos con la columna vertebral. Tenemos que admitir igualmente que estas corazas sólidas, que están formadas por placas distintas separadas unas de otras en la juventud del animal, provienen de otras cuyas placas no estaban tan intimamente unidas.

«Por eso mismo debemos considerar a los extinguidos Gliptodontes como seres que habían alcanzado un grado de evolución más avanzado que los armadillos existentes. Estos últimos, por sus placas dérmicas incompletamente unidas y todos sus demás caracteres osteológicos, representan un tipo primitivo que tiene que haber precedido en su aparición a los primeros. Este tipo primitivo debe a su vez haber sido precedido por otros cuyas placas eran aún más distintas, lo que de etapa en etapa, puede conducirnos a encontrar el tronco primitivo de los mamíferos en un reptil acorazado (7) ». Y al año siguiente, estudiando los mamíferos fósiles de los terrenos terciarios antiguos del Paraná, agregaba, ocupándome del mismo tema:

«Pero si bien el Chlamydotherium representa una etapa de evolución menos avanzada que los Gliptodontes, sucede otro tanto con los armadillos existentes, cuyo tipo fundamental, según las leyes de la evolución, debe haber precedido a los Gliptodontes y al mismo Chlamydotherium...

«Confiado en estas deducciones que son el resultado de cálculos filogénicos hechos con los datos que nos proporcionan los armadillos existentes y los Gliptodontes extinguidos, no dudo un instante que se han de encontrar en los yacimientos del Paraná loricados del mismo tipo que los actuales armadillos (8)». Estas predicciones han sido completa-

(7) AmeghiNo: Filogenia, página 274, 1884; y página 430 del volumen IV de esta edición.

(8) Amegrino en el «Boletín de la Academia Nacional de Ciencias», tomo VIII, pág. x7o. 
mente confirmadas por los descubrimientos posteriores, pues no sólo se han encontrado restos de verdaderos armadillos en las formaciones oligocenas del Paraná sino también en los terrenos mucho más antiguos de Patagonia austral, que datan del principio de la época eocena; en las formaciones de esta última época, los restos de verdaderos armadillos son muy abundantes, pero los de Gliptodontes son más raros y de una conformación más parecida a la de los armadillos que los que se encuentran en las formaciones recientes.

Que los Gliptodontes representan una etapa de evolución mucho más avanzada que la de los armadillos lo demuestran claramente todos los detalles de su conformación, entre los cuales sólo mencionaré acá los tres culminantes.

Primeramente la columna vertebral, cuyas vértebras están soldadas unas a otras por secciones en los Gliptodontes, mientras permanecen separadas en los armadillos; que esto es el estado más primitivo lo ciemuestra claramente la circunstancia de que las mismas secciones del tubo dorsal de los Gliptodontes están compuestas en la juventud de vértebras separadas.

La forma y el número de los dientes. Estos nunca pasan de ocho en cada lado de cada mandíbula en los Gliptodontes, mientras que en los armadillos hay nueve, diez y hasta más de veinte en cada lado. Estos dientes son, además, en los armadillos, casi siempre simples, de una forma más o menos cilíndrica, pero en los Gliptodontes, presentan una forma más complicada, resultado de una evolución posterior, como lo demuestra el Chlamydotherium, que muestra sus muelas en una etapa de evolución intermedia entre la más primitiva de los armadillos y la más evolucionada de los Gliptodontes.

Por último, la forma de la coraza, formada en toda su extensión de placas soldadas unas a otras, demuestra claramente que representa un estadio de evolución que ha alcanzado en esa dirección sus últimos limites; que la coraza de los antecesores de los Gliptodontes estaba formada por bandas transversales movibles lo demuestra también la existencia en los bordes laterales de las corazas de los verdaderos Gliptodontes, de algunas hendeduras perpendiculares entre las filas de placas que constituyen la coraza, hendeduras que representan los últimos vestigios de las bandas movibles de sus antecesores. Sin embargo, la descendencia de los Gliptodontes, de los verdaderos armadillos, debe remontar a la época secundaria, puesto que en la base del eoceno ya se nos presentan ambos tipos bien separados.

Pero los armadillos o Dasypoda no constituyen el tipo de Hicanodontes más primitivos, pues para ligar el Priodon y el Chlamydophorus, ei primero más primitivo por su sistema dentario y el segundo por su coraza dorsal, a los Pleiodontes de dientes numerosos y con esmalte, 
c incisivos en ambas mandibulas, hay que intercalar todo un grupo, el du los Peltatcloidea, con dientes en numero no menor que el del Priodon y la coraza formada por placas suelfas y simplemente imbricadas en toda su extensión, grupo que debe haber alcanzado su gran desarrollo en la época secundaria, pero del cual hasta principios del eoceno existian algunos representantes, de los cuales se conoce un género típico, el Stegotherium, que quizí puede ser también el antecesor de todos los armadillos.

De los armadillos actuales, el Priofon es el más primitivo por el numero considerable de sus muelas y también por la coraza en bandas transversales en toda su extensión, y el Chlamydophorus es igualmente de un tipo primitivo por la coraza y por su tamano diminuto pero no for el aparato dentario. No es posible derivar estos dos tipos uno de otro, y sin duda remonta su origen a uno o más antecesores de tipo parecido, que reunian el número considerable de dientes del Priodon, con una coraza de placas sucltas y el tamaño diminuto del Chlamydophorus.

Ninguno de los demas géneros mas recientes parece tener relación inmediata con el Chlamydophorus, pero todos ellos pueden referirse al Priodon o a un tipo parecido, aunque a este último le faltan los intermedios mis inmediatos que permitan ligarlo sin discontinuidad a los géneros más recientes.

Un grupo subordinado, el de los Dasypodida, parece tener por más antiguo antecesor un tipo parecido al género Zaëdy $u s$, que puede considerarse como el antecesor de Dasypus, al que se ligan igualmente los géneros Eututus, Prauphractus y Macrauphractus. El Xenurus y el Tolypeutes tambien son froximos aliados del Zaëdyus, pero faltan los tipos intermedios que permitan ligarlos a una forma antecesora. Otro tanto sucede con los Prappidu, que probablemente se ligan con uno de los más inmediatos sucesores del tipo Priodon.

El grupo de los Chlumydotheride parece haberse separado inmediatamente despućs de constituido el tipo de los Dasypoda, evolucionando asi hacia el tipo de los Glyptodontia, de los cuales pueden considerarse como los verdaderos antecesores.

De los dos tipos principales de Gliptodontes, los de cola corta, cónica, gruesa en la base y de punta roma, formada por una sucesión de anillos movibles en toda su longitud, es la forma mas evolucionada y de consiguiente la de aparición más reciente; y los de cola larga. formada por varios anillos movibles en la base, es el tipo más primitivo y más antiguo, si bien cada uno de ellos ha sufrido en su evolución modificaciones especiales. La cola del Glyptodon es la misma cola del tipo del Hoplophorus cuyos primeros anillos, que forman el tubo caudal, han quedado separados; y la punta del mismo tubo se ha perdido, constitu- 
yéndose así la cola corta, cónica y anillada de los Gliptodontes. El tipo más primitivo de este grupo que hasta ahora me sea conocido es el Cochlops, cuya cola, aunque anillada y con tubérculos cónicopuntiagudos, era probablemente más larga y de consiguiente más cercana a las del otro tipo; a este género se liga también probablemente el Neothoracophorus.

Las colas formadas por anillos movibles planos en la base y seguidos de un tubo terminal más o menos cilindricoaplastado, como en el Hoplophorus, el Plohophorus y el Paluhoplophorus, debieron presentarse en sus más antiguos antecesores con todo el tubo igualmente anillado, o dividido por secciones transversales que se unian de adelante hacia atrás para formar el mencionado tubo; en esta forma dehia presentarse la cola del Propalchoplophorus, que no debía ser asi muy diferente de la de los Dasypodidu. Estas secciones del tubo caudal se fueron uniendo unas a otras hasta formar un tubo continuo como en el Hoplophorus, que es descendiente del Palwhoplophorus, que a su vez tuvo por antecesor al Propalchoplophorus.

Del Palchoplophorus empieza a manifestarse una nueva complicación en los dibujos de la superficie de las placas, que consiste en el aumento, en el número de las figuras periféricas de cada placa y una diminución proporcional en el tamaño, que conduce al género Plohophorus, de edad un poco más reciente, que es a su vez un antecesor del-género Nopachtus, alcanzando esta línea de evolución su último desarrollo en el género mas reciente, el Panochtus, que es también el más gigantesco, en el que han desaparecido completamente en el centro de la coraza las figuras centrales, presentándose toda la superficie cubierta por un crecido número de figuritas iguales.

Constituye tipo especialísimo en este grupo el género Dxdicurus, cuya coraza, enormemente esférica, ha perdido todo dibujo externo, presentando grandes agujeros que la atraviesan de parte a parte y una cola cuya extremidad en vez de terminar en punta presenta una parte terminal ensanchada en forma de clava, caracteres todos adquiridos en una larga evolución. El Dodicurus ha sido precedido por el Pluxhaplus, con agujeros más pequeños, cola menos ensanchada en la extremidad y con dibujos en toda su extensión y la coraza de forma general menos esférica y más alargada. El Plaxhaplus ha sido precedido a su vez por el Neuryurus, cuya cola era más normal y la coraza igualmente sin dibujos, pero no tan lisa como en el Dredicurus y el Plaxhaplus sino más áspera o rugosa, últimos vestigios de la antigua existencia de figuritas o esculturas superficiales, pero con los agujeros de Plaxhuplus y Dodicurus apenas acentuados, encontrándose este género en el verdadero principio de su formación.

Estas vistas pueden expresarse gráficamente en la siguiente forma: 


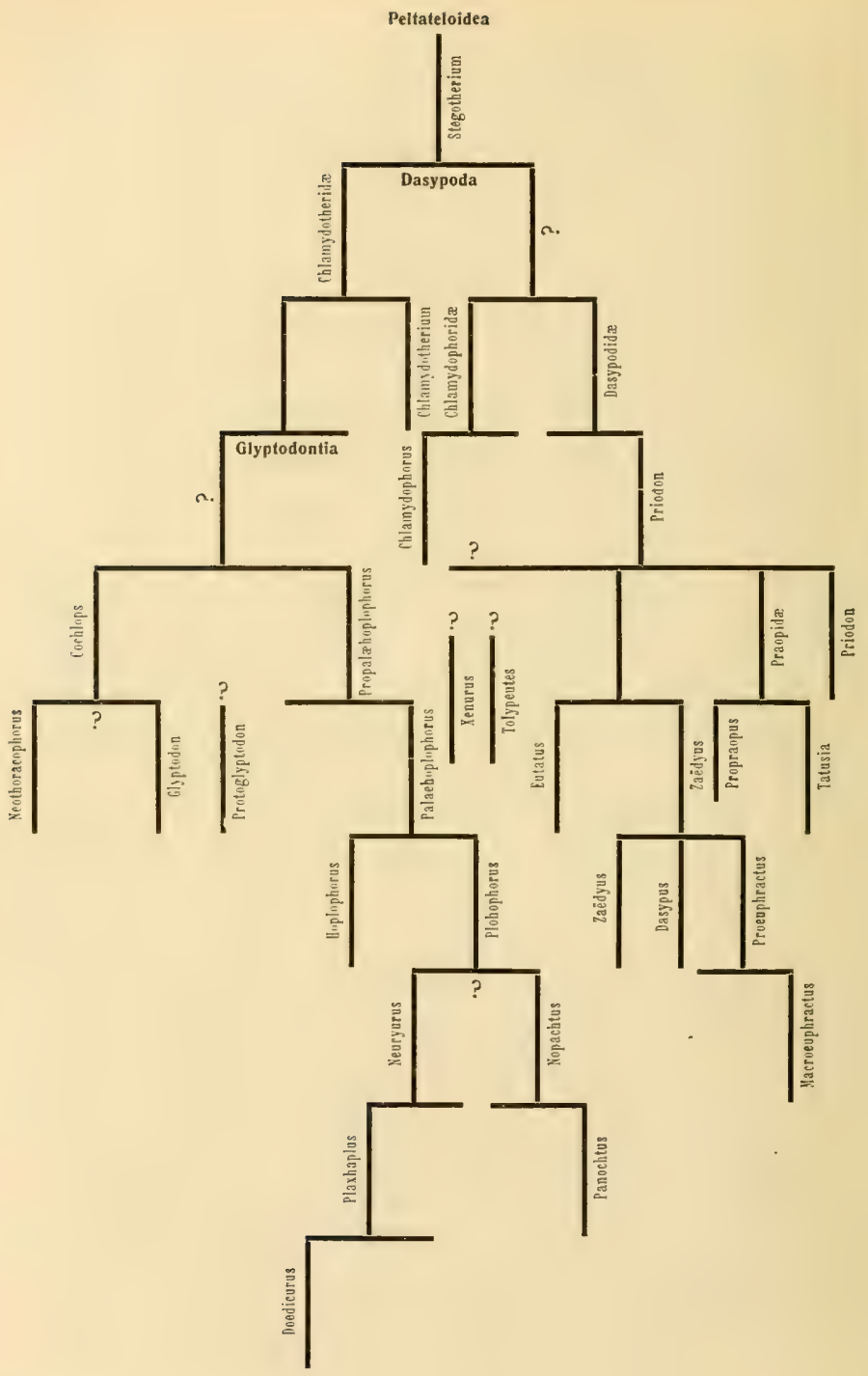




\section{CETACEA}

Mamíferos homalodontes con los miembros transformados en órganos de locomoción acuática.

Mandíbula inferior larga, delgada y sin rama ascendente; articulación húmerorradial inflexible; huesos carpales discoideos; dedos separados por cartílagos.

Se dividen en tres órdenes, caracterizados de este modo:

I. Miembros posteriores presentes.

a. Dientes numerosos: Proteroceta.

II. Miembros posteriores ausentes.

a. Dientes siempre presentes: Odontoceta.

$b$. Sin dientes o presentes sólo en el estado fetal: Mystacoceta.

\section{PROTEROCETA}

Miembros posteriores presentes y bien desarrollados, pero no tanto como los anteriores. Dientes numerosos, cónicocilíndricos, de base abierta y con esmalte. Grupo teórico, sucesor de los Prionodonta y antecesor de los Odontoceta. No le conozco hasta ahora representantes.

\section{ODONTOCETA}

Miembros posteriores ausentes o reducidos a un rudimento de cadera. Dientes siempre presentes, generalmente numerosos, cónicocilíndricos, de base abierta y con esmalte, a veces en número de más de doscientos. Timpánico siempre libre, no anquilosado al periótico.

Los representantes conocidos de este orden, se dividen en cinco familias que se distinguen por los siguientes caracteres:

A. Sínfisis de la mandíbula inferior que sobrepasa la mitad del largo de la rama horizontal.

1. Dientes numerosos. Todas las vértebras cervicales libres: Platanistida.

B. Sinfisis de la mandibula que no sobrepasa un tercio del largo de la rama horizontal.

1. Mandíbula superior con dientes.

a. Dientes numerosos en ambas mandíbulas: Delphinido.

$b$. Dientes reducidos a un solo par implantados en el maxilar superior: Monodontide.

2. Mandibula superior desprovista de dientes.

a. Dientes inferiores numerosos y bien desarrollados:

Physeterida.

$b$. Dientes inferiores rudimentarios, con excepción de uno o dos pares: Ziphiida. 


\section{Platanistidæ}

Rostro excepcionalmente largo, acompañado de mandibulas muy largas, estiliformes y con una parte sinfisaria que sobrepasa la mitad del largo total de la rama horizontal. Dientes pequeños, cónicopuntiagudos y excesivamente numerosos. Vértebras cervicales todas separadas.

\section{PONTOPORIA Gray}

Gray, en Zoology of the Voy. of «Erebus» and «Terror».

Este género es, entre los conocidos de la misma familia, el de rostro y sínfisis más larga y también el que lleva un mayor número de dientes, pues tiene de 53 a 59 en cada lado de cada mandíbula, de 212 a 236 en todos, que es el mayor número que se haya observado hasta ahora entre los mamíferos.

La columna vertebral consta de 42 vértebras: 7 cervicales, 10 dorsales, 6 lumbares y 19 caudales; 4 costillas esternales; esternón de 2 piezas; carpo formado por substancia cartilaginosa, incluyendo cuatro huesos pequeños; 5 metacarpianos; falanges reducidas a un prolongamiento cartilaginoso con un hueso cada una. En el individuo joven el número de dientes es completo de ${ }_{59}^{59}$.

\section{Pontoporia BratnVILLEt (Gervais) Gray}

Delphinus Blainvillei. Gervars: «Bullet. Soc. philom.», 1844, página 38 .

Stenodelphis Blainvillei. Gervais en D'Orbigny: Voyage dans l'Amérique Méridionale, tomo IV, parte $2^{\text {n }}$, página 31 , lámina XXIII, 1847 .

Pontoporia Blainvillei. Grax: Zool. of the voy. of \&Erebus» and eTerrors, página 46, lámina XXIX, año 1846 . - Idem: Catal, of Seals, página 23 .

Flower: Trans. Zool. Soc, tomo VI, página 113.

Burarister: «Anales del Museo Público de luenos Aires», tomo I, páginas 303 y $3 \mathrm{~S} 9$, láminas XXIII, XXV, XXVIII. - Idem: Description physigue, etc., tomo III, pág. 533.

Habita la embocadura del río de la Plata.

Sus restos fósiles se encuentran en los bancos de conchilla del piso querandino, en La Plata, Quilmes, etc.

\section{PONTISTLS Burmeister}

BURMEIster: «Anales del Museo Nacional», tomo III, página i38, $188_{5}$.

Este género, del cual hasta ahora sólo se conoce el cráneo con la parte posterior del paladar, pero sin el prolongamiento anterior del rostro, es muy cercano del de la Pontoporia, de la cual se distingue principalmente por el rostro proporcionalmente mán ancho y bastante más deprimido, en lo que se acerca un poco más al tipo de los Delphinide que la Pontoporia; pero la superficie del paladar, a lo menos en la parte existente, presenta una conformación casi idéntica con este género, como también la parte posterior del cráneo. 
Los dientes son más grandes que los de Pontoporia y no tan apretados, por lo que es posible que su número fuera menor, aunque al respecto no puede decirse nada con seguridad, pues ello depende también del largo del rostro, que no es posible determinar sin el conocimiento de esa parte.

\section{PoNTISTES RECTIFRoNS (Bravard) Burmeister}

Delphinus rectifrons. Bravard: Monografía de los terrenos marinos del Paraná, I859.

- Delplinus paranensis. Bravard: Catalogue des espèces fossiles, etc.

Pontoporia paranensis (Bravard). H. Gervals y AMEGHino: Los mamíferos fósiles, etc.

Pontistes rectifrons. Burmerster: «Anales del Museo Nacional», tomo III, página 139, lámina II, figura 12 .

El animal tuvo una talla un poco mayor que la Pontoporia Blainvillei, y los dientes, de raíz larga y cerrada en la base, presentan una corona corta, cónica y muy engrosada en su parte inferior inmediata al cuello, casi en forma de bulbo.

El ancho máximo del cráneo, en su parte posterior, es de unos 22 centímetros.

Procedencia: - Los restos de esta especie fueron descubiertos por Bravard en las barrancas de los alrededores de la ciudad del Paraná.

Horizonte:- Piso paranense de la formación patagónica (eoceno superior).

\section{Delphinidx}

El rostro es siempre menos prolongado que en los Platanistidae; y la sínfisis de la mandibula nunca sobrepasa un tercio del largo total de la rama horizontal de la mandíbula inferior. Las vértebras cervicales primera y segunda están siempre soldadas; y a menudo también las siguientes; pero cuando algunas de las posteriores permanecen libres, presentan un cuerpo vertebral sumamente comprimido de adelante hacia atrás.

\section{IINNEO: Systema naturae.}

\section{DELPIINUS Linneo}

Rostro bastante alargado, pero no tanto como en los Platanistidae. Dientes pequeños, todos iguales y no menos de veinte en cada mandí. bula. Vértebras lumbares numerosas.

\section{DeLPHINUS CAERLLEO-ALBUS Meyen}

Delphinus: caeruleo-albus. Mexen: Nova acta phys. med. Soc. Caes. Leop. Carol. N. C., tomo XVI, parte I, página 609, tb. VII, figura 2. - Idem: Beitr. 2. Zooli, página I2I.

BurMEISTER: Description physique, etc., tomo III, página 534.

Lagenorhynchus caerulco-albus, Grax: Catal, of Seals, página 262. - Idem CAssin: Un. St. expl. exped., página 31 , lámina VI, figura 2.

Delphinus albi-rostris. PEALE: Zool. expl. exped. Mammal, página 38.

Habita las costas de la provincia Buenos Aires. No se conoce fósil. 
TURSIOPS Gervais

GerVars: Histoire Naturclle des Mammifères, volumen II, página 323, 1855 .

Se distingue del género Delphinus por su rostro bastante más corto y por los dientes menos numerosos pero un poco más grandes.

TURSIOps CrModoce Gray

Tursio Cynodoce. Grax: Zool. of «Erebus» and «Terror», página 38, lámina XIX.Idem: Catal. of Seals, página 257, 4.

Bukmetster: anales del Museo Público de Buenos Aires», tomo I, página 306. - Idem: Description pliysique, etc., tomo III, página 535.

Habita las costas argentinas al Norte del río Negro; $y$ se han encontrado sus restos fósiles en los estratos marinos de la formación cuaternaria.

Procedencia:- Alrededores de La Plata.

Horizonte:-Piso querandino de la formación cuaternaria.

\section{TuRSIOPS OBSCURUS Gray}

Tursio obscurus. Gray: Spicil. Zool, tomo II, lámina II, tiguras 2 y 3.-Idem: Zool. ¿Erebus» and «Terror», página 37, lámina XVI. - Idem: Catal. of Seals, página 264, 12.

BurMetster: Description physique, etc., tomo III, página 536.

Delphinus cruciger. Quoy y GaImard: Voy'. de l'«Uranie», lámina XII, figura 2.

Delphinus bivittatus. D'OrBignx: Voyage dans l'Amérique Méridionale, Mammifères, lá$\operatorname{mina}$ XXI.

Delphinus superciliosus. Schleger: $A b h_{\text {, }}$ etc., página 22, tb. II, figura $3, \mathrm{y}$ tb. IV, fig. 4 . Delphinus Fitzroyi. Waterhouse: Zoology of the «Beagle», tomo II, lámina $X$.

Phocaena australis. PEALE: Zool. cxpl, exped. Mamme, página 33.

Habita las costas argentinas de Patagonia. No se conoce fósil.

ORCA Rondelet

RONDELET: De piscibus, página $483,1554$.

Rostro corto y ancho, 11 a 13 dientes en cada lado de cada mandíbula, que ocupan casi todo el largo del rostro, muy gruesos pero de corona cónicopuntiaguda y arqueada. Las dos o tres primeras vértebras cervicales están reunidas en una sola pieza y las demás separadas. Todas las especies de este género son de talla gigantesca.

\section{ORCA MAGEILANica Burmeister}

Burmeister: «nales del Museo Público de Buenos Aires», tomo I, página 373, lámina XXII. - Idem: «Ann, and Mag. Nat. Hist.», $3^{\mathrm{n}}$ serie, tomo XVIII, página 10I.

Gervais: Ostíographie des Cétacés, página 540.

Es uno de los delfines más gigantescos entre los existentes. Habita toda la costa Atlánticoargentina; y sus restos se encuentran en estado fósil en las capas marinas de la formación cuaternaria. 
Procedencia:-Distintos puntos de la costa del Plata y del Atlántico en la provincia Buenos Aires.

Horizonte:- Piso querandino de la formación cuaternaria.

\section{PSEUDORCA Reinhardt}

Rinnitardx: Ozers, Kongl. Danske, Videns. Selsk. Acad., 1862.

Cráneo más pequeño que el de Orca y de frente mucho más convexa. De 8 a 9 dientes en cada lado de cada mandíbula, menos gruesos y no tan puntiagudos como en el género precedente. Intermaxilares muy anchos.

\section{Pseudorca Grayi (Burmeister) Reinhardt}

Globicephalus Grayi. Burneister: \$Ann. and Magazine Nat. Hist.», $4^{2}$ serie, tomo I, página 52, lámina II. - Idem: *Anales del Museo P'úblico de Burenos Aires», tomo I, páginas 308 y 367 , lámina XXI.

Pseudorca meridionalis. ReinuardT: Vidensk. Meddels., Febrero de 187 y y Nov, de 1872.

Gervais: Ostéographie des Cétacés, página 540.- Idem: \$Journal de Zoologie», tomo I, página 68.

Pseudorca Grayi. BuRMeISTER: «Ann, and Magazine Nat. Hist.», 6² serie, tomo X, página 5I. - Idem: Description pliysique, etc., tomo III, página $53^{8 .}$

Habita la costa Atlánticoargentina de la provincia Buenos Aires. No se conoce fósil.

PHOCAENA Rondelet

RONDEL,EX: De piscibus, página 473,1554 .

Cabeza pequeña. Rostro corto y no separado por un pliegue frontal. Frente convexa. Dientes de 16 a 26 en cada lado de cada mandíbula, pequeños y de corona generalmente truncada. Todas las especies de este género son pequeñas.

\section{Procaena SPInipinnis Burmeister}

BuRMEISTER: Proceed. Zool. Soc., 1865, pág. 228. - Iden: «Ann. and Magaz. Nat. Hist.», $3^{\text {n }}$ serie, tomo XVI, página 132. - Idem: «Anales del Museo Público de Buenos Aires», tome $\mathrm{I}$, páginas 308 y 380 , lámina XXIII, figura 2 y lámina XXIV.--Idem: Description physique, etc., tomo III, página 540 .

Gray: Catal. of Seals, página 304.

Gervais: Ostéographie des Cétacés, página 571 .

Habita la costa Atlánticoargentina de la provincia Buenos Aires. No se conoce fósil.

\section{Monodontidx}

Este grupo, muy próximo de los Delphinidae, se distingue por la ausencia de dientes en la mandibula inferior. Los dientes superiores son siempre en pequeño número; y en algunos géneros reducidos a un 
solo par, de los cuales el izquierdo, en el macho del Monodon, se desarrolla en forma de una formidable defensa cilíndrica, dirigida hacia adelante. Vértebras cervicales generalmente separadas.

No se le conocen representantes en la República Argentina.

\section{Physeteridæ}

Este grupo se distingue por la ausencia de dientes en la mandíbula superior, pero existen bien desarrollados y en número considerable en la mandibula inferior, estando implantados en un surco longitudinal, en parte dividido por tabiques alveolares imperfectos.

\section{PHYSETFR Linneo}

IINNEO: Systema naturae, tomo I, página I07, 1766.

Mandibula larga y estrecha con la sinfisis ocupando más de la mitad del largo total. Dientes sin esmalte y en número de 20 a 35. Vértebras cervicales reunidas en una pieza, con excepción del atlas.

\section{Physeter macrocephates Iinneo}

Lrnneo: Obra y página citadas.

LYDEKKER: Catal. of Foss. Mamm., parte V, página $53,188_{\bar{\gamma}}$.

Habita la costa Atlánticoargentina de la provincia Buenos Aires. No se conoce fósil de la República Argentina; pero Lydekker, cita algunos restos fósiles como procedentes del Uruguay (?), probablemente de la República Oriental del Uruguay, por lo cual es casi seguro que también debe encontrarse fósil en nuestro suelo. Esos restos proceden probablemente del piso querandino de la formación cuaternaria.

\section{Ziphiidæ}

En este grupo faltan asimismo los dientes en la mandibula superior; y en la inferior son rudimentarios o atrofiados, quedando reducidos a uno, y, más raramente, a dos pares. El cráneo es por lo general muy asimétrico.

Ziphius Cuvier

Cuvier: Ossements fossiles, tomo V, página 350.

Los huesos nasales se levantan fuertemente hacia arriba, formando una fuerte elevación o protuberancia que domina todo el cráneo y la apertura nasal, dándole a la cabeza un aspecto característico particular. los intermaxilares son fuertemente cóncavos en su parte posterior, en 
donde limitan la abertura nasal. El rostro es largo, deprimido y puntiagudo. La mandíbula inferior tiene la punta fuertemente arqueada hacia arriba y con un solo diente bastante grueso implantado en un alvéolo que se prolonga hacia atrás en forma de surco longitudinal.

ZipHit's Australis Burmeister

Ziphiorhyrelius australis, BURMEISTER: «Ann. and Magaz. Nat. Hist., $3^{\mathrm{a}}$ serie, vol. XVII, páginas 94 y 303 .

Delphinorhynchus atistralis. Burmeister: Zeitschr, $f$. d. gesamt. Naturw, tomo XXVI, página 262 .

Epiodon australis. Burmeister: «Anales del Museo Público de Buenos Aires», tomo I, página 312, láminas $\mathrm{XV} \cdot \mathrm{XX}$.

Ziphius anstralis. Burmerster: Description phy'sique, etc., tomo III, página 542.

Habita la costa Atlánticoargentina. No se conoce fósil.

\title{
MYSTACOCETA
}

Miembros posteriores ausentes o reducidos a un pequeño rudimento de cadera. Dientes ausentes, siendo reabsorbidos desde el estado fetal. Cráneo simétrico. Timpánico anquilosado con el periótico.

\section{Balæuidæ}

Paladar provisto de láminas córneas perpendiculares, llamadas ballenas.

\author{
? PALAEOBALAENA Moreno
}

Moreno: Patagonio, resto de un continente hoy sunergido, pág. 26,1882 (nomen mudun).

? Palaeobalaena Bergi Moreno

Moreno: Obra y página citadas (nomen $n u d u m$ ).

\section{BAL,AENA Linneo}

LinNEO: Systcma naturac, volumen I, página $105,1766$.

Cabeza excesivamente grande y cuerpo grueso. Vértebras cervicales reunidas en una sola pieza.

\section{BALAENA AUSTRALIS Gray}

Balaena australis. VAN BENEDEN: Ostéographie des Cétacés, página 385 , láminas I y II. BuRMEISTER: Description physique, etc., tomo UI, página 547 .

Eubalaena australis. GraY: Catal. of Seals, página 91.

Habita la costa Atlánticoargentina. No se conoce fósil. 
Esta especie fué fundada por Bravard en restos de ballenas procedentes de las formaciones terciarias antiguas de las barrancas del Paraná, pero sus caracteres no han sido todavía bien establecidos. En esas formaciones, los restos de ballenas son muy abundantes y sin duda pertenecen a varias especies y a más de un género, pero el tamaño voluminoso de los restos de estos animales y la falta de materiales de comparación no me permiten emprender su determinación.

He aqui cuanto dice Bravard con respecto a su Balana dubia y que se reduce a esta nota que transcribo integra: «La presencia de estos animales en los terrenos del Paraná había sido establecida por medio de algunos fragmentos casi completamente desfigurados, pero hemos hallado después un hueso timpánico, que es una de las partes más características de sus esqueletos. Lo hemos comparado con el diseño del mismo hueso dado por R. Owen, en su «History of British Mammals», etc., figuras $220,221,222,223,224$ y 225 , cada uno de los cuales procede de una especie diferente, y hemos reconocido que, ya por la forma general, ya por las dimensiones, tenia mayor afinidad con el de la Balana definita, figura 222, que con todos los demás; sin que pueda, sin embargo, ser relacionada con esta especie. Se distingue, por lo demás, perfectamente de todas las especies vivientes, pero más esencialmente de la Baliena australis. Debemos, pues, buscar en una especie fósil, también de Inglaterra, las afinidades de esta nueva especie». (Bravard, obra citada).

La especie con la cual Bravard le encuentra más analogía, que es la Balana definita de Owen, entra hoy en el género Balcnoptera, por lo que es probable que la Balcna dubia de Bravard sea una Balonoptera y no una verdadera Balcena.

Procedencia: - Barrancas de los alrededores de la ciudad del Paraná.

Horizonte:- Piso patagónico de la formación patagónica.

\section{BALAFNOPTERA Lacepede}

LACEPEDE: Histoire des Cétacés (Table des ordres), etc., Jámina XXXXvi, página rou.

Cabeza más pequeña y cuerpo más delgado. Las siete vértebras cervicales más pequeñas. 
BALAENORTERA rONARIENSIS Burmeistet

Burmetster: Proceed. Zool. Soc., 1867, página 707. - Idem «Boletín del Museo Público de Buenos Aires», tomo II, láminas V y XIV. - Idem: Description physique, etc., tomo III, página 545. - Idem: Atlas de la «Description physique», etc., página 2.

VAN BENEDEN y Geryars: Ostéographic des Cétacés, página 229.

Habita toda la costa Atlánticoargentina. Sus restos fósiles encuéntranse en abundancia en los bancos marinos de la costa del río de la Plata y del Atlántico.

Horizonte:- Piso querandino de la formación cuaternaria.

Balaenoptera patacionica Gray

Balaenoptera patachonica. BURmerster: Proceed. Zool. Soc, 1865, página 191, - Idem: Ann, and Magazine of Nat. Hist.», serie $3^{\mathrm{n}}$, tomo XVI, página 59. - Idem: Description physique, tomo III, página 545. - Idem: Atlas de la Description physique, etc, pág. I2.

VAN Beneden y Gervals: Ostéographie des Cétacés, página a25.

Physalus patachonicus. Gray: Catal. of Seals and Whales, página 373.

Burmerster: «Anales del Museo Público de Buenos Aires», tomo I, página 310.

Habita la costa Atlánticoargentina; sus restos fósiles se encuentran en las capas marinas postpampeanas de la costa.

\section{Balaenoptera antarctica Gray}

Sibbaldius antarcticus. Gray: Proceed. Zool. Soc., 1865, página 7r3. - Idem: Catal, of Seals and $I V h$. , etc., página $38 \mathrm{r}$.

Balaenoptera intermedia. Burmerster: «Boletín del Museo Público de Buenos Aires», lá. mina XIV, I866. - Idem: Description physique, etc., tomo III, página 546. - Idem: Atlas etcétera, página 22 .

Habita la costa Atlánticoargentina. No se conoce fósil.

MECAPTERA Gray

Gray, en Zool. of «Erebus» and eTerror», página $16,18+6$.

\section{Mreaptera Burmeisteri Gray}

Megaptera Burmeisteri. Gray: Catal. of Seals and Whales, página $8 \mathrm{r}$.

Evruerster: Atlas de la \&Description physique, etc.», página 34.

Megaptera, sp. ? Burmerster : Actas de la Sociedad Paleontológica, 1866. - Idem: «Ana. les del Museo Público de Buenos Aires», tomo I, página 310.

Balaena australis. Burmerster: Description physique, etc., página $547,1879$.

Los restos que sirvieron para fundar esta especie, consistentes en un atlas, un axis y otros restos incompletos, fueron encontrados en una de las islas del Delta del Paraná, al remover terreno para agricultura, y atribuídos por Burmeister a una Megaptera, que Gray incluyó luego en su Catálogo con el nombre de Megaptera Burmeisteri. En el tercer tomo de la «Description physique», Burmeister atribuye esos restos a la Balocna australis, pero últimamente, habiendo podido obtener el tim- 
pánico con el petroso vuelve a considerarlos como de una verdadera Megantera. Sería de desear la publicación de nuevos datos y sobre todo de dibujos de los últimoś restos mencionados.

Procedencia: - Islas del delta del Paraná, en la provincia Buenos Aires.

Horizonte:- Aluviones recientes del piso aimarense.

\section{MONOTREMATA}

Los caracteres culminantes que permiten reconocer inmediatamente a los representantes de esta subclase, son: el coracoides independiente, la existencia de una verdadera cloaca, la presencia de un epicoracoides y un episterno y el peroné articulado con la extremidad proximal del astrágalo.

Divido esta clase en tres secciones, a las cuales distingo por los siguientes caracteres:

A. Dientes ausentes o no calcificados.

a. Vértebras planas: Cacodonta.

B. Dientes bien desarrollados.

a. Vértebras planas: Agathodonta.

b. Vértebras bicóncavas: Spondilocœlia.

\section{CACODONTA}

Sin dientes o con uno o dos no calcificados. Dedos ${ }_{5}^{5}$. Plantigrados. Carpo y tarso en serie lineal. Una rama externa del canal alveolar. Huesos marsupiales presentes.

En esta sección entran todos los monotremos existentes. No tienen representantes conocidos en el continente americano.

Los Cacodonta son descendientes de los Agathodonta.

\section{AGATHODONTA}

Con dientes numerosos, todos cónicocilindricos. Rostro largo. Mandíbulas estiliformes. Cinco dedos en cada pie. Carpo y tarso en serie lineal. Huesos marsupiales presentes.

Grupo teórico, antecesor de los Cacodonta y descendiente de los. Spondilocalia.

No le canozco hasta ahora representantes. 


\section{SPONDILOCCELIA}

Con dientes numerosos, cónicocilíndricos y puntiagudos. Ramas mandibulares estiliformes y sin rama ascendente. Hueso cuadrado transformado en la apófisis cigomática del temporal. Huesos marsupiales ausentes. Cinco dedos en cada pie. Plantígrados. Vértebras bicóncavas.

Grupo teórico, descendiente probable de los Pelycosauria y antecesor de los Agathodonta y, de consiguiente, de todos los mamíferos.

No le conozco hasta ahora representantes.

\section{RÁPIDAS CONSIDERACIONES GENERALES}

\section{SOBRE LA CLASIFICACIÓN Y DESCENDENCIA DE LOS MAMÍFEROS}

Los sorprendentes descubrimientos verificados durante estos últimos años en Europa y Norte América, han cambiado por completo las ideas que se tenían acerca de la aparición y distribución de los mamíferos y han reducido a la nada las clasificaciones clásicas basadas en los mamíferos existentes, que no representan más que una mínima parte de los que, a partir de su primera aparición, se han sucedido sobre la superficie de la tierra.

El descubrimiento de las antiguas faunas de la República Argentina viene a completar el derrumbe del sistema de clasificación hasta hace poco adoptado, pero aporta al mismo tiempo un valioso contingente de datos para rehacer el cuadro de la clasificación de los mamíferos sobre un plan más natural y más de acuerdo con lo que hasta ahora conocemos sobre la aparición y descendencia de los distintos grupos.

Para que un sistema de clasificación de los mamíferos sea bueno, no sólo debe comprender a los actuales y extinguidos distribuídos en grupos naturales, sino que debe también concordar con el orden de aparición de esos grupos y además con las grandes líneas de la evolución filogenética. Sin ser perfecto, el sistema de clasificación adoptado en este trabajo, se aproxima al objeto deseado; y convenientemente estudiado y perfeccionado, puede servir de base a un sistema de clasificación verdaderamente natural de los mamíferos. Por el momento, en la distribución de los grandes grupos él concuerda con lo que hasta ahora sabemos sobre su descendencia y aparición.

Considerando los mamíferos actuales, con exclusión de los extinguidos, desde el punto de vista de la elevación de su organización, se aisla desde luego un grupo que no tiene más que un cortísimo número de representantes, pero que es sin disputa de una organización muy inferior a la de todos los demás: es el grupo de los monotremos. Fuera de toda duda, 
éstos son los más inferiores de los mamíferos, no sólo por su manera de reproducirse, que evidentemente los acerca a los reptiles, sino también por la conformación particular del esqueleto, que también presenta las mismas afinidades. Según Cope, los monotremos están muy cerca de los reptiles del grupo de los Pelycosauria, a los cuales considera él como sus antecesores y de consiguiente de todos los mamíferos. Los monotremos constituyen así entre los mamíferos una subclase bien caracterizada, sin que sea posible establecer entre los demás una división de igual importancia, pues es evidente que no la tiene la división en marsupiales y placentarios, debiendo constituir todos en conjunto la segunda subclase de mamíferos que se distinguirá con el nombre de Ditremata, que tuvo por antecesora a la de los Monotremata. Hasta hoy no se conocen representantes fósiles de esta última subclase en los terrenos anteriores a la época cuaternaria, pero no hay duda de que tarde o temprano se encontrarán restos de monotremos, tanto en los terrenos terciarios como en los secundarios, pues el cortísimo número de representantes de la época actual no pueden ser considerados de otra manera que como los últimos vástagos de un árbol inmensamente ramificado, cuyo máximo desarrollo debe ser preterciario.

Los monotremos actuales se distinguen por la ausencia de dientes o porque éstos son en pequeño número y no calcificados; y como casi todos los mamíferos están provistos de dientes e igualmente lo están los reptiles, y como se ha probado que cuando faltan, ello es debido al resultado de una evolución secundaria, es claro que los antecesores de los monotremos actuales debían estar provistos de dientes, todos simples y en número considerable como en los ditremos inferiores actuales o sea los delfines; este grupo de monotremos extinguidos provistos de dientes, antecesores de los actuales, puede designarse con el nombre de Agathodonta, por oposición al grupo actual, al cual designaremos con el de Eacodonta.

$\mathrm{Si}$ bien los Agathodonta presentan grandes diferencias con los Cacodonta por la presencia de dientes numerosos y cónicos, no debian ellos diferir mucho de estos últimos en la conformación general del esqueleto, de manera que para ligarlos a sus antecesores reptílidos del orden de los Pelycosauria, con notocorda persistente, hay que suponer la existencia de un grupo intermedio con una columna vertebral de una evolución más avanzada, en el cual la notocorda había desaparecido por completo, pero las vértebras se conservaban bicóncavas, mientras que el hueso cuadrado de los Pelycosauria debía estar ya soldado a la parte escamosa del temporal para formar la apófisis cigomática de éste, que es el carácter osteológico culminante de la clase de los mamíferos, que la distingue de la de las aves, los reptiles y los peces. Este grupo primitivo de monotremos, antecesor de los demás mamíferos y descen- 
ciente directo de los reptiles, debe remontar por 10 menos en su primera aparición a fines de los tiempos primarios y podemos desde ya designarlo con el nombre de Spondilocolia.

El grupo de monotremos que dió origen a los ditremos, no puede ser e! de los Cacodonta, que es el más reciente y de evolución regresiva por la pérdida de los dientes, ni el de los Spondilocolia que por sus vértebras bicóncavas se liga directamente a los reptiles, sino el de los Agathodonta, del cual también descienden los Cacodonta.

La división de los ditremos en marsupiales y placentarios no es natural, pues si bien el estado marsupial representa una etapa de evolución poco avanzada, ha persistido en ciertos grupos que han avanzado en todo el resto de su organización, mientras que ha desaparecido en otros que conservan en toda su conformación un sello de inferioridad bien acentuada.

El sistema dentario proporciona una división más natural. Unos han conservado todos los dientes de forma simple que distinguia a los $\mathrm{Aga}$ thodonta, sin presentar nunca más de una raíz, aunque en su evolución posterior han sufrido después varias modificaciones, disminuyendo a veces en el número o desapareciendo por completo en algunos grupos; hemos distinguido a esta gran división de los ditremos con el nombre de Homalodonta; y comprende los mamíferos de organización más inferior, exceptuando los monotremos. Los dos grupos principales de los Homalodonta, son los Brutos o Desdentados y lus Cetáceos, entre los cuales se encuentran representantes que conservan en la conformación y en la disposición del aparato dentario, caracteres reptílidos evidentes.

Todos los demás mamíferos ditremos presentan muelas más o menos complicadas, con dos o más raíces; y cuando muestran todos los dientes con una sola raíz o de base abierta, ello es siempre como resultado de una evolución regresiva secundaria; en estos mamiferos, los dientes simples, pequeños y cónicos de los Agathodonta, se han reunido de a dos, de a tres y de a cuatro para formar muelas compuestas que presentan dos, tres o cuatro raíces, aunque el número de éstas ha podido disminuir luego, ya por la soldadura de dos en una, o por absorción completa. A este grupo de mamíferos ditremos 10 hemos distinguido con el nombre de Heterodonta.

Los Heterodonta se dividen en tres grandes secciones que tienen por nombres: Unguiculata, Planungulata y Ungulata. De estas tres, desde el punto de vista de su conformación general, la más primitiva es la de los Unguiculata y la más evolucionada la de los Ungulata.

Los más antiguos representantes de la sección de los Unguiculados tenían dientes numerosos, unos simples, y otros, aunque en corto número, compuestos, pero siempre con cúspides agudas y dispuestos alternando unos y otros con irregularidad; constituyen éstos el orden de los 
Stylodontheria, cuyo género mejor caracterizado es el Stylodon. De éste se desprenden dos ramas principales, que constituyen: una, la sección de los Hydrothereuta, hoy completamente extinguida; y otra, el orden de los Phascolotheria. De éstos descienden los Sarcobora, los Alloidea y los Ptetica.

De los Stylodontheria se constituyó otro grupo de Unguiculados: el de los Atava, todas cuyas muelas estaban formadas por la reunión de cuatro dientes simples, presentando cada una cuatro raíces separadas $y$. cuatro cúspides agudas en la corona. De este orden desciende la tribu de los Trogodonta hasta los roedores actuales.

De los Atava desciende el grupo de los Platyarthra, animales planungulados, cuya evolución conduce por una parte a los Dolodonta, que son los antecesores de los lemúridos, los simios y los antropoides; y por otra a los Ungulata, representados por seis tribus distintas: la de los Amblypoda, hoy completamente extinguida; la de los Pachytheria, de la cual descienden también la de los Halobioidea y la de los Amphiaactyla, casi completamente extinguida, pero de la cual descienden las tribus todavía existentes de los Perissodactyla y los Artiodactyla.

Me falta espacio y tiempo para extenderme en detalles sobre la filiación de todos estos grupos, lo que espero haré en otra ocasión, contentándome por ahora con presentar el siguiente cuadro de clasificación de los mamiferos, que, si no es perfecto, servirá, lo repito, por lo menos de base para otro con menos deficiencias. He suprimido los caracteres de los distintos grupos, en parte por falta de espacio y en parte por encontrarse ya indicados en el cuerpo de esta obra, en sus lugares respectivos.

\section{DITREMATA}

\section{A. Heterodonta}

\section{a. Planungulata}

1. Anthropoidea.

Hominidae, Anthropomorphidae.

2. Simioidea.

3. Prosimia.

4. Eosimia.

5. Daubentonioidea.

- 6. Dolodonta.

* 7. Condylarthra.

* 8. Platyarthra.

Cercopithecidae, Cynocephalidae, Semnopithecidae, Cebidae, Pithecidae, Hapalidae.

f Tarsidae, Lemuridae, *Anaptomorphidae, * Mixodectidae.

* Adapidae.

Cheiromyidae.

Térico. "Microchoeridae?

$\int$ * Periptychidae, * Phenacodontidae, * Meniscotheridae.

Teórico. 
9. Hyracoidea.

- 10. Toxodontia.

- 11. Cristava.

- 12. Archaeodonta.

13. Stereopterna.

14. Litopterna.

15. Ruminantia.

* 16. Proruminantia.

17. Suina.

* 18. Stereoarthra.

* 19. Taligrada.

- 20. Pantodonta.

* 21. Dinocerata.

22. Proboscidea.

23. Proproboscidea.

- 24. Choerodonta.

25. Sirenia.

26. Prosirenia.

- 27. Taeniodonta.

- 28. Tillodonta.

- 29. Trogosa.

30. Rodentia.

\section{b. Ungulata}

aa. Amphidactyla

Hyracidae.

"Toxodontidae, *Xotodontidae, *Typotheridae, "Protoxodontidae, "Interatheridae, "Atryptheridae.

Teórico.

Teórico.

bb. Perissodactyla

Rhinocerotidae, Tapiridae, "Palaeotheridae, Equidae, "Hyracodontidae, "Menodontidae, "Lophiodontidae, "Chalicotheridae, "Triplopodidae.

I "Macrauchenidae, "Proterotheridae, "Homalodontotheridae.

\section{cc. Artiodactyla}

I Camelidae, *Poebrotheridae, Tragulidae, Cervidae, Giraffidae, Antilopidae, Bovidae.

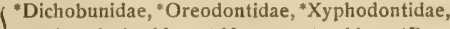
"Anoplotheridae, "Merycopotamidae, "Pantolestidae, "Caenotheridae, "Dichodontidae.

( Suidae, Hippopotamidae, "Listriodontidae, Phacochoeridae.

Teórico. "Anthracotheridae?, "Elotheridae?.

dd. Amblypoda

"Astrapotheridae, "Pantolambdidae.

"Coryphodontidae, "Pyrotheridae.

*Eobasilidae.

ee. Pachytheria

"Elephantidae, "Dinotheridae.

Teórico.

Teórico.

\section{ff. Halobioidea}

Halitheridae, Rhytinidae.

Teórico.

\section{c. Unguiculata}

aa. Trogodonta

*Ectoganidae, *Calamodontidae.

-Tillotheridae.

Teórico.

Caviidae, Hystricidae, Dasyproctidae, Lagomyidae, Leporidae, Myoxidae, Muridae, Spalacidae, Sciuridae, Eriomyidae, "Theridomyidae, Echinomyidae, Castoridae, Octodontidae, Dipodidae, Arvicolidae, Capromyidae. 
31. Insectivora.

32. Microbiotheria.

33. Peramelia.

34. Macropoda.

- 35. Plagiaulacoidea.

36. I'honoctonia.

37. Dasyura.

38. Pedimana.

- 39. Creodonta.

40. Carnivora.

41. Pinnipedia.

42. Atava.

- 43. Phascolotheria.

44. Myrmecobia.

45. Stylodontheria.

46. Chiroptera.

- 47. Prochiroptera.

- 48. Zeuglodonta.

- 49. Squalodonta.

- 51. Delotheria.

- 50. Priodonta.

\section{bb. Alloidea}

Soricidae, Erinaceidae, Macroscelidae, Myogalidae, Tupaidae, ${ }^{*}$ Arctocyonidae, Talpidae, Chrysochloridae, Centetidae, Geomyidae, Galeopithecidae.

- Microbiotheridae.

Peramelidae, Triconodontidae,

Macropodidae, Phascolarctidae, Plialangistidae, Phascolomyidae, Nototheridae, Diprotodontidae, Tarsipidae, Thylacoleontidae.

("Plagiaulacidae, "Abderitidae, "Epanorthidae, Hypsiprymnidae, "Polymastodontidae, "Macropristidae, "Tritylodontidae.

\section{cc. Sarcobora}

Térico.

Dasyuridae.

Didelphyidae, - Peratheridae.

-Oxyaenidae, "Mesonychidae, "Amblyctonidae, "Myacidae, "Estonychidae, "Proviverridae, - Acyonidae.

( Ursidae, Canidae, Felidae, Mustelidae, Hyaenidae, Viverridae, "Ailuridae, "Nimravidae.

Phocidae, Trichecidae.

\section{dd. Archoroidea}

Térico.

-Phascolotheridae, "Spalacotheridae.

Myrmecobidae.

*Stylodontidae.

\section{d. Ptetica}

I Pteropidae, Vespertilionidae, Phyllostomidae, Rhinolophidae.

Teórico.

e. Hydrothereuta

* Zeuglodontidae.

* Squalodontidae.

\section{B. Homalodonta}

a. Bruta

aa. Priodonta (Teórico)

\section{bb. Pleiodonta}

\footnotetext{
*Entelopsidae.
} 


\section{cc. Anicanodonta}

52. Vermilinguia,

53. Tardigrada.

(Manidae, Orycteropidae, Myrmecophagidae, "Phororhacidae, "Macrotheridae.

Bradypodidae.

"Megatheridae, "Orthotheridae, "Megalonychi-

- 54. Gravigada. dae, "Lestodontidae, "Scelidotheridae, "Mylodontidae.

\section{dd. Hicanodonta}

* 55. Glyptodontia.

56. Dasypoda.

* 57. Peltateloidea.

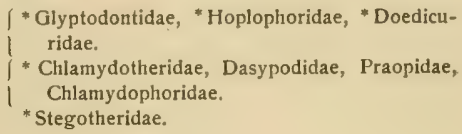

b. Cetacea

- 58. Proteroceta.

59. Odontoceta.

60. Mystacoceta.

61. Cacodonta.

- 62. Agathodonta,

- 63. Spondilocoelia.
Teórico.

( Platanistidae, Delphinidae, Monodontidae, Physetheridae, Xiphidae.

Balaenidae.

\section{MONOTREMATA}

Echidnidae.

Teórico.

Teórico.

Los grupos a los cuales precede un asterisco (*) están completamente extinguidos.

Eiste cuadro tiene sobre los que hasta ahora se han trazado la ventaja de que concuerda con los datos que nos proporciona la. Paleontología y puede ser dispuesto en una serie evolutiva $\sin$ que descomponga los grupos, como lo demuestra el cuadro que va a continuación. 



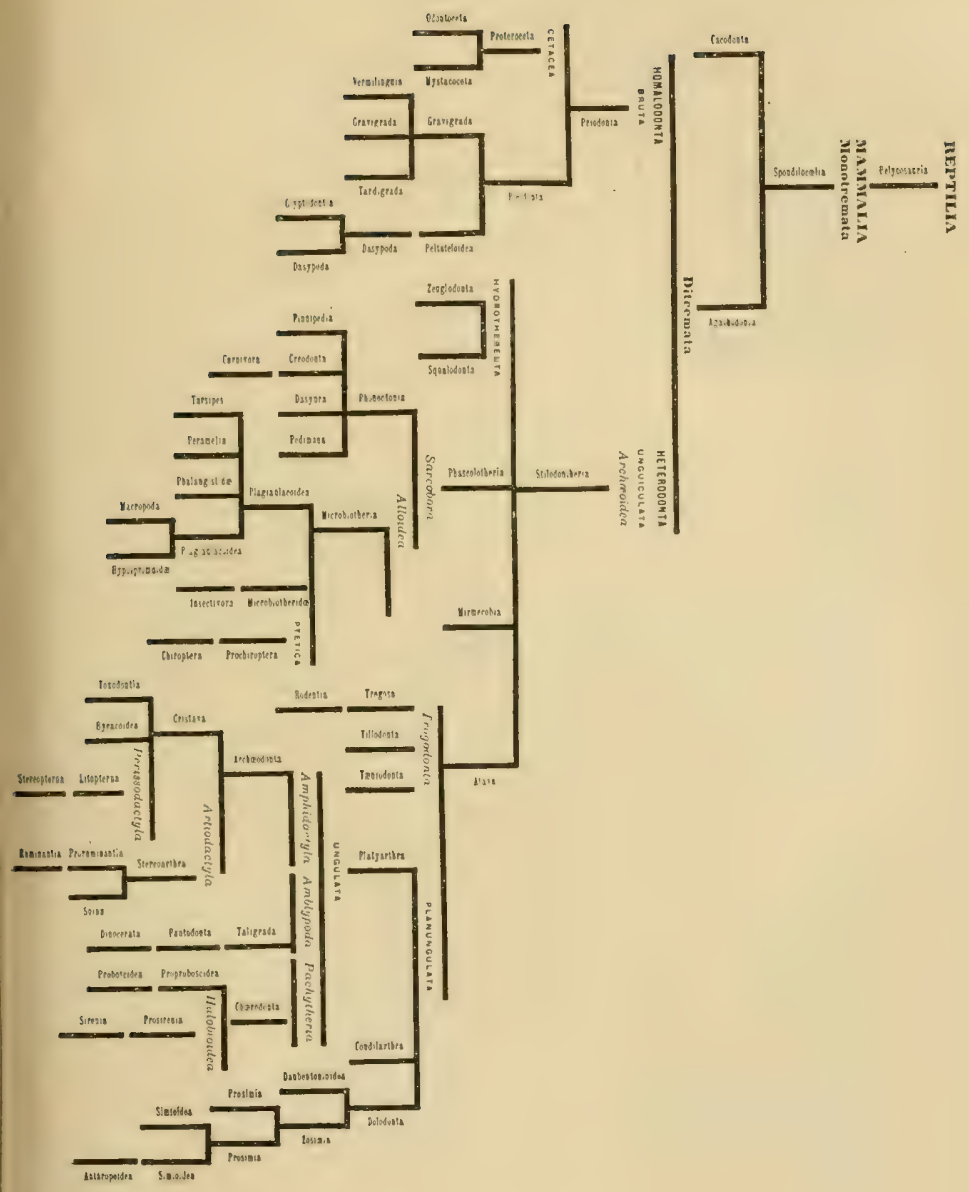



El cuadro sucediente es igual que el antecedente; y en él he suprimido los nombres de los grupos superiores y he dispuesto los demás de manera que cada lector pueda formarse una idea de los claros más notables que todavía faltan por llenar, para ligar entre sí a los diferentes órdenes de mamíferos conocidos hasta ahora.

Esos claros, sin duda considerables, pertenecen en su mayor parte a los más inferiores de los mamíferos, notándose que los antecesores directos de los grupos actuales, o los que forman el entroncamiento de dos o más grupos, son en su mayor parte tipos que han aparecido en el transcurso de los tiempos terciarios, época geológica relativamente moderna en comparación de la grandísima antigüedad de los mamíferos, cuya primera aparición se remonta por lo menos al periodo pérmico, puesto que se han encontrado restos que indican una evolución regularmente avanzada en las capas triásicas.

Pero los mamíferos fósiles preterciarios conocidos hasta el día son poco numerosos y representados por fragmentos muy pequeños e incompletos, que no siempre permiten establecer con facilidad sus verdaderas afinidades. No obstante, es seguro que no se conocen ni ungulados ni planungulados, siendo todos ellos unguiculados, habiéndolos omnivoros, carnivoros, herbívoros e insectívoros, presentando unos el aparato dentario con una conformación excesivamente primitiva y de tipo reptílido, mientras otros ya habían alcanzado en ese sentido un grado de especialización a todas luces notable, por lo que es dado esperar que el día en que el número conocido de sus formas sea mayor, será dado llenar con facilidad esos claros y seguir sin discontinuidad el encadenamiento de los grupos de mamíferos actuales hasta su entroncamiento con los grupos especializados y reptílidos de los primeros tiempos de la época secundaria.

Ambos cuadros demuestran, por otra parte, a las claras, que si bien el estado marsupial es un carácter primitivo que indica una notable inferioridad en el grado de viviparicidad, no puede servir de base para una clasificación natural por representar una etapa de evolución. en la cual quedaron estacionados unos grupos que no por eso dejaban de evolucionar en el resto de su conformación, mientras que otros pasaron del estado marsupial al estado placentario evolucionando por separado y dando origen, también por separado, a las ilistintas formas de placenta que distinguen a los distintos grupos de los monodelfos, encontrándose en ellos variaciones notables hasta entre los representantes de un mismo orden. 




\title{
SUPLEMENTO
}

\author{
ADICIÓN AL PISO PEHUENCHE
}

(Página $4 \mathrm{r}$ del volumen VI)

En el reciente viaje que a Patagonia septentrional ha efectuado Carlos Ameghino, ha encontrado las areniscas rojas de este horizonte ocupando una vasta extensión de la cuenca del río Senguel, afluente principal del Chubut, conteniendo en todas partes una inmensa cantidad cie huesos de Dinosaurios, habiendo descubierto, entre otros restos, un esqueleto casi completo, cuya talla es aproximadamente de unos 40 a 45 metros de largo. Es el primer depósito de esta naturaleza que se encuentra en pleno territorio patagónico.

\section{ADICIÓN A LA BIBLIOGRAFía SOBRE EL HOMBRE FÓSIL ARGENTINO}

(Página 86 del volumen VI)

En esta parte he pasado por alto involuntariamente la Memoria del doctor Lovisato que lleva por título: «Di alcune armi e vtensili dei Fueghini e degli antichi Patagoni» (año 1883), en la que el autor menciona el hallazgo hecho por él de algunos objetos de la industria humana encontrados con huesos de Toxodon y otros animales extinguidos de la Pampa, y da el dibujo de uno de esos objetos, una especie de pulidor encontrado en una mandibula de Toxodon Burmeisteri.

\section{ADICIÓN A L̨A RESEÑA HISTÓRICA}

(Página 87 del volumen VI)

El doctor Francisco Javier Muñiz fué quien probablemente encontró entre nosotros los primeros vestigios del hombre fósil, pues con fecha 29 de Junio de 1841 envió a Rozas una crecida colección de fósiles, acompañada de un catálogo, en el cual encuentro, bajo el número 9 , indicado «el carpo del Orangoutang o de una especie análoga» sobre la que da otros datos en sus manuscritos, agregando que era de idéntica conformación. Como Muñiz, siguiendo las ideas de la época, no creía o no suponía la posibilidad de la existencia del hombre fósil, nada más natural que atribuyera al Orangután el mencionado carpo. 


\section{LOS VESTIGIOS DEL HOMBRE}

\section{EN EL. PLIOCENO INFERIOR DE LA PLATA}

(Página 105 del volumen VI)

Los vestigios de la presencia del hombre en el plioceno inferior (piso ensenadense) de La Plata, son más abundantes todavía de lo que creia al redactar la respectiva parte del texto. Posteriormente he recogido, entre otros vestigios, una cantidad considerable de tierra cocida, en parte formando trozos de hasta 500 gramos de peso, llenos de pequeñas cavidades esféricas, que presentan un aspecto completamente igual a los que he recogido en Monte Hermoso y que alguien ha tenido la peregrina ocurrencia de considerarlos como productos volcánicos! Es cierto que el mismo autor, en presencia de un grueso fragmento de tierra cocida encontrado en las excavaciones del puerto de La Plata, a 9 metros de profundidad y a 4 metros debajo de las capas consolidadas de la formación pampeana, conjuntamente con huesos de Scelidotherium, no tuvo dificultad para considerarlo como un trozo de teja del tiempo de los españoles que se había hundido (al través de capas compactas) hasta esa profundidad!

\section{SOBRE LA ÉPOCA GEOLÓGICA DE LOS CRÁNEOS HUMANOS DESCUBIERTOS POR LUND EN LAS CAVERNAS DE BRASIL \\ (Página 140 del volumen VI)}

Me es satisfactorio anunciar que en un trabajo importante que acaba de aparecer consagrado al estudio de la Raza de Lagôa Santa ( «Lagôa Santa Racen», en «Anthropologisk Undersogelse af jordfundne Menneskelevninger fra brasilianske Huler»), cuyos autores son los señores Sören Hansen y Fr. Lütken, se llega a las mismas conclusiones que he expuesto más arriba, esto es: que no hay ningún dato que pueda hacer creer que los cráneos recogidos en las mencionadas cavernas fueran contemporáneos de las especies de mamíferos extinguidos que poblaron la misma comarca durante las últimas épocas geológicas.

\section{PiranotherUs Marginatus, gen. et $s p$. $n$.}

Lhmina LXXII, Grura in

Este animal, del cual conozco un diente incisivo, es seguramente un género nuevo, que supongo forme parte del orden de los Taeniodonta. Sería el primer representante de este grupo que hasta el día se conozca en Sud América.

Es un diente incisivo inferior del lado izquierdo, de base abierta, que se distingue de los incisivos inferiores de los representantes del orden de los Toxodontia por ser sumamente comprimido, presentando 
la corona cortada en bisel y la base abierta como en los incisivos de los roedores, de los cuales se distingue fácilmente, porque presenta dos caras esmaltadas, la anterior y la posterior, formando dos bandas longitudinales separadas.

El prisma del diente es doble más grueso que ancho, pues ticne 10 milímetros de ancho o diámetro transverso en la cara anterior, sólo 6 milímetros en la posterior y 20 milímetros de grueso o diámetro anteroposterior. La cara anterior es fuertemente convexa y completamente esmaltada, con la capa de esmalte dando vuelta por sobre ambos lados, formando ángulos redondeados, pero sin extenderse por sobre las caras laterales, que son casi planas y sin esmalte. La cara posterior, muy angosta y convexa, muestra una banda longitudinal de esmalte muy angosta, de sólo 4 milímetros de ancho, colocada sobre el lado posterior externo. La parte cortada en declive tiene 8 milímetros de ancho y 20 milímetros de largo. E1 largo del trozo existente es de 7 centímetros, estando un poco gastado en la base, pero como ésta se muestra ya completamente abierta, se conoce que entero no debía tener un largo mayor de 8 centímetros.

Esta pieza, propiedad del Museo provincial de la ciudad del Paraná, Frocede de las barrancas de los alrededores de esa localidad; y es posible que pertenezca a un horizonte más antiguo que el mesopotámico, quizá al paranense, que constituye la base de la formación patagónica.

Está representada por la rama mandibular izquierda, que se distingue de las demás especies por ser un poco más robusta y por el ancho desproporcionado del incisivo. Las muelas inferiores se distinguen de las correspondientes del Myopotamus coypus, por su cara perpendicular posterior que, en vez de ser aplastada como en la especie actual, es fuertemente convexa, particularmente en la última muela inferior, la que es además proporcionalmente más grande que en la especie existente.

DIMENSIONES

Ancho del incisivo inferior

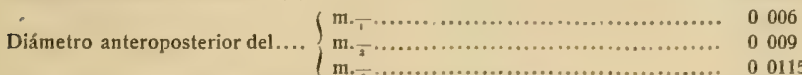

Longitud del espacio ocupado por las tres muelas verdaderas .............. 0022

Procedencia: - Ha sido recogida en los alrededores del Paraná y pertenece al Museo provincial de la misma ciudad.

Horizonte:- Piso hermósico (?). 
Dispongo ahora de restos de este género, pero provenientes de una especie distinta de la que he descripto. Es una rama mandibular izquierda con el incisivo y todas las muelas, cuya pieza denota que se trata de un animal mucho más particular que lo que era dado suponerlo por el examen de los dientes aislados conocidos por mí antes. La rama horizontal de la mandibula es más parecida a la de Lagostomus que a la de Myopotamus, pero la forma y el número de las muelas no permite acercarlo a ninguno de los dos mencionados géneros. El Olenopsis sólo tiene tres muelas inferiores; y lo que es más raro, ello es que estas tres muelas no corresponden a los tres verdaderos molares como en los ratones, sino que la anterior es realmente el p. ${ }_{4}$ de los roedores provistos de cuatro muelas y las otras dos corresponden a los dos primeros verdaderos molares, faltándole, por consiguiente, al Olenopsis el m. $\overline{3}$. El cambio del p. ${ }_{4}$ se efectúa cuando ya están completamente desarrollados los dos verdaderos molares; por esta pieza sé ahora que todos los premolares que he descripto en su lugar, son de la primera dentición, unos muy viejos y completamente gastados y otros que apenas empezaban a ser atacados por la masticación; este diente caedizo está provisto de raíces distintas y es probable que sucediera otro tanto con las muelas persistentes. Las muelas persistentes inferiores del Olenopsis, ya un poco gastadas, están formadas en la corona por cuatro láminas transversales, las tres anteriores reunidas sobre el lado externo y separadas sobre el interno y la posterior completamente separada sobre ambos lados. Cada muela se presenta dividida sobre el lado externo en dos lóbulos desiguales, el anterior muy grande y el posterior muy pequeño, separados por una hendedura perpendicular. Sobre el lado interno presenta cuatro columnas perpendiculares separadas por tres hendeduras. Tanto la hendedura externa como la hendedura y los pliegues internos se pierden pronto hacia abajo, en donde el prisma de cada muela está envuelto en una capa de esmalte continua, pero es más que probable que todas las muelas concluyen en una base dividida en raices distintas.

El incisivo se prolonga hasta el lado de la parte posterior de la última muela.

OLEPNOSIS TYPICUS Scalabrini, $n, s p$.

Lamina $1 \times x \times 11,6$ gura 4

La mandíbula mencionada, pertenece al Museo provincial de Entre Rios, en el Paraná, en cuyas colecciones estaba clasificada por el profesor Scalabrini como representando un nuevo género, para el que había adoptado el nombre de Paranomys typicus, que yo hubiera empleado, 
si ya en la primera parte de esta obra no tuviese el de Olenopsis. Pero la especie del Paraná es distinta de la de Santa Cruz y debe conservar su bien expresivo nombre de Olenopsis typicus.

El incisivo inferior es de cara anterior casi plana, apenas un poco ligeramente convexa, muy angosto y muy grueso, siendo el diámetro anteroposterior bastante mayor que el diámetro transverso.

La parte sinfisaria es de la misma forma que en la vizcacha. La primera muela inferior corresponde a la última muela inferior de leche de los mamíferos placentarios y ya está en condiciones de caer, viéndose debajo el diente definitivo que debe reemplazarla, que es el p. $\overline{4}$ de la dentición persistente. La corona del diente caedizo es muy larga y baja, con el lóbulo anterior externo mucho más grande que el posterior y sin pliegues entrantes sobre el lado interno, conservándose sólo tres láminas de esmalte aisladas en la superficie de la corona del lóbulo ánterior, la primera sumamente pequeña y penetrando el pliegue de esmalte externo hasta cerca del borde interno de la corona. La base se divide en dos grandes raíces, una anterior y otra posterior, debajo de las cuales se ve surgir el p. ${ }_{4}$ persistente, que, probablemente, cuando estaba bien desarrollado presentaba la misma forma que los verdaderos molares.

El verdadero molar que sigue está muy apretado al anterior e implantado un poco oblicuamente, con la corona corta y ancha, dividida en dos partes desiguales; la anterior es mucho más grande, angosta y en forma de columna sobre el lado externo, ancha y con dos profundos pliegues de esmalte sobre el interno que la dividen en tres columnas, el pliegue anterior muy pequeño y el posterior mucho mayor; la parte posterior es en forma de lámina aislada y delgada, de menor diámetro transverso que la cara posterior de la parte anterior.

La muela que sigue, o última, es absolutamente de la misma forma que la precedente, con la única diferencia de la lámina posterior que es un poco menos desarrollada.

\section{DIMENSIONES}

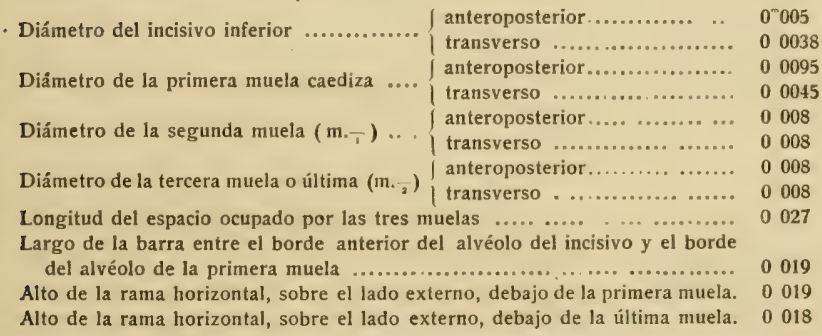


Esta pieza ha sido descubierta en las barrancas de los alrededores de la ciudad del Paraná, en las capas del piso mesopotámico de la formación patagónica.

Discolomys cuneus Ameghino

(Página 258 del volumen VI)

Lamipa LXXX, figura 13

La primera muela superior derecha de este animal, descripta por mi en el texto, está muy gastada sobre los contornos laterales, probablemente por provenir de un individuo sumamente viejo, por lo cual, tanto el dibujo como la descripción no son absolutamente exactos y no dan una idea bien clara de los caracteres de este curioso género. Identifiqué esta muela con otra más completa figurada por Burmeister, y de una complicación aparente parecida a la del ejemplar que obra en mi poder, que tampoco le permitieron a él determinar con exactitud la composición de dicho diente. Ahora dispongo de otro ejemplar absolutamente intacto, de un individuo no muy viejo, que permite determinar exactamente la estructura de la muela, cuyo dibujo doy en su tamaño natural, asi como la vista de la corona aumentada. Por este ejemplar, que es la primera muela superior del lado izquierdo, se ve a las claras que el animal era muy cercano del Myopotamus; pero la corona, en vez de mostrar pliegues laterales entrantes, presenta un cierto número de láminas transversales superficiales. Estas láminas son en número de cinco, la anterior un poco más pequeña que la segunda, que es la mayor, disminuyendo sucesivamente el tamaño de las láminas desde la segunda a la quinta, que es completamente rudimentaria. Cada lámina presenta una hoja de esmalte gruesa anterior en forma de arco de círculo, seguida atrás de otra hoja sumamente delgada y con numerosos repliegues en ziszás; esta hoja posterior, en la lámina anterior se une en sus extremos con la hoja de esmalte gruesa anterior, pero en las láminas siguientes se reune, por lo contrario, a la hoja de esmalte gruesa que le sigue, dando a la muela un aspecto particular, pues como las láminas no están abiertas por entalladuras sobre los costados, aparecen como aisladas en el centro de la corona, que está rodeada por una hoja de esmalte interrumpido. La corona tiene 8 milimetros de diámetro anteroposterior y 7 milimetros de diámetro transverso máximo.

Esta pieza es propiedad del señor León Lelong Thévenet.

ORTHOMYS fROCEDENS Ameghino

(Página 262 del volumen VI)

Inmina EXXII, Agura is

A la descripción del incisivo inferior puedo agregar ahora la del incisivo superior. Es un diente considerablemente más grueso que ancho, 
de cara anterior fuertemente convexa y con una pequeña depresión longitudinal, con el esmalte liso y la cara tritoria corta y fuertemente excavada en forma de canaleta, como en el incisivo superior que me sirvió de tipo para establecer el Orthomys dentatus. La superficie tritoria tiene 14 milímetros de largo. El ancho del diente en la cara anterior es de 9 milímetros, pero de sólo 5 en la posterior, teniendo en cambio 12 milímetros de grueso o de diámetro anteroposterior.

Procedencia:- Barrancas del río Paraná en la ciudad del mismo nombre, siendo la pieza mencionada propiedad del Museo provincial de dicha localidad.

Horizontc: - Piso mesopotámico de la formación patagónica.

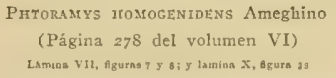

Al ocuparme de esta especie no indiqué el número de las figuras que en el Atlas la representan, cuyo olvido, como se ve, queda subsanado.

Perimys Scalabrintanus, $n$. $s p$.

Lamura LXXII, Gipura 16

Conozco esta especie por una rama derecha de la mandíbula inferior con el incisivo y las cuatro muelas. Tiene una talla comparable a la del Perimy's erutus de Santa Cruz, del cual se distingue por la sinfisis más corta, por la parte que se extiende delante de las muelas, que no es tan larga, por las muelas más angostas en el lado interno y por la última muela inferior, que muestra la lámina fosterior reunida a la anterior de la misma manera que en las muelas precedentes, mientras en la otra especie se reune por medio de una hoja de esmalte muy delgada, formando una columna distinta sobre el lado interno. El incisivo tiene 2 milímetros de ancho. La distancia desde el borde anterior de la primera muela hasta el borde posterior del alvéolo del incisivo es de sólo 5 a 6 milímetros; y hasta el borde anterior del mismo incisivo es de unos 11 milímetros. Las cuatro muelas, al parecer del mismo tamaño, ocupan un espacio longitudinal de 13 milimetros.

Dedico la especie al profesor Scalabrini, Director del Museo provincial del Paraná.

Procedencia: - Barrancas de los alrededores de la ciudad del Paraná.

Horizonte:- Piso mesopotámico de la formación patagónica. 
Dispongo ahora de una rama mandibular izquierda de esta especie, con parte del alvéolo del incisivo y las cuatro muelas intactas. El incisivo inferior sólo llega hasta el lado de la parte anterior de la tercera muela $(m,-\overline{2})$. Las cuatro muelas son de tamaño casi igual, con excepción de la primera que es un poco más chica. Estas muelas se distinguen por estar colocadas en la mandibula menos oblicuamente que en las otras especies; por ser proporcionalmente de mayor diámetro anteroposterior y de menor diámetro transverso, afectando una forma más cuadrada. Las dos láminas transversales que constituyen cada muela se presentan separadas por un surco perpendicular tanto sobre el lado externo como sobre el interno, pero de una manera más acentuada en el primero que en el segundo.

\section{DIMENSIONES}

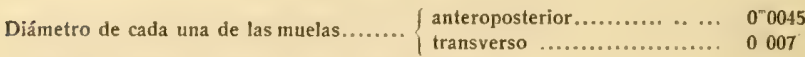

Longitud del espacio ocupado por las cuatro muelas..................... 0025

Alto de la rama horizontal, sobre el lado externo, debajo del m. ......... 0017

Procedencia: - Se ha descubierto en las barrancas de la ciudad del Paraná y pertenece al Museo provincial de Entre Ríos.

Horizonte:- Piso mesopotámico de la formación patagónica.

\section{EUPHILUS, $n . g c n$.}

Nuevo género cercano de Lagostomus y de Megamys, caracterizado por las muelas inferiores compuestas de tres láminas, las dos anteriores reunidas sobre el lado externo y separadas sobre el interno en forma de $U$, siendo la primera mucho más pequeña que la segunda y la lámina tercera o posterior mucho más grande, en forma de segmento de círculo y separada de la que la precede por un ancho depósito de cemento. Estas muelas aumentan de tamaño de la primera a la tercera; la cuarta inferior permanece todavía desconocida. El incisivo inferior llegaba hasta debajo de la cuarta muela.

EuphiLUS AMBrosettianus, $n$. sp.

Lamuna L.X.Kir, Agura,

Es la especie de mayor tamaño, cuya talla no debía ser inferior a la de un gran carpincho; y me es conocida por un fragmento de la rama izquierda de la mandibula inferior, en el que se encuentran implantadas 
las dos muelas intermedias intactas $\left(m \cdot \frac{-}{1} y_{\frac{2}{2}}\right)$ mostrando adelante la parte anterior del alvéolo del p. ${ }_{4}$ y atrás la parte anterior del alvéolo del $\mathrm{m} \cdot \overline{3}$.

El m. - tiene la lámina anterior muy pequeña, casi rudimentaria, de apenas 1 milímetro de diámetro anteroposterior y 7 milimetros de diámetro transverso, prolongándose al lado externo en forma de hoja de esmalte simple, que se une, formando una columna perpendicular, a la lámina segunda, de 2 milímetros de espesor y 10 milimetros de diámetro transverso; ambas láminas están separadas sobre el lado interno por una hendedura profunda, de cerca de dos milímetros de ancho, que atraviesa la muela casi por completo, dando a las dos láminas anteriores la forma de $\mathrm{U}$, pero completamente rellenada de cemento. La lámina posterior o tercera, mucho más grande, en forma de segmento de círculo, un poco cóncava adelante y muy convexa atrás, tiene algo más de 3 milímetros de grueso y 11 milimetros de diámetro transverso, estando separada de la lámina segunda por un depósito intermedio de cemento de dos milímetros de espesor. La muela entera tiene 13 milímetros de diámetro anteroposterior, 11 milímetros de diámetro transverso máximo y 3 centímetros de largo desde la raiz a la corona, mostrando dos columnas perpendiculares sobre el lado externo $y$ tres sobre el interno.

La muela que sigue (m. $\frac{2}{2}$ ) es absolutamente de la misma forma, con la única diferencia de su tamaño, que es un poco mayor; tiene 15 milímetros de diámetro anteroposterior y 12 milímetros de diámetro transverso en la lámina posterior.

Las dos muelas juntas ocupan un espacio longitudinal de 28 milimetros.

Dedico la especie al señor Juan B. Ambrosetti, director de la Sección Zoológica del Museo del Paraná.

Procedencia:- Ha sido descubierta por el señor León Lelong Thévenet en las barrancas de los alrededores del Paraná.

Horizonte:-Piso mesopotámico de la formación patagónica.

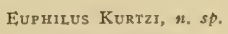

Conozco una rama derecha de la mandíbula inferior de esta especie, con el incisivo y las tres primeras muelas, distinguiéndose de la precedente por su tamaño mucho menor, apenas comparable al de una vizcacha. El incisivo tiene 0.0045 de ancho. La distancia desde el borde anterior del alvéolo del incisivo hasta el alvéolo de la primera muela es de un poco más de 2 centímetros. La primera muela es considera- 
blemente más pequeña que la segunda y con su lámina tercera más próxima a la que la precede. Las tres muelas juntas ocupan un espacio longitudinal de sólo 24 milímetros. Dedico la especie al distinguido botánico doctor Federico Kurtz, catedrático en la Universidad de Córdoba.

Procedencia: - Barrancas del río Paraná, en los alrededores de la ciudad del mismo nombre.

Horizonte:-Piso mesopotámico de la formación patagónica.

BRIAROMYS, $n$,gen.

Nuevo género cercano del Megamys y el Lagostomus, caracterizado por muelas inferiores compuestas de cinco láminas delgadas muy apretadas unas a otras, las dos anteriores reunidas sobre el lado externo y separadas sobre el interno y las tres siguientes completamente separadas en sus dos extremidades, pero sin presentar los gruesos depósitos intermedios de cemento que caracterizan a las muelas del género Megamys.

BRtAROMYS TROUESSARTIANUS

LAmina LXXI1, Aguth is

Hasta ahora sólo se conoce un fragmento de la rama derecha de la mandibula inferior de este animal, con el incisivo y las tres primeras muelas. El incisivo tiene cerca de 4 milímetros de ancho. La primera muela tiene la primera lámina rudimentaria y unida a la segunda sobre el lado externo; la muela entera tiene unos 9 milímetros de diámetro anteroposterior y unos 5 milímetros de ancho. Las tres muelas tienen más o menos el mismo tamaño y ocupan juntas un espacio longitudinal de 28 milimetros. La distancia desde el borde anterior de la primera muela hasta el borde anterior del alvéolo del incisivo, es de unos $13 \mathrm{mi}$ límetros.

Dedico la especie al distinguido naturalista E. Trouessart.

Procedencia: - Barrancas de los alrededores de la ciudad del Paraná. Horizonte:- Piso mesopotámico de la formación patagónica.

\footnotetext{
MEgamys paTagoniensis Laurillard

(Página 333 del volumen VI)

Lamina $2 x x x$, figurna of
}

Conozco varias otras muelas, tanto superiores como inferiores, que atribuyo a este animal. Un carácter constante de las muelas de esta especie, parece consistir en el número de láminas reunidas sobre uno de los costados, que parece ser constantemente de tres en las muelas 
formadas por cinco láminas y de dos en las que sólo están formadas por cuatro láminas. Las dos muelas intermedias parecen ser siempre más anchas y las superiores fuertemente arqueadas hacia afuera.

Una de las muelas que puede determinarse con seguridad como del lado derecho de la mandibula superior, tiene 5 columnas sobre el lado externo y tres sobre el interno, con una corona de 17 milímetros de diámetro anteroposterior y 12 milímetros de diámetro transverso máximo.

Los depósitos de cemento que separan a las láminas entre sí parecen ser siempre muy delgados.

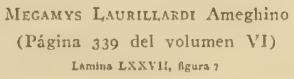

Conozco un incisivo superior derecho de esta especie, que por su tamaño corresponde exactamente al inferior más arriba descripto. Es muy arqueado, no muy grueso y de cara anterior fuertemente estriada en sentido longitudinal. Tiene 16 milímetros de ancho en la cara anterior y 14 milímetros de grueso. La parte existente tiene 10 centimetros de largo en línea recta.

Es propiedad del señor Lelong Thévenet.

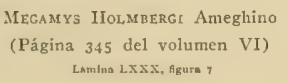

Como nuevas piezas de esta especie, conozco un fragmento de maxilar superior izquierdo con la tercera muela intacta y parte de los alvéolos de las dos muelas anteriores y de la última posterior. La tercera muela superior se compone de cuatro láminas que disminuyen de tamaño desde la primera a la cuarta, las dos anteriores completamente separadas y las dos posteriores separadas sobre el lado externo y reunidas sobre el interno, de manera que presenta tres columnas perpendiculares sobre el lado interno y cuatro sobre el externo. La corona tiene 0 milímetros de diámetro anteroposterior y 8 milímetros de diámetro transverso. Las otras tres muelas superiores debian tener la misma forma y más o menos el mismo tamaño. Esta pieza es propiedad del señor León Lelong Thévenet.

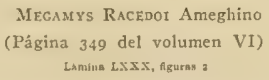

Atribúyole provisoriamente a esta especie la muela.inferior representada por la figura arriba indicada, compuesta de cinco láminas, las tres anteriores reunidas sobre el lado externo y separadas sobre el 
interno y las dos posteriores completamente separadas. Esta especie se distingue por los depósitos intermedios de cemento muy gruesos, por su tamaño generalmente considerable (que no permite confundirla con el .llegamys patugoniensis), y por el gran diámetro transverso de las laminas intermedias, que prueban que tampoco proviene del Megamys praependens. La corona tiene 26 milimetros de diámetro anteroposterior y 23 milimetros de diámetro transverso. El largo de la muela en linea recta, desde la raiz hasta la corona, es de unos 6 centímetros.

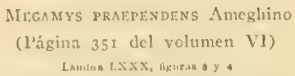

Conozco dos muelas mis de esta especie. Una de ella es de la mandibula inferior y casi igual a la precedente, que me sirvió de tipo para la fundación de la especic. Está formada por cinco láminas, de las que sólo las dos anteriores estin reunidas sobre el lado externo, lo que parece ser un distintivo de todas las muelas de esta especie, formadas por cinco líminas, presentando, por consiguiente, tres columnas sobre cl lado externo y cinco sobre el interno, todas estas últimas sobre un mismo plano. La corona tiene 23 milímetros de diámetro anteroposterior, 9 milimetros de dímetro transverso en la lámina anterior, 17 en la penúltima y casi el mismo ancho en la última. Tiene cinco centímetros y medio de largo desde la raiz hasta la corona.

La otra muela es de la mandihula superior y probablemente la última. Está formada por seis líminas cuyo tamaño disminuye gradualmente desde adelante hacia atrás, has tres anteriores completamente separadas $y$ ias tres posteriores reunidas sobre el lado interno y separadas sobre el externo, presentando asi la muela tres colummas perpendiculares sobre el lado interno y sicte sobre el externo. La corona tiene 28 milímetros de diámetro anteroposterior, 6 milimetros de diámetro transverso en la limina posterior y 21 milimetros en la anterior. Ticne 52 milimetros de largo desde la raíz hasta la corona.

Mranmys rormosus Ameghino

(Pigina 355 del volumen VI)

El género Megamly's, que hasta ahora sólo se habia encontrado en las capas oligocenas y miocenas de la región oriental de la República, on las harrancas del Paraná, en Monte Hermoso y en la costa atlíntica al sur de la embocadura del río Negro, se acaba de descubrir también en la región occidental, en el valle Santa Maria de la provincia Catamarca, de cuya procedencia he visto una mucla y algunos incisivos, que prucban pertenecen a la misma especie que ha dejado sus restos en Monte Hermoso, esto es: al Megamys formosus. 
Nép Piblema horRidula Ameghino

(Página 357 del volumen VI)

Lumira LXXII, Bgura a

La figura arriba mencionada muestra los caracteres especiales de esta especic, y particularmente la continuación interrumpida de la hoja de esmalte, de una manera más exacta que la figura precedentemente citada en la página 357 del tomo VI.

NEORLIBEMA ? CONTORTA, $n, S P$.

Lamina $\operatorname{Lxx}$, Aguras 1 y 14

Algunas muelas de un roedor particular, cercano del género Megamys. pero con la hoja de esmalte contorneada y formando láminas transversales muy aplastadas desde adelante hacia atrás, me parecen pertenecer probablemente al género Neocpiblema, pero constituirian una especie distinta de la precedente, de tamaño mucho mayor, pues las muelas mencionadas indican un animal cuya talla no era seguramente inferior a la del Megamy's Laurillardi. Mencionaré particularmente dos muelas inferiores. Una de ellas (lámina LXXX, figura 14) la más pequeña, es de corona angosta adelante y ancha atrás, de 13 milímetros de diámetro anteroposterior, 8 milímetros de diámetro transverso adelante, 19 milímetros atrás y 43 milímetros de alto desde la raíz hasta la corona, siendo fuertemente estriada en sentido perpendicular en su cara posterior.

La otra muela (lámina LXXX, figura 1) es de corona un poco más cuadrada, de 14 milímetros de diámetro anteroposterior, 13 milímetros de diámetro transverso adelante, 19 milímetros atrás y 40 milímetros de largo desde la raíz a la corona, siendo asimismo fuertemente estriada en sentido perpendicular en su cara posterior.

Procedencia:- Barrancas de los alrededores de la ciudad del Paraná.

Horizonte:-- Piso mesopotámico de la formación patagónica.

Tetrastylus laevigatus Ameghino

(Página 358 del volumen VI)

Lamina LXXXII, ggura a

De esta especie, de la que sólo conocía un pequeño fragmento de mandibula con las dos muelas anteriores completamente mutiladas. dispongo ahora de una rama izquierda de la mandíbula infericr, casi entera, con el incisivo y las cuatro muelas. Las cuatro muelas inferiores son absolutamente de la misma forma. Cada muela está formada por cuatro láminas, las dos anteriores unidas sobre el lado externo y separadas sobre el interno, y las dos posteriores completamente separadas 
en toda su extensión, de manera que presentan tres columnas perpendiculares separadas por dos surcos sobre el lado externo y cuatro columnas perpendiculares separadas por tres surcos sobre el interno. La lámina anterior de cada muela es casi rudimentaria, la penúltima ES la más grande y la última es un poco más angosta que la penúltima. Las cuatro muelas son de tamaño casi igual, pero la anterior y la posterior son un poco más angostas que las dos del medio. El prisma de cada muela es de una misma forma en todo su largo, concluyendo en base abierta.

Las cuatro muelas están colocadas con su mayor diámetro de adelante hacia atrás y dispuestas en fila formando sus bordes internos una línea casi recta. La base del incisivo se prolonga más allá de la parte posterior de la última muela ascendiendo casi hasta el nivel de la corona de ésta. La forma general de la mandibula es parecida a la de la vizcacha.

\title{
DIMENSIONES
}

Diámetro transverso del incisivo 0 "n 006

Diámetro de la primera muela .......

(anteroposterior .................... 00085

transverso ........................ 00065

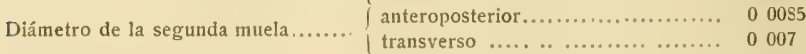

Diámetro de la tercera muela ....... f anteroposterior.................... 0009

Diámetro de la cuarta muela......... I anteroposterior................... 00098

Longitud del espacio ocupado por las cuatro muelas...................... 00037

Alto de la rama horizontal, sobre el lado interno, debajo de la primera muela. 0026

Alto de la rama horizontal, sobre el lado externo, debajo de la cuarta muela. 0025

Longitud de la barra entre el borde anterior del alvéolo de la primera muela

y el borde del alvéolo del incisivo ............................... 0023

Esta pieza procede de las capas del piso mesopotámico de los alrededores del Paraná y es propiedad del Museo provincial de Entre Ríos.

\author{
Terrastylus diffissus Ameghino \\ (P’ágina 360 del volumen VI) \\ Inmian LXX11, figuras to i y tamiun Lxxxir, Agara ,
}

De esta especie, que sólo me era conocida por fragmentos de incisivos, puedo examinar ahora una rama izquierda de mandibula inferior con el incisivo y las cuatro muelas. Difiere de la especie anterior por su tamaño, que es casi dos veces mayor, por el incisivo mucho más ancho y por las muelas proporcionalmente mán anchas y más fuertemente apretadas entre si. 


\section{DIMENSIONES}

Anclıo del incisivo sobre la cara anterior

Diåmetro de la primera muela ........

Diámetro de la segunda muela........

Diámetro de la tercera muela........

Diámetro de la cuarta muela.

... \{

| anteroposterior..................... 0008

transverso máximo.................. 0008

anteroposterior................... 0009

| transverso máximo .................. 00085

anteroposterior....................... 0011

transverso máximo................... 0010

anteroposterior..................... 0012

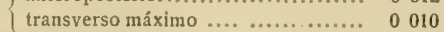

Longitud del espacio ocupado por las cuatro muelas..................... 0042

Alto de la rama horizontal, sobre el lado externo, debajo de la cuarta muela. 0029

Procede de las barrancas del Paraná y es propiedad del señor Lelong Thévenet.

DoLicirotis CENTRALIS Weyenberg

(Página 376 del volumen VI)

Entre las especies existentes no cité, por olvido, el Dolichotis centralis de Weyenberg, que habita el interior de la República y se distingue por un color algo distinto y un tamaño bastante menor que el del Dolichotis patachonica. No he podido comparar el Dolichotis centralis con las especies fósiles, de manera que no sería imposible que alguna de las especies fósiles de pequeña talla, mencionada como nueva, fuese idéntica al Dolichotis centralis.

\section{Nroprocavia mesopotamica Ameghino \\ (Página $40 \mathrm{r}$ del volumen VI) \\ Lamina LXXX egura is}

Conozco un fragmento de la rama izquierda de la mandibula inferior de otro individuo de esta especie, con parte de la sínfisis y las dos primeras muelas. Sólo se distingue de la precedente por un tamaño algo menor y una conformación bastante distinta. La primera muela es apenas un poco más pequeña, pero la segunđa tiene el mismo tamaño El incisivo falta, pero por el alvéolo se conoce que no podía tener más de 3 milímetros de ancho. La parte anterior que se extiende delante de las muelas, aunque rota adelante, se conoce que no podía tener más de 2 centímetros de largo.

Procedencia: - Esta pieza ha sido descubierta por el señor León Lelong Thévenet en las barrancas de los alrededores de la ciudad del Paraná.

Horizonte:- Piso mesopotámico de la formación patagónica. 
Cardomys cavinus Ameghino

(Página 403 del volumen VI)

Lsmiva LXXI1, figora 12

Dispongo ahora, proveniente de esta especie, una rama derecha de la mandibula inferior con el incisivo y las tres últimas muelas. $\mathrm{La}$ última muela inferior es absolutamente de la misina forma que la penúltima. Las tres últimas muelas ocupan un espacio longitudinal de 20 milímetros aproximadamente; y la serie dentaria completa, o sea las cuatro muelas, ocupaban 28 milimetros. Delante de las muelas, la parte anterior de la mandíbula presenta una prolongación extraordinaria en proporción al tamaño del animal, pues la distancia desde el borde anterior del alvéolo de la primera muela hasta el borde anterior del alvéolo del incisivo es de 3 centímetros, es decir: una extensión mayor que la que ocupan las cuatro muelas.

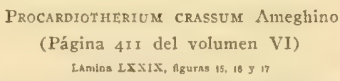

Conozco de esta especie, otras dos muelas, ambas inferiores. Una es la primera inferior derecha, absolutamente idéntica a la que me sirvió de tipo para la fundación de la especie.

La otra es una muela intermedia (la segunda o tercera), de una conformación casi idéntica a la del Procardiotherium simplicidens, pero de un tamaño mucho más considerable y con la figura intermedia menos separada, de manera que no forma arista perpendicular independiente sobre el lado externo. La corona tiene 14 milímetros de diámetro anteroposterior y 12 milimetros de diámetro transverso máximo.

\section{Cardiotheriug Doeringt Ameghino}

(Página 416 del tomo VI)

Latrina LXXIX, Agurss 10, 12 y 14

Como pieza nueva de esta especie, conozco un fragmento de paladar con las dos muelas intermedias del lado izquierdo y parte de los alvéolos de la primera y de la última. Las dos muelas existentes están formadas por dos prismas triangulares, el anterior bipartido en el lado externo en dos ramas y el posterior simple, presentando tres columnas perpendiculares externas separadas por dos surcos. La muela segunda (m. 1) tiene 12 milímetros de diámetro anteroposterior y 11 milímetros de diámetro transverso máximo. La muela tercera $\left(\mathrm{m} .{ }^{2}\right)$ tiene 10 milímetros de diámetro anteroposterior por 10 milímetros de diámetro transverso máximo; y las dos muelas juntas ocupan un espacio longitudinal de 23 milímetros. La muela primera (p. 4), a juzgar por el alvéolo, parece era de tamaño un poco mayor que la segunda.

El paladar es completamente triangular, sumamente angosto adelante y muy ancho atrás, con dos depresiones o surcos longitudinales 
separados por una cresta longitudinal media bastante elevada. La región interdentaria tiene 6 milimetros de ancho entre la parte posterior de los p. $-4,15$ milimetros entre la parte posterior de los m. 1 y 25 milimetros entre la parte posterior de los m. 2 .

Esta pieza es propiedad del señor Lelong Thévenet.

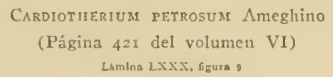

Esta especie sólo me era conocida por un fragmento de mandibula inferior del lado izquierdo con las dos primeras muelas completamente envueltas en piedra dura y en parte destruídas. Ahora dispongo de una rama izquierda de la mandibula inferior con las cuatro muelas intactas, y perfectamente bien conservadas, que me permiten dar un dibujo más exacto de las muelas anteriores que el precedente.

La primera muela inferior consta de tres prismas dispuestos de modo que forman tres columnas y dos surcos sobre el lado externo y cuatro columnas y tres surcos sobre el interno, pero sin que el prisma anterior presente vestigio de surco perpendicular interno. Las demás muelas están construídas sobre el mismo tipo que las del Cardiotherium Docringi, con excepción de la cuarta muela inferior que presenta la última lámina completamente separada por un depósito de cemento.

\section{DIMENSIONES}

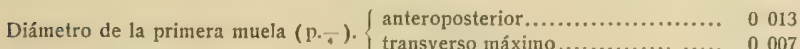

Diámetro de la segunda muela $(m$, , $\{$ anteroposterior................... 0011

Difmetro de a

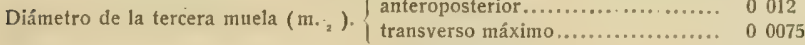

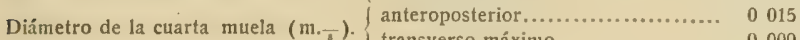

La base del incisivo llega hasta enfrente de la mitad del largo de la tercera muela $(\mathrm{m}, \overline{2})$.

Esta pieza es propiedad del señor León Lelong Thévenet.

Cardiotherium minutum Ameghino

(Página 425 del volumen VI)

Limina $2 \times x i x$, figura

De esta especie conozco ahora un paladar incompleto con los tres alvéolos vacios de las tres primeras muelas, que por su tamaño relativamente pequeño concuerda perfectamente con el fragmento que me 
sirvió de tipo para la fundación de la especie, confirmando la existencia de ésta. El tamaño de los tres alvéolos de las tres primeras muelas disminuye del primero al tercero; y, naturalmente, otro tanto debía suceder con las muelas que en ellos se implantaban. El alvéolo de la primera tiene 8 milímetros de diámetro anteroposterior, el de la segunda 5 milimetros y el de la tercera 4 milimetros, ocupando los tres alvéolos un espacio longitudinal de 20 milímetros. El paladar es triangular en forma de $\mathrm{V}$, teniendo la región interdentaria 2 milímetros de ancho en la parte anterior de los p. ${ }^{4}, 9$ milímetros enfrente de la parte media de los m. 1 y 17 milímetros al nivel de la parte posterior de los m. ${ }^{3}$. La parte de los maxilares que se extiende delante de las muelas es muy ancha.

Esta pieza pertenece al señor León Lelong Thévenet.

Plexochorrus paranensis Ameghino

(Página 427 del volumen VI)

Lomina $2 \times \operatorname{six}$, figuta of

Conozco una muela inferior aislada de esta especie (la segunda o tercera) que difiere de la de Cardiotherium por el prisma anterior, que es profundamente bipartido al lado interno, y por estar, además, completamente separado del segundo prisma por un delgado depósito de cemento, interrumpiéndose en este punto la lámina de esmalte, existiendo ahí en vez de la columna convexa del Cardiotherilum un pequeño surco perpendicular. La corona tiene 15 milímetros de diámetro anteroposterior por 10 milímetros de diámetro transverso.

Además, dispongo de otra muela cuarta superior en mejor estado que todas las que hasta ahora había examinado. Como en los ejemplares anteriores, está compuesta de 9 láminas, representadas por 9 columnas perpendiculares internas, la lámina anterior bipartida en el lado externo y todas las láminas reunidas por una hoja de esmalte ininterrumpida. La corona tiene 27 milímetros de diámetro anteroposterior y 11 milímetros de diámetro transverso máximo.

\footnotetext{
Plexochoerus aduis Ameghino

(Página 430 del volumen VI)

Lamina LXXIS agurs ti $y$ lamuna LXXX, Aguras o 5 in
}

De esta especie de gran tamaño, cuya talla no debía ser muy inferior a la del carpincho actual, conozco varias piezas, las más importantes de las cuales son:

Un ejemplar de la última muela superior del lado derecho, un poco más completa que la que me sirvió de tipo para fundar la especie y de tamaño también algo mayor. Consta igualmente de 10 láminas re- 
Fresentadas por diez columnas perpendiculares internas, lo que demuestra que esto es realmente un carácter específico. La corona tiene 38 milimetros de diámetro anteroposterior, 8 milimetros de diámetro transverso adelante, de 15 a 16 milímetros en el medio y 8 milímetros en la parte posterior. La muela tiene 44 milimetros de largo desde la raíz hasta la corona.

Un fragmento de la parte anterior del paladar con la primera muela del lado derecho, parte del alvéolo de la segunda muela y el alvéolo de la primera muela del lado izquierdo. La parte interdentaria del palaciar es de una reducción extraordinaria, pues en la parte de la primera muela de cada lado tiene apenas un milímetro de ancho, pudiendo clecirse que las muelas de ambos lados casi se tocan; y a juzgar por los restos de los alvéolos de la segunda muela de cada lado, apenas debian de estar separadas adelante por un. espacio de 2 milímetros.

La primera muela implantada en este fragmento consta de dos láminas prismáticotriangulares, ambas bipartidas en el lado externo y además con un surco perpendicular intermedio entre ambos prismas en el lado externo, presentando asi cuatro column ss perpendiculares separadas por tres surcos, conformación idéntica a la que presenta la misma muela del Hydrochorus, de la cual no se distinguiría si no fuese por la hoja de esmalte continuo que une a los dos prismas, separados en el Hydrocharus por un depósito intermedio de cemento. La corona de esta muela tiene 12 milímetros de diámetro anteroposterior y cerca de 11 milimetros de diámetro transverso oblicuo máximo en el prisma posterior. El largo de la muela, desde la raíz hasta la corona, en línea recta, es de 4 centímetros aproximadamente.

Un trozo de la rama izquierda de la mandíbula inferior, con las dos primeras muelas. La primera muela inferior está formada por tres prismas, cada uno bipartido en el lado interno, el primero reunido al segundo por una columna interna ancha con una depresión perpendicular en el medio y el segundo separado del tercero por un surco perpendicular interno profundo. Esta muela presenta así cinco columnas internas separadas por cuatro surcos profundos, ostentando además la segunda columna interna más ancha una depresión perpendicular bastante acentuada. Los tres prismas están reunidos por una hoja de esmalte ininterrumpido. La corona de la muela es casi del mismo ancho adelante y atrás, teniendo 20 milímetros de diámetro anteroposterior y 10 milímetros de diámetro transverso.

La segunda muela inferior está formada por tres prismas, dispuestos casi del mismo modo que en el carpincho: el primero separado del segundo como en el animal actual, pero el segundo y el tercero reunidos por una hoja de esmalte ininterrumpida. La corona de la muela tiene 18 milímetros de diámetro anteroposterior y 10 milímetros de diámetro 
transverso tanto adelante como atrás. Las dos muelas juntas ocupan un espacio longitudinal de 39 milímetros.

Todas estas piezas pertenecen al Museo provincial del Paraná.

PLEXOCHOERUS LYNCHI, $n . s p$.

Lamua LXXIX, figuras of $\mathrm{g}$ is

Especie de talla muy pequeña, de la cual conozco un paladar con las tres últimas muelas de cada lado y una última muela superior aislada de otro individuo. Las muelas superiores, segunda y tercera, tienen cada una 5 milímetros de diámetro anteroposterior y 6 milímetros de diámetro transverso máximo. La última muela superior está construída sobre el mismo tipo que la del Plexochœrus paranensis, formada 1gualmente por láminas que constituyen nueve columnas perpendiculares internas, pero es de un tamaño muchísimo menor, pues sólo tiene 16 milímetros de diámetro anteroposterior por 7 milímetros de diámetro transverso máximo. La región interdentaria del paladar en proporción del tamaño del animal es sumamente ancha, pues tiene 14 milimetros de ancho en la parte anterior de la segunda muela, 20 milímetros en la parte anterior de la tercera, 21 en la parte anterior de la cuarta y 24 en la parte posterior de la misma. Las tres últimas muelas ocupan un espacio longitudinal de 27 milímetros.

La última muela superior aislada es absolutamente de la misma forma, pero de un individuo un poco mayor, pues tiene 19 milimetros de diámetro anteroposterior por 8 milímetros de diámetro transverso máximo.

Dedico la especie a mi amigo el distinguido naturalista Félix Lynch Arribálzaga.

Procedencia: - Barrancas de los alrededores de la ciudad del Paraná. Horizonte: - Piso mesopotámico de la formación patagónica.

IIYDROCHOERUS GICANTEUS Lund

(Página 433 del volumen VI)

Limina XII, figura 84

Volviendo a examinar con más detención los dibujos y la descripción del Hydrochocrus fósil de Tarija, dados por Gervais, veo que el tamaño es demasiado considerable para que pueda considerarse como idéntico a la especie actual. Aunque la última muela superior no difiere por la forma de la del carpincho actual, tiene 50 milímetros de largo y 20 milimetros de ancho, proporciones que no alcanzan los más grandes individuos de la especie existente. Esas medidas concuerdan con el tamaño del Hydrochorus gigantcus de Lund, a cuya especie los atribuyo, cuando menos hasta que nuevos materiales no prueben lo contrario. 
Hyorochoerus anagus II. Gervais y Ameghino

(Página $43+$ del volumen VI)

Lamma LXXIX, figuras

Dispongo ahora de una rama mandibular izquierda de esta especie, cn la cual se conservan las cuatro muelas casi intactas, que me permiten reconocer otros caracteres que separan netamente a esta de las demás especies, particularmente en la última muela inferior, la que en vez de estar formada por seis láminas separadas, como en la especie actual, está constituída por cuatro láminas como la muela tercera, pero la primera y última compuestas. La lámina anterior de la última muela inferior se compone, en realidad, de dos láminas, pero que sólo están separadas sobre el lado interno mientras que permanecen reunidas sobre el externo, representando una $\mathrm{V}$ con la abertura en el lado interno y el vértice en el externo. Las dos láminas que siguen están completamente separadas, pero las dos últimas o posteriores están unidas en el lado interno y separadas en el externo. La primera muela inferior presenta sus prismas unidos por una hoja de esmalte continua, como en el género Plexochœrus.

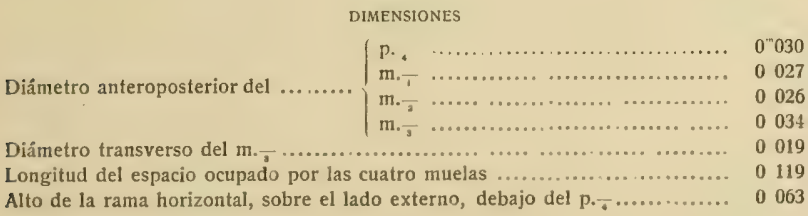

Esta pieza ha sido descubierta por el Director de la Sección Paleontológica del Museo provincial de Entre Ríos, señor Toribio E. Ottiz, en la formación pampeana del arroyo Alcaraz; y es propiedad del mencionado establecimiento.

IIYDROCHTERUS JRRORITUS, $n, s p$.

Lamina LXXix, firturas $? \mathrm{y}$ a

Esta especie me es conocida por dos ejemplares de la úitima muela superior, provenientes de dos individuos diferentes, que prueban que por la talla se acercaba al carpincho actual, pero tienen una conformación algo distinta, particularmente una lámina de más, presentando trece columnas internas en vez de doce, lo que no deja duda de que se trata de una especie distinta extinguida. Además, las lảminas son más comprimidas; y las muelas enteras, aunque tienen casi el mismo largo que las del Hydrocharus capybara, son un tercio más angostas, 10 
que confirma de una manera inequívoca su diferencia especifica. El ejemplar más pequeño pero más completo tiene en la corona 37 milímetros de diámetro anteroposterior por 10 a 11 milimętros de diámetro transverso oblicuo máximo. La otra es de tamaño apenas un poco mayor.

Procedencia: - Estas piezas han sido recogidas por el señor Lelong Thévenet en las barrancas de ios alrededores de la ciudad del Paraná.

Horizonte:-. Piso hermósico (?) de la formación araucana (?).

La colocación de este género, en el texto, en el orden de los Macropoda debe considerarse sólo como provisoria; y su colocación definitiva quizá no pueda ser determinada hasta que no se conozcan materiales más completos. No tengo duda de que es un alloideo; pero lo he puesto en el grupo mencionado por no saber en donde colocarlo. Ahora, fijándome más en los caracteres de la dentición, me parece más probable que represente una forma gigantesca del orden de los Plugiuula coidea, probablemente aliada de los géneros norteamericanos Catopsalis y Polymastodon.

\section{NOTICTIS, $n: g e n$.}

Nuevo género del orden de los Creodontu, cercano de Proviverra y Stypolophus. El p. ${ }_{\uparrow}$ tiene una sola cuspide media sectorial y un engrosamiento basal en forma de reborde. El m. $\frac{1}{1}$, de tamaño un poco mayor, presenta tres clispides casi iguales y un callo basal posterior. El m. 2 de tamaño todavia mayor, presenta dos cúspides bajas pero agudas, la anterior más baja que la posterior, acompañadas de un callo basal posterior. El $\mathrm{m} \cdot \overline{3}$, es más elevado pero no más largo, con dos puntas o cúspides elevadas casi iguales y un callo basal posterior inuy desarrollado.

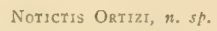

Conozco esta especie por dos fragmentos de la rama izquierda de la mandibula inferior, uno de ellos con los cuatro últimos dientes. El p. y $\operatorname{los} \mathrm{m} \cdot \overline{2}_{2}$ y m. ${ }_{1}$, tienen unos 4 milimetros de diámetro anteroposterior cada uno, pero la corona se eleva gradualmente del p. $\overline{4}$ al m. $\overline{2}$ El $\mathrm{m} . \overline{3}$ es de diámetro anteroposterior un poco menor, pero de corona 
más elevada, alcanzando su cúspide más alta unos 5 milimetros de clevación. Las cuatro muelas juntas ocupan un espacio longitudinal

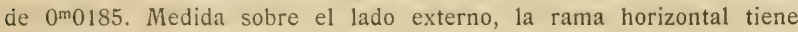
8 milímetros de alto debajo del m. ${ }_{3}$ y 6 milímetros debajo del p. ${ }_{4}$. Existe una perforación mentoniana debajo de la parte anterior del p. ${ }_{3}$, una segunda debajo de la parte anterior del p. ${ }_{4}$ y una tercera debajo de la parte anterior del $\mathrm{m}$. , las tres en fila más o menos a la misma altura.

Dedico la especie al señor Toribio E. Ortiz, Director de la Sección Paleontológica del Museo del Paraná.

Procedencia: - Barrancas de los alrededores de la ciudad del Paraná.

Horizonte:-Piso mesopotámico de la formación patagónica.

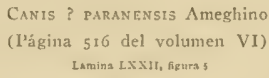

La figura del canino de esta especie, dada en la figura citada en el cuerpo de la obra, tomada de frente, da una idea imperfecta del diente, que podrá completarse por el examen de la figura que indico y que representa el mismo objeto visto de lado.

\section{Cyonasua argentina Ameghino \\ (Página 528 del volumen VI) \\ LAmirn LXXIX, figura I}

De este curioso carnivoro primitivo dispongo ahora de la rama izquierda de la mandibula inferior casi completa, que prueba que el animal tuvo sólo seis muelas inferiores como lo había supuesto en mis primeras noticias sobre este género («Boletín de la Academia», etc., tomo VIII, página 19, año 1885) y no siete como lo creí después, inducido en error por fragmentos incompletos de mandíbulas.

Esta pieza confirma, sin embargo, de una manera indiscutible que el animal ha sido cercano de Nasua y también de Procyon.

En la parte anterior y lado interno del canino se ven los alvéolos de los tres incisivos del lado izquierdo. Los alvéolos de los i. $\overline{1}$ e i. $\frac{2}{2}$ son muy pequeños, el primero aún más que el segundo, y colocados el uno encima del otro. El alvéolo del i. $\frac{-}{3}$ colocado entre los dos precedentes y el canino es de tamaño mucho más considerable y fuertemente apretado al canino.

El canino es muy grueso, de sección elíptica y de corona muy baja y roma, casi como truncada a causa del fuerte desgaste producido

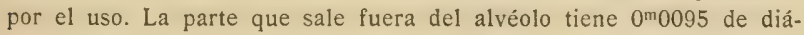


metro anteroposterior, $0^{\mathrm{m}} 0065$ de diámetro transverso y sólo 11 milímetros de alto.

Sigue al canino un pequeño diastema de menos de 3 milímetros de ancho, donde se implantaba el primer premolar de este animal, que es realmente el p. $\frac{-}{1}$; sólo queda el alvéolo casi completamente obliterado que demuestra era un diente sumamente pequeño, caedizo en edad avanzada y de una sola raíz.

El p. $\overline{2}$ es birradiculado, con una sola cúspide central sectorial, con un engrosamiento basal casi en forma de reborde o cingulum; y su corona tiene 6 milímetros de diámetro anteroposterior y 5 milímetros de alto. El p. $\frac{-}{3}$ tiene en seguida de la cúspide central sectorial un pequeño tubérculo colocado hacia la mitad de la altura de la muela y un callo basal poco desarrollado; la corona tiene $0^{\mathrm{m}} 0075$ de diámetro anteroposterior, 5 milímetros de diámetro transverso en la base y $5 \mathrm{mi}$ límetros de alto.

El p. \& se distingue por un gran callo basal posterior muy ancho, dividido hacia arriba en dos cúspides, una interna y otra externa; y la corona tiene 9 milímetros de diámetro anteroposterior, 6 milímetros de diámetro transverso máximo y 5 milimetros de alto.

El m. - me es desconocido; sólo quedan en este ejemplar, como en el primero que conocí, los alvéolos vacíos, que ocupan un espacio longitudinal de 11 milimetros. Del . $_{2}$ quedan igualmente los dos alvéolos, que sólo ocupan un espacio longitudinal de $0^{\mathrm{m}} 0075$, lo que prueba que el diente que ahí se implantaba era considerablemente más pequeño que el m. $\frac{-}{1}$. No existía el m. ${ }_{3}$, en lo que también coincide con la conformación de los géneros actuales Nasua y Procyon.

La distancia del borde anterior del alvéolo desde el canino al borde posterior del alvéolo del m. $\overline{2}$, es de 56 milímetros.

La sínfisis es sumamente corta y gruesa y la rama horizontal de la mandíbula tiene, medida por su lado externo, 18 milímetros de alto debajo del p. 2 y 17 milímetros debajo de la parte anterior del $\mathrm{m} . \overline{2}$.

Hay dos perforaciones mentonianas, colocadas más o menos a la misma altura, la anterior más grande debajo del p. - y la posterior más pequeña, debajo de la parte intermedia, entre $p \cdot \frac{-}{3}$ y $p \cdot \frac{\pi}{4}$.

Esta pieza es propiedad del señor León Lelong Thévenet.

Procyon CANCrivorus G. Cuvier y Et, Geoffroy Saint-Hilaire

Esta especie no ha sido citada hasta ahora entre las actuales de la República Argentina, pero existe, sin embargo, en la provincia Entre Ríos, y probablemente también en Corrientes y el Chaco. He comparado sus restos con los de Cyonasua, notando las mismas diferencias genéricas que entre aquél y Nasua. Son, pues, tres géneros completamente distintos. 
ApEra sanceisarta Ameghino

(Página 575 del volumen VI)

Lamina LXXVil, figurae 1, a yo

Este animal, descripto por Burmeister sobre una sola muela inferior bajo el nombre de Eutemnodus americanus de Bravard, ha sido considerado por el autor como un felino; y tal es la colocación que le he dado en el cuerpo de la obra, bajo la responsabilidad de Burmeistar, agregando que no exponía mi opinión definitiva por carecer de origı. nales y porque la pieza descripta me parece diferir notablemente del diente carnicero inferior de los gatos.

Ahora dispongo de tres muelas: el primer premolar superior intacto, el tercer premolar superior roto y el cuarto premolar inferior, que, por su superficie de esmalte fuertemente rugosa y cubierta de impresiones en forma de redecilla, provienen evidentemente del mismo animal descripto por Burmeister.

El examen de estas piezas demuestra que no se trata de un felino, sino de un carnívoro del grupo de los Creodonta y precisamente bastante cercano del Hyaenodon, como lo había reconocido Bravard al larle el nombre de Eutemnodus, que es un sinónimo de Hyaenodon.

La muela figurada y descripta por Burmeister como siendo el carnicero inferior de un felino ( $\mathrm{m}_{1}$ ) resulta así ser la última muela inferior $(\mathrm{m} \cdot \overline{3}$ ) de un animal parecido a Hyaenodon, pero de un individuo sumamente joven, pues su tamaño no está en proporción con el de las muelas del individuo adulto de que dispongo, y por otra parte eso mismo lo demuestra de una manera evidente la ausencia de raíces y la gran cavidad basal que según el dibujo presenta la mencionada muela.

El diente, que supongo sea el $\mathrm{p} . \overline{1}$, tiene dos raices desiguales, la posterior más larga y más gruesa que la anterior y ambas fuertemente inclinadas hacia atrás, pero particularmente la posterior. La corona se eleva formando una cúspide central sectorial fuertemente inclinada hacia adelante casi en forma de gancho, presentando un aspecto igual al del mismo diente del género Hyacnodon; tiene 9 milímetros de diámetro anteroposterior y 7 milímetros de alto, con un principio de cíngulo basal y toda la superficie del esmalte fuertemente rugosa cón impresiones reticulares.

Del que supongo ser el p. $\overline{3}$ sólo existen los dos tercios anteriores, con una cúspide central elevada y dos anteriores sobre la misma línea sectorial, la primera en la base y la segunda hacia la mitad de la altura de la corona; la parte posterior es muy ancha y debía presentar en la parte que falta un gran callo basal con dos o más tubérculos. La superficie del esmalte es igualmente rugosa; y la base de la corona presenta un fuerte reborde o cíngulo basal tanto en su lado interno como en 
el externo. La parte existente de la corona tiene aproximadamente 10 milímetros de largo, pero cuando entera no debía tener menos de 15 milimetros de diámetro anteroposterior; tiene 7 milímetros de diámetro transverso en la parte rota y 10 milímetros de alto.

El que supongo sea el p. ${ }_{4}$ tiene dos raíces divergentes de 13 milimetros de largo y una corona de 13 milímetros de diámetro anteroposterior, con una cúspide central más elevada y comprimida y dos tubérculos más bajos, uno anterior y otro posterior colocados sobre la línea sectorial, con la superficie del esmalte fuertemente rugosa y en todo su contorno un cíngulo basal bien desarrollado.

Estos ejemplares son propiedad del señor Lelong Thévenet, quien los ha recogido en las capas del piso mesopotámico de la formación patagónica de los alrededores del Paraná.

TOXODON PARANENSIS Laurillard

(Página 54 del volumen VII)

Lamina Lxxru, ngura ?

De esta especie conozco un fragmento de mandibula inferior del lado derecho con las tres últimas muelas y el borde inferior de la mandíbula que faltaba en el ejemplar precedente, proveniente también de un individuo algo más pequeño. El m. i tiene 35 milímetros de diámetro anteroposterior, el $\mathrm{m}_{2}, 36$ milímetros y el m. $\frac{3}{3}, 53$ milímetros; este último diente tiene sólo 12 milímetros de ancho adelante y 9 milímetros en el medio. Las tres muelas juntas ocupan un espacio longitudinal de cerca de 13 centímetros. El alto de la rama horizontal, sobre el lado externo, debajo de la última muela, es de 105 milímetros.

Toxodos vircatus Ameghino

(Página $63^{-}$del volumen VII)

Lamina LXXiti, figura ,

Dispongo ahora de un fragmento de maxilar superior derecho con las tres últimas muelas, de un individuo todavía bastante joven, que supongo proviene de esta especie, pero en el cual las muelas ya habian adquirido su completo desarrollo, con excepción de la última.

Los verdaderos molares superiores se distinguen fácilmente de los cie las otras especies, por la columna interna poco desarrollada, por el pliegue del esmalte que penetra en la corona sobre el lado interno, siempre simple, y por la cara perpendicular externa bastante excavada.

El m. ${ }^{1}$ tiene 27 milimetros de diámetro anteroposterior por 11 milimetros de diámetro transverso. E1 m. ${ }^{2}$. tiene 29 milímetros de diámetro anteroposterior por 12 milimetros de diámetro transverso máximo. El m. 3 en la corona sólo tiene 25 milímetros de diámetro anteroposterior porque no ha adquirido todavia su completo desarrollo, pero 
en la base tiene 30 , que es el diámetro que debía presentar en la corona cuando completamente adulto. Los tres verdaderos molares ocupan un espacio longitudinal de 69 milimetros, que debía alcanzar a 74 o 75 cuando la última muela estaba completamente desarrollada.

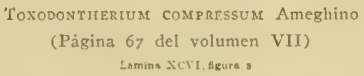

A pesar de que se me hacen cargos por aumentar, se dice, de una manera injustificada el número de especies, la verdad es que he sido demasiado prudente, pues por no aumentar su número de una manera exagerada, he reunido a veces restos de dos o tres especies, conocidas por escasos fragmentos, en una sola, que ahora, con el descubrimiento ae nuevos materiales, se hace forzoso separar. Así, en un principio, bajo el nombre de Toxodontherium compressum reuni muelas aisladas de tres animales diferentes, aunque hasta cierto punto de una conformación parecida.

Una muela última de la mandibula superior que en mi segunda Memoria sobre los mamíferos fósiles del Paraná atribuí al Toxodontherium compressum ha resultado pertenecer al Haplodontherium Wildei, como se verá más adelante, en su lugar correspondiente.

Aunque las demás muelas descriptas como de esta especie, en realidad pertenecen al género Toxodontherium, hay que distribuirlas ahora en dos especies distintas, tal como lo preveía y lo manifesté al redactar mi tercera Memoria sobre los fósiles del Paraná; agregando que las conservaba reunidas hasta que nuevos materiales no permitieran abrigar la menor duda sobre su distinción específica.

Hoy, los nuevos materiales que conozco me permiten reconocer dos especies bien diferentes y fáciles de distinguir.

Del Toxodontherium compressum conozco los tres verdaderos molares y los dos últimos premolares de la mandíbula superior. Todos estos dientes son de corona muy larga y comprimida y con la cara externa cubierta en toda su extensión por una capa de esmalte ininterrumpido.

El p. 3 es de corona elipticoprolongada, muy angosta, sin columna interna, pero con un pequeño surco perpendicular en su parte posterior y con sólo dos capas de esmalte, una interna y otra externa. El p. 4 - es de corona igualmente larga y comprimida, pero bilobada en el lado interno, con tres capas de esmalte y una gran columna interna.

Los tres verdaderos molares siguientes, son sucesivamente más grandes, pero todos de corona muy comprimida y con la gran columna interna muy desarrollada. La capa de esmalte que cubre la cara externa llega en todas las muelas hasta el borde posterior; $y$ todos los dientes tienen la cara externa fuertemente ondulada. 


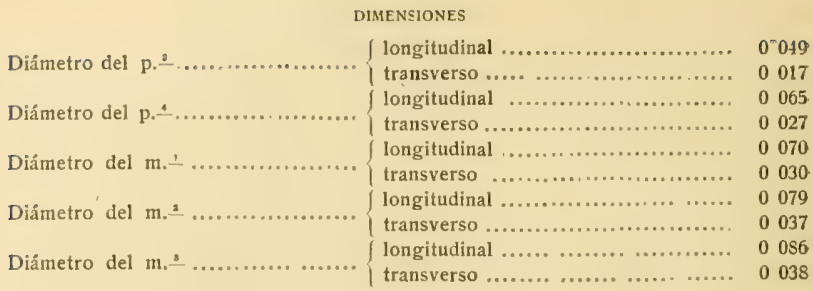

Lamian XeVI Bgara !

Esta especie, cuyos restos aislados confundí al principio con los de la especie precedente, presenta las muelas superiores con la gran columna interna igualmente desarrollada, pero se distingue por un tamaño un poco menor, por la corona de los verdaderos molares superiores un poco menos comprimida y más triangular, por la cara externa de todos los dientes mucho más ondulada y por la capa de esmalte del lado externo que nunca cubre toda la cara externa, concluyendo bastante antes de llegar al borde posterior, de manera que queda siempre en la parte posterior de la cara externa una ancha banda no esmaltada.

Conozco de esta especie las cuatro últimas muelas superiores que presentan las siguientes dimensiones:

\begin{tabular}{|c|c|c|}
\hline & & \\
\hline Diámetro del p. & $\left\{\begin{array}{l}\text { longitudinal } \ldots \ldots \ldots \ldots \ldots \ldots \ldots \ldots \ldots \ldots \ldots \ldots \ldots \ldots \ldots \ldots \ldots \ldots \ldots \ldots \ldots \ldots \\
\text { transverso } \ldots \ldots \ldots \ldots \ldots \ldots \ldots \ldots\end{array}\right.$ & $\begin{array}{l}0^{\mathrm{m}} 057 \\
0022\end{array}$ \\
\hline iản & idinal ..... . . & $\begin{array}{l}0060 \\
0029\end{array}$ \\
\hline n. - & 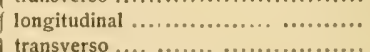 & $\begin{array}{ll}0 & 071 \\
0 & 035\end{array}$ \\
\hline iámet & $\begin{array}{l}\text { longitudinal } \ldots \ldots \ldots \ldots \ldots \ldots \\
\text { transverso } \ldots \ldots \ldots \ldots \ldots \ldots \ldots\end{array}$ & $\begin{array}{ll}0 & 081 \\
0 & 042\end{array}$ \\
\hline
\end{tabular}

\footnotetext{
HAFlodontherium WiLdet Ameghino

(Página 7 I del volumen VII)

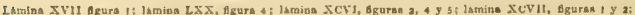
$y$ lamins XeriH, fgurs
}

El género Haplodontherium sólo me era conocido hasta ahora por las muelas superiores. Afortunadamente, antes de concluir este trabajo, ha llegado a mis manos un verdadero molar inferior del mismo animal, el m. - o el m. $\overline{2}$, de una conformación particular que prueba que ha sido más cercano del Trigodon que del Toxodon. Esta muela es de corona muy ancha y de un diámetro transverso casi igual adelante y atrás. Sobre 
el lado externo está dividida en dos lóbulos muy desiguales, el anterior muy angosto y convexo en forma de columna y el posterior mucho más ancho, aunque igualmente convexo, separados ambos por un gran surco perpendicular que forma un pliegue de esmalte profundo que penetra en la corona de atrás hacia adelante. Sobre el lado interno la muela es. ancha adelante, deprimida en el centro y con un profundo pliegue que penetra en la corona, cerca de su extremidad posterior.

Esta muela presenta únicamente dos capas o bandas perpendiculares. de esmalte, una que cubre toda la cara externa y la otra la parte media de la cara interna.

Sobre el lado externo, el primer lóbulo más pequeño tiene 13 milímetros de diámetro anteroposterior y el segundo, mucho más grande, 43 milímetros. La corona de la muela tiene 56 milímetros de diámetro anteroposterior, 20 milímetros de diámetro transverso en la parte anterior, 15 milímetros en el medio y 18 milímetros en la parte posterior. El largo de la muela, desde la raíz hasta la corona, es de cerca de 13 centímetros.

Además de esta muela inferior, conozco otras muelas superiores encontradas conjuntamente con dientes incisivos, que por su aspecto no. permiten dudar que provienen de un mismo individuo.

Se confirma que el incisivo interno superior (i. ${ }^{1}$ ) es de aspecto un poco triangular, excavado longitudinalmente adelante y atrás, de corona truncada horizontalmente, con capa de esmalte únicamente sobre la cara anterior y de base completamente abierta. Tiene en la corona 15 milímetros de diámetro anteroposterior máximo sobre el borde externo y 28 milímetros de diámetro transverso; su longitud total en línea recta es de sólo 7 centímetros.

E1 incisivo segundo (i. 2 ) es igualmente triangular, pero de tamaño bastante mayor, más ancho y más largo y de ángulos redondeados, delgado sobre el borde longitudinal externo y grueso sobre el interno. La cara posterior es regularmente convexa y la anterior plana y cubierta por una capa de esmalte, que sólo deja una faja no esmaltada sobre el borde longitudinal externo que se levanta sobre la cara anterior en forma de columna redondeada; la capa de esmalte mencionada da vuelta sobre la cara longitudinal del lado interno, cubriéndola casi por completo, con excepción de una pequeña banda longitudinaí sobre el lado interno. La corona está cortada en bisel, terminando en ápice triangular y agudo. Tiene 25 milímetros de diámetro anteroposterior máximo sobre el lado interno, 11 milímetros sobre el externo y $39 \mathrm{mi}-$ límetros de diámetro transverso.

Un diente elípticocilindrico, con dos bandas longitudinales de esmalte, cuya corona tiene unos 20 milímetros de diámetro mayor por 17 de diámetro menor, grueso casi igual al del canino, con dos bandas. 
de esmalte dispuestas del mismo modo e igualmente muy arqueado, pero muchísimo más largo, pues tiene en línea recta cerca de 12 centímetros, por lo que creo representa el incisivo tercero superior, que también existe en el Trigodon con una forma muy parecida.

Por fin, conjuntamente con un cierto número de premolares y molares elipticos, como los ya descriptos, se ha encontrado una gran muela triangular, con un gran surco y una gran columna interna y de cara externa convexa, completamente igual a la que en el tomo $\mathrm{V}$, página 105 del «Boletín de la Academia Nacional de Ciencias», he descripto como representando la última superior del Toxodontherium, presentando igualmente las mismas dimensiones. Esta muela es también la última superior, seguida adelante de un fragmento de muela elíptica de gran tamaño, de manera que no dudo ahora sea, tanto ésta como la precedentemente atribuida al Toxodontherium, la última superior del Haplodontherium, que en vez de ser elíptica como las que la preceden, es triangular y más parecida al tipo de los molares del Trigodon, el Toxodon y el Toxodontherium. Por otra parte, la cara externa convexa la distingue muy bien de las del Toxodonthcrinm, que son todas de cara externa ondulada, incluso la última superior. La última muela superior dol Haplodontherium Wildei tiene en la corona 68 milímetros de diámetro anteroposterior, 40 milimetros de diámetro transverso máximo y su gran columna interna, 23. milímetros.

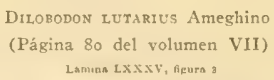

La figura que dejo mencionada representa la primera muela inferior de esta especie, que en este género corresponde al pm. $\overline{4}$.

Trigodon Gaudryt Ameghino

(Página 82 del volumen VII)

Nuevos restos de este animal, que por ahora ya no dispongo de tiempo para examinar en detalle, vienen a revelar afinidades con el Haplodontherium y con los Protoxodontida. Los incisivos superiores son en número de 6 , tres en cada lado, los externos (i. 2 ) grandes, triangulares y de base abierta como en el Toxodon, los dos del medio (i.1) más pequeños, de raíz delgada, separada de la corona y de base completamente cerrada como en el Adinotherium y el Protoxodon, y los dos posteriores (i. 3 ), mucho más pequeños y elipticos. Las muelas superiores son en número de 6: las tres anteriores, de contorno más o menos elíptico y sin columna perpendicular como las del Haplodontherium y las tres últimas con una columna perpendicular interna como la corres- 
pondiente del Toxodon y parecidas a las del Toxodontherium. El canino superior es pequeño, eliptico y parecido al incisivo tercero.

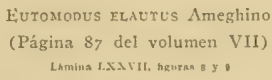

De este animal conozco otras dos muelas superiores; un premolar de una conformación casi idéntica al que he descripto más arriba y otro diente mucho más grande, aunque de forma casi igual, que supongo sea un verdadero molar o uno de los últimos premolares. Según astas muelas, el Eutomodus es cercano del Haplodontherium porque sus muelas son elípticas, sin columna ni surco entrante interno, y posee únicamente dos bandas perpendiculares de esmalte: una interna y otra externa; pero se distingue muy fácilmente por su talla pequeña y por las muelas sumamente comprimidas y no casi cilindricas como las del Haplodontherium.

La corona del premolar tiene 17 milímetros de diámetro anteroposterior por 9 milímetros de diámetro transverso, siendo mucho más delgada adelante y más ancha atrás.

El que supongo sea un verdadero molar o el último premolar, tiene la corona de 21 milímetros de diámetro anteroposterior, 11 milímetros de diámetro transverso máximo y $0^{\mathrm{m}} 055$ de largo en línea recta desde la raíz hasta la corona.

Estos objetos pertenecen al Museo provincial del Paraná:

\section{Stenotephanos plicidens Ameghino \\ (Página 98 del volúmen VII) \\ Laminn 1.Xxvull, figura \&}

Como nuevas piezas de este animal, conozco una parte de la rama derecha de la mandibula inferior con las tres últimas muelas, que presentan un notable parecido con las del Xotodon. Cada muela tiene un pliegue y surco perpendicular cerca del borde anterior de la cara externa y dos pliegues sobre la interna colocados mucho más atrás. La última muela presenta la misma forma que la penúltima con la diferencia de que su tamaño es un poco mayor.

\section{DIMENSIONES}

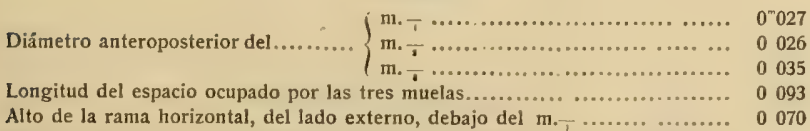

Alto de la rama horizontal, sobre el lado externo, debajo de la parte posterior del $\mathrm{m}$. 
Encuentro esta especie citada por Burmeister en la entrega XV de los «Anales del Museo Nacional», tomo III, página 179, repartida en Octubre de 1888, con el nombre de Typotherium Bravardi, siento éste, por consiguiente, un sinónimo de Typotherium maendrum, publicado en Abril de 1887.

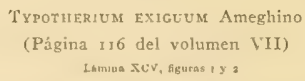

La familia del finado don Manuel Eguia, me ha facilitado un cráneo casi completo, procedente de la colección que fué del mencionado paleontólogo, pieza que confirma por completo la existencia de esta especie enana, pues dicho cráneo reune a su tamaño mucho menor que el del Typotherium cristatum la circunstancia de provenir de un individuo sumamente viejo, como a las claras lo indican la textura del hueso y el estado de las suturas, que están casi todas obliteradas.

Su tamaño en longitud es dos tercios del que presenta el cráneo del Typotherium cristatum, lo que indica un volumen de apenas un tercio del de éste.

La región interdentaria del paladar, con excepción de la diferencia de tamaño, es casi igual en ambas especies, pero la parte que se extiende adelante de las muelas es proporcionalmente más ancha y más corta, particularmente la región formada por el intermaxilar, que es proporcionalmente más ancha y más robusta que en el Typotherium pachygnathum y con los agujeros incisivos reemplazados por una depresión profunda y muy ancha, que se angosta un poco hacia atrás en su punto de unión con los maxilares.

En la región superior del cráneo, la parte anterior de los frontales y la región posterior de los nasales forman una superficie muy convexa y casi aglobada que le da un aspecto muy distinto del que presenta en las demás especies. Además, no existen en este cráneo las cavidades semilunares que entre los frontales y la parte posterior de los nasales presentan las demás especies.

\section{DIMENSIONES}

Diámetro transverso del incisivo superior $(\boldsymbol{i} . \perp-\ldots \ldots \ldots \ldots \ldots \ldots \ldots \ldots \ldots, 0 . \ldots \ldots$

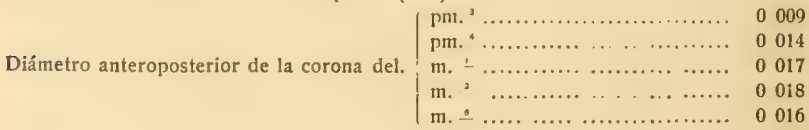


Longitud del espacio ocupado por las cinco muelas superiores ............. 0 07067

Longitud del intermaxilar sobre la cara palatina........................ 0031

Diảmetro transverso máximo del intermaxilar ......................... 0012

Ancho del paladar inmediatamente adelante de la primera muela (p. m.-)... 0031

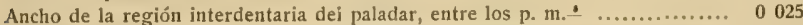

Ancho de la región interdentaria del paladar, entre la parte posterior del m. $\because 0016$

Longitud del paladar sobre la línea media ............................... 0121

Longitud total del crâneo ................................................ 0195

Diámetro transverso máximo del cráneo, entre las órbitas ............... 0130

Procedencia: - Toscas del río de la Plata, enfrente de los Olivos. Horizonte:- Piso ensenadense.

Pactryticos TYPICUS Ameglino

(Página 129 del volumen VII)

En la entrega XV de los «Anales del Museo Nacional», tomo III, página 179, distribuída en Octubre de 1888, el doctor Germán Burmeister, publica este animal con el nuevo nombre de Pedotherium insigne, aunque reconoce que el Pedotherium parece ser idéntico con Pachyrucos. El Pachyrucos typicus fué publicado en Abril de 1887, siendo de consiguiente el nombre de Pedotherium insigne un sinónimo de Pachyrucos typicus (1).

(r) $\Lambda$ propósito de esta especie y otros fósiles encontrados en Monte Hermoso por el señor Carlos Burmeister, hijo del doctor Germán Burmeister, no me es posible pasar en silencio una especie de acusación que me dirige en la siguiente nota, publicada en la relación de su viaje ( 8 Anales del Museo», tomo III, entrega XV, página 380, Octubre de I888).

Dice el sefior Burmeister en la nota mencionada: «En esta excursión a Monte Hermoso fui acompañado, como en la mayor parte del viaje, por el señor Adolfo Obrégón como ayưdante voluntario. Esste señor participó el resultado obtenido en este lugar a un amigo suyo, que publicó en un periódico de esta ciudad datos referentes a los objetos extraídos y a la siqueza fosilifera del terreno.

\&A consecuencia de esta publicación, don Florentino Ameghino fué al mismo lugar con objeto de buscar fósiles, publicando después de su regreso en el diario «La Niación», del Io de Marzo de I887, un extenso artículo sobre dicha localidad, para obtener la prioridad del descubrimiento.»

Cualquiera que lea este párrafo sin estar en antecedentes, si se aliene a lo que en él hay escrito, de seguro que me considera un nuevo Brander, siempre dispuesto a apropiarse del trabajo ajeno para darlo como propio. Afortunadamente, todos los que me conocen saben perfectamente que no he hecho carrera con el branderisno, como algún encumbrado pretendiente o titulado naturalista de nuestro país, a quien como tal lo conocemos todos.

El artículo a que se refiere el sefior C. Burneister expone simplemente las impresiones que recibi en Monte Hermoso al explorar el yacimiento fosilifero, fué escrito sobre el terreno y enviado desde alli a \&La Nacións; y es $\tan \sin$ fundamento la acusación de que he pretenäido con él obtener la prioridad del descubrimiento, que precisamente empiezo por decla. rar lo contrario. He aqui, en prueba de ello, la transcripción literal de los dos primeros párrafos del mencionado articulo:

\&Después de casi un año de vida sedentaria, aburrido del trabajo de laboratorio, decidi ausentarme para el campo unas semanas, si no para tomar descanso, para variar de ocupación.

\& $\mathrm{A}$ dónde dirigirme? Aún no conocía la parte austral de la provincia Buenos Aires y sus formaciones geológicas me eran absolutamente desconocidas. Además, por ese lado, no muy lejos de Bahía Blanca (once o doce leguas) existe un punto llamado Monte Hermoso, 
AMEGHINo: Trachytherns Sfogazzinianus, nucs'o manifero fósil del orden de los Torodentes, Marzo de I889.

Nuevo género del orden de los Toxodontia y de la familia de los Typotheride, representado por un paladar casi completo con la mayor parte de la dentadura.

El aparato dentario de la mandíbula superior consta de tres incisivos y siete muelas en cada lado colocados todos en serie continua, sin la más mínima discontinuidad y al parecer todos, sin excepción, de base abierta y con toda la superficie del prisma de cada diente cubierta for una capa de cemento, muy delgada, sobre los incisivos pero muy gruesa encima de los verdaderos molares.

El i. 1 es de gran tamaño, grueso sobre la línea media, delgado sobre el lado externo, convexo adelante, con la corona arqueada y en declive de la línea media hacia afuera, afectando una forma casi idéntica al incisivo principal del Hegetotherium; la cara anterior es esmaltada y la posterior sin esmalte.

Del i. ${ }^{2}$ sólo existe el alvéolo, que demuestra era un diente muchísimo más pequeño que el precedente y cilindrico, pues el alvéolo es circular.

El i. 3 es todavía más pequeño, casi rudimentario; y a juzgar por el alvéolo, igualmente casi circular.

El diente que sigue inmediatamente, ya implantado en el maxilar, que supongo es el p. ${ }^{1}$, es igualmente pequeño, casi rudimentario y probablemente también cilindrico, pues sólo existe de él la raíz implantada en el alvéolo.

El tamaño de todos los demás dientes, sumamente apretados unos a otros, va aumentando gradualmente desde el p. $2 \underline{2}$ al m. 3 .

El p. 2 tiene la corona casi tan ancha como larga, con un pequeño surco perpendicular en la parte anterior de la cara externa, con la superficie masticatoria de la corona sin esmalte y con el esmalte del prisma del diente interrumpido adelante y atrás.

El p. $\underline{3}$ es muy comprimido de adelante hacia atrás y de diámetro transverso mucho más considerable que el diámetro anteroposterior, con el mismo surco perpendicular sobre la parte anterior de la cara externa y con el esmalte igualmente interrumpido adelante y atrás.

donde Darwin hizo algunos de sus más notables descubrimientos paleontológicos, olvidado desde entonces por los hombres de ciencia, hasta que volvió a sonar últimamente con ocasion de una visita que a él hizo el joven Carlos Burmeister, hijo del ilustre Director ciel Mfuseo de la Capital Federal, anunciando que en ese paraje habia hecho el hallazgo de algunos fósiles de importancia; atractivo, este último, que cual poderoso imán me condujo a Monte Hermosoy.

La acusación es, pues, por demás injusta y seria de desear que no se repitiera. 
E1 p. \pm es de la misma forma, con la única diferencia de que presenta un tamaño bastante mayor y un pequeño pozo de esmalte aislado en la superficie masticatoria de la corona.

El $\mathrm{m}$. I se distingue del diente precedente por un tamaño dos veces mayor, por un contorno más triangular con la esquina anteroexterna formando un ángulo prominente, por carecer del surco perpendicular de la parte anterior de la cara externa y por la cara interna dividida en dos lóbulos casi iguales por un gran pliegue de esmalte que penetra en el centro de la corona, dividiéndose luego en dos ramas, una más larga dirigida hacia adelante y la otra mucho más corta hacia atrás.

El m. ${ }^{2}$ es absolutamente de la misma forma con la única diferencia del lóbulo interno anterior, que aparece decididamente como un poco más grande que el posterior.

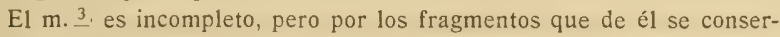
van parece que no difería del anterior.

El paladar es muy parecido al del Typotherium, con la parte anterior formada por el intermaxilar del mismo ancho adelante y atrás, presentando dos pequeñas perforaciones incisivas. Las series dentarias son muy poco convergentes adelante; y cada fila de muelas forma una línea casi recta, pero con el p. $\frac{4}{y}$ el $\mathrm{m} .11$ que avanzan un poco más sobre el paladar que los otros dientes.

\section{Trachythert's SPEgazinianus Ameghino}

Lamira LXXIX figuras i y a i y lamina Xevit, fixura

ANEghiNo: Trabajo citado.

El animal ha tenido la talla del Typotherium cristatum, pero con el paladar poco excavado y sin estrechamiento detrás del intermaxilar, pareciéndose en esto al Typotherium pachygnathum.

\section{DIMENSICNES}

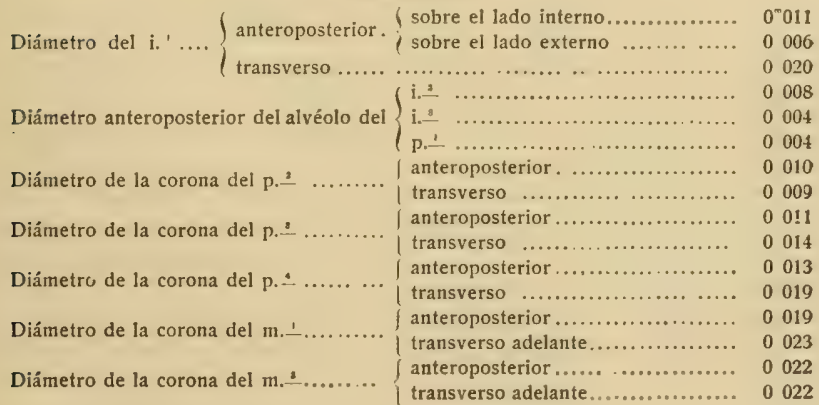


Distancia desde la parte anterior del $\mathrm{i} . \mathrm{\perp}$ hasta la parte posterior del m.2. ... $0^{\mathrm{m}} 126$ Longitud probable del espacio ocupado por la serie dentaria completa ....... 0150 Longitud del intermaxilar en el paladar, detrás de los incisivos................ 0032 Ancho del espacio ocupado por los dos incisivos medios ................. 0042 Ancho al nivel de la sutura del intermaxilar con el maxilar................. 0050 Ancho de la región interdentaria del paladar, al nivel de los p. $2 \ldots \ldots \ldots \ldots .0037$ Ancho de la parte interdentaria del paladar, entre la parte anterior de los m. $\_, \quad 0059$

Dedico la especie a mi amigo el distinguido botánico doctor Car los Spegazzini.

Procedencia:- Gobernación del Neuquen.

Horizonte:- Piso pehuenche (?) del palaeoceno.

(?) Einues australis Moreno

(Página 274 del volumen VII)

Moreno: Informe frcliminar, etc., Julio de 1888 , página i4 (nomen nudum).

En los salones del Museo Nacional abiertos al público se ha puesto últimamente en exhibición una rama de mandíbula inferior con todas las muelas, en la cual se ha colocado un marbete con el nombre de Hippidium nanum Burmeister. Se trata realmente de una especie nueva de Hippidium, un tercio más pequeño que el Hippidium neogaeum. Procede del yacimiento de Tarija e ignoro si su descripción ya ha sido publicada.

ScAlabrintTherium Rothi Ameghino

Lamina LXXVII, figura o

He recibido comunicación de un trozo del lado derecho de la mandíbula inferior de esta especie, con los alvéolos de los tres incisivos, del canino y del primer premolar y los tres últimos premolares implantados en la mandíbula.

Los premolares muestran, tanto en el lado interno como en el externo, un cíngulo basal enormemente desarrollado.

El p. ${ }_{2}$ tiene 17 milimetros de diámetro anteroposterior, el p. $\overline{3}$ tiene 22 milímetros y el p. ${ }_{4}-24$ milímetros. La distancia desde el borde del alvéolo del i. $\bar{i}$ hasta la parte posterior del $p_{4}-\overline{\text { es de }} 103$ milímetros. La rama horizontal de la mandibula tiene 26 milímetros de alto debajo del p. , y 33 milímetros debajo de la parte posterior del p. $\frac{4}{4}$. 
Palaeolama prosiesolititica, $n$. sp.

Ya al concluir mi trabajo, he recibido los restos de una especie de Paloolama evidentemente distinta de todas las mencionadas, por su tamaño muy pequeño, inferior al de Palocolama mesolithica y comparable al del guanaco actual. Una rama de la mandíbula inferior, proveniente de un individuo adulto, conserva las cinco muelas, que sólo ocupan juntas un espacio longitudinal de 70 milímetros.

Procedencia:- Excavaciones del puerto de La Plata.

Horizonte:- Piso ensenadense de la formación pampeana.

Pratatierium pampaeum Ameghino

(Página 446 del volumen V'II)

Este animal ya era conocido por el doctor F. J. Muñiz, pues entre los restos por él regalados a Rozas, en 1841, figuran huesos del Aurochs, que es evidente no pueden ser más que de Platatherium.

ASTRAPOTIEERIUM EPHEBICUM, $n, s p$.

En el último momento, y sin tiempo ya para figurarlos, recibo los restos de una segunda especie de Astrapotherium, de tamaño mucho menor que la precedente y de una época bastante más antigua, correspondiente al mismo horizonte del Pyrotherium Romeroi. La talla de esta especie no alcanzaba a la mitad de la del Astrapotherium magnum pues la corona del primer verdadero molar inferior apenas tiene un poco más de 3 centímetros de diámetro anteroposterior.

Procedencia:- Territorio del Neuquen.

Horizonte:- Piso pehuenche (?) del palaeoceno.

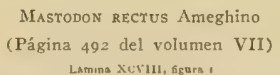

El señor Julio Migoya me ha facilitado el último molar superior izquierdo, con la corona casi completa, de esta especie, recogido por él mismo en un arroyo cerca de la costa Atlántica del Sur de la provincia Buenos Aires. Esta muela presenta en la forma de los mamelones un parecido bastante notable con la correspondiente del Mastodon andium. pero es de tamaño bastante mayor, más grande todavía que la misma muela del Mastodon Humboldti, y sobre todo notabiemente más ancha. Tiene cuatro colinas transversales y un talón basal posterior poco des- 
arrollado. Cada cresta está formada por dos tubérculos principales en los cuales no existe la tendencia a la disposición alterna que se nota en los mamelones de las muelas del Mastodon Humboldti y más todavia en las del Mastodon superbus. El mamelón externo de cada colina es comprimido de adelante hacia atrás y muy extendido en sentido transversal, de cúspide elevada y que por el desgaste presenta una figura transversal muy angosta y elevada, más o menos del mismo ancho en todo su largo. Los mamelones internos son, al contrario, angostos sobre el borde interno y anchos sobre el externo, donde presenta tubérculos accesorios que, con el desgaste, le dan a la superficie de trituración, la forma de una hoja de trébol.

\section{DEILOTIIERIUAI \\ (Página 8 del volumen VIII)}

Ya casi concluida la impresión de esta obra, llega a mis manos un trabajo de Filhol, en el cual encuentro que este distinguido naturalista ha aplicado con anterioridad el mismo nombre (Deilotherium) para distinguir un animal parecido al Dichobune y al Cainotherium, del oligoceno de Francia; y por consiguiente cambio el nombre del género argentino Deilotherium por el de Dideilotherium.

Promegatherium smaltatum Ameghino

(Página 43 del volumen VIII)

Lamins LXxvt, Ggurs 2

Aca々o de recibir la comunicación de piezas importantísimas de este animal, que demuestran era más diferente del Megatherium que no permitian suponerlo los dientes aislados, que son las únicas partes que me eran conocidas. Entre los nuevos materiales que conozco hay una rama derecha de mandíbula inferior casi completa, con las cuatro muelas. Esta pieza presenta en su conformación general un gran parecido con la parte correspondiente del Megatherium, pero con algunas particularidades de conformación que lo alejan tanto del Megatherium como de los géneros cercanos. Entre estos caracteres se encuentra la posición del agujero de la rama externa del canal alveolar que no se abre al lado interno de la base de la rama ascendente, como en el Megatherium y el Neoracanthus, ni tampoco en la parte anterior de la misma base de la rama ascendente, como en los Orthotherida, estando, al contrario, colocado sobre la cara externa de la base de la rama ascendente como en los Megalonychide, Mylodontida y Scelidotheridae. La parte inferior de la rama horizontal forma debajo de las muelas una parte descendente como en el Megatherium, pero no tan acentuada; y la sínfisis es proporcionalmente mucho más corta. 
Las tres muelas anteriores tienen casi absolutamente la misma forma y tamaño, que es la de un prisma cuadrangular, con su mayor diámetro en dirección al eje transversal de la mandibula; pero la última muela inferior se distingue por ser de diámetro transverso un poco menor y por sus caras posterior e interna, las que en vez de ser casi planas, son muy convexas, dando a la muela un contorno elípticocilíndrico.

\section{DIMENSIONES}

Diámetro de la corona de la primera / anteroposterior ................. 0 m 018 muela inferior. $\quad$ transverso ....................... 0024

Diámetro de la segunda muela..... f anteroposterior .................. 0020

Diămetro de la segutida mitela..... | transverso .................. 0025

Diámetro de la tercera muela....... | anteroposterior ................. 0020

(anteroposterior $\quad \begin{array}{lll}0 & 023 \\ 0 & 020\end{array}$

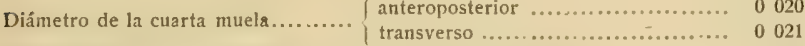

Longitud del espacio ocupado por las cuatro muelas inferiores............... 0095

Alto de la rama horizontal debajo de la segunda muela .................. 0100

Longitud aproximada de la mandibula inferior.... .................. 0340

Promylodon paranensts Ameghino

(Página 154 del volumen VIII)

Latoina Lxxvit, Asura 4

Ya casi concluido mi trabajo, recibo comunicación del hallazgo de una media mandíbula inferior izquierda con las cuatro muelas, que aun cuando son de un individuo todavía bastante joven, puede dar una idea suficientemente exacta de los caracteres que distinguen a este animal.

La primera muela inferior está separada de la segunda por una barra corta, es más elevada que las otras, de aspecto algo caniniforme y con un pequeño surco perpendicular en la cara anterior; tiene 10 milímetros de diámetro anteroposterior; y la barra que le sigue, 13 milimetros de largo.

Los dos dientes que siguen, segundo y tercero, tienen una sección rectangular, con su mayor diámetro en dirección transversal al eje longitudinal de la mandíbula, de ángulos redondeados, más angostos sobre el lado externo y más anchos sobre el interno, en donde cada uno presenta un surco perpendicular sobre su parte media. La corona de cada una de estas muelas tiene unos 8 milímetros de diámetro anteroposterior por 10 u 11 de diámetro transverso, siendo la segunda un poco más pequeña que la tercera. La cuarta muela, de tamaño mucho mayor, es bilobada en forma de ocho, casi como en el Lestodon, sin las columnas suplementarias que presenta en el Mylodon y el Pseudolestodon. Tiene 23 milímetros de diámetro anteroposterior y 13 milímetros de diámetro transverso en el lóbulo anterior. Las cuatro muelas juntas ocupan un espacio longitudinal de 77 milímetros; sin embargo, hay 
que tener presente que como se trata de un individuo algo joven, todas estas medidas debian aumentar un poco con la edad.

La parte que se extiende adelante de la primera muela es muy corta, de sólo 4 centímetros de largo; y la mandibula completa tiene un poco más de 20 centímetros de longitud.

PLohophorus AMEghinoI Moreno

(Página 288 del volumen VIII)

Lamina XCTII, figurat a o

El doctor Guillermo Bodenbender me ha facilitado la extremidad proximal de un tubo caudal de esta especie, cuyo dibujo doy en las figuras que dejo indicadas.

Esta pieza confirma la singularidad ya mencionada, de ser fuertemente comprimida, de manera que presenta su mayor diámetro en sentido vertical, en vez de transversal como en los Hoplophorus. Toda la parte anterior del tubo está adornada con grandes figuras elipticas, de las cuales, las que adornan la cara superior sólo presentan alrededor una que otra figura periférica, pero las de la cara ventral ostentan una fila completa e ininterrumpida de pequeñas figuras periféricas.

La abertura proximal del tubo, algo deformada por la presión de la roca en que estaba envuelta, tiene 111 milimetros de diámetro vertical y 75 milímetros de diámetro transverso.

DASYPUS HESTERNUS, $u$. $s p$.

LAmIua LXXX3, ggaras 11 a 14

Nueva especie extinguida, de tamaño como el del Dasypus villosus, o quizá algo más pequeña, de la cual se distingue fácilmente por las placas de las bandas movibles, que presentan en la cara externa dos filas de grandes perforaciones circulares y profundas, cada fila compuesta de sólo 2 a 4 agujeros, colocados en el fondo de los surcos que delimitan la figura longitudinal del centro de cada placa.

Procedencia:-Río Gallegos, en Patagonia austral.

Horizonte:- Piso santacruceño.

ADICIÓN AL CONOCIMIENTO DE LOS CRÁNEOS HUMANOS FÓSILES DESCUBIERTOS EN LOS RÍOS ARRECIFES Y SAMBOROMBÓN

(Páginas 120, 121, I50, 15I y I52 del volumen VI)

En el texto menciono como braquicéfalo el cráneo hallado en el río Arrecifes, paraje de Pontimelo (Fontezuelas), y como que probablemente debe referirse a la misma raza el esqueleto encontrado en el 
Samborombón, porque en ambos la mandibula inferior presenta una conformación parecida. Sólo conocía una fotografía de perfil del esqueleto de Pontimelo (Fontezuelas), de manera que no podía precisar con seguridad su conformación; pero Virchow había estudiado con el mismo objeto dos fotografías que se completaban entre sí, llegando a la conclusión de que era un cráneo braquicéfalo; y De Quatrefages, que también disponía de dos fotografias reproducidas por él en grabado, dice también que se trata de un cráneo braquicéfalo e hipsostenocéfalo.

Posteriormente, la colección que comprendía el mencionado cráneo, ha sido comprada por el doctor Laussen, de Buenos Aires, y regalada al Museo Zoológico de la Universidad de Copenhague.

El doctor Sören Hansen, en la notable Memoria ya mencionada, sobre la raza fósil de Lagôa Santa, ha examinado igualmente el mencionlado cráneo y ha encontrado con sorpresa que en vez de braquicéfalo era fuertemente dolicocéfalo, de manera que las fotografías habian inducido en error a los autores precedentes.

Este hecho es de notable importancia, pues por la forma de la mandíbula idéntica permite referir a la misma raza el esqueleto humano del Samborombón, al mismo tiempo que concuerda con la conformación del segundo cráneo fósil encontrado en el río Arrecifes, mencionado en el texto, del cual poseo igualmente dos fotografias, pero que habiendo podido examinar, aunque a la ligera, el original, pude inmediatamente determinar que se trataba de un cráneo dolicocéfalo.

Con éstos son cuatro los cráneos humanos fósiles, más o menos completos, que se han encontrado en la provincia Buenos Aires y en los mismos depósitos que contienen los huesos de Glyptodon y Megatherium $y$ demuestran una uniformidad de conformación verdaderamente notable.

Todos son dolicocéfalos e hipsostenocéfalos e indican una raza de talla muy pequeña, cuya única columna vertebral conocida hasta el día se distingue por estar constituída por 18 vértebras dorsolumbares. 



\section{Distribución de los mamíferos fósiles argentinos por horizontes y determinación de la época relativa de cada fauna}

\section{PISO PEHUENCHE}

La fauna mastológica del piso pehuenche permanece hasta ahora casi completamente desconocida, reduciéndose a un representante todavía no determinado de la sección de los Bruta, que parece tener alguna relación con los Gravigrada; un representante del orden de los Pantodonta llamado Pyrotherium Romeroi; un género de marsupiales aliado del Polymastodon, que ha recibido el de Macropristis Marshi; y un Toxodonte particular que he designado con el nombre de Trachytherus Spegazzinianus, acompañado de restos del género Astrapotherium y placas de un dasipódido aparentemente del género Dasypus.

Es indudable que esta es la fauna mastológica más antigua que hasta ahora sea conocida en la República, pues los terrenos que la contienen forman parte de la formación guaranítica de D'Orbigny, que descansa debajo de los estratos de las formaciones patagónica y santacruceña, sin que los pocos géneros que de ella se conocen presenten hasta ahora ninguna relación inmediata con los que le han sucedido posteriormente, excepción hecha del Astrapotherinm y del que parece ser un Dasypus.

\section{PISO SANTACRUCEÑO}

Los estratos del piso santacruceño son sumamente ricos en fósiles, habiendo proporcionado hasta ahora las especies siguientes:

\section{Unguiculata \\ TROGODONTA \\ RoDeNTrA \\ Cercolabiciae}

1. Acaremys murinus.

2. Acaremys messor.

3. Acaremy's minutus.

4. Acaremys minutissimus.

5. Sciamys principalis.

6. Sciamys varians. 
7. Steiromys detentus.

8. Steiromys duplicatus.

9. Neoreomy's australis.

!). Neoreomys indivisus.

11. Neoreomy's decisus.

12. Neoreomys insulatus.

13. Scleromys angustus.

14. Adelphomys candidus.

15. Stichomys regularis.

16. Spaniomys riparius.

17. Spaniomys modestus.

18. Olenopsis uncinus.

19. Sphoromys irruptus.

20. Sphodromys scalaris.

21. Sphiggomys zonatus.

22. Perimys onustus.

23. Perimys procerus.

24. Perimys erutus.

25. Pliolagostomus notatus.

26. Prolagostomus pusillus.

27. Prolagostomus divisus.

28. Prolagostomus profluens.

29. Prolagostomus imperialis.

30. Lagostomus lateralis.

31. Lagostomus primigenius.

32. Scotoumys imminutus.

33. Eocardia montana.

34. Eocardia divisa.

35. Eocardia perforata.

36. Schistomys erro.

37. Phanomys mixtus.

38. Hedimys integrus.

39. Callodontomys vastatus.

40. Microbiotherium patagonicum.

41. Microbiotherium tehuelchum.

42. Stilotherinm dissimile. 


\section{I'LAGIAUl,acoIdeA}

Abderitidac

43. Abderites meridionalis.

\section{Epanorttidae}

44. Acdestis Oweni.

45. Epanorthus Arato.

46. Epanorthus Lemoinei.

47. Epanorthus pachygnathus.

48. Eparnorthus intermedius.

49. Epanorthus minutus.

50. Epanorthus pressiforatus.

\section{SARCOBORA}

Cremodonta

51. Cladosictis patagonica.

52. Hathliacynus lustratus.

53. Agustylus cynoides.

54. Borhycena tuberata.

55. Anatherium defossus.

56. Acrocyon sectorius.

57. Acyon tricuspidatus.

58. Acyon? bardus.

59. Sipalocyon gracilis.

\section{Ungulata \\ AMPIIDACTYLA \\ ToxodontrA \\ Xotodortidae}

60. Stenotephanos speciosus.

61. Lithops pravius.

\section{Typotheridae}

62. Pachyrucos Moyanoi.

63. Pachyrucos teres.

64. Pachyrucos trivius.

65. Pachyrucos absis.

66. Pachyrucos novius.

67. Hegetotherium mirabile.

68. Hegetotherium strigatum.

Protoxodontidae

69. Protoxodon Sullivani.

70. Protoxodon conspurcatus.

71. Protoxodon marmoratus. 
72. Protoxodon obliteratus.

73. Adinotherium magister.

74. Adinotherium splendidum.

75. Adinotherium proximum.

76. Adinotherium ferum.

77. Adinotherium nitidum.

78. Acrotherium rusticum.

79. Phobereotherium sylvaticum.

80. Adelphotherium ligatum.

81. Gronotherium decrepitum.

82. Rhadinotherium limitatum.

Interatheridac

83. Interatherium rodens.

84. Interatherium supernum.

85. Icochilus excavatus.

86. Icochilus undulatus.

87. Icochilus rotundatus.

88. Icochilus extensus.

89. Protypotherium australe.

90. Protypotherium prorutilum.

91. Protypotherium attenuatum.

92. Protypotherium claudum.

93. Patriarchus palmidens.

Atrytheridac

94. Atryptherium bifurcatum.

95. Scopotherium cyclops.

96. Nesodon ovinus.

97. Nesodon imbricatus.

PERISSODACTYLA

LTTORTERNA

Macrauthenidae

98. Theosodon Lydekkeri.

Homalodonfotheridae

99. Homalodontotherium Cunninghami.

Proterctheridae

100. Proterotherium australe.

101. PProterotherium cavum.

102. Thoatherium minusculum.

103. Diadiaphorus velox.

104. Diadiaphorus majusculus.

105. Licaphrium Floweri.

106. Licaphritum parvulum. 
AMBLYPODA

TAzicRANA

Istrapotheridae

107. Astrapotherium magnum.

I'ANTODONTA

108. Planodus ursinus.

Coryphodontidae

109. Adelotherium scabrosum.

110. Adrastotherium dimotum.

111. Entelops dispar.

112. Dideilotherium venerandum.

Bruta

PIEIODDNTA

Entelcpsidae

ANICANODONTA

VerMitinguia

113. Scotcops simplex.

Orycteropidae

Phororhacidae

114. Phororhacus longissimus.

115. Zamicrus admirabilis.

Gravigrada

isegatheridae

116. Schismotherium fractum.

117. Hapalops rectangularis.

118. Hapalops ellipticus.

119. Hapalops indifferens.

120. Planops longirostratus.

121. Xyophorus rostratus.

122. Xyophorus simus.

123. Eucholœops ingens.

Orthotherivae

124. Eucholøops infernalis.

125. Eucholoops adteger.

126. Trematherium intermixtum.

Mylodontidae

127. Nematherium angulatum.

128. Nematherium sinuatum.

I1ICANODONTA

Glyptodontra

129. Cochlops muricatus.

Glyptodontidae 
Hoplophoridae

130. Propalohoplophorus australis.

131. Propalahoplophorus incisivus.

132. Asterostemma depressa.

133. Asterostemma granata.

134. Asterostemma lavata.

DASYPODA

Chlamydotheridae

135. Chlamydotherium? allstrale.

136. Peltephilus strepens.

137. Peltephilus pumilus.

Dasypodidoe

138. Dasypus patagonicus.

139. Zadyus proximus.

140. Zadyus exilis.

141. Eutatus œnophorus.

142. Eutatus lagena.

143. Entatus distans.

PELTA2TLOIDE.1

Stegotheridae

144. Stegotherium tesselatum.

Esas 144 especies de mamíferos están todas por completo extinguidas y se reparten en 85 géneros distintos.

Los grupos predominantes son los roedores y los Toxodontes, que constituyen por sí solos aproximadamente los tres quintos del número total de especies.

Todos los roedores son de pequeña talla, predominando entre ellos los equinómidos y los eriómidos; los cercolábidos o histricidios son también bastante numerosos, y los cávidos relativamente escasos, faltando completamente representantes del grupo de los octodóntidos así como también de los murinos.

Entre los Toxodontes no hay ningún representante de la familia de los toxodóntidos y está escasamente representada la de los xotodóntidos; la de los tipotéridos está mejor representada; pero el mayor núnero de los Toxodontes de esta época forman parte de la familia de los protoxodóntidos, que no tiene representantes en los terrenos más modernos. La familia de los interatéridos se presenta en el apogeo de su desarrollo; pero la de los atriptéridos, aunque parece característica de esta época, no es muy abundante. Todos los Toxodontes de estos terrenos son más bien de dimensiones pequeñas, encontrándose tan 
sólo algunos animales de talla algo notable entre los protoxodóntidos, pero sin que ninguno de ellos alcance ni de cerca las grandes proporciones de los Toxodontes de los últimos tiempos terciarios.

En estos terrenos es digna de mención la existencia de animales parecidos a los géneros Plagianlax, Neoplagianlax y Ptilodus del continente boreal, desaparecidos desde el principio de la época terciaria, y de toda una serie de géneros de carnivoros primitivos del grupo de los Creodontes, a los que tampoco se les encuentra representantes en los terrenos de épocas más recientes.

Entre los paquidermos es notable la existencia de animales de la tribu de los amblipodos, uno de cuyos géneros, el Astrapotherium, parece ser el mamífero terrestre más colosal de esa época. No hay vestigios de los perisodáctilos del grupo de los estereopternos, y todos los géneros conocidos de esa época entran en el de los litopternos, entre los cuales los proterotéridos parecen ser los más abundantes y en su completo desarrollo.

Los desdentados de la división de los gravígrados son relativamente abundantes, pero todos ellos de talla pequeña y caracteres mucho menos especializados que los que vivieron en épocas más recientes.

Entre los desdentados acorazados, los Gliptodontes son relativamente escasos, de dimensiones pequeñas y de caracteres que los aproximan más a los otros desdentados que sus descendientes de los últimos tiempos terciarios; los dasipódidos son, al contrario, excesivamente numerosos, de formas variadas y ya habian alcanzado un grado de especialización tan elevado como los actuales, puesto que ya se habían constituído los géneros existentes más característicos de este grupo.

Faltan en esta fauna representantes de los grupos de los carnivoros, de los primatos, de los proboscidios, de los perisodáctilos esteropternos y todos los artiodáctilos.

Que los mamíferos del piso santacruceño son más modernos que los del piso pehuenche, aparte las consideraciones estratigráficas, lo demuestra de una manera evidente el hecho de que en esa época habian desaparecido por completo los vestigios de los grandes dinosaurios que tanto abundan en los terrenos del piso pehuenche. Pero la gran variedad de formas de los mamíferos del piso santacruceño y la elevada especialización que presentan algunos de sus grupos, demuestran claramente que ellos fueron precedidos por un considerable número de formas agrupadas en varias faunas sucesivas, que aún permanecen por completo desconocidas para nosotros.

Resulta fácil establecer de una manera inequívoca la relación de antigüedad de la fauna del piso santacruceño con las otras conocidas de la República, examinando la distribución de los géneros de la fauna santacruceña en los distintos horizontes, sirviéndonos para ello de 
cuadros sinópticos, que hablan a la vista con mayor claridad que todas las explicaciones que pudiéramos dar y ofrecen la ventaja de que no pueden interpretarse de diferente manera que no sea la natural, puesto que los hechos se nos presentan en conjunto en un orden cronológico fácil de comprender.

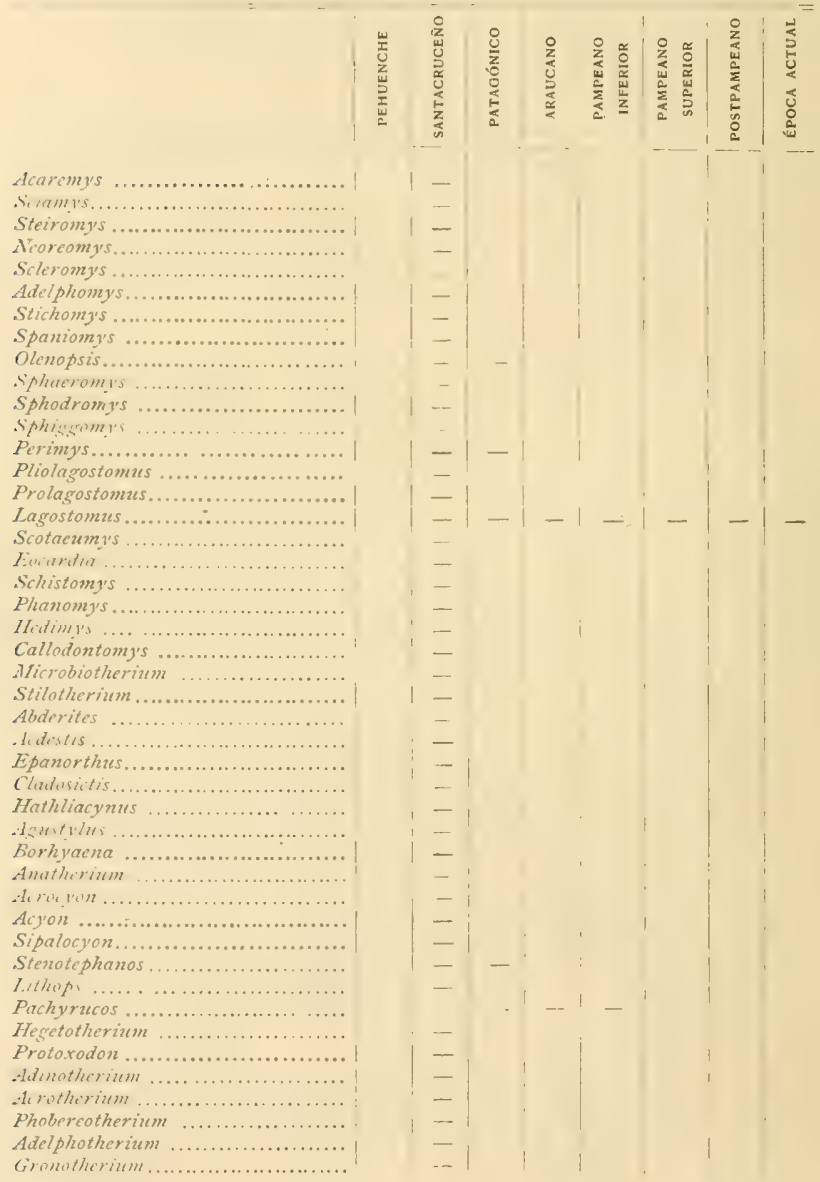


Rhudinotherium

Interathitizm.

forlitus

Frotypotherium

Patrintizus.

Atryptherium

Scopotherium

Nésodon.

Therasoden

Protevalherium

Hemalidontotheriam

Thoathiriant.

Diadiaphorus

Licuplerium

Planodus

Adelotherium

Adrastotherium

Astrapotherium

Entilops

Didcilotherium

Siotacops.

Phororhacos

Zamicnes

Sihismotherizm

Ilapalops

Planops.

Irophorus

Euiholocops.....

Trematheriam

Nematherium

Cirlitups

Propalaehoplophorus

Chlimidotherium

Pilteplititus

Dasypus

Zaridyus

Eutatus.

Stisotherim

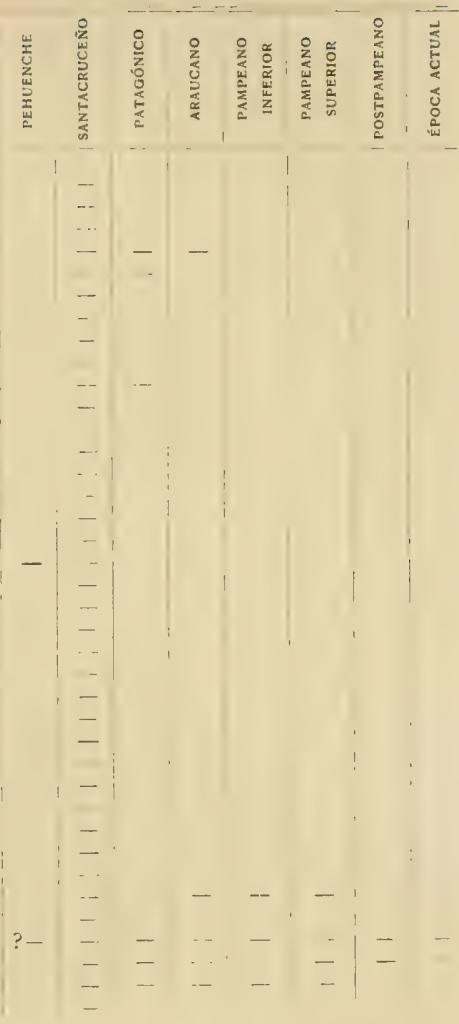

De estos 83 géneros, 80 son hoy completamente extinguidos, de manera que han prolongado su existencia hasta nuestra época sólo 3 , que son: el Lagostomus, el Dasypus y el Zaedyus. Hasta el pampeano superior llegaron 5 géneros y al pampeano inferior 6 , lo cual prueba que éste es más antiguo que el pampeano superior y más próximo del piso santacruceño. La formación araucana comprende 7 géneros de la fauna santacruceña, lo que demuestra que dicha formación es un poco más antigua que la pampeana. La formación patagónica tiene 12 géneros de la formación santacruceña, lo que demuestra que en orden 
ce antigüedad es la que más se acerca a esta última, pero quedan 71 géneros, que, cuando menos hasta ahora, parecen exclusivos de la formación santacruceña, lo que da a la fauna de esta época un carácter tan especial y tan diferente del que presenta la fauna que le sigue inmediatamente en orden de menor antigüedad, o sea la de la formación patagónica, que entre ambas es forzoso admitir la existencia de dos o tres faunas intermedias que hasta ahora permanecen desconocidas, si bien el espacio de tiempo que ha requerido su desarrollo está, por 10 menos en parte, representado por la vasta formación marina que constituye la base de la formación patagónica, conocida con el nombre de piso paranense.

Si en vez de los géneros se examina por el mismo sistema las familias que constituyen la fauna de mamíferos de la formación santacruceña, se llega al mismo resultado, pero de una manera más clara y evidente. Aun cuando los Creodontes forman sin duda varias familias son considerados aquí como un solo grupo.

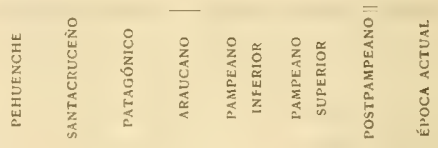

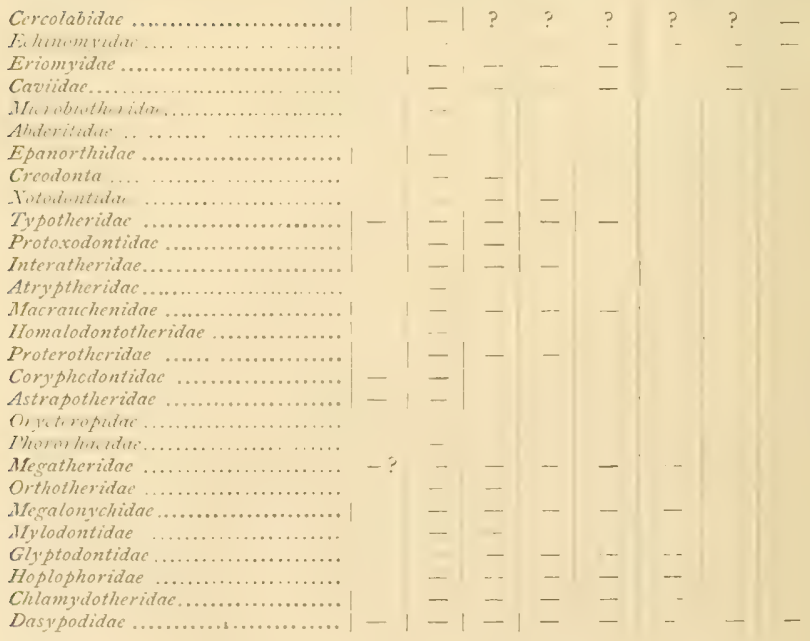


La fauna de mamíferos de la formación santacruceña se reparte en 28 grupos, de los cuales 23 son completamente extinguidos y sólo 5 todavía existentes. Cinco familias, y a buen seguro puede agregarse que seis, pues los cercolábidos, aun cuando sus restos no se hayan encontrado aún, no deben haber dejado de existir en el territorio de la República, han prolongado su existencia hasta los tiempos postpampeanos, once familias han llegado al pampeano superior, doce al pampeano inferior, quince a la formación araucana y diez y nueve a la formación patagónica, quedando seis familias que parecen exclusivas de la formación santacruceña. Estos datos demuestran de una manera evidente que después de la guaranítica (pehuenche), esa es la más antigua de todas, que le sigue en orden de menor antigüedad la formación patagónica y luego las demás en el mismo orden en que están colocadas en el cuadro que antecede.

\section{FORMACIÓN PATAGÓNICA}

Los estratos de la formación patagónica han dado hasta ahora las siguientes especies de mamíferos, casi todas procedentes de la parte intermedia de la formación conocida con el nombre de piso mesopotámico.

\section{Unguiculata \\ TROGODONTA \\ THILOUONTA \\ Anclippodontidac}

1. Phanotherus marginatus.

\section{Rontritis \\ Paradoromyidae}

2. Paradoxomys cancrivorus.

3. Paradoxomys patagonicus.

\section{Eclinomyidac}

4. Myopotamus paranensis.

5. Myopotamus obesus.

6. Morenia elephantina.

7. Morenia complacita.

8. Discolomys cuneus.

9. Olepnosis typicus.

10. Orthomys procedens.

11. Orthomys resecans.

12. Orthomys dentatus. 
13. Perimys Scalabrinianus,

14. Lagostomus antiquus.

15. Lagostomus pallidens.

16. Megamys patagoniensis.

17. Megamys Laurillardi.

18. Megamys depressidens.

19. Megamys Holmbergi.

20. Megamys Racedoi.

21. Megamys propendens.

22. Megamys Burmeisteri.

23. Neoepiblema horridula.

24. Neoepiblema contorta.

25. Euphilus Ambrossetianus.

26. Euphilus Kurtzi.

27. Tetrastylus lavigatus.

28. Tetrastylus diffisus.

29. Briaromys Troulessartianus.

30. Neoprocavia mesopotamica.

31. Neoprocavia egena.

32. Cardiomys cavinus.

33. Anchimys Leidyi.

34. Cardiodon Marshi.

35. Procardiotherium simplicidens.

36. Procardiotherium crassum.

37. Cardiotherium Doringi.

38. Cardiotherium petrosum.

39. Cardiotherium denticulatum.

40. Cardiotherinm minutum.

41. Plexochœrus paranensis.

42. Plexochœrus adluis.

43. Plexochœrus Lynchi.

44. Hydrochœrus irroratus.

45. Caviodon multiplicatus.

46. Strata elevata.

47. Apera sanguinaria.

48. Notictis Ortizi.

49. Canis paranensis. 
50. Cyonasua argentina.

U'rsidac'

51. Arctotherium vetustum.

Ungulata

AMPIIDACTYLA

TOXODONTIA

Torodontidae

52. Toxodon paranensis.

53. Toxodon proto-Burmeisteri.

54. Toxodon virgatus.

55. Toxodontherium compressum.

56. Haplodontherium Wildei.

57. Haplodontherium limum.

58. Dilobodon lutarius.

59. Eutomodus elautus.

60. Xotodon foricurvatus.

61. Stenotephanos plicidens.

Typotherilae

62. Pachyrucos $s p$ ?

Protorodontidac

63. Colpodon propinquus.

Interatheridac

64. Protypotherium antiquum.

PERISSODACTYLA

STEREOPTERNA

Tapiridae

65. Ribodon limbatus.

\section{Ẽquidae}

66. Hipphaplus entrerianus.

\section{IITOPTERNA}

Macranclienidae

67. Macrauchenia antiqua.

68. Scalabrinitherium Bravardi.

69. Scalabrinitherium Rothi.

70. Oxyodontherium Zeballosi.

71. Mesorhinus pyramidatus. 
72. Proterotherium cervioides.

73. Proterotherium americanum.

74. Brachytherium cuspidatum.

75. Megatherium antiquum.

Bruta
ANICANODONTA
Gravigrana
Megatheridae

76. Promegatherium smaltatum.

77. Promegatherium remulsum.

78. Interodon crassidens.

Orthotheridac

79. Orthotherium laticurvatum.

80. Pliomorphus mutilatus.

.Megalonyclidae

81. Pliomorphus robustus.

82. Diodomus Copei.

83. Diodomus Annaratonei.

84. Lestodon antiquus.

Lestoduntidae

85. Lestodon paranensis.

86. Scelidotherium? bellulum.

87. Stenodontherium modicum.

88. Nephotherium ambiguum.

89. Pseudolestodon aqualis.

Mylotontidae

90. Pseudolestodon injunctus.

91. Promylodon paranensis.

IIICANODONTA

GLYPTODONTIA

Hoplophoridae

92. Palchoplophorus pressulus.

93. Palahoplophorus Scalabrinii.

94. Protoglyptodon primiformis.

95. Hoplophorus paranensis.

96. Hoplophorus verus.

97. Lomaphorus cingulatus.

98. Neuryurus interundatus.

99. Psêudoeuryurus Lelongianus.

100. Comaphorus concisus. 
DAsyroni

Chlamydotheridae

101. Chlamydotherium paranense.

102. Chlamydotherium extremum.

Dasypodidae

103. Dasypus sp?

104. Zaëdyus sp?

105. Prauphractus limpidus.

106. Eutatus sp?

Estas 106 especies de mamíferos se reparten en 71 géneros, casi todos extinguidos.

Los mamíferos predominantes por el número son todavía los roedores, pero relativamente son menos abundantes que en la época precedente. Los representantes de las familias de los equinómidos se reducen a unos pocos géneros y otro tanto sucede con la de los eriómidos, pero éstos estaban representados por numerosas especies, muchas de un tamaño en verdad considerable, y de un modo especial los Megamys, que pueden contarse entre el número de los mamiferos más corpulentos que hayan existido en la superficie de la tierra. La familia de los cávidos, en la época precedente escasamente representada y por especies de pequeña talla, adquiere ahora un desarrollo notable, siendo los roedores entonces más numerosos y muchos de talla considerable, aunque no comparable a la de los gigantescos representantes del grupo de los eriómidos.

Los marsupiales del grupo de los plagiaulacoideos han desaparecido por completo, 10 mismo que la mayor parte de los carnívoros del grupo de los Creodontes, que en parte son substituídos por verdaderos carnívoros de las familias de los perros y de los osos, aunque muy escasos.

Los Toxodontes han disminuido de una manera considerable, particularmente los del grupo de los protoxodóntidos, que parece han desaparecido casi por completo. De los atriptéridos no se encuentran vestigios. Los interatéridos tienen un escaso número de representantes. Los xotodóntidos y los tipotéridos parecen adquirir un mayor desarrolla que en el periodo anterior y aparecen los primeros representantes de los verdaderos toxodóntidos, de tamaño mucho más considerable que los más grandes individuos del grupo anterior de los protoxodóntidos.

Entre los paquidermos perisodáctilos aparecen los primeros indivicuos del grupo de los estereopternos, pertenecientes a la familia de los tapires y de los caballos, pero en escasísimo número; en cambio continúa en completo desarrollo el grupo de los litopternos, entre los cuales los macroquénidos parecen alcanzar el apogeo de su evolución, pero los proterotéridos aparecen en decadencia. 
Los desđentados son más numerosos, de formas más variadas y en general de tamaño mucho mayor que los de la formación santacruceña. Los megatéridos adquieren un tamaño gigantesco. Los ortotéridos, en cambio, permanecen pequeños y su número disminuye extinguiéndose en esta formación. Los megalonicidios se conservan más o menos en el mismo estado, pero los milodóntidos aumentan considerablemente en número y tamaño; aparecen en esta época los primeros representantes conocidos del grupo de los Lestodontes, algunas de cuyas especies tienen un tamaño gigantesco, así como también las primeras especies del grupo de ios Escelidoterios.

Entre los desdentados acorazados, los Gliptodontes aumentan en número y en tamaño, evolucionando rápidamente hacia la especialización que adquieren en tiempos posteriores, apareciendo los primeros representantes del grupo de los døedicúridos, pero en cambio los dasipódidos permanecen más o menos en el mismo estado de desarrollo que en la época precedente, disminuyendo más bien el número de sus formas.

Hasta esta época no se conoce en este continente ni un solo representante del grupo de los artiodáctilos.

Los géneros de mamíferos de la formación patagónica se distribuyen en los demás horizontes de la manera siguiente:

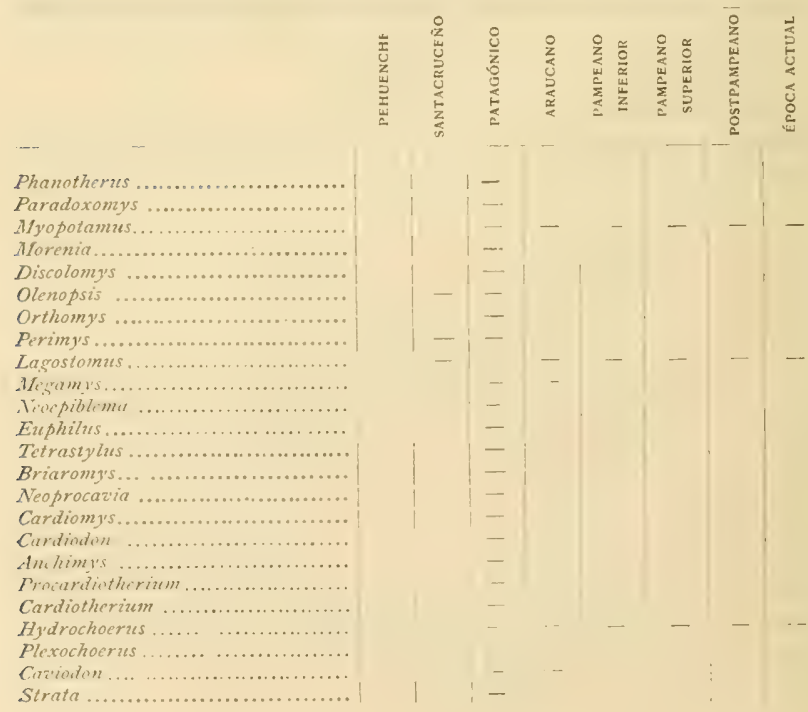




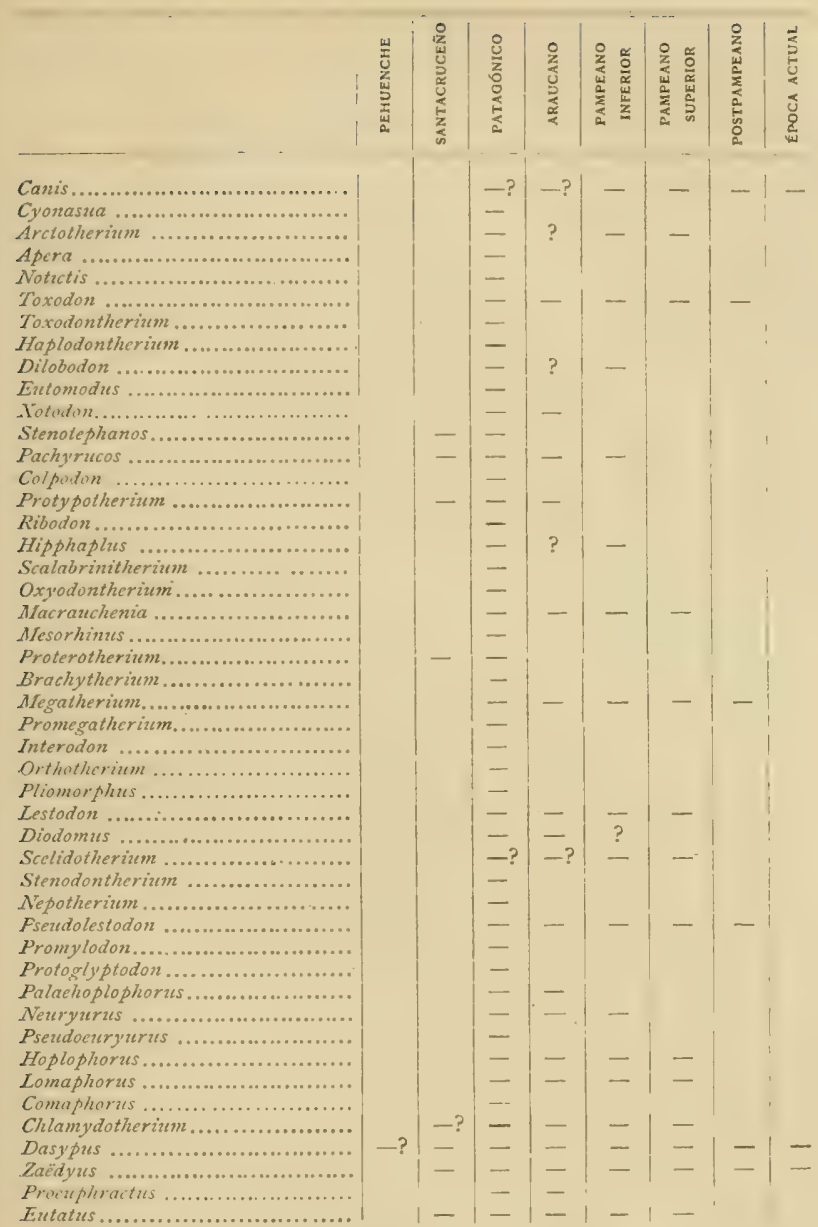

De estos 71 géneros sólo existen en la actualidad 6; 9 géneros llegaron hasta el postpampeano; 17 hasta el pampeano superior; 21 hasta e! pampeano inferior y 28 hasta el terreno araucano, lo cual demuestra 
que éste es el más próximo al patagónico. Once géneros de los patagónicos ya existieron en la formación santacruceña; y 39 géneros, esto es, más de la mitad, son, o parecen ser, hasta ahora, especiales de la formación patagónica, lo que demuestra bien a las claras que ésta se coloca entre la formación santacruceña (que es bastante más antigua) y la formación araucana, que es de época algo más reciente.

La circunstancia de que sólo una séptima parte de los géneros del fiso mesopotámico de la formación patagónica se encuentra entre la fauna del piso santacruceño, demuestra que ambas faunas están separadas por un espacio de tiempo considerable y que se interponen entre ambas dos o tres faunas mixtas que aún son desconocidas.

La fauna de la formación araucana es, al contrario, mucho más próxima de la patagónica, pues más de un tercio de los géneros de esta formación sc encucntran asimismo en la más reciente, demostrando yue ambas faunas estín separadas por un espacio de tiempo notablemente menor que el que debió transcurrir entre la patagónica y la santacruceña, si bien también resulta evidente que entre la fauna del riso mesopotímico de la formación patagónica y la del piso hermósico Le la formación araucana, debe intercalarse por lo menos una fauna mixta, desconocida hasta el día.

El examen de las familias en que se agrupan los mencionados géneros de la fauna patagónica conduce absolutamente a las mismas conclusiones.

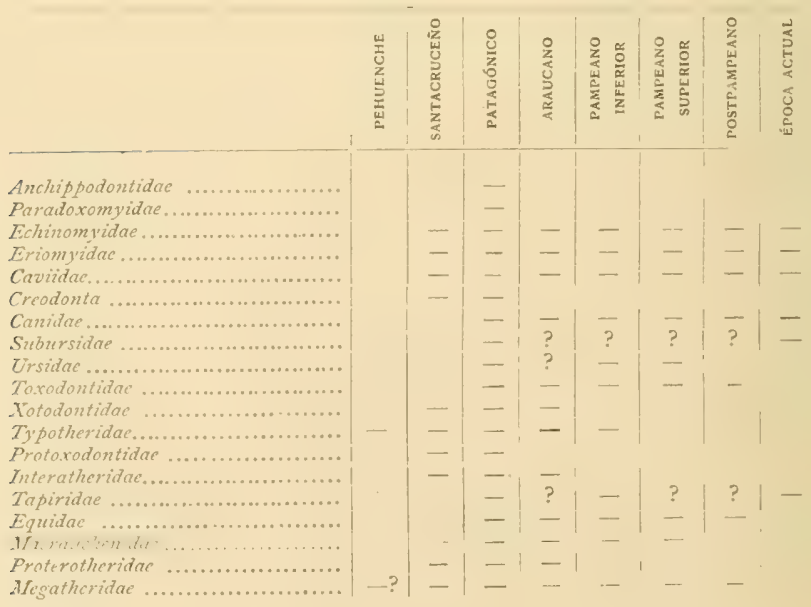


()) Hhethiritere

Metralonyclidae

Lestodontidae

Mrlodontida

Glyptodontidae.

Hoplophoridae

Doedicuridae

Chlamydotheridae..................

Dasypoditae

Los mamíferos de la formación patagónica se reparten en 29 familias, de las cuales sólo hay siete existentes; 9 familias han conservado representantes hasta el postpampeano, 18 hasta el pampeano superior y 20 hasta el pampeano inferior. La formación araucana ticne igualmente 21 familias del piso mesopotámico, pero con todo se acerca más a éste que al pampeano, pues hay 3 familias que tienen representantes en la fauna patagónica y que han sido halladas también en los terrenos pampcanos o existen en la actualidad y todavia no han sido descubiertos en la formación araucana, donde forzosamente tienen que existir, lo que elevaría a 24 el número de familias de esta formación, todas iguales a las de la formación patagónica. Diez y ocho familias de la fauna patagónica son igualmente comunes a la fauna santacruceña, lo que demuestra que se coloca inevitablemente entre ésta y la de la formación araucana.

De las 28 familias de la fauna patagónica, no hay más que dos que hasta ahora parecen especiales de esta formación: la de los paradoxómidos y la de los anquipódidos. Dos familias: la de los protoxodóntidos y la de los ortotéridos se extinguen en esta época y aparecen en ella diez nuevas que pasan a las otras formaciones: las de los cánidos, los subúrsidos, los úrsidos, los felinos, los toxodóntidos, los tapíridos, los équidos, los lestodóntidos, los escelidotéridos, los milodóntidos y los dœedicúridos.

\section{FORMACIÓN ARAUCANA}

Aun cuando la fauna mastológica de la formación araucana es numerosa y sus restos son abundantes, no es tan bien conocida como la de las dos formaciones precedentes, de donde resulta que aparentemente es más pobre. Las especies de esta época que hasta ahora me son conocidas, son las siguientes: 


\section{Planungulata}

ANTHROPOIDEA

Hominidae

1. Anthropopithecus?

\section{Unguiculata \\ TROGODONTA \\ RODENTIA \\ Echinomyidae}

2. Myopotamus diligens.

3. Tribodon clemens.

4. Eumysops plicatus.

5. Eumysops loviplicatus.

6. Eumysops robustus.

Octoiontidae

7. Dicœlophorus latidens.

8. Dicolophorus simplex.

9. Dicolophorus celsus.

10. Dicolophorus priscus.

11. Phtoramys homogenidens.

12. Platonomys scindens.

13. Pithanotomys columnaris.

14. Pithanotomys similis.

15. Pithanotomys intermedius.

16. Pithanotomys macer.

Eriomsidae

17. Lagostomus incisus.

18. Lagostomus spicatus.

19. Megamys formosus.

20. Orthomyctera rigens.

21. Orthomyctera vaga.

22. Orthomyctera lacunosa.

23. Microcavia prona.

24. Palcocavia impar.

25. Palcocavia avita.

26. Diocartherium australe.

27. Phugatherium cataclisticum.

28. Hydrochœrus perturbidus.

29. Caviodon obtritus. 
SARCOBORA

PEDIMANA

Didelphyidac

30. Didelphys inexpectata.

31. Didelphys triforata.

$$
\begin{aligned}
& \text { Carvivors } \\
& \text { Camidae }
\end{aligned}
$$

32. Canis acutus.

$$
\begin{gathered}
\text { Ungulata } \\
\text { AMPHIDACTILA } \\
\text { Toxonosis } \\
\text { Torodontidac }
\end{gathered}
$$

33. Toxodon ensenadensis.

34. Trigodon Gaudryi.

\section{Yolodontidae}

35. Xotodon prominens.

\section{Typotheridae}

36. Typotherium insigne.

37. Typotherium pachygnathum.

38. Typotherium mondrum.

39. Typotherium exiguum.

40. Pachyrucos typicus.

41. Pachyrucos ictus.

42. Pachyrucos impressus.

43. Pachyrucos diminutus.

Interatheridae

44. Protypotherium obstructum.

PETISISODACTYLA

STEREOPTERNA

Fquidae

45. Hippidion sp.?

$$
\begin{gathered}
\text { L,ITOPTERNA } \\
\text { Macranchenidae }
\end{gathered}
$$

46. Macrauchenia antiqua.

$$
\text { Proteroticridae }
$$

47. Epitherium laternarium.

$$
\begin{gathered}
\text { ARTIODACTYIA } \\
\text { Ruminan'ra } \\
\text { Camelidac }
\end{gathered}
$$

48. Auchenia Weddelli. 
Tragnlidae

49. Eoauchenia primitiva.

Coruidae

50. Paraceros avius.

PACIIYTIILRIA

Pronoscidea

Elephantidae

51. Mastodon rectus.

52. Mastodon argentinus.

Bruta

ANICANODONTA

Gravigrada

Iegatheridec

53. Megatherium antiquum.

Lestodontidae

54. Lestodon antiquus.

55. Diodomus Copei.

Scelidotheridae

56. Scelidodon patrius.

57. Scelidotherium $s p$.?

Mylotontidae

58. Pseudolestodon sp. ?

IIICANODONTA

Girptodontia

Glyptodontidae

59. Glyptodon lavis.

Hoplophoridae

60. Palahoplophorus disjunctus.

61. Hoplophorus lineatus.

62. Hoplophorus cordubensis.

63. Plohophorus figuratus.

64. Plohophorus Ameghinoi.

65. Panochtus bullifer.

66. Nopachtus coagmentatus.

Doodicuridae

67. Neuryurus antiquus.

68. Plaxhaplus antiquus. 
DASYPODA

Chlamydotheridae

69. Chlamydotherium intermedium.

Dasypodidac

70. Dasypus sp.?

71. Zaëdyus sp.?

72. Prophractus recens.

73. Macrouphractus retusus.

74. Eutatus sp.?

Esta fauna presenta en su conjunto general un aspecto notablemente más moderno que la del periodo precedente.

Los roedores han continuado disminuyendo en número y en formas, particularmente los de las familias de los equinómidos y de los eriómidos, habiendo desaparecido casi por completo los gigantescos representantes de este grupo de la formación patagónica. Los cávidos, si bien no presentan una variedad tan grande, continúan bien representados, con algunas especies de gran tamaño. Pero el cambio más notable que se efectúa en el orden de los roedores es la aparición casi puede decirse súbita y el gran desarrollo que adquiere el grupo de los octodóntidos, de los cuales no se han encontrado hasta el día vestigios en los terrenos de las épocas precedentes.

Los Toxodontes tienen algunos representanies gigantescos de la familia de los toxodóntidos; y los tipotéridos alcanzan ahora el máximum cie su desarrollo. En los terrenos de esta época desaparecen los últimos representantes de las familias de los xotodóntidos y de los interatéridos.

Entre los perisodáctilos, los estereopternos son escasísimos y los litopternos están en completa decadencia; el grupo de los macroquénidos ya no está representado más que por una sola especie; y el de los proterotéridos por otra, que sin duda representa el último vástago de esta familia, que fué tan numerosa en las épocas precedentes.

Un carácter particular de la fauna de esta época, consiste en la primera aparición de los artiodáctilos, sin duda por vía de inmigración, representados por algunas escasas formas del orden de los rumiantes; y en la primera aparición del Mastodonte.

Entre los desdentados adquieren un considerable desarrollo los escelidotéridos, y los Gliptodontes del grupo de los dœdicúridos.

Las 74 especies de mamíferos de esta época que hasta ahora me son conocidas, entran en 50 géneros, cuya distribución en los distintos horizontes es la siguiente: 
Antrhopopitecus?

Myopotamus .......................

Tribodon

Diveleflumes.

Fhtoramys

Plataeomys

Pithanotomys ....................

filigestemus.

Megamys

ifivionititir

Palacocavia.

Plusatherium.

Diviarthersum

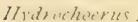

Cariodert

Dielilphys .......................

Canis

Toxodon

Tizisoden

Antedina.

Typotherium

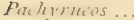

Drots putherim

Iippidizm.

Macranchenia.

Efithrium

Alithiniar.

Fontulemet

Pircations.

. Wetstedon....

If sitheritm

Lestiding

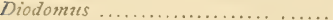

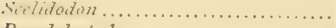

Pserdolestodon

Glyptodor .

Uloplizhlarits

Palachoplophorus .

Meihophorus

- Vipaititus

Pantelitus

Nézryurus

Plathouplus

Cïlemsidutherume.

Dasypus

Preithluatus.

Macroeuphractus.

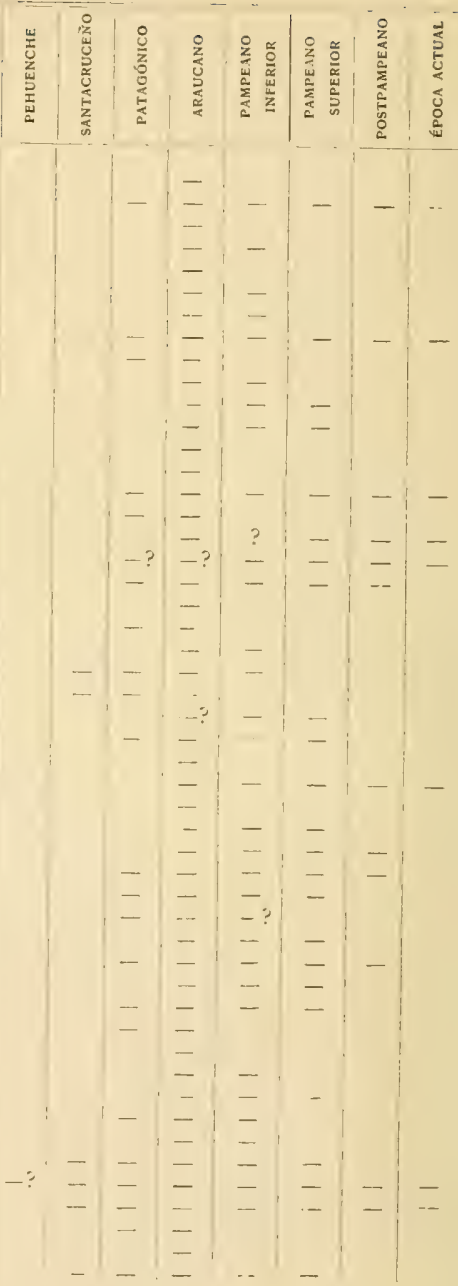

Futertu. 
De estos 50 géneros, sólo 8 existen todavía; 12 de ellos alcanzaron hasta los terrenos postpampeanos; 24 hasta el pampeano superior y 33 pasaron al pampeano inferior. Veintitrés géneros ya existian en la formación patagónica y 7 datan desde la formación santacruceña. Una simple ojeada al cuadro precedente demuestra que la fauna de la formación araucana se intercala entre la de la formación pampeana y la de la formación patagónica, pero que encuentra su colocación más cerca de aquélla que de ésta, representando una época particular con una fauna característica, que se distingue fácilmente por la presencia de 10 géneros que hasta ahora parecen exclusivos de esta formación.

Esos 50 géneros se agrupan en 28 familias, cuya distribución por horizontes está indicada en el cuadro siguiente:

\begin{tabular}{|c|c|c|c|c|c|c|c|c|}
\hline & 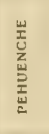 & 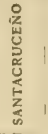 & 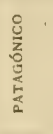 & 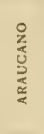 & 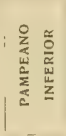 & 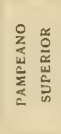 & 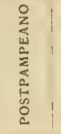 & 党 \\
\hline Hominidas & & & & - & - & - & - & \\
\hline$\ldots \ldots \ldots \ldots$ & & - & - & - & - & - & - . & \\
\hline . & & & & & - & - & & \\
\hline ae ....... & & - & - & - & - & $1-$ & - & \\
\hline ............ & & -. & - & -. & - & - & & \\
\hline Dit & & & & - & ? & - & -- & \\
\hline 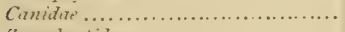 & & & - & - & 一 & - & - & \\
\hline$P t$ & & & $-\cdot$ & - & - & 一 & & \\
\hline ….................. & & & - & - & & & & \\
\hline$T_{1}$ & - & - & - & - & - & & & \\
\hline Int & & - & 一 & - & & & & \\
\hline & & & $\cdots$ & - & - & - & - & \\
\hline e ........................ & & - & - & - & - & - & & \\
\hline ridae $\ldots \ldots \ldots \ldots \ldots \ldots$ & & - & - & - & & & & \\
\hline , n & & & & - & & - & - & \\
\hline … & & & & - & - & - & - & \\
\hline ….................. & & & & & & - & 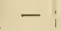 & \\
\hline & ...? & - & - & - & - & - & - & \\
\hline & & & - & -- & - & - & & \\
\hline$\varepsilon^{2}, \ldots \ldots \ldots \ldots \ldots \ldots \ldots$ & & - & - & - & & - & & \\
\hline & & & - & - & - & - & & \\
\hline 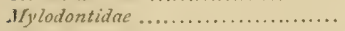 & & - & - & - & & - & - & \\
\hline Glyptodontidae... & & -. & - & - & & & & \\
\hline Hopl & & - & - & 一 & - & & & \\
\hline . & & & - & 然 & & - & & \\
\hline$C h t$ & & - & - & 一 & - & 一 & & \\
\hline Dasypodidae. & - & - & - & - & $\cdots$ & - & - & \\
\hline
\end{tabular}

De esas 28 familias, 10 aún existen en la actualidad, 15 llegaron hasta los tiempos postpampeanos, 23 hasta el pampeano superior, e igualmente 23 hasta el pampeano inferior; 21 familias ya tenían repre- 
sentantes desde la formación patagónica y 15 desde la formación santacruceña.

Sólo una familia aparece hasta ahora como exclusiva de esta época: la de los tragulidios. Durante la formación araucana viven los últimos representantes de dos familias que antes fueron numerosas y se extinguen por completo: la de los xotodóntidos y la de los interatéridos: en cambio aparecen cinco familias nuevas que no tenían representantes en las épocas anteriores: los octodóntidos, los didélfidos, los camélidos, los cérvidos y los elefántidos.

\section{FORMACIÓN PAMPEANA}

La fauna mastológica de la formación pampeana es la que ha sido objeto de estudios más completos; $y$, por consiguiente, la mejor conocida y la que está representada por mayor número de especies. De éstas, las que me son conocidas hasta ahora, son las siguientes:

\section{Planungulata}

\section{ANTIIROPOIDEA}

IIominidac

1. Homo sapiens (?)

2. Reithrodon typicus.

\section{Unguiculata \\ TROGODONTA \\ RODFNTIA \\ Hesperonyidae}

3. Ptissophorus elegans.

4. Oxymycterus rufus.

5. Oxymycterus impexus.

6. Calomys Bravardi.

7. Calomys longicaudatus.

8. Holochilus vulpinus:

9. Bothriomys catenatus.

10. Hesperomys molitor.

11. Tretomys atavus.

12. Necromys conifer.

13. Myopotamus priscus.

14: Ctenomys bonariensis.

15. Ctenomys magellanicus. 
16. Ctenomys lujanensis.

17. Dicolophorus latidens.

18. Plataomys scindens.

19. Pithanotomys cordubensis.

Eriomyidae

20. Lagostomus angustidens.

21. Lagostomus debilis.

22. Lagostomus minimus.

23. Lagostomus cavifrons.

24. Lagostomus heterogenidens.

Caziidae

25. Orthomyctera lata.

26. Dolichotis minor.

27. Dolichotis major.

28. Dolichotis intermedia.

29. Dolichotis platycephala.

30. Cerodon turgeo.

31. Cerodon antiquus.

32. Cerodon priscus.

33. Cerodon pygmaeus.

34. Microcavia typica.

35. Microcavia robusta.

36. Microcavia dubia.

37. Microcavia uncinata.

38. Microcavia intermedia.

39. Palaocavia pampara.

40. Palceocavia minuta.

41. Hydrochorus giganteus.

42. Hydrochorus capybara.

43. Hydrochorus magnus.

SARCOBORA

Pedimana

Didelphyidae

44. Didelphys incerta.

45. Didelphys juga.

46. Didelphys grandava.

47. Dimerodon mutilatus.

Carnivora

Canidac

48. Canis ensenadensis.

49. Canis Azarce.

50. Canis bonariensis. 
51. Canis cultridens.

52. Canis protojubatus.

53. Canis avus.

54. Macrocyon robustus.

Ursidae

55. Arctotherium bonariense.

56. Arctotherium angustidens.

57. Lutra paranensis.

Mustelidne

58. Mephitis primava.

59. Mephitis mercedensis.

60. Mephitis cordubensis.

61. Lyncodon lujanensis.

Felidae

62. Felis longifrons.

63. Felis platensis.

64. Felis palustris.

65. Macharodus ensenadensis.

66. Smilodon populator.

\section{Ungulata \\ AMPHIDACTYLA \\ TOXODONTA \\ Torodontidoe}

67. Toxodon platensis.

68. Toxodon ensenadensis.

69. Toxodon bilobidens.

70. Toxodon Burmeisteri.

71. Toxodon Darwini.

72. Toxodon paradoxus.

73. Toxodon gracilis.

74. Dilobodon lujanensis.

75. Typotherium cristatum.

Typotheridae

76. Typotherium pachygnathum.

77. Typotherium mandrum.

78. Typotherium exiguum.

79. Entelomorphus rotundatus.

80. Pachyrucos bonariensis.

PERISSODACTYLA

STEREOPTERNA

Tupirilas

81. Antaodon cinctus. 
82. Plicatodon perrarus.

83. Equus curvidens.

84. Equus argentinus.

85. Equus rectidens.

86. Hippidium neogaeum.

87. Hippidium principale.

88. Hippidium compressidens.

89. Hippidium nanum.

90. Hippidium angulatum.

91. Hipphaplus Bravardi.

92. Hipphaplus antiquus.

93. Macrauchenia patachonica.

94. Macrauchenia boliviensis.

95. Macrauchenia ensenadensis.

96. Diastomicodon lujanensis.

ARTIODACTYLA

SuINA

Suidae

97. Dicotyles tajacu.

98. Dicotyles stenocephalus.

Proruminantia

Oreodontidae

99. Diplotremus agrestis.

Ruarinantia

Camelidae

100. Auchenia intermedia.

101. Auchenia gracilis.

102. Auchenia frontosa.

103. Auchenia Castelnaudi.

104. Auchenia ensenadensis.

105. Auchenia lujanensis.

106. Auchenia Weddelli.

107. Mesolama angustimaxilla.

108. Palceolama leptognatha.

109. Palceolama major.

110. Palcolama promesolithica.

111. Stilauchenia Oweni.

112. Hemiauchenia paradoxa. 
113. Eulamaops parallelus.

114. Protauchenia Reissi.

115. Cervus brachyceros.

Cerridae

116. Cervus lujanensis.

117. Cervus palaoplatensis.

118. Cervus latus.

119. Cervus tuberculatus.

120. Paraceros ensenadensis.

121. Paraceros fragilis.

i22. Paraceros vilneratus.

123. Blastoceros campestris.

124. Blastoceros paludosus.

125. Blastoceros azpeitianus.

126. Antifer ultra.

127. Furcifer sulcatus.

128. Furcifer seleniticus.

129. Epicuryceros truncus.

PACHYTIIERIA

PromoscideA

Elephantidae

130. Mastodon andinm.

131. Mastodon platensis.

132. Mastodon argentinus.

133. Mastodon Humboldti.

134. Mastodon superbus.

135. Mastodon rectus.

Bruta

$\triangle$ NICANODON'A

Gravigrada

Megatheridae

136. Megatherium americanum.

137. Megatherium tarijense.

138. Megatherium Lundi.

139. Essonodontherium Gervaisi.

140. Neoracanthus Burmeisteri.

141. Neoracanthus Brackebuschianus.

142. ?Gnathopsis Oweni.

143. Nothropus priscus.

144. Coelodon tarijensis.

145. Valgipes deformis. 
146. Lestodon armatus.

147. Lestodon trigonidens.

148. Lestodon Bocagei.

149. Lestodon Gaudryi.

150. Lestodon Blainvillei.

151. Lestodon Bravardi.

152. Laniodon robustus.

153. PPlatyodon Annaratonei.

Scelidotheridae

154. Scelidotherium leptocephalum.

155. Scelidotherium Bravardi.

156. Scelidotherium Floweri.

157. Scelidodon patrius.

158. Scelidodon tarijensis.

159. Scelidodon Capellinii.

160. Scelidodon Copei.

161. Platyonyx Oliverae.

162. Glossotherium Darwini.

163. Glossotherium Zeballosi.

164. Glossotherium bonariense.

165. Mylodon robustus.

Mylodontidas

166. Mylodon Sauvagei.

167. Mylodon Wieneri.

168. Mylodon intermedius.

169. Pseudolestodon myloides.

170. Pseudolestodon Reinhardti.

171. Pseudolestodon Morenoi.

172. Pseudolestodon debilis.

173. Pseudolestodon bisulcatus.

174. Pseudolestodon trisulcatus.

175. Pseudolestodon Lettsomi.

176. Glyptodon clavipes.

IIICANODONTA

Givprodonisis

Glyptodontidae

177. Glyptodon Oweni.

178. Glyptodon reticulatus.

179. Glyptodon euphractus.

180. Glyptodon subelevatus.

181. Gliptodon principalis.

182. Glyptodon Muñizi. 
183. Glyptodon minor.

184. Glyptodon elongatus.

185. Glyptodon lavis.

186. Glyptodon Fiorinii.

187. Glyptodon perforatus.

188. Glyptodon rudimentarius.

189. Glyptodon Falkneri.

190. Glyptodon gemmatum.

191. Neothoracophorus elevatus.

192. Neothoracophorus depressus.

193. Neothoracophorus minutus.

Hoplophoridae

194. Hoplophorus Meyeri.

195. Hoplophorus ornatus.

196. Hoplophorus pseudornatus.

197. Hoplophorus perfectus.

198. Hoplophorus Migoyanus.

199. Hoplophorus scrobiculatus.

200. Hoplophorus evidens.

201. Hoplophorus Heusseri.

202. Hoplophorus Lydekkeri.

203. Hoplophorus Bergi.

204. Hoplophorus Clarazianus.

205. Lomaphorus imperfectus.

206. Lomaphorus compressus.

207. Lomaphorus elevatus.

208. Lomaphorus elegans.

209. Lomaphorus gracilis.

210. Nopachtus coagmentatus.

211. Panochtus tuberculatus.

212. Panochtus Morenoi.

213. Panochtus Frenzelianus.

214. Panochtus Vogthi.

215. Panochtus Nodotianus.

216. Neuryurus rudis.

Doedicuridae

217. Plaxhaplus canaliculatus.

218. Dxdicurus clavicaudatus.

219. Dodicurus Poucheti.

220. Dœdicurus Kokenianus.

DASYPODA

Chlanydotheridae

221. Chlamydotherium typum. 
222. Tatusia hybrida.

Praopidae

223. Tatusia novemcincta.

224. Propraopus grandis.

Dasypodidae

225. Dasypus sexcintus.

226. Dasypus villosus.

227. Dasypus major.

228. Zaëdyus minutus.

229. Zaëdyus minutissimus.

230. Eutatus Seguini.

231. Eutatus brevis.

232. Eutatus punctatus.

233. Eutatus minutus.

234. Tolypeutes conurus.

235. Chlamydophorus truncatus.

La fauna pampeana se diferencia de las precedentes por una mayor abundancia de representantes de órdenes comunes a ambos continentes, que en las épocas precedentes eran mucho menos numerosos.

Los roedores continuaron disminuyendo; y las familias de los equirómidos y de los eriómidos casi desaparecieron, quedando cada una de ellas representada por un solo género. La de los octodóntidos también presenta una menor variedad de formas que en el período precedente. En cambio la de los cávidos presenta un considerable número de formas de pequeña talla $\mathrm{y}$ aparece $\mathrm{y}$ se desarrolla en esta época la gran familia de los hesperómidos.

Los carnivoros, que hasta ahora eran escasos, se hacen numerosos.

Los Toxodontes sólo están representados por dos familias, alcanzando su máximo desarrollo la de los toxodóntidos.

Los paquidermos perisodáctilos del grupo de los estereopternos presentan una mayor variedad de formas, siendo sobre todo notable la abundancia de especies de la familia de los caballos. Los litopternos continúan, al contrario, disminuyendo de número.

El carácter más sobresaliente de la fauna de esta época es la grandísima abundancia de artiodáctilos, casi todos del orden de los rumiantes; los suideos son, al contrario, raros.

Los proboscidios, representados por el Mastodonte, adquieren un gran desarrollo, y el número de sus especies aumenta notablemente.

Entre los desdentados sin coraza, adquieren su máximo desarrollo los grupos de los megatéridos, escelidotéridos, milodóntidos y lestodóntidos. Entre los acorazados, los verdaderos Gliptodontes aumentan extraordinariamente en número y tamaño, apareciendo en los doedicúridos los 
representantes del género Dodicurus, que son los más gigantescos mamíferos acorazados que hayan hollado la superficie de la tierra. Los dasipódidos aumentan en la variedad de sus formas, pero no en tamaño.

En esta época aparecen por primera vez unas cuantas especies de mamíferos que parecen idénticas a algunas de las existentes, pero generalmente en los estratos superiores, pues hay que tener presente que, la fauna pampeana, tan notable por el considerable número de sus especies, no es una fauna única, sino una sucesión de tres o cuatro faunas distintas, que se ligan y pasan sin discontinuidad de unas a otras y de las cuales, la más antigua presenta un carácter arcaico particular, que la liga en parte a la de la formación araucana, mientras que la más reciente presenta, al contrario, un notable parecido con la de la época actual, de la cual se distingue principalmente por la presencia de un cierto número de desdentados gigantescos hoy desaparecidos.

La época de la formación pampeana representa un espacio de tiempo considerable, durante el cual la fauna se ha modificado casi por completo, pero nos faltan todavía algunos eslabones para trazar el entero cuadro de esas modificaciones, pues aun cuando la fauna de los últimos tiempos pampeanos ya es conocida de una manera altamente satisfactoria, la de los primeros tiempos pampeanos guarda todavía muchos secretos.

Aunque destinada sin duda a sufrir importantes modificaciones en lo futuro, la siguiente distribución por horizontes resulta la más completa que sea posible determinar por el momento:

(Las especies precedidas por el signo - son existentes)

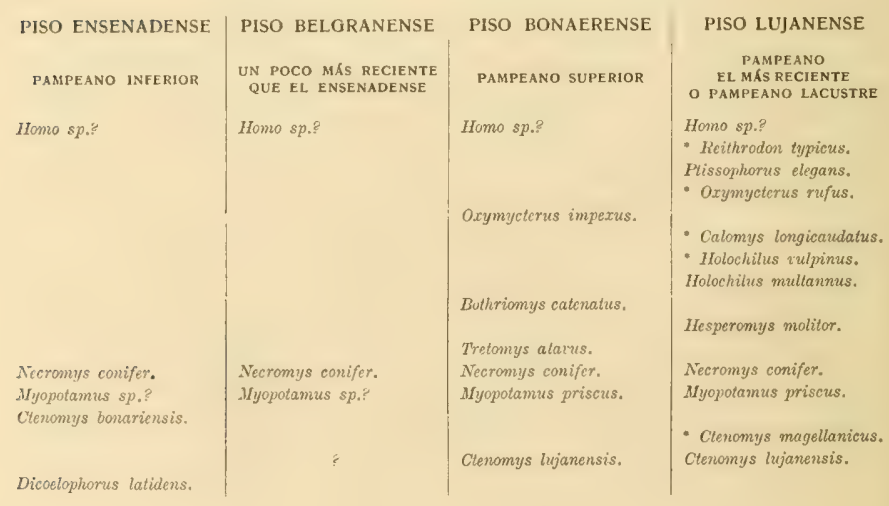


(Las especies precedidas por el signo ${ }^{\circ}$ son existentes)

\section{PISO ENSENADENSE \\ PAMPEANO INFERIOR}

Platacomys scindens.

Pithanotomys cordubensis.

Lagostomus minimus.

Orthomyctera lala.

Dolichotis minor.

Dolichotis platycephalx.

Palaeocaria yampaea.

Canis ensenadensis.

Canis bonarionsis.

Arctotherium bonariense.

Mrachizerolus ensenculensis Sinilodon populator.

Toxalon ensenadersis.

\section{PISO BELGRANENSE. \\ UN POCO MAS RECIENTE QUE EL ENSENADENSE}

Lagostomus cavifrons.

Orthomyctera lata.

Iydroekoerus magnus.

Canis bonriensis.

Aretotherium bonarionse. Aretotherium angustidens.

Smilodon populator. Toxolon platensis.

\section{PISO BONAERENSE \\ PAMPEANO SUPERIOR \\ Lagostomus debitis. \\ PISO LUJANENSE \\ PAMPEANO \\ EL MÁS RECIENTE o PAMPEANO LACUSTRE \\ -Lagostomus trichodactylus \\ Lagostomus debilis.}

Lagostomus cavifrons.

Lagostomins heterogenủdens (irthomyctera lata.

Dolichotis intermedia.

Cerollon turgco

Cerolon antiquus.

Microcaria robusta.

Mierocatia typica.

Mierocatia dubia.

Jicrocaria uneinata.

Microcaria intermetlia.

Palacocaria minuta.

Ifydrochocrus magnus.

Didelphys juga.

Didelphys grandneta.

Dimerodon mutilatus.

Canis arus.

Macrocyon robustus.

Aretotherium angustiders.

Mephilis primaera.

Mejhtis merecdensis.

Mephitis cordubensis.

Lyncodon lujanensis.

Felis longitrons.

Felis palustris.

Smiledon populator.

Toxcdon plalensis.
Dolichotis major.

Ceroulon priscus.

Cerodon mygmaeus.

Microcavia robusta.

Microcavia typica.

Hydrochoerus giganteus.

- Hydrochoerus capybara.

Didelphys incerta.

- Canis Ararae.

Canis cultrilens.

Canis protojubatus.

Canis arus.

Nacrocyon robustus.

- Lulra paranensis.

- Mephitis suffocans?

Lyncodon lujanensis.

Felis platensis

Felis palustris.

Smilodon jopulator.

Torodon platensis. 
(Las especies precedidas por el signo ' son existentes)

\section{PISO ENSENADENSE \\ PAMPEANO INFERIOR}

Toxodon Daruini.

Dilobodon lujanensis. Typotherium cristatum. Typotherium pachygnathum Typotherium maendrum. Typotherium exigum. Entelomorphus rotundalus Pachyrucos bonariensis. Antaodon einctus.

Hippidium angulalum. Hippidium compressidens. Hippidium nanum

Macranchenia boliviensis? Macrauchenia ensenadensis

Diplotremus agrestis.

Auchenia gracilis.

Auchenia Castelnaudi. Auchenia ensenadensis. Auchenia Weddelli.

Paraceros ensenadensis.

\section{PISO BELQRANENSE \\ UN POCO MÁS RECIENTE QUE EL. ENSENADENSE}

Toxodon Burmeisteri. Toxodon Daruiri.

Dilobodon lujanensis. Typotherium cristatum.

\section{Plicatodon rerrarus}

Hippidium principale. Hippidium angulalum.

Auchenia gracilis

ucchenia lujanensis.

Nesolama angustimaxilla.

Paraceros fragilis.

\section{PISO BONAERENSE}

PAMPEANO SUPERIOR

Toxodon Burmeisteri.

Toxolon gracilis

Equus curvidens.

Hippilinm neogaeum.

Hippidium principale.

Mipphaplus Bravardi. Hipphaplus antiguus.

Macrauchenia patachonica

- Dicotyles tajacu.

Dicotyles stenocephalus?

Auchenia intermedia.

Auchenia frontosa.

Auchenia hijanensis.

Palaeolama major.

Stilauchenia Oxemi.

Hemiauchenia paradoxa.

Protauchenia "Keissi.

Cervis brachyceros

Cervus lujanensis.

Cerrus palacoplatensis.

Cemus tuberculatus.
PISO LUJANENSE

PAMPEANO

EL MÁS RECIENTE

- PAMPEANO LACUSTRE

Toxalon bilobidens.

Toxodon Burmeisteri.

Toxodon paradoxus.

Equus curvidens.

Equus argentinus?

Equus reclidens.

Hippidizm neogaeum.

Macrauchenia patachonica

Diastomicodon lujanensis.

- Dicotyles tajacr.

Auchenia intermedia.

Palaeolama leptognatha.

Eulamiops parallelus.

Cerus lujanensis.

Cerrus lalus.

Paraceros vulneratus. 
(Las especies precedidas por el signo * son existentes)

\section{PISO ENSENADENSE}

\section{PAMPEANO INFERIOR}

Epieuryceros truncus. Iastodon andium.

Mastodon platensis.

Mastodon argentinus.

Muslodon rectus.

Megatherium tarijense.

Neoracanthus Brackebuschianus.

Coelolon tarijensis. Lestodon armatus.

Scelidotherivm Bravardi.

Scelilodon patrizs.

Scelidodon tarijensis. Scelidodon Capellinii. Scelilodon Copei.

Fserdolestodon Lettsomi.

Glyptodon principalis. Glyptodon Munixi.

\section{PISO BELGRANENSE \\ UN POCO MÁS RECIENTE QUE EL ENSENADENSE}

Mastodon andium.

Mastodon platensis

Yegatherivm americanum. Megatherium tarijonse.

Neoracanthus Burmeisteri

Lestodon armatus.

Laniodon robustus.

Scelidotherium Brazardi. Scelidotherium Flonceri.

\section{Scelidodon sp?}

Glossotheriun bonariense.

Platyonyx Oticerae.

Glossotherium Darwini.

Afylodon robustus.

Mylodon intermedius.

Pseudolestodon myloides.

Fsevdolestodon debilis.

Pseudolestodon bisulcatus. Fseulolestodon trisulcatus

Psevdolestodon Letisomi.

Glyptodon subelevatus.
Gluptodon clavipes.
Glyptodon euphractus.
PISO LUJANENSE

\section{PAMPEANO}

EL. MÁS RECIENTE

O PAMPEANO LACUSTRE

- Blastoceros campestris.

- Blastoceros palzdosus.

Blastoceros azpeitianus.

\section{Mastodon Humboldti} Mastodon supcrbus.

Megathorium americanum.

Essonodontherium Gervaisi

Lestodon trigonidens.

Lestodon Gaudryi.

Seelidotherium

leptocephalum.

Glossotherium Zeballosi.

Mylodon robustus.

Mylodon Sauvagei.

Mylodon Tieneri.

Pscudalestodon myloides.

Pseudolestodon Reinhardti.

Pseudolestodon Morenoi. 
(Las especies precedidas por el signo ' son existentes)

\section{PISO ENSENADENSE}

PAMPEANO INFERIOR

Glyptodon laeris.

Neothoracophoms clevatus.

Hoplophorus ornatus.

Hoplophorus psendorhatus.

Hoplophorus perfectus.

Lomaphorus imperfectus.

Lomaphorus compressus. Nopachtus coagmontatus.

Neuryames rudis.

Plaxiaplus antiquns.

Docdicurus Kotenianus. Chlamydotherium typum.

Propraoms yrandis.

- Dasypus sexcinctus.

- Dasymis villosus?

Eivtalus Scguini.

- Tolypeules comarus?

\section{PISO BELGRANENSE \\ PISO BONAERENSE}

UN POCO MAS RECIENTE QUE EL ENSENADENSE

Glyptodon minor.

Glyptodon veticulatus.

Glyptodon gemmatus.

Hoplopiorus ormalus.

Hoplophorus nerfectus.

Hoplophorus Heusseri.

Lomaphorus imperfectus.

Lomajihorus eleratus.

Lomaplworus gracilis.

Panochtus Fronzelianus.

Flaxhaplus canaliculatus.

Doedicurus Poncheti.

Doedicurus Kokcnianus.

Chlamydotherium typum.

Propraopus grandis.

Eutatus muctatus.

Eutalus minulus.

- Tolypeutes conurus?
PAMPEANO SUPERIOR

Glyptodon reticulatus. Glyptodon elongatus.

Glyptodon rudimentarius. Glyptodon Falkneri.

Neothoracoph. depressus.

IIoplophorus Meyeri.

Hoplophorus Migoyanus.

Lomaphorus eleratus. Lomaphoris elegans.

Panochtus tubereulatus. Panochtus Morenoi.

Doedicurus Poucheti.

Chlamydotherium typum.

- Tatusia noremcincta.

Propraopus grandis.

- Dasypus villosus.

Eutatus brevis.

Eutatus punctatus.

- Tolypeutes conurus?

Chlamydophorus truncatus?
PISO LUJANENSE

PAMPEANO

EL MÁS RECIENTE O PAMPEANO LACUSTRE

Glyptodon reliculatus. Glyptodon clongatus.

Glyptodon perforatus.

Glyptodon rudimentarius.

Neothoracophorus minutus

Panochtus tuberculatus.

Panochtus Fogti.

Doedicurus claricaudatus.

- Talusia hybrida.

- Dasypus villosus

Dasymis major.

* Zaëdyus minutus.

Eutatus breqis.

- Tolypertes conurus.

Examinando esta distribución por horizontes de las especies que constituyen la fauna pampeana, ya no sorprende su número, pues se ve que no fueron contemporáneas sino que se sucedieron unas a otras, pero sin interrupción, pues la fauna de cada horizonte sólo tiene un corto 
número de especies que le sean propias, siendo las demás comunes a dos o más horizontes.

El espacio de tiempo que ha durado la formación pampeana es considerable, pues si bien las faunas contiguas se parecen, tomando los extremos se notan entre ellas diferencias grandísimas.

Así, la fauna del piso ensenadense, que es la más antigua, carece de especies todavía existentes, con excepción de dos o tres y de carácter muy dudoso, presentando en cambio un considerable número de tipos específicos o genéricos propios de la formación araucana.

La fauna del piso lujanense, que es la más moderna, se distingue por la desaparición de todos los tipos de la formación araucana, y por la presencia de un número notable de especies todavía existentes. El espacio de tiempo geológico que separa a la fauna ensenadense de la fauna lujanense, es tan considerable, que, con excepción de dos o tres, todas las especies de la primera han desaparecido en la segunda.

Las faunas de los pisos belgranense y bonaerense presentan un carácter mixto por la mezcla de las especies de los horizontes contiguos. Sin embargo, se nota que en la fauna del piso belgranense predominan las especies del piso ensenadense, sobre las del piso bonaerense, lo que permite simplificar hasta cierto punto la clasificación, trazando en el pampeano dos grandes divisiones: la inferior, que comprendería los pisos ensenadense y belgranense; y la superior, los pisos bonaerense $y$ lujanense. Estas dos grandes divisiones, presentan en su fauna una diferencia considerable, no tan sólo en las especies sino también en los géneros, como lo demuestra fácilmente la nómina adjunta:

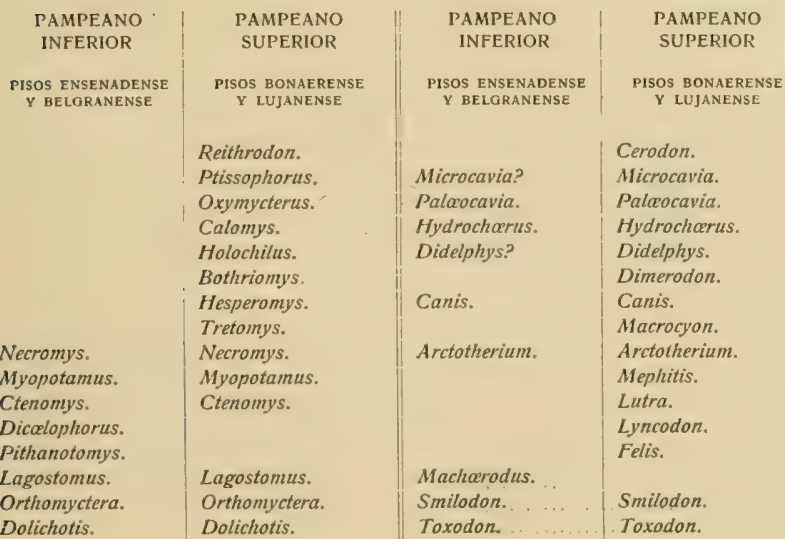




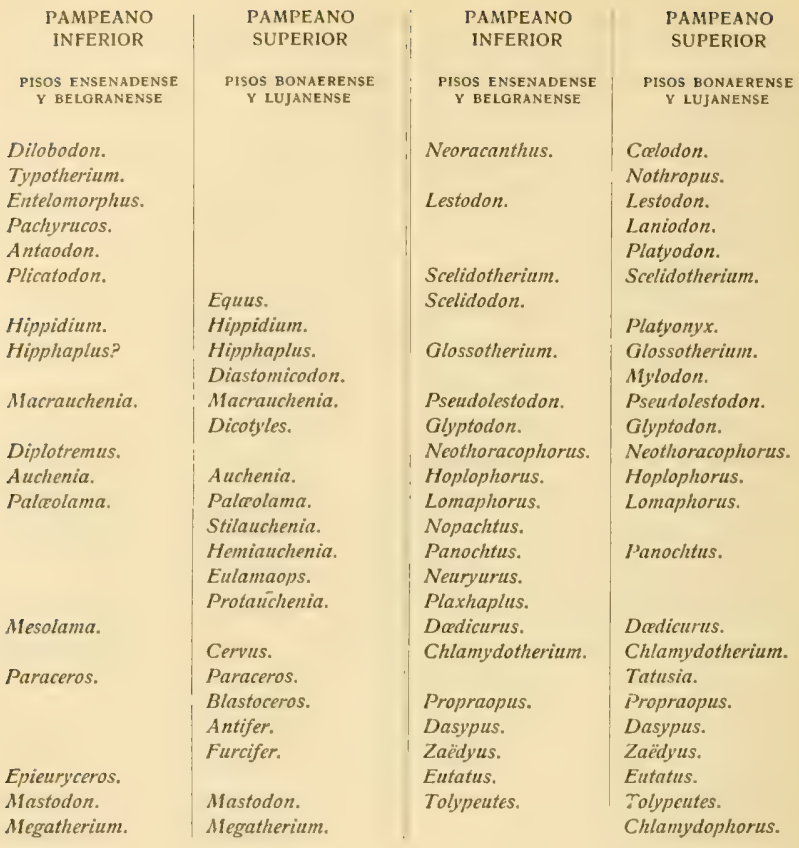

Sobre los 88 géneros de esta lista sólo hay 38 que sean comunes a ambos horizontes, lo que demuestra de una manera evidente tanto su separación como el inmenso espacio de tiempo que ellos representan.

Los géneros del pampeano inferior se distribuyen en los distintos horizontes de los terrenos cenozoicos de la siguiente manera:

\begin{tabular}{|c|c|c|c|c|c|c|c|c|}
\hline & 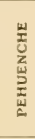 & 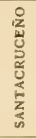 & $\begin{array}{l}\text { o } \\
\frac{0}{z} \\
0 \\
\vdots \\
\vdots \\
\Sigma\end{array}$ & 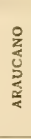 & 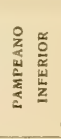 & 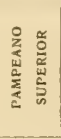 & 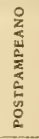 & 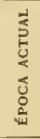 \\
\hline 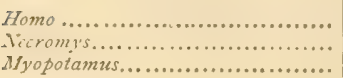 & & & - & - & $\underline{-}$ & $\overline{-}$ & - & - \\
\hline
\end{tabular}


Cinomi's

Ditedophorus .....................

Pithanotomys

Lagostomus.

Orthomyctera

Dolichotis...

Microcavia

Palaeocavia

Hydrocheerus

Ditelphys

Canis

Arctotherium

Machaerodus.

Smilodon

Torodon

Typotherium.

Entelomor pluzs

Pachyrucos

Antaodon.

Plicatoion.

Hippidium ... .................

Hipphaplus

IMacranchenia

Diplotremus

Auchenia..

Mesolama

Paraceros.

Epieuryceros.

Mastodon.

Megatherium

Neoracanthus

Le'studon

Scelidotherium

Sielidodon...

Glossotherium.

Pserudolestodon

Glyptodon

Neothoracophoris

Hoplophorus.

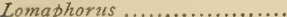

Nopachtus

Panochtus

Veurvorus .

Plaxhaplus.

Doedicurus ..........................

Chlamydotherium.

Propraopus.

Dasipus

Zaïlius.

Entatus.

Tolvpeutes .

. . . . . .. , .. $\ldots$ . . $\ldots$ $\ldots$ . .

$$
\text { (n) }
$$

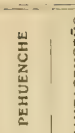

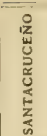

\begin{tabular}{|c|c|c|}
\hline $\begin{array}{l}\frac{0}{z} \\
\vdots \\
0 \\
\vdots \\
\vdots \\
a\end{array}$ & $\begin{array}{l}0 \\
\frac{1}{2} \\
\text { d } \\
3 \\
\frac{\alpha}{\alpha} \\
\alpha \\
\alpha\end{array}$ & 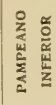 \\
\hline
\end{tabular}

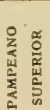

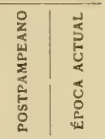

$\left|\begin{array}{|c|c|c|c|}\mid & - & - & - \\ - & - & & -\end{array}\right|-$

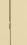
$\ldots$ $\ldots$ . . . . 
Sólo 12 de esos 55 géneros aún existen en nuestros días; 16 prolongaron su existencia hasta los tiempos postpampeanos y 38 hasta el pampeano superior; 36 de esos géneros existieron ya en la formación araucana, 21 en la formación patagónica y 6 aparecieron en la formación santacruceña. Estos números demuestran con la mayor evidencia que el pampeano inferior se coloca entre el pampeano superior por una parte y la formación araucana por la otra, pero con una fauna particular, compuesta de géneros del pampeano superior y de la formación araucana en proporción casi igual, a los que se agregan unos cuantos géneros que parecen (cuando menos por ahora), exclusivos de este horizonte.

Los 55 géneros de mamíferos del pampeano inferior, comprenden 31 familias, que por horizontes se distribuyen de esta manera:

\begin{tabular}{|c|c|c|c|c|c|c|c|c|}
\hline & 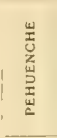 & 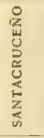 & 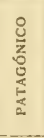 & 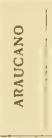 & 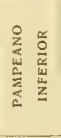 & 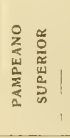 & 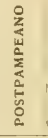 & 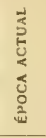 \\
\hline Hominidae..... & & & & - & - & - & - & \\
\hline nyidae. & & & & & - & - & - & \\
\hline jidac ..... & & - &. & - & - & - & m & \\
\hline Octodonitidae.... & & & & - & - & - - & . & \\
\hline Eriomyidae ........................... & & - & - & - & - & - & - & - \\
\hline Caviidae ........................... & & - & - & - & - & - & - & - \\
\hline 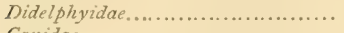 & & & & - & - & - & 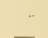 & - \\
\hline 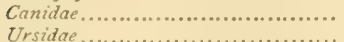 & & & - & - & - & - & - & \\
\hline 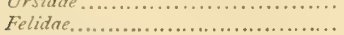 & & & & & - & - & - & \\
\hline dontidac .......................... & & & & - & - & & - & \\
\hline Typotheridae ....................... & - & - & - & - & - & & & \\
\hline ....................... & & & & $-? !$ & - & $-?$ & - & 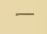 \\
\hline , n..., & & & & - & - & - & & \\
\hline 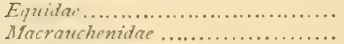 & & - & - & - & - & - & & \\
\hline 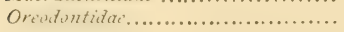 & & & & & & & & \\
\hline $\mathrm{Co}$ & & & & - & & - & - & - \\
\hline (n...................... & & & & - & - & - & - & \\
\hline (......................... & & & & - & & - & 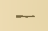 & \\
\hline ridae ......................... & $-?$ & - & - & - & - & - & - & \\
\hline dontidae ........................... & & & & - & - & - & & \\
\hline e... & & & & - & & - & & \\
\hline dae $\ldots . . . . . . . .$. & & 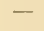 & - & - & - & - & & \\
\hline 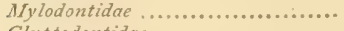 & & - & - & - & 二 & $\overline{-}$ & - & \\
\hline Glyptodontidae ........................ & & - & - & - & 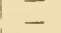 & - & & \\
\hline 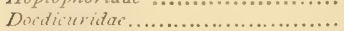 & & & & & & 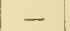 & & \\
\hline 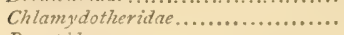 & & - & - & - & . & - & & \\
\hline Praopidae. & & & & & & 一 & - & 一 \\
\hline Dasypod & - & & & 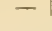 & & & & \\
\hline
\end{tabular}

Sólo 14 de esas 31 familias aún tienen representantes vivos en la actualidad, 19 alcanzaron hasta los tiempos postpampeanos y 28 hasta 
el pampeano superior; 26 de esas familias tenian representantes en la formación araucana, 20 en la formación patagónica y 12 en la formación santacruceña. Sólo dos familias: la de los oreodóntidos y la de los rinoceróntidos, parecen especiales de este horizonte.

En la fauna del pampeano inferior se encuentran los últimos representantes de las familias de los tipotéridos, pudiendo decirse que la presencia de estos animales es, sobre todo, lo que distingue a la fauna del pampeano inferior de la del pampeano superior. En cambio aparecen dos familias, a las que hasta ahora no se le conocen representantes en los terrenos más antiguos: la de los hesperómidos (representada po: un solo género) y la de los praopidios.

Los géneros que constituyen la fauna del pampeano superior se distribuyen en los distintos horizontes según lo indica el siguiente cuadro:

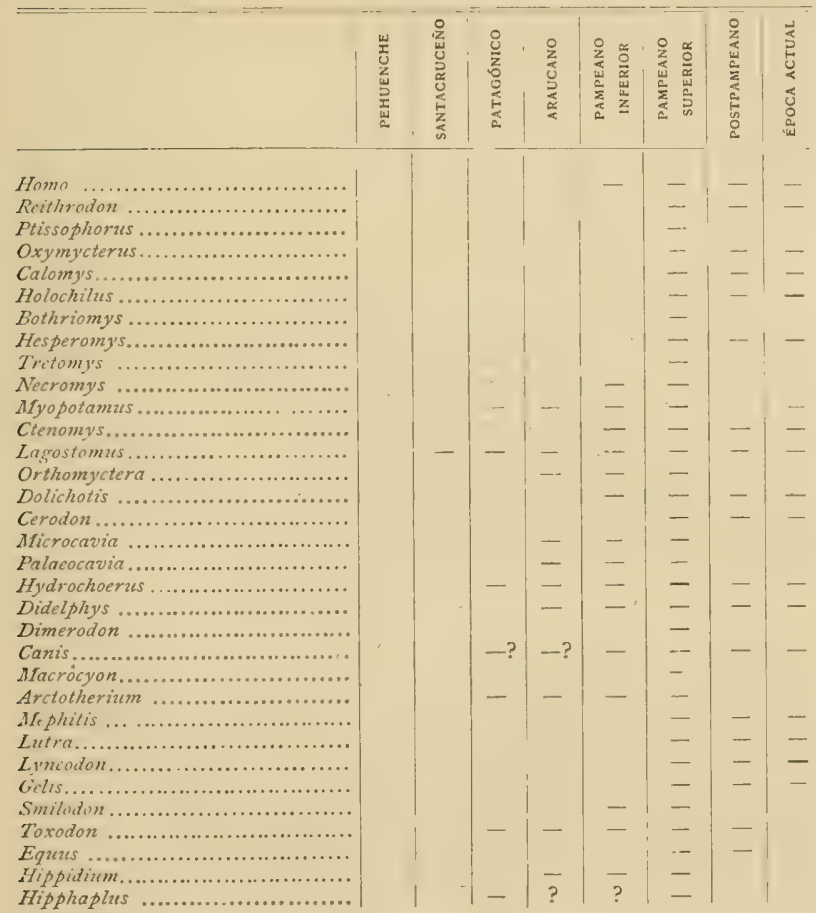




\begin{tabular}{|c|c|c|c|c|c|c|c|c|}
\hline & 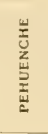 & 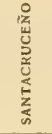 & 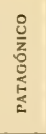 & 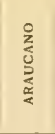 & 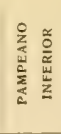 & 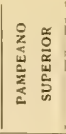 & 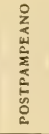 & 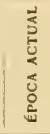 \\
\hline 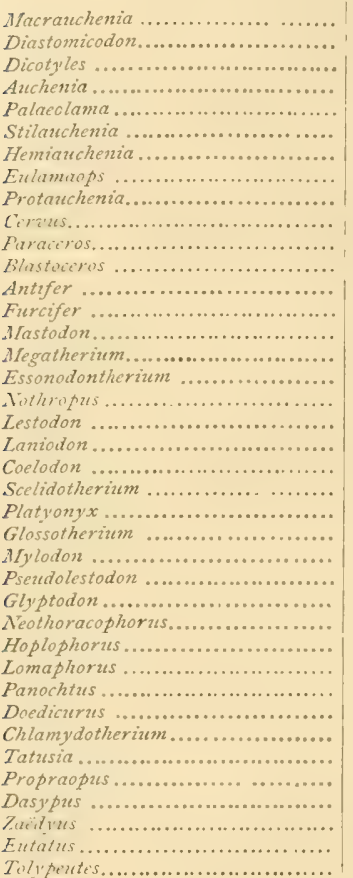 & -? & $\overline{-}$ & $\bar{z}$ & $\begin{array}{l}- \\
- \\
- \\
-\end{array}$ & $\begin{array}{l}- \\
- \\
- \\
- \\
- \\
- \\
- \\
- \\
- \\
- \\
- \\
- \\
-\end{array}$ & 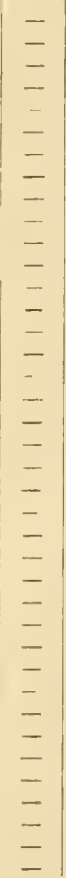 & $\begin{array}{l}- \\
- \\
-\end{array}$ & - \\
\hline
\end{tabular}

De los 72 géneros que comprende la fauna del pampeano superior, aún existen 25 en la actualidad y 33 llegaron hasta el postpampeano; 38 géneros existian ya en el pampeano inferior, 27 en la formación araucana, 17 en la formación patagónica y 5 en la formación santacruceña; por fin, 16 géneros son especiales de este horizonte. De los 22 géneros que aún existen, 13 han aparecido por primera vez en este horizonte, lo que demuestra de una manera evidente que es más moderno que el pampeano inferior, como ya quedó demostrado antes, al indicar el considerable número de géneros propios del pampeano inferior y de 
las formaciones más antiguas, que faltan en la fauna del pampeano superior.

Lo que distingue esencialmente la fauna del pampeano superior de la del pampeano inferior es la ausencia absoluta de representantes de la familia de los tipotéridos y el enorme desarrollo que adquieren los hesperómidos, los camélidos y los cérvidos.

Las familias que constituyen esta fauna se distribuyen en los mismos horizontes, en la forma siguiente:

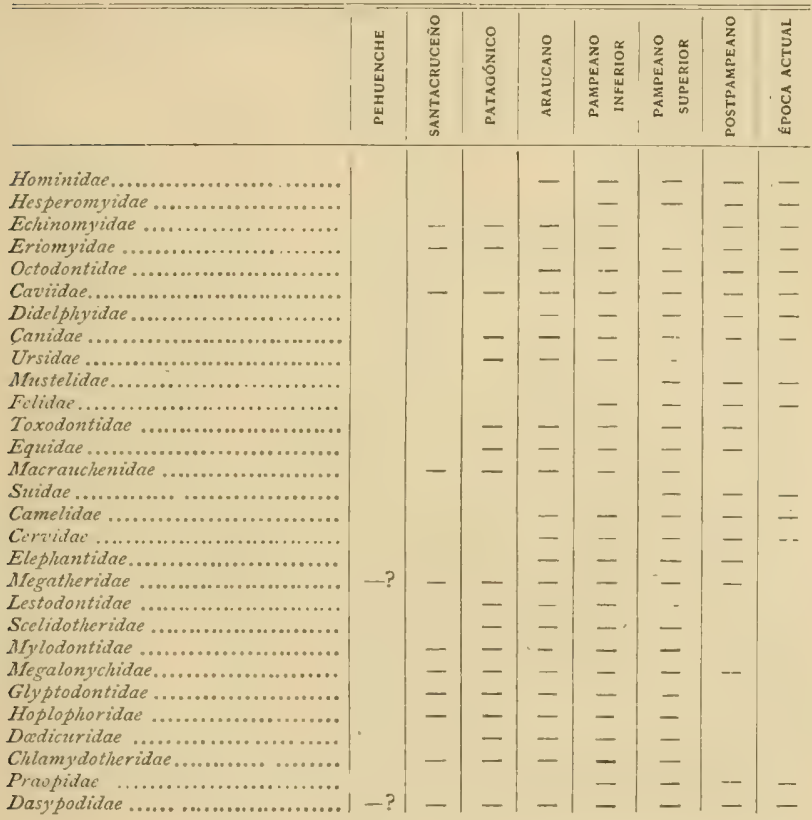

De las 29 familias que constituyen la fauna de mamíferos del pamfeano superior, 15 tienen todavía representantes en nuestros días y $\left.1^{\prime \prime}\right)$ los tuvieron hasta la formación de los primeros terrenos postpampeanos. Pasando a los terrenos anteriores, 27 de estas familias existieron ya en 1* fauna del pampeano inferior, 24 en la fauna de la formación araucana, 18 en la formación patagónica y sólo 11 en la formación santacruceña, $\sin$ que haya ninguna familia que sea exclusiva de la fauna del pampeano superior. 


\section{FORMACIÓN POSTPAMPEANA O CUATERNARIA}

La fauna postpampeana, que se encuentra en los pequeños sedimentos lacustres que descansan en el fondo de la hondonadas de la parte superior de la formación pampeana, permaneció desconocida hasta inis primeros trabajos. Desde entonces he tratado de completarla tanto cuanto me ha sido posible y hoy puedo presentar de ella la siguiente lista en la cual las especies extinguidas están precedidas por un asterisco:

\section{Planungulata}

\section{ANTHROPOIDEA}

Hominidae

1. Homo sapiens.

\section{Unguiculata \\ TROGODONTA \\ RODENTIA \\ Hesperomyidae}

2. Reithrodon typicus.

3. Oxymycterus rufus.

4. Habrothrix arenicola.

5. Habrothrix internus.

6. Calomys longicaudatus.

7. Calomys bimaculatus.

8. Calomys auritus.

9. Holochilus vulpinus.

10. Hesperomys tener.

11. Hesperomys molitor.

Echinomyidae

12. Myopotamus coypus.

Uctorontiliae

13. Ctenomys magellanicus.

\section{Eriomzalae}

14. Lagostomus trichodactylus.

15. Dolichotis patachonica.

16. Cerodon leucoblepharus.

17. Cavia porcellus.

18. Hydrochœrus capybara.

19. *Hydrochœrus giganteus. 


\title{
SARCOHORA
}

I'EDIMANA

Didelphyidae

20. Didelphys Azarce.

21. "Didelphys lujanensis.

Carnivora

Canidae

22. Canis Azarae.

23. * Canis cultridens.

24. Canis gracilis.

25. Canis jubatus.

26. * Canis lycodes.

Mustelidae

27. Lutra paranensis.

28. Mephitis suffocans.

Felidae

29. Felis concolor.

30. Felis onça.

\author{
Ungulata \\ AMPHIDACTYIA \\ ToxodonTIA \\ Torodontiāae
}

31. * Toxodon platensis.

\section{PERISSOUACTYLA}

STEREOPTERNA

32. * Equus rectidens.

\section{ARTIODACTYLA \\ SUINA \\ Suidae}

33. Dicotyles tajacu.

\section{Ruminantia}

Camelidae

34. * Auchenia cordubensis.

35. Auchenia lama.

36. * Auchenia mesolithica.

37. * Palcolama mesolithica.

38. Coassus rufus.

Ceridae

39. Coassus nemorivagus. 
40. * Coassus mesolithicus.

41. Blastoceros campestris.

42. Blastoceros paludosus.

Antilopidae

4v. *Platatherium pampaeum.

PACHYTHERIA

Proboscidea

Elephantidae

44. * Mastodon superbus.

\section{Bruta}

ANICANODONTA

Gravigrada

Megatheridae

45. Megatherium americanum.

46. *Essonodontherium Gervaisi.

47. * Mylodon robustus?

48. "Pseudolestodon myloides.

\section{DASYPODA}

Praopidac

49. Tatusia hybrida.

\section{Dasypodidae}

50. Dasypus villosus.

51. * Dasypus major.

52. * Dasypus platensis.

53. Zaëdyus minutus.

54. Tolypeutes conurus.

De estas 54 especies de mamíferos de los terrenos postpampeanos, sólo 19 son extinguidas y pertenecen en su casi totalidad a géneros que aún existen. La fauna del postpampeano difiere de la del pampeano superior, principalmente por la desaparición de un considerable número de géneros y numerosas especies de distintos órdenes, pero principalmente de desdentados.

Los roedores están en decadencia completa, con excepción de la familia de los hesperómidos, entre los cuales, sin embargo, han desaparecido varios géneros pampeanos.

Del extinguido orden de los Toxodontes, antes tan numeroso, no queda más que un solo representante. Los perisodáctilos litopternos han desaparecido por completo; y de los esteropternos no queda más que un solo representante del género Equus, al que sin duda se agregaba el 
tapir, aunque hasta ahora no se han encontrado sus restos. Entre los rumiantes, la familia de los camélidos ha perdido la mayor parte de sus representantes; y la importancia de la de los ciervos también ha disminuído, apareciendo en cambio un representante del grupo de los antílopes, de los cuales no se encuentran vestigios en los terrenos más antiguos.

Los proboscidios tienen todavía un representante: el último que vivió en estas comarcas y es el de tamaño más gigantesco. Entre los desdentados, los gravígrados han desaparecido casi completamente, quedando sólo unos pocos representantes, y un escaso número de la familia de los Megatéridos y los Milodontes; los representantes del grupo de los Gliptodontes, sumamente abundantes en todos los terrenos anteriores, han desaparecido por completo, pero persisten los dasipódidos, entre los cuales hay algunas formas que son especiales de esta época.

Los géneros que constituyen esta fauna, se distribuyen en los distintos horizontes de la siguiente manera:

\begin{tabular}{|c|c|c|c|c|c|c|c|c|}
\hline . & 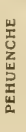 & 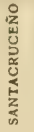 & 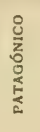 & $\begin{array}{l}0 \\
z \\
\vdots \\
\vdots \\
\vdots \\
\vdots \\
z \\
z\end{array}$ & 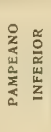 & 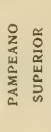 & 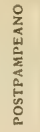 & 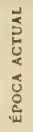 \\
\hline 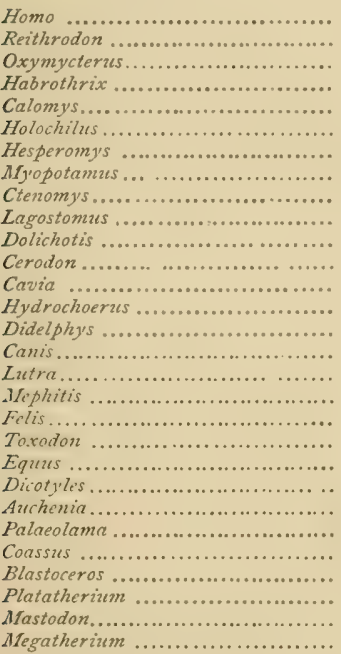 & & - & $\begin{array}{l}- \\
-?\end{array}$ & $\begin{array}{l}- \\
-?\end{array}$ & $\begin{array}{l}- \\
- \\
-\end{array}$ & $\begin{array}{l}- \\
- \\
- \\
- \\
- \\
- \\
- \\
- \\
- \\
- \\
- \\
- \\
- \\
- \\
- \\
-\end{array}$ & $\begin{array}{l}- \\
- \\
- \\
- \\
- \\
- \\
- \\
- \\
- \\
- \\
- \\
- \\
- \\
- \\
- \\
- \\
- \\
- \\
- \\
- \\
- \\
- \\
- \\
- \\
- \\
- \\
- \\
- \\
- \\
- \\
- \\
- \\
- \\
- \\
- \\
- \\
- \\
- \\
- \\
- \\
- \\
- \\
- \\
- \\
- \\
- \\
- \\
- \\
- \\
- \\
- \\
- \\
- \\
- \\
- \\
- \\
- \\
- \\
- \\
- \\
- \\
- \\
- \\
- \\
- \\
- \\
- \\
- \\
- \\
- \\
- \\
- \\
-\end{array}$ & $\begin{array}{l}- \\
- \\
- \\
- \\
- \\
- \\
- \\
- \\
- \\
- \\
- \\
-\end{array}$ \\
\hline
\end{tabular}




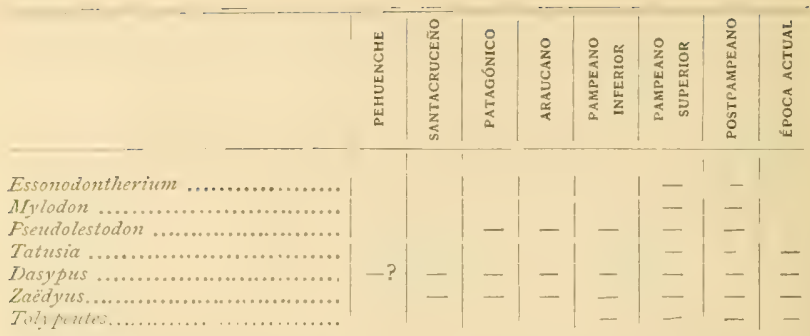

De estos 36 géneros sólo hay 8 extinguidos, los 26 restantes todavía existen en la actualidad. Remontando hacia los tiempos más antiguos, 32 géneros existian ya en el pampeano superior, 17 en el pampeano inferior, 12 en la formación araucana, 9 en la formación patagónica y sólo 3 en la formación santacruceña. Sólo un género parece exclusivo de esta época.

El carácter culminante de la fauna del postpampeano es la presencia de representantes del grupo de los gravígrados y la ausencia absoluta de Gliptodontes.

Las familias que constituyen esta fauna, se distribuyen por horizontes de esta manera:

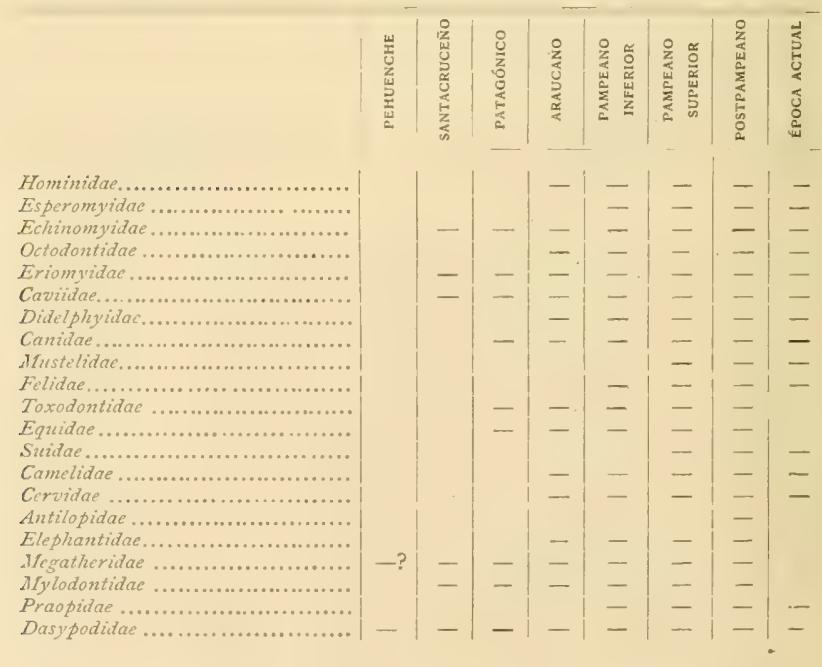


- De estas 21 familias sólo 15 existen aún, mientras que todas ellas, con excepción de una sola, cuya duración en Sud América parece haber sido pasajera, existian ya en la época precedente o del pampeano superior, lo que demuestra que la fauna del postpampeano se distingue de la del pampeano superior por la extinción de un considerable número de tipos característicos de aquella formación y de la fauna de la época actual por la persistencia de unos pocos tipos pampeanos. Estas diferencias no permiten confundir la fauna postpampeana con la de la época actual, ni tampoco reunirla a la de la época pampeana, constituyendo una fauna intermedia, que se coloca entre las dos, pero más próxima de la existente que de la del pampeano superior.

Esta fauna, en su conjunto, es de época geológica relativamente reciente, pues de las 21 familias que la forman, se encuentran 20 en el pampeano superior, 18 en el pampeano inferior, 15 en la formación araucana, 9 en la formación patagónica y sólo 6 en la formación santacruceña.

\section{ÉPOCA ACTUAL}

La fauna actual de mamíferos de la República Argentina, sin tomar en cuenta las especies introducidas por los europeos, comprende las especies siguientes, de las cuales, las que están precedidas por un asterisco se han encontrado fósiles en los terrenos cuaternarios o en la formación pampeana, en la República Argentina o en otros puntos de Sud América:

\section{Planungulata \\ ANTHROPOIDEA \\ Hominidae}

1. *Homo sapiens.

2. Mycetes carayá.

SIMTIOIDEA

Cebidae

3. Cebus libidinosus.

4. Nyctipithecus felinus.

5. Hapale penicillata.

Pithecidae

Hapolidae

Unguiculata

TROGODONTA

RODENTIA

Leporidae

6. * Lepus braziliensis. 
7. Sciurus aestuans.

Sciuridae

8. Reithrodon typicus.

Hesperomyidae

9. Reithrodon cuniculoides.

10. Reithrodon chinchilloides.

11. * Oxymycterus rufus.

12. * Habrothrix arenicola.

13. Habrothrix microps.

14. Habrothrix obscurus.

15. Calomys griseo-flavus.

16. Calomys elegans.

17. Calomys anguya.

18. Calomys canescens.

19. Calomys xanthorhinus.

20. * Calomys longicaudatus.

21. Calomys magellanicus.

22. Calomys xanthopygos.

23. * Calomys bimaculatus.

24. Calomys flavescens.

25. * Calomys auritus.

26. Holochilus vulpinus.

27. * Hesperomys tener?

Cercolabidae

28. * Sphingurus prehensilis.

29. * Sphingurus insidiosus.

Dasyproctidae

30. Dasyprocta Azare.

Echinomyidae

31. * Myopotamus coypus.

Octodontidae

32. Ctenomys braziliensis.

33. * Ctenomys magellanicus.

34. Schizodon fuscus.

35. * Lagostomus trichodactylus.

Eriomyidae

36. Lagidium peruanum.

37. Eriomys laniger.

38. * Dolichotis patachonica.

Cariidae

39. Dolichotis centralis.

40. * Cerodon lencoblepharus. 
41. Cerodon australis.

42. * Cavia porcellus.

43. * Hydrochœrus capybara.

\section{SARCOBORA \\ Pentmana \\ Didclphyidae}

44. * Didelphys Azarce.

45. Didelphys crassicaudata.

46. Didelphys dorsigera.

47. * Didelphys elegans.

48. * Didelphys cinerea.

\section{Carntuora}

Canidae

49. * Canis Azara.

50. * Canis gracilis.

51. Canis griseus.

52. * Canis jubatus.

53. Canis culpous.

54. Canis cancrivorus.

Sub-utrsidae

55. * Nasua narica.

56. Procyon cancrivorus.

Mustelidae

57. * Lutra paranensis.

58. * Galictis barbara.

59. Galictis vittata.

60. * Mephitis suffocans.

61. Lyncodon patagonicus.

62. Felis jaguarundi.

Felidae

63. Felis eyra.

64. Felis pajeros.

65. Felis colocolo.

66. Felis Geoffroyi.

67. * Felis mitis.

68. *Felis concolor.

69. * Felis onça.

\section{Ptetica}

70. Phyllostoma superciliatum.

71. Phyllostoma lineatum.

72. Phyllostoma lilium. 
73. Glossophaga ecaudata.

74. Desmodus rotundatum.

75. Desmodus D'Orbignyi.

76. Noctilio leporinus.

Braclyuridae

Gymnuridae

77. Nyctinomus nasutus.

78. Promops bonariensis.

Vespertilionidae

79. Nycticejus ruber.

80. Atalapha bonariensis.

81. Atalapha villosissima.

82. Vespertilio Isidori.

83. Vesperugo nigricans.

84. Vesperus velatus.

85. Vesperus montanus.

Ungulata

PERISSODACTYLA

STEREOPTERNA

Tapiridae

86. * Tapirus americanus.

ARTIODACIYIA

Surna

Suidae

87. Dicotyles tajacu.

88. *Dicotyles labiatus.

Ruminantia

Camelide

89. * Auchenia lama.

90. Auchenia vicunna.

91. * Coassus rufus.

92. * Coassus nemorivagus.

93. Coassus rufinus.

94. "Blastoceros campestris.

95. * Blastoceros paludosus.

96. Furcifer bisulcus. 


\section{Bruta \\ ANICANODONTS \\ VERMIILINGUIA \\ MIymecopliagidae}

97. Myrmecophaga jubata.

98. Myrmecophaga tetradactyla.

HICANODONTA

DASYPODA

Proopidae

99. * Tatusia hybrida.

100. * Tatusia novemcincta.

101. * Dasypus sexcinctus.

Dasypodidae

102. * Dasypus villosus.

103. * Zaëdyus minutus.

104. * Tolypeutes conurus.

105. * Priodon gigas.

106. *Xenurus unicinctus.

Chlamydophoridae

107. Chlamydophorus truncatus.

De estas 107 especies de mamíferos terrestres actuales de la República Argentina sólo se conocen 49 especies en estado fósil. La fauna actual es la misma de la época anterior, de la que difiere principalmente por la desaparición de unas cuantas especies y por la aparición del grupo de los murciélagos, cuya ausencia en los terrenos de las épocas precedentes, es posible que sólo sea aparente. Aparte esta excepción, no ha aparecido en la época actual ningún género nuevo; y la mayor parte de las especies que aparecen como exclusivas de nuestra época, es posible que también existan en el cuaternario.

Los géneros actuales de la lista precedente, se distribuyen en los distintos horizontes de los terrenos cenozoicos de la República Argentina, de la siguiente manera:

\begin{tabular}{|c|c|c|c|c|c|c|c|c|}
\hline & 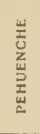 & 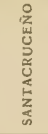 & $\begin{array}{l}0 \\
\vdots \\
z \\
o \\
\vdots \\
\vdots \\
\vdots \\
a\end{array}$ & 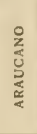 & 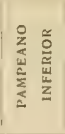 & 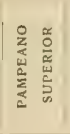 & 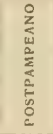 & 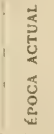 \\
\hline 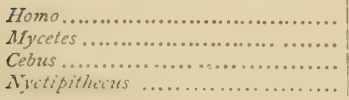 & & & & & - & - & - & - \\
\hline
\end{tabular}




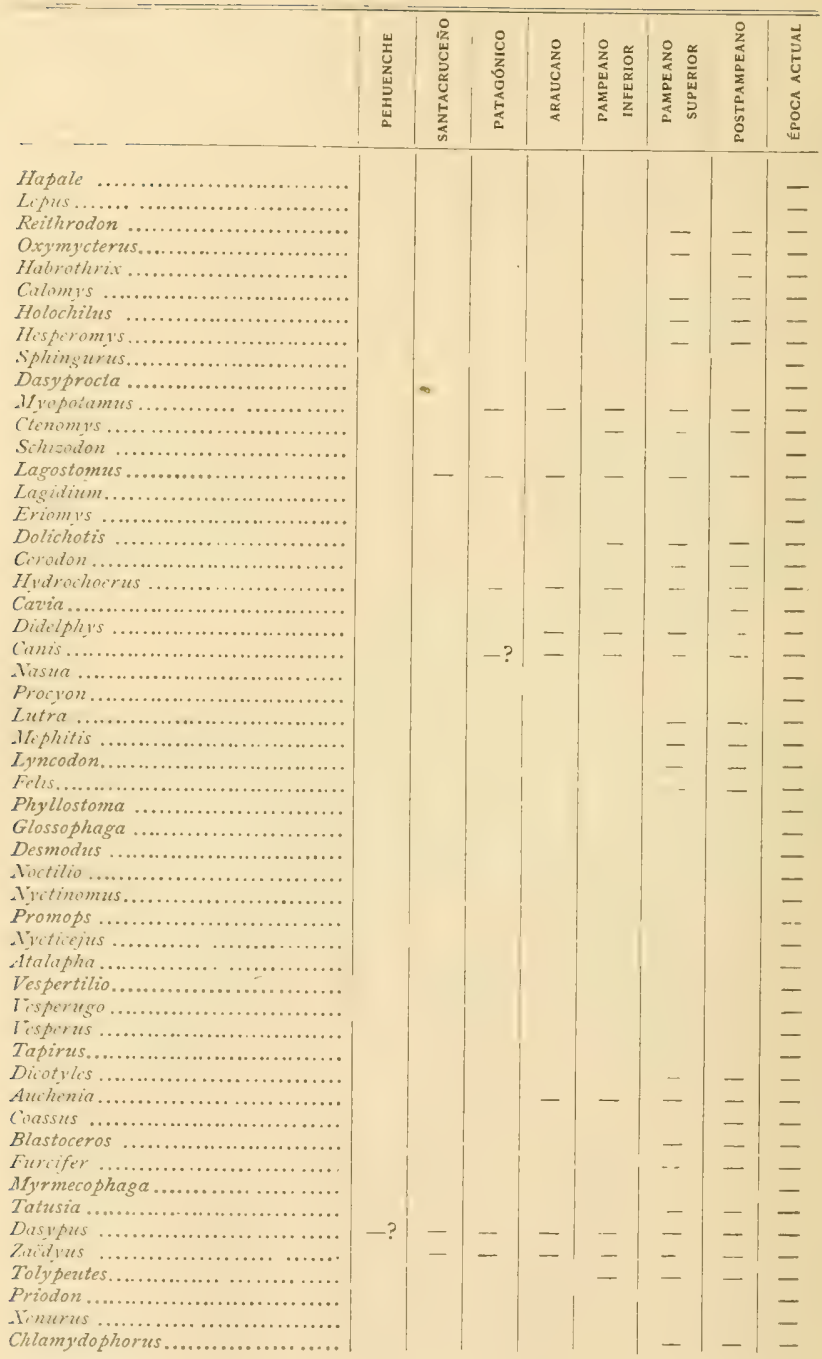


Por esta lista se ve que el número de géneros actuales va disminuyendo continuamente hasta la formación santacruceña, mientras que ya hemos visto que los géneros de la formación santacruceña disminuyen gradualmente en número hasta la época actual, lo que demuestra que las distintas faunas se han sucedido realmente en el mismo orden indicado, como lo demuestra igualmente la siguiente distribución de las familias actuales:

\begin{tabular}{|c|c|c|c|c|c|c|c|c|}
\hline & 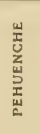 & 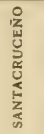 & 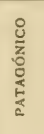 & 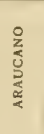 & 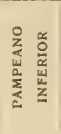 & 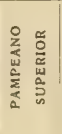 & 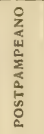 & 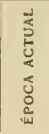 \\
\hline 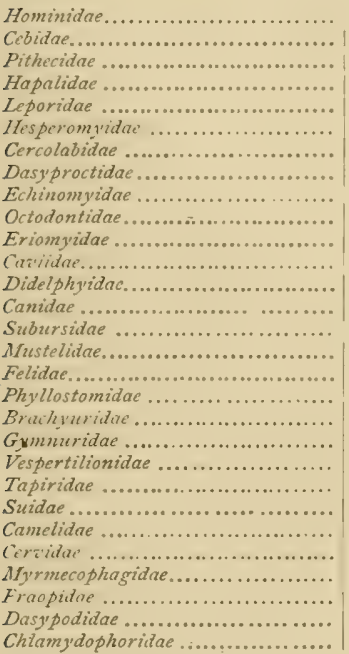 & - & $\begin{array}{l}- \\
- \\
-\end{array}$ & $\begin{array}{l}- \\
- \\
- \\
-\end{array}$ & $\begin{array}{l}? \\
- \\
- \\
\overline{-} \\
\overline{-}\end{array}$ & $\begin{array}{l}? \\
\overline{-} \\
\overline{-} \\
\overline{-} \\
\bar{z} \\
-\end{array}$ & $\begin{array}{l}? \\
- \\
-- \\
- \\
- \\
\overline{-} \\
\overline{-} \\
-\end{array}$ & $\begin{array}{l}\bar{?} \\
\overline{-} \\
\overline{-} \\
\overline{-} \\
\bar{?} \\
\overline{-}\end{array}$ & $\begin{array}{l}- \\
- \\
I \\
- \\
- \\
- \\
-\end{array}$ \\
\hline
\end{tabular}

De estas 29 familias 16 existieron en el postpampeano y en el pampeano superior, 14 en el pampeano inferior, 10 en la formación araucana, 7 en la formación patagónica y 5 en la formación santacruceña.

Es inútil que me extienda en comentarios sobre los cuadros de las distintas faunas mastológicas de la República Argentina, pues la conclusión es por demás evidente. La fauna más antigua después de la del piso pehuenche, es la de la formación santacruceña, siguiéndoles en orden de menor antigüedad: la de la formación patagónica, la de la for- 
mación araucana, la del pampeano inferior, la del pampeano superior, la del postpampeano $y$, por último, la de la época actual.

Los datos contenidos en los cuadros mencionados serán seguramente aumentados dentro de poco y quizá también modificados en algunos de sus detalles; algunos tipos que parecen característicos de ciertos horizontes se encontrarán sin duda también en otros; se encontrarán otras taunas que se intercalarán entre las conocidas, llenando las grandes lagunas que separan algunas de ellas, pero todo eso no podrá modificar ya los resultados generales a que hemos llegado respecto a la edad relativa de las distintas faunas extinguidas de esta región del continente sudamericano.

\section{PARALELO CRONOLÓGICO \\ DE LAS FAUNAS MASTOLÓGICAS DE LA REPÚBLICA ARGENTINA CON LAS DE LAS OTRAS REGIONES DEL GLOBO}

La discontinuidad de las formaciones de ambos continentes, producida for los dos grandes océanos que se interponen entre las dos grandes masas continentales, impiden por ahora establecer un sincronismo exacto entre las capas sedimentarias de las formaciones americanas en general y las del otro continente. Sin embargo, aunque la evolución de la fauna se ha efectuado desde tiempos geológicos antiquísimos, en centros geográficos distintos, que raras veces se han puesto en comunicación, nos presenta un paralelismo bastante notable y datos suficientes para encontrar una correspondencia bastante satisfactoria entre las faunas de las grandes épocas de cada una de las grandes regiones continentales de nuestro globo.

Un estudio comparativo de esta índole sería del mayor interés; deșgraciadamente ya me falta tiempo y espacio para llevarlo a cabo con la extensión que hubiera deseado. Tengo, pues, que limitarme a poner en paralelo las listas de los géneros de las distintas formaciones, acompañándolas de rápidas observaciones que bastarán por ahora para dar una idea general de la correspondencia de las faunas de la República Argentina con las mejor conocidas de las otras regiones de la tierra.

Como me falta tiempo para verificar todos los datos, es posible que entre los nombres genéricos que menciono haya algunos sinónimos, pero eso no puede alterar en lo más mínimo las deducciones generales que se desprendan de la comparación de las distintas faunas.

\section{FAUNA PALAEOCENA}

La fauna palaeocena de mamíferos de la República Argentina, es hasta ahora casi completamente desconocida; sólo se conoce como procedente con toda seguridad de esta formación, el Macropristis (que está 
acompañado por numerosos restos de reptiles terrestres gigantescos del extinguido orden de los Dinosauria) y tres o cuatro otros géneros aún no bien conocidos.

En Norte América, la única faura comparable a la del piso pehuenche de la República Argentina, es la del larámico, en donde se encuentra igualmente la mezcla de huesos de gigantescos dinosaurios con los de mamíferos. Cope caracteriza esta época por la presencia de reptiles dinosaurios $y^{\bullet}$ de mamiferos marsupiales y la ausencia de mamíferos placentarios, lo que concuerda bastante bien con lo que se observa en el piso pehuenche, donde los dinosaurios están igualmente acompañados for mamíferos marsupiales, faltando hasta ahora los mamíferos placentarios, pues el Pyrotherium, que yo creía procedente de los mismos yacimientos, procede de un horizonte algo más reciente, en el que parece ya no se encuentran restos de dinosaurios.

Por cuanto se sabe hasta ahora, en Europa desaparecen igualmente los dinosaurios alli donde aparecen los primeros mamíferos placentarios conocidos.

\section{FAUNA EOCENA}

La fauna de mamíferos de la República Argentina atribuída a la época eocena es numerosa y sin duda procedente de distintos horizontes hasta ahora no bien determinados.

La fauna eocena de Norte América es igualmente numerosa y parece representar un espacio de tiempo bastante mayor que el que representa la fauna eocena de la República Argentina.

La fauna eocena de Europa, también muy rica en formas distintas. representa, sin embargo, un espacio de tiempo bastante menor que la fauna eocena de Norte América, debido, sobre todo, a que se ha segregado su parte superior o más reciente para incluirla en la época oligocena.

La siguiente lista da una idea de la composición relativa de las tres faunas mencionadas. Los géneros existentes están precedidos por un asterisco,

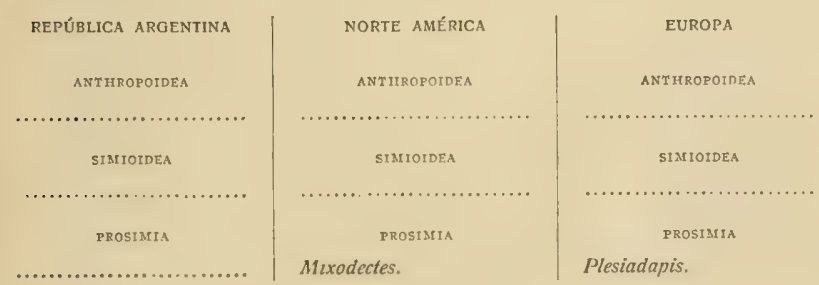




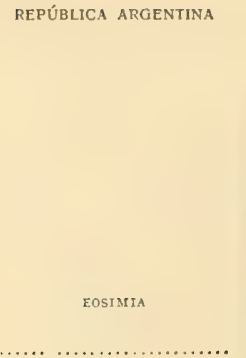

CONDILARTHRA

TOXODONTIA

\section{Stenotephanos.}

Lithops.

Pachyrucos.

Hegetotherium.

Tracliyterus.

Protosodon.

Adinotherium.

Acrotherium.

Phobereotherium.

Adelphotherium.

Gronotherium.

Rhadinotherium.
NORTE AMÉRICA

Chriacus.

Tricentes.

Indrodon.

Lenturavts.

A naptomorphus.

Cynodontomys.

Omomys.

Microsyops.

EOSIMIA

Hyopsodus.

Loxolophus.

Tomitherium.

Hypposyus.

Notharctus.

Sarcolemur.

Thinolestes.

Telmatolestes.

Thinotheriun.

Mesacodon.

Pelycodus.

Opisthotomus.

Apheliscus.

CONDILARTIIRA

Periptychus.

Mexodon.

Ectoconus.

Haploconus.

Anisonchus.

Hemithlaus.

Conorcytes.

Zetodon.

Protogonia.

Phenacodus.

TOXODONTIA
EUROPA

Protoadapis.

EOSIMIA

Opisthotomus.

CONDILARTIIRA

Phenacodus.

TOXODONTIA 
REPÚBLICA ARGENTINA

\section{Interatherium.}

Icochilus.

Protypotherium.

Patriarchus.

Atryptherium.

Scopotherium.

Nesodon.

\section{STEREOPTERNA}

LITOPTERNA

Theosodon.

Proterotherium.

Thoatherium.

Diadiaphorts.

Licaphrium.

Homalodontotherium.

PRORUMINANTIA

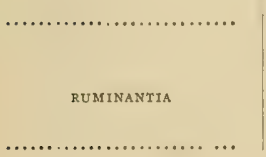

NORTE AMÉRICA

EUROPA

STEREOPTERNA

\section{Ectocyon.}

Helohyus.

Hyracotherium.

Dilophodon.

Orotherium.

Helatetes.

Oligotomus.

Heptodon.

Palceosyops.

Diplacodon.

Limnohyus.

Hyrachius.

Colonoceras.

Triplopus.

Orthocynodon.

Systemodon.

Lambdotherium.

Desmatotherium.

Epihippus.

Mleniscotheriunt.

Leurocephalus.

Telmatotherium.

Amynodon.

Lophiodon.

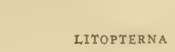

LITOPTERNA

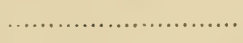

PRORUMINANTIA

Pantolestes.

Ithygrammodon.

RUMINANTIA

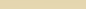

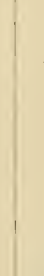

Metriotherium.

Tetraselenodon.

RU BIINANTIA

\section{Lophiodon.}

ITTOPTERNA

Lophiotherium,

Brachydiastematherium.

Hyracotheryus. 
REPÚBLICA ARGENTINA

SUINA

ANBLYPODA

Astrapotherium.

Pyrotherium.

Pinnodus.

Adelotherium.

Adrastotheritum.

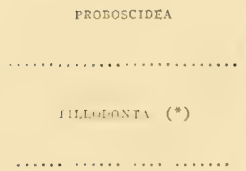

RODENTIA

Acaremys.

Sciamys.

Steiromys.

Neoreomys.

Scleromy's.

Adelphomys.

Stichomys.

Spaniomys.

Olenopsis.

Spharomys.

Sphodromys.
NORTE AMÉRICA

SUINA

Heloyus?

Eohyus.

Achncedon.

AMBIYPODA

Pantolambda.

Manteadon.

Ectacodon.

Coryphodon.

Bathmodon.

Metalophodon.

Eiachoceras.

Bathyopsis.

Eobasilens.

Loxolophodon.

Uintatherium.

PROLOSCIDEA

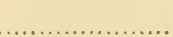

TILLODONTA

Heniganus.

Dryptodon.

Psithacotherium.

Calamodon.

Tillotherium.

Anchippodus.

Stylinodon.

Apatemys.

Esthonyx.

Ectoganus.

RODENIIA

Colonimys.

Taximys.

Tillomys.

Plesiarctomys.

Paranys.

Sciuravis.

Mysops.
EUROPA

SUINA

Lophiocharts.

AMBL,YPODA

Coryphodon.

PROBOSCIDEA

TILLกดชัง

RODE,NTIA

Decticadapis.

( ${ }^{*}$ Incluso los Toniodonta. 
REPÚBLICA ARGENTINA

Sphigoomys.

Perimys.

Pliolagostomus.

Prolagostomus.

- Lagostomus.

Scotizunys.

Eocardia.

Sclistomys.

Phanomys.

Hedimys.

Callodontomy's.

INEECTIVORA

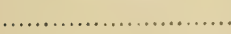

PIAGIAUTLACOIDEA

Abderites.

Acdestis.

Epanorthus.

Microbiotherium.

Stilotherium.

CARNIVORA

\section{CREODONTA}

Cladosictis.

Hathliacynus.

Agrtstylus.

Borhycena.

Anatherium.

Acrocyon.
NORTE AMÉRICA

EUROPA

INSECTIVOR.

Centetodon.

Talpavus.

Palacocodon.

Sinopa.

Euryacodon.

Hemiacodon.

Stenacodon.

Bathrodon.

I'assalacodon.

Anisacodon.

Centracodon.

Entomodon.

Diacodon.

Ictops.

PIAGIAULACOIDEA

Ptilodus.

Catopsalis.

Neoplagiaulax.

Polimastodon.

Chirox.

Meniscoessus.

CARNIYORA

CARNIVORA

\section{Liotomus.}

Neoplagiaulax.

Orthaspidotherium.

Adapisorex.

Adapisoriculus.

Diacodon.

\section{PL,AGIAULACOIDEA}

CREODONTA

CREODONTA

Micloënus.

Deltatherium.

Tritsodon.

Dissacus.

Sarcothraustes.

Didimyctis.

(") Incluso Microbiotheria. 
REPÚBLICA ARGENTINA

Acyon.

Sipalocyon.

CIIROPTERA

PEDIMANA

VERMILINGUIA

Scotocops.

Phororinacos.

PLEIODONTA

Entelops.

Dideilotherium.

TARDIGRADA

GRAVIGRADA

Zamicrus.

Schismotherium.

Hapalops.

Planops.

Xyophorus.

Eucholaeops.

Trematherium.

Nematherium.

CLYPTODONTIA

\section{Cochtops.}

Eropalaehoplophorus.

Asterostemma.
NORTE AMÉRICA

EUROPA

Mesonyx.

Patriofelis.

Mincis.

Dromocyon.

Didelphodus.

Stipolophus.

Oxyaena.

Protopsalis.

Ambioctonus.

CHIROPTERA

Nyctilestes.

Nyctitheritm.

-Vesperugo.
Tricuspiodon.

Procynictis.

Miacis.

Argillotherium.

Miolophus.

Stipolophus.

Oxyaena.
PEDIMANA

VERMILINGUIA

GRAYIGRADA

GRAVIGRADA

CIIIROPTERA

PEDIMIANA

VERMILINGUIA

PLEIODONTA

TARDIGRADA

GLYPTDDONTIA 
Chlamydotherium.

Peltephilus.

* Dasypus.

- Zaedj'iss.

'Eutatus.

Stegotherium.

De este cuadro se deduce que ya desde esa lejana época, la fauna sudamericana era muy distinta de la de Norte América y Europa y que las de estas dos regiones eran mucho más parecidas entre sí que comparadas con la de la República Argentina.

La fauna de la República Argentina se distingue de la de los otros continentes, especialmente por la presencia del grupo de los Toxodontes y los paquidermos litopternos y las distintas subdivisiones de la gran sección de los Brutos, de los que no aparecen vestigios en los terrenos de esta época, de Europa y Norte América. A su vez la fauna mastológica de estas dos regiones se distingue por la presencia de los prosimios, los eosimios, los paquidermos primitivos del grupo de los Condylarthra (que sin embargo hasta ahora no se puede decir falten en Sud América), los paquidermos estereopternos, los prorrumiantes y los insectívoros.

De los 27 grupos mencionados, sólo 21 existen fósiles en los terrenos que contienen la fauna eocena; de éstos hay 11 en la República Argentina, 13 en Norte América y 11 en Europa; 7 grupos parecen especiales de la República Argentina y sólo 2 de Norte América. No hay ningún grupo que sea común a la República Argentina y Norte América y que falte en Europa, pero hay 7 grupos comunes a Norte América y Europa que faltan en la República Argentina.

Lo que da el sincronismo casi exacto de estas tres faunas es la ausencia en las tres de seis grandes grupos que todavía tienen representantes vivos y cinco de ellos son o fueron comunes a las tres regiones; y la presencia en las tres regiones de tres grandes grupos: los Plagiaulacoidea, los Creodonta y los Amblypoda, completamente extinguidos y que en todas partes se presentan como característicos del eoceno, particularmente los Plagiaulacoidea que en el hemisferio boreal parecen ser exclusivos de la época secundaria y de la base del eoceno. La gran abundancia de representantes de este grupo en la fauna del piso santacruceño, unida a la de los Crcodonta y Amblypoda de los subgrupos de los Taligrada y Pantodonta no permite dudar que se trata de una fauna de los primeros tiempos eocenos, pues también aparecen en Europa y Norte América como característicos de la mencionada época. 
La discordancia más notable entre las tres faunas aparece en el grupo de los roedores, que, siendo común a las tres regiones, tiene, sin emhargo, escasos representantes en el hemisferio boreal, donde hasta parece que faltan completamente en la base del eoceno, mientras que son sumamente numerosos en la República Argentina; pero esto tiene su explicación en que probablemente se trata (como ocurre con los desdentados) de un grupo originario de este continente y que recién en esa época empezaba a invadir las tierras emergidas del hemisferio septentrional.

Por'lo demás, el sincronismo entre las tres faunas se establece igualmente de una manera no menos evidente por la ausencia en esa época le géneros todavia existentes, con excepción de dos o tres de caracteres sumamente primitivos, que se han conservado invariables a través de todas las épocas.

\section{FAUNA OLIGOCENA}

La fauna oligocena está constituída en Europa por los seres fósiles que se encuentran en la parte superior del eoceno de los antiguos autores y la parte inferior del mioceno, con la que se ha constituído la época oligocena, intermedia entre el eoceno y el mioceno.

Esa división no ha sido hasta ahora adoptada en Norte América, por lo que no es posible por el momento establecer una relación exacta entre las faunas de ambos continentes. En la Republica Argentina se han atribuido a la época oligocena los estratos de los pisos mesopotámico y patagonico de la formación patagónica, cuya fauna de mamíferos terrestres, en paralelo con la del oligoceno de Europa, es la siguiente:

(Los nombres precedidos de un asterisco son géneros existentes)

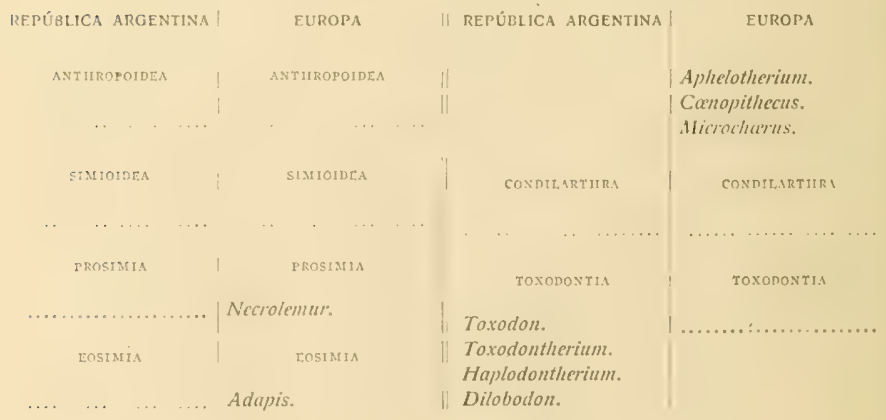


(Los nombres precedidos de un asterisco son géneros existentes)

\section{REPÚBLICA ARGENTINA}

Eutomodts.

Xotodon.

Stenotephanos.

Pachyrucos.

Colpodon.

Protwpotherium.

STEREOPTERNA

Ribodon.

Hipphaplus.

Scalabrinitherium. Oxyodontherium. Macrauchenia. Mesorhinus. Proterotherium. Brachutherium.

RUMINANIIA

\section{RUMINANTIA}

Lophiomeryx.

Cryptomeryx.

Tragulohyus.

Bachytherium.

Protomeryx.

Prodemotherium.

Phaneromery'x.

PRORUMINANTI

PROREMINANTIA

Anoplotherium.

Dacrytherium.

Plesidacrytherium.

Mixocharus.

Deilotherium.

Spaniotherium.

Dichobune.

Ragatherium.

Amphimeryx. .

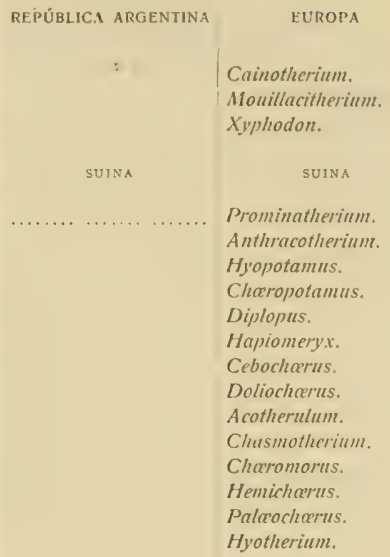

Paradoxomys.

* Myopotamis.

Morenia.

Olenopsis.

Discolomys.

Orthomys.

Perimy's.

- Lagostomits.

Megamys.

Eupluilus.

Neoepiblema.

Tetrastylus.

Briaromys.

Neoprocavia.

Cardiomyss.

Cardiodon.

Anchimys.

Procardiotherium.

Cardiotheritum.

Plexocharts.

Caviodon.

Strata.
- Sciurus.

Sciurodon.

Scinroides.

Plestarctomus.

Plesiospermophilus.

- Myoxus.

Sciuromys.

Cricetodon.

Eomys.

Theridomys.

Protechimys.

Trechomys.

Nesokerodon. 
(Los nombres precedidos de un asterisco sen géneros existentes)

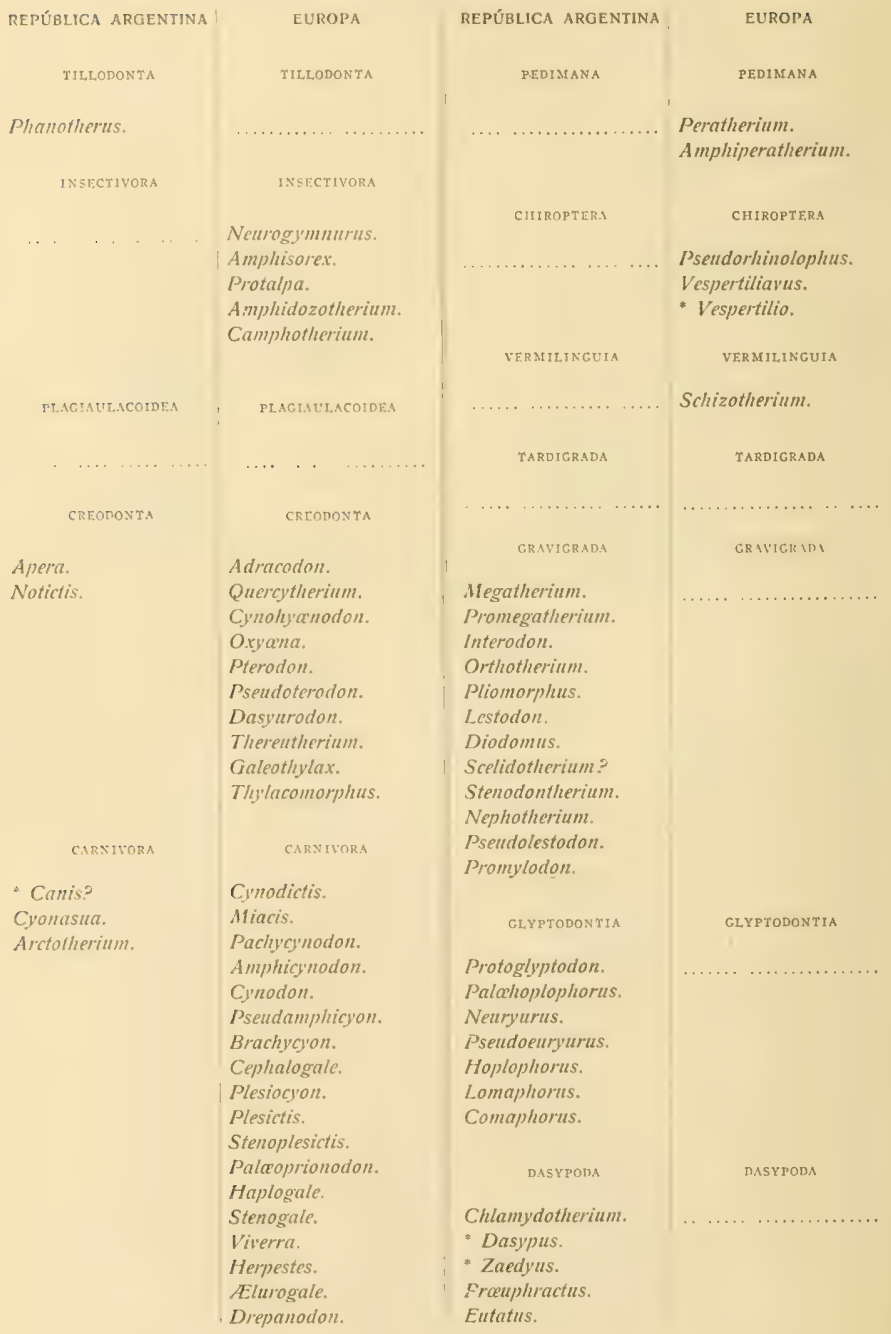


De estos 25 grupos sólo existen 18 en estado fósil durante esta época, 9 en la República Argentina y 13 en Europa, habiendo por consiguiente cuatro grupos: los Stereopterna, Rodentia, Creodonta y Carnivora, comunes a ambos continentes.

Lo que da el sincronismo general de la fauna oligocena de Europa con la de la República Argentina es la presencia de algunos representantes del grupo de los Creodontu que coexisten ací con los verdaderos carnívoros (Carnilora) bastante más numerosos; la desaparición en ambas faunas de los Plagiaulacoidea y los Amblypoda; y la ausencia, tanto en una como en otra, de los Anthropoidea, los Simioidea y los Proboscidea que todavía no han hecho su aparición. La fauna oligocena de Europa presenta un aspecto general más moderno que la de la República Argentina por la presencia de numerosos representantes del grupo de los Ruminantia, que todavía no han hecho su aparición en Sud América, mientras que la fauna oligocena argentina presenta un carácter más primitivo por el predominio de los Perisodáctilos del grupo de los Litopterna, que faltan tanto en Europa como en Norte América.

La fauna europea continúa distinguiéndose de la de Sud América por la presencia de los Inscctivora; y la de Sud América sigue distinguiéndose de aquella por la presencia de los Toxodontia y los Bruta.

Tanto en Europa como en Sud América la fauna mastológica oligocena se compone en su casi totalidad de géneros extinguidos.

\section{FAUNA MIOCENA}

(Los nombres precedidos de un asterisco son géneros existentes)

REPÚBLICA ARGENTINA

ANTIROROIDEA

Anthropoptthects?

SIMIOIDEA

ROSIMIA

EOSIMIA

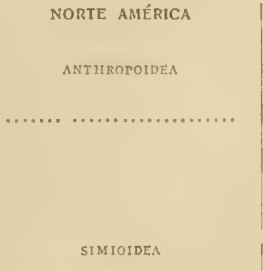

Menotherium.

PROSIMI:

EOSIMIA
EUROPA

ANTHROPOIDEA

Anthropopithecus?

Oreopithecus.

Pliopithectus.

Dryopithecus.

SIMIOIDEA

IROSIMIA

EOSIMIA 
(Los nombres precedidos de un asterisco son géncros existentes)

REPÚBLICA ARGENTINA

CONDILARTHEA

TOXODONTHS
NORTE AMÉRICA

CONDILARTIIRA

TOXODONTHA
EUROPA

CONDII,ARTIIRA

Toxodon.

Trigodon.

Xotodon.

Typotherium.

Pachyrucos.

Protypotherium.

STEREOPTERNA

STLREOPTERNA

STERLOR'TERNA

\section{Hipuidim?}

LITOPTIRNA

Macranchenia.

Epitherium.

IRORUMINANTIA

\section{Hipparion.}

Anchitherium.

Anchippus.

Aceratherium.

Menodus.

Megacerops.

Diconodon.

Brontotherium.

Anchisodon.

Hyracodon.

Diceratherium.

Aphelops.

Peraceras.

Tapiravus.

Lophiodon.

ITTOPTERNA

LITOPTERNA

Hipparion.

Anchithcrium.

Chalicotherium.

Aceratherium.

* Rhinoceros.

Cadurcotherium.

* Tapirus.

PRORUMINANTIA

Eucrotapluss.

Merjcocharus.

Leptauchenia.

Agriocharus.

Coloreodon.

Oreodon.

RUMINANTIA

Hypisodus.

Hypertragulus.

Stibarts.
PRORUMINANTIA

Amplimeryx:

Plesiomeryx.

Cainotherium.

Oxacron.

Xyphodon.

RUMINANTIA

* Hyamoschus.

Gelocus.

Rutitherium. 
(Los nombres precedidos de un asterisco son géneros existentes)

REPÚBLICA ARGENTINA

seris.

AMBLYTODA

PROROSCIDE!I

Mastodon.

RODENIIA

\section{* Ayyopotamus.}

Tribodon.

Ettinysops.

Dicalophorus.

Plitoramys.

Plataomys.

Pithanotomy's.

* Lagostonitrs.

Meganys.

Orthomyctera.

Microcavia.

Palcocavia.

NORTE AMERICA

EUROIA

Perbrotheritum.

Gomphotherium.

Protomery.x.

Procamelins.

SUINA

Hyopotanus.

Percharres.

Nanohytes.

Chanohyus.

Thinohyus.

* Dicotyles.

Eusyodon.

Elotherium.

Pelonax.

Boocharns.

Thinotherium.

$A M B I, Y P O D N$

PRONOSCIDE.

Coenobasileus.

Mrstodon.

RODENTIA

- Sciturtis.

Allomys.

Meniscony's.

Steneofiber.

- Castor.

Heliscomys.

Ischyromys.

Gymnoptychus.

Eumys.

* Vesperimus.

Entoptychus.

Pleurolicus.
AMEI,YTODA

Amphimoschus.

- Moschus.

rocerinlits,

Cervilus.

Amphitragulus.

Palaeomeryx.

Orotherium.

Micromery.x.

- Cerrus.

* Capreolus.

Antilope.

Hippotragus.

SUIXA

Anthracothcrium.

Hyopotamus.

Choeropotamis.

Cebochoeris.

Palaeochoerus.

Hyotherium.

* Sus.

Elotherium.

Listriodon.

PROPOSCIDEs

Dinotherium.

Mastodon.

RODENTIA

* Sciurtus.

Psertdosciurtus.

Sciuroides.

Steneofiber:

* Myoxus.

Eliomys.

Oreomys.

Cricetodon.

Theridomys.

Onegodus.

Archaeomy's.

Issiodoromys. 
(Los nombres precedidos de un asterisco son géneros existentes)

REPÚBITCA ARGENTINA

Phugatherium.

Diocartherium.

Hydrochoerus.

Caviodon.

INELCIILORI

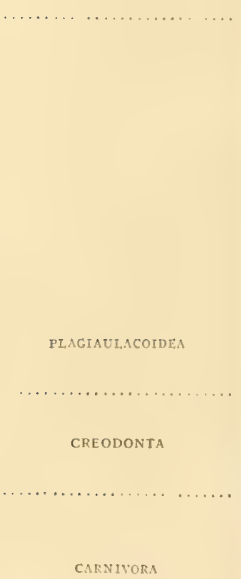

* Canis
NORTE AMÉRICA

Mylagaulus.

Paciculis.

Palacolagtus.

INSETIVORA

Lepticlis.

Mesodectes.

Geolabis.

PLAGIAULACOLDE:

CREODONTA

Hemipsalodon.

Hyaenodon.

\section{CARNIVORA}

\section{Tennocyon.}

Galecynus.

* Canis.

Oligobnnis.

Enhydrocyon,

Bunacluris.

Hyanocyon.

Archaclurus.

Nimuavis.

Dinictis.

Pogonodon.

Hoplophoneus,
EUROPA

Dipoides.

* Hystrix.

Titanomy's

Myolagus.

INSECTIVORA

* Erinacetis.

Palacoerinaceus.

Tetracus.

Dimilus.

Cordilodon.

Parasorex.

Plesiosorex.

* Sorex.

Mlysarachne.

* iyogale.

* Talpa.

Echinogale.

PLAGIAULACOIDEA

\section{CREODONTA}

CARNIVORA

Amphicyon.

Galecynus.

Dinocyon.

Crnelos.

Amphictis.

Potamotherium.

* Lutra.

Trochictis.

Trochotherium.

Proplesictis.

Plesictis.

- Martes.

Soricictis.

Stenogale.

Psendictis.

Palaeogale.

* Alistela. 
(Los nombres precedidos de un asterisco son géneros existentes)

REPÚBLICA ARGENTINA

PLUTMANA

- Didelphys.

CIIROPTERA

$\ldots \ldots \ldots \ldots \ldots \ldots \ldots$
vERMILINGUIA
$\ldots \ldots \ldots \ldots \ldots \ldots \ldots$

GRAVICRADA

Megatherium.

Lestodon.

Diodomus.

Scelidodon.

Psendolestodon.

GLYPTODONTIA

Glyptodon.

Hoplophorus.

Lomaphorus.

Palaehoplophortus.

Plohophorus.

Panochtus.

Nopachtus.

Neuryurus.

Plaxhaplus.

DASYPODA

Chlamydotherium.

- Dasypus.

- Zaedyus.

Proeuphractus.

Afacroeuphractus.

Eutatus.
NORTE AMÉRICA

EUROPA

Proailurus.

* Viverra.

Thalassictis.

Herpestes.

Drepanodon.

Machacrodus.

Palaeonicteris.

PFDIMANA

PIDDIMANA

Peratheritum.

Amphiperatherium.

* Didelphys.

Embassis.

CIIROPTERA

CIIIROPTERA

Domnina.

VERMILINGUIA

* Vespertilio.

VERMILINGUIA

Limognitherium.

Ancylotherium.

Alacrotherium.

GR.IVICRAD.

GRAVIGRADA

Moropus.

GLYPTODONTIA

DASYPODA
GLYPTODONIIA 
De estos 24 grupos hay 19 en estado fósil en terrenos que en ambos cuntinentes son considerados como miocenos. De estos 19 grupos hay 12 en la República Argentina, 13 en Norte América y 12 en Europa, siendo 6 de ellos comunes a las tres regiones.

Lo que distingue a la fauna miocena de la oligocena, es la desaparición de los Creodontes, pues si bien en la lista precedente se encuentran como formando parte de la fauna miocena de Norte América, ello ss debido a que no habićndose adoptado alli la división del oligoceno, la parte superior o más moderna de esta formación está incluida en el mioceno y debe ser precisamente la que contiene los Creodontes.

Lo que da el sincronismo de estas tres faunas es la aparición de los proboscidios, representados en todas partes por géneros extinguidos, y la primera aparición de los rumiantes provistos de apéndices frontales.

Los insectivoros continuan siendo exclusivos del hemisferio septentrional y los Toxodontes del hemisferio austral, pero los rumiantes pasan al hemisferio austral y los gravigrados pasan por primera vez a Norte América. Los roedores son numerosos en todas partes y los Gliptodontes y dasipódidos continúan siendo exclusivos de Sud América.

La proporción de los géneros existentes ha aumentado notablemente, constituyendo el 20 por ciento de la fauna miocena de Europa, el 16 por ciento en la de la República Argentina y sólo el 8 por ciento en la de Norte América, 10 que es debido a lo que antes he mencionado, esto es: a que la fauna miocena de Norte América comprende igualmente la fauna de la parte más reciente de los terrenos oligocenos.

Aparte esta discordancia, el sincrónismo es evidente y en ningún caso podria considerarse la fauna miocena argentina como mas reciente que la fauna miocena europea.

FAUNA PLIOCENA

(Los nombres precedidos de un asterisco_son los géneros todavia existentes)

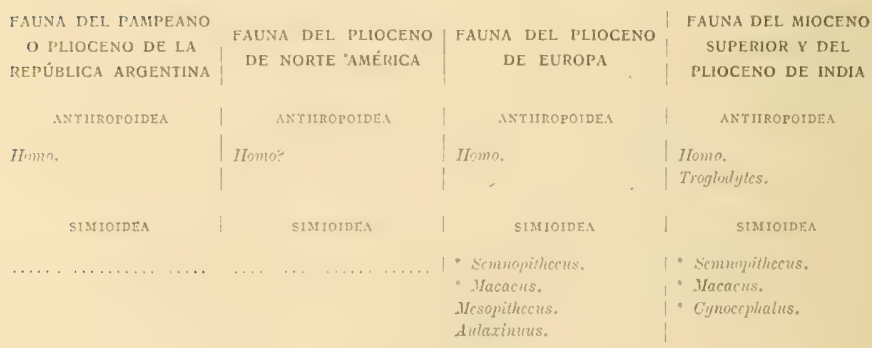


(Los nombres precedidos de un asterisco son los géneros todavia existentes)

FAUNA DEL PAMPEANO

O PLIOCENO DE LA REPÚBLICA ARGENTINA

TOXODONTIA

Tus iven.

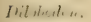

Typuthin inu.

Pieleyrates.

STIRLIII LKN

Anstul...

Eifrom.

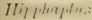

Minatiolore.

IIipilinus.

LITOPTERNA

Wersedente.

Jliats mitall wh.

PRORUMINAYTIA

Diplotremess.

RUMINANTIA

- Consing

Piraeros.

- Cereus.

- Blastoceros.

Antifer.

- Fureifor.

Epicuryceros.

\section{FAUNA DEL [PLOCENO I'AUNA DEL PLIOCENO DE NORTE AMÉRICA}

rOXODONTIA

Tortulin.

STERLATHRNA

- Tapirims.

- Eipues.

Hillarion.

Ajhclups.

Anchipuss.

Mcrychijpus.

Protoltippus.

Thohimmes.

Iipputixn.

Mipahipus.

LITOPTERNA

LITOPTFRNA

LITOPTERNA

- Tavirus

- Eiruses.

IIipparion.

- Rkinsacros.

Leptortore.

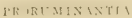

PRORUM1N:ANTEA

Cyelopidins.

Fithecistes.

Uerycochocrus.

RUMINANTIA

RUMINANTIA

RUMINANTIA

- Cariacus.

* Corizs.

- Elophlus. rupirus.

- Equhs.

IIiprarion.

- Phimoceros.

Chalicotherism.
Agriochocrus.

Cerrulus.

Palaconery.r.

- Corrus.

- Cameulus.

- Avis.

- Elaphizs.
FAUNA DEL MIOCENO SUPERIOR Y DEI. PLIOCENO DE INDIA

TOXODONTIA

biuclatoreras.

Strongyloccros.

- Dama.

- Ceriates.

- Tarcundus.

- Cameloparialis.

Ifellarinthicium.

- Antilopc.

- Gazclir.

Talacotragus.

Tragocoros.

Palizeorens.

IIippotragus.

Protragelighus.

- Corrus.

- Aleclaphus.

- Cameloparilalis.

Ifrlladotizerimo.

- Tetraceros.

- Gasella.

- Tragulus.

* Stropsiccros.

- Oreas.

Hippotragus.

Cubas. 
(Los nombres precedidos de un asterisco son los géneros todavia existentes)

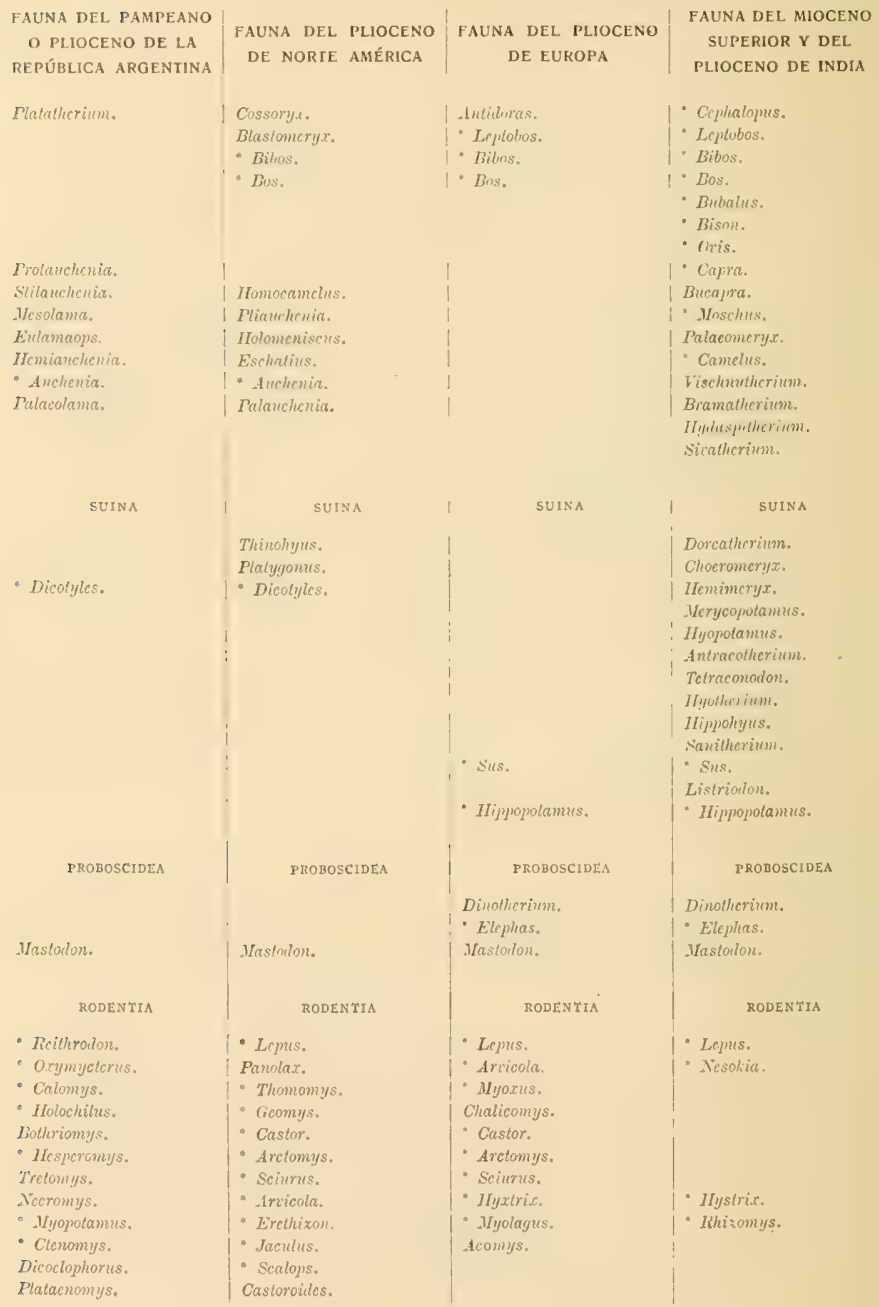


(Los nombres precedidos de un asterisco son los géneros todavia existentes)

\section{FAUNA DEL PAMPEANO \\ O PLIOCENO DE LA \\ REPÚBLICA ARGENTINA}

Pithanotomys.

- Lagnstomus,

Orthomycterct.

- Mulichotis.

- Cerodon.

Hicroracia.

Palapocavia,

- Higircelencrus.
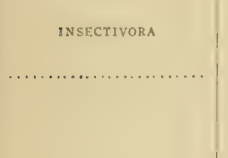

CRE,ODONTA

CARNIVORA

- Canis.

Macrucyon.

Arctotherime.

- Lutro.

- Mephitis.

- Iyncodon.

Machaerortus.

sinilaton.

- Felis.

PEDIMANA

- Diteljhliss.

Dimeroden.

CIIIROPTERA

VERMILINGUTA
FAUNA DEL PLIOCENO DE NORTE AMÉRICA

Amblythisa.

* Hyelrnchocmes.

INSECTIVORA

CRFODONTA

................

CARNIVORA

- Caris.

Leptarctos.

- Arciodis.

Aretotherium.

- Lutra.

Tomaretus

- Martes.

I,uirictis.

- Mustela.

+ Taxidea.

- Froeyon.

Prohizacna.

Smitomur.

* Felis.

PEDIMANA

. $\ldots \ldots \ldots \ldots \ldots \ldots$

CIIROPTER

YFrMITIXGTH
SUPERIOR $Y$ DEL.

PLIOCENO DE INDIA
INSECTIVORA

- Erinaceus.

- simer.

- Mirruli.

- Talpa.

CREODONTA

CIITROPTERA

- Fespertilio.

VERMIITNGUIA

INSECTIVORA

CREODONTA

Hyaenondon.

\section{CARNIYORA}

- Canis.

Hyaenaretos.

* Trsis.

Simocyon.

- Lutra.

Troclictis.

- Martes.

Rhabdngale.

Promephitis.

- Mustela.

Guico.

Ictitheriom.

* Hyaena.

Ityaenictis.

Ifacherermis.

" Felis.

PEDINANA

IIjaenurelos.

- Ursus.

Amphicyon.

- Inetra.

Tieriugt.

Jilimpes.

- Hitrmer.

- Mustela.

Mellivorodon.

* Mellienra.

- ITyaena.

Lepthyaena.

Machaeroibs.

- Felis.

\section{VERMILINGUTA}

Ancylotheriam.

Maerotherimm. 
(Los nombres precedıdos de un asterisco son los géneros todavía existentes)

\begin{abstract}
FAUNA DEL PAMPEANO
O PLIOCENO DE LA
\end{abstract}

REPÚBLICA ARGENTINA
FAUNA DEL PLIOCENO | FAUNA DEL PLIOCENO DE NORTE AMÉRICA DE EUROPA
FAUNA DEL MIOCENO SUPERIOR Y DEL PLIOCENO DE INDIA
GRITIGRADI

- If gatherimm.

(x)

Cuetalom.

Vemacanthus.

Nothropus.

Ifstoutem.

Intionton.

Ilatyrlum.

Srelulalhrimm.

firelitoel m.

I If e, ,

Gibssothrium.

Jalyijes.

Wyloimer.

Pservidestoulon.

GIYPTODONTIA

1, , , , ....

Ficolhoracophenus.

lloplophorns.

Lomecphorus.

Nonachtus.

Panochitus.

Vewryurus.

In whantus.

Inifulicurus.

D.1SYPODA

chamentuth rium

- Trutasiar.

I'orprautas.

- Jasmins

* Zanedyris.

Eutitus.

- Tulingutes.

- Clitamayeloyitionis.
GR.IUTGRADA

GRAYICRADA

CRAIIGRADA

Wryallerrimu.

Horopus.

Horalleriman.

Hegalony.x:

1. Mylotin.

CLYPTODONTIA

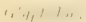

Carysterna.

En esta época la fauna de mamíferos es de un carácter más uniforme sobre toda la superficie de la Tierra, con excepción de Australia. Los insectivoros continuan siendo exclusivos del hemisferio boreal, pero los Gliptodontes pasan a Norte América y los gravigrados resultan allí numerosos.

La proforción de géneros existentes es mucho mayor que en la época anterior, representando el 57 por ciento en la fauna de Europa, el 49 por ciento en la de India, el 42 por ciento en la de Norte América y sólo el 32 
por ciento en la de la República Argentina, siendo así evidente que ésta no puede ser de época más reciente que las otras tres.

Por el número de géneros existentes, la que tiene un carácter más moderno es la de Europa, siguiendole luego la de India; pero es indudable que ésta representa un espacio de tiempo mucho más considerable; por lo menos asi parece demostrarlo la existencia en ella de representantes del grupo de los Creodonta, que se extinguen en el oligoceno y la de varios géneros característicos del mioceno de Europa, donde no tienen representantes en el plioceno.

Las faunas de Norte América y de Sud América aparecen más próximas que en la época miocena; y si en la última hay un mayor número de géneros extinguidos, ello depende del gran desarrollo que aquí toman los grupos de los gravígrados y Gliptodontes.

La relación de época entre las cuatro regiones se establece por la aparición de los géneros Equus, Cerrus, Cunis, Lutra y Felis, todavía existentes y comunes a las cuatro faunas; y por los géneros extinguidos Macharodus y Mastodon.

El sincronismo entre la fauna de India y la de Europa se establece por medio de los géneros Semnopithecus, Haracus, Tapirus, Equus, Hipparion, Rhinoceros, Cervus, Camelopurdalis, Helludotherium, Gazella, Hippotragus, Leptobos, Bibus, Bus, Sus, Hippopotumus, Dinotherium, Elcphas, Mastodon, Lepus, Hystrix, Canis, Hywnarctos, Ursus, Lutra, Fclis, Mustela y Machorodus, comunes a ambas faunas.

El sincronismo entre la fauna pliocena de Europa y la de Norte América se establece de una manera satisfactoria por los géneros comunes Tapirus, Equas, Hipparion, Aphclops norteamericano que representa el Rhinoceros de Europa, Cern'lls, Elaphus, Bibos, Bos, Hastodon, Lepus, Arvicola, Castor, Arctomy's, Sciurus, Canis, Leptarctos norteamericano que representa el Hywnarctos europeo, Lutra, Martes, Mustela, Fclis y Smilodon norteamericano que representa el Machurodus europeo.

El sincronismo de la fauna pliocena norteamericana con la de la Republica Argentina se establece de una manera no menos evidente por medio de los géneros comunes Toxodon, Equus, Hipphuplus argentino que corresponde a Hipparion norteamericano, Plicatodon argentino que representa Aphelops, norteamericano, Hippidium, Diplotremus argentino que corresponde a Cyclopidius norteamericano. Cormus, los géneros de camélidos argentinos Stilaucheniu, Mesolama, Eulamaops, Hemianchenia, Auchenia y Palcolama en paralelo con los géneros norteamericanos Homocamelus, Holomeniscus, Eschutiuts, Auchenia y Palauchenia, los géneros Dicotyles, Mastodon, Hydrocharus, Canis, Lutra, Felis, Smilodon, Arctotherium, Megatherium, Wegalonyx, Myludon y Glyptodon. 


\section{FAUNA CUATERNARIA}

(Los nombres precedidos de un asterisco son los géneros existentes)

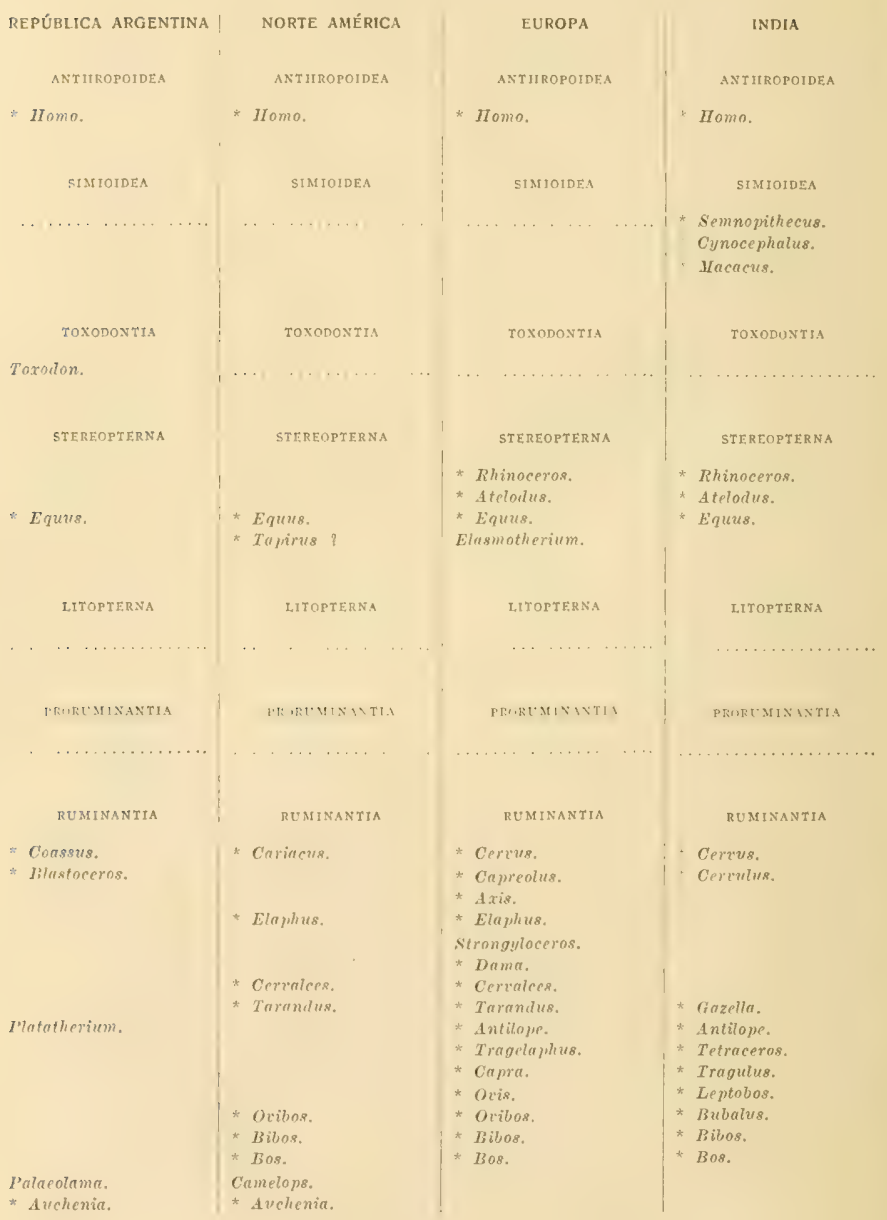


(Los nombres precedidos de un asterisco son los gëneros existentes)

\section{REPÚBLICA ARGENTINA}

SUINA

Dicotyles.

PROBOSCIDEA

Jastodon.

RODENTIA

- Reithrodon.

* Oxymycterus.

Habrothrix.

* Calomis.

* Holochilus.

* Nesperomys.

* IIvopotamus.

+ Ctenomys.

- Lagostomus

* Dolichotis

* Ceredon.

* Cavia.

* Indrochoerus.

ITSECTIVORA

INSECTIVORA

* Anomodin.

CARNIVORA

CARNIVORA

Canis.

Lutra.

If phitis.

Lyncodon.

Felis.

Fils.

\section{EUROPA \\ SUINA \\ * Sus. \\ * Ulimpopotemus. \\ PROBOSCIDEA \\ * Elephas. \\ RODENTIA \\ * siciurus. \\ Trogontherium. \\ * Castor. \\ * Spermoyhilus. \\ * Myoxus. \\ * MInscarilinus. \\ * Arctomys. \\ * Cricetus. \\ * Mus. \\ * Siminthas. \\ * Lepus. \\ Pellegrinit. \\ * Hystrix. \\ * Myolagus. \\ * Lagomys.}

INSTC'PIYOR.I

* Sorex.

* Erinacers.

* Crocillera.

* Myogale.

Talpa.

CARNIVORA

Cornis.

Lycroun.

* Trews.

Lutra.

* Martes.

* Merstrle.

* Gulne.

- Meles.

* Hisarnar

- Felis.

Jasharerortus.

PEDIMANA
CARNIVORA

INDLA

SUINA

* Sus.

Hipponotamus.

PROBOSCIDEA

Elephas.

RODENTIA

* Sciurus.

* Gerbillus.

* Nesolia.

* Hus.

- Golundar.

* Lemus.

- Hystrix.

INSECTIVOR.

sorex.

troxs.

- Viverra.

Herpestes.

* IIyaena.

* Ielis.
* Atkerura. 
(Los nombres precedidos de un asterisco son los géneros existentes)

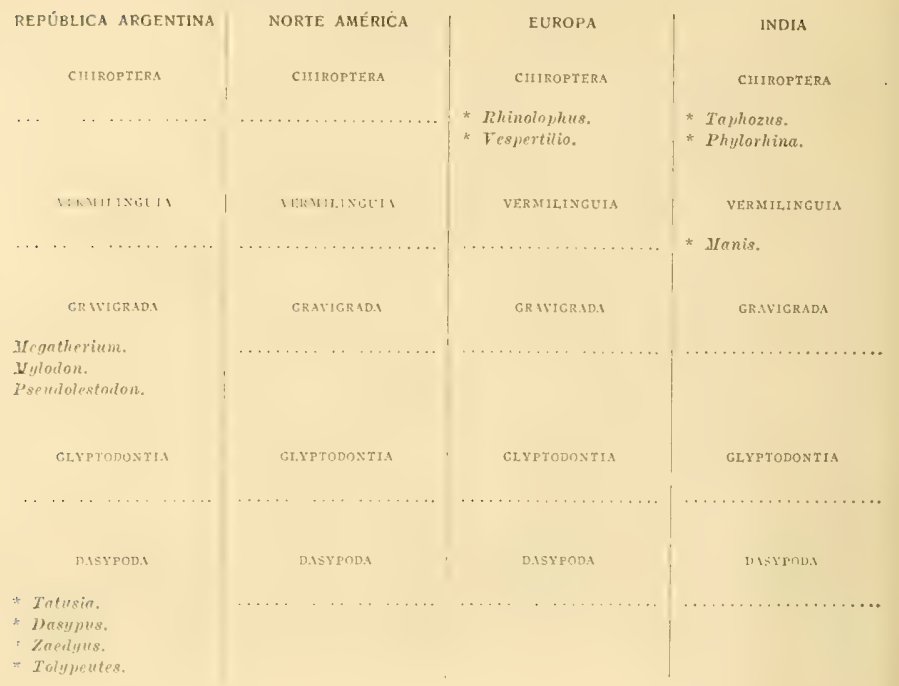

Esta fauna se distingue fácilmente de la del plioceno por ser la mayor parte de los géneros que la forman todavia existentes, constituyendo los extinguidos, a lo más un 25 por ciento, y esto sólo en Norte América, donde es posible sea debido a la inclusión en la fauna cuaternaria de algunos géneros pliocenos, pues muchos de los géneros mencionados en esta lista como cuaternarios son considerados por varios autores como exclusivamente pliocenos.

La fauna cuaternaria de la República Argentina contiene el 17 por ciento de géneros de mamiferos extinguidos, debido principalmente a la persistencia de varios géneros de desdentados pliocenos o pampeanos.

La fauna cuaternaria de Europa sólo tiene un 9 por ciento de géneros extinguidos; y la de India parece estar constituida exclusivamente por géneros existentes, pero muchos de ellos están representados por especies extinguidas. 


\section{RELACIÓN DE LAS FAUNAS DE MAMÍFEROS PLIOCENAS Y CUATERNARIA DE LA REPÚBLICA ARGENTINA, CON LA QUE SE ENCUENTRA EN ESTADO FÓSIL EN LAS CAVERNAS DE BRASIL.}

Las especies precedidas de un asterisco son existentes; y las seguidas de dos asteriscos son caracteristicas de la parte stiperior o más reciente de la formación pampeana (piso lujanense). Los géneros extinguidos están en bastardilla.

\begin{abstract}
1'AMPEANO INFERIOR DE LA
REPÚBLICA ARGENTINA (PLOCENO INFERIOR)
\end{abstract}

* IIomo.

Necromys conifer.

\section{PAMPEANO SUPERIOR \\ DE LA}

REPÚBLICA ARGENTIN (PLIOCENO SUPERIOR)

* IIomo.

* Reithruton typicus ** Ptyssophorus clegans ** Oxymycterus impexus.

* Oxymycterus rufus **

* Calomys longicaud. * *

IIolochilus vulpinus **

* Holochilus multan. ** Bothriony's cutenatus. Ilesperomys molitor **

Treiomys atazizs.

Necromys conifer.
CAVERNAS DE BRASIL.

CUATERNARIO DE LA REPÚBLICA ARGENTINA

* Honio.

Protopithecus brasilicus.

* IIomo.

* Cebus a pella.

Callithrix primeva.

* Mycetes ursinus.

* Hapale penicillata.

Ifapale grandis.

* Oxymycterus rufus.

Oxymycterus breviceps.

Oxymycterts talpinus.

Oxymycterus cosmodts.

* Calomys longicaudat.

Calomys plebejus.

Calomys rex.

Calomys coronatus.

* Calomys laticeps.

* IIolochilus vulpinus.

IIesperomys molitor.

* Hesneromys tener.

* Hesperomys simplex.

* Hesperomys expulsus.

* Habrothrix cursor.

IIabrothrix clivigenis.

* IIabrothrix orycter.

* IIabrothrix lasiurus.

* Scapteromys labiosus.

* Scapteromys princip.

Scapteromys fronto.

Scapteromys anoblepas.

* Rhipidomys mastac.

- Nectomys scuamipes.

* Sphingurus insicliosus.

Sphingurus magnus.

Sphingurus prehensilis.
* Calomys Iongicaud.

* Calomys binaculatus.

* Calomys auritus.

* Reithrodon typicus.

* Oxymycterus rufus.

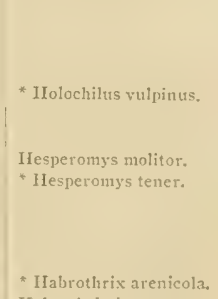

* IIolochilus yulpinus.

Ifesperomys molitor.
"Hesperomys tener.

Iesperomys molitor.
"Hesperomys tener.

s.

* Habrothrix arenicola. Habrothrix internus. 
Las especies precedidas de ut asterisco son existentes; y las seguidas de dos asteriscos son caracteristicas de la parte superior o más reciente de la formación pampeana (piso lujanense). Los géneros extinguidos eslán en bastardıl]a.

\section{PAMIPEANO INFERIOR DE LA \\ REPÚBLICA ARGENTINA (PLIOCENO INFERIOR)}

Myopotamus, sp. ?

Ctenomys bonariensis.

Dicoclophorns latidens. Plataenomys scindens.

Lagostomus minimus. Lagostomus cavifrons.

Orthomyelera lata.

Jolichotis minor.

Dolichotis platycephala.

Paracarin fampaca.

Hydrocherus magnus.

\section{PAMPEANO SUPERIOR I)E LA \\ REPÚBLICA ARGENTINA (PLIOCENO SUPERIOR:}

ifyopotamus priscus.

* Myopotamus corpus.

* Dactylomys amblion.

* Lasiuromys villosus.

* Loncheres armatus.

* lichinomys cajennen.

* Nelomys antricola.

* Mesomys spinosus.

Mesomys mordax.

* Carterodon sulcidens.

Dicolponys fossor.

* Sciurus iestuans.

Ctenomys magellan. " *

Ctenomys lujanensis.

"Lagostomus trichod, *t

Lagostomus debilis.

Lagostomus cavifrons. Lagrostomus heterogen,

Orthempetera lata.

Dolichotis major ** Dolichotis intermedin.

Ccrodon antipuus.

Cerodon turgeo.

Cerodon priscus **

Cerorlon pygmeus "t

Microcatia rabusta.

Micracueia typica.

Microcarin dubia.

Microcasia uncinata.

Wicrecnetio intermadic.

Palacocuria minuta.

Cavia porcellixs.

Cavia? vates.

* IIvdrechertus capy, ** * IIydrocherus cajyb,

\begin{tabular}{l|l} 
Hydrocherus gigant. * " & Ifycltochcerus giganteus.
\end{tabular}

syprocta aguti.

* Coelogenis paca.

Celogetis laticeps.

* Crelogenys major.

- Cermlon buliviensis.

* Cerodion flavidens.

Iytrachcerus magnts,
CUATERNARIO DE LA REPÚBLICA ARGENTINA

* Myopotamus coypus.

Ctenomys magellanic.

* Lagostomus trichodac.

* Dolichotis patachonic.

* Cerodon leucobleph.

* Cavia porcelius.

* IIydrochcerus capyb. IIydrochrerus giganteus. 
Las especies precedidas de un asterisco son existentes; $y$ las seguidas de dos asteriscos son caracteristicas de la parte superior o mis reciente de la formacion pampeana (piso fujanense). Los gínetos extinguidos estân en bastardilla.

\section{PAMPEANO INFERTOR ${ }^{\circ}$ DE LA \\ REPÚBLICA ARGENTINÁ (PLIOCENO INFERIOR)}

* Canis bonariensis.

* Canis bonariensis.

Arctotheritu bonarien. Arctotherium angustid.

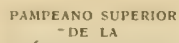

Didelphys incerta **

Didelphys juga.

Didelphys grandrva.

Dimeroton mutilutus.

* Canis Azarce *

Canis cultridens **

Canis protojubatus **

Canis aytre,

Macrocjon robustus.

Arctollerium angustid.

* Lutra paranensis **

Mephitis primava.

Mephitis mercedensis.

* Mephitis suffocans *

Lyneodon lujanensis.

Fclis longifrons.

Felis platensis **
CAVERNAS DE BRASIL

CUATERNARIO DE IA REPÚBLICA AROENTINA

* Lepus brasiliensis.

* Iidelphys Azara.

* Didelphys cinerea.

* I)idelphys murina.

* Didelpliys pusilla.

* Didelphys crassicaud.

* Dielelpliys nudicaud.

* Didelphys elegans.

* Didelphys grisea.

Canis lycodes.

Canis protalopex.

Canis Lydekkeri.

1.Canis fulvicaudus.

* Canis vetulus.

* Canis brasiliensis.

* Speothos pacivorus.

* Icticyon venaticus.

Icticyon major.

Palacocyon zalidus.

Palacocyon troglodytes.

* Nasua narica.

Ursus? btasiliensis.

* Jutra brasiliensis.

Mephit is fossilis.

Galictis major.

Galictis intermedia.

* Galictis barbara.

- Felis concolor.

lielis onca.
* Didelpliys Azare.

Didelphys lujanensis.

- Canis Izare.

Canis cultrilens.

* Canis jubatus.

* Canis gracilis.

Canis lycodes.

- Lutra paranensis.

* Mephitis suffocans.

* Felis concolor.

* Felis onça. 
Las especies precedidas de un asterisco son existentes; y las seguidas de dos asteriscos son caracteristicas de la parte superior o más reciente de la formación pampeana (piso lujanense). Los gẻneros extinguidos están en bastardilla.

PAMPEANO INFERIOR DE IA

REPÚBLICA ARGENTINA (PLIOCENO INFERIOR)

Machacrodis ensenad.

Similodor populator.

Torodon ensenadonsis.

Toxodon platensis.

Toxodon Burmeisteri.

Torodon Darzoini.

Dilobodon Injanensis. Typotherium cristatum. Typotherim pachyonat. Typothcrimm maendr. Typolkcrium exigunm. Fintelomorphas rotund. Pachyrucos bonariensis. Autaodon cinctics.

Plicatodon perrarus.

Tippidium principalc. Hippidium angulatum. Hippidium compressid.

Macranchenia boliriens.

Macranchenia ensenad.

Diplotremus agrestis.

Auchenia gracilis.

Auchenia Castelnaudi.

Auchenia ensenadensis. Anchenia Weddelli.

\section{PAMPEANO SUPERIOR DE LA \\ REPÚBILCA ARGENTINA (PLIOCENO SUPERIOR)}

Felis palustris.

Similodon fopmlator.

Toxodon platensis.

Torodon Burncisteri.

Torodon paradorus ** Torodon gracilis.

İquus curvidens.

Eqquus 1 ectidens.

Fiquus argentinus.

Hifpidium ncogacum.

Hipridim principale.

Hiph haplus Brasardi. Hirplaplus antiguns.

Macrauchenia patachon.

Diastomicolon lujanen. Dicotyles stenoceph. ?

* Dicotyles tajacu.

Auchenia intermedia.

Axchania frontosa.
CAVERNAS DE BRASIL

CUATERNARIO DE LA REPÚBLICA ARGENTINA

Felix protopanther.

* Felis pardalis.

* Felis mitis.

* Felis macroura.

Felis pusilla?

Machacrodus Pradosí.

Smilodon, populator.

* Dysopes Temminchi.

* Pliyllostoma spectrum.

? Terodon crtansidens.

Toxodon platcnsis.

* 'Tapirus americanus.

Tapirus suinus.

jquus curvidens.

Fquus rectidens.

Hippidium ncogaenm.

Hippidium principale.

Dicotyles stenocephalus.

* Dicotyles labiatus.

* Dicotyles tajacu.
* Dicotyles tajacu. 
Las especies precedidas de un asterisco son existentes; y las seguidas de dos asteriscos son caracteristicas de la parte superior o más reciente de la formación pampeana (piso lujanense). Los géneros extinguidos están en bastardilla.

\section{PAMPEANO INFERIOR DE LA \\ REPUEBLICA ARQENTINA (PLIOCENO INFERIOR)}

Auchenia lujanensis.

Nesolama angustimar.

Paraceros ensenadensis. Paraceros fragilis.

\section{Epieuryceros truncus.}

Mastodon andium. Mastodor platensis. Mastodon argentinus. Míastodon rectis.

Megatherium tarijense.

Neoracanthus Burmcist. Neoracanthus platcnsis.

Lestodon armatus.

\section{PAMPEANO SUPERIOR DE L.A \\ REPÚBLICA AROENIINA (PLIOCENO SUPERIOR)}

Auchenia lujanensis.

Palacolama major. I'alaeolama icptogn. * *

Stilanchenia Orucmi.

Hemianclienia paradora. Profanchenia Reissi. Eulamaops parallelus.

Cervus brachyceros.

Cervus Iujanensis.

Cervus palreoplatensis,

Cervirg latus.

Cervus tuberculatus

Paraceros :ulucratus.

*Blastoceros campes. **

* Blastoceros paludosus.

Antifer wltra.

Furcifer sulcatus.

Furcifer seleniticus.

Platatheriam pamp. **?

Mastodon platensis.

Mastodon Humboldti.

Mastodon superbus.

Megatherium ancrican.

Megatheriwm tarijensc.

Megatherium Gern: **

Megatherimm Lundi.

Nuthropus priscus.

Lestodon trigonidens.

Lestodon Bocagci.

Lestodon Gaudryi.

Lestodon Bravardi.

I.aniodon robustus.

Scelidotheritu leptocep.

\section{CAVERNAS DE BRASIL CUATERNARIO DE LA \\ REPÚBLICA ARGENTINA}

Auchenia minor.

Auchenia mesolithica.

Auchenia cordubensis.

Auchenia lama.

Talacolama leptognatha.

Palacolama mesolithica.

* Coassus nemorivagus.

* Coassus rufus.

* Coassus rufinus.

* Blastoceros campest.

* Dlastoceros paludosus.

* Blastoceros paludosus.

Platalherium pants.

Mastodon Humboldi.

Megatherium american.

Mastodon superbus.

IIegatherium american.

Essonodontherium Ger.
* Blastoceros campest.

* Coassus nemorivagus.

* Coassus rufus.

Coassus mesolithicus.

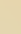

Ocnopus Laurillardi.

Lestodon armatus ? 
Las especies precedidas de un asterisco son existentes; y las seguidas de dos asteriscos son características de la parte superior o más reciente de la formación pampeana (piso lujanense). Los géneros extinguidos están en bastardilla.

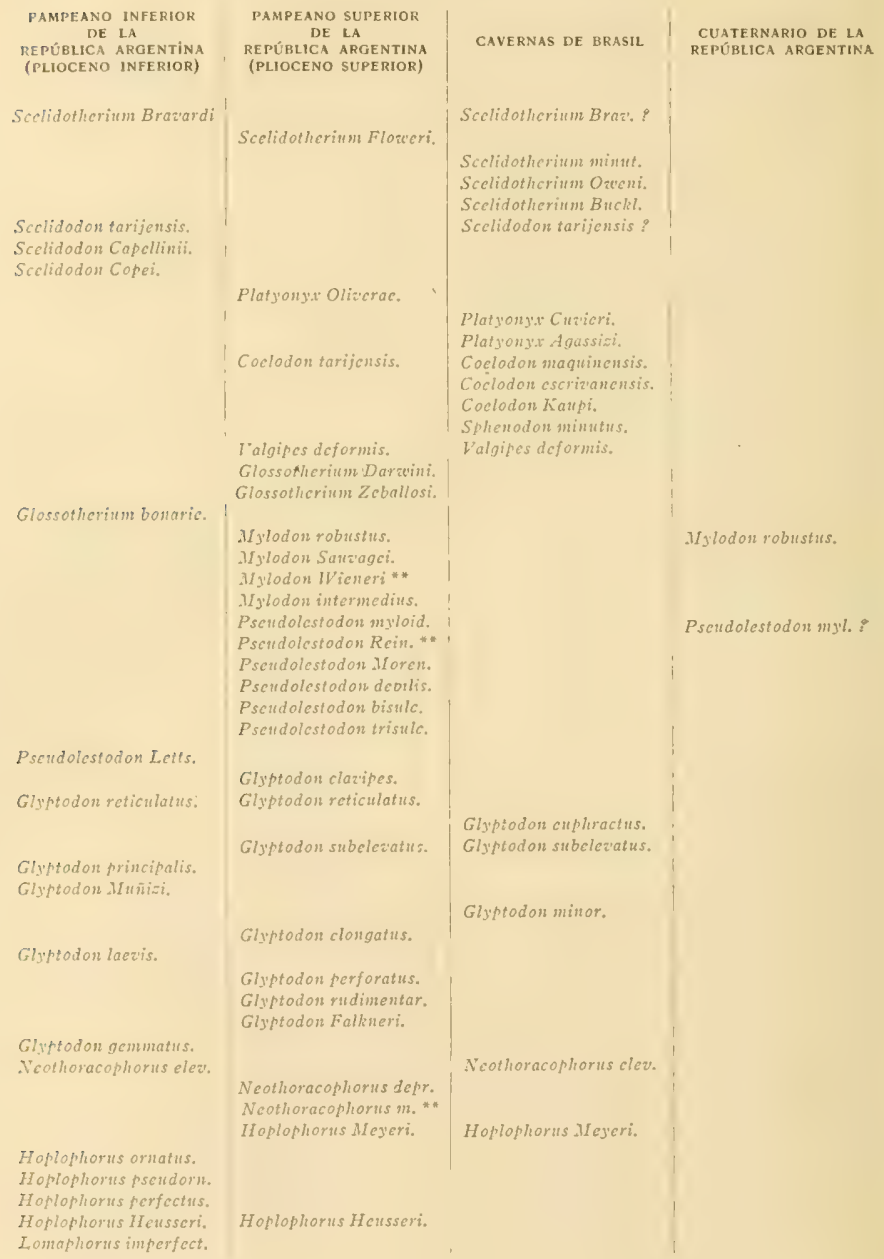


Las especies precedidas de un asterisco son existentes; y las seguidas de dos asteriscos son caracteristicas de la parte superior o más reciente de la formación pampeana ( piso lujanenee). Los géneros extinguidos estän en bastardilla. PAMPEANO INFERIOR
DE LA
REPÚBIICA ARGENTINA (PLIOCENO INFERIOR)

\section{Lomaphortus elezutus.}

\section{Lomathorus compress.}

Nopachtus coagmentat.

Panochius Frenzelianus.

Plothaplus canaliculat.

Docdicurus Poucheti.

Docdicurus Kokenianus.

Chlamydotherium typ.

Propraopus grandis, -

- Dasypus sexcinctus.

* Dasypus villosus.

\section{Eulatus Seguini.}

Eutatus punctatus.

Eutafus minutus.

- Tolypentes contarus.

\section{PAMPEANO SUI'ERIOR} DE $L A$ REPÜBLICA AROENTIMA (PLIOCENO SUPERIOR)

Lomaphorus clez'atus. Lomaphorus elegans. Lomathorus gracilis.

Panochitus tubcrculatus. Parochitus Morenoi.

Panochtus Frenzclianus. Panochitus Vogti **

Plaxhapius caualiculat. Doedicurus claz'icaudat. Doedicurus Poncheti.

Chlanydolherium typ.

"Tatusia hybrida **

* Tatusia novencincta.

Propraopus grandis.

* Dasypus villosus.

Dasypus major.

Eutatus breqis.

Eutatus punctatus.

* 'Tolypentes conurus.

Chlamydophorus trunc.
CAYERNAS DE BRASIL

CUATERNARIO DE LA REPÚBLICA ARGENTINA

Champdotherium $\mathrm{Hum}$. Chlamydotherium gigas.

* 'Tatusia novemcincta.

* Tatusia punctata.

Tatusia hybrida.

* Dasypus villosus.

Dasypus major.

Dasypus platensis.

* Zaedyus minutus.

* Tolypeutes conurus.
Furyodou latidens.

IIterodon dizersidens.

* Xenurus nudicaudus.

- Myrunecophaga jubata.

- Myrmecophaga tetrad.

Resulta de estas listas que el pampeano inferior tiene el 96 por ciento de especies extinguidas, el pampeano superior 89 por ciento, la fauna de las cavernas de Brasil el 50 por ciento y la fauna cuaternaria de la República Argentina sólo el 38 por ciento. E1 pampeano inferior tiene el 78 por ciento de géneros extinguidos, el pampeano superior el 52 por ciento, la fauna de las cavernas de Brasil el 32 por ciento y la del cuaternario de la República Argentina sólo el 23 por ciento.

De aquí se sigue que la fauna de las cavernas de Brasil no puede ser más antigua que la del pampeano superior, ni más moderna que la del cuaternario. 
No es posible poner en paralelo la fauna de las cavernas de Brasil con la del pampeano inferior, pues apenas si hay una sola especie y uno que otro género que le sean comunes. La relación se establece un poco más estrecha con el pampeano superior, en el que se encuentra un cierto número de especies y muchos géneros de los que constituyen la fauna de las cavernas brasileñas, pero cuando las especies son idénticas, se observa que en la República Argentina sólo se encuentran en la parte más reciente del pampeano superior, la que constituye el piso lujanense. En las cavernas de Brasil hay un considerable numero de especies actuales que no se encuentran un la formación pampeana, pero muchas de ellas, así como también algunas de las extinguidas, se encuentran en el cuaternario de la República Argentina. Hay once especies que son comunes al cuaternario de Buenos Aires, a las cavernas de Brasil y al horizonte lujanense de la formación pampeana y siete especies, algunas de ellas extinguidas, que se encuentran en el cuaternario de la República Argentina $y$ en las cavernas de Brasil, pero que faltan en las capas más recientes de la formación pampeana.

De todo esto se deduce con la mayor evidencia que la fauna de mamiferos de las cavernas de Brasil pertenece a dos épocas distintas, una en la que entran sin duda la mayor parte de las especies existentes, que corresponde al cuaternario de la República Argentina, y otra, de la cual forman parte casi todas las especies de géneros extinguidos, que corresponde a la fauna de la parte más reciente del pampeano superior o sea del piso lujanense. 


\section{APÉNDICE}

Ya concluída la impresión de las páginas precedentes, llega a mis manos un opúsculo titulado «Breve reseña de los progresos del Museo de La Plata, durante el segundo semestre de 1888, por su director Francisco P. Moreno». Lleva fecha de 1889, habiéndose distribuído en los últimos días del mes de Marzo.

En este folleto el doctor Moreno se ocupa de paleontología de una manera más desgraciada aún que en el primer informe, ya repetidas veces mencionado. Agrava tal falta de preparación la circunstancia de que al tratar de refutar algunos errores que pretende he cometido, to hace sirviéndose de calificativos que a nadie mejor que a él le serian aplicables $y$ que no deberia haber empleado quien por todos sus actos se ha hecho mil veces acreedor a ellos.

Es para mí altamente doloroso ocuparme en una obra de ciencia de trabajos que no tienen de científicos ni la apariencia, pero es un deber que imperiosamente me impone la ley que obliga a tomar en consideración todo aquello que aparece impreso; y en este caso, especialmente, determíname a ello la doble circunstancia de tratarse de paleontologia argentina y de ocuparse su autor de mi personalidad en términos y de una manera que no aboga en su favor.

Por segunda o tercera vez me inculpa de que me resisto a hacer entrega del Catálogo de la colección de antropología y paleontología que para el Museo me fué comprada por el Superior Gobierno de la Provincia, cuando ella fué recibida conjuntamente con los catálogos correspondientes, a plena satisfacción, seis meses antes de que se efectuara la compra. Es hasta cierto punto ridículo que reclame el Catálogo de 10 que se ha comprado hace dos años y recibido y dispuesto hace treinta meses. Pero lo que deja de ser cómico, y seguramente es poco hidalgo, ello es que con el pretexto mencionado trate de justificar la falta de catálogo, el desarreglo, la confusión e indeterminación en que se encuentran todas las colecciones del Museo, pretendiendo arrojar la culpa sobre quien no tiene ingerencia alguna en el establecimiento, cuando él es el único culpable, sin duda no por falta de competencia, sino debido probablemente al exceso de ocupaciones que dice pesan sobre él y que supongo deben ser voluntarias. 
Tal proceder es demasiado grave para que yo lo deje pasar impasible; $y$ en esta fecha me dirijo al Excelentísimo Superior Gobierno de la Provincia a fin de que ponga término a los ataques injustificados que me dirige el doctor Moreno en vías de descargo por lo que no puede, no quiere o no sabe llevar a término.

Dicho lo cual, paso a la parte científica.

A propósito de fósiles pampeanos no trae nada digno de mención, a pesar de afirmar que se han coleccionado en el semestre cientos y cientos de cajones y de contener las colecciones infinidad de esqueletos y miles de cráneos, mandíbulas, etc., etc., pues el doctor Francisco P. Moreno discurre siempre de cientos y de miles. Añade, sin embargo, que deben existir entre ellos algunas especies desconocidas, pudiendo señalar desde ya como tales (página 26) los restos de un Megatherium muy pequeño, que sería bueno describiera y dibujara para tener la completa seguridad de que se trata realmente de un llegatherium; y los de un Homorhinoceros más pequeño que el Homorhinoceros Bra2'ardi, especie que sirviendo de tipo de comparación, debería ser conocida, pero cuya existencia, sin embargo, ignoro, por lo cual le agradecería citara la obra, sin duda excesivamente rara, en que se encuentra mencionada, pues hasta ahora no conozco más que la especie que me sirvió de tipo para la fundación del género: el Homorhinoceros platensis.

A la zaga de los fósiles pampeanos se ocupa de los de Monte Hermoso, cuya fauna perdida descubrió Darwin, según lo afirma el doctor Moreno, 10 que hasta ahora era completamente ignorado, pues guiándonos por la relación del viaje de aquel gran naturalista creíamos que sólo habia recogido allí algunos fragmentos de un Ctenomys y una muela de un roedor parecido al carpincho. ¡Pobre historia! Sin embargo, siempre según Moreno, Jas colecciones del Museo contienen, prozedentes de esa localidad, los restos de cerca de cien especies de mamíferos diferentes, aunque él en su reseña sólo se ocupa de tres, una que reconoce es ya conocida y otras dos que lo son igualmente, aunque él las considera nuevas.

El primero de esos tres mamíferos es el Trigodon Gaudryi, acerca del cual escribe largas páginas, aparentemente de carácter científico, pero cuya lectura sorprende hasta el asombro, porque en ella no hay la más ligera indicación sobre quién es el autor del género y de la especie, de modo que quienes no conozcan la descripción original quedan muy ilustrados al respecto y en aptitud de poder recurrir con facilidad a la primera descripción. Es un método especial de investigación, exclusivo del autor.

El mencionado animal estaba representado en el Museo únicamente for la mandibula inferior que recogi personalmente en Monte Hermoso 
y luego regalé al establecimiento; y Moreno refiere ahora a la misma especie, probablemente con razón, un cráneo algo incompleto, pero con casi toda la dentadura, cuyos caracteres ya me eran conocidos, tal como puede verse en el Suplemento (página 436 de este tomo). Los tres premolares únicos de esta especie se parecen a los premolares y a los dos primeros molares del Haplodontherilum, mientras que los verdaderos molares están construidos sobre el tipo de los del Toxodon y son parecidos a los del Toxodontherium. De aquí deduce que los géneros Haplodontherium y Toxodontherium son idéntidos al Trigodon y que deben desaparecer, empleando para fundar su proposición términos bastante inconvenientes, por cierto.

¿Qué significaría que yo hubiera tomado restos diferentes de un mismo animal, por los de tres animales distintos? ¿ No han incurrido en parecidos errores todos los paleontólogos, desde Cuvier hasta los más célebres de la actualidad, sin excepción alguna? Si él bubiera leído la introducción a mi cuarta Memoria sobre los fósiles oligocenos del Paraná, que menciona, habría visto que indico la dificultad que para su estudio y determinación ofrecen los fósiles de esa localidad, precisamente por la circunstancia de tratarse de piezas aisladas, sin que esa sea una razón para no emprender su estudio, pues si fuéramos a esperar siempre el conocimiento de partes completas, como lo pretende el autor del folleto en cuestión, peligrariamos pasar nuestra existencia esperando siempre la última palabra, hasta quedar rezagados. como a él le sucede ahora. Bueno es que sepa que de las seis mil especies de mamíferos fósiles conocidas hasta hoy, el noventa y seis por ciento han sido fundadas sobre pequeñas partes del esqueleto.

Pero bien sabe eso Moreno, que si ha insistido tan largamente sobre el punto es precisamente porque ha creído encontrar en mis trabajos un error que podria explotar fácilmente para levantarse un poco del desprestigio o abismo sin fondo en que ve hundida su personalidad científica.

Por desgracia, las apariencias, que no habrían inducido en error a un paleontólogo de mediana experiencia, lo han engañado; y olvidándose de que me acusa de precipitación, funda con la mayor ligereza, sin meditar un instante sobre las graves responsabilidades en que incurre y como si en los dominios de la ciencia ya no tuviera nada que perder, identificaciones más que problemáticas.

Identificar los restos de un género con otro, ambos ya definidos, por el examen de algunas piezas que proceden de yacimientos distintos. separados por trescientas leguas de distancia, y pertenecientes a horizontes geológicos de épocas muy diferentes, es a huen seguro un hecho de incuestionable importancia en Paleontologia, qui por lo mismo que afecta a la nomenclatura sistemítica, sólo puede hacerse cuando se tiene 
la certeza que da el conocimiento completo de la materia de que se trata, y que me parece no posee el doctor Moreno ni aun de una manera superficial, a lo menos si hemos de juzgar por la desgraciada muestra que de él nos da en el ensayo mencionado.

¿Quién le ha dicho a Moreno que una semejanza en la construcción de ciertas muelas es una prueba de identidad genérica? ¿Ignora él acaso que por regla general los géneros de una misma familia natural, presentan siempre en la dentadura una conformación fundamental idéntica?

Y para el caso, lo único que prueba es que el Trigodon es un género cercano del Haplodontherium, lo que ya me era conocido; pero de eso a la identificación genérica hay un precipicio que sólo puede salvarlo la ligereza sin igual del autor del trabajo que critico, atribuyéndome como definitivas determinaciones que sólo he dado de una manera provisoria, pues afortunadamente, a pesar de lo que él dice, medito lo que escribo con un detenimiento que a él no le es dado concebir.

Asi, por ejemplo, da como un hecho definitivo que los premolares de! Trigodon corresponden a los que yo he descripto como la $4^{n}, 5^{n}$ y $6^{n}$ muelas del Haplodontherium, cuando la verdad es que en mis trabajos precedentes no he dado como segura la determinación de ninguna muela, contentándome con decir en el caso mencionado que suponía correspondieran a la $4^{\prime \prime}, 5^{n}$ y $6^{n}$, por cuanto describía la especie tomando por tipo el Hciplodontherium Wildei, cuyas muelas también estaban determinadas de una manera provisoria. Si el autor se toma la molestia de leer mi monografía acerca de los Toxodontes, escrita hace alrededor de dos años para los «Anales» del Museo que él dirige, que no ha distrihuído y que, por consiguiente, posee en el establecimiento en número de mil ejemplares, verá en las páginas 43 y 44 que la determinación y la colocación de cada muela está seguida de un punto interrogante, espejo en el que sería bueno se mirara antes de aventurarse a dar como hechos comprobados, suposiciones más que aventuradas.

Asi, es dar prueba de gran inexperiencia y poca habilidad, decir que los verdaderos molares del Trigodon son idénticos a los del Toxodontherium, para compararlos luego, casi a renglón seguido, con los que él supone premolares de Huploduntherium, porque unos y otros presentan la misma depresión perpendicular de la parte anterior de la cara externa, que también se encuentra en el Nesodon, en el Protoxodon, en el Trachytherus, en el Adinotherium y en tantos otros géneros que ni siquiera son del mismo grupo.

En mis trabajos he descripto incisivos tanto del Toxodontherium como Lel Haplodontherium que no concuerdan en lo más mínimo con los del Trigodon, y żqué prueba tiene Moreno de que esos dientes no pertenezcan a los animales a los cuales los he atribuído? ¿Porque no se pare- 
cen a los del Trigodon? ¡Pues si es lo natural! ¡Cómo que provienen de géneros distintos!

Que los molares verdaderos del Trigodon presentan un notable parecido con los del Toxodontherium, es evidente; pero en el Trigodon sólo los tres verdaderos molares están provistos de columna interna, mientras que en el Toxodontherium, también participa del mismo carácter el último premolar; y si el autor hubiera consultado mis trabajos antes de lanzarse a especulaciones mentales sin fundamento positivo, habría visto que el premolar posterior del Toxodontherium está definido como un diente de corona muy alargada, comprimido y con una columna interna, lo que es el polo opuesto de la forma eliptica ovalada y sin columna que presenta en el Haplodonthcrium. En la lámina XCVI del Atlas, encontrará figuradas las dos series dentarias superiores de dos especies de Toxodontherium, que podrá comparar con las del Trigodon para convencerse del injustificable error en que ha incurrido al querer reunir ambos animales en un mismo género, sin que tenga necesidad de insistir en otros detalles, tales como: la forma de los incisivos medios superiores sobre el tipo de los del Toxodon en el Toxodontherium y sobre el del Protoxodon en el Trigodon, el incisivo segundo del Toxodontherium, elíptico y completamente distinto del mismo diente del Trigodon, etc.

Dejemos el Toxodontherium que ya vemos no hay medio de reunirlo al Trigodon y pasemos al Haplodontherium, al que con tanta insistencia lo compara. Por lo visto, entusiasmado en presencia del cráneo del Trigodon, Moreno ha creido que ningún otro animal podía presentar premolares elípticos de la misma forma, mientras que existen más o menos parecidos en el Haplodontherium, en el Pachyrucos, en el Hegetotherium, en el Eutomodus y en el Xotodon.

El autor del desgraciado folleto, en vez de la vista externa del Museo que no tiene la más mínima utilidad, deberia haber dado una figura del cráneo del Trigodon, que permitiría poner en mayor relieve la lamentable confusión en que ha incurrido. A mi, que toda la vida he tenido que luchar con la escasez de recursos pecuniarios, érame hasta cierto punto permitido publicar nuevas especies o descripciones $\sin$ acompanarlas de ilustraciones, pero Moreno, a quien nunca le han faltado los mencionados recursos, que ha contado continuamente con el apoyo oficial, que ha invertido en el Museo sumas fabulosas, que tiene miles y miles de ejemplares, que dispone de miles de clichés ya preparados, que tiene grabadores, fotógrafos, impresores, etc., en el mismo establecimiento, que cuenta con talleres y laboratorios de fotografía, litografía, cincografía, fototipía, etc., etc., ¿ cómo comete, con todos esos elementos contados por cientos y por miles, la imperdonable falta de describir nuevas especies y nuevos materiales sin acompañarlos con las ilustraciones correspondientes? 
Pero ya que por 10 visto parece que el Museo tiene para él mucha mayor importancia como edificio que como contenido científico, puesto que anuncia la publicación de otras láminas destinadas a dar a conocer la disposición interior, que se complace en creer el summum de la perfectibilidad, cuando en realidad está trazado sobre un plan raquítico encerrado en un circulo de hierro que no concuerda de ninguna manera con la evolución natural a la que inconscientemente dice que obedece su plan, pasémonos sin esas ilustraciones y analicemos un instante los datos que proporciona acerca del cráneo del Trigodon comparado con el del Haplodontherium.

Según Moreno, la serie dentaria completa a partir del borde anterior del segundo incisivo hasta la parte posterior del tercer molar es de 422 milímetros, de los cuales 260 están ocupados por las muelas, quedando pues, 162 milímetros para los dos incisivos externos, el canino y los correspondientes diastemas intermedios. El diámetro anteroposterior del incisivo segundo es de 32 milimetros; el del tercero de 13 milímetros; el del canino de 15 ; y los tres diastemas que los aislan tienen del primero al último, respectivamente, 27, 21 y 22 milímetros, lo que da un total de 130 milímetros. Para alcanzar a los 162 , faltan 32 . ¿ Podría decirnos el doctor Moreno, qué se han hecho?

Examinemos ahora la conformación del aparato dentario. La dentadura inferior del Trigodon es bien conocida por la mandibula inferior que he descripto; de consiguiente, si el Haplodontherium fuera idéntico al Trigodon, debería presentar en la mandibula inferior la misma identidad de conformación que presenta en la mandibula superior, según lo pretende Moreno erróneamente. Es cierto que las muelas inferiores del Haplodontherium me eran hasta hace poco desconocidas; pero como se ha visto en el Suplemento, conozco ahora como indiscutiblemente provenientes del mismo animal, verdaderos molares inferiores, que, si bien son parecidos, no son iguales a los del Trigodon, distinguiéndose por el lóbulo externo posterior más ancho y más convexo y por la parte o lúbulo intermedio del lado interno, que es casi completamente plano y doble más ancho que los lóbulos anterior y posterior, mientras que en el Trigodon dicho lóbulo interno es un poco más convexo y mucho más angosto.

No quiero insistir sobre las grandes diferencias que presentan los incisivos inferiores que he atribuido al Haplodontherium comparados con los del Trigodon, pues habiéndose encontrado sueltos todos ellos, podría suceder que en realidad no provinieran del mismo animal; pero estas dudas no pueden existir por lo que concierne a los incisivos superiores, de los cuales conozco un considerable número de ejemplares, entre los cuales los hay que por su forma, desgaste, estado de conservación, la ganga que los envuelve y la localidad donde fueron 
recogidos, provienen evidentemente del mismo individuo que una dentadura casi completa del Haplodontherium Wildci, bien caracterizado por la forma de sus molares y premolares.

El incisivo primero superior del Haplodontherium es más angosto que el segundo, de sección algo triangular, de corona truncada horizontalmente, más grueso en el lado interno que en el externo, bastante corto y profundamente excavado sobre la cara longitudinal tanto en el lado interno como en el externo. Este diente se hace más ancho desde la corona hacia la base, que es completamente abierta, presentando una gran cavidad infundibuliforme, parecida a la que muestran los premolares y los molares, mientras que en el Trigodon el mencionado diente se angosta desde la corona a la base hasta concluir en una raiz delgada, cónicocilíndrica, esto es: absoluramente al revés de lo que sucede en el Haplodontherium.

Moreno describe el incisivo segundo del Trigodon como triangular, plano sobre la cara interna, convexo sobre la externa y con sólo la mitad anterior cubierta por una faja de esmalte que da vuelta sobre Ia interna, terminando en cúspide triangular cortada en bisel. El mismo diente del Haplodontherium es igualmente triangular y de cúspide cortada en bisel, pero la cara posterior en vez de ser convexa es plana, estando cubierta por una capa de esmalte que en vez de cubrir sólo su mitad anterior, la cubre en casi toda su extensión, quedando únicamente sin esmalte una banda longitudinal del borde externo que se levanta sobre la cara anterior en forma de columna longitudinal convexa, como sucede, aunque de una manera menos acentuada, en el Toxodon ensenadensis. La diferencia no puede ser mayor.

Moreno afirma que el incisivo tercero del Trigodon es pequeño, elíptico y con la corona cortada en bisel; el del Haplodontherium es de corona cortada horizontalmente y más excavada en el centro que en la periferia; y el canino presenta la misma forma, mientras que en el Trigodon, según ese autor, tendria la corona igualmente cortada en bisel.

Moreno describe el primer verdadero molar superior del Trigodon como triangular y con la cara externa fuertemente ondulada, agregando que le parece que la muela que he descripto como cuarta o quinta del Toxodontherium ( Boletin», etc., tomo IX, página 97) es el primer verdadero molar del Trigodon; pero puesto que he descripto la mencionada muela como de cara externa regularmente convexa, no me es dado - comprender cómo puede ser de un animal en el cual la misma muela (se dice) es de cara externa no convexa sino ondulada.

Las otras dos muelas verdaderas del Trigodon que Moreno afirma son las mismas que he designado con el nombre de Toxodontherium y que también corresponden al Haplodontherium, es evidente que no pueden compararse con las muelas excesivamente largas y comprimidas del 
Toxodontherinm ni con las muelas sumamente anchas del Trigodon. Todos los verdaderos molares superiores del Trigodon son más anchos que los últimos premolares y esta diferencia se acentúa más aún entre el último premolar y el primer verdadero molar, mientras que los verdaderos molares del Toxodontherium compressum, de tamaño igual a los del Trigodon, son notablemente más angostos que las más grandes muelas elipticas que conozco del Haplodontherium, que, sin embargo, son bastante más pequeñas que los últimos premolares del Trigodon, lo que demuestra el muy poco o ningún tino y la gran inexperiencia de quien pretende reunir en uno tres animales tan distintos.

Por lo que se refiere a los premolares del Trigodon es indudable que se parecen a los del Haplodonthcrium, pero para demostrar que ambos animales no son idénticos basta el tamaño completamente distinto que presentan los del Trigodon comparados con los del Haplodontherium. Moreno pone en paralelo el fragmento con tres muelas que he descripto como de Haplodontherium limum con los tres premolares de Trigodon, pero las medidas que da de los dientes de este último no concuerdan de ninguna manera con los del Haplodontherium. Insiste ese autor sobre una pequeña depresión perpendicular que afirma presentan los premolares del Trigodon en la parte posterior del lado interno, cuya depresión, dice, encuéntrase también en los dientes del Haplodontherium, lo que es verdad, e indica afinidad entre ambos animales, pero no identidad, pues la misma particularidad existe en los primeros premolares del Toxodontherium y en los últimos del Eutomodus, que tienen una forma bastante parecida, a pesar de lo cual el género no puede ser más distinto. Hay todavia algo más que no dejará de sorprender al doctor Moreno, y ello es que el animal, que, basándose él sobre un pequeño fragmento de intermaxilar con los incisivos, designa algunas páginas más adelante con el nombre de Pseudotoxodon formosus, considerándolo como nuevo, - y que dicho sea de paso ya es conocido desde hace tiempo con otro nombre - presenta premolares que son igualmente de la misma forma.

A cualquier parte que se dirija la vista en el trabajo de Moreno se encuentran tantos errores que enmendar y tantas apreciaciones erróneas que refutar, que no acabaria de mencionarlas en veinte veces más espacio que aquel en que él con una inhabilidad sin ejemplo ha sabido reunirlos; pero no puedo prescindir de mencionar uno de aquellos que por su importancia quiero esperar que baste para convencerlo de su error, al mismo tiempo que es una prueba evidente de la ligereza con que ha procedido y que, por lo demás, le es habitual.

Afirma que el Trigodon no tiene más que tres premolares elípticos; siguiendo adelante una larga barra y atrás los verdaderos molares prismáticos; y luego, examinando el modelo de un fragmento del maxilar 
de Huplodontherium limum conteniendo tres muelas elipticas (que son las que me sirvieron de tipo para la fundación de la especie), dice que esos tres dientes corresponden a los tres premolares del Trigodon. Si hubiera examinado la pieza con un poco menos de precipitación, se habría dado cuenta de que adelante del diente más pequeño del maxilar mencionado del Haplodontherium, sigus inmediatamente un alvéolo en parte destrozado, donde se implantaba un diente de la misma forma, de manera que en este solo pedazo tiene la prueba palpable de que el $\mathrm{Ha}$ plodontherium tuvo por lo menos cuatro dientes seguidos de esa forma. Puede pasar un vistazo a la lamina XCVI, en donde se encuentra dibujada la serie dentaria completa del maxilar superior del Haplodontherium, y verá que tiene seis muelas elípticoovaladas, en vez de sólo tres que tiene el Trigodon, que tiene cuatro premolares en vez de tres que tiene el Trigodon, que sólo la última muela es triangular y provista de columna interna, mientras que en el Trigodon son las tres últimas las que presentan este carácter; y verá, por fin, que la serie dentaria completa del Haplodontherium consta de siete muelas en vez de seis como en el Trigodon, y entonces comprenderá que no le era permitido reunir ambos animales en uno sin incurrir en un error altamente censurable. Queda así, pues, bien justificada la separación genérica de los tres animales que he designado con los nombres de Trigodon, Haplodontherium y Toxodontherium.

De los otros dos mamíferos que Moreno da como nuevos, uno es un armadillo gigantesto designado por él con el nombre de Dasypotherium australis, fundado sobre restos de coraza y una rama izquierda de la mandibula inferior, que caracteriza de esta manera:

«Dasypotherium australis! (género y especie nueva). - Otra de las piezas de valor extraídas de Monte Hermoso, fórmanla mucha parte de la coraza articulada y el ramo izquierdo de la mandíbula inferior de un gran dasipídeo, desconocido hasta ahora. Su talla ha sido mucho mayor del doble de la del Eutatus Seguini. La figura central de sus placas se asemeja mucho a la de la mulita (Praopus hybridus) pero es relativamente más difusa, tendiendo a desaparecer en algunas placas, acercándose así al Chlamydotherium; no tienen ninguna de las placas las aspe. rezas de las de los Eutatus. La mandibula inferior se distingue de la de todos los dasipídeos conocidos de la Pampa; a juzgar por sus alvéolos ha tenido ocho muelas, la primera muy pequeña, la segunda enorme, caniniforme, encorvada, como en Lestodon, la tercera ha sido angosta, implantada de la misma manera, siendo en esa dirección su mayor diámetro y ha tenido un surco perpendicular suave en su cara interna anterior y otro en la externa posterior; la siguiente parece haber sido más cuadrada con surcos y la quinta mayor que ésta, oblicua, rectangular, con los mismos surcos; la sexta más cuadrada, pero no tanto como la 
tercera; la séptima y octava tienden a ser cilindricas progresivamente, pero también con un pequeño surco interno la primera de ellas. Esta mandibula denota en su forma general un animal de cráneo más corto que los Eututus y Praopus. Indudablemente pertenecen estas piezas a un animal de un género nuevo que llamaré Dasypotherium. Pudiera resultar una vez conocido el cráneo de los Propraopus que éstos pertenecen al mismo género que el Dasypotherium, cuyos caracteres dentarios son muy distintos de los de los Praopus y por lo tanto deberá desaparecer el género Propraopus basado sólo en placas dorsales»!

No se le ocurre a nadie un desconocimiento más completo de las leyes de la nomenclatura, ni una ligereza mayor que la que se transparenta en las mencionadas lineas.

E1 Dusypus, como el Eutatus, pertenecen a un grupo de armadillos de una conformación profundamente distinta de aquel de que forman Farte los géneros Praopus y Propraopus. El pretendido Dasypotherium o se acerca a uno o se acerca al otro; si es más cercano de Dasypus y de Eututus, es absolutamente imposible que se pueda confundir con el Propraopus.

Pero la singularidad del caso consiste en que, al fundar el pretendido nuevo género Dasypotherium, declara, yo no sabría si con la mayor candidez o sin el menor escrúpulo, pero de cualquier modo en forma que pone en evidencia que no alcanza a comprender la importancia de estas cuestiones, que, en el caso de resultar más tarde que el género Dasypotherium, cuyos caracteres dentarios son muy distintos de los de Praopus, es idéntico al Propraopus, deberá desaparecer este último

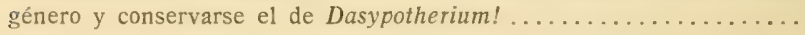

Linneo, Tournefort, Agassiz, de Candolle, de Saporta, Cope, Scudder, Bronn, Mayer, Douvillé. Fischer y demás distinguidos naturalistas, que habéis pasado la mayor parte de vuestra existencia estableciendo las leyes de la nomenclatura: ¡ habéis perdido vuestro tiempo! - Desde el fondo de un desordenado bazar disfrazado con el nombre de Museo, se levanta una voz que pretende desconocer la grandiosa obra que constituye el más alto título de gloria de los naturalistas!

Ahora me explico la siguiente frase cabalistica, que en forma parabólica y sentenciosa se lee en la página 8 del mismo folleto de Moreno, refiriéndose a ciertos fósiles por él descubiertos: «Estas primeras vislumbres de un magnífico pasado biológico del hoy «Museo de La Plata» por derecho de herencia de su descubridor, está destinado a aclararlas mostrando un mundo nuevo de formas no sospechadas muchas de ellas y necesarias para la existencia de las actuales».

Afortunadamente, no bastan unos cuantos rasgos mal hechos de pluma de un visionario que hasta invoca en ciencia el derecho de herencia para 
cchar por tierra esa majestuosa obra en cuya construcción se han empleado dos siglos, y que descansa en la inconmovible resistencia que le da el conjunto de todos los naturalistas contemporáneos de algún mérito.

Si, pues: no lo dude Moreno; si llega a descubrirse que el Dasypotherium es idéntico al Propraopus, éste será el nombre conservado; y el de Dasypotherium es el destinado a desaparecer.

Pero no se inquiete, pues tal identidad nunca se llegará a demostrar por la sencilla razón de que el Dasypotherium y el Propraopus son dos géneros completamente distintos, que entran en dos grupos diferentes. Con todo, es sorprendente que poseyendo una parte considerable de la coraza dorsal del Dasypotherium no se ha dado cuenta de que es imposible que los dos mencionados géneros puedan confundirse. Es probable que ello sea debido a la escasez de materiales del género Propraopus; y si así fuere, pongo desde ya a su disposición mis colecciones, en las cuales encontrará la coraza casi completa de este género y partes notables del esqueleto y de la dentadura que bastarán para disipar en su espiritu hasta la más mínima duda. Aunque no me permite el examen de las colecciones del Museo, que no son de él sino del Estado, puede venir a mi casa en cualquier momento, donde siempre encontrará a su disposición una mesa de trabajo y los materiales de que dispongo. Esta ha sido siempre mi conducta, con todos, y es la verdadera manera de servir a la ciencia.

Duéleme, empero, tener que disipar en él una ilusión más, pues si bien el Dasypotherium no es idéntico al Propraopus, tampoco es un género nuevo, pues fué descubierto por mí en Monte Hermoso y descripto hace dos años, en la página 16 del primer número del «Boletín del Museo de La Plata», del cual repartí unos pocos ejemplares (conservándose los demás en ese establecimiento, sin distribuirse, en número de 600 ejemplares) bajo el nombre de Macrocuphractus retusus; y lo encontrará caracterizado por los únicos restos que conocia, en la página 364 de este tomo, aunque sin dar dibujos, por encontrarse las piezas originales en el Museo de La Plata.

El otro mamífero, que él se imagina nuevo, es un representante del grupo de los Toxodontes, designado por Moreno con el nombre de Pscudotoxodon formosus (?) (página 37) dando de él la siguiente descripción:

«Pseudotoxodon formosus (?) género y especie nueva. - Posee el Museo la parte anterior del cráneo de un toxodóntido, que comprende los cuatro incisivos, un fragmento del canino izquierdo y el primer premolar del mismo lado. Pertenece a un género que considero nuevo aún, sin asegurarlo, puesto que pudiera resultar que más adelante, cuando se descubran nuevos restos, resulte ser uno de los toxodontinos descrip- 
tos, según dientes aislados, por el doctor Ameghino, lo que es imposible decir hoy. No es el Toxodon proto-Burmeisteri que tuvo, según el doctor Ameghino, tres incisivos superiores de cada lado, ni corresponde por su tamaño con el Toxodon virgatus, lo que no obstaría, sin embargo, a que pertenezcan ambos a una misma especie; tampoco es el Toxodon antiqullıs, a juzgar por el extremo de la mandíbula inferior puntiaguda. Los incisivos medios encorvados, no se inclinan en su extremo coronal hacia adentro como en los Toxodontes pampeanos; la cara anterior es Flana; cubierta con una capa de esmalte en toda su extensión, la corona algo =xcavada, de bordes anteriores cortantes; su parte interna es casi Ĺbiemente más ancha que la externa, teniendo la parte interna de la cara bosterior la forma de cuña triangular, mientras el resto es paralelo a la vara anterior. Asi los extremos de la cara interna y posterior de estos incisivos de cada lado reunidos, presentan la forma de una $M$ de base ancha. El ancho de estos incisivos es de 0.031 , su fondo en el borde externo 0.007 y en el interno 0.013 . Los segundos incisivos son prismáticos triangulares; han tenido la corona cortada en bisel desde el ángulo anterior externo hacia el opuesto. Su cara externa es plana y convexa la interna, poco convexa la anterior, y plana y muy poco excavada en el centro la posterior; una ancha capa de esmalte parece haber cubierto la cara anterior.

«El diámetro transverso de este incisivo es de 0.027 y el anteroposterior en la cara externa 0.165 ; estos incisivos están situados oblicuamente detrás de la cara externa de los internos. Del canino, que ha sido muy pequeño, sólo se ve la base, cilíndrica, colocada oblicuamente siguiendo la dirección del maxilar; está separado por un diastema de 0.061 del incisivo segundo. Otro diastema de 0.012 lo separa del primer premolar que es prismáticorrectangular, encorvado y colocado en la misma dirección que el canino; mide su diámetro longitudinal 0.012 y el transverso 10.006; una ancha faja de esmalte ocupa la faz externa y hay rastros de otra en la interna».

La precipitación en los juicios y la falta de preparación se manifiestan en esta descripción en el grado más elevado que sea dado concebir. En ella, para establecer que el pretendido Pseudotoxodon formosus es un animal diferente de algunos con los cuales innecesariamente lo compara, entre otras herejías científicas, dice textualmente que difiere del «Toxodon proto-Burmeisteri que tulo, según cl doctor Ameghino, tres incisivos superiores de cada lados.

¿Tendría a bien el doctor Moreno indicarme en qué trabajo he publicado yo tan descomunal disparate? Un toxodóntido que tuviera tres incisivos superiores de cada lado, no sería un Toxodon; y mis conocimientos en paleontología, aunque limitados, hace años que no son tan superficiales, para cometer un error tan craso, tan descomunal y tan sin fun- 
damento, como el que con la máxima candidez (?) me atribuye él. Hay más todavia: no conozco hasta ahora los incisivos superiores del Toxodon proto-Burmeisteri; $y$, por consiguiente, no es concebible que haya podido hablar de ellos en parte alguna.

He buscado con empeño la fuente del error y no encuentro más que la siguiente. En mi monografía sobre los Toxodontes (Observaciones generales sobre el orden de los Toxodontes) al dar, en la página 41, la diagnosis del Toxodon proto-Burmeisteri, empleo los siguientes términos: «Talla un tercio de la del Toxodon Burmeisteri; i. ${ }_{3}$ triangular, con dos caras inferiores externas y una superior interna, cada una con una faja de esmalte más angosta», etc.

El símbolo i. 3 , que indica el diente incisivo tercero de la mandíbula inferior, no ha sido entendido por Moreno, que ha creído sin duda que eso queria decir que el animal tuvo tres incisivos; y parece que hasta ignora que la colocación del número debajo de la rayita horizontal, se refiere a la dentición de la mandíbula inferior, puesto que me atribuye nada menos que el enorme desatino de haber atribuido al mencionado animal tres incisivos superiores a cada lado.

Esto me ocasiona un profundo desconsuelo, pues parecería indicar que Moreno ignora la nomenclatura de la dentadura y el conocimiento de los símbolos que sirven para representarla, ya en conjunto, ya a cada diente tomado por separado, símbolos en el día universalmente empleados por todos los paleontólogos. Y si así fuera, me pregunto con dolor: ¿qué habrá comprendido en todo el resto de la monografía de los Toxodontes, en la que se encuentra la descripción de la especie mencionada, puesto que toda ella está llena de los mismos símbolos? y ¿con qué provecho consultará las obras de Paleontología? Me desespera la conclusión poco agradable a que esta observación me conduce, pues ¿qué fe podrá tenerse ahora en las descripciones de ese autor no acompañadas de dibujos, cuando parece, cuando menos aparentemente, que no comprende o que ignora la manera de leer una fórmula dentaria?

Doblemos esta hoja, desagradable en supremo grado, y pasemos a otro tema.

¿Cómo es que el doctor Moreno, - que tanto me critica, porque dice que fundo especies sobre datos incompletos, que el mayor número de ellas son producto de mi rica imaginación, hasta llegar a designarme con el nombre de fabricante de especies - ¿ cómo es, digo, que él incurre en el mismo delito, fundando una especie y un género sobre restos incompletísimos - como lo ha hecho, por otra parte, en todos los demás casos - y en la inseguridad, que él mismo declara, de que ya sea conocida?

Si en vez de comparar esos restos con los que preceden de regiones distantes y épocas diferentes, los hubiera comparado más detenida- 
mente con los que proceden del mismo yacimiento, probablemente habría advertido que es la misma especie ya por él descripta en el «Informe» de Julio del año pasado, como Toxodon antiquts, siendo, con todo, tanto este como el otro nombre, simples sinónimos, pues forma parte del género Xotodon, al cual caractericé hace unos dos años, siendo la especie de Monte Hermoso la que di a conocer bajo el nombre de Kotodon prominens, con mucha anterioridad a las publicaciones de Moreno.

Ya lo ve el doctor Moreno: esgrime un arma cuyo filo se vuelve en su contra, siendo altamente sensible que pretenda justificar sus pasiones con dichos de personas cuyos nombres son queridos y respetados, pues no puede considerarse de otra manera que como un desprecio a la memoria del ilustre y malogrado sabio, la frase que a propósito de sus propios devaneos le atribuye.

Tal conducta está reagravada con insinuaciones de mal gusto, como aquella: «Es lástima que un paleontólogo de la talla del doctor Ameghino incurra en estas precipitaciones, que no soy desgraciadamente el primero en indicar», lo que es posible; pero a lo que por mi parte podría contestar diciendo que otros le llaman a él fabricante de sinónimos, inventor de disparates y algo peor, lo que es más desagradable que ser fabricante de especies.

Toda la manera de proceder del doctor Moreno es tan excesivamente informal y poco correcta, y sus disertaciones tendrán en el adelanto de la ciencia una influencia tan poco sensible. que en realidad no hubiera merecido la pena que malgastara tanto espacio y tanta tinta en lo que no tiene valor científico. Pero hay una circunstancia agravante, y ello es que no se trata de trabajos que en realidad estén destinados a los hombres de ciencia, sino de «Informes oficiales» dirigidos al Ministro de Obras Públicas de la Provincia y destinados al público con el evidente objeto de llamar sobre sí la atención, deprimiendo a otros; y como quien calla otorga, si yo no le contestara poniendo las cosas en su lugar, el público, en gran parte ajeno a estos conocimientos, habría podido creer en la ciencia del doctor Moreno.

Desearía poner funto final a este incidente, en el que hay tantísimo que decir que, de continuar, no concluiría nunca, y tanto más desagradable cuanto que ya en el transcurso de esta obra he tenido ocasión de criticar, quizá no con la merecida severidad, las ligerezas inconcebibles del doctor Moreno como hombre de ciencia, a propósito de sus conatos de determinaciones paleontológicas; pero no puedo prescindir de transcribir a continuación mi justificación completa, dada por él mismo en la página 31 del «Informe» en cuestión, donde se lee lo que sigue: « $Y$ es esta ocasión de confesar errores en que he incurrido en el transcurso de mi primer informe, errores debidos en mucha parte 
a la irremediable precipitación con que fué escrito. En oportunidad trataré de corregir esos errores, prometiéndome para en adelante más cautela, aun cuando deba sacrificar la enumeración de las piezas nuevas que se incorporen a estas galerías».

Es lástima que tan buenos propósitos no hayan sido sino vanas palabras. El autor ha querido jugarle al Ministro una mala partida. Si no es así, para ser consecuente con la precedente declaración, y por aquello de que pecado confesado es medio perdonado, debe sin pérdida de tiempo dirigirse al señor Ministro, poniendo en su conocimiento que, a pesar de la gran cautela que se proponía usar para en adelante, el segundo informe ha sido redactado con la misma ligereza y la misma precipitación que el primero, de lo que por desgracia ha resultado un mayor número de errores de tamaño considerablemente más abultado. 

ÍNDICES 



\section{LISTA ALFABÉTICA \\ DE LOS NOMBRES DE LOS AUTORES, COLECCIONISTAS, ETC. MENCIONADOS EN ESTA OBRA}

\section{A}

Agassiz: $37,5+8$.

Ambrosetti Juan B.: 415.

Ameghino (Carlos): $8,12,15,20,57,58,59$, $60,61,62,63,70,71,72,76,172,232,236$, $242,246,250,344,346,357,359,360,369$, $370,377,407$.

Andrade (Eloisa G. de): 293 .

Andrade (Olegario V.): 293 .

Angelis (Yedro de): 178 .

Azara: 348 .

\section{3}

Berg (Carlos): 273 .

Blainville (De): $15,28,84,97,102,142,144$. $156,157,158,278,28 \mathrm{r}, 183,309,327$.

Iilumembach: 27 .

Bodenbender (Guillermo): 446 .

Brackebusch: 42 .

Bravard (Augusto): 65, 66, I17, I21, I26, I28, $129,137,138,140,142,158,161,162,183$, $184,187,188,190,219,225,256,282,302$, $325,349,37 \mathrm{r}, 385,390,43 \mathrm{x}$.

Bronn: $178,204,548$.

Buckland: 28,65 .

Buckland Wiel: 27, 65 .

Burmeister (Carlos): 439, 440.

IBurmeister (Germán) : 19, 20, 21, 27, 35, 36, 37, $4 x, 42,64,65,66,76,78,79,80,81,84,85$, S6, $87,88,89,90,91,96,97,98$, roo, II6, II 7 。 $118,119,121, I 26,128,129,138,139,140$ $141,142,143,144,145,149,155,156,157$, $158,159,16 \mathrm{r}, 164,180,18 \mathrm{r}, 182,184,185$, $186,188,189,190,192,194,195,204,209$. $210,213,214,219,220,22 \mathrm{r}, 222,223,224$. $225,229,255,256,257,258,259,269,270$ $27 \mathrm{I}, 275,282,283,296,298,302,303,305$, $309,320,32 \mathrm{y}, 325,328,343,347,348,354$. $355,358,365,371,373,375,384,385,386$, $3^{8} 7,389,391,412,43 \mathrm{I}, 438,439,44^{2}$,

\section{C}

Candolle (De): 548 .

Capellini: I28.

Carles (Iinrique de): So.

Cassini: 385 .
Castelnatu (F. de): 373 .

Claraz (Jorge): 275 .

Claussen: 349,374 .

Clift: 177,178 .

Cope (I;. D.): $394,507,548$.

Cornalia: 27, 28, I88, $219,222,224$.

Cuvier (F. R.): 347,372 .

Cuvier (Jorge): $13,24,27,28,35,36,65,177$, 373. $388,430,54 \mathrm{r}$.

D

D'Aiton:' I 78 , 179.

Darwin (Carlos): $64,8 \mathrm{r}, 82,112,117,137$ $178,348,358,440,540$.

Dejardin: 84 .

Desmarest: $27,348,354,358,373,374$.

D'Orbigny (Alcides): $384,386,449$

Douvillé: 548 .

1)ipotet: 181,230 .

\section{E}

Figtia (Mantel) : $43^{8}$

$\mathrm{F}$

Falkner: 177,228 .

Fillool: 444 .

Fiorini (Angel): $228,230,292$.

Fischer: 548 .

llower: 384 .

Frenzel (Juan): 307 .

\section{G}

Garriga (José) y Bry (Juan B.): 27,28 ,

Gay: 358 .

Geoffroy Saint-Hilaire (Et.): 373,430 .

Geoffroy Saint-Hilaire (Isid.): 371 .

Gervais (Henri): $31,34,85,97,100,102,12 \mathrm{r}$, $126,128,152,156,159,160,161,163,180$, $183,189,190,216,230,314,325,327$.

Gervais (H.) y Ameghino (F.): $30,31,34,84$, $97,98,99,100,101,102,104,116,126,128$, $144,151,152,154,156,157,160,161,163$, $164,192,210,213,214,216,218,219,224$, $230,231,255,256,263,279,282,283,302$, $314,316,321,325,327,336,348,349,354$, $355,365,366,371,385,427$. 
Gervais (Paui): $30,66,81,84,85,91,96,97$, $98,99,100,101,104,116,11 \%, 121,122,126$, 127 , I $28,140,156,157,158,189,190,354$, $316,354,365,373,384,386,387,426$.

Ciebel: $116,210,371$.

Gilliss: 375 .

Gray: $348,354,358,371,373,375,384,385$, $386,387,389,391$.

Griffith: $35+, 373$.

H

IIarlan: SI, 374, 375 .

Ifeusser (Christian): $274,275,332$.

110ll: 27 .

Iurxley: $184,210,212$.

IIytt: 375 .

Illiger: 370,374 .

$$
\text { J }
$$

Tefierson: 64 .

Koken (E.) : 192, 312, 313.

Kroyer: 84.85 .

Kurtz (Federico): 416 .

\section{L}

I.acepede: 390 .

I,amas (Andrés): $177,293$.

Larrañaga (Dámaso): 293.

Laurillard: $177,178,416,432$.

Laussen: 137,447 .

Leidy: $27,34,35,64,65,81$.

I,elong Thévenet (I,eón): 55, IIO, I11, 245 , $283,312,333,362,412,415,417,42 \mathrm{I}, 423$. $424,428,430,432$

L.esson: $348,358,373$.

I.ettsom (W. G.): 165,275 .

Liais: 13,373 .

Linneo: 12, $13,145,348,353,374.355,388$, $389,5+8$.

Joreto (Marqués de): 28 .

Lovisato: 407 .

I,und: $35,36,64,65,79,133,134,1,5,179$, I So, $185,186,187,188,190,192,213,214$ $218,250,255,256,282,283,336,339,349$, $37+408,4 \geq 6$.

Lutken: $35,37,255,408$.

1.ylekker: $27,31,32,97,98,115,114,117$, $118,119,126,128,131,142,149,15 \%, 15 \%$, - $159,164,165,182,189,192,195$. zoo, 210, $213,214,215,219,220,255,256,258,259$. $270,271,275,283,302,316,321, i-3,348$, $349,355,365,371,372,374 ; 388$.

r,ynch Arribálzaga (Félix) : 426 .

\section{MI}

Martin: 3.8

Mayer: 548 .

Meyen: 385 .

Migoya (Julio): 278,443 .
Moreno (F. P.): 30, 32, 33, 108, 120, 123, $191,192,236,237,261,267,287,288,295$, $330,389,442,446,539,540,541,542,543$, $544,545,546,547,548,549,550,551,552$. Moyano (Carlos M.): Io.

Muñiz (Francisco Javier): 65, I8I, $407,443$. Muller (J.) : 210.

Murie: 371 .

\section{N}

New Wied (Principe Maximiliano de): 373 , 374.

Nodot:-1So, ISI, $1 S_{2}, 183,18_{4}, 185,186,187$, $189,190,191,192,204,210,213,215,219$, $220,229,230,231,255,256,265,283,284$, $302,309,325,327,336$.

\section{O}

Obregón (Adolfo): 439 .

Oken: 27.

Ortiz (Toribio F.) : 427,429 .

Owen (Richard): $2 \%, 28,64,65,66,81,84$, $89,112,116,117,118,134,137,138,142$, $143,147,149,156,164,178,179,180,181$, $182,183,184,185,186,187,188,189,190$, $204,210,211,212,213,214,219,220,256$, $265,270,282,302,325,373,390$.

\section{P}

Paclieco (José): 1 S8.

Pander y $D^{x}$ Niton: 27, 28.

Parisla (Woodbine): I78, 204, 210.

Peale: $385,386$.

Pentland: 1,8 .

Philippi: 31,32 .

Pictet: I16, 142, 180, I90, 210.

Pouchet (J.) = I $85,186,256,325,326$.

\section{Q}

Quatrefages (De): 447 .

()uoy y Gaimard: 386 .

\section{R}

Rapp: 373 .

Reinhardt: $35,79,84, S_{5}, 88,97,137,140$, I41, 142, If 4, 188, 214, 219, 387.

Richert $y$ Du Jiois-Reymond: 256 .

Kobin (Ch.): 325 .

Rondelet: 386,387 .

Roth (Santiago): 32, 308 .

Rozas (Juan M. de): I8I, $407,443$.

Rydér (J. A.): 302 .

\section{$\triangle$}

Saint-Hilaire (Augusto): 177 .

Saporta (De): 548 .

Scalabrini (Pedro): 33, 46, 47, 50, 55, 74, 75, 105, 106, I10, 120, 133, 137, $167,168,170$, $19 \mathrm{t}, 248,250,268,312,320,342,343,410$, 413.

Scudder: 548 .

Schaffter: 79 .

Sliaw: 27 .

Schlegel: 386 .

Schreber: $3+8$. 
Séguin (Francisco): $35,128,285,317$.

Sellow: 177,178 .

Serres: 185, IS6, 1SS, 256, 30z, 325, 326. Sören Ilansen: 408, 447 .

Spegazzini (Carlos): 442 .

\section{T}

Tournefort: 548 .

Trouessart (E.): 416 .

Turner: 348 .

V

Van Beneden: 389.

Van Beneden y Gervais: 39 r.
Vilardebo: : 1So, $190,216,3$ ro.

Virchow: 447 .

Vogt (Carlos): 30 S.

W

Wagler: $353,373,374$.

Wagner-Schreber: $348,354,37 \mathrm{I}, 373,375$ :

Waterhouse: 386 .

Weddell: 121,354 .

Weiss: $28,177,278$.

Weyenberg: $42 \mathrm{I}$.

\section{Y}

Yarrel: 375 . 



\section{ÍNDICE ALFABÉTICO \\ DE LOS NOMBRES TÉCNICOS MENCIONADOS EN ESTA OBRA INCLUSO LOS SINÓNIMOS}

Abclerites: $456,51 x$.

Abderites meridionalis: 451 . Abderitidae: $398,45 \mathrm{I}, 458$. Acaremys: 456, 5 to.

Acaremys messor: 449.

. Icaremys minutissimus: 449.

Acaremys minutus: 449.

Acaremys murinus: 449 .

Icdestis: 456,511 .

Icclestis Oweni: $45 \pi$.

Aceratherim: 518 .

Acomys: 524 .

Acotherulum: 515:

Icrocyon: 456, 51 i.

Acrocyon sectorius: $45 \mathrm{I}$.

Acrotherium: 456,508 .

Acrotherium rusticum: $45 \mathrm{I}$.

Icyon: 456, 512,

Icyon tricuspidatus: $45 \mathrm{r}$.

Acyon ? bardus: $45 \mathrm{~T}$.

Acyonidae: 398 .

Achaenodon: 510.

- Idapidae: 396.

Adapis: 514.

Adapisorex: 5 Ir.

Adapisoriculus: $51 \mathrm{r}$.

. Jelphomys: 456, 510 .

Adelphomys candidus: 450 .

Adelphotherium: 456,508 .

Alelphotherium ligatum: 452 .

Adelotherium: 457, 5 ro.

Idelotherium scabrosum: 453 .

Adinotherium: $436,456,508,542$.

Adinotherium ferum: 452 .

Idinotherium magister: 452.

Wdinotherium nitidum: 452 .

Ndinotherium proximum: 452.

Alinotherium splendidum: 452 .

Adracodon: 516 .

Adrastotherium: $457,510$.

Idrastotherium dimotum: 453 .

Aelurogale: 516,525 .

.leluropsis: 525 .

.Ipheliscus: 508 .

- Iphelops: 518, 523, 527.

Aplielotherium: 514.
Agatliodonta: 6, 392, 393, 394, 395, 399, 401, 405.

Agriochoérus: 518, 523.

Agustylus: 456 , 511 .

Agustylus cynoides: $45 \mathrm{I}$.

Ailuridae: 398.

Nlcelaplius: 523.

Nlloidea: $396.398,401,450$.

Allomys: 519 .

Ambloctonus: 512 .

Amblyctonidae: 398 .

Amblypoda: $396,397,401,453,5$ ro, 513,5 r5, $517,519$.

Amblyrhiza: $5 \geq 5$.

Amphictis: 521 .

Amphicynodon: 5 te.

Amphicyon: 520, 525.

Amphidactyla : $396,397,40 \mathrm{r}, 45 \mathrm{I}, 46 \mathrm{r}, 469$, 476,495 .

Amplidozotherium: 516 .

Amplimeryx: 5 15, 518 .

Amphimosclutus: 519 .

Amphiperatherium: 516,521 .

Amphisorex: 516.

Amphitragulus: 5 I9.

Amynodon: 509.

Anaptagenia: 529 .

Anaptomorphidae: 396 .

Anaptomorphus: 508 .

Anatherium: 456,5 II.

Anatherium defossus: $45 \mathrm{I}$.

Ancylotherium: 52x, 525 .

Anchimys: 464,515 .

Anchimys Leidyi: 460 .

Anchippodontidae: 459,466 .

Anchippodus: 5 to.

Anchippus: $518,523$.

Anchisodon: 518 .

Anchitherium: 578 .

Anchilophus: 515.

Anicanodonta: $5,10,175,399,453,462,470$, $478,496,503$.

Anisacodor: 511 .

Anisonchus: 508 .

A:lomodon: 529 .

Anoplothericlae: 397 .

Anoplotherium: 515 . 
Antaodon: $488,489,523$.

Intaodon cinctus: $476,48+534$.

Anthracotheridae ?: 397 .

Anthracotherium: $515,519,524$.

Anthropoidea: $396,40 \mathrm{r}, 405,468,474,494$ 199, $507,514,517,522,528$.

Inthropomorphidae: 396 .

Inthropopithecus ?: $468,472,517$.

Antidloras: 524.

Antifer: $488,492,523$.

Intifer tiltra: $478,485,535$.

Antilope: $519,523,528$.

- Intilopidae: $397,496,498$.

Apatemys: 510.

- Ipera: $₫ 65,516$.

Apera sanguinaria: 431,460 .

Arctocyon: 511 .

Arctocyonidae: 39 S.

Arctodus: 525 .

Aretomys: $524,527,-20$.

Arctotherium: $465,487,489,49 x, 516,525$. $52 \%$.

Arctotherium angustidens: $476,483,533$.

Arctotheritum bonariense: $476,483,533$.

Arctotherium vetustum: 465 .

- Irchaelurus: 520.

Irchaeodonta: $397,401,405$.

Archaeoiclea: $398,40 \mathrm{x}$.

Arcliaeomys: 510.

Argillotherium: 5 I2.

Artiodactyla: $396,397,40 \mathrm{I}, 469,477,495,502$. Arvicola: $524,527$.

Arvicolidae: 397.

Asterosternma : 284,512

Asterostemna depressa: $285,286,287,454$.

- Isterostemma granata: 285,454 .

Asterostema laevata: 286,454 .

Astrapotheridae: $397,453,458$.

Astrapotherium: $443,449,455,457,510$.

Astrapotherium ephebicum: 443 .

Istraptherium magnum: $443,453$.

Atalapha: 504 .

Atalapla bonariensis: 503.

Atalapha villosissima: 502 .

Atava: $396,398,401,405$.

Atelodus: 528 .

Atherura: 529 .

Atryptheridae: $397,452,458$.

- itryptherium: $457,509$.

Atryptherium bifurcatum: 452 ,

Auchenia: $472,488,489,492,497,504,518$, 524. 527,528

Auchenia Castelnaudi: $477,484,534$.

Auchenia cordubensis: 495,535 .

Auchenia ensenadensis: $477,484,534$.

Auchenia frontosa: $477,484,534$.

Auchenia gracilis: $477,484,534$.

Juchenia intermedia: $477,484,33.4$.

Auchenia lama: 495, 502, 53.5 .

Auchenia lujanensis: $477,484,535$.

Archenia mesolithica: 495, 535.

- Auchenia minor: 535.

Auchenia vicunna: 502 .

Auchenia Weddelli: $469,477,484, \div 34$.
Aulaxinuus: 522 .

Aurochs: 443 .

Axis: 523,528

\section{I,}

Bachytherium: 5 I5.

Balaena: $389,390$.

Balaena australis: $389,390,391$.

J halaena definita: 390 .

Balaena dubia: 390 .

Jhalaenidae: 389,399 .

Lalaenoptera: 390 .

Balaenoptera antarctica: 391 .

Balaenoptera bonariensis: 391.

Balaenoptera intermedia: $39 \mathrm{r}$.

Balaenoptera patachonica; 391 .

Bathmodon: 510.

Lathrodon: 511.

Bathyopsis: 510 .

Bibos: 524, 527, 528 .

Hiloricata: 186,189 .

Iison: 524 .

Blastoceros: $488,492,497,504,523,528$.

Iblastoceros azpeitianus: 478,485 .

Blastoceros campestris: $478,485,496,502$, 535.

Blastoceros paludosus: $478,485,496,502,535$.

Blastomeryx: 52.4 .

Boochoerus: 510 .

Borliyaena: 456, SII.

liorhyaena tuberata: $45 \mathrm{r}$.

Bos: $524,527,528$.

Bothriomys: $487,491,524$.

Bothriomys catenatus: $474,482,531$.

Bovidae: 397.

Brachycyon: 516 .

Brachydiastematherium: 509 .

Brachytherium: 465,515 .

Brachytherium cuspidatum: 462 .

Brachyuridae: 502,505 .

liradypodidae: 399 .

Bradypus: $8,27,50,65,67,68,70,75,78$.

liradypus giganteus: 27 .

Bramatherium: 524 .

Briaromys: $416,464,515$.

Briaromys Trouessartianus: $4 \mathrm{r} 6,460$.

Irontotherium: 518 .

Bruta: 5, 398, $401,449,453,462,470,478$, $496,503,517$.

Bubalus: 524,528 .

Bucapra: 524 .

Bunaelurus: 520 .

C

Cacodonta: 392, 394, 395, 399, 401, 405.

Cadurcotherium: 518 .

Caenotheridae: 397.

Cainotherium: 444, 515, 518.

Calamodon: 510 ,

Calamodontidae: 397 .

Calomys: $487,491,497,504,524,539$.

Calomys anguya: 500 .

Calomys auritus: $494,500,53 \mathrm{I}$. 
Calomys bimaculatus: 494, 500, 531.

Calomys Lravardi: 474 .

Calomys canescens: 500 .

Calonys coronatus: $53 \mathrm{r}$.

Calomys elegans: 500.

Calomys flavescens: 500.

Calomys griseo-flavus: 500 .

Calomys laticeps: 531 .

Calomys longicaudatus: $474,482,494,500$, 531.

Calomys magellanicus: 500 .

Calomys plebejus: 531 .

Calomys rex: $53 \mathrm{t}$.

Calonys xanthopygos: 500.

Calomys xanthorhinus: 500 .

Callithrix primaeva: 531 .

Callodontomys: 456,511 .

Callorlontomys vastatus: 450 .

Camelidae: $397,469,473,477,490,493$, Fo : $408,502,505$.

Camelopardalis: 523,527 .

Ciamelops: 528 :

Camelus: 524.

Camplotherium: 516 .

Canilae: $398,460,466,469,473,475,490$, $493,495,498,501,505$.

Canis: $455,472,487,489,491,497,504,516+$ $520,525,527,529$.

Canis acutus: 469 .

Canis avus: $476,483,533$.

Canis Azarae: $475,483,495,501,533$.

Canis bonariensis: $475,483,533$.

Canis brasiliensis: 533 .

Canis cancrivorus: $50 \mathrm{x}$.

Canis culpaeus: 501 .

Canis cultridens: $476,483,495,533$.

Canis ensenallensis: $475,483,533$.

Canis fulvicaudus: 533 .

Canis gracilis: 495, 501, 533 .

Canis griseus: 501.

Canis jubatus: $495,501,533$.

Canis lycodes: $495,533$.

Canis Lydekkeri: 533 .

Canis ? paranensis: 429,460 .

Canis protalopex: 533 .

Canis protojubatus: $476,483,533$.

Canis vetulus: 533

Capra: 524,528 .

Capreolus: 519, 523, 528 .

Capromyidae: 397 .

Cardiodon: 464, 515 .

Carcliodon Marshi: 460.

Carcliomys: 464, 515.

Cardiomys cavinus: 422,460 .

Cardiotherium: $424,464,515$.

Cardiotherium denticulatum: 460 .

Cardiotherium Doeringi: 422, $423,460$.

Cardiotherium minutum: 423,460 .

Cardiotherium petrosum: 423,460 .

Cariacus: $523,528$.

Carnivora: $398,40 \mathrm{r}, 405,460,469,475,495$, $501,5.11,516,517,520,525,529$.

Carterodon sulcidens: 532 .

Caryoderma: 526 .
Castor, 519, 524, 527, 529 .

Castoridae: 397.

Castoroides: $524,529$.

Catopisalis: $428,51 \mathrm{r}$.

Cavia: 497, 504, 529 .

Cavia porcellus: $494,501,532$

Cavia ? vates: 532.

Caviidlae: $397,450,458,460,466,468,473$. $475,490,493,494,498,500,505$.

Cavioton: $464,473,555,520$.

Caviodon multiplicatus: 460 .

Caviodon obtritus: 468 .

Cebilae: $396,+29,505$.

Cehochoerus: 515, 5 ig.

Celus: 503 .

Cehus apella: 531 .

Cebus lihidinosus: 499.

Cephalogale: 516 .

Cephalopus: 524 .

Centeticlae: 398 .

Centetodon: $51 \mathrm{x}$,

Centracodon: 511 .

Cercolabidae: $449,458,500,505$.

Cercopithecidae: 396 .

Cerodon: 487, 491, 497, 304, 525, 529.

Cerodon antiquns: $475,483,532$.

Cerodon australis: 501 .

Cerorlon boliviensis: 532 .

Cerodion flavidens: 532 .

Cerodon leucoblepharus: $494,500,532$.

Cerodon priscus: $475,483,532$.

Cerocion pygmaeus: $475,4 \mathrm{~S}_{3}, 532$.

Ceroilon turgen: $475,483,53 z$.

C'ervalces: 523,528 .

Cervilae: $397,470,473,478,490,493,495$. $498,502,505$.

Cervulus: $519,523,528$.

Cervus: $488,492,519,523,527,32 x$.

Cervus brachyceros: $+78,484,53:$.

Cervus latus: $478,484,535$.

Cervus lujanensis: $478,484,535$.

Cervus palaeoplatensis: $478,484,535$.

Cervus tuberculatus: $47 \mathrm{~S}, 484,535$.

Cetacea: $5,383,399,401$, ,

Cládosictis: $456,51 \mathrm{I}$.

Cladosictis patagonica: 451 .

Coassus: $497,504,523,528$.

Coassus mesolithicus: 496,535 .

Coassus nemorivagus: $495,502,535$.

Coassus rufinus: 502,535 .

Coassus rufus: $495,502,535$.

Cobus: 533 .

Cochlops: 233, 381, 382, 457, 512 .

Coclilops muricatus: $234,453$.

Coelodion: $20,21,35,36,37,41,49,52,63$, 64, $76,78,79,80,81,82, S_{3} ; 115,133,1+0$, 149, $488,492,526$.

Coelodon escrivanensis: 79,536 .

Coeloulon Kaupi: 79, 536 .

Coeludon maquinensis: 79,536 .

Coelodon tarijensis: $80,81,478,485,536$.

Coelogenys laticeps: 532 .

Coelogenys major: 332 .

Coelogenys paca: 532 . 
Coenobasileus: 519.

Coenopithecus: 514 .

Colonimys: 5 ro.

Colonoceras: 509.

Coloreorlon: 518 .

Colpodon: 465, 515.

Colpodon propinqusus: 461 .

Colutoulonta: 20 .

Comaphorus: $3 x+, 320,322,465,516$.

Comaphorus concisus: $192,320,462$.

Condylarthra: $396,401,405,508,513,514$, 518.

Conorcytes: 508 .

Cordilodon: $5 \geq 0$.

Coryphodon: 510

Corypholontidae: $397,453,458$.

Cossoryx: 524.

Creodonta: $398,40 \mathrm{I}, 405,428,43 \mathrm{I}, 45 \mathrm{I}, 458$, $460,466,51 \mathrm{I}, 513,516,517,520,525$.

Cricetodon: 515,519

Cricetus: $5=9$.

Cristiva: $397,401,405$.

Crociclura: 529 .

Cryptomeryx: 515 -

Ctenomys: $17,487,489,491,49 \pi, 504,524$, 529. 540

Ctenomys bonariensis: $474,482,532$.

Ctenomys brasiliensis: 500 .

Ctenonys lujanensis: $473,482,532$,

Ctenomys magellanicus: $474,4 \mathrm{~S}_{2}, 494,500$, 532.

Cyclopislius: 523,527 .

Cynelos: 520 .

Cyrocephalidae: 396 .

Cynocephalus: $522,5 \geq 8$.

Cynodictis: 516

Cynodon: 516 .

Cysodontomys: 508 ,

Cynoliyaenodon: 516 .

Cyonasua: $430,+65,516$.

Cyonasua argentina: $429,46 \mathrm{r}$.

\section{CII}

Chacnolyys: 510

Chalicomys: $5=4$.

Chalicotheridae: 397 .

Chalicotherium: 515, 518, 523 .

Chasmotherium: 515

Cheiromyilae: 396 .

Chiroptera: 398, for, $405,50 x, 512,516,521$, $5-5,530$.

Chirox: 511 .

Chlamydephoridae: $335,374,382,399,503$, 505.

Chlamyrlophorus: $37 t, 375,379,380,382,488$, $504,536$.

Chlamydophorus tuncatus: $375,48 \mathrm{r}, 486,503$. 537.

Chlamyclophorus trumcatus? fossilis: 375 .

Chlamydotheridae: $335,380,382,399,454$, $458,463,467,471,473,480,490,493$.

Chlamydotherium: $178,204,321,336,338,340$, $341,342,343,344,345,378,379,38=457$,
$465,472,488,489,492,513,516,521,5=6$, $5+7$.

Chlamydotherium ? australe: 343,454,

Chlamydotherium ? extremum: 342,463 .

Chlamydotherium gigas: 537 .

Chlamydotherium Ifumboldti: 339, 537.

Chlamydotherium intermedium: 343,470 .

Chlamydotherium paranense: $337,338,340$, $342,343,344,463$.

Chlamydotherium typum: $336,338,339,343$, $344,364,480,486,537$.

Chlamydotherium typus: 336 .

Choenohyus: 519.

Choerodonta: $397,401,405$.

Choeromeryx: 524 .

Choeromorus: 5 r 5 .

Choeropotamus: 515,519 .

Choloepus: $21,66,67,68,78$.

Chriacus: 508.

Chrysochloridae: 398 .

\section{D}

1)acrytherium: 515 .

1)actylomys amblionyx: 532 .

1)ama: 523,528 .

Dasypoda: $176,284,333,335,336,376,377$, 379, $3 \mathrm{So}, 3 \mathrm{Sz}, 399,40 \mathrm{r}, \$ 05,454,463,47 \mathrm{~s}$, $480,496,503,513,516,521,526,530$.

Dasypodidae: $335,352,380,38 \mathrm{r}, 382,399,454$, $458,463,467,471,473,481,490,493,496$, $498,503,505$.

Dasypotherium: 548,549 .

Dasypotherium australe: $5+7$.

Dasyprocta: 504 .

Dasyprocta aguti: 532 .

1)asyprocta Azarae: 500 .

1)asyproctidae: $397,500,505$.

1)asypus: $336,353,355,357,358,361,362$, $363,364,365,375,380,382,449,457,463$. $465,471,472,488,489,492,498,504,513$. $516,521,526,530,548$.

Dasypus antiquus: $180,190$.

Dasypus apareoides: 371 .

1)asypus conturus: $37 \mathrm{I}$.

Dasypus duodecimcinctus: 374 .

Dasypus giganteus: 373 .

Dasypus gigas: 373 .

1)sypus gymnurus: 374 .

Dasypus hesternus: 446 .

Dasypus liybridus: 348 .

1)asypus major: $355,481,486,496,537$.

Dasypus maximus: 180 , 290.

1)asypus minutus: 357,358 .

Dasypus novemcinctus: 348 .

Dasypus octocinctus: 348 .

Dasypus off. octocincta: 349 .

I)asypus patagonicus: $356,358,454$.

I)asypus pela: 348 .

1)asypus platensis: $356,496,537$.

Dasypus septemcinctus: 348 .

Dasypus sexcinctus: $353,355,367,48 \mathrm{~S}, 486$, $4503,537$.

1)asypus aff. sexcinctus: 354 .

Dasypus tatomay: 374 
Jasypus unicinctus: 374 .

J)asypus villostr: $354,355,356,357,358,446$, $488,486,496,503,537$.

J)asypus villosus fossilis: 354,355 .

I)asypus aff. villosus: 355 .

1)asyura: 393 , for, 405 .

1)asyuriclae: 398 .

1)asyurodon: 516 .

1)aubentonioiden: $396,40 x, 405$.

lecticadapis: 510 .

Deilotherium: $8,10,444,515$.

Deilothérum venerandum: 9 .

1)elphinidae: $383,384,385,387,399$.

1)elphinarliynchus australis: 389 .

1)elphinus: 385,386 .

i)elphinus albi-rostris: 385 .

1)elphinus bivittatus: 386 .

Delphinus Blainvillei: 384 .

Delphinus caeruleo-albus: 385 .

Delphinus cruciger: 386.

Delphinus litzroyi: 386.

Delphinus paranensis: 385 .

Delphinus rectifrons: $3 S_{5}$.

Delphinus superciliosus: 386 .

Delotheria: 398 .

1)eltatherium: $5 \mathrm{rx}$.

Desmatotherium: 509 .

I)esmodus: 504 .

Desmotus J'Orbignyi: 502 .

Desmodus rotundatum: 502 .

1)iacodon: 511:

Diacliaphorus: 45\%, 509 .

Diadiaphorus velox: 452 .

Diadiaphorus majusculus: 452 .

Diastomicodon: $488,492,523$.

Niastomicodon lujanensis: $477,484,534$.

Diceratherium: 518 .

Dicoelophorus: $472,487,489,519,524$.

Dicoelophorus celsus: 468 .

Dicoelophorus latidens: $468,475,482,532$.

Dicoelophorus priscus: 468 .

Dicoelophorus simplex: 468 .

1)icolpomys fossor: 532 .

Diconodon: 518 .

Dicotyles: $488,492,49 \%, 504,519,524,527$, 5.9.

1)icotyles labiatus: 502,534 .

Dicotyles stenocephalus: $477,484,534$.

Dicotyles tajacu: $477,484,495,502,534$.

Dichobune: 444,515 .

Dichobunidae: 397 .

Dichodontidae: 397 .

Dideilotherium: $444,457,512$.

Dideilotherium venerandum: 453 .

Didelphodus: 512 .

Didelphyidae: $39 \mathrm{~S}, 469,473,475 * 490,493$. 495, 498, 50r, 505 .

Diclelphys: $472,487,489,491,497,504,521$, 525, 529.

Didelphys Azarae: $495,501,533$.

Didelphys cinerea: 501,533 .

Didelphys crassicaudata: $50 \mathrm{~s}, 533$.

Didelpluys dorsigera: 501 .

Didelphys elegans: 501, 333.
Didelphys grandacra: $475,483,533$.

Itidelphys grisea: 533 .

J)idelplys incerta: $475,483,533$.

Jidelphys inexpectata: 469 .

Didelphys juga: $475,483,533$.

Didelphys lujanensis: 495,533 .

Didelphys murina: 533 .

Didelphys nudicaudata: 533 .

Didelphys pusilla: 53.3 .

Didelphys triforata: 469 .

Didimyctis: 531 .

Dilobodon: $465,488,489,514,523$.

Dilobodon lujanensis: $476,484,534$.

Inilobodon lutarius: 436,461 .

Dilophodion: 509 .

1)imerodon: $487,491,525$.

bimerodon mutilatus: $475,4 S_{3}, 533$.

1)imilus: 520 .

Dinictis: 520 .

Dinocerata: $397,401,405$.

Dinocyon: 520 .

Dinosauria : 507 .

Dinotheridae: 397.

Dinotherium: $529,524,527$.

Diocartherium: $472,5=0$.

Diocartherium australe: 468 .

Biodomus: $16,84,107,198,109,465,472$, 516,521 .

I)iodomus Annaratonei: 110,462 .

I)iodomus Copei: 108, $11 \mathrm{r}, 462,470$.

Diplacodon: 509.

1)iplopus: 515 .

Diplotremus: $488,489,5-3 . ; \therefore 7$.

Diplotremus agrestis: 47 . : ‘゙ $=31$.

Dipodidae: 397 .

Dipoides: 520 .

Diprotodontidae: 398 .

Discolomys: 464,515 .

Discolomy's cuneus: 412,459 .

Dissacus: 5 II.

1)itremata: $394,396,40 \mathrm{r}$.

Doerlicuridae: $203,353,399,462,467,470$, $473,480,490,493$.

Doedicurus: $18 \mathrm{r}, 184,185,186,188,189,19 \mathrm{r}$, $192,195,204,208,209,299,314,316,318$, $319,320,321,322,324,329,330,331,375$, 3 S: $382,482,488,489,492,526$.

Doedicurus antiquus: $192,330$.

Doedicurus clavicaudatus: $189,192,325,328$, $480,486,537$.

Doedicurus Copei: 330.

Doedicurus giganteus: $188,189,190,192,321$, 325,328 .

Doedicurus Kokenianus: $327,328,330,480$, $486,537$.

Doedicurus Poucheti: $190,327,32 \mathrm{~S}, 480,486$, 537.

Doedicurus urugnayensis: $1 \mathrm{S9}, 192,325$.

Dolichotis: $487,489,49 \mathrm{r}, 497,504,525,529$.

Dolichotis centralis: $42 t, 500$.

Dolichotis intermedia: $475,483,532$.

Dolichotis major: $475,483,532$.

Dolichotis minor: $475,483,532$.

Dolichotis patachonica: $421,494,500,532$. 
Dolichotis platycephala: $475,483,532$.

Doliochoerus: $5 \pm 5$.

Dolodonta: $396,401,405$.

Dommina: 521 .

Dorcatherium: 524 .

Drepanodon: 516,521 .

Dromocyon: 512 .

Dryopithecus: $51 \%$.

1)ryptodon: 510 .

1)ysopes 'Temmincki: 534 .

\section{E}

Fictacodon: 510.

Ectoconus: 508 .

Fictocyon: 509 .

Jictoganidae: 397 .

Iictoganus: 5 ro,

Fichidnidae: 399.

Echinagale: 520 .

J.chinomyidae: $397,450,458,4.59,466,468$, $473,47+, 490,493,494,498,500,505$.

Jichinomys cajennensis: 532 .

Jiffodientia: 335 .

1ilachoceras: 510.

Elaphus: $523,527,5=8$.

Jilasmotherium: 5.28 .

Filephantidae: $397,470,473,478,490,493$. 496,498 .

Elephas: $524,527,529$.

Filentheracercus: 312,329 .

Jilentherocercus setifer: 192, 313.

Jiomys: 519.

Eilotheridae?: 397.

Jilotherium: 529 .

Embassis: 521 .

Enhydrocyon: 520.

Eintelomorphus: 488,489 .

Entelomorphus rotundatus: $476,484,-534$.

Eintelops: 6, 457, 5 I2.

Fintelops dispar: 6,453 .

Entelonsidae: 6, 398, 453 .

Entomodon: $51 \mathrm{r}$.

Entontyclius: 519 .

Foauclienia: 472,518 .

Toauchenia primitiva: 470 .

Fobasileus: 510.

Eobasilidae: 397 .

Eocardia: 456,511 .

Jiocardia divisa: 450.

Focardia montana: 450.

Focardia perforata: 450 .

liohyus: 510 ,

Jomys: 515 .

Fosimia: 396, 401, 405, 508, 514, 517.

Epanorthidae: $398,45 x, 458$.

Epanorthus: 456,511 .

Pipanorthus Aratae: 45I,

Epanorthus intermedius: $45 \mathrm{I}$.

Epanorthus Lemoinei: $45 \mathrm{r}$.

Epanortlus minutus: $45 \mathrm{I}$.

Tipanorthus pachygnathus: $45 \mathrm{x}$.

Eipanorthus pressiforatus: $45 \mathrm{x}$.

Fipieuryceros: 488, 489. 523 .

Epieuryceros truncus: $478,485,535$.
Eipihippus: 509.

Eipiodon australis: 389 .

Epitherium: 472,518 .

Epitherium laternarium: 469 .

Equidae: $397,46 \mathrm{r}, 466,469,473,477,490$, 493, 49 s.

Equus: $488,491,496,497,523,527,528$.

Equus argentinus: $47 \overline{7}, 484,534$.

Equus australis: $44^{2}$.

Equus curvidens: $477,484,534$.

Equus rectidens: $477,484,495,503,534$.

Erethizon: 524,529 .

Erinaceidae: 398 .

Erinaceus: $520,525,529$.

Eriomyidae: $397,450,458,460,460,408,473$ ? $475,490,493,494,498,500,505$.

Iiriomys: 504.

Eriomys laniger: 500

Eischatius: 524, 527 .

Essonodontherium: $23,34,35,36,51,52,492$, 498.

Essonodontherium Gervaisi: $34.35,478,485$, 496,535 -

Listhonyx: 510 :

listonychidae: 39 S.

Eubalaena australis: $3 \mathrm{Sg}$.

Iucladoceros: 523 .

Eucrotaplaus: 5 I8.

Iitucholoeops: $63,66,67,71,82,83, S S, 89$, $457,5 \mathrm{r} 2$,

Kucholoeops adteger: 75,453 .

lincholoeops infernalis: $70,71,453$.

Fucholoeops ingens: $68,70,71, .72,453$.

İuphilus: $414,464,515$.

Euphilus Ambrosettianus: 414,460 .

Fuphilus linrtzi: 415,460 .

Euphractus exilis: 350 .

Euphractus major: 355 .

Vuphractus minimus: 360 .

Euphractus patagonicus: 356 .

liuphractus proximus: 359 .

liuphractus sexcinctus: 353 .

Fiphractus off. sexcinctus: 354 .

Fuphractus villosus: 354,376 .

Euphractus aff. villosus: 355 .

Eulamaops: $488,492,524,527$.

Eulamaops parallelus: $478,484,535$.

Fimys: 519.

Eumysops: 5 ro.

Eumysops laeviplicatus: 468 .

Ėumysops plicatus: 468 .

Lumysops robustus: +68 .

Euryacodon: $51 \mathrm{x}$.

Euryodon latidens: 537.

Fîuryurus: $184,190,192,314$.

Furyurus antiquus: $192,317$.

Furyurus interundatus: 192,319 .

Êryurus rudis: 192, 316 .

Einsyodon: 519 ,

Equtatus: $350,355,360,363,365,366,36$ \%, $368,380,382,457,+63,465,471,472,488$, $489,492,513,516,528,526,547,548$.

Futatus bipunctatus: 368 .

E,utatus brevis: $366,367,48 \mathrm{I}, 486,537$. 
Lutatus listans: $370,454$.

Èutatus lagena: 369,454 .

Eutatus minutus: $367,368,481,486,537$.

Lutatus oenophorus: $368,369,454$.

Fiutatus punctatus: $367,368,481,486,537$.

retutatus Seguini: $285,350,365,367,48 \mathrm{r}, 486$, $537,5+7$.

Eutemnodus: 43 .

Eutemnodus americanus: $43 \mathrm{r}$.

Liutomodus: $437,465,515,543,546$.

Eutomodus elautus: $437,46 \mathrm{r}$.

\section{F}

Felidae: $398,476,490,493,495,498,501,505$. Felis: $48 \%, 491,497,504,525,527,529$.

Felis colocolo: 501 .

Felis concolor: 495, 501, 533 .

Felis eyra: 501

Felis Geoffroyi: $50 t$.

Felis jaguarundi: $50 \mathrm{r}$.

Felis longifrons: $476,483,533$.

Felis macroura: 534 .

Felis mitis: $50 \mathrm{r}, 534$.

Felis onça: 495, 501, 533 .

Felis pajeros: $50 \mathrm{r}$.

Felis palustris: $476,483,534$.

Felis pardalis: 534.

Felis platensis: $476,483,533$.

Felis protopanther: 534 .

Felis pusilla ?: 534 .

Furcifer: $488,492,504,523$.

Furcifer bisuleus: 502 .

Furcifer seleniticus: $478,485,535$.

Furcifer sulcattus: $478,485,535$.

\section{Ph}

Phacochoeridae: 397 .

Phalangistidae: $398,401,405$.

Plianeromeryx: 515 .

l'Lanomys: 456, 51 .

Phanomys mixtus: 450.

Phanotherus: 464,516 .

Phanotherus marginatus: $408,459$.

Phascolarctidae: 398.

Phascolomyidae: 398,405 .

Phascolotheria: 396, 398, 40r, 405.

Phascolotheridae: 398.

Phenacodontidae: 396.

Phenacodus: 508 .

Phobereotherium: 456, 508 .

Phobereotheritum sylvaticum: 452 .

Phocaena: 387.

Phocaena australis: 386 .

Phocaena spinipinnis: 387 .

Phocidae: 398.

Phonoctonia: $398,40 \mathrm{r}, 405$.

Phororhacidae: I1, I3, 399, 453, 458 .

Phororhacos: $13,457,512$.

Phororhacos longissinus: $13,453$.

Phtoramys: 472,5 I9.

Phtoramys homogenidens: 413,468 .

Phugatherium: 472,520 .

Phugatherium cataclisticum: 468 .
Ptiyllorhina: 530 .

I'hyllostome: 504 .

I'hyllostoma lilium: 50 t.

Phyllostoma lineatum: $50 \mathrm{r}$.

I'lyllostoma spectrum: 534 .

Phyllostoma superciliatum: $50 \mathrm{x}$.

Phyllostomidae: 398, 501, 505.

Physalus patachonicus: 391 .

Physeter: 388 .

Physeter macroceplialus: 388.

Physeteridac: $383,388,399$.

\section{G}

Galecynus: 520 .

Galeopithecidae: 398 .

Galeothylax: 516.

Galera: 529 .

Galictis barbara: 501,533 .

Galictis intermedia: 533 .

Galictis major: 533 .

Galictis vittata: $50 \mathrm{r}$.

Gazella: 523, 527, 528

Gelocus: 518

Geolabis: 520 .

Geomyidae: 398 .

Geomys: $5=$.

Gerbillus: 529 .

Giraffidae: $39 \%$.

Globicephalus Grayi: $38_{7}$.

Glossophaga: 504.

Glossophaga ecaudata: 502 .

Glossotherium: $37,86,87,88,89,90,91,93$. $108,112,134,135,136,137,138,139,140$, $141,142,145,146,147,148,488,489,492$, 326 .

Glossotherium bonariense: $144,479,485,536$.

Glossotherium Darwini: $134,142, I+3,144$. $145,479,485,536$.

Glossotherium Zeballosi: $143,144,479,485$, 536 .

Glyptodon: 17, 28, 177, 178, $779,180,18 \mathrm{r}$, $182,183,185,186,187,188,189,190,19 \mathrm{r}$ 192, 195, 204, 206, 207, 208, 209, 210, 211 , 213. $217,218,220,226,228,230,231,239$, $244,251,252,254,255,266,271,288,297$, 299, 300, 301, 303, 307, 311, 315, 316, 321, $322,324,341,380,382,447,472,488,489$, $492,521,526,527$.

Glyptodon asper: $180,185,187,188,190,192$, $219,220$.

Glyptodon clavicandatus: $181,183,18_{5}, 186$, $188,325$.

Glyptodon clavipes: $178,179,180,181,182$, $183,184,185,186,187,188,190,191,192$. $209,210,211,212,213,214,215,216,217$, $218,220,221,229,253,256,257,258,259$. $265,270,271,479,485,536$.

Glyptodon D'Orbignyi: 183,184 .

Glyptodon dubius: $188,214$.

Glyptodon elevatus: $182,185,19 \mathrm{r}, 230,23 \mathrm{r}$.

Glyptodon elongatus: $183,184,185,188,190$, $22 \mathrm{I}, 222,224,229,480,486,536$.

Glyptodon eupluractus: $192,214,215,255,479$, $485,536$. 
Glyptodon Falkneri: $226,480,486,536$.

Glyptodon Fiorinii: 228, 480 .

Glyptodon genmatus: $190,229,4 \mathrm{So}, 486,536$.

Glyplodon geometricus: $183,184,190$.

Glyptodon giganteus: $185,186,188,302,325$.

Glyptodon gigas: $183,184,188,325,326$.

Glyptodon gracilis: $188_{3}, 187,189,283,284$.

Glyptodon laevis: $185,188,224,226,470,480$, $486,536$.

Glyptodon minor: $218,480,486,536$.

Glyptodon Mufizi: I91, 217, 479, 485, 536 .

Glyptodon ornatus: $179,180,182,184,185$. $186,18 \%, 256$.

Glyptodon Oweni: $182,183,184,210,256$ 479.

Glyptodon perforatus: $182,191,225,4$ So, 486 , 535 .

Glyptodion principalis: $180,191,216,228,479$, 485. 536 .

Gyptodon pumilio: $184,187,269$.

Glyptodon quadratus: 183 .

Glyptodos radiatus: $183,184,187,190,282$.

Glyptodon reticulattus: $180,182,183,184,185$, $187,388,292,212,213,214,217,210,220$, $222,223,224,225,229,270,302,479,486$, 536

Glyptodon robustus: 302 .

Glyptorlon rudimentarius: 191, 226, 480, 486 , 536.

Glyptodon rudis: $189,190,314,316$.

Giyptodon Sellowi: $2 \mathrm{~T} 4$.

Giyptodon spinicaudus: $184,185,219$.

Glyptodon sub-elevatus: $183,18,215,479$, $485,536$.

Glyptodon tuberculatus: $180,18 \mathrm{I}_{1} 183,18_{3}$. $184,185,219,302$.

Glyptodon typum: I90, 219, 220.

Glyptodon typus: $219,220$.

Glyptodon verrucosus: 183,302 .

Glyptodontia: $176,177,193,203,230,335$ $340,376,377,380,382,399,401,405,453$. $462,470,479,512,516,521,526,530$

Glyptodontidae: $203,204,235,236,399,453$, $458,467,470,473,479,490,493$.

Golunda: 529 .

Gomphotherium: 519 .

Cinathopsis: $63,64, S_{1}, S_{2}$.

Gnathopsis Oweni: $8 \mathrm{I}, 478$.

Gravigrada: $11,16,19,78,175,399,401,405$. $4+9,453,462,470,478,496,312,516,521$, $5 \geq 6,530$.

Gravigrada mylomorpha: $=0$.

Gravigrada rodimorpla: 20.

Gronotherium: 456, 508 .

Gronotherium decrepitum: 452.

Grypotherium: 138, 144 .

Grypotherium Darwini: $134,142$.

Gulo: 525, 529 .

Gymnoptyclitus: 510 .

Gymmuridae: 502, 505.

\section{II}

IIabrothrix: 497, 504, 529 .

Ilabrothrix arenicola: $494,500,531$.
Habrothrix clivigenis: 531 .

IIabrothrix cursor: 531 .

Ilabrothrix internus: $494,53 \mathrm{I}$.

Habrothrix lasiurus: $53 \mathrm{t}$.

Ifabrothrix microps: 500.

IIabrothrix obscurus: 500 .

Habrothrix orycter: $53 \mathrm{I}$.

Halitheridae: 397.

Ilalobioidea: $396,397,401$.

IIapale: 504.

Hapale grandis: 531 .

Hapale penicillata: 499,531 .

Ilapalidae: $396,499,505$.

IIapalops: $53,57,75,83,174,457,512$.

IIapalops ellipticus: 58,453 .

Hapalops indifferens: 59,453 .

Hapalops rectangularis: 57,453 .

Haplaconus: 508 .

Ilaplodontherium: $434,436,437,465,514,54 \mathrm{r}$, $542,5+3,544,545,546,547$.

ILaplodontherium limum: $46 \mathrm{r}, 546,547$.

Haplodontheriumi Wildei: $433,434,436,46 \mathrm{r}$, $5+2,545$.

Haplogale: 516 .

Haplomeryx: $5 \pm 5$.

Ifathliacynus: 456 , 511 .

IIathliacynus lustratus: 45 I.

Ifedimys: 456 , $5 \mathrm{II}$.

Hedimys integrus: 450 .

Ilegetotherium: $440,456,508,5+3$.

Hegetotherium mirabile: $45 \mathrm{r}$.

Hegetotherium strigatum: $45 x$.

Helatetes: 509.

Ifeliscomys: 5 I9.

IIelohyus: 509 .

IIeloyus ?: 510.

Helladotherium: 523,527 .

Iemiacodon: 511 .

IIemiauchenia: $488,492,524,527$.

Hemiauchenia paradoxa: $477,484,535$.

Hemichoerus: 515.

Hemiganus: 510.

Hemimeryx: 524 .

Ilemipsalodon: 520 .

Hemithlaeus: 508 .

Heptodon: 509.

Ilerpestes: $516,521,529$.

Hesperomyidae: $474,490,493,494,498,500$, 505.

IIesperomys: 487, 491, 497, 504, 524, 529.

Ilesperomys expulsus: $53 \mathrm{I}$.

Hesperomys molitor: $474,482,494,53 \mathrm{I}$.

Hesperomys simplex: $53 \mathrm{r}$.

llesperomys tener: $494,500,331$.

Heteroborus: $51 \mathrm{r}$.

Ifeterodon diversidens: 537 .

Heterodonta: $395,396,40 t$.

Hexodon: 508 .

Hicanodonta: $5,176,399,453,462,470,479$, 503.

Hipohippus: 523 .

Hipparion: $518,523,527$.

Hipphaplus: $465,488,489,491,515,523,527$. Ilipphaplus antiquus: $477,484,534$. 
Mipphaplus liravardi: $477,484,534$.

Ilipphaplus entrerrianus: $46 \%$.

Ilippidium: $472,469,472,488,489,49 \mathrm{r}, 518$, $523,527$.

Ilippidium angulatum: $4 \pi 7,484,534$.

Hippidium compressidens: $477,484,534$.

Ifippiditum nanum: $442,477,48.4$.

Ilippidium neogaeum: $44 z, 47 \overline{7}, 484,534$.

Ilippidium principale: $45,484,534$.

Ilippolyus: 524 .

Ilippopotamidae: 397 .

Iippopotamus: $524,527,529$.

Ilippotragsis: $519,523,527$.

Holochilus: $487,491,497,504,524,529$.

IIolochilus multannus: 482,531 .

Ilolochilus vulpinus: $474,482,494,500,531$.

Ilolomeniscus: 524,527 .

Ilomalodonta: $5,395,398,401$.

Homalodontotheridae: $397,452,458$.

IIomalodontotherium: 457,509 .

IIomalodontotherium Cunninghami : 452 .

Hominidae: $396,468,473,474,490,493,494$, $498,499,505$.

Homo: $482,488,491,497,503,523,528,531$.

IIomo sapiens: 474, 494, 499 .

Homocamelus: $524,5 \geq 7$.

Ilomorhinoceros: $5+0$.

IIomorlinoceros Bravardi: $\$ \neq 0$.

Jomorhinoceros platensis: $5 \neq 0$.

Hoplophoneus: 520 .

IIoplophoridae? $203,235,399,454,458,462$, $+67,470,473,480,490,493$.

Iloploptiorus: $178,179,1 \mathrm{So}, 182,183,184,185$, $187,188,189.190,19 \mathrm{r}, 192,204,206,207$, $208,211,212,213,214,216,218,232,235$. $236,238,239,246,247,249,250,251,252$, $253,259,26 \mathrm{r}, 266,270,27 \mathrm{I}, 272,276,27 \mathrm{~S}$, $279,280,282,283,287,288,289,290,291$, $292,297,314,316,317,318,324,329,342$, $346,364,380,381,382,446,465,472,488$. $489,492,516,521,526$.

IIoplophorus Ameghinoi: $191,288$.

IIoplophorus asper: 188, 219.

Ifoplophorus australis: 191, I92, 236, 237.

IIoplophorus liergi: $27 \mathrm{I}, 278,480$.

IIoplophorus Burmeisteri: 188.

IIoplophorus Clarazianus: $275,278,480$.

Yoplophorus clavicaudatus: 325 .

IIoplophorus compressus: 191, 280.

Iloplophorus cordubensis: $192,265,266,278$, $+70$.

1loplophorus discifer: 789 .

Ifoplophorus elegans: $180,184,187,190,192$, 28 .

IIoplophorus elevatus: 191,281 ,

Iloylophorus elongatus: I $88,222$.

Hoplophorus euphractus: $178,179,180,185$, $186,187,188,189,214,255,256,282$.

IIoplophorus evidens: $264,278,480$.

IIoplophorus formosus: $26 \mathrm{t}$.

IIoplophorus gracilis: 255,283 .

Iloplophorus IIeusseri: $271,273,278,480$. 486,536 .

IIoplophorus imperfectus: $190,279$.
Iloplophorus laevis: is8, 224.

Hoplophorus lineatus: 192, 261, 2-2, $4-11$.

Hoplophorus Lydehkeri: $270,278,480$.

Iloplophorus Neyeri: $180,185,186,187,180$. $190,592,255,256,278,283,480,486,536$.

IIoploplorus Migoyantis: $276,278,480,486$.

Hoplophorus minor: $179,180,190,218$.

Ilopiophorus ornatus: $187,188,190,192,213$. $215,218,226,234,237,255,256,259,260$, $263,264,265,267,268,269,271,273,275$, $278,279,280,287,291,317,336,480,486$, 536.

Iloplophorus paranensis: $191,267,278,46 z$.

IIoplophorus perfectus: $190,263,278,+80$, 486,536 .

Iloplophorus pseudornatus: $259,26 \mathrm{r}, 278,480$, 486,536 .

Hoplophorus pumilio: $269,2,-$, .

IIoplophorus radiatus: 282 .

Hoplophorus reticulatus: 210 .

Hoplophorus Scalabrinii: 101 .

Ifoplophorus scrobiculatus: $\because-3, \quad-i, j$, inn.

Iloplophorus Sellowi: 179, 214 .

IIoplophorus spinicaudus: 219 .

II oplophorus verus: $269,278,+62$.

IIyaemoschus: 518 .

Ilyaena: 525,529 .

IIyaenarctos: $; \because, \quad ; .$,

IIyaenictis: 525 .

IIyaenidae: 398 .

IIyzenocyon: $5 \geq 0$.

IIy-aenodictis: $5 \mathrm{II}$.

Hyaenodon: $431,511,52.1,5 ; 5$.

Hydaspitherium: 5 ' $t$.

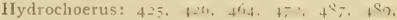
$49 x, 497,504,520,525,527,5241$.

IIydrochoerus capybara: $427,475,483,496$, $50 \mathrm{r}, 532$.

Ilydrochoerus giganteus: $426,473,483,494$. 532.

Hydrochoerus irroratus: 427,460 .

IIydrochoerus magnus: $427,475,483,532$.

Hydrochoerus perturbidus: 468 .

If ydrotherenta: 396,398, for.

Ifyodectes: $51 \mathrm{r}$.

Hyopotamus: $515,519,524$.

Ilyopsodus: 508.

Ifyotherium: 515, 519, 524.

Hypertragulus: 518 .

IIypisodus: 518 .

Ifipposyus: 508 .

Ifypsiprymniclae: $398,401$.

IIypsiprymnts: 405.

Tiyracidae: 397 .

IIyracodon: 518 .

IIyracodontherium: 5 I5.

Hyracodontidae: 397 .

IIyracoidea: $397,401,405$.

Hyracotlerium: 509, 515 .

Hyracotherius: 509 .

IIyrachyus: $509,515$.

IIystricidae: 397 .

Ifystrix: 520, 524, 527, 529 . 
Icochilts: 457,509 .

Icochilus excavatus: 452 .

Icochilus extensus: 452 .

Icochilus rotundatus: 452 .

Icochilus undulatus: 452 .

Icticyon major: 533 .

Icticyon venaticus: 533 .

Ictitherium: 525 .

Ictops: $51 \mathrm{x}$.

Ichthyoulorulithes: 37 .

Indrodion: 508 .

Insectivora: $39 \$, 401,405,511,516,517,520$, $5 \geq 5,5 \geq 9$.

Interatheridae: $397,452,458,461,466,469$. $4-3$.

Interatherimm: 457,509 .

Interatherium rodens: 452 .

Interatherium supernum: 452.

Interodon: $23,35,36,4 \pi, 48,49,5 r, 52,135$, $465,516$.

Interodon crassidens: $48,50,135,462$.

Iscliyromys: $5 \mathrm{rg}$.

Issiodoromys: 5 If,

Ithygrammodon: 500 .

Tavulus: 524,529

\section{I.}

Lagenorhynchus caeruleo-albus: 385.

Isagidium: $50 \%$.

Lagidium peruanum: 500 .

I. Lgonyidae: $39 \%$.

Lagory : 5:0.

Lagostomus: $410,414,416,456,457,46.4,472$, $487,489,491,497,504,511,515,519,525$, 529 .

I.agostomus angusticlens: 475 .

Lagostomus antiquus: 460 .

Iagostomus brasiliensis: $53=$.

Lagostomus carifrons: $475,483,532$.

I,agostomus debilis: $475,483,532$.

Lagostomus heterogenidens: $475,483.533$.

Ingostonus incisus: 468 .

Iagostonus Iateralis: 450 .

Lagostonus minimus: $475,483,532$.

Lagostomus pallidens: $4 \mathrm{I} 4,460$.

Iagostomus primigenius: 450 .

I.agostomus spicatus: 468 .

Jagostomus trichodactylus: $483.494 .500,532$. Irambdotherium: 509 .

I,aniodon: $48,84,106,488,492,526$.

Ianiodon robustus: $306,479,485,535$.

Lasiuromy's villosus: 532 .

I.emuravus: 508 .

Lemuridae: 396 .

Leporidae: $397,499,505$.

Leptaretos: 525,527 .

Leptauchenia: 518 .

Jeptlyaena: 525 .

Leptictis: 520 .

Leptohos: $524,527,528$.
J.eptodou: $5=3$.

Lepus: $504,524,527,529$.

Lepus brasiliensis: 499, 533.

Lestodon: $x 6,27,20,2 x, 47,49,65,66,67$, $82,84,85,86,87,88,90,91,92,93,94,95$, $97,105,107,108,109,110,113,115,14 \pi$, I 42,149, I 55, I $56,445,465,472,488,489$, $492,516,521,526,547$

Iestodon antiquts: $103,104,108,462,470$.

Lestodon armatus: $84,85,96,97,98,99,100$, I01, 102, 103, 104, 479, 485, 535.

Lestodon Blainvillei: $85,102,479$.

I, estodon Bocagei: $85,100,103,104,479,485$, 535.

Lestodon Bravardi: 85 , IOI, I02, 479, 485, 535 . Lestodon Garrachicoi; ro8.

Lestodon Gaudryi: $85,101,103,479,485,535$.

Lestodon giganteus: 97,98 .

Lestodon myloides: $84,85,155,156,157$, I 58 .

Lestodon paranensis: 105,462 .

Lestodon trigonidens: $S_{5}, 96,98,99,100,50 \mathrm{r}$, $102,103,104,106,107,109,158,4,9,485$. 5is.

Lestodontidae: $22,83,91,174,175,176,399$, $462,467,470,473,479.490,493$.

Leurocephalus: 509 .

Licaphrium: 457,509 .

Licaphrium Floweri: 452.

Licaplarium parvulum: 452 .

Limnohytus: 509.

Limognitherium: 521 .

Liotomus: 5 II.

Listriodon: 519,524 .

Listriodontidae: 397 .

Lithops: 456 , 508 .

Lithops praevius: $45 \mathrm{I}$.

Litopterna: $397,401,405,452,461,469,477$, $509,515,517,518,523,528$.

Lophiochoerus: $5 \pm 0$.

Lophiodon: $509,515,518$.

Lophiodontidae: 397

L,ophiomeryx: 515 .

Lophiotherium: 509,5 I5.

Lomaphorus: $18_{3}, 235,275,276,278,279,282$, $283,315,318,465,488,489,492,516,521$, 526 .

Lomaphorus cinguiatus: $28_{3}, 462$.

Lomaphorus compressus: $2 \mathrm{So}_{2} 2 \mathrm{Sr}, 4 \mathrm{So}, 486$, 537.

Lomaphorus elegans: $282,283.350,480,486$, $\$ 37$.

Lomaphorus elevatus: $28 \mathrm{I}, 282,480,486,537$. Lomaphorus gracilis: $283,284,480,486,537$. Lomapliorus imperfectus: $279,280,2 \mathrm{~S}, 480$, $486,536$.

Loncheres armatus: $\mathbf{5 3 2}$.

Loricata cingulata: $186,189$.

Loxolophodion: 510 .

Loxolophus: 508 .

Lutra: $487,49 \mathrm{I}, 49 \%, 504,520,525,527,529$.

Lutra brasiliensis: 533 .

Lutra paranensis: $476,483,495,501,533$.

Lutrictis: 525 .

Lycaon: 529 . 
Lyilcodon: $48 \%, 498,504,525,529$.

Lyncodon lujanensis: $476,483,533$.

Lyncodon patagonicus: 50 .

\section{MI}

Macacus: $5 \geq 2,527,528$.

Macratuchenia: $465,472,488,489,492,515$. $518,523$.

Macrattchenia antiqua: $46 \%, 469$.

Macrauchenia boliviensis: $477,484,534$.

Macrauchenia ensenadensis: $477,484,534$.

Macrauchenia patachonica: $477,484,534$.

Macrauchenidae: $397,452,458,46 \mathrm{r}, 466,469$. $473,477,490,493$.

Alacrocyon: $487,491,525$.

Macrocyon robustus: $476,483,533$.

Macroeuphractus: $364,380,382,472,521$.

Macroeuphractus retusus: $36 \&, 471,549$.

Macropoda: $398,40 \mathrm{r}, 428$.

Macropodidae: 398,403 .

Macropristidae: 398 .

Macropristis: 428,506 .

Macropristis Marshi: 449.

Macroscelidae: 398 .

Macrotheridae: 399.

Mactotherium: 521,525 .

Machaerodus: $487,489,521,525,-22,520$.

Machaerodus ensenadensis: $476,4.3 .534$.

Machaerodus Pradosi: 534.

Mammatia: $5,32 \mathrm{I}, 40 \mathrm{I}$.

Manidae: 399.

Manis: $12,530$.

Manteodon: 510

Martes: $520,525,527,529$.

Mastodon: $47 x, 488,489,492,497,519,524$, 527,529 .

Mastodon andium: $443,478,485,535$.

Mastodon argentinus: $470,478,485,535$.

Mastodon Flumboldti: $443,444,478,485,535$.

Mastodon platensis: $478,485,535$.

Mastodon rectus: $443,470,478,485,535$.

Mastodon superbus: $444,478,485,496,535$.

Ifephitis: $487,491,497,504,525,529$.

Mephitis cordubensis: 476,483 .

Mephitis fossilis: 533 .

Mephitis mercedensis: $476,483,533$.

Mephitis primaeva: $476,483,533$.

Mephitis suffocans: $483,495,501,533$.

Megacerops: 518 .

Megalochnus: $16,20,35,36,86,88,89,108$, I09.

Megaloclinus rodens: 108, III.

Megalonychidae: 22, 63, 174, 175, 176, 399 . $444,453,458,462,467,473,478,490,493$. Miegalonyx: $52,63,64,65,66,73,79, \mathrm{SI}_{1} 82$, $83,84,86,87,88,89,91,92,93,95,110$ 113, 115, 137, 147, 526, 527

Megalonyx maquinensis: 79 .

Megalonyx meridionalis: 65,66 .

Megalonyx Jeffersoni: $64,66,79,81$.

Megalonyx Käupi: 79.

MIegamys: $414,416,418,419,463,464,472$, 515. 519 .
IIegamys liturmeisteri: $\$ 60$.

Megamys lepressidens: 460 .

Megamys formosus: $418,468$.

Negamys Ilolmbergi: 417,460 .

Megamys Laurillardi: $417,410,460$.

Megamys patagoniensis: $416,418,460$.

Megamys praependens: $418,460^{\circ}$

Megamys Racedoi: 417,460 .

Megaptera: $39 \mathrm{r}, 392$

Megaptera liurmeisteri: $39 \mathrm{l}$.

Megatheridae: 22, 47, 51, 52, 81, 174, 175, $176,399,453,458,462,466,470,473,478$, $490,493,496,498$.

Megatherium: $17,18,20,23,24,27,28,30$, $31,32,33,34,35,36,37,38,39,42,43$. $45,46,47,48,49,50,51,53,64,65,66$, $67,76,77,78,79,80,84,85,86,90,91$, $92,95,99,108,114,115,117,140,142,347$, $148,149,156,157,175,177,178,444,447$. $465,472,488,489,492,497,516,521,526$, $527,530,540$.

Megatherium americanum: is, 27, 28, 30, 3i, $32,33,34,35,46,47,478,485,496,535$.

Megatherium antiouum: $32,462,470$.

Megatherium australe: 27.

Megatherium Cuvieri: 27.

Megatherium Filholi: 30 .

Megatherium Gaudryi: 32, 33 .

Megatherium Gervaisi: 34,535 .

Megatherium Leidyi: 33 .

Megatheriun Lundi: $31,32,478,485,535$.

Megatherium Medinae: 3 I, 32 .

Megatherium mirabile: 34 ,

Megatherium tarijense: $30,31,478,485,535$.

Meles: 529.

Mellivora: 5 :

Mellivorodon: 525.

Meniscoessus: 512 .

Meniscomys: 519 .

Meniscotheridae: 396 .

Meniscotherium: 509 .

Menodontidae: 397.

Menodus: 5 is.

Menotherium: 5t 7 .

Merichyppus: 523 .

Merycochoerus: $518,523$.

Merycopotamidae: 397.

Merycopotamus: 524 .

Mesacodon: 508 .

Mesodectes: 520.

Mesodon Zeballosi: r44.

Mesolama: $488,489,524,527$.

Mesolama angustimaxilla: $477,4 \mathrm{~S}_{4}, 535$.

Mesomys mordax: 532 .

Mesomys spinosus: 532 .

Mesonychidae: 398 .

Mesonyx: 512.

Mesopithecus: 522.

Mesorhinus: $465,5 \times 5$.

Mesorlinus pyramidatus: $46 \mathrm{x}$.

Metalophodon: 510 .

Metriotherium: 509.

Miacis: $512,516$.

Micloénus: 5 tr. 
Microbiotheria: $308,401,405,450,511$.

Microbiotheridae: $39 \mathrm{~S}, 40 \mathrm{I}, 405,450,45 \mathrm{~S}$.

Microbiotherium: 456, $5 \mathrm{rI}$.

Micriobiotherium patagonicum: 450 .

Microbiotherium tehuelchum: 450 .

Microcavia: $472,487,489,491,519,525$.

Microcavia dubia: $475,483,532$.

Mlicrocavia intermedia: $475,483,532$.

Microcavia prona: 468 .

Microcavia robusta: $475,483,532$.

Microcavia typica: $475,483,532$.

Microcavia uncinata: $475,483,532$.

Microchoeridae ?: 396.

Microchoerus: 514 .

Micromeryx: 519.

Microsyons: 508 .

Miolophus: 512.

Mixochoerus: 515.

Mixodectes: 507.

Mixodectidae: 396 .

Monodon: 385 .

Monodontidae: $3 S_{3}, 387,399$.

Monotremata: $392,394,399$, 401 .

Morenia: $464,515$.

Morenia complacita: 450 .

Morenia elephantina: 459 .

Mforopus: 521,526 .

Morotherium: 526 .

Moschus: 519,524 .

Mouillacitheriun : 5 I5.

Muletia septemcincta: $3+3$.

Muridae: 397 .

Nus: 539 .

Muscardinus: 520 .

Místela: $520,525,527,529$.

Ifusteliclae: $398,476,493,495,498,501,505$.

Myacidae: 398 .

Mycetes: 503 .

Mycetes carayá: 499.

Mycetes ursinus: $53 \mathrm{r}$.

Mlylagaulus: 520 ,

Mylodon: $17,20,21,23,32,37,47,49,61,65$, $66,67,68,74,79,84,85.86,87,88,89$, no, 91, 92, 93, 94, 95, 97, 98, 103, 105. $110,111,113,114,115,133,134,135,137$, $138,139,1+0,141,142,147,149,151,152$, 153. I54, $155,156,165,168,170,172,173$. $4+5,+88,+92,+98,526,527,530$.

Myloden ambiguus: 134 .

Mylodon armatus: 97.

Mylodon Darwini: 87, 88, 89, 90, 9I, 137 , $138,142,144$.

Mylodon giganteus: $65,84,85,86,87,88$, $90,91,96,97,100$.

Mylodon gracilis: $86,88,156,157,158,159$.

Mylodon Ifarlani: 137 .

Mylodon intermedits: $153,479,485,536$.

Mylodon Lettsomi: 164.

Mylodon Martinii: 153.

Mylodon Oweni: $158,161,162,164$.

Mylodon ? paranensis: 154 .

Miylodon robustus: $50,86,87,88,90,91,98$, $103,137,149,151,152,153,155,156,157$, $759,479,485,496,536$.
Mylodon robustus intermedius: $1+2,344$.

Mylodon robustus major: 9\%, 102.

Mylodon Sauvagei: 151, 165, 479, 485, 536 .

Mylodon Wieneri: $140,152,153,479,485,536$.

Alylodon Zeballosi: r44.

Mylodontidae: $22,146,175,176,399,444,453$. $458,462,467,470,473,479,490,493,498$.

Myogale: $520,525,529$.

Myogalidae: 398 .

Myolagus: $520,524,529$.

Myopotantus: $410,412,464,472,482,487,488$, $491,497,504,515,519,524,529,532$.

Myopotainus coypus: 409, 494, 5no, 532 .

Myopotamus diligens: 468 .

Myopotamus obesus: 409, 459 .

Myopotamus paranensis: 459 .

Myopotamus priscus: $474,482,532$.

Myoxidae: 397.

Myoxus: $515,519,524,529$.

Myrmecobia: $398,401,405$.

Myrmecoloidae: 398 .

Myrmecophaga: 12, 13, 504 .

Myrmecophaga jubata: $13,503,537$.

Myrmecophaga tetradactyla: $13,503,537$.

Myrmecophagidae: 11, 12, 399, 503, 505.

IIysops: 510 .

Mysarachne: 520 .

Mystacoceta: $383,389,399$, for, 405.

$\mathrm{N}$

Yanolyyus: 510.

Nasua: $429,430,504$.

Nastra narica: $50 \mathrm{r}, 533$.

Necrolemur: 5 I 4 .

Necromys: $487,488,49 \mathrm{i}, 524$,

Necromys conifer: $474,482,531$.

Nectomys squamipes: 531 .

Nephotherium: $112,13 t, 135,146,465,516$.

Nephotherium ambigtum: 134,462 .

Nelomys antricola: 532 .

Nematherium: $147,170,173,457,512$.

Nematherium angulatum: $170,453$.

Nematherium sinuatum: 172,453 .

Neoepiblema: $419,464,515$.

Neoepiblema ? contorta: 419,460 .

Neoepiblema horridula: 419,460 .

Neoplagiaulax: $455,5 \mathrm{II}$.

Neoprocavia: 464,515 .

Neoprocavia mesopotamica: $4=1,460$.

Neoprocavia egena: 460 .

Neoracanthus: 20, 21, 23, 35, 37, 51, 52, 67, Sr, 444, $488,489,5=6$.

Neoracanthus Brackebuschianus: $41,42,478$. 485 .

Neoracanthus Burmeisteri: $37,41, f 2,46,478$, 485,535 .

Neoracanthus platensis: 535 .

Neoreomys: 456 , 510 .

Neoreomys australis: 450 .

Neoreomys decisus: 450 .

Neoreomys indivisus: 450 .

Neoreomys insulatus: 450 .

Neothoracophorus: $204,228,230,231,322$, $38 \mathrm{r}, 38 z,+88,489,49 z, 5 z 6$. 
Neothoraconliorus depressus: 232, 233, 480 , $486,536$.

Neothoracophorus elevatus: $23 \mathrm{r}, 232,480,486$, 536 .

Neotlioracophortis minutus: 233,4 So, 486,536 .

Neotoma: 529 .

Nesodon: 457, 509, 542.

Nesodon imbricatus: 452.

Nesodon ovinus: 452 .

Nesokerodon: 515 .

Tesolia: 524,529 .

Neurogymurus: 516 .

Neuryurus: $313,314,320,332,381,382,465$, $47=488,489,516,521,5=6$.

Neuryurus antixuts: $317,319,470$.

Neuryurus interundatus: 319,462 .

Neuryurus rudis: $316,317,318,319,480,486$.

Nimraviclae: 398 .

Nimravus: 520 .

Noctilio: 504 .

Noctilio leporinus: 502.

Nopachtus: $192,235,294,297,305,329,330$, $38 \mathrm{I}, 382,472,488,489,521,526$.

Nopachtus coagmentatus: $192,295,470,480$, $+86,53 \pi$

Notharctus: 508 .

Nothropus: $2 \pi, 36,37,76,78,80,8 \mathrm{r}, 82,83$, Bo, $488,492,526$.

Nothropus priscus: $76,80,478,485,535$.

Notictis: $428,465,516$.

Notictis Ortizi: 428,460 .

Nototheridae: 398

Nycticejus: 504.

Nyeticcjus ruber: 502 .

Nyctilestes: $5 \mathrm{Iz}$.

Nyctinomus: 504 .

Nyctinomus nasutus: 502 ,

Nyctipithecus: 503.

Nyctipithecus felinus: 499.

Nyctitherium: 512 .

\section{O}

Ocnopus: $23,35,36,526$.

Oenopus Laurillardi: 535 .

Octodontidae: $397,468,473,474,490,493$. $494,+98,500,505$.

Odontoceta: $383,399,401,405$.

Olenopsis: $410,411,456,464,510,515$.

Olenopsis typicus: $410,411,459$.

Olenopsis uncinus: 450 .

Oligobunis: 520 ,

Oligodon: 168 .

Oligodon psetrdolestoides: 168 .

()) ligotomus: 509.

Omegodik: $5 x 9$.

Omomyts: 508 .

Opisthotomus: $50 \$$.

Oracanthus: $35,36,37$.

Oracantluss IBurmeisteri: $35,36,37$.

Orca: 386,387 .

Orca magellanica: 386 .

Oreas: 523 .

Oreolon: 51 \&

Oreodontidae: $397,477,490$.
Oreonys: $51 \%$.

Oreopithecus: $51 \%$.

Orotherium: $500,5: 9$.

Orthaspidotherium: $51 \mathrm{x}$.

Orthocynodon: 509 .

Orthomyctera: $472,487,489,491,519,525$.

Orthomyctera lacunosa: 468 .

Orthomyctera lata: $475,483,532$.

Orthomyctera rigens: 468 .

Orthomyctera vaga: 468 .

Orthomys: 464,515 .

Orthomys dentatus: 413,459 .

Orthomys procedens: $412,459$.

Urthomys resecans: 459 .

Orthotheridae: $22,47,50,52,63,83,174,175$. $176,399,444,453,458,462,467$.

Orthotherium: $53,56,465,516$.

Orthotherium laticurvatum: 53,462 .

Orycteropiclae: II, 399, 453, 458 .

Orycteropus: 1I, 137.

Orycterotherium: 178,204 .

Ovibos: $5 \geq 8$.

Ovis: $524,5-\cdots$

Oxacron: 5 I

Oxyaena: $512,516$.

Oxyaenidae: 398 .

Oxyodonta: 20 ,

Oxyodontherium: 465,515 .

Oxyodontherium Zeballosi: 461 .

Oxymycterus: $487,491,497,504,524,5 z 9$.

Oxymycterus breviceps: $53 \mathrm{I}$,

Oxymycterus cosmodus: $53 \mathrm{r}$.

Oxymycterus impexus: $474,482,531$.

Oxymycterus rufus: $474,482,494,500,53 \mathrm{r}$.

Oxymycterus talpinus: 531 .

Paciculus: 520 .

Pachycynodon: 516.

Pachynolophus: 515.

Pachypus: izo.

Pachyrucos: $439,456,46 \mathrm{r}, 465,472,488,4 \mathrm{~S}$, $508,515,518,523,543$.

Pachyrucos absis: $45 \mathrm{r}$.

Pachyrucos bonariensis: $476,484,534$.

Pachyrucos diminutus: 460.

Pachyrucos ictus: 460 .

Pachyrucos impressus: 469 .

1'achyrucos Moyanoi: 451 .

Pachyrucos naevius: $45 \mathrm{r}$.

Pachyrucos teres: $45 \mathrm{t}$.

Pachyrucos trivius: $45 \mathrm{~T}$.

Pachyrucos typicus: 439,469 .

Pachytheria: $396,397,401,470,478,496$.

Pachytherium: 170.

Palaehoplophorts: 19r, 235, 246, 284, 313, 38I, $382,465,472,516,521$.

Palaehoplophorus disjunctus: $250,470$.

Palachoplophorus pressulus: 192, 248, 462 .

1'alaehoplophorus Scalabrinii: $246,462$.

? Palaeohalsena: 380 .

? Palaeohalaena liergi: $3 \mathrm{Sg}$.

Palaeocavia: $472,487,489,491,519,525$.

Palaeocavia avita: 468 . 
I'alaeocavia impar: 468 .

Palaeocav minuta: $475,483,532$.

Palaeocavia pampaea: $475,483,532$.

Palaeccorlon: $51 \mathrm{I}$.

Palaeocyon troglodytes: 533 .

Palaeocyon validus: 533 .

Palaeochoerus: $515,519$.

Palaenerinaceus: 520 .

Palaegoale: 520 .

Palaeolagus: 520 .

Palaeolama: $443,488,492,497,524,=2,, 4.8$

Palaeolama leptognatha: $477,48+, 53:$

Palaeolama major: $477,484,535$.

Palaeolama mesolithica: $4+3,495,535$.

I'alaeolama promesolithica: $443,+77$.

Fat:um 1, : $519,5 \geq 3,5=4$.

l'nlaonicteri: $\$ 21$.

I'alaeonictis: $\$ 11$.

I'alaeoprionodon: $5: 6$.

Palaeoreas: 523.

I'alaeosyops: 509 .

I'alaeotheridae: 397.

Palaeotherium: 515.

l'alaeotragus: 523 .

Palauchenia: $5=4,5=7$.

I'ampatherium: 336 .

Yampatherium typus: 336 .

I'anochtus: $177,181,182,183,185,186,188,190$, $192,195,204,205,206,207,208,236,251$, $252,253,254,287,294,295,296,297,299$, $300,303,309,31 \mathrm{I}, 312,313,314,315,316$, $317,319,321,322,323,324,329,333,343$. $381,382,472,488,489,492,521,526$.

Panochtus lirocheri ?: 295.

I'anochtus bullifer: $186,305,307,309,470$.

1'anochtus clavicaudatus: $185 ;$ i 86 .

l'anoclitus Frenzelianus: $306,307,480,486$, 537.

I'anochtus giganteus: $3 \geq 5$.

1'anochtus Lundi: $186,187,255$.

Y'anochtus Morenoi: 191, 304, 305, 306, 307. $480,486,537$.

Ianochtus Nodotianus: $309,480$.

Janochtus Trouessarti: 287 .

I'anochtus tuberculatus: $182,183,184, \pi 85$. $192,220,295,302,304,305,306,307,308$, $309,316,325,480,486,537$.

I'anochtus Vogti: $308,480,486,537$.

l'anolax: 524 .

l'antodonta: 397, 401, 405, 449, +53, 513.

Pantolambila: 510.

Pantolambdidae: $39 \%$.

Pantulestes: 509.

Jantolestidae: 397 .

Paraceros: $472,488,489,492,518,523$.

Paraceros avius: 470 ,

Paraceros ensenadensis: $478,484,535$.

Paraceros fragilis: $478,484,535$.

Paraceros vulnexatus: $478,48+, 533$.

Paradoxomyidae: 459,466 .

Paradoxomys: 464,515 .

Paradoxomys cancrivorus: 459 .

Paradoxomys patagonicus: 459 .

l'aramys: 5 I0.
Paranomys typicus: 410.

1'arasorex: 520 .

P'assalacoton: 5 I1 .

Patriarclus: $457,509$.

Patriarchus palmidens: 452.

l'atriofelis: 512 .

I'edimana: $398,401,405,469,475,495,501$, $51<516,521,5+5,5-1$,

I'edomys: $5 \geq 9$.

I'edotherium: 439 .

Pedotherium insigne: +39 .

Pelonax: 510.

Peltateloidea: 176,$3 ; 6,377,3$ So, $382,399,401$, 405, 454 .

Peltephilus: $345,376,457,513$.

Peltephilus pumilus: 346,454 .

Peltephilus strepens: $3+6,+5+$.

Pelycodus: 508.

Pelycosauria: 393, 394, 401,405 .

Pellegrinia: 529 .

Peraceras: 518 .

Peramelia: 398, tor, 405.

Peramelidae: 398 .

Peratheridae: 398 .

Peratherium: 516, 521.

l'erchoerns: 519 .

Perimys: $456,464,511,515$.

l'erimys erutus: 4 r 3,450 .

l'erimys onustus: 450 .

Perimys procerus: 450 .

Perimys Scalabrinianus: 413,460 .

Periptychidae: 396.

Periptychus: 508 .

Perissodactyla: $396,397,401,452,461,469$, $476,495,502$.

Pinnipedia: $398,401,405$.

Pithanotomys: $472,487,489,519,525$.

Pithanotomys columnaris: 468 .

Pithanotomys cordubensis: $475,4{ }_{3}$.

Pithanotomys intermedius: 468 .

Pithanotomys macer: 468 .

Pithanotomys simils: 468 .

Pithecidae: $396,499,505$.

'ithecistes: 523 .

Pitimys: 520 .

Plagiaulacidae: 398,405 .

Plagiaulacoidea: $398,401,405,428,451,5 \mathrm{II}$, 513. ₹16, $51,-., 521$.

I'lagiaulax: 455.

Plagioloplus: 515.

Planodus: 457,510 ,

l'lanodus ursinus: 453 .

Planops: $53,60,457,513$.

Planops longirostratus: 60,453 .

Planungulata: $395,396,401,468,474,494,499$.

Plataeomys: $472,519,524$.

Plataeomys scindens: $468,475,483,532$.

Platanistidae: $383,384,385,399$.

Platatheritum: $413,497,524,528$.

Platatherium pampacum: $4+3,496,535$.

Platyarthra: $396,40 \mathrm{r}, 405$.

Platygnathus platensis: $8_{4}, 8_{5}$.

Platygonus: $524,5 \geq 9$.

Platyodon: 107, 108, 488, 526. 
Platyodon Annaratonci: $110,479$.

Platyonyx: $64,86,88,90,112,133,138,1.49$, $488,+9 \geq, 5=6$.

Platyonyx Agassizi: 134, 536 .

Platyonyx Blainvillei: 134 .

Platyonyx, Brongniarti: 134.

Platyonyx Bucklandi: 133,134 .

Platyonyx Cuvieri: $134,536$.

Platyonyx minutus: 134 .

Platyonyx Olivetae: $x 33,479,485,536$.

l'laxhaplus: $192,313,317,320,321,328,329$. $330,332,38 i, 382,472,488,489,521,526$.

Plaxhaplus antiquus: $330,+70,486$.

Plaxhaplus canaliculatus: 191, 329, 480,456 , 537.

Mejodonta: $5,6,39 \mathrm{~S}, 40 \mathrm{~T}, 405,453,512$.

Plesiadapis: 507.

Plesiarctomys: $510,515$.

Plesictis: 516,520 .

Plesidacrytherimu: 515 .

Plesiocyon: 516.

l'lesiomeryx: 518 .

l'lesiosorex: 520 .

I'lesiospermophilus: 5 r 5 .

Pleuraspidotherium: $51 \mathrm{I}$.

Pleurolicus: 519.

Plexochoerus: $427,464,515$.

Plexochoerus adluis: 424,460 .

Plexochoerus Lynchi: $\$ 26,460$.

I'lexochoerus paranensis: $424,426,460$.

Plianchenia: $5 \geq 4$.

Plicatodon: $488,489,523,527$.

P'licatodon perrarus: $477,484,534$.

Pliohippus: 523 .

Pliolagostomus: $456,5 \mathrm{Ir}$.

Pliolagostomus notatus: 450 .

Pliomorplius: $17,36,50,63,73, \$_{2}, 8_{3}, 86$ $87,88,89,110,465,516$.

l'Jiomorphus mutilatus: $73,74,462$.

Pliomorphus robustus: $7 t_{1}+62$.

Pliopithecus: 517 .

Plohophorus: I9I, 192, 235, 236, 237, 2S7, $289,29 \mathrm{r}, 292,294,295,305,38 \mathrm{r}, 383,47 \div$ 521 .

Plohophorus Ameghinoi: 288, 291, 446, 47u. Plolrophorus figuratus: $192,28 \%, 288,292$, 293,470

Plohophorus (?) orientalis: 292.

Poebrotheridae: 397.

Poebrotherium: 5 I9.

Pogonodon: 520 .

Polymastodon: 428, 449, 511.

Polymastodontidae: 398 .

Pontistes: 384 .

I'ontistes rectifrons: 385 .

Pontoporia: 384,385 .

Pontoporia Hainvillei: 384,385 .

Pontoporia paraneлsis: 385 .

lotamotherium: 520 .

Praopidae: $285,335,346,352,353,380,382$, $399,48 \mathrm{I}, 490,493,496,498,503,505$.

Praopus: 347,548 .

Praopus aff. hybridus: 348 .

Praopus aff. longicaudatus: $3+9$.
Praopus liybriclus: $348,547$.

I'raorus longicaudatus: 348 .

Praotherium: 529 .

1'riodon: $3+5,37=379,380,382,504$.

Priodon giganteus: 365,373 .

Priodon gigas: 373,503 .

Priolon gigas fossilis: 373 .

Priodonta: $5,6,398,401,405$.

Priodontes gigas: 373 .

Prionodonta: 383 .

Prionoulus gigas: 373 .

Proailurus: $52 \mathrm{r}$.

Probosciden: $397,401,405,470,478,496,510$,

515. $517,519,524,529$.

Procamelus: 519 .

Procardiotherium: $46+4,515$.

Procardiotherium crassum: $+22,+60$.

Procardiotherium simplicidens: 422,460 .

Procervulus: 519.

Procynictis: 512.

Procyon: $+29,430$. 504, $525,5=2$.

Procyon cancrivorus: 430,501 .

Prochiropters: $398,40 \mathrm{r}, 405$.

I'rodemotherium: 515 .

P'rocuphractus: $360,362,363,350,382,+65$. $4 ; 2,516,521$

Proeuphractus limpidus: 361,463 .

Proeuphractus recens: 363,471 ,

Proliyaena: 523 .

I'rolagostomus: $456,5 \mathrm{ir}$.

Prolagostomus divisus: 450 .

Prolagostomus imperialis: +50 .

Prolagostomus profluens: 450 .

Prolagostomus pusillus: 450 .

Promephitis: 525 .

Promegatherium: 23, 33, $43,47,50,51,52$, $321,465,516$.

Promegatherium remulsum: $+6,462$.

Promegatherium smaltatum: $43,46,444,462$.

Promisatherium: 515.

Promylodon: $147,153,172,173,465,516$.

Promylodon paranensis: $154,4+5,462$,

Promops: 504.

Promops bonariensis: 502 .

Propalaehoplophorus: $19 \mathrm{r}, 192,235,236,284$. $313,38 \mathrm{r}, 382,457,512$.

Propalaehoplophorus australis: $23 \%, 454$.

Propalaehoplophorus incisivus: $192,242,454$.

Proplesictis: 520 .

Propraopus: $189,349,363,382,488,489,492$, $5=6,548,549$.

Propraopus grandis: $350,352,481,486,537$.

Proproboscidea: $397,401,405$.

Proruminantia: $397,401,405,477,509,515$. $518,523,528$.

Prosimia: 396, 401, 405, 507, 514, 517.

Prosirenia: 397, for, to5.

Protalpa: 516.

Protauchenia: $488,492,524$.

Protatuchenia Keissi: $478,484,535$.

Protechimys: 5 I5.

Proteroceta: $383,399,401,405$.

Proterotheridae: $397,452,458,462,466,469$, 473. 
Proterotherim: 457, 465, 509, 515.

Proterotherium americanum: 462 .

Proterotherium australe: 452 .

? I'roterotherium cavum: 452 ,

Proterotherium cervioides: 462 .

I'rotoalapis: 508 .

Protoglyptodon: $192,236,310,382,465,516$. Protogiyptodon primiformis: $192,310,462$,

Protogonia: 508.

I'rotolippus: 523.

I'rotomeryx: 515,519 .

Protopithecus brasiliensis: 531 .

Protopsalis: 512 .

Protoxodon: $436,456,508,542,543$.

P'rotoxolion conspurcatus: 451 .

Protoxodon marmoratus: $45 \mathrm{I}$.

Protoxodon obliteratus: 452 .

Protoxodon Sullivani: $45 \mathrm{x}$.

Protoxodonticlae: $397,436,45 I, 458,46 \pm, 466$.

Protragelaphus: 523 .

Protypotherium: $457,+65,472,509,515,518$.

Protypotherium antiqusm: $46 x$.

Protypotherium attenuatum: 453 .

Protypotherium australe: 452 .

Protypotherium claudum: 452 .

Protypotherium praerutilum: 452,

l'rotypotheriun obstructum: 460 .

1'roviverra: 428 .

Proviverridae: 398 .

I'seulamplicyon: $5 \pm 6$.

Pseudictis: 520.

Pseudoenryarus: 332, tó $5,516$.

I'seudoeuryurus Lelongianus: 333,462 .

Pseudolestodon: $49,67,74,79,85,86,87,88$, S9, 90, 91, 92, 93, 94, 103, 105, II4, II5, $133,147,149,152,153,154,155,156,157$, $163,164,165,168,169,170,173,445,465$, $470,472,488,489,492,498,516,521,526$, 530.

Psendolestodon aequalis: $165,166,462$.

P'seudolestodon bisulcatus: $163,479,485,536$.

1'senclolestodon debilis: $158,16 \mathrm{x}, 164,479,485$, 536.

1'sevilolestodon gracilis: 156,157, I50.

? Pseudolestodon injunctus: 168,462 .

P'seuclolestodon Lettsomi: $164,479,485,536$.

Pseudolestodon Morenoi: $161,479,485,536$.

Psemilolestodon myloides: 67, $156,158,159$, 160, $166,479,+85,496,536$.

Pseudolestoulon Reinhardti: 160, 479, $485,536$. Pseudolestodon? pseulolestoides: I 68 .

Psendolestodon trisulcatus: $163,479,485,336$.

Psendorca: 387 .

Pseudurea Grayi: 387.

Pseudorea meridionalis: 387 .

Pseudorhinalophus: 516.

Psendosciurus: 519.

Psemdoteruflon: 516.

Pseudotoxodon formosus: 546,549 .

Psithacotherium: 510 .

P'terodon: 516.

Pteropiclae: $39 \mathrm{~S}$.

Ptetica: $396,398,401,50 \mathrm{r}$

Ptilod'1s: $455,511$. l'tyssophorus: $487,49 \mathrm{r}$.

T'tyssophorus elegans: $4 \bar{\jmath} 4,4 \mathrm{~S}_{2}, 53 \mathrm{I}$.

Pyrothericlae: 397.

Pyrotherium: 507, 510.

Pyrotherium Romeroi: 443, 449.

\section{Q}

Quatriodon: 145.

Quatriodon bonacriensis: 144.

Quercytherium: 516.

Rabdiodon Oliverae: $\mathbf{1 3 3 .}$

Ragatherium: 515 .

Reitlirodon: 487, 491, 497, 504, 524, 529.

Reithrodon cuniculoides: 500 .

Reithrodon chincliilloides: 500.

Reithrodon typicus: $474,48 z, 494,500,531$.

Reptilia: for.

Khabdogale: 525 .

Rhadinotherium: 457,508 .

Rhadinotherium limitatum: 452 .

Rhinoceros: 5 I $8,523,527,528$.

khinacerotilae: $397,477,490$.

Klinolophidae: 398 .

Rhinolophus: 530 .

Rhipidomys mastacalis: $53 \mathrm{I}$.

Rhizomys: 524 .

Rhytiniclae: 397.

Ribodon: $465,5 \times 5$.

Ribodon limbatus: 461 .

Rodentia: $39 \overline{7}, 40 \mathrm{x}, 405,449,459,468,474$, $494,499,510,515,517,519,524,529$.

Ruminantia: $397,401,405,469,477,495,502$, $509,515,517,518,523,528$.

Rutitherium: 518 .

\section{S}

Sanitheritum: 524 .

Sarcobora: $396,398,40 \mathrm{I}, 45 \mathrm{~T}, 460,469,475$, 495, 501.

Sarcolemur: 508 .

Sarcothraustes: $51 \mathrm{I}$.

Scalabrinitherium: 465,515 .

Scalabrinitherium Bravardi; $46 \mathrm{I}$.

Scalabrinitherium Rothi: $442,46 \mathrm{r}$.

Scalops: 524,529 .

Scapteromys anoblepas: $53 \mathrm{x}$.

Scapteromys fronto: 531 .

sicapteromys labiosus: $53 \mathrm{r}$.

Scapteromys principalis: 531 .

Scelidodon: 89, 90, $112,121,122,123,128$, I $29,139,140,141,146,14 \%, 472,485,488$, $489,521,526$.

Scelidodon Capellinii: $123,124,125,128,129$, I $30,131,479,485,536$.

Scelidoxlon Copei: $122,130,13 \mathrm{I}, 479,485,536$. Scelidodon patrius: 119, $122,123,127,129$, I30, I $3 \mathrm{t}, 470,479,4 \mathrm{~S}_{5}$.

Scelidodon tarijensis: $124,126,137,128,129$, $130,131,470,485,536$. 
Sceliclothericlae: 22, 8\$, 89, $112,134,839,175$, $x 76,399,444,462,467,470,473,479,490$. 493.

Scelidotherium: $20,37,49,64,65,66,78,79$, $85,86,87,88,89,90,91,92,93,95,105$. $112,113,114,115,119,120,125,122,123$, $125,126,127,129,131,132,133,134,135$. $136,137,138,139,140,141,142,145,146$, $1+7,1+8,171,408,465,450,488,489,492$, 516,526 .

Sceliclotherium ankylosopum: $137,142$.

Scelidotherium australis: 123 .

? Sceliclotherium bellulum: 320,462 .

Siceliclotherium Bravardi: $117,119,479,485$. 536.

Siceliclotherium litucklandi: 536 .

Sicelidotherium Capellinii: $131, x 22,12 \mathrm{~S}$.

Sicelidotherium chiliense: 118,131 .

? Scelidotherium elegans: 120 .

Scelidotherium Floweri: $119,479,485,536$.

Scelidotherium leptocephalum: $14,115,116$, 117. 118, 119, $121,122,123,124,125,127$, $128,129,133,+79,485,535$.

Sceliclotheritum magnum: $121,126,128,129$.

Sicelislotherium mintutum: 536 .

Sicelitotherim Oweni: 536 .

Scelidotherium patrium: 123.

? Scelidotherium Pozzii: 120 .

Sicelidotherium tarijense: $12 \mathrm{r}, 122,126,128$.

Sciamys: $456,510$.

Sciamys principalis: $4+9$.

Sciamys varians: 449 .

Siciuravus: 510 .

Sciuritae: 397,500 .

Siciurodon: 515 .

Sciuroides: $515,519$.

Sciuromys: 515 .

Sciurus: $515,519,524,527,529$.

Siciurus aestıans: 500,532 .

Scleromys: 456,510 .

Scleromys angustus: +50 .

Scopotheritm: 457,509 .

Scopotherium cyclops: 452

Sicotaeops: $12,457,512$.

Scotaeops simplex: 12,453 .

Scotaeumys: $456,5 x$.

Scotaeumys imminutus: 450

Schismotherim: $53,56,457,512$.

Schismotherium fractum: 56,453 .

Schistomys: 456,511 .

Schistomys erro: 450 .

Schistopleurnm: $181,182,185,186,187,188$, $189,190,191,204,213,321$.

Schistopleurum? asperum: 190, 219.

Schistopleurum elongatum: $190,222$.

Schistopleurum euplaractum: $188,214$.

Schistopleurum gemmatum: 182 .

Schistopleurtum laeve: 22t.

Schistopleurum tuberculatum: $182,302$.

Schistopleurum typum: $180,18 \mathrm{r}, 182,184$, $185,190,192,219.220,230$.

Schizodon: 504

Schizodion fuscus: 500 .
Schizotherium: 516 .

Semnopithecidae: 396 .

Semnopithecus: $522,527,528$.

Silhaeromys: 456,510 .

Splizeromys irruptus: 450 .

Sphenodon minutus: 536 .

Sphiggomys: 456,511 .

Sphiggomys zonatus: 450 .

Sphiugurus: 504 .

Splingurus insidiosus: $500,53 \mathrm{r}$.

Sphingurus magnus: $53 \mathrm{r}$.

Sphingurus prehensilis: 500, $53 \mathrm{t}$.

Sphodromys: 456,510 .

Sphodromys scaliris: 450 .

Sibbalclius antarcticus: $39 \mathrm{r}$.

Simioidea: $396,401,405,499,507,514,517$, 522,528 .

Simocyon: 525 .

Sinopa: 511 ,

Sipalocyon: $456,5 \mathrm{I} 2$.

Sipalocyon gracilis: $+5 \mathrm{r}$.

Sirenia: 397, for, 405 .

Sivatherium: 524 .

Smilodion: $487,489,49 x, 525,527$.

Smilodon populator: $476,483,534$.

Sminthus: 520 .

Sorex: $520,525,529$.

Soricictis: 520 .

Soricidae: 398 .

Spalacidae: 397.

Spalacotheridae: 398 .

Spaniomys: 456,510 .

Spaniomys modestus: 450 .

Spaniomys riparius: 450 .

Spaniotherium: 515 .

Speothos nacivorus: 533 .

Spermophilus: 529 .

Spondilocoelia: 392, 393, 395, 399, 401, 405 .

Squalodonta: $398,401,405$.

Squalodonticlae: 398 .

Stegotherillae: $376,399,454$.

Stegotherium: $376,380,382,457,513$.

Stegotherium tessellatum: $376,377,454$.

Steiromys: $456,510$.

Steiromys detentus: 450 .

Steiromys duplicatus: 450 .

Stenacodon: 511.

Steneofiber: $\$ 19$

Stenodelphis Hainvillei: $38_{4}$.

Stenodon: $13 x$

Stenodon modicus: 132 .

Stenodontherium: $112,131,146,465,516$.

Stenoulontherium morlicum: $132,462$.

Stenogale: 516,520 .

Stenoplesictis: 516 .

Stenotephanos: $456_{1},+65,508,515$.

Stenotephanos pliciclens: $437,46 \mathrm{r}$.

Stenotephanos speciosts: 451 .

Stereoartlira: 397, $40 \mathrm{r}, 405$.

Stereopterna: $397.401,405,461,469,476$, $495,503,509,515,517,518,523,528$.

Stii)arus: 518 .

Stichonys: 456,510 .

Stichomys regularis: 450 . 
Stilauchenia: $488,492,524,527$.

Stilauchenia Oweni: $477,484,535$.

Stilotherium: 456,511 .

Stilotherium dissinile: 450 ,

Stypolophus: 428,512 .

Sirata: 464,515 .

Strata elevata: 460 .

Strepsiceros: $5 \geq 3$.

Strongyloceros: $5 \geq 3,5=8$.

Stylinodon: 510.

Stylodon: 396.

Stylodontheria: $396,398,401,405$.

Stylodontidae: 398 .

Sub-ursidae: $46 \mathrm{I}, 466,50 \mathrm{r}, 505$.

Suidae: $397,477,493,495,498,502,505$.

Suina: $397,401,405,477,495,502,510,515$, $510,524,529$.

Sus: $519,524,527,529$.

Systemodon: 509 .

\section{$\mathrm{T}$}

Taeniorlonta: $397,40 \mathrm{r}, 405,40 \mathrm{~S}, 510$.

'Taphozus: 530.

Taligrada: $397,40 \mathrm{r}, 405,453,513$.

Talpa: $5 \geq 0,525,5=9$.

Talpavus: $51 \mathrm{r}$.

Talpidae: 398 .

Tamias: 529.

Tapiravts: 518 .

Tapiridae: $397,46 \pi, 466,476,490,502,505$.

Tapirulus: 515 .

Tapirus: $504,518,523,527,528$.

Tapirus americanus: 502.534 .

Tapirus suinus: 534 .

Tarandus: 523,528 .

Tardigrada: II, 55, $19,78,175,176,399,401$, $405,512,516$

Tarsidae: 396.

Tarsipes: $401,405$.

'larsipidae: 398 .

Iatusia: $25 \mathrm{~T}, 347,349,35 \mathrm{~T}, 352,365,382,488$, $492,498,504,526,530$.

Tatusia hybrida: $348,48 \mathrm{I}, 486,496,503,537$.

Tatusia hybrida fossilis: $3+8$.

T'atusia minuta: 358 .

Tatusia novemcincta: $348,349,48 \mathrm{I}, 486,503$. 537.

Tatusia novemcincta fossilis: 349 .

Tatusia punctata: 537 .

raxidea: 525.

T'aximys: 510.

Telmatolestes: 508.

'Telmatotherium: 509.

'Temnocyon: $5 \geq 0$.

Tetraceros: 523,528 .

retraconodon: 524 .

Tetracus: 520 .

Tetraselenodon: 509.

Tetrastylus: $464,515$.

Tetrastylus diffissus: 420,460 .

Tetrastylus laevigatus: 419,460 .

Tetrodon: I45.

Tetrodon bonariensis: 144 .
Thalassictis: $52 \mathrm{I}$.

Theosodon: 457,509 .

Theosodon Lydekkeri: 452 .

Thereutherium: 516 .

Theridomyidae: 397.

Theridomys: $515,519$.

Thinohyus: 519, 524 .

Thinolestes: 508

Thinotherium: 508,519 .

Thoatherium: 457,509 .

Thoatherium minusculum: 452 .

Thomomys: 524 .

Thoracophorus: $183,191,230$.

Thoracophorus depressus: I9I, 232 .

Thoracophorus elevatus: $231,232$.

Thoracophorus minutus: $19 \mathrm{r}, 233$.

Thylacoleontidae: 398 .

Thylacomorphus: $5 \mathrm{r} 6$.

Tillodonta: $397,40 \mathrm{r}, 405,459,510,516$.

Tillomys: 510.

Tillotheridae: 397.

Tillotherium: 510 .

Titanomys: 520 .

Tolypeutes: $370,371,372,380,38 z, 488,489$, $49 \geq, 498,504,526,530$.

Tolypeutes conurus: $371,48 x, 486,496,503$, 537.

Tolypeutes aff. conurus: $37 \mathrm{x}$.

Tolypeutes conurus fossilis: 37 .

Tomarctus: 525 .

Tomitherium: 508 .

Toxodon: $407,434,436,437,465,472,487$. $489,+91,497,514,518,523,527,5 \geq 8,54 x$, $5+3,550$.

'roxodon antiquus: $550,552$.

'Toxodon bilobidens: 476,484 .

Toxodon Burmeisteri: $407,476,484,534,55 \mathrm{r}$.

Toxodon Darwini: $476,484,534$.

Toxodon ensenadensis: $469,476,483,534,545$.

? Toxodon expansidens: 534 .

Toxodon gracilis: $476,484,534$.

Toxodon paradoxus: $476,484,534$.

Toxodon paranensis: $432,46 \mathrm{I}$.

Toxodon platensis: $476,483,495,534$.

Toxodon proto-Burmeisteri: $46 \mathrm{t}, 550,55 t$.

Toxodon virgatus: $432,461,530$.

Toxodontherium: $433,436,437,465,514,54 \mathrm{r}$, $542,543,545,546,547$.

Toxodontherium compressum: 433, 46t, 546 .

Toxodontherium reverendum: 434 .

Toxodontia: $397,40 \mathrm{I}, 405,408,440,45 \mathrm{I}, 46 \mathrm{~s}$, $469,476,495,508,514,517,518,523,528$.

Toxodontidae: $397,46 \mathrm{I}, 466,469,473,476$, $490,493,495,498$.

Tracliytherus: $440,508,542$.

Trachytherus Spegazzinianus: $440,4+1,449$.

Tragelaphus: 528 .

Tragoceros: 523 .

Tragulidae: $397,470,473$.

'Tragulohyus: 515 .

Tragulus: 523,528 .

Trechomys: 5 r 5 .

Trematherium: $63,75,82,83,457,512$. 
"Prematherium intermixtum: $75,453$.

Tretomys: $48 \%, 49 \mathrm{I}, 524$.

'Tretomys atavus: $474,482,53 \mathrm{r}$.

Tribodon: 472,519 .

l'ribodon clemens: 468 .

Tricentes: 508 ,

'T'riconodontidae: 39 S,

'Tricuspiodon: 512 .

Trichecidae: 398.

'rigodon: $434,436,472,518,54 \mathrm{I}, 542,543$. $544,545,546,547$.

T'rigodon Gaudryi: $436,469,540$.

Triisodon: 5 Ir.

'Triplopodidae: 397.

'Triploplus: 509 .

Tritylodontidae: 398 .

Trochictis: 520,525 .

Trochotherium: 520 .

'roglodytes: 522 ,

Trogodonta: $396,397,40 \mathrm{r}, 449,459,468,474$, $494,499$.

'rogontherium: 529 .

Trogosa: $39 \pi, 401,405$.

Tupaidae: 398 .

Tursio Cymodoce: 386 .

'Tursio obscurus: 386 .

Tursiops: 386.

Tursiops Cymodoce: 386 .

I'ursiops obscurus: 386 .

Typotheridae: $397,440,45 I, 458,46 I, 466$, $469,473,476,490$.

Typotherium: 441, 472, 488, 489, 518, 523 .

Typotherium Bravardi: 438 .

Typotherium cristatum: $438,441,476,484$, 534.

Typotherium exiguum: $438,469,476,484,534$.

Typotherium insigne: 469.

Typotherium maendrum: $438,469,476,484$, 534.

Typotherium pachygnathum: 438, 44I, 469 . $476,484,534$

\section{U}

Uintatherium: 510.

Unguiculata: $395,39 \%, 401,449,459,468,474$, 494, 499 .

Ungulata: $395,396,397,40 \mathrm{I}, 45 \mathrm{I}, 46 \mathrm{I}, 469$, $476,495,502$.

Iirsidae: $398,46 x, 466,476,490,493$.

Ursus: $525,527,529$.

Ursus ? Irasiliensis: 533 .

\section{V}

Valgipes: $63,81,526$.

Valgives deformis: $8 \mathrm{I}, 478,536$.

Vermilinguia: $11,175,176,399,401,405,453$, $503,512,516,521,525,530$.
Vesperimus: 519 .

Vespertiliavus: 516 .

Vespertilio: $504,516,521,525,530$.

Vespertilio Isidori: 502 .

Vespertilionidae: $398,502,505$.

Vesnerugo: 504. 512

lesperugo nigricans: 502 .

Vesperus: 504.

Vesperus velatus: 502 .

Vesperus montanus: 502 .

Vischnutherium: 524 .

Viverra: $516,52 \mathrm{r}, 525,529$.

Viverridae: 398 .

\section{$\mathrm{X}$}

Nenurus: $373,380,382,504$.

Nenurus antiquus: 374 .

Xenurus aff. nudicaudo: 374 .

Xenurus nudicaudus: $374,537$.

Xenurus unicinctus: 374,503 .

Jenurus unicinctus fossilis: 374 .

Xiphidae: 399.

Xotodon: $437,465,472,515,5 \mathrm{IS}, 543,552$.

Xotodon foricurvatus: $46 \mathrm{r}$.

Xotodon prominens: $469,552$.

Cotodonticlae: $397,45 \mathrm{I}, 458,46 \mathrm{r}, 466,460$, 473.

Xiphocion: $515,518$.

Xyphodontidae: 397

Xyophorus: $53,6 \mathrm{r}, 457,512$.

Xyophorus rostratus: $6 r, 62,453$.

Xyophorus simus: 62,453 .

\section{Z}

Zaedyus: $357,358,374,380,382,457,463$, $465,471,472,488,489,492,498,504,513$, $516,521,526,530$.

Zaedyus exilis: $359,360,454$.

Zaedlyus minimus: 360 .

Zaedyus minutissimus: $48 \mathrm{r}$.

Zaedyus minutus: $357,358,359,360,48 \mathrm{r}$, $486,496,503,537$.

Zaedyus minutus fossilis: $35 \mathrm{~S}$.

Zaedyus proximus: 359,454 .

Zaphilus: 235, 293, 313 .

Zaphilus Larrañagae: 293 .

Zamicrus: $23,50,51,52,176,457,512$.

Zamicrus admirabilis: 50,453 .

Zetodion: 508 .

Zeuglodonta: $398,401,405$.

Zeuglodontidiae: 398 .

Ziphiidae: 383,388 ,

Ziphiorhynchus australis: $3 \$ 9$.

Ziphitus: 388 .

Ziphius australis: 389 . 



\section{ÍNDICE DE MATERIAS}

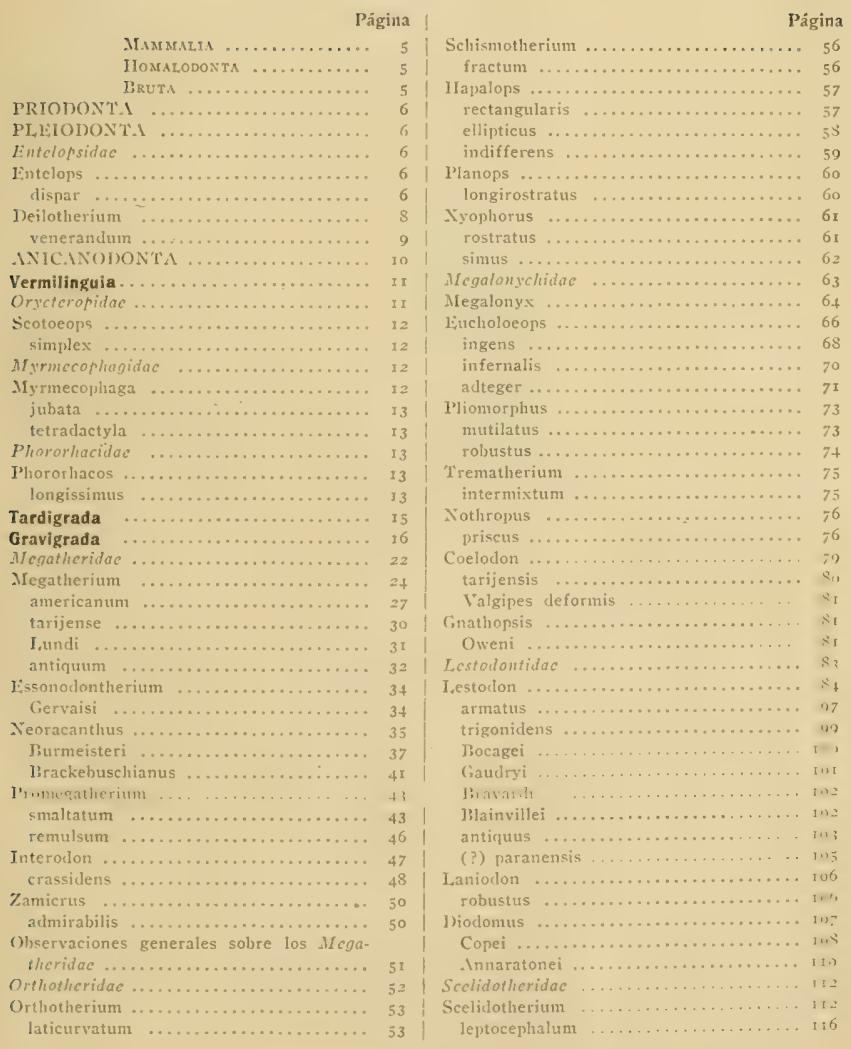




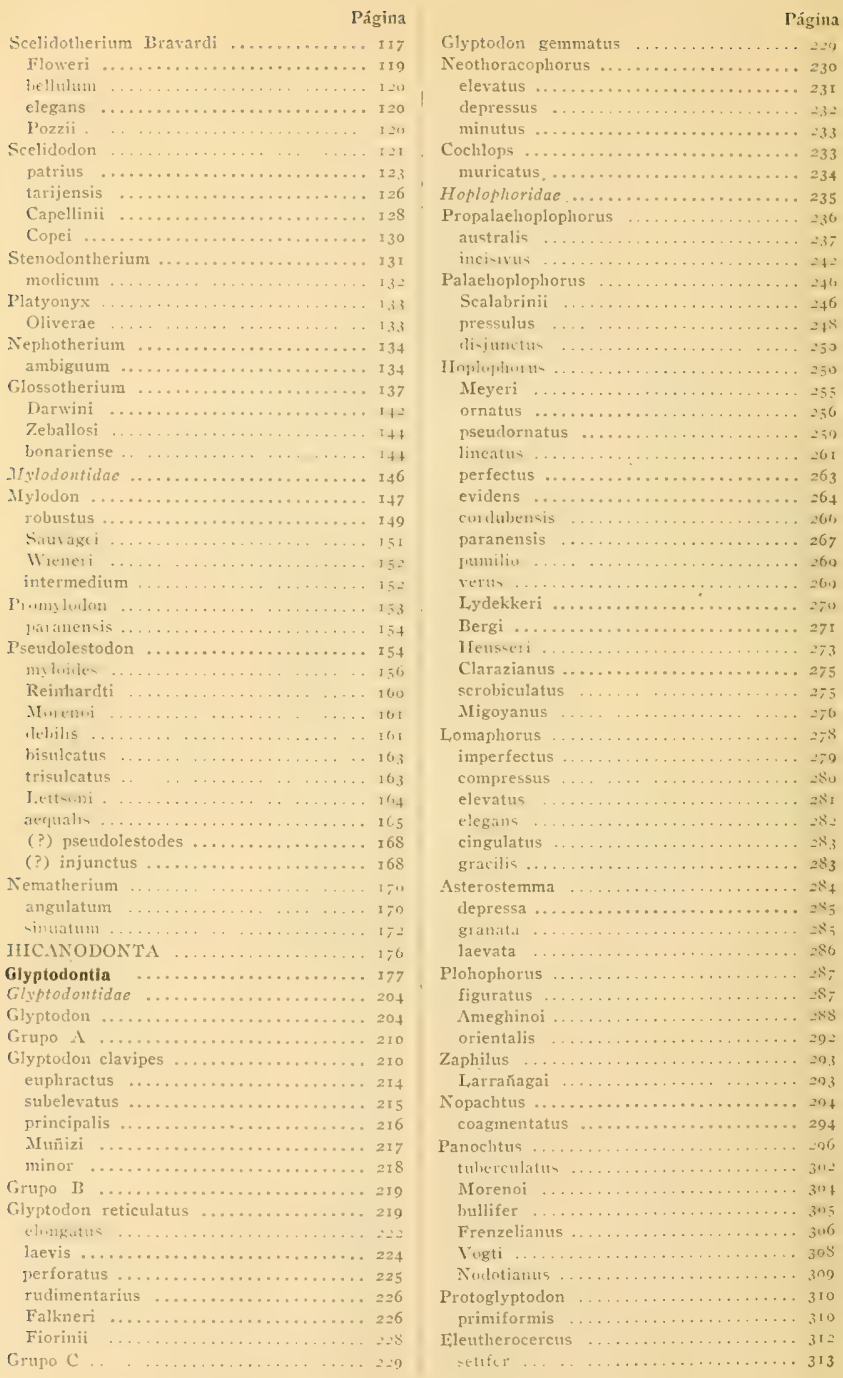


Pigrina

Dosicuridac ....................... 313

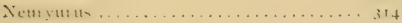

rudis $\ldots \ldots \ldots \ldots \ldots \ldots \ldots \ldots \ldots, 316$

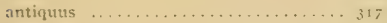

interusclatus ................. 310

Comaphorus . . . . . . . . . . . . . . $3=0$

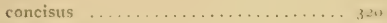

leneticurat $\ldots \ldots \ldots \ldots \ldots \ldots \ldots \ldots, 3=1$

clavicattdatus $\ldots \ldots \ldots \ldots \ldots \ldots \ldots \ldots, 3<5$

Poucheti .................... 327

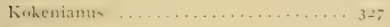

I’axhaplus $\ldots \ldots \ldots \ldots \ldots \ldots \ldots \ldots \ldots, 3-1$,

canaliculatus $\ldots \ldots \ldots \ldots \ldots \ldots \ldots \ldots .6 \ldots$

antiqus $\ldots \ldots \ldots \ldots \ldots \ldots \ldots \ldots \ldots 3^{\circ}$

Psendoentyurus $\ldots \ldots \ldots \ldots \ldots \ldots \ldots .332$

Lelongianus . . . ................3.3

Dasypoda ..................... 333

Chlamydotheridac .................. 335

Chlamydotherium . . . . . . . . . . . 3.36

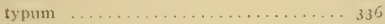

paranense $\ldots \ldots \ldots \ldots \ldots \ldots \ldots \ldots . . \ldots \ldots 37$

? extremum $\ldots \ldots \ldots \ldots \ldots \ldots \ldots \ldots, 3+2$

intermedium ................... 343

? australe ................... $3+3$

Ineltephilu .................... 345

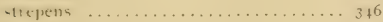

pumilus ......................... $3+6$

Praopidac ..................... $3+6$

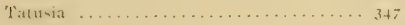

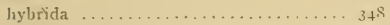

liybrida fossilis . . . . . . . . . . . . 348

novemcincta ................. 348

novemcincta fossilis . . . . . . . . . $3+9$

Propraopus $\ldots \ldots \ldots \ldots \ldots \ldots \ldots \ldots \ldots, 3+9$ grandis . . . . . . . . . . . . . . 350

Dasypodidac ..................... 353

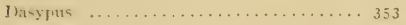

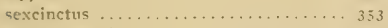

affinis sexcinctus $\ldots \ldots \ldots \ldots \ldots \ldots . . \ldots 54$

villusun ..................... 354

villosus fossilis ................. 354

affinis villosus $\ldots \ldots \ldots \ldots \ldots \ldots \ldots .35$

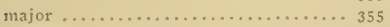

1. Iatemin . ...................... 356

patagonicus .................. 356

Zacilus .................... 357

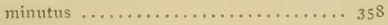

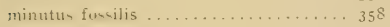

proximus ..................... 359

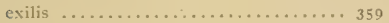

minimus .......................... 360

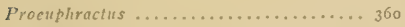

limpidus .................... $36 \mathrm{I}$

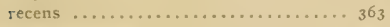

Macinetwhractus ................ $36+$

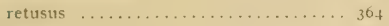

lutatus .................... 365

Segruini ......................... 36

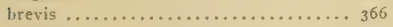

punctatus ..................... 367

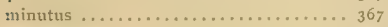

menmhorus .................... 368
Página

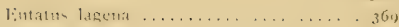

tlintan . . . . . . . . . . . . . . . 370

1olypeutes ................... $3 ; 0$

сониutt .................

conturus fossilis ..............

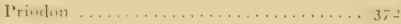

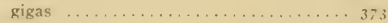

gigas fossilis .................... 373

Xinurus . . . . . . . . . . . . . . . 373

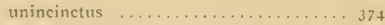

unincinctus fossilis ........... 374

Chlamydophoridac $\ldots \ldots \ldots \ldots \ldots \ldots . . \ldots . \ldots \ldots+4$

Chlamydophorus . . . . . . . . . . . . 374

t:uncatus $\ldots \ldots \ldots \ldots \ldots \ldots \ldots \ldots \ldots, 375$

truncatus (?) fussilr ............. 373

Peltateloidea $\ldots \ldots \ldots \ldots \ldots \ldots \ldots \ldots, 3 \pi^{t h}$

Stcgotheridac .................. 376

Stegotherium .................. $37^{\sqrt{5}}$

tessellatum ................. $3 ; 0$

Observaciones generales sobre los mamiferos del grupo de los Ilicanodontes.. 377

$$
\text { Cemactia } \ldots \ldots \ldots \ldots \ldots \ldots \mathrm{S}_{3}
$$

Proteroceta $\ldots \ldots \ldots \ldots \ldots \ldots \ldots \ldots \ldots .3 k_{3}$

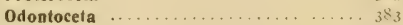

Platanistidac ........................ $3^{s+}$

I'ontoporia . . . . . . . . . . . . . . . $3_{4}$

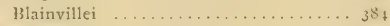

I'ontintes ................... $33_{4}$

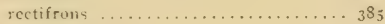

Delphinidac $\ldots \ldots \ldots \ldots \ldots \ldots \ldots \ldots \ldots 3^{8}$;

Delphinus $\ldots \ldots \ldots \ldots \ldots \ldots \ldots \ldots \ldots 3^{k_{5}}$

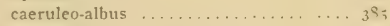

Tursions .................... ${ }_{3}{ }^{96}$

cymodoce $\ldots \ldots \ldots \ldots \ldots \ldots \ldots \ldots{ }_{3} \mathrm{s6}$

obeurus $\ldots \ldots \ldots \ldots \ldots \ldots \ldots \ldots \ldots 3_{3} 86$

Orea .......................... ${ }_{3} \$ 6$

magellanica $\ldots \ldots \ldots \ldots \ldots \ldots \ldots \ldots . \ldots \ldots \ldots$

P.emlurea ...................... $3^{3}$;

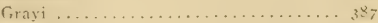

I'lucaena .................... $3^{87}$

spinipinnis . . . . . . . . . . . . . . $3 \mathrm{j}^{2}$ -

Monodontidac . . ................ $3^{5} 7$

Physetcridac ..................... 3 ss

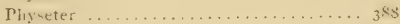

macrocephaltss ................. $3^{88}$

Ziphiidac ...................... 388

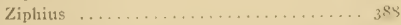

australis ................... 380

Mystacoseta ..................... $3^{e_{9}}$

Balaenidac ..................... $3^{8, n}$

? Palaeobalaena .... . . . . . . . . . $3^{*}, 2$

liergi ....................... 35i,

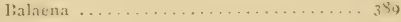

australis .................. $3 \varepsilon_{n}$

dulia ...................... 390

Bahenoptera ................... 300

honariensis ................ 301

patachonica ................... $39 \mathrm{r}$

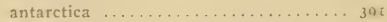

Megatera ...................... 391

bumeigteri $\ldots \ldots \ldots \ldots \ldots \ldots \ldots \ldots$ t 
Página

Monotremata ......... 392

Cacononta .............. 392

Ag.thononta ............ 392

SpondLocoelia ........... 393

Rápidas consideraciones generales sobre la clasificacion y descendencia de los ma11.1 ferm

SUPLEMENTO $\ldots \ldots \ldots \ldots$.

Adición al piso Peluenche ......... to-

Adición a la bibliografia solure el hombre fósil argentino 407

Adición a la reseña histórica .......... f t

Los vestigios del hombre en el plioceno inferior de La Plata ............. y os

Sobre la época geológica de los cráneos humanos descubiertos por I, und en las cavernas de lirasil .............. 408

Phanotherus marginatus ............ to

Myopotamus obesus ............... 409

Olenopsis ........................ 410 typicus ..................... 110

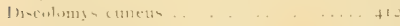

Orthomys procedens $. . \ldots \ldots \ldots \ldots \ldots \ldots+412$

I'htoramys homogenidens ........... +13

P'erimys Scalabrinianus ............. $\ldots+13$

Lagostomus pallidens ..... .... $+1+$

Euphilus ............ . . . . . $+1+$

Ambrosettianus $\quad . . \ldots \ldots, \ldots \ldots \ldots+1-1$

Kurtzi . . . ... . ............ . . 15

Briaromys $\quad \ldots \ldots \ldots \ldots \ldots+1 \%$

Trouescartianus ................ +16

Mregamy's patagoniensis ... $\quad \ldots \ldots+10$

Laurillardi $\ldots \ldots \ldots \ldots \ldots \ldots \ldots \ldots \ldots$, 1 .

II olmbergi $\ldots . \quad \ldots \ldots \ldots+\ldots \ldots+11$;

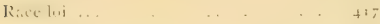

jraependens $\ldots . \quad \ldots \ldots \quad \ldots \ldots \ldots+1 k$

formosus ............ ... . . tis

Neoepiblema horridula ... ...... . tin

? contorta ... $\quad \ldots \quad \ldots \ldots \ldots \ldots+\ldots$

'Tetrastylus laevigatus $\ldots \ldots \ldots \ldots \ldots \ldots$ 110

ihffinste ... ... . . . ........

Molichotis centralis .............. $t+1$

Meoprocavia mesopotamica .......... +21

Cardiomys cavinus ................ 422

P'rocardiotherium crassum .......... 422

Cartiotherium Doeringi .............. 422 vetiosum $\quad \therefore \ldots \ldots \ldots \ldots \ldots \ldots \ldots \ldots+23$ minutum ...................... 423

Plexochoerus pranensis ............ 424

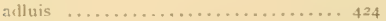
Lynchi ...................... 426

IIydrochoerus giganteus ............ +26 magnus .................... 427 irroratus ...................... 427

Macropristis ................... $4 \geq 8$

Notictis . $\quad \ldots \ldots \ldots \ldots \ldots \ldots$ Ortizi . . . .............. . .

Canis ? paranensis ............... 429

Cyonasua argentina ................. 429

Pracyon cancrivorus ............... 430

Apera sanguinaria . ...........
Página

Toxodon paranensis ............... +32

vngatur ... . . . . . . . . . . . + +32

Toxodontherium compressum ........ +33

reverendum ................... +34

IFaplodontherium Willei ............ +34

Dilobodon lutarins ................ +36

Trigodon Gaudry . ................ +36

Eitomodus elautus ............... 437

Stenotephanos plicidens ............ 437

Typotherium maendrum $\ldots \ldots \ldots \ldots \ldots \ldots+38$

(')

Pachyrucos typicus ................ +39

1ischithe ut ..... .............

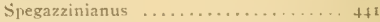

(?) Equus australis $. \ldots \ldots \ldots \ldots \ldots \ldots+42$

Hipridium nanum ............... $4+2$

Scalabrinitherium Rothi ............ +42

Palaeolama promesolithica . .......... +43

Platatlerium pampaeum ............. 443

Astraprotherium ephehicum ........... +43

Mastodon rectus .................. $4+3$

Deilotherium .................. $+4+$

Promegatherium smaltatum ............ $4+4$

Promylodon paranensis $\ldots \ldots \ldots \ldots \ldots \ldots++5$

Plohophorus . Imeghinoi . . ..... +46

Dasypus hesternus ................ +46

Adición al conocimiento de los cráneos humanos fósiles descubiertos en los rios

Arrecifes y Samborombón ............ +46

Itistribución de los mamíferos fósiles argentinos por horizontes y determinación de la época realtiva de cada fauna ... $4+9$ Piso Pehuenche . . .... . . ... 449 Piso Santacruceño ..... . . . . $4+9$ Formación l'atagónica .... . ... 459

Formación Aratucana .... $\quad \ldots \quad \ldots \ldots+67$

Formación Pampeana .............. 474 Formación Postpampeana o Cuaternaria.. 494 Iipoca actual ................... 499

Paralelo cronológico de las faunas mastológicas de Ja Repiblica Argentina con las de las otras regiones del globo.... 506 Fauma palaeocena ................ 506 Fauna eacena ................. 507 Fauna oligocena .. . . . ......... $5 t+$ Fauna miocena $\ldots . . . \ldots \ldots \ldots .517$ Fauna pliocena . . .............. 522 Fauna cuaternaria ............... $5 z 8$ Relación de las fatmas de mamíferos pliocena y cuaternaria de la República . A:gentina, con la que se encuentra en ectado fósil en las cavermas de Brasil $53 \mathrm{x}$ Ipéndice . ................... 539

Lista alfabética de los nombres de los autores, coleccionistas, etc., mencionados en este volumen .............. 557

Indice alfabético de los nombres técnicos mencionados en este volumen, incluso los sinónimos 


\section{FE DE ERRATAS}

\begin{tabular}{|c|c|c|c|}
\hline Página & Linea & Donde dice: & Debe decir: \\
\hline $27 \ldots$ & $21 \ldots$. & Megatherium americantm... & $\begin{array}{l}\text { Megatherium americanum. (Lá- } \\
\text { mina XLI, figura } 4 ; \text { y lámina } \\
\text { LXXXI, figuras } 1 \text { a } 6 \text {. }\end{array}$ \\
\hline $37 \ldots$ & 9. & Ictyodonilhites & Ichthyodorulites. \\
\hline $38 \ldots$ & 36. & como. & romo. \\
\hline $49 \ldots$ & $32 \ldots \ldots$ & 16 milimetros ............. & 18 milimetros. \\
\hline $49 \ldots$ & $43 \ldots \ldots$ & lago .............. & algo. \\
\hline $61 \ldots$ & $27 \ldots \ldots$ & $18 S 5 \ldots \ldots \ldots$ & 1887. \\
\hline $62 \ldots$ & $19 \ldots \ldots$ & inferior ..................... & anterior. \\
\hline $121 \ldots$ & $14 \ldots \ldots$ & $1889 \ldots \ldots \ldots \ldots \ldots \ldots \ldots \ldots \ldots \ldots \ldots \ldots \ldots$ & 1880. \\
\hline $126 \ldots$ & $40 \ldots \ldots$ & Lámina LXIII ................ & Lámina XLIII. \\
\hline $123 \ldots$ & $12 \ldots \ldots$ & 147 milimetros ............. & 157 milimetros. \\
\hline $142 \ldots$ & $23 \ldots \ldots$ & Lámina XIIV, figuras 6 y 7 & Lámina XLV, figuras 4 y 6 . \\
\hline $147 \ldots$ & $16 \ldots \ldots$ & eliptica y subeliptica........ & eliptica o subeliptica. \\
\hline $157 \ldots$ & $21 \ldots \ldots$ & no para agregar ............. & y para agregar. \\
\hline $167 \ldots$ & $34 \ldots \ldots$ & masal ......................... & basal. \\
\hline $186 \ldots$ & $1 \ldots \ldots$ & o manera .................... & a manera. \\
\hline $217 \ldots$ & $41 \ldots \ldots$ & 25 a 30 centimetros ......... & 25 a 30 milímetros. \\
\hline $223 \ldots$ & $27 \ldots \ldots$ & $1600 \ldots \ldots \ldots \ldots \ldots \ldots \ldots \ldots$ & 1160. \\
\hline $225 \ldots$ & $16 \ldots \ldots$ & Lámina LXXXI, & Lámina XCI, \\
\hline $260 \ldots$ & $39 \ldots \ldots$ & $1885 \ldots \ldots \ldots \ldots \ldots \ldots \ldots \ldots$ & 1887. \\
\hline $267 \ldots$ & $2 \ldots \ldots$ & con los lados ............... & en los lados. \\
\hline $268 \ldots$ & 6 y $7 \ldots$ & La forma elipticocircular .. & $\begin{array}{l}\text { La cara externa de cada placa } \\
\text { está ocupada por una gran fi- } \\
\text { gura central de forma eliptico- } \\
\text { circular. }\end{array}$ \\
\hline $275 \ldots$ & $2 \ldots \ldots$ & Lámina LXXIV , ............ & Lámina LXXXIV. \\
\hline $280 \ldots$ & $29 \ldots \ldots$ & 25 a 40 milímetros ........... & 25 a 30 milímetros. \\
\hline $290 \ldots$ & $3 \ldots \ldots$ & plazas ......................... & placas. \\
\hline $315 \ldots$ & $35 \ldots \ldots$ & una zona periférica .......... & $\begin{array}{l}\text { hasta formar en el medio una fi- } \\
\text { gura eliptica o subcircular ro- } \\
\text { deada de una zona periférica. }\end{array}$ \\
\hline $346 \ldots$ & 2. & figuras 1 a & figuras 1 a 6. \\
\hline $359 \ldots$ & $25 \ldots \ldots$ & PRoeufractus Ameghino. & ZAEDYUS EXILIS Ameghino. \\
\hline $430 \ldots$ & 27 y 28 & $\begin{array}{l}\text { La distancia del borde an- } \\
\text { terior del alvéolo desde el } \\
\text { canino al borde posterior. }\end{array}$ & $\begin{array}{l}\text { La distancia desde el borde an- } \\
\text { terior del alvéolo del canino } \\
\text { liasta el borde posterior. }\end{array}$ \\
\hline $468 \ldots$ & $20 \ldots \ldots$ & Patacnomys .................. & Platucomys. \\
\hline 46 & 31. & Hippidion ..... & Hippidium. \\
\hline & & Gelis ............................. & Felis. \\
\hline
\end{tabular}



El volumen IX contendrá:

\section{LOS MAMÍFEROS FÓSILES}

DE LA REPÚBLICA ARGENTINA

ATLAS 






